\title{
CERÁMICA, TERRITORIO Y EXPLOTACIÓN DE LA SAL EN EL VALLE DEL SALADO (GUADALAJARA) EN ÉPOCA ANDALUSÍ
}

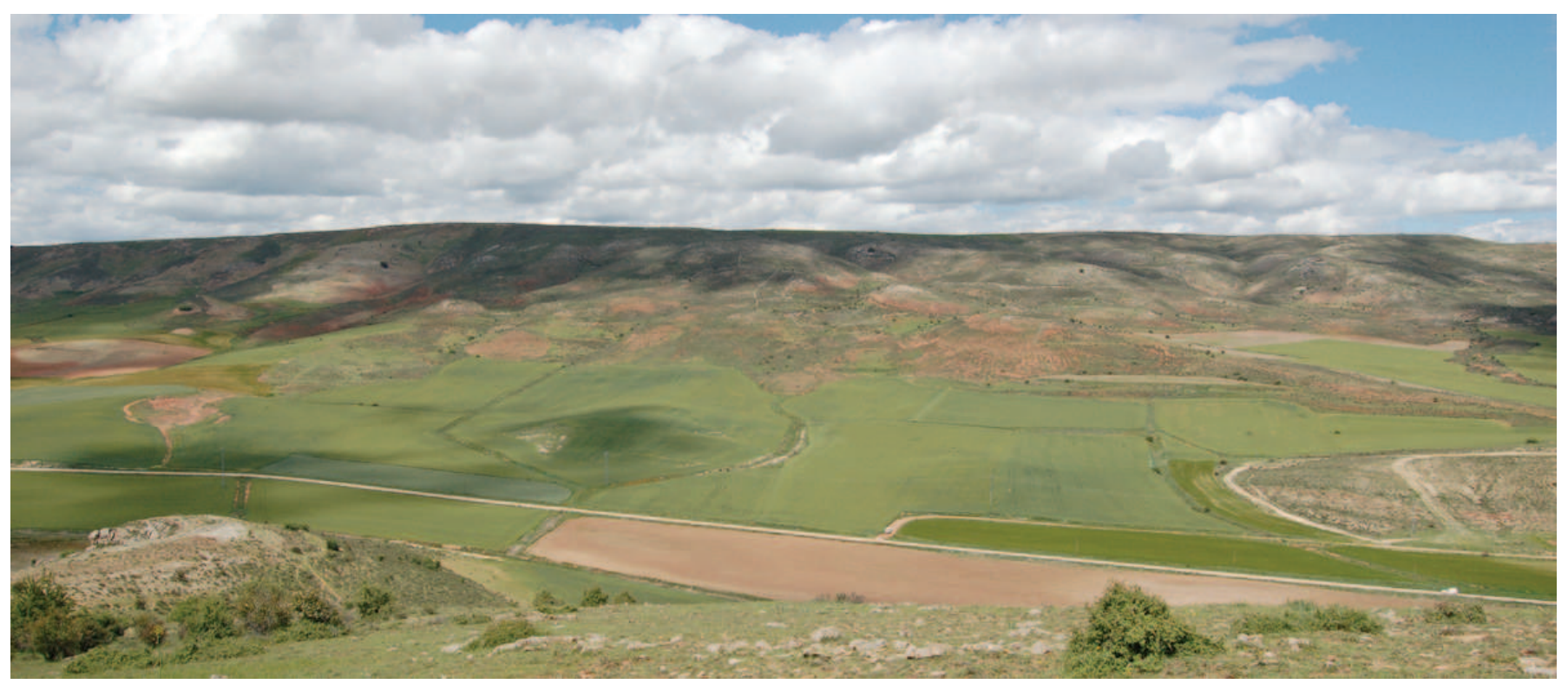

Guillermo GaRCíA-ConTRERAS RUIZ

Director: Antonio MALPICA CUELLO

Trabajo de investigación para la obtención del DEA

Master Arqueología y Territorio

Universidad de Granada 


\section{ÍNDICE}

\section{Bloque I: Aspectos introductorios ( $p .1)$}

- 1.1. Introducción y presupuestos de partida. Marco teórico y proyecto de investigación (p. 2)

\section{Bloque II: EI Marco historiográfico ( $p .8)$}

- 2.1. La sal en al-Andalus (p. 9)

- 2.1.1. La sal y su importancia en la historia de la humanidad (p. 9)

- 2.1.2. Historiografía: de la alimentación al comercio y la fiscalidad, de la producción al paisaje ( $p .13)$

- 2.1.3. Uso y consumo de la sal en al-Andalus ( $p .15)$

- 2.1.4. Los espacios productivos: el agua salada y las salinas en al-Andalus ( $p$. 29)

- 2.1.5. Cómo estudiar las salinas en al-Andalus. Algunos ejemplos ( $p .42)$

○ 2.1.6 Conclusiones y perspectivas (p. 52)

- 2.2. El hábitat y el poblamiento rural altomedieval en la zona oriental de la Marca Media: de los Banu Salim a la conquista castellana. (p. 56)

- 2.2.1. La época tardorromana (p. 57)

- 2.2.2. En la frontera de al-Andalus: el poblamiento en las fuentes escritas ( $p$. 62)

- 2.2.3. Beréberes y Omeyas: de la dominación de los Banu Salim a la presencia del Estado Omeya (p. 71)

- 2.2.4. El poblamiento según las investigaciones arqueológicas ( $p .76)$

- 2.2.5. El fin del período andalusí y la conquista castellana ( $p .88$ )

\section{Bloque III: EI valle del Salado en época altomedieval ( $p .92)$}

- 3.1. Marco Físico y contexto Geográfico: una tierra ligada a la sal ( $p .93)$

- 3.2. Resultados de la prospección: catálogo y descripción de yacimientos ( $p$.

112)

- 3.2.1. Consideraciones sobre la prospección (p. 119)

- 3.2.2. Catálogo de yacimientos (p. 119)

- Llano de los Perícales (p. 120)

- Cuevas de los Poyatos y las Conejeras (p. 123)

- Cueva de las Calzadizas o de las Viñas (p. 126)

- Cueva de Valdelcubo (p. 128)

- Corrales de El Puente (p. 129)

- Cerro de la Horca (p. 132)

- La Alquería (p. 133)

- Castillo de Riba de Santiuste (p. 134)

- Castillejo de la Riba (p. 139)

- Cerro de Villacorza (p. 141)

- La Asomadilla (p. 143)

- Castro de Riosalido (p. 145)

- Cerrillo de las Monjas (p. 148)

- Bujalcayado (p. 150)

- Bonilla (p. 152)

- Villavieja (p. 154)

- La Quebrada (p. 157)

- Baides (p. 160)

- 3.3.3. Plano de situación de los asentamientos y su relación con las áreas salinas (p. 163)

- 3.3. Sal, salinas, agua salada y prados halófilos en el valle del Salado (p. 164) 
Bloque IV: Estudio cerámico (p. 177)

- 4.1. Historiografía de los estudios de cerámica altomedieval andalusí en la Marca Media (p. 178)

- 4.2. Objetivos y metodología de nuestro estudio (p. 191)

- 4.2.1. Consideraciones previas (p. 191)

- 4.2.2. Indicadores referentes a la pasta, el modelado del alfarero y la cocción ( $p$. 195)

- 4.2.3. Tipología (p. 200)

- 4.2.4. Decoración (p. 203)

- 4.2.5 Huellas de uso y procesos posdeposicionales ( $p .204)$

- 4.2.6 Cuantificación y estudio estadístico ( $p .205)$

- $\quad 4.3$ Resultados del análisis cerámico (p. 208)

- 4.3.1. Procesos tecnológicos (p. 208)

- 4.3.2. Decoración (p. 217)

- 4.3.3. Tipología y cronología (p. 224)

○ 4.3.4. Grupos cerámicos (p. 244)

Bloque V: Conclusiones (p. 252)

- 5.1. Síntesis y perspectivas de estudio (p. 253)

Bloque VI: Fuentes y bibliografía ( $p$. 259)

- 6.1. Fuentes (p. 260)

- 6.2. Bibliografía (p. 263) 


\section{ASPECTOS INTRODUCTORIOS}

1.1. Introducción y presupuestos de partida. Marco teórico y proyecto de investigación 


\subsection{INTRODUCCIÓN Y PRESUPUESTOS DE PARTIDA. MARCO TEÓRICO Y PROYECTO DE INVESTIGACIÓN}

Este trabajo pretende exponer de manera breve y descriptiva el estado actual de las investigaciones que estamos llevando a cabo en el marco de dos proyectos de investigación, por un lado uno propio que pretende conducir a la obtención del título de doctor $^{1}$, y por otro lado un proyecto de carácter más general en el cual se desarrolla nuestro trabajo ${ }^{2}$, ambos dirigidos por el profesor Antonio Malpica Cuello de la Universidad de Granada. Es por ello por lo que no debe considerarse esta aportación como una investigación cerrada que presenta sus conclusiones, sino más bien como un estado de la cuestión cuando apenas se lleva un año de trabajo, y que obviamente tiene mucho camino que recorrer por delante.

El objetivo de nuestro estudio es fundamentalmente el de relacionar la organización del poblamiento en época andalusí con la gestión de los recursos naturales en la serranía norte de Guadalajara, y muy especialmente con un recurso de gran importancia como es la sal. En este mismo sentido, a largo plazo pretendemos analizar las diferencias que existen entre el período tardorromano y el posterior a la conquista castellana con la época que estudiamos, con el objetivo de analizar la diferente gestión de los recursos naturales en diferentes contextos sociales y momentos históricos distintos. No se trata de una tarea fácil, ya que como iremos describiendo, apenas si se tienen referencias a la explotación de este recurso no sólo en el área del Alto Henares, sino prácticamente en la totalidad del territorio de al-Andalus. Ante la ausencia de fuentes escritas, será el método arqueológico la principal herramienta de la que pretendemos valernos para producir algo de conocimiento histórico sobre una cuestión de difícil resolución. No obstante, como señaló en su día Miquel Barcelo, si el objetivo de toda arqueología también de la medieval - ha de ser «producir conocimientos históricos; es decir, producir informaciones adecuadamente contrastadas sobre la estructura, funcionamiento y cambios de las sociedades humanas» ${ }^{3}$, las preguntas que le hagamos a ese registro han de ser lo más incómodas posibles, sin ninguna complacencia. Los resultados obtenidos del registro cuando metodológicamente se cumplen estas premisas así lo permiten y alientan. Además han de ir destinadas a sacar de las respuestas nuevas preguntas. En definitiva,

\footnotetext{
${ }^{1}$ Financiado por el Ministerio de Educación y Ciencia a través de la concesión de una beca FPU, que lleva por título «El Alto Henares entre la Antigüedad Tardía y la Alta Edad Media: La organización del poblamiento y su relación con las explotaciones salineras»

${ }^{2}$ Proyecto I+D titulado «Organización del territorio y explotación de la sal desde la Tardía Antigüedad a la formación de la sociedad feudal en el área del Sistema Central: zonas de Guadalajara y Madrid» (HUM2007-66118).

${ }^{3}$ BARCELÓ, Miquel, «Los límites de la información documental escrita» en BARCELÓ, Miquel et alii, Arqueología Medieval. En las afueras del «medievalismo», Barcelona, 1988, p. 80.
} 
ni la arqueología ni cualquier otra técnica o método científico pueden resolver problemas no planteados previamente, lo que significa que los datos no existen en sí mismo, no están ahí indeterminadamente, sino que son producidos a partir de un problema o un conjunto de problemas explícitos y mediante técnicas y métodos, también explícitos, que permitan hacer valoraciones fundamentadas de las inferencias deducidas de los datos ${ }^{4}$

Partimos de una idea fundamental acerca de lo que es pertinente investigar y cuales son los límites de la práctica arqueológica: las distintas sociedades, especialmente las preindustriales, se definen en primer lugar por el tipo de relación que establecen con el marco físico en el que se desarrollan, y en segundo lugar el tipo de relaciones que establecen entre sí y con otras sociedades para la producción y reproducción social. El resto de los aspectos son, en gran medida, una consecuencia de ellos, como es el caso de la fiscalidad o las mentalidades, y siendo además temáticas inaccesibles para la disciplina arqueológica, entendida en su sentido más estricto, pero no así para la historia en sentido más amplio. Empezar el estudio de una sociedad por el tipo de Estado que la define nos parece, en cierto modo, una incongruencia.

Es la gestión de los recursos naturales, por tanto, el extremo por el que hay que empezar a estudiar y definir a la sociedades a lo largo de la historia. En el caso que nos ocupa, el recurso más abundante en el marco geográfico que estudiamos es la sal, un producto vital para el desarrollo de la vida humana y que está presente en muchas de las actividades diarias de las sociedades, y por supuesto también de la andalusí. La forma de acercarnos al estudio de la gestión de éste recurso natural es deudora, en su totalidad, de quien dirige nuestras investigaciones, el profesor Antonio Malpica Cuello. Dedica su investigación al estudio del paisaje, de las evidencias que quedan en el medio físico de las actividades productivas y reproductivas que llevaron a cabo la sociedades medievales, y especialmente en al-Andalus. De manera muy resumida, diremos aquí que sus propuestas se centran en la movilización de todo el tipo de información posible, tanto arqueológica como documental, incluso de fechas muy distintas a la estudiada en primera instancia, con el objetivo de analizar problemas cuya dimensión histórica, o más bien deberíamos decir su tiempo histórico, es el de la longuee dureé braudeliana. Es decir, el de las transformaciones lentas y paulatinas que han dejado marcados para siempre los medios geográficos con los que nos relacionamos hoy en día.

Con todas estas premisas se elaboraron los proyectos de investigación que sirven de base a este trabajo sobre la explotación de la sal. Su estudio supone mucho más que el examen de las tecnologías y de la gestión del medio que lo hacen posible. Sobre todo, y esta es la propuesta específica del proyecto, es preciso atender a la organización global

\footnotetext{
${ }^{4}$ BARCEló, Miquel, «Los límites de la información documental escrita» en BARCELÓ, Miquel et alii, Arqueología Medieval. En las afueras del «medievalismo», Barcelona, 1988, p. 27.
} 
del territorio, marcando los hitos del poblamiento y su estructuración en el espacio. Con una experiencia de varios años en esta temática centrada en la zona oriental de Andalucía, en la que la arqueología espacial y del paisaje ocupan un lugar importante, parecía que había llegado el momento de dilatar el campo de trabajo y establecer un examen de una zona distinta a la que hasta ahora era la de referencia preferente de una parte del equipo y especialmente del director del proyecto. Si bien el estudio de los territorios de Andalucía oriental han ofrecido informaciones suficientes, no ha sido posible trazar una secuencia cronológica tan ajustada y al mismo tiempo dilatada como se percibe en el área que ahora proponemos. Se configura como un espacio idóneo para este tipo de investigación. Por eso mismo parece que es evidente la idoneidad de la zona para poder estudiar la evolución de un territorio basado en la explotación de la sal, aunque no de forma exclusiva, y la de su poblamiento. Al compás de la misma se podrá ir trazando el proceso de transformación del territorio desde la época Tardoantigua, cuando la crisis del sistema romano es más que evidente, hasta la instalación de la sociedad andalusí, para terminar con la expresión del dominio feudal de la zona, ya en el siglo XII. Para ello hay que atender, como queda dicho, a los planteamientos de la arqueología del paisaje, pero también al examen atento de una masa documental que se genera en el proceso de conquista feudal.

Dentro de estas premisas del proyecto en estudio, en este trabajo nos dedicamos a un único espacio de todos los posibles dentro del marco geográfico abarcado que incluye todo el Sistema Central. En concreto, nos dedicamos al estudio del valle del Salado, un río tributario del Henares que transcurre en la Serranía norte de Guadalajara, justo en el punto de encuentro entre el Sistema Central y el Sistema Ibérico, y que ha sido la zona más estudiada por parte del equipo de investigación. Entre junio y octubre de 2008 se han llevado a cabo estudios en el valle del río Salado ${ }^{5}$ y un reconocimiento general del territorio en que se enmarca ${ }^{6}$. La zona en la que centramos el proyecto se sitúa entre las estribaciones orientales del Sistema Central y los límites occidentales del Sistema Ibérico y del sector norte de la Meseta Sur, siendo el territorio cabecera de distintas cuencas fluviales. El Henares es el eje principal, que cruza en dirección noreste-suroeste para continuar después por la Alcarria. La riqueza en sal mineral de éste territorio, que es debida a sus específicas condiciones geológicas, es conocida y reputada, además de bien documentada, ya desde época romana, y sobre todo, desde los siglos finales de la Edad Media a nuestros días. La explotación de estas importantes salinas están aun hoy día en curso, aunque progresivamente se ha ido abandonando a lo largo de los tiempos en pro de una concentración en explotaciones más grandes y rentables. En época

\footnotetext{
${ }^{5}$ Las dos campañas de prospección arqueológica se han llevado a cabo en junio y en octubre del año 2008, bajo la dirección de Nuria Morère Molinero y Jesús Jiménez Guijarro, y con la participación de Alberto García Porras, Ángel González Escudero, Teresa Koffler Urbano, Pilar Sánchez Duarte y quien subscribe estas líneas.

${ }^{6}$ Se llevó a cabo en septiembre de 2008 por Antonio Malpica Cuello.
} 
altomedieval, el valle que forma, sinuoso y salpicado de pequeños cerros, ha sido tradicionalmente interpretado como uno de esos vacíos poblacionales tan manidos por parte de determinados sectores de la historiografía medieval. Tan sólo los castillos, muchos de ellos aún hoy en pie, se citaban como la evidencia de una frontera sin gente que la habitara. Y sin embargo, a partir de la conquista castellana en el siglo XII, proliferan por el territorio los pequeños asentamientos explotando directamente la sal con un sistema de salinas por insolación del que se desconoce su origen.

Faltos de información documental, lo se ha pretendido poner en práctica en estas primeras fases del proyecto es una «arqueología sin excavación», denominada desde los años '80 como «arqueología extensiva o espacial» y más recientemente como «Arqueología del Paisaje». Para ello, la prospección arqueológica se revela fundamental ${ }^{7}$, imbricada necesariamente con el estudio de los materiales recuperados, en su mayoría cerámicas, y con el análisis minucioso de los asentamientos localizados y las características geográficas actuales y pasadas de la zona trabajada. Nos centramos, por tanto, en el hábitat y el poblamiento, que en nuestro caso concreto es eminentemente rural. Y precisamente por ello, está en estrecha relación con la explotación de los recursos naturales, fundamentalmente la sal, aunque no sólo. Es quizás uno de los campos más difíciles de analizar para la época medieval, ya que las referencias en las fuentes documentales son muy escasas y el registro arqueológico directo suele ser casi «invisible» en comparación con otros espacios, como las fortificaciones o las ciudades.

Hemos decidido dividir nuestro trabajo en tres grandes bloques, a los que añadimos las pertinentes valoraciones finales y los apartados dedicados a recoger las fuentes y la bibliografía utilizada. El primero de estos bloques está dedicado al examen de la historiografía sobre el tema que abordamos, y está dividido a su vez en dos apartados. En el primero, centramos nuestra atención en la sal en al-Andalus, recogiendo todas las referencias que hemos podido localizar que hacen mención a su uso en este período, así como los estudios que sobre los centros productivos, las salinas, se han llevado a cabo. Este apartado nos sirve, además, para sentar las bases teóricas y metodológicas para el estudio de la explotación de los recursos salinos en la alta edad media peninsular que tomamos de distintos investigadores, así como para examinar algunos ejemplos estudiados en la Península Ibérica de salinas relacionadas con el poblamiento andalusí. El segundo apartado de este primer bloque lo dedicamos al hábitat y el poblamiento rural en el sector oriental de la Marca Media en el que queda inserto el valle del Salado durante la vigencia de al-Andalus. Hemos tratado de ofrecer una panorámica lo más

\footnotetext{
${ }^{7}$ Las dos campañas de prospección arqueológica en el valle del Salado se han llevado a cabo en junio y en octubre del año 2008, bajo la dirección de Nuria Morère Molinero y Jesús Jiménez Guijarro, y con la participación de Alberto García Porras, Ángel González Escudero, Teresa Koffler Urbano y Pilar Sánchez Duarte, además de quien subscribe estas líneas. En septiembre de 2009 el propio Antonio Malpica llevó a cabo un reconocimiento general de todo el territorio en el que se enmarca el valle.
} 
completa posible de los datos que tenemos para el período tanto a partir de las fuentes escritas como de los, lamentablemente escasos, estudios arqueológicos que se han llevado a cabo. A partir de ahí trazamos las líneas generales que se han detectado en la evolución del poblamiento en esta área, tratando de referirnos siempre a los espacios rurales.

Hasta el último momento hemos dudado si incluir aquí el marco historiográfico del tercero de los aspectos que tratamos en este trabajo, el de la cerámica. Finalmente, para darle coherencia a los apartados en que queda dividido este texto, hemos optado por incluirlo en el bloque dedicado a la cerámica.

El segundo de estos grandes bloques, el tercero de nuestro índice, está dedicado al examen más minucioso del valle el Salado a partir de los resultados que hemos obtenido en las prospecciones arqueológicas y en el análisis del territorio, y siempre con la sal y su explotación como telón de fondo. Este bloque queda dividido a su vez en tres apartados, el primero dedicado al contexto geográfico del propio valle; en el segundo recogemos un catálogo de los yacimientos, conocidos o localizados por nosotros, que suman una veintena, describiendo los elementos que los caracterizan y relacionándolos en todo momento con el marco físico en el que se insertan; y en el último realizamos una serie de consideraciones sobre la sal y postulamos, con distintos argumentos, su más que probable explotación en época andalusí.

Una vez que hemos analizado el valle y sus asentamientos, el tercer bloque, cuarto de nuestro índice, está dedicado al examen minucioso de los materiales cerámicos. Como ya hemos indicado, el primer apartado de este bloque es el referente a la historiografía de los estudios cerámicos en la Marca Media. En segundo lugar, desarrollamos toda la metodología empleada, justificando en todo momento el porqué de los indicadores tomados en consideración así como los pasos que hemos seguido en la creación de la base de datos $^{8}$ que ha servido de base a nuestro estudio. A presentar los principales resultados del trabajo que hemos llevado a cabo con estos materiales está dedicado el tercer y último apartado de este bloque, en el que a partir de distintas analíticas estadísticas y junto con la descripción morfológica y tecnológica, se extraen varias conclusiones de los 1113 fragmentos de cerámica que han sido estudiados. En este apartado exponemos también las bases del estudio tipológico así como algunas reflexiones sobre los aspectos decorativos.

No queremos dejar pasar la oportunidad de dedicar unos más que sentidos agradecimientos a todos los que, directa o indirectamente, han colaborado y han hecho posible este trabajo de investigación. Fundamentalmente a nuestros compañeros, colegas y en ocasiones amigos que son miembros, de hecho o por derecho, del grupo de

\footnotetext{
${ }^{8}$ La base de datos utilizada es la conocida SPSS, Statistical Package for the Social Sciences en la versión 17 (2008) para Microsoft Windows XP.
} 
investigación «Toponimia, Historia y Arqueología del Reino de Granada» de la Universidad de Granada, a quienes no enumeramos porque sería largo y prolijo y seguramente caeríamos en el error de dejarnos fuera a alguno. Las virtudes que este trabajo puedan tener son consecuencia del trabajo en equipo y el intercambio de ideas, la comparación de resultados, los prestamos bibliográficos y los debates que de forma casi natural y a veces inconsciente surgen entre nosotros. Los fallos, omisiones o errores de interpretación deberán ser, en cualquier caso, siempre achacados a nosotros. Si que queremos dedicar un agradecimiento muy especial a Ángel González y Teresa Koffler, compañeros infatigables de los días de prospección y a quienes debemos algunos de los dibujos de cerámica que se recogen en los últimos apartados. Este trabajo tampoco hubiera sido posible sin la participación de Nuria Morère y Jesús Jiménez, de la Universidad Rey Juan Carlos de Madrid, quienes dirigieron las prospecciones, y quienes nos han abierto los ojos en el estudio de este territorio que tan bien conocen con una perspectiva diacrónica más amplia que abarca desde la prehistoria a nuestros días.

Pero nuestro más sentido agradecimiento va destinado a Antonio Malpica Cuello, al que siempre consideraremos maestro sin atrevernos a llamarnos aún discípulo. Su estricta disciplina, su entregada vocación, su rigurosidad científica y su preocupación por los problemas reales de la Historia es lo que hace posible el trabajo de muchos de nosotros, incluido éste.

Este trabajo está dedicado a Candela Fuentes Navarro, la sal de mi vida. 


\section{EL MARCO HISTORIOGRÁFICO}

2.1 La sal en al-Andalus

2.2. El hábitat y el poblamiento rural altomedieval en la zona oriental de la Marca Media: de los Banu Salim a la conquista castellana 


\subsection{LA SAL EN AL-ANDALUS}

Y sazonarás con sal toda ofrenda que presentes, y no harás que falte jamás de tu ofrenda la sal del pacto de tu Dios; en toda ofrenda tuya ofrecerás sal (LEvíTICO, 2, 13)

«Nihil esse utilius sale et sole» (PLINIO, XXXI, 102)

\section{La sal y su importancia en la historia de la humanidad}

La palabra sal es un término de la química que designa una sustancia producida por la reacción de un ácido con una base. Cuando el sodio, un metal inestable que puede inflamarse repentinamente, reacciona con un gas venenoso mortífero conocido como el cloro, se convierte en el alimento básico que es el cloruro sódico, o cloruro de sodio, cuya fórmula química es $\mathrm{NaCl}$. Se trata de la única familia de piedras que utilizan los seres humanos para su alimentación ${ }^{1}$. Otras denominaciones frecuentes son: sal marina y sal común. No obstante, existen muchos tipos de sales, de las cuales una gran cantidad son comestibles y a menudo se encuentran combinadas. La preferida, y la más común, es el cloruro sódico que proporciona el sabor denominado salado. Otras sales tienen un sabor amargo o agrio no deseable, pero presentan valiosas propiedades para la dieta humana: el cloruro de magnesio, cloruro potásico etc.

El cloruro es esencial para la respiración y la digestión. Y el sodio, que el cuerpo humano no puede fabricar, es imprescindible en el transporte de nutrientes y oxígeno, la transmisión de impulsos nerviosos o la actividad de los músculos, incluido el corazón. Se calcula que un ser humano adulto cuenta en su composición con aproximadamente doscientos cincuenta gramos de sal, que se pierde continuamente a través de las funciones corporales, por lo que es de vital importancia reponerla.

En estado natural se presenta disuelto en agua o en estado sólido, por lo que se obtiene fundamentalmente de la evaporación del agua marina o de su extracción minera en forma de roca-mineral denominada halita. Hay otra forma de obtención de la sal por evaporación en el interior: en algunas zonas donde hay grandes masas de sal sólida asociada a diapiros, la halita, que se encuentra en el subsuelo, es erosionada y arrastrada de forma natural por corrientes de agua dulce, superficiales o interiores, convirtiéndose en agua salada o salmuera. Esta agua, bien tomada de los cursos y arroyos salados, o bien mediante pozos directamente del subsuelo, puede ser usada para obtener los granos de sal.

\footnotetext{
${ }^{1}$ KURLAnSKy, Mark, Sal. Historia de la única piedra comestible, Barcelona, 2002. Muchas de las referencias al uso histórico de la sal de estas primeras páginas están tomadas de su obra.
} 
La sal proporciona a los alimentos uno de los sabores básicos: el salado, debido a que en la lengua poseemos receptores específicos para el «sabor salado». El consumo de sal modifica nuestro comportamiento frente a los alimentos ya que es un generador del apetito e incita su ingesta. Se emplea fundamentalmente en dos áreas: condimento de algunos platos y como un conservante típico de los salazones de carnes y pescado (incluso de algunas verduras), así como en la elaboración de ciertos encurtidos. Desde un punto de vista químico y biológico, una aportación complementaria de sal es necesaria a partir de la ingestión de proteínas vegetales cuyo exceso de potasio produce pérdidas de sodio y de cloro que hay que restituir en forma de cloruro sódico, es decir, de sal común. Es por ello por lo que su consumo se hizo imprescindible a partir del Neolítico, ya que con anterioridad el abundante consumo de carne resultaba de por sí suficiente. Es además a partir del Neolítico cuando surge la necesidad, o el interés, por conservan los alimentos, las salazones de carnes o de pescado, debido a la creciente estacionalidad de la producción asociada a un hábitat cada vez más sedentario. Y junto a ello, asistimos a la revolución de los productos secundarios, tales como los lácteos y sus derivados, o la producción masiva del textil, actividades todas ellas que cuentan con la sal en alguna de sus fases ${ }^{2}$. Olivier Weller lo ha puesto de manifiesto:

L'exploitation du sel dès le Nèolitique s'intégrarait ainsi parmi les profonds bouleversement qui caractérisent cette période: intensification de l'agriculture et de l'elevage, croissance démographique, exploitation intensive du milieu naturel (déboisements massifs, carrières de pierres, mines de silex, d'obsidienne, de cuivre...) acompagnées par le développement d'importants réseaux d'échanges à grande distance et par une compétition et une hierchistation sociale bien marquée... ${ }^{3}$

La ubicación de depósitos de sal tuvo especial relevancia en los emplazamientos finales de asentamientos humanos primitivos. Debido a que, no sólo es una necesidad humana su consumo, sino que permite además conservar los alimentos prolongando su vida comestible. Se han documentado numerosos yacimientos prehistóricos en los que hay testimonios cerámicos de la obtención de sal por medio de cerámicas para la ignición de la salmuera, conocidos como «briquetage»" ${ }^{4}$, una técnica ampliamente documentada, también en la Península Ibérica ${ }^{5}$, que se daba en climas en los que la sal era difícil de

\footnotetext{
${ }^{2}$ Sobre los orígenes de la producción de sal vid. WELLER, Olivier, «Aux origines de l'exploitation du sel: questions de méthode», Journal of Salt History, 4 (1996), pp. 101-116 y JiMÉNEZ GuiJARro, Jesús, «¿Aprovechamiento o explotación?: reflexiones acerca de la minería y uso de la sal durante la Prehistoria» MORÉRe Molinero, Nuria (Ed.), Las salinas y la sal de interior en la historia: economía, medio ambiente y sociedad, Madrid, 2008, pp. 185-216.

${ }^{3}$ WeLler, Olivier, «Aux origines de l'exploitation...», p. 114.

4 OLIVIER, Laurent y KovACIK, Joseph, «The "Briquetage de la Seille" (Lorraine, France): protoindustrial salt production in the European Iron Age», Antiquity, 80 (309) (2006), pp. 558-566.

${ }^{5}$ Aunque hay varios yacimientos, quizás el más significativo sea el de Villafafila, en Zamora. DELIBES DE Castro, German, Fernández Manzano, Julio, Rodríguez Rodríguez, Elías, Val Recio, Jesús del,
} 
obtener por insolación. Pero además, también se han detectado salinas al borde del mar que se han adscrito a los momentos de la neolitización ${ }^{6}$.

Además de condimento, la sal es esencialmente un conservante. Los egipcios usaban la sal en los procesos de momificación. Pero ya antes, una de las culturas que antes ha documentado el uso y extracción de la sal es la china (desde el siglo XXVII a. C.). Hacia el año 2697 a. C. se publicó en este país oriental probablemente el tratado de farmacología más antiguo conocido, titulado Peng tzao kang-mu. Se trata de una obra inconclusa recopilada por mandato del emperador Shemmeng. Gran parte de este escrito se dedicaba a discutir sobre más de 40 clases de sal, incluyendo descripciones de dos métodos de extracción de sal y de puesta en uso que son asombrosamente similares a los procesos usados hoy en día. Los chinos se dieron cuenta de que todo el mundo necesitaba consumir sal, por lo que crearon impuestos para dicho producto.

Ya en el Imperio Romano se crearon rutas específicas en Europa para facilitar el mercadeo de sal entre diversas regiones, por ejemplo en Roma tiene origen en una ruta destinada al transporte de sal denominada via salaria ${ }^{7}$, no sólo a Roma sino hacia todo el interior de la Penínusula Italiana; otros ejemplos pueden verse también en: Alemania con la Alte Salzstrasse o en Francia con la Route du Sel. Los intereses existentes entre los mercaderes y los diferentes Estados han hecho que se hayan producido numerosas guerras por controlar no sólo los depósitos sino que también los mercados de la sal. Se ha llegado a argumentar que los primeros caminos fueron hechos para su transporte y que las primeras ciudades fueron establecidas como centros de su comercio ${ }^{8}$. Aún sin llegar a este extremo, las investigaciones llevan años poniendo de relieve como la sal fue una fuente de ingresos básica para el gobierno de muchos estados antiguos ${ }^{9}$, hasta tiempos relativamente recientes; además fue uno de los pilares de la economía de Venecia, uno de los primeros Estados comerciales de Europa ${ }^{10}$. Llamada a veces «oro blanco», la sal ha sido comercializada desde tiempos antiguos, habiendo sido incluso utilizada como instrumento de cambio, sustituyendo en ocasiones a la moneda. Así el término castellano «salario» procede del latín «salarium», ya que parte del sueldo que

«Molino Sanchón II: un salín de época campaniforme en las lagunas de Villafafila (Zamora)», en Morére Molinero, Nuria (Ed.), Las salinas y la sal de interior en la Historia: economía, medio ambiente y sociedad, Madrid, 2008, t. I, pp. 47-72.

6 Escalena, J. L., Rodríguez de ZuloagA, M., «La Marismilla ¿Una salina neolítica en el Bajo Guadalquivir?», Revista de Arqueología, IX/89 (1988), pp. 15-24.

7 BAtTAglini, Giovanna, «La sal en los orígenes de la ciudad de Roma», Molina VidAL, Jaime y SÁNCHEZ FERnÁNDEZ, Ma José (Eds.), III Congreso Internacional de Estudios Históricos. El Mediterráneo: la cultural del mar y de la sal, Santa Pola, 2005, pp. 65-75.

${ }^{8}$ BLOCH, Maurice R., «The social influence os Salt», Scientific American, 209 (1963), pp. 89-98.

${ }^{9}$ Morère Molinero, Nuria, «Hommes et sel: Archèologie et Histoire jusqu'au premier millènaire au notre ère», en FIGULS, A. y WeLLER, O. (Eds.), Trobada internacional d'arqueologia envers l'explotació de la sal a la prehistòria i protohistoria, Cardona, 2007, pp. 97-110.

${ }^{10}$ HocQueT, Jean-Claude, «La navegación de la sal en el Atlántico (siglos XIII-XVIII)», en MALPICA Cuello, Antonio (Ed.), Navegación marítima del Mediterráneo al Atlántico, Granada, 2001, pp. 17-57. 
se pagana a las tropas romanas se hacía en este mineral o para que se aprovisionasen de él.

La sal ha sido a lo largo de la historia un producto de primera magnitud, tanto para su consumo directo, como para posibilitar un excedente productivo al permitir la conservación de los alimentos. Teniendo en cuenta que las posibilidades que hay de obtenerla son limitadas, debido a que en estado natural sólo aparece en determinadas regiones geográficas, para su obtención hubo que poner en marcha o bien medios técnicos más o menos sofisticados, o bien determinadas prácticas económicas de cierta envergadura como el comercio. De este modo, el estudio de la sal se convierte en un medio esencial para conocer la técnica, la economía o la fiscalidad de gran parte de las sociedades a lo largo de la historia. Incluso, determinados aspectos relacionados con la mentalidad, la cultura, la religión y la mitología encuentran en la sal un vehículo de estudio de gran interés ${ }^{11}$. Para los antiguos hebreos, y aún hoy día para los judíos, es el símbolo del carácter eterno de la alianza de Dios con Israel: «Hay una alianza de sal eterna, ante Dios», «El Dios de Israel concedió para siempre el reino de Israel a David, y en ese mismo momento también a sus hijos mediante una alianza de sal». Los viernes por la noche, los judíos toman el pan del Sabbath con sal. También en el cristianismo, la sal está presente, asociada con la longevidad y la permanencia, así como con la verdad y la sabiduría. La Iglesia Católica, además del agua bendita, ha suministrado a lo largo de su historia sal bendita, Sal Sapientia.

Nuestro estudio, no obstante, adopta otra óptica algo diferente, ya que pretendemos situar a la sal, y todo el proceso desde su captación y explotación hasta su consumo, como objeto de estudio histórico y arqueológico.

Como todo estudio arqueológico, es necesario comenzar por el medio físico en el que se inserta y con el que se interrelacionan los diferentes grupos humanos. En este sentido, en primer lugar hemos de señalar que no en todas partes se puede producir sal, y allí donde es posible su obtención, no siempre se ha podido llevar a cabo por los mismos procedimientos. En el interior la realidad geológica condiciona la existencia de halita, y en las zonas costeras en donde hay límites climáticos, por la necesidad de temperaturas elevadas que permitan la evaporación, e incluso morfológicos, ya que no todas las costas tienen amplias llanuras donde provocar el estancamiento del agua salada.

Durante miles de años la búsqueda de sal ha supuesto un reto para la tecnología y la ingeniería, dando lugar a más de un invento ingenioso. Algunas de las mayores obras públicas vinieron por la necesidad de transportar la sal. Se desarrollaron las rutas comerciales, que han seguido siendo en muchos casos las vías de comunicación primordiales, se establecieron alianzas y se forjaron imperios y revoluciones. Asimismo, la sal ha estado presente en la vanguardia del desarrollo de ciencias como la química o

\footnotetext{
${ }^{11}$ Bloch, Maurice R., «The social influence...». Resulta interesante también la lectura de BARBE, Noël, «Sur quelques équivalences symboliques du sel», Journal of Salt History, 5 (1997), pp. 83-93.
} 
la geología. Como señala Multhauf, el tema de la sal «es una hebra característica en la tela de la historia humana» ${ }^{12}$.

\section{Historiografía: de la alimentación al comercio y la fiscalidad, de la producción al paisaje}

El análisis histórico de la sal ha llenado un buen número de páginas, siendo muy diversos los estudios a lo largo del tiempo. Son varias las tendencias que se pueden documentar en su estudio. Podemos resumir la historiografía sobre la sal en cuatro o cinco tendencias muy generales: las referentes a la alimentación, las referentes a la producción, las referentes al comercio, los estudios que se ocupan de la fiscalidad y por último aquellos dedicados al estudio de los paisajes de la sal. De alguna manera, estas cinco tendencias se han sucedido de manera cronológica aproximadamente en el mismo orden en el que las hemos enumerado, como ponen de relieve las fechas de publicación de los que podemos considerar los principales títulos sobre el tema que pueden encontrarse en la historiografía española ${ }^{13}$.

Especialmente importantes han sido los estudios referentes a la fiscalidad y el control de la producción. Y ello como resultado de la propia naturaleza de la documentación escrita más usada, los documentos escritos, que en este sentido han sido muy abundantes. La tendencia a monopolizar la sal y a controlar su circulación, dada la necesidad de su consumo directo o su uso indirecto, ha dado lugar a una hacienda que adquiere su verdadera dimensión en época bajomedieval y en la primera época moderna $^{14}$. Lamentablemente, para el ámbito andalusí, este tipo de documentación o no se ha conservado o bien no existía, en línea con lo que ocurre de manera general con la documentación escrita en al-Andalus.

Algo más de información tenemos acerca de otra de las temáticas: la historia de la técnica de producción salinera. De las acciones más primitivas, en muchos casos simplemente de recolección, se pasa a las más complejas, con máquinas que sirven para elevar el agua salada y deslizarla por construcciones de madera hasta obtener su evaporación y cristalización. Y todo ello sin olvidar la práctica minera.

En 1956 Le Goff y Jeannin publicaron un valioso trabajo en el que exponen un método racional y coherente a seguir, prestando atención a los aspectos técnicos, mercantil,

\footnotetext{
${ }^{12}$ Multhauf, Robert P., El legado de Neptuno. Historia de la sal común, México D. F., 1985, p. 9.

${ }^{13}$ Nos referimos, de alguna forma, a las referencias bibliográficas que sirven de base a los estudios que se han llevado a cabo en nuestro país, y que de manera indirecta, junto con los propios títulos de las monografías y congresos, reflejan por donde han transcurrido las preocupaciones en la investigación de la sal: HocQuet, Jean-Claude, Le sel et le pouvoir. De l'An mil à la Révolution française, Paris, 1984; Malpica Cuello, Antonio y GonzÁlez AlCAnTud, José Antonio, (Eds.), La Sal: del gusto alimentario al arrendamiento de salinas, Granada, 1997; MorÉRE Molinero, Nuria (Ed.), Las salinas y la sal de interior en la historia: economía, medio ambiente y sociedad, Madrid, 2008.

${ }^{14}$ HoCQUET, Jean-Claude, «La navegación de la sal...».
} 
político-administrativo y social, con el objetivo, quizás demasiado pretencioso, de construir una síntesis histórica sobre la sal ${ }^{15}$. Este trabajo supuso el inicio de numerosos estudios en Francia, que vieron sus frutos recogidos en una obra coordinada por Michel Mollat $^{16}$. Toda una década de trabajos sobre los diversos aspectos de la historia de la sal fueron recogidos más tarde en otra obra colectiva, en esta ocasión abriendo el arco cronológico aún más para recoger trabajos desde la prehistoria hasta nuestros días, y en el aspecto geográfico se recogían estudios no sólo de Francia, también de Alemania, España y otros ${ }^{17}$. Todos estos trabajos, junto a los del profesor Jean-Claude Hocquet ${ }^{18}$, van a marcar las pautas de trabajo y las líneas de interés en lo que al estudio de la sal se refiere. Se prestaba atención, fundamentalmente, a sus aspectos fiscales y comerciales, coincidiendo con el agua de la Historia social y económica en gran parte de Europa.

El inicio del interés por los estudios históricos de la sal, que toma carta de nacimiento en los años '60 y sobre todo en los '70, se centró en las latitudes más septentrionales, Inglaterra, Alemania, Austria y la fachada atlántica de Francia. Dejando a un lado el caso particular del Venecia, quedaba un gran vacío de conocimiento para el Mediterráneo y las regiones atlánticas más meridionales.

En España esta línea de trabajo ha sido mucho más fecunda en unos territorios que en otros. En Castilla ha habido tradición de estudio de la sal desde el punto de vista de su importancia fiscal ${ }^{19}$. El punto de partida fue sin duda la obra de Cristóbal Espejo, punto de partida para muchas de las investigaciones posteriores, a pesar de sus numerosos defectos, como no especificar la procedencia de los documentos y de no prestar atención al período anterior al cuatrocientos. Para los territorios de la Corona de Aragón carecemos de un trabajo de conjunto similar a los citados para Castilla, salvo para un período muy concreto, el de Jaime $\mathrm{I}^{20}$. Junto a estos trabajos debemos citar el de Reyna Pastor $^{21}$ dedicado a la época temprana y central de la Edad Media en Castilla y León, que aún hoy es referente obligado tanto por lo exhaustivo del listad de salinas como por sus acertadas conclusiones acerca del proceso que siguió la explotación de la sal hasta desembocar en un monopolio real. No obstante, mayor impacto tuvo el trabajo de Gual Camarena en el que recoge las referencias documentales a las salinas de prácticamente

\footnotetext{
15 JeAnnin, P. y Le GofF, J., «Questionnaire por une énquete sur le sel dans 1'Histoire, au Moyen Age et au temps modernes», Revue du Nord, XXXVIII (1956), pp. 225-233.

${ }^{16}$ Mollat, Michel, (Ed.), Le rôle du sel dans l'Histoire, Paris, 1968. El trabajo anteriormente citado fue recogido en esta obra colectiva, pp. 307-322.

${ }^{17}$ Le sel et son histoire, Nancy, 1981.

${ }^{18}$ HoCQUET, Jean-Claude, Le sel et le pouvoir...

${ }^{19}$ ESPEJO, Cristóbal, «La renta de salinas hasta la muerte de Felipe II», Revista de Archivos, Bibliotecas y Museos, 38, 39 y 40 (1918-1919); LADERo QuESADA, Miguel Ángel, «La renta de la sal en la Corona de Castilla (Siglos XIII-XVI)», Homenaje al profesor Juan Torres Fontes, Murcia, 1987, t. I, pp. 821-838.

20 Arroyo IlerA, Rafael, «La sal en Aragón y Valencia durante el reinado de Jaime I», Saitabi, XI (1961), pp. 253-261.

${ }^{21}$ PASTOR DE TOGNERI, Reyna, «La sal en Castilla y León. Un problema de la alimentación y del trabajo y una política fiscal (siglos X-XIII)», Cuadernos de Historia de España, 37-38 (1963), pp. 42-87.
} 
la totalidad de la Península Ibérica ${ }^{22}$, trabajo que luego sería completado para otras regiones siguiendo el mismo esquema, como por ejemplo Granada ${ }^{23}$.

En los casos en los que no disponemos de fuentes escritas o éstas hacen referencias genéricas y descriptivas, sólo es posible trazar unas líneas generales y el tiempo histórico es necesariamente de larga duración ${ }^{24}$. Por eso podría pensarse que la evolución de la economía salinera es muy lenta y apenas se observan transformaciones. Pero lo que ocurre realmente es que la dimensión del cambio es más lenta y acumulativa, y no aparece con la inmediatez con la que ha podido documentarse durante el proceso de organización de la economía salinera primero feudal y luego propia del Estado Moderno.

\section{Uso y consumo de la sal en al-Andalus}

Lo primero que llama la atención es que en las fuentes escritas árabes de al-Andalus no haya apenas referencias a la sal, siendo, como hemos visto, un producto de primera importancia y de consumo habitual. A pesar de que los distintos textos, sobre todo los geográficos, nos informan sobre la gran mayoría de los recursos naturales de alAndalus, es notable la ausencia de algunos de ellos como es la sal. Podría pensarse que era un producto sin importancia para los andalusíes, pero si atendemos a las referencias indirectas, y a su aparición constante en los textos culinarios y en menor medida en los de agronomía, zootecnia y farmacología, todo indica que era un producto muy común. Es probable que su ausencia en determinadas fuentes sea el resultado de la falta de control directo de su producción por parte del Estado y sus agentes, si bien es una idea ésta que aún está por dilucidar, y a la que dedicaremos el siguiente epígrafe. Vamos a centrarnos ahora en su consumo directo y en los distintos usos que hemos podido documentar.

Como decíamos, tenemos toda una serie de referencias al uso y consumo de la sal en alAndalus que nos indican acerca de su presencia en la vida cotidiana de los andalusíes. La primera referencia a la sal en al-Andalus que debemos hacer, que en árabe se escribe al-Milh o simplemente Milh para referirse a la sal común, es su recurrente uso como condimento en la cocina andalusí. De la sal se nos dice en un texto nazarí que «es caliente y seca en segundo grado, hace desaparecer la indigestabilidad de las comidas,

\footnotetext{
${ }^{22}$ Gual Camarena, Miguel, «Para un mapa de la sal hispana en la Edad Media», Homenaje a Jaime Vicens Vices, Barcelona, 1965, pp. 483-497.

${ }^{23}$ SÁnChez DíAz, Candida, «Mapa de la sal del Reino de Granada», Cuadernos de estudios medievales, XII-XIII (1984), pp. 199-204.

${ }^{24}$ MAlPiCa CUELlO, Antonio, «Producción y comercio de la sal marítima en la España Mediterránea en época altomedieval», Molina Vidal, Jaime y SÁnchez Fernández, Ma José (Eds.), III Congreso Internacional de Estudios Históricos. El Mediterráneo: la cultural del mar y de la sal, Santa Pola, 2005, p. 130.
} 
y suaviza los alimentos pesados» ${ }^{25}$. Es una idea que parece persistente a lo largo de todo el medioevo andalusí, pues ya Averroes señalaba respecto a la sal que «Todas las clases de sal con calientes y secas. El bórax posee la facultad limpiadora en alto grado y es un gran emoliente» ${ }^{26}$.

El primer uso de la sal en la cocina es como antiséptico en la conservación de los alimentos, fundamentalmente los pescados, pero también las carnes:

Todas las noches se pondrá sal en el tajo, para que no críe gusanos, cubriéndolo con una funda de esparto que atará con el fin de que los perros no $\operatorname{laman}^{27}$

La sal ha sido, y no sólo en época andalusí sino incluso hasta épocas muy recientes, el principal conservante de alimentos, toda vez que el hielo tiene una perdurabilidad muy escasa $^{28}$. Este uso de la sal se debe tanto a la diversidad de lugares en los que se puede obtener, como por ser uno de los elementos más estables y prácticamente inalterable salvo por la acción del agua en la que es soluble. Tanto en las zonas costeras donde se desarrolla una actividad pesquera, como en las zonas interiores para la conservación de la carne, es imprescindible el uso de la sal, sin la cual sería inconcebible el comercio de muchos productos ${ }^{29}$. Es decir, la sal en al-Andalus, al igual que en gran parte de Europa y el Mediterráneo durante la Edad Media, permitía tanto la conservación de excedentes como su comercialización a grandes distancias.

El comercio de la mayor parte de estos productos iba dirigido a la cocina y la alimentación. Todo apunta a que la alimentación en al-Andalus se caracterizaba por ser variada y compleja ${ }^{30}$, con determinados tabúes a la hora de mezclar ciertos productos, y

\footnotetext{
${ }^{25}$ DiAz GARcíA, Amador, «Un tratado nazarí sobre alimentos: Al-Kalâm 'Alà l-Agdiya de Al-Arbuli. Edición, traducción y estudios, con glosarios (II)», Cuadernos de estudios medievales, X-X) (1982-1983), p. 19.

${ }^{26}$ Averroes, El libro de las generalidades de la Medicina [Kitan al-Kulliyyat fil-tibb], Abu-l-Walid ibn Rusd (Averroes), Trad. de VÁzQuez De Benito, Ma de la Concepción y Álvarez Morales, Camilo, Madrid, 2003, p. 331.

${ }^{27}$ Chalmeta Gendrón, Pedro, «El "Kitab fi adab al-hisba (libro del buen gobierno del zoco) de alSaqati. (continuación)», Al-Andalus, XXXIII (1968), p. 170.

${ }^{28}$ MAS BARÓN, Albert, «Historia de la conservación de los alimentos», SALAS-SALVADÓ, Jordi, GARCÍALORDA, Pilar, SÁNCHEZ RipolléS, José Ma (Eds.), La alimentación y la nutrición a través de la Historia, Barcelona, 2005, pp. 447-462.

${ }^{29}$ MALPICA CuELlO, Antonio, «El pescado en el reino de Granada a fines de la Edad Media: especies y nivel de consumo», Manger et boire au Moyen Ages. Actes du Colloque de Nice, Niza, 1984, t. I, pp. 103117; Idem, «La pesca en el mar de Alborán en época nazarí (siglos XIII-XV» en AA.VV. La pesca en la Edad Media, Murcia, 2009, pp. 193-219.

${ }^{30}$ Bolens, Lucie, La cocina andaluza, un arte de vivir: siglos XI-XIII, Málaga, 1992; ElÉXPURU, Inés, La cocina de al-Andalus, Madrid, 1994; Huetos Solano, Ma Dolores y SAlAS-SAlvadó, Jordi, «Alimentación, dietética y nutrición en al-Andalus», SALAS-SALVADÓ, Jordi, GARCÍA-LORDA, Pilar, SÁNCHEZ RIPOLLÉS, José Ma (Eds.), La alimentación y la nutrición a través de la Historia, Barcelona, 2005, pp. 217-246; RoSEMBERGER, B., «Dietética y cocina en el mundo musulmán occidental según el Kitab al-Tabij, recetario de época almohade» en Cultura alimentaria Andalucía-América, México D.F., 1996; GARCÍA SÁNCHEZ, Expiración, «La gastronomía andalusí», en Salvatierra Cuenca, Vicente (Ed.), El Zoco. Vida económica y artes tradicionales en al-Andalus y Marruecos, Madrid, 1995, pp. 49-57; Idem, «La alimentación en la Andalucía islámica. Estudio histórico y bromatológico. I. Cereales y
} 
una cuidada presentación, si bien son aspectos que nos han transmitido los recetarios que se han conservado y que probablemente estaban destinadas a la cocina de una clase social determinada. La alimentación popular era fundamentalmente vegetariana, basada en cereales y legumbres, con la aportación de proteínas de origen animal cuando era posible. Muchas de las comidas eran líquidos en los que se hervían grasas y se mezclaban con cereales o pan troceado, y se terminaban con especias. Sopas, migas y gachas de cereales fueron las formas más usuales del consumo de alimentos de las clases populares.

De la cotidianeidad de la sal en la vida de las clases populares andalusíes también nos da constancia su normal presencia en la elaboración de otros productos de primera necesidad, como por ejemplo el pan. En la Málaga del primer tercio del siglo XIII era costumbre echar sal en la preparación de la harina, pero en gran cantidad parece que era perjudicial:

La mucha sal aumenta el peso del pan, pero produce vómitos; esto se pone de manifiesto con el cotejo. Si lleva natrón suelta el vientre, produce sed y origina hemorroides $^{31}$

Hay que llamar la atención sobre el abundante uso de condimentos y especias en la preparación de alimentos en al-Andalus, desde canela, miel o pimienta hasta cilantro, tomillo, menta o similares. Y la sal está siempre presente en el amplio recetario andalusí ${ }^{32}$ :

Has de saber que el conocimiento del uso de las especias es la base principal de los platos de cocina, porque es el cimiento del guisar y sobre él se edifica (...) en ellas está también lo que distingue los manjares y les da sabor y los mejora. ${ }^{33}$

Según un tratado sobre alimentos de época nazarí ${ }^{34}$, la sal está presente en la preparación de los garbanzos junto al tomillo y la pimienta ${ }^{35}$, en el mejor de los panes que es el fermentado si se amasa con sal y agua ${ }^{36}$.

leguminosas», Andalucía islámica. Textos y Estudios, II-III (1981-1982), pp. 139-176; Idem, «La alimentación en la Andalucía islámica. Estudio histórico y bromatológico. II. Carne, pescado, huevos, leche y productos lácteos», Andalucía islámica. Textos y Estudios, IV-V (1983-1986), pp. 237-278; GARCÍA BAENA, Andrés, La alimentación en al-Andalus: cereales y aceite, Málaga, 2008.

${ }^{31}$ Chalmeta Gendrón, Pedro, «El "Kitab fi adab...»p. 161.

32 Son notables las constantes referencias. HUICI MIRANDA, Ambrosio, «La cocina hispano-magribi durante la época almohade», Revista del Instituto Egipcio de Estudios Islámicos, 5, 1-2 (1957), pp. 137155; Idem, La cocina hispano-magribi en la época almohade según un ms inédito. Kitâb al-tabij fi lMagrib wa-l-Andalus fi ásr al-Muwahhidin, ed. Madrid, 1965, trad. Madrid 1966, pp. 88-90.

${ }^{33}$ HUICI MIRANDA, Ambrosio, La cocina hispano-magribí... texto árabe p. 65, traducción p. 85.

${ }^{34}$ DiAz GARcíA, Amador, «Un tratado nazarí sobre alimentos: Al-Kalâm 'Alà l-Agdiya de Al-Arbuli. Edición, traducción y estudios, con glosarios (I)», Cuadernos de estudios medievales, VI-VII (19781979), pp. 5-45. 
También la sal es uno de los ingredientes que aparece en la preparación de quesos y mantequillas: «La mantequilla, en general, es fría y húmeda; calma [el dolor de] las quemaduras. Si se emplea en los guisos, disminuye su humedady, con el fuego y la sal, gana un poco de calor» ${ }^{37}$.

En la preparación de las carnes, la sal prácticamente está presente en todos los casos. En la carne de caza, cuando se cocina en el zoco al aire libre, se recomienda lo siguiente:

Traerán la caza fresca, tal como la vende la gente, asándola en las mencionadas cazuelas, con su consabida salsa de vinagre, almaro, aceite, especias, ajo machacado y en dientes y sal ${ }^{38}$

También tenemos recetas para las carnes de animales domesticados, sobre todo en el caso del carnero:

Se coge la caña del pulmón de un carnero grueso con todo lo demás, excepto la pajarilla, y se corta en trozos grandes y se limpia. Se coge el bandullo, se deja bien limpio lavándolo, se corta y se pone todo ello en una olla nueva y se le echa agua, sal, aceite, cilandro seco, y cebollas cortadas en dos, en la cantidad que se quiera y se pone la olla a la lumbre (...) Si se quiere preparar con carne de las patas y del lomo [del carnero], se coge la carne y se cuece sin cortar, en una olla grande con agua y sal. Cuando está cocida se saca de la olla y se deshila con la mano... ${ }^{39}$

También al comer el tuétano, que debe prepararse con tomillo sal y pimienta, o en la preparación de las patas, los hocicos, las orejas y la careta de la carne de reses, a las que «Es necesario ponerles mucho aceite y salmuera» ${ }^{40}$. También al comer la carne de las mamas y de las criadillas del ganado hay que prepararlas con tomillo, sal y pimienta ${ }^{41}$, tríada que como vemos se repite con frecuencia en la preparación de otras carnes, como la de ojos y el hígado. En la carne de aves, como no podía ser menos, también la sal es uno de los ingredientes de su preparación, por ejemplo para los buches y mollejas que hay que cocinas «con salmuera, aceite y especias picantes» ${ }^{42}$.

\footnotetext{
${ }^{35}$ DiAz GARCíA, Amador, «Un tratado nazarí...», p. 12.

${ }^{36}$ DiAz GARCíA, Amador, «Un tratado nazarí...», p. 16.

${ }^{37}$ AbU MARWAN, Tratado de los alimentos, Ed. y Trad. GARCÍA SÁnCHEZ, Expiración, Madrid, 1992, p. 62.

${ }^{38}$ Chalmeta Gendrón, Pedro, «El "Kitab fi adab...», p. 181.

${ }^{39}$ HUICI MIRANDA, Ambrosio, La cocina hispano-magribí... p. 49.

${ }^{40}$ DiAz GARCÍA, Amador, «Un tratado nazarí...», p. 8.

${ }^{41}$ DiAz GARCíA, Amador, «Un tratado nazarí...», p. 8.

${ }^{42}$ DiAz GARCÍA, Amador, «Un tratado nazarí...», p. 12.
} 
Otros derivados de la carne animal, como la grasa y la manteca, se recomienda sean comidas con sal, pimienta y salsa de mostaza ${ }^{43}$. Y la sal es uno de los condimentos que se usa para preparaba el condimento de las longanizas a principios del siglo XIII:

Coste de las longanizas: un arrelde de carne, arrelde menos cuarto de sebo, especias, ajo y sal, vinagre, almaro, agua para regarlo y tripa. ${ }^{44}$

También junto a la mostaza, la sal se recomienda para aderezar las carnes fritas ${ }^{45}$.

En lo que respecta a la cocina del pescado, también la sal es uno de los ingredientes con los que se recomienda preparar cuando es cocido ${ }^{46}$. Aunque por lo general se recomienda el consumo de pescado fresco, la salazón debió ser muy frecuente:

La gente también pone el pescado en salazón; de ello ya se trató cuando hablamos, en general, del pescado. El reposo, al producir cierta alterazín, le confiere calor, lo mismo que sucede con el calor de la sal y la sequedad de la misma. Su naturaleza es más delicada [que la del fresco], aunque resulta menos nutritivo; su quimo, en la mayoría de los caso, es flemático y salado. El pescado fresco es mucho mejor que el que está en salazón, del mismo modo que el queso fresco es, de cualquier forma, mejor que el añejo. $^{47}$

De lo frecuente que debió ser el consumo de pescado salado tenemos constancia por distintas fuentes. De hecho, a comienzos del siglo XIII, se recomendaba para el buen gobierno del zoco que se vigilara que el consumo de pescado fuera salado si no era fresco del día:

Porfíe [hasta conseguir] que los vendedores de pescado no entreguen el de la víspera, mezclado con el fresco; ni conserven pescado del día anterior, como no sea salado. El de la víspera se venderá aparte y lo mismo hará con el fresco; esto incluye también a aquellos que lo vendan frito o guisado. ${ }^{48}$

Respecto a las propiedades del pescado salado leemos que:

\footnotetext{
${ }^{43}$ DiAZ GARCÍA, Amador, «Un tratado nazarí...», p. 9.

${ }^{44}$ Chalmeta Gendrón, Pedro, «El "Kitab fi adab...», p. 165. Sobre la fabricación de dicho condimento cf. HUICI MIRANDA, Ambrosio, La cocina hispano-magribi..., p. 88.

${ }^{45}$ DiAz GARCíA, Amador, «Un tratado nazarí...», p. 16.

${ }^{46}$ DiAz GARCíA, Amador, «Un tratado nazarí....», p. 26.

${ }^{47}$ ABU MARWAN, Tratado de los alimentos..., p. 67.

${ }^{48}$ Chalmeta Gendrón, Pedro, «El "Kitab fi adab...», p. 172
} 
estimula el apetito y limpia el estómago de flema. Si se abusa de él produce prurito, sarna y mucha sed. Ayuda muy bien a provocar el vómito, y en definitiva se parece más a un medicamento que a un alimento ${ }^{49}$

Para época bajomedieval, entrando ya en el reino nazarí, tenemos noticias de una potente industria de salazón de pescado que se llevaba a cabo a lo largo de toda la costa granadina, y especialmente desde Vélez Málaga a Marbella ${ }^{50}$, siendo las anchoas malagueñas famosas en todo el Mediterráneo.

Como veremos más adelante, son las mismas propiedades que se le atribuyen a la sal por sí sola en los tratados farmacológicos andalusíes. Siguiendo con los «frutos del mar», en el caso de las anguilas se recomienda que «hay que quitarles la piel, echarles sal y aliñarlas con aceite y almorí, y cocerlas en el horno hasta que estén a punto» ${ }^{51}$.

Este almorí que se cita es también uno de los alimentos en los que la sal estaba presente, del árabe al-muri y éste del latín muria, que no significa sino salmuera, una especie de pasta a base de mezcla de harina con varias especias, vinagre, miel y frutos secos, en el que la sal era uno de los ingredientes principales, que se desmenuzaba y agregaba a las salsas más variadas ${ }^{52}$. Tradicionalmente se ha venido identificado el almorí con el garum romano, pero el primero se elaboraba a base de cebada y el segundo con restos de pescado. Ambos se usaban como potenciadotes del sabor, y los dos se mezclaban con numerosos productos para dar lugar a bebidas y comidas muy diferentes. En función de la mezcla que se hiciera, se hablaba de distintos tipos de almorí, entre los que cabe destacar el almorí de pescado (Murrí al-hut), que se hace:

...con pescado podrido, sal y zumo de uva, que se deja hasta que toma el color y la consistencia del vino, y que calienta mucho, sin producir embriaguez. ${ }^{53}$

Junto al almorí hay otras salsas y preparados en los que la sal es uno de los ingredientes que no debe faltar. En el tratado sobre los alimentos de que tradujo Huici (s. XIII) se nos indica como la carne en escabeche, además del ingrediente principal, carne y vinagre, lleva también pasas, pimienta, cilantro seco, cebolla majada con cilantro verde, ajo y sal, y a todo ello se le añade luego yemas de huevo cocidas y sopas de $\operatorname{pan}^{54}$. Pero además de estar presente en la cocina andalusí, la sal tenía otros muchos usos.

\footnotetext{
${ }^{49}$ DIAZ GARCÍA, Amador, «Un tratado nazarí...», p. 31.

${ }^{50}$ IBN AL-JATIB, Mi'yâr al-ijityâr fî̀ dikr al-ma'âhid wa-l-diyâr, Ed. y trad. por KAMAL CHABANA, Mohammed, S.L., 1977, p. 115.

${ }^{51}$ DiAz GARCÍA, Amador, «Un tratado nazarí...», p. 30.

${ }^{52}$ GARCÍA BAENA, Andrés, La alimentación en al-Andalus: cereales y aceite, Málaga, 2008, pp. 85-88.

${ }^{53}$ Es descrito en el tratado de cocina nazarí de al-Arbulí. DiAz GARCíA, Amador, «Un tratado nazarí...», p. 23.

${ }^{54}$ Huici Miranda, Ambrosio, Traducción española de un manuscrito anónimo del siglo XIII sobre la cocina hispano-magribi, Madrid, 1966, pp. 103 y 124.
} 
Para preparar aceitunas, hay diferentes tipos de aliños, pero en todos está presente la sal, bien en aquellos a base de sal, hinojo y comino o bien en aquellas que se preparan con vinagre o vino dulce. Las referencias son abundantes en distintos autores:

Las aceitunas verdes curadas en agua y sal son más bien calientes y secas de complexión, despiertan el apetito, confortan el estómago, pero son de escaso alimento.

Las que se curan con vinagre y sal son más fuertes para despertar el apetito.

En cuanto a las aceitunas curadas con sal y aceite, son calientes con cierta tendencia a la humedad, muy alimenticias, pero dañan la boca del estómago.

Las aceitunas gordales curadas en sal y agua son calientes y secas y abren las obstrucciones producidas por el hígado y en el bazo por la flema. ${ }^{55}$

Adobo de las aceitunas de mesa. Se recogen las aceitunas con las manos y se machaca sólo la cantidad necesaria: se colocan en un recipiente y se lavan echándoles agua caliente. Luego se les retira ésta y se echa otra agua y sal molida, se tapa el recipiente con hojas de hinojo, laurel y cidro, y se deja unos días. Más tarde se les esparce comino y sal, y se cogen cuando se necesiten comer: se vierte sobre ellas orégano y se comen. ${ }^{56}$

De hecho, la sal es fundamental en todos los encurtidos, que se hacían incluso con berenjenas, ya que «Todos los encurtidos adquieren del agua y de la sal una fuerza que se añade a la suya propia y a la que se impone generalmente» ${ }^{57}$.

Incluso la sal está presente en el mismo momento de la recogida de la aceituna, iniciando de ésta forma otro de los capítulos de su uso, el de la manufactura:

Quien quiera extraer su aceite de forma rápida e inmejorable las recogerá del modo dicho, pero quien desee reunir el producto de varios días, habrá de echar al atardecer sal sobre lo que ha recolectado durante la jornada, hasta reunir cuantas quiera (...) Si están bajo tierra, toleran ser colocadas sin sal, pero con ésta resultan mejores y más ricas en aceite. $^{58}$

Incluso se indica que

Si deseas obtener un buen aceite de aceitunas de mala calidad, muélelas en el momento de recogerlas, y coloca encima y debajo de ellas sal con hojas tiernas de olivo, pero sin poner unas sobre otras. ${ }^{59}$

\footnotetext{
${ }^{55}$ DiAz GARCíA, Amador, «Un tratado nazarí...», p. 17.

${ }^{56}$ ABU L-JAYR, Kitãb al-Filãha. Tratado de agricultura, Ed. y trad. CARABAZA, Julia Ma, Madrid, 1991, p. 311 .

${ }^{57}$ DiAz GARCÍA, Amador, «Un tratado nazarí...», p. 18.

${ }_{58}^{58}$ ABU L-JAYR, Kitãb al-Filãha..., p. 310.

${ }^{59}$ ABU L-JAYR, Kitãb al-Filãha..., p. 311.
} 
Relacionado con el aceite, también nos consta como la sal está presente en su preparación. Por ejemplo, para depurar el aceite turbio:

Se consigue de una de dos formas: la primera consiste en cocerlo en ollas, y colocar sobre él sal sin cubrirlo totalmente; después lo filtras y vuelves a cocer y colar el resto; así hasta que lo depures en su totalidad. La segunda consiste en ponerlo en una gran tinaja al sol en el período estival, espolvorearle sal molida, y limpiarlo varias veces de lo que se muestre en mal estado (...) Todo aceite hervido en el fuego y rociado con sal se librará de la acritud y fetidez. ${ }^{60}$

Como hemos indicado anteriormente, la sal es un producto indispensable para el ganado, y también lo era en al-Andalus. Por una parte, la infesta de sal ayuda al engorde del ganado, al aumentar la retención hídrica de los tejidos, aparte de suponer una reserva de agua que facilita la supervivencia del animal en la época estival o en años de sequía. Igualmente, la sal es especialmente necesaria para el ganado rumiante, y conviene recordar que la ganadería en al-Andalus se abastecía fundamentalmente de bovinos, ovinos, caprinos y camélidos, todos ellos pertenecientes a este grupo. Necesitan la sal para digerir el bolo alimenticio, ya que facilita la conversión de la fibra vegetal con consume el animal. Toso estos datos eran conocidos por los andalusíes, y así contamos con una referencia en la obra del sevillano Ibn al- 'Awwâm, del siglo XIIXIII:

En quanto á dar á las bestias sal á comer, dice Aben Abí Asma, que á la bestia que se alimentare de verde es importante darle alguna sal molida, omitiéndolo dos dias, y que no conviene dársela mas de tres; que si no se la hubieres dado, conviene se la des á la semana uno ó dos dias sin dexar alguna en que no se les dé a comer la sal, especialmente estando ella descansada; que si las bestias no quisieren comer la sal de buen grado, se les abra la boca y se les meta en ella levantándoles la cabeza para que no se les derrame; y que si la rehusaren, se les abra la boca con un palo y se les meta la sal, siendo también conveniente acostumbrarlas á esto con blandura de suerte que no se necesite la fuerza. ${ }^{61}$

Con frecuencia los pastores daban sal para lamer a los animales para así incrementar su sed y, al necesitar beber más líquido las reses, aumentar su peso y con ello su precio en los mercados, tal y como está documentado se hacía en los territorios castellanos ${ }^{62}$. Vemos, por tanto, como los agrónomos andalusíes eran conscientes de la necesidad de sal que tenía el ganado «que se alimentare de verde». Esta relación sal-ganadería es

\footnotetext{
${ }^{60}$ ABU L-JAYR, Kitãb al-Filãha..., pp. 310-311.

${ }^{61}$ IBN AL- 'AwWÂM, Libro de Agricultura, Madrid, 1802 (reed. 1988), t. II, p. 531.

${ }^{62}$ KleIN, Julius, La Mesta, Madrid, 1979, p. 41.
} 
fundamental a la hora de analizar los espacios de explotación de la sal, como tendremos ocasión de ver más adelante. Hay una relación muy estrecha entre sal y ganadería, que obligará a los ganaderos a tener en cuenta siempre en sus desplazamientos la presencia de salinas o salmueras, o al menos prados halófilos, estableciéndose unas ciertas transhumancias obligadas.

Además, como han señalado distintos autores, el uso de la sal también está en relación con los tratamientos de las pieles, cueros y lanas, aunque no hemos encontrado referencias concretas en este sentido ${ }^{63}$.

También en las prácticas agrícolas la sal jugaba un papel importante, fundamentalmente como fertilizante, junto al estiércol ${ }^{64}$, a la hora de plantar determinadas especies. Así lo recoge un autor de finales del s. XI-principios del s. XII:

Plantío de la Palmera. Coges los dátiles con su propia envoltura, separas los huesos, se plantan en un terreno salobre y arenoso (colocando un agujero que hay en mitad de dichos huesos hacia arriba) en una zanja de un codo de profundidad, y se llena con tierra mezclada con estiércol putrefacto y sal en la siguiente disposición: dos espuertas de tierra y abono, señalen unos cuatro arrates de sal y una arroba de arena al igual que de estiércol. Se mezcla todo hasta que se amalgame y se llena con ello la zanja, se colocan en ésta los huesos y se cubren con estiércol humano. Se echa un dedo de tierra sobre ellos, y se riegan dos veces por semana. Cuando germinen, descubres su pie, coges un poco de sal, la mezclas con estiércol humano y la colocas alrededor de las raíces. Esto se hace a lo largo de todo el otoño... ${ }^{65}$

Este autor coge esta cita de otro agrónomo andalusí anterior a él, el toledano Ibn Bassal, del s. XI, aunque las palabras no son exactamente las mismas:

Plantación de la palmera. La plantación de la palmera se verificará en el mes de enero, y la operación se hará del modo siguiente: Tomaremos un dátil con su pulpa o carne, lo henderemos por su dorso, hacia la parte de la estría que se forma cabe el dorso del hueso o carozo; en la tierra salada cavaremos un hoyo de un codo de profundidad,

\footnotetext{
${ }^{63}$ Sobre la industria textil en al-Andalus SERRANO-PIEDECASAS FERNÁNDEZ, Luis, «Elementos para una historia de la manufactura textil andalusí (siglos IX-XII)», Studia Historica. $H^{a}$ Medieval, IV (1986), pp. 205-227; y VALLVÉ, Joaquín, «La industria en al-Andalus», Al-Qantara, I (1980), pp. 225-236.

${ }^{64}$ No obstante, no aparece en ninguno de los siete tipos de estiércol que cita Ibn Bassal (s. XI), ni siquiera en los compuestos, e incluso recomienda que no se use el abono de los baños porque «está dotado de sequedad y es salino». IBN BASSAL, Libro de agricultura, editado, traducido y anotado por MiLlás VALLicrosa, José Ma . y AZIMAN, Mohamed, Tetuán, 1955, p. 58.

${ }^{65}$ ABU L-JAYR, Kitãb al-Filãha..., p. 254 y nota al pie 66. Ibn al-Áwwâm realiza una cita con respecto a este plantío que no coincide con la de Abu 1-Jayr más que en algunas frases. Dice así: «...hecho el hoyo de dos codos de profundo y otro tanto de ancho; y lleno después de mezcla de tierra y estiércol de manera que quede medio codo de vacio, se ponga después el hueso del datil en medio de la tierra, fixándole, no levantado, sino tendido, y se le eche tierra mezclada de estiércol y sal hasta cubrirle; que después acabado de hinchir el hoyo con sarmientos, y regado cada dia hasta que nace, se traslade su planta á otro sitio.» IBN AL-'AWWÂN, Libro de Agricultura ..., p. 344.
} 
sacaremos la tierra de este hoyo y la mezclaremos con estiércol bien maduro, en la proporción de un cuarto del peso de la tierra. Si la cantidad de tierra que tenemos dispuesta es de dos espuertas le adjuntaremos cuatro libras de sal, y si la cantidad de tierra es inferior o bien superior, entonces añadiremos sal según dicha proporción (...) Cada semana los regaremos dos veces y en el principio del otoño nutriremos los tiernos tallitos con sal, del modo siguiente: Al germinar las plantas descubriremos sus raíces, y les pondremos una mezcla de sal con estiércol. Tendremos cuidado de no trasplantar hasta transcurridos dos años... ${ }^{66}$

También se usa como parte de un remedio insecticida natural. Por ejemplo, para combatir a los gusanos que afectan a los árboles:

Se limpian los gusanos que haya a su alrededor y se trasplanta su cepellón; más tarde se coge ceniza de palomina (que contiene este estiércol quemado) y se mezcla con arena y sal, siendo preferible que esta última ocupe un sexto del total, que la arena esté en menor cantidad y la ceniza en mayor proporción. Se mezcla todo esto con la tierra superficial y se va incorporando a ella... Cuando acabes con la ceniza, la tierra será inmejorable. ${ }^{67}$

En el caso de las hortalizas:

... vete al lugar que quieras plantar, riégalo y excávalo. Coge después la aludida ceniza, arena y sal en esta proporción: una gran cantidad de ceniza, menos de sal, una porción mediana de estiércol putrefacto y otra bien repleta de arena. Se bate todo bien y se vierte en cada almáciga dos espuertas de esta tierra ya preparada. A continuación, se siembran los granos y otras simientes y se riegan con agua varias veces... ${ }^{68}$

Encontramos referencias a la sal en otrasa de las disciplinas que alcanzron un gran desarrollo por parte de los musulmanes en la Edad Media, y especialmente en alAndalus, como son la farmacología ${ }^{69}$ y la medicina. Una de las referencias más usuales es a los efectos del agua salada, tal y como nos indica Ibn Baytâr:

La facultad y acción del agua salada es como la de la sal excepto en que con ella, se provoca la evacuación, el estreñimiento y la suavización y se administra en lavativas para las úlceras malignas de los intestinos y la ciática crónica. Es conveniente para los

\footnotetext{
${ }^{66}$ IBN BASSAL, Libro de agricultura ..., p. 68.

${ }^{67}$ ABU L-JAYR, Kitãb al-Filãha..., p. 232. En este caso también el texto es recogido por Ibn al-'Awwân con leves modificaciones, aunque esta vez si lo atribuye al agrónomo sevillano. IBN AL- 'AWWÂN, Libro de Agricultura ..., p. 630.

${ }^{68}$ ABU L-JAYR, Kitãb al-Filãha ..., pp. 232-233.

69 JACQUART, Danielle, «Islamic Pharmacology in the Middle Ages: Theories and Substances», European Review, 16 - 2 (2008), pp. 219-227.
} 
derrames de los miembros. Sucedáneo del agua del mar: si se necesita el agua de mar, puede ocupar su puesto el agua salada con provecho. ${ }^{70}$

Precisamente uno de los tratados médicos más destacados es el de Ibn Baytâr, de principios del s. XIII, en donde se recogen la descripción y uso de miles de productos usados como fármacos, en un completo compendio que se inscribe plenamente en la tradición cultural clásica. ${ }^{71}$ Con respecto a la sal ${ }^{72}$ nos refiere al pensamiento de los autores clásicos así como de otros autores árabes, remarcando respecto a su uso como condimento y como potenciador de vómitos y evacuaciones.

Ayuda a la evacuación y al vómito. Disuelve los medicamentos, extrae la flema viscosa del estómago y el pecho, limpia los intestinos, excita los vómitos y los múltiplica. Secunda la acción de los medicamentos que atraen la atrabilis del interior de los órganos (...) La sal bituminosa evacua las serosidades, la atrabilis y la pituita corrupta (...) Expulsa los vientos, relaja el vientre, evacua la pituita, excita el corazón y calma los dolores, devuelve el apetito y hace desaparecer la palidez del rostro. ${ }^{73}$

También advierte de que «su uso excesivo inflama la sangre, debilita de la vista, disminuye los espermatozoides y causa el prurito y la sarna». Frente a estos efectos negativos, también destaca su uso como colutorio y como producto que, junto con el vinagre, ayuda a eliminar los elementos negativos del organismo, sirviendo para purificar el cerebro y las inflamaciones de las amígdalas, o para mejorar las pústulas y heridas por contusión y torceduras. Pero no sólo son éstas sus propiedades médicas, sino que además, mezclada con otras sustancias, tiene otras propiedades: triturada y mezclada con resina de olivo cicatriza las heridas, y disuelta en vinagre se emplea como colutorio y para aliviar las afecciones bucales y de garganta, además de otra serie de usos:

... detiene las hemorragias de las encías y la que sobreviene tras las extracciones dentales. Calentada e introducida en la boca, esta mezcla calma los dolores dentales.

\footnotetext{
${ }^{70}$ GARIJO GALÁN, Ildefonso, «Usos medicinales del agua en al-Andalus: Ibn al-Baytar», ÁlVAREZ DE Morales, Camilo (Ed.), Ciencias de la Naturaleza en al-Andalus. Textos y Estudios V, Granada, 1998, p. 108.

${ }^{71}$ IBN AL-BAYTÂR, Traité des simples, Trad. al francés LECLERC, Licien, Paris, 1883. Sobre la figura y la extensa obra del científico malagueño se celebró un congreso cuyas actas han sido publicadas GARCÍA SÁNCHEZ, Expiración (Ed.), Ibn al-Baytar al-Malaqi y la ciencia árabe: actas de los simposios internacionales sobre el cientifico árabe Ibn Al-Baytar, Málaga, 2008, 2 tomos.

${ }^{72}$ No hemos podido consultar la obra original, por lo que las referencias que aquí realizamos han sido tomadas de otros dos trabajos que lo refieren: MALPiCA CuEllo, Antonio, «La cultura de la sal en Andalucía Oriental en la Baja Edad Media. Formas de trabajo y explotación», en Just, Rüdiger (Ed.), Das Leben in der Saline. Arbaiter und Unternehmer, Halle (Saale), 1996, pp. 263-265; QUESADA QUESADA, Tomás, «El agua salada y las salinas», en El agua en la agricultura de al-Andalus, Barcelona, 1995, pp. 58-60.

${ }^{73}$ IBN AL-BAYTÂR, Traité des simples, trad. de LECLERC, L., Paris, 1883, vol. III, pp. 334-335.
} 
Empleada como gargarismo, saca la pituita y purifica el cerebro y los tumores de amígdalas... ${ }^{74}$

Además de estos usos, la mezcla de sal y vinagre servía también como antiséptico y cicatrizante: «Si con sal y vinagre se lavan, durante algún tiempo y todos los días, el prurito y las llagas postulantes, se les cura». Disuelta en vinagre con jabón calentado «es conveniente contra los tumores blandos y la inflamación de las extremidades» ${ }^{75}$.

También mezclada con otros productos, bastante más exóticos en este caso, la sal aparece en los preparados que vienen bien al corazón:

[Se toma] medio ratl de mirobálano indio, un cuarto de ratl de mirobálano de Kabul, cuatro uqiyyas y media de sal, dos uqiyyas y media de belérica, una uqiyya de agracejo, otra de goma de ciruelo, diez dirhames de semillas de albahaca, media uqiyya de tragacanto y otra media de canela china. Se tritura el conjunto, se disuelve, se mezcla con tres uqiyyas de aceite de almendra dulce y dos uqiyyas de aceite de rosas y aceite de sésamo a partes iguales y se amasa con cuatro ratles de azúcar y dos de miel. Por cada ratl de preparado se pone un cuarto de dirham de almizcle. Es útil, si quiere Dios, ¡ensalzado sea!. ${ }^{76}$

Otra de las aplicaciones médicas de la sal a las que hace referencia Ibn al-Baytâr son las dolencias oculares:

si se asocia sal pura y compacta con los medicamentos oftálmicos, agudiza la vista, disminuye la uña, difumina las nubes del ojo y es conveniente contra la grasa. ${ }^{77}$

Y en otras preparaciones farmacológicas para usos muy variados nuestro producto también está presente:

Mezclada con áloe y aplicada sobre el cráneo es útil contra las fluxiones del cerebro. Pulverizada, calentada y aplicada sobre las fracturas, los esguinces y las contusiones recientes, después de que se haya previamente aplicado en la región miel o aceite, o bien contenido con un vendaje, calma el sufrimiento (...) Disuelta en oximiel o en vino diluido, desobstruye toda obstrucción y extrae la pituita viscosa. ${ }^{78}$

\footnotetext{
${ }^{74}$ IBN AL-BAYTÂR, Traité des simples..., pp. 335-336.

${ }^{75}$ IBN AL-BAYTÂR, Traité des simples..., p. 336.

76 Álvarez de Morales y Ruiz-Matas, Camilo, «El libro de la Almohada» de ibn Wafid de Toledo (Recetario médico árabe del siglo XI), Toledo, 1980, p. 149. Sobre las medidas dadas en el texto, un ratl son aproximadamente 454,3 grs, una uqiyya 31,01 grs. y un dirham equivale a 2,90 grs, aproximadamente. Vid. Álvarez De Morales y RuIZ-MATAS, Camilo, «El libro de la Almohada» de ibn Wafid de Toledo (Recetario médico árabe del siglo XI), Toledo, 1980, p. 475.

${ }^{77}$ IBN AL-BAYTÂr, Traité des simples..., p. 336.

${ }^{78}$ IBN AL-BAYTÂR, Traité des simples..., p. 336.
} 
Con un sentido sanitario, también está presente nuestro producto en los preparados que se mandaban hacer para usar como dentífrico:

Dentífrico que refuerza la limpieza y elimina la corrupción de la raíz de los dientes. Se toman cabezas de sardinas saladas y se colocan en un pote de arcilla nuevo hasta que se quemen. Luego se pulverizan perfectamente, se le añade una parte de harina y cebada y se vuelve a quemar. Más tarde se amasa esto con miel y se usa disolviéndolo en zumo de uva y un poco de vinagre; con este preparado se frotan los dientes (...)

Dentífrico usado contra la infección de las encías y la caída de los dientes. Se toma un ratl de cal viva pulverizada y medio ratl ${ }^{79}$ de sal. Se vierte sobre ambos agua hasta que los cubra un dedo por encima y se deja tres días. Luego se coloca en un trapo tupido que se tuerce par sacar el agua, no cesando de hacerlo hasta que el agua salga pura (...) Se bate perfectamente hasta que tome una consistencia semejante a la miel, se coloca en un recipiente y se frotan los dientes con esto... ${ }^{80}$

También como receta para paliar el dolor de dientes:

Se toma ruda, se tritura y se le añade un cuarto de dirham de polvo de acíbar y medio dirham $^{81}$ de sal. Se abre la boca al paciente y se le aplica el mucílago obtenido, después de haber escarificado la envía. Si quiere Dios, ¡ensalzado sea! ${ }^{82}$

En algunas recetas y tratamientos de belleza y en las recomendaciones de higiene en los baños también está presente el cloruro sódico:

Para este mismo fin emplean también el atutia pulverizado, cernido y lavado, con agua y sal, posteriormente con agua de rosas y alcanfor, haciendo unos polvos que utilizan. ${ }^{83}$

Los mozos de baño dejarán sus piedras pómez, con las que raspan los pies e la gente, todas las noches en agua y sal para que no huelan. ${ }^{84}$

Otro de los usos que se le da a la sal en la Edad Media es el de estar presente en numerosos rituales de tipo religioso. Para el Islam andalusí no hemos encontrado referencia alguna a la presencia de sal en este tipo de actos, pero si que encontramos a este producto participando en el ritual de los cristianos en territorio andalusí, es decir, el

\footnotetext{
${ }^{79}$ Un ratl son aproximadamente 454,3 gr. Vid. ÁlvareZ DE MORALES Y RUIZ-MATAS, Camilo, «El libro de la Almohada..., p. 475.

${ }^{80}$ Álvarez de Morales y Ruiz-Matas, Camilo, «El libro de la Almohada...,p. 121.

81 Dirham aparece como una unidad de medida, de aproximadamente 2,90 gr. Vid. ÁlvarEZ DE Morales y Ruiz-MATAS, Camilo, «El libro de la Almohada..., p. 475.

${ }^{82}$ Álvarez de Morales y Ruiz-Matas, Camilo, «El libro de la Almohada...., p. 123.

${ }^{83}$ Chalmeta Gendrón, Pedro, «El "Kitab fi adab..., p. 378.

${ }^{84}$ Chalmeta Gendrón, Pedro, «El "Kitab fi adab..., p. 411.
} 
ritual mozárabe. Se empleaba para bendecir los lugares o casas al modo en que se emplea el agua bendita en la liturgia romana. De hecho, en el Liber Ordinum se recomienda que

la sal se eche sobre el hábito religioso impuesto a la mujer que se consagra a Dios, en el tálamo de los futuros esposos y en el sepulcro donde se va a depositar al difunto. ${ }^{85}$

En todas estas referencias a la sal no encontramos preocupación en ningún momento porque sea un producto que escasea o que tenga un precio demasiado elevado. Tan sólo alguna advertencia, la de evitar «las cosas saladas y las salazones» en el mes de agosto $^{86}$. Parece deducirse que la sal era un producto común, de fácil acceso y en abundancia suficiente, lo que nos llevaría a plantear entonces toda una serie de cuestiones en torno a su producción y distribución, quien ejercía el control de ambos procesos, o lo que es lo mismo, hasta que punto existía un control por parte del Estado, bien directo o bien indirecto a partir de algún tipo de impuesto o fiscalización. Lo cierto es que sobre su valor económico apenas tenemos noticias, salvo algunas escasas referencias a su venta en zocos y mercados. Tenemos algunos tratados que regulaban el mercado, los Kitab al-Hisba o simplemente hisba, que nos dan idea de la presencia de la sal en los mercados y zocos. Aunque la información que proporcionan sea escasa, nos da idea de lo que debería ser más o menos habitual entorno a los siglos XI-XIII en lo que a las prescripciones legales y mercantiles sobre la sal se refiere:

Debe ordenarse a los vendedores de sal que la tengan tapada, para que no entren bichos. ¿Se logrará algo? Solo Dios lo sabe. ${ }^{87}$

La sal era, de algún modo, valor de cambio en los mercados andalusíes. Por ejemplo, en Málaga en el primer tercio del siglo XIII la sal se usaba a la hora de calcular el coste de las longanizas ${ }^{88}$, así como también era costumbre que los panaderos calcularan el precio del pan a partir de los gastos invertidos en su elaboración, siendo uno de estos gastos el de la sal que se daba al hornero:

Para trabajarlo son precisos 3 amasadores, a razón de un dirham y medio, un asistente, un hornero, a medio dirham, medio ochavo de sal y agua, y cinco ochavos de leña, con un total de 33 dirhemes y medio ochavo. ${ }^{89}$

\footnotetext{
${ }^{85}$ Ferotin, Marius, OSB, Le Liber Ordinum, etc., París, 1904, pp. 63 y 119.

${ }^{86}$ NAVARro, Ma Ángeles, (Ed. y trad.), Risala fi awqat al-Sana. Un calendario anónimo andalusí, Madrid, 1990, p. 218.

${ }^{87}$ LÉvi-ProvenÇAL, Évariste y García GómeZ, Emilio, Sevilla a comienzos del siglo XII. El tratado de Ibn 'Abdûn, Madrid, 1948, pp. 169 y 200.

${ }^{88}$ Vid. supra

${ }^{89}$ Chalmeta Gendrón, Pedro, «El “Kitab fi adab..., pp. 156-157.
} 
Ante la imposibilidad de estudiar los aspectos fiscales y las cargas tributarias que llevaría aparejada la venta de la sal, debemos fijarnos ahora a los aspectos más esenciales de este producto, aquellos relacionados con su producción.

\section{Los espacios productivos: el agua salada y las salinas en al-Andalus}

Desde el punto de vista arqueológico, el problema para las salinas de al-Andalus es el mismo que para las del período fenicio o romano, que no se han documentado estructuras pertenecientes a un centro de producción de sal. En palabras de Michel Ponsich:

La realidad es que nunca se ha podido encontrar un vestigio arqueológico de depósitos de sal, naturalmente fosilizada, ni de salinas romanas. Sin embargo, sabemos que la sal era consumida en cantidades muy importantes por las fábricas de salazón... En cuanto a la sal marina, hay que destacar que encontramos salinas modernas en las proximidades de las antiguas fábricas de salazón..$^{90}$

En este sentido, tenemos un ejemplo en la provincia de Granada. En Almuñécar, ciudad de fundación fenicia y de posterior colonización romana, se conservan en buen estado los restos de una factoría de salazón de pescado romana, que parece tener un origen anterior, posiblemente fenicio.

Estos restos se encuentran puestos en valor, insertos en el parque botánico-arqueológico de "El Majuelo", situado a los pies de la fortaleza árabe de de San Miguel, en pleno casco antiguo de Almuñécar. Según las investigaciones arqueológicas llevadas a cabo en ella, la factoría fue fundada en el siglo V-IV a. C. manteniendo un buen grado de producción hasta el siglo $\mathrm{V}$ d. $\mathrm{C}^{91}$. Dicha factoría hay que ponerla en relación con algún centro productivo de sal, del que no hay constancia alguna. Cabe pensar, por lógica geográfica, que serían las salinas de Motril, localizadas concretamente en Torrenueva, sobre las cuales hablaremos más adelante, y que se encuentran a escasos kilómetros de distancia de la ciudad sexitana. La navegación de cabotaje permitiría llevar sal a éste y otros puntos de la costa en los que había pesca, tal y como se hacía en la Edad Media. También se ha propuesto que el posible centro salinero estuviera aún más cerca, pero haya quedado sepultado por las variaciones que se han sucedido en la

\footnotetext{
90 Ponsich, Michel, Aceite de oliva y salazones de pescado. Factores geo-económicos de Bética y Tingitania, Madrid, 1988, p. 44.

91 Molina FAJARdo, Federico y JimÉnez CONTRERAS, S., «Estado actual de las excavaciones en la factoría de Salazones El Majuelo», Almuñécar, Arqueología e Historia II, Granada, 1984, pp. 185-204 y Molina FAJARDO, Federico, Almuñécar romana, Granada, 2000, pp. 129-186.
} 
costa en los últimos siglos con crecientes aluvionamientos procedentes de las montañas cercanas que hubieran acabado por colmatar una infraestructura no monumental ${ }^{92}$.

Lo que está claro es que Almuñécar desde finales del siglo V a. C. o principios del siglo IV a. C., fundamenta básicamente su economía en esta industria de la salazón de pescado que adquirirá gran fama en todo el imperio. Y en esta industria, la sal estaba necesariamente presente.

Viendo los diversos usos que se le daban a la sal, y especialmente su presencia en la cocina o en otras actividades domésticas, no cabe duda que en al-Andalus debía haber un abastecimiento de sal suficiente. Dadas las buenas condiciones geológicas y climáticas de la Península Ibérica, es fácil pensar que su obtención se producía localmente, sin necesidad de exportarla de otras zonas del Europeas o del Mediterráneo. Tampoco tenemos referencias a una exportación de sal hacia al-Andalus en la documentación escrita. Todo apunta, de hecho, a que su obtención era de la manera más tradicional, mediante el aprovechamiento del agua del mar y los cursos y lagunas saladas del interior sin descartar tampoco el aprovechamiento de la sal gema ${ }^{93}$.

Del uso de la sal en la Península Ibérica tenemos constancia por referencias escritas ya desde la Antigüedad, cuando se citan las montañas de sal — mons ex sale, montanus sal- por autores como Aulo Gelio, Columela, Paladio o San Isidoro ${ }^{94}$. Varrón distingue incluso entre la sal «fossilis» o «fossicius» oponiéndola a la «marinis»o «maritimum»; es decir, distingue entre la sal de interior y las sal obtenida del mar.

La sal común o halita $(\mathrm{ClNa})$ es muy abundante en toda la Península, localizándose en dos tipos de depósitos. Por una parte, aparece disuelta en el agua marina, de donde se obtiene mediante la evaporación de ésta, provocando la precipitación del mineral. Por otro lado, aparece en depósitos fósiles procedentes de la desecación de mares antiguos, del Paleozoico esencialmente, como es el caso del mar de thetys, formando estratos de sedimentos de sal gema. Estos depósitos geológicos son explotados bien a modo de minas, con la apertura de socavones o galerías al igual que en la extracción de otros minerales, o bien aprovechando su disolución de forma natural en agua, bien en arroyos o surgencias superficiales o bien en las aguas subterráneas que se llevan a la superficie mediante pozos. En este último caso, es nuevamente mediante un proceso de evaporación, en esencia similar al llevado a cabo en el litoral, como puede obtenerse el preciado grano.

Para obtener el mineral disuelto en el agua salobre es necesario volver a reproducir las condiciones que lo generaron, es decir, hay que provocar la evaporación de agua para conseguir su nueva precipitación. Para ello es necesario obtener una fuente de energía

\footnotetext{
92 MalpiCa Cuello, Antonio, «Producción y comercio de la sal...», p. 138.

93 Solamente en las salinas del Cabezón de la Sal y en Guipúzcoa se documenta la producción de sal por ignición, esto es, por aplicación de fuego para acelerar el proceso de evaporación.

94 Morère Molinero, Nuria, «La sal en la Península Ibérica. Los testimonios literarios antiguos», Historia Antiqua, XVIII (1994), 235-250.
} 
que permita su calentamiento y posterior evaporación, lo que se consigue bien por el calentamiento artificial mediante la ignición, o bien por la acción del sol y el aire al poner la salmuera en estanques de gran extensión y poca profundidad para conseguir favorecer este proceso.

Atendiendo a estos distintos tipos de condicionamientos geológicos y geográficos se pueden distribuir los distintos tipos de salinas en grupos tipológicos ${ }^{95}$ :

- Marítimas

○ Del Mediterráneo

○ Del Atlántico

- Interior

- Por minería

- Por aprovechamiento de las aguas saladas

- De montaña, con origen en arroyos y manantiales salados

- De llanura

- Aprovechamiento de lagunas endorreicas o cursos salados

- Extracción mediante pozos.

Estas distinciones ya las hizo T. Quesada, advirtiendo además de cómo unas y otras generan a su vez unos paisajes característicos pero distintos entre sí:

Por una parte, hemos de considerar los espacios de montaña, con sus característicos paisajes abruptos, con fuertes pendientes y barrancos encajonados, que generan un aprovechamiento agrícola, y salinero, muy apegado al terreno, con una fuerte inversión en la adecuación del mismo y con una importante presencia de las actividades ganaderas; en segundo lugar las tierras de campiña, más llanas y extensas, que originan campos abiertos donde se pueden desarrollar en extensión los aprovechamientos, tanto agrícolas como salineros, con unos paisajes totalmente distintos a los anteriores. ${ }^{96}$

No obstante, hemos de señalar que en la Península Ibérica, debido a las condiciones geológicas, las salinas de montaña sólo se dan, casi exclusivamente, en tres conjuntos: el Sistema Penibético, el Sistema Ibérico y los Pirineos. En ambos casos, la forma, el tamaño y la topografía de estas salinas de evaporación por insolación se ven condicionadas, principalmente, por las características del sustrato sobre el que se implantan (roca o fango) y por las condiciones climáticas de la zona. Con el paso de los

\footnotetext{
${ }^{95}$ Esta tipología toma como punto de partida la elaborada por Tomás Quesada. QUESADA QUESADA, Tomás, «Las salinas de interior de Andalucía oriental: ensayo de tipología», en Agricultura y regadio en Al-Andalus, sintesis y problemas: actas del II coloquio Historia y Medio Físico, Almería, 1995, pp. 317334; Idem, «El agua salada y las salinas», en El agua en la agricultura de al-Andalus, Barcelona, 1995, pp. $57-80$.

${ }^{96}$ QUESADA QUESADA, Tomás, «Las salinas de interior...», pp. 319-320.
} 
siglos este método extractivo se ha ido perfeccionando para aumentar la velocidad de evaporación en función del nivel de insolación, pluviosidad, régimen de vientos, etc. de cada zona.

No obstante, todas las salinas disponen de una estructura similar, en la que se diferencian cinco tipos de áreas o infraestructuras:

- Los sistemas de captación de agua salada, que resultan ser uno de los elementos fundamentales. Según sea el origen subterráneo o superficial, se adoptarán soluciones tecnológicas diferentes:

- Derivación a partir de aguas superficiales, sean arroyos, torrentes o surgencias de agua salada. El agua es desviada de su curso natural, bien mediante presas o canales de derivación, conduciéndola hasta la zona de albercas.

- Extracción del agua desde la capa freática mediante pozos, movidos por tracción animal o eólica ${ }^{97}$. Los pozos suelen ser norias de sangre, aunque también los hay con sistemas de poleas. Hay que señalar que en ocasiones nos encontramos con sistemas mixtos, con pozos junto a los lechos de los cursos de agua para solventar las épocas en las que éstos no tengan caudal suficiente.

- Minas de agua. extracciones que, en lugar de buscar el nivel freático, buscan los acuíferos mediante galerías subhorizontales que permiten que el agua mane por gravidez.

- Los depósitos de almacenamiento donde se acumula el agua salobre que alimenta la salina. Se hace tanto para tener reservas suficientes en época de trabajo en la salina, que suele ser en verano cuando desciende el nivel de las aguas, como para comenzar el proceso de concentración de la salmuera con un calentamiento previo que aumente el grado de salinidad. La presencia de grandes contenedores de agua es imprescindible en las salinas, y generalmente se trata de albercas, aunque también aparecen otros tipos como balsas de tierra o incluso aljibes, como en la salina de Casería de Badulla en Jimena (Jaén). Se distinguen de los contenedores de agua para regadío en su gran extensión y poca profundidad, pues como ya se ha dicho se busca el calentamiento del agua. La fábrica de estas albercas es muy variada. Las hay de sillares, como en la Hoya Real en Peal de Becerro o las de Barchel en Bacor, o con construcciones más

\footnotetext{
${ }^{97}$ Hay ejemplos en Sicilia, en las salinas de Trapani. HoCQuet, Jean-Claude, MALPICA CuelLO, Antonio y Weller, Olivier, Hommes et paisajes du sel: une aventure millénaire, Arles, 2001, pp. 49-50 y 79.
} 
pobres. Debemos señalar, finalmente, que lo normal es que las salinas cuenten con más de una balsa de almacenamiento, sobre todo en las de mayor tamaño.

- La conducción de agua en el interior de la salina, para facilitar la distribución de la salmuera en el interior de la misma, así como desde el punto de obtención hasta las distintas balsas. Las soluciones son variadas, como también las distintas distancias a recorrer. En el caso de las salinas de Barchel, el pozo de agua salada dista $1 \mathrm{Km}$ de la salina, solucionándose la distancia mediante la construcción de una acequia que bordea la ladera del barranco y que lo cruza mediante un acueducto. En otros casos son simples canales de mucha menor envergadura, a menudo simplemente labrados en el terreno al igual que las acequias. También es frecuente el uso de las canalizaciones de madera o de cerámica. Por supuesto, la gravedad juega un papel importante en estas conducciones, máxime en el caso de las piletas que simplemente están conectadas entre sí.

- Las zonas de evaporación o cristalizadores, en las que se retiene el agua mientras es sometida a un proceso de evaporación y concentración salina por exposición solar. Se pretende conseguir la máxima concentración salina, cristalizando los cloruros. De alguna forma, podríamos considerarlo como los «campos de cultivo» de la sal ${ }^{98}$. Se trata de una superficie plana y extensa, en la que la pendiente existente ha sido estudiada o modificada para aprovechar al máximo la gestión del agua salada y su evaporación. Son un conjunto de estanques de gran superficie y muy poca profundidad, que se llaman piletas, pozas o eras, según las zonas, y que se disponen a lo largo del espacio aplanado en grupos, que forman los llamados «cuerpos» de las salinas, que a menudo reciben nombres que los identifican. Cada cuerpo tiene un número diferente de piletas dependiendo tanto del caudal de agua disponible como de la orografía del terreno. Prácticamente en todas las salinas, las piletas tienen una forma cuadrada o rectangular, con una profundidad no superior a los 20-30 cm, y están construidas en mampostería, cantos rodados o pizarra. La impermeabilización de estas estructuras se consigue con una capa de arcilla compactada situada bajo el suelo y las paredes empedradas, aunque en algunos casos se aprecia la existencia de enlucidos de cal o almagra.

En estas zonas es donde se lleva a cabo la producción de sal y donde se concentra, propiamente, el trabajo del salinero. Son diversas las taréas, desde la distribución del agua al rastrilleo de la salmuera para evitar la formación de

\footnotetext{
${ }^{98}$ QuESADA QUESADA, Tomás, «Las salinas de interior...», p. 330.
} 
grandes bloques de sal y obtener sal de cristales finos de mayor calidad; así como la recolección que se lleva a cabo una vez se ha secado por completo la pileta. La última fase de producción de sal, antes de la recolección, es la de secado, para lo cual se efectúa el amontonado de la sal al sol. En ocasiones se ha creado una infraestructura específica para esta última fase, o bien se utilizan las zonas de paso entre los cuerpos de la salina.

- La zona de almacenamiento de la sal, llamadas comúnmente alfolíes. Deben ser lugares secos, resguardados del viento, la lluvia y la humedad.

Como señala Malpica,

\begin{abstract}
El hecho de que haya sal no quiere decir que se produzca o pueda producir a una escala conveniente para la sociedad concreta que la quiere explotar. Es más, en cuanto se pasa de un volumen y se llega al de la necesidad de conseguir de forma regular, sistemática y constante, tenemos que se precisa no ya la creación de una "factoría", que hemos de denominar "salina", sino de una organización social de su espacio y del inmediato a ella, porque fijar el punto de producción no es una decisión que se pueda tomar a la ligera. Incluso hay que hacer obras de adecuación y unas inversiones que puedan ser colectivas o de un grupo reducido. Una u otra opción obligan a una determinada organización social y espacial. ${ }^{99}$
\end{abstract}

La geografía de la sal es muy limitada, como ya señalamos, y se reduce a determinadas áreas interiores y a espacios marítimos $\operatorname{concretos}^{100}$. Podemos decir que la sal es un producto relativamente abundante en la naturaleza, pero que no es posible conseguirlo siempre, ya que requiere tanto de unas condiciones técnicas como de una organización social determinada, que permita tanto la creación de los centros productores, como su mantenimiento, así como su rendimiento y productividad de acuerdo con unas necesidades de producción y reproducción concretas.

Para el caso de al-Andalus, tenemos constancia, por menciones en distintas fuentes, de que se explotaban las salinas en la costa de Cádiz, Almería, Alicante e Ibiza ${ }^{101}$, los mismos núcleos de explotación tradicional en España y de los que hay bastante documentación a partir de la conquista castellana. Del último ejemplo, nos dice al-

\footnotetext{
99 MALPICA CUELLO, Antonio, «El medio físico y la producción de sal. Propuesta para el análisis de las salinas granadinas desde una perspectiva arqueológica», MARTín Civantos, José María (Ed.), Medio Ambiente y Arqueología Medieval, Granada, 2008, p. 149.

${ }^{100}$ Gual Camarena, Miguel, «Para un mapa de la sal hispana en la Edad Media», Homenaje a Jaime Vicens Vices, Barcelona, 1965, pp. 483-497.

${ }^{101}$ VALLVÉ, Joaquín, «La industria en al-Andalus...», p. 220.
} 
Himari que «Alli se encuentra una salina cuya sal nunca se agota» ${ }^{102}$. La información que tenemos acerca de las salinas costeras es mayor respecto a la que tenemos sobre las salinas de interior, en el que las referencias son bastante más escasa. Probablemente éstas últimas escapaban del control directo del Estado, sirviendo para el abastecimiento de una población en gran medida autosuficiente. Las salinas costeras, sin embargo, tienen una estrecha relación con el comercio, bien directamente bien a través de la conservación de los alimentos, lo que motivaría una mayor atención por parte de los cronistas. También hay que pensar que el tamaño de éstas últimas, y su impacto visual en la línea de costa, sería mayor que en las de interior.

Decíamos que eran escasas las noticias que tenemos sobre las salinas de interior, pero no por ello faltan referencias. Es el caso del territorio de Loja, en donde el visir Ibn alJatib se refiere en el s. XIV a unas $m^{\prime}$ adin al-mallaha o mina de sal ${ }^{103}$. Antonio Malpica puso de relieve como esta cita podía hacer referencia no a unas minas de sal como tales, de las que no hay evidencia ninguna en el territorio, sino a la recolección directa de costras o barros salinos sin necesidad de un proceso de insolación ${ }^{104}$.

Si que nos encontraríamos ante una auténtica extracción de sal gema en el caso de la Zaragoza del siglo XII, tal y como nos informa el geógrafo Ibn Gâlib: «Tiene una mina de sal gema, muy blanca y brillante, incomparable» ${ }^{105}$. De estas minas ya nos informó dos siglos antes al-Razi:

Ca. E ay venero de sal gema muy blanca e muy luziente, que lo non ha en toda tierra de Espana

Mo. E ay venero de sal gema muy blanca e muy luziente, que no a en tierra d'España.

Es. E ay venero de sal gema muy blanca e muy luciente, que lo non ha en toda tierra de España. ${ }^{106}$

Y también al-Himyari nos indica que «Una especialidad de Zaragoza es la sal gema, se explota en minas de la región; es de una calidad superior a la que se puede encontrar en otras partes» ${ }^{107}$. Es probable que, como señaló Vallvé, esta cita a Zaragoza debamos tomarlas por las de Remolino, situado cerca del río Ebro, en su orilla izquierda, a unos

\footnotetext{
${ }^{102}$ LÉVI-ProvenÇAL, Évariste, Le Péninsule Ibérique aun Moyen-âge d'après le Kitab ar-rawd, Leiden, 1938, p. 198 téxto árabe y p. 240 de la traducción francesa.

${ }^{103}$ IBN AL-JATIB, Mi'yâr al-ijityâr $\ldots$, p. 66.

${ }^{104}$ Malpica Cuello, Antonio, «Fiscalidad y comercio de la sal en el reino de Granada en la edad media», Das Salz in der Rechts und Handelsgeschichte. Internationaler Salzgeschichtekongress, Berenkamp, 1991, p. 79.

${ }^{105}$ VALlVÉ, Joaquín, «Una descripción de España de Ibn Gâlib», Anuario de Filología de la Universidad de Barcelona, I (1975), p. 377.

${ }^{106}$ AL-RAZI, Crónica del moro Rasis. Versión del Ajbar muluk al-Andalus de Ahmad ibn Muhammad ibn Musa al-Eazi, 889-955, Ed. y Trad. CATAlán, Diego y AndRÉs, Ma Soledad de, Madrid, 1975, p. 55.

${ }^{107}$ LÉvi-Provençal, Évariste, Le Péninsule Ibériqu..., p. 97 texto en árabe y pp. 119-120 de la traducción francesa.
} 
$35 \mathrm{Km}$ al NO de la ciudad de Zaragoza. A partir de la conquista cristiana por parte de Alfonso el Batallador, estas salinas entraron a formar parte del patrimonio regio ${ }^{108}$. Junto a las fuentes árabes, tenemos algunos datos más sobre la existencia de salinas en época andalusí que nos vienen datos por la documentación cristiana cuando, tras la conquista de diversos territorios, hacen referencia a salinas y a fuentes de agua salada en el proceso de incorporación de los territorios conquistados, o en el reparto de las tierras que llevó aparejada la repoblación. Estos textos proceden de documentos fiscales en los que los reyes informan y reclaman diversas rentas generadas por salinas existentes en ese momento, y que por tanto son de origen anterior, al menos andalusí ${ }^{109}$. Junto a ello tenemos cartas de donación y privilegios en los que hacen merced a unos $\mathrm{u}$ otros señores de diversos territorios conquistados con todas sus riquezas, incluyendo las salinas. Reproducimos aquí uno de estos ejemplos, fechado en 1124, meses después de consultado el territorio de Sigüenza, siendo el donatario Alfonso VII y el receptor el obispo Don Bernardo:

...facio cartam donationis sancti Mariae seguntine ecclesie et tibi venerabile ejusdem sedis episcopo domino Bernardo tuisque succesoribus ibi deo canonice servientibus de castro sancti justi cum omnibus suis hereditatibus,et cum illa villa de la Riba cum toto suo directo videlicet cum salinis, portaticis, pratis, turribus, molendinis, montibus, fontibus, exitibus et regressibus, et cum omnibus terminis qui ad illud castellum pertinent jure hereditario pro ut regale jus exigit. ${ }^{110}$

También es el caso de la donación en 1257, pocos años después de la conquista por los castellanos del Alto Guadalquivir, cuando el rey Alfonso X dona a la Orden de Calatrava las salinas de Baeza y Úbeda, que ya debían estar en explotación desde antes, ya que la cesión de las salinas se hace apenas 30 años después de la conquista:

Do e otorgo a uso don Pedryuannes, maestre de la caballería de la Orden de Calatrava, e a uestra Orden, aquellos que agora hy son e a los que serán daquí adelante pora siempre iamás, Xauiot, con el mío cellero e con la salinas que ha este cellero en Baeça e en Vbeda, e con sus molinos, e con sus pastos, e con sus ríos, e con sus fuentes, e con sus montes, e con todos sus términos... ${ }^{111}$

\footnotetext{
${ }^{108}$ ARroyo Ilera, R., «La sal en Aragón y Valencia durante el reinado de Jaime I»; Saitabi, XI (1961), pp. 253-261.

${ }^{109}$ Ejemplo de un trabajo de tales características, dedicado únicamente al Reino de Granada, es el de MALPICA CuELlo, Antonio, «Fiscalidad y comercio de la sal...»

${ }^{110}$ Minguella, Toribio, Historia de la diócesis de Sigüenza y sus obispos, Madrid, 1910, Vol. I, Colección diplomática $\mathrm{n}^{\circ}$ II, p. 348.

111 Documento fechado el 20 de mayo de 1257 en Monteagudo. GonZÁLEZ JimÉNEZ, Manuel, Diplomatario andaluz de Alfonso X, Sevilla, 1991, p. 214.
} 
Una tercera fuente de información sonre las salinas andalusíes podría ser la toponimia, aunque en la práctica apenas quedan topónimos de origen árabe que hagan referencia a la sal o salinas. Solamente podemos traer a colación en este aspecto la localidad granadina de La Malahá, literalmente «La salina» (en árabe al-mallaha $^{112}$ ), donde existe una gran salina conocida documentalmente ya desde el siglo XV y arqueológicamente desde época romana ${ }^{113}$. También dentro de este campo podemos hacer referencia a la nisba de algunos personajes, como el rebelde de finales del siglo IX Umar b. Mudimm al-Hatruli, llamado al-mallahi por su lugar de nacimiento en referencia a algunas de las numerosas salinas existentes en la campiña giennense, y del que tendremos ocasión de volver a hablar más adelante ${ }^{114}$.

También con un sentido lingüístico, aunque en una línea que aún está por estudiar, nos encontramos con una serie de términos asociados a la explotación de la sal, que van a aparecer en la documentación cristiana bajomedieval, y cuyo origen está en la terminología árabe. Nos referimos al «alfolí», que hace referencia al almacén de la sal, el «almudín» nombre que recibía el edificio comercial en los territorios de la corona de Aragón, y a los «alamines», los jueces u oficiales encargados de contrastar pesas y medidas en la venta del producto.

Tenemos por tanto constatado tres formas de explotación de la sal en al-Andalus: el aprovechamiento directo de costras y barros salados, la minería de la sal y las salinas por insolación. Dado que de las dos primeras no hay apenas más referencias que las que hemos expuesto, vamos a detenernos en describir las últimas, que corresponden además a la forma tradicional de explotación y producción de la sal.

La producción de sal mediante insolación requiere de unas condiciones climatológicas, edafológicas, hidráulicas y geológicas muy determinadas, por lo que no es posible su aplicación en cualquier parte. No obstante, la península Ibérica cuenta con todas estas características en buen grado, permitiendo una proliferación de lugares en los que potencialmente se puede obtener la sal bastante notable.

Debido a que es necesario una alta temperatura y unas condiciones de sequedad que permitan la evaporación del agua que contiene la sal, son los meses de verano los más óptimos para dedicarse a la recolección de este producto. De hecho, según se nos informa en uno de los calendarios andalusíes, de entre los siglos XIII-XIV, es precisamente a finales del verano, en septiembre, cuando «la sal se solidifica y se

\footnotetext{
112 Asin Palacios, Miguel, Contribución a la toponimia árabe de España, Madrid-Granada, 1944, p. 118.

${ }^{113}$ MalPiCA Cuello, Antonio, «Fiscalidad y comercio de la sal...», pp. 81-84; RUIZ JiMÉNEZ, Ana, Las salinas de la Malaha, Proyecto de investigación inédito. Granada, 2007; Idem, «Estudio arqueológico del entorno de las salinas de la Malahá», www.arqueologiamedieval.com, (Publicado el 29/02/2008) http://arqueologiamedieval.com/articulos/articulos.asp? $r e f=97$

${ }^{114}$ Aguirre SÁDABa, F. J. y Salvatierra Cuenca, Vicente, «Cuando Jaén era Yayyan», Jaén, vol. II (1989), pp. 461-462.
} 
cosecha el trigo» ${ }^{115}$. Aunque con algo de duda y polémica en su traducción, también en el calendario de Córdoba del siglo X se menciona como es en septiembre cuando la sal se «coagula» coincidiendo con la fecha de recogida del grano ${ }^{116}$. Se trata, por tanto, de una auténtica recolección de una cosecha. De hecho, por información que tenemos de la primera época castellana, era normal que se recogieran varias «cosechas» a lo largo del verano. No obstante, eso no quiere decir que la actividad salinera se concentrase únicamente en verano. Durante varios meses antes hay que preparar la actividad acumulando agua salada, y en los meses de invierno la actividad en la salina no cesa totalmente, ya que durante este tiempo hay que mantener el suelo, procurar que las lluvias no provoquen el estancamiento del agua dulce y que no se forme barro que impida la circulación del agua salada.

Las salinas costeras o marítimas, que utilizan el agua del mar como materia prima, cabría agruparlas en función de si están ubicadas en el mar Mediterráneo o en el Océano Atlántico, ya que las condiciones de ambos son distintas y van a marcar la propia configuración de la instalación productiva. En el caso de las oceánicas, cuentan con un grado de salinidad menor del agua, así como con una temperatura también menor, lo que obliga a una insolación mayor para calentar el agua. Esto determina la propia ubicación de las salinas atlánticas, que se concentran preferentemente en las costas meridionales, y especialmente en el golfo de Cádiz. Están situadas normalmente en la desembocadura de los distintos ríos, aprovechando los estuarios y deltas de los mismos. Estas salinas aprovechan los esteros y marismas provocadas por la pleamar, conteniendo con diques el agua en bajamar, formando estas balsas la reserva de agua a utilizar para la evaporación. Toda la zona del golfo de Cádiz, en la que se documentan bastantes salinas (la de Ayamonte, Isla Cristina, las de Lepe, las de Punta Umbría, las de San Juan del Puerto, las de San Fernando o las del Puerto de Santa María) ha sido desde la Antigüedad uno de los principales focos de comercio del pescado salado y las salazones, con importantes almadrabas históricas y restos arqueológicos, por ejemplo ánforas, que así lo avalan, y que no cabe duda de la importancia de la sal en esta área a partir de la conquista castellana ${ }^{117}$. Nuevamente nos encontramos con un silencio tanto en las fuentes como en la historiografía acerca de lo que ocurrió durante la época

\footnotetext{
${ }^{115}$ NAVARro, Ma Ángeles, (Ed. y trad.), Risala fi awqat al-Sana..., p. 224. Hay que advertir, no obstante, que en muchos aspectos en este calendario aparece información referente a Egipto, de donde copia bastante información, por lo que la referencia a la obtención de la sal en el mes de septiembre hay que tomarla con cautela.

${ }^{116}$ Le calendrier de Cordoue, ed. Dozy, R. y trad. al fr. Pellat, Ch, Leiden, 1961, pp. 144-145.

${ }^{117}$ Alonso Villalobos, Carlos, Gracia Prieto, F. Javier y MÉnAnteau, Loïc, «Las salinas de la bahía de Cádiz durante la Antigüedad: visión geoarqueológica de un problema histórico», SPAL: Revista de prehistoria y arqueología de la Universidad de Sevilla, 12 (2003), pp. 317-332; TORREJÓN CHAVES, Juan, «Las salinas de la bahía de Cádiz. Una aproximación a su historia económica», MALPICA CuELlo, Antonio y GonZÁlez AlCANTUD, José Antonio, (Eds.), La Sal: del gusto alimentario al arrendamiento de salinas, Granada, 1997, pp. 169-194; MARTín GUTIÉRREZ, Emilio, «Salinas y explotaciones salineras en la bahía de Cádiz a finales de la Edad Media», Morère Molinero, Nuria, (Ed.), Las salinas y la sal de interior en la historia: economía, medio ambiente y sociedad, Madrid, 2008, pp. 535-560.
} 
andalusí. Tan sólo algunas referencias, que permiten una constatación de su explotación en época islámica. En el amojonamiento de Medina Sidonia, la Puente de Cádiz y El Portal de 1269 se habla de «Las salinas que se dicen de Sarraque» asociadas a una alquería homónima, topónimo cuyo significado se ha relacionado con la salida de agua $^{118}$. En el repartimiento de El Puerto se incluía la alquería de Grañina, identificada con Galyana o Ghaliana junto a las salinas de Porluengas, en la actual laguna del Gallo $^{119}$. También sabemos que en época nazarí el producto de las salinas del Puerto de Santa María eran llevadas a Málaga para la industria conservera de la anchoa. Aunque la información es escasa, resulta suficiente para establecer una relación entre los núcleos de población rural y la explotación del recurso salino.

En lo que respecta a las salinas marítimas situadas en las costas mediterráneas, que fueron las más abundantes en al-Andalus, presentan algunas diferencias con las del Atlántico en virtud de ser unas aguas más cálidas, con una concentración de sal mayor. Estos condicionantes positivos se ven, en cambio, mermados por la escasez de mareas, lo que imposibilita la aportación de agua salada a tierra adentro, y por el relieve de la costa mediterránea, con una morfología montañosa que hace que el litoral sea muy abrupto, apenas sin transición de la montaña al mar, por lo que no abundan las llanuras costeras. La instalación de salinas en la línea costera mediterránea se ha visto obligada a tener en cuenta todos estos condicionantes, necesitando fundamentalmente una mínima llanura costera y un cierto desnivel entre la tierra y el mar que permita la entrada de agua salada o, al menos, que facilite la apertura de canales desde los que aportar agua marina. Esta diferencia de nivel topográfico entre el agua salada y la tierra se ve facilitada por la existencia de albuferas, marjales, presencia de barras litorales o de restingas. Estas condiciones sólo se dan en algunos lugares de la costa, por lo que en este caso podemos hablar de un cierto límite ecológico impuesto a la explotación de los recursos humanos por parte de los andalusíes. Además, esto requiere una inversión inicial para la adecuación de las áreas terrestres, así como un mantenimiento. Es una inversión necesaria para la creación y la preservación de la instalación salina y no

\footnotetext{
118 Ladero Quesada, Miguel Ángel y GonZÁlez JimÉNEZ, Manuel, «La población en la Frontera de Gibraltar», Historia, Instituciones, Documentos, 4 (1977), pp. 226-228; MARTÍN GUTIÉRREZ, E., «Análisis de la toponimia y aplicación al estudio del poblamiento del alfoz de Jérez de la Frontera durante la Baja Edad Media», Historia, Instituciones, Documentos, 30 (2003), pp. 291-292. Cit. en MARTín GUTIÉRREZ, Emilio, «Salinas y explotaciones salineras en la bahía de Cádiz a finales de la Edad Media», Morère Molinero, Nuria, (Ed.), Las salinas y la sal de interior en la historia: economí, medio ambiente y sociedad, Madrid, 2008, p. 540.

${ }^{119}$ GonZÁlez JimÉneZ, Manuel, (Ed.), Repartimiento de El Puerto de Santa María, Sevilla, 2002, pp. 8283; López Amador, J. J. y Ruiz GiL, J. A., «Arqueología de la repoblación alfonsí: Pocito Chico en la laguna del Gallo de el Puerto de Santa María (Cádiz)», Revista de Historia de El Puerto, 35 (2005), pp. 17-18. Cit. en MARTín GutiÉrRez, Emilio, «Salinas y explotaciones salineras en la bahía de Cádiz a finales de la Edad Media», Morère Molinero, Nuria, (Ed.), Las salinas y la sal de interior en la historia: economía, medio ambiente y sociedad, Madrid, 2008, p. 540.
} 
únicamente desde un punto de vista técnico, aunque en contrapartida, el transporte de la producción de sal viene facilitado por las rutas marítimas. ${ }^{120}$

Son varios los ejemplos de salinas mediterráneas explotadas por los andalusíes. Vamos a centrarnos en algunas, por ejemplo en la región de Murcia, en torno al Mar Menor, donde encontramos las de San Pedro del Pinatar al norte y las de Marchamalo y Rasall al sur. De las primeras hay constancia de su explotación en fechas anteriores a la conquista castellana, cuando eran conocidas como las salinas de Patína, por lo que nos indican los documentos de donación de Alfonso X a la orden Franciscana, en $1266^{121}$. Otro ejemplo sería el de las salinas de la Mata, en Torrevieja, de las que hablaremos más adelante.

Más al sur tenemos otro de los ejemplos más interesantes de la instalación de salinas, como son las de Cabo de Gata, en Almería, en las que se aprecia claramente una diferencia de nivel negativa de su situación con respecto al mar.

Dejando a un lado las salinas marítimas, el resto de las salinas se sitúan tierras adentro, por lo que se conocen como salinas de interior, conformando unos paisajes característicos $^{122}$. En esencia, como ya dijimos, las instalaciones salineras son similares estén en la costa o tierras adentro. No obstante cuentan con una ventaja respecto a las marítimas, y es que por lo general es el propio terreno el que ofrece unas condiciones topográficas óptimas para controlar la circulación y estancamiento del agua salada. En la Península Ibérica abundan los afloramientos de aguas saladas procedentes de los estratos de halita formados en la Era Secundaria. Aunque no es exclusivo de estas tierras, ya que afloran en otros espacios de Europa, si que es una de las pocas regiones en las que su explotación, debido al clima, puede hacerse de forma similar a como se hace en la costa, mediante la evaporación y cristalización gracias a la insolación, mientras que en el resto de Europa se requiere un calentamiento artificial del agua. Esto hace que las instalaciones sean muy distintas, y que además dejen un rastro arqueológico más patente, mientras que en España y Portugal prácticamente son iguales a los centros productivos costeros. Incluso contamos con un buen número de lagunas endorreicas que, acondicionadas con obras muy simples, aprovechan las subidas del nivel del agua de las épocas de otoño e invierno para después, durante el estiaje, obtener la sal. Es lo que se aprecia, por ejemplo, en la laguna de Fuente Piedra, cerca de Antequera (Málaga) ${ }^{123}$.

Todo esto no quiere decir que no se requiera una inversión inicial, además de un mantenimiento si no constante, si al menos anual. Pero, en cualquier caso, todo apunta a

\footnotetext{
${ }^{120}$ MaLPICA CUello, Antonio, «El medio físico y la producción...», p. 152.

${ }^{121}$ FonTES FonTES, Juan, «Las salinas de San Pedro del Pinatar», Murgetana, XVI (1961), pp. 59-66; Idem, «Las salinas de Murcia en la Edad Media», Murgetana, 113 (2005), pp. 9-32.

${ }^{122}$ CARRASCO VAYÁ, Jesús-F. y HuESO KorteKAAS, Katia, Los paisajes ibéricos de la sal. 1. Las salinas de interior, Guadalajara, 2008.

${ }^{123}$ Rendón Martos, Manuel y Garrido, Araceli, «La laguna de fuente Piedra», PÉREz Hurtado de MendozA, Alejandro (Ed.), Salinas de Andalucía, Sevilla, 2004, pp. 121-125.
} 
que es menor que en el caso de las litorales, aunque hay que estar muy pendientes de las variaciones del flujo de agua que pueden sufrir fuentes, manantiales y cursos salados. En el caso de éstos últimos son indicativos de la existencia de una capa freática que se puede usar para la obtención de la salmuera cuando el estiaje es grande y se deseca el curso superficial. Así, suele ser habitual la producción mediante la existencia de pozos que ayudan a extraer el agua salada, sobre todo en producciones a pequeña escala.

Cómo vemos, esta explotación del recurso salino en el interior nos aproxima al mundo campesino, tanto en los necesarios conocimientos del terreno y su estacionalidad, como en el nivel técnico a emplear. El sistema de apropiación de la tierra, la tecnología empleada y la misma gestión del agua salada es muy similar a la del agua dulce para irrigar las tierras y obtener cosechas agrícolas, aunque en este caso las cosechas sean de $\mathrm{sal}^{124}$. De hecho, «recolección» y «cosecha» es un vocabulario habitual en la documentación que se refiere a la producción de sal en los territorios cristianos, y creemos más que probable que fuera similar para el territorio andalusí. Para obtener la «cosecha» de sal se necesita calor y humedad, como en la producción agrícola, y el agua salada sufre un proceso similar al del agua dulce: es buscada mediante minas y pozos, derivada de su curso, almacenada en albercas, conducida por acequias... y no sólo el agua, sino también el terreno en el que se instala la salina ha de ser transformado y acondicionado, como si de campos de cultivo se tratase. Así nos encontramos con aterrazamientos del terreno en zonas de pendiente pronunciada, protección de las avenidas de las aguas mediante muros de contención... Así pues, aunque con una finalidad distinta a la del regadío, el estudio de la salinería tradicional entronca con los mecanismos y tecnologías agrícolas de las comunidades campesinas.

En al-Andalus parece constatarse como lo más habitual son las pequeñas comunidades campesinas con una gestión agrícola directa, con tendencia al arrendamiento en algunos casos. En el caso de las salinas todo indica que la práctica era prácticamente la misma. De hecho, contamos con fórmulas jurídicas que así lo constatan, como la de al-Yaziri, natural de Algeciras, muerto en 1189:

Fulano arrienda a Fulano la totalidad de los cuatro estanques de la salina tal en la provincia tal. Delimitarás todos los estanques citados, diciendo "a cuyo sur queda tal cosa", si cada uno tiene nombre lo citarás, así como definirás sus emplazamientos y límites si están dispersos, diciendo al terminar de delimitarlos "con sus servicios, dependencias y derechos inherentes y provenientes, explanadas, canales y suministros de agua de sus ensenadas o pozos, por tantos dinales". Y luego completarás el contrato. Jurisprudencia: No es lícito arrendar la salina por la sal pues sería venta aleatoria, aunque una versión de la 'Utbiyya lo autoriza, lo que fue seguido por Ibn al- 'Attar

\footnotetext{
${ }^{124}$ Malpica Cuello, Antonio, «Techniques et aménagements des salines médiévales de l'intérieur des terres en Andalousie orientale», en Weller, Olivier, Dufraisse, Alexa y PÉTrequin, Pierre (Eds.) Sel, eau et forêt D'hier à aujourd'hui, Paris, 2008, pp. 433-450.
} 
quien redactó contratos de dicho tipo, argumentando en su jurisprudencia que la sal no sale de la salina, sino que se genera en ella por industria, consistente en traer el agua a los estanques y dejarla al sol hasta cuajar, aunque diciendo que la analogía no lo permitiría si no fuera por la versión conocida. Esto fue rechazado por Ibn al-Fahhar y dado por erróneo, argumentando en su contra que el dátil fresco no se hace seco sino cortándolo y trayéndolo al secadero donde es dejado al sol hasta hacerse, lo cual es correcto puesto que lo similar a lo lícito y perteneciente por analogía a lo prohibido debe evitarse. ${ }^{125}$

De hecho, la cita de al-Yaziri recogida por E. Molina parece referirse claramente a salinas de interior a juzgar por la expresión «y suministros de agua de sus ensenadas o pozos».

Aunque hay que pensar, por tanto, en una acción campesina en la acción de creación y mantenimiento de ese «cultivo de la sal», el desarrollo tecnológico que va unido a este tipo de actividad no era, por supuesto, exclusivo del campesinado. Otros grupos serían capaces de invertir en la creación de salinas, como lo hicieron en tierras de regadío vivificadas. Es más, por lo que conocemos de la ubicación de las explotaciones salineras del reino nazarí, tal y como señalamos en otro punto, la relación con de éstas con los territorios controlados por las principales ciudades nos hace pensar que así fuera.

No obstante, las dimensiones de las salinas de interior, dejando a un lado las marítimas, siempre de pequeñas o medianas dimensiones, nos hace descartar la idea de grandes explotaciones con fines comerciales. No se han podido hacer cálculos sobre su productividad, pero si conocemos las cifras de la carga fiscal en los años inmediatamente posteriores a la conquista castellana, y no parece en ningún caso muy alta, aunque si importante debido a la capacidad impositiva de los Reyes Católicos ${ }^{126}$.

\section{Cómo estudiar las salinas en al-Andalus. Algunos ejemplos}

Llama la atención que de entre todas las riquezas que mencionan los geógrafos árabes para todas las regiones de al-Andalus no haya apenas menciones a la producción de sal. Solo tenemos referencias a salinas marítimas en la costa de Cádiz, Almería, Alicante e Ibiza, y ninguna referencia a salinas de interior. Del último ejemplo, nos dice al-Himari que «Alli se encuentra una salina cuya sal nunca se agota». Si tenemos algunas

\footnotetext{
${ }^{125}$ Emilio Molina sólo cita parcialmente la nota, refiriendo a al-Yaziri de quien tomamos la totalidad del escrito en la traducción de Asunción Ferreras. Molina PÉREZ, Emilio, «Economía, propiedad, impuestos y sectores productivos», Historia de España / Ramón Menéndez Pidal, t. VIII «El retroceso territorial de al-Andalus. Almorávides y almohades Siglos XI al XIII», Madrid, 1977, pp. 211-300; AL-YAZIRI, Ali b. Yahya, Al-Maqsad al-Mahmud fi Tal his al-'Uqud (Proyecto plausible de compendio de fórmulas notariales), estudio y edición crítica FERRERAS, Asunción, Madrid, 1998, p. 44.

${ }^{126}$ Gual CAmarena, Miguel y López de Coca CastaÑer, José Enrique, «La sal del reino de Granada. Documentos para su estudio», Cuadernos de estudios medievales, II-III (1974-75), pp. 259-296; LADERO QUESADA, Miguel Ángel, «La renta de la sal...», pp. 821-838.
} 
menciones a la minería de la sal, como por ejemplo en Zaragoza donde se dice que hay «una sal gema muy blanca y brillante, incomparable» ${ }^{127}$ o «Una especialidad de Zaragoza es la sal gema, se explota en minas de la región; es de una calidad superior a la que se puede encontrar en otras partes» ${ }^{128}$. También en Loja, en el territorio de Granada, donde en el siglo XIV se habla de una mina de sal, aunque es probable que haga referencia a la recolección de costras y barros salinos y no a una mina como tal como ha apuntado Malpica ${ }^{129}$

Una segunda fuente de información sobre las salinas podría ser la toponimia y la onomástica. Pero son muy escasos los datos en este sentido, ya que con el nombre de almallaha (en árabe, la salina), solo podemos mencionar una localidad granadina, donde efectivamente hay unas salinas desde época romana, y otro lugar en Jaén que conocemos por el apodo de un caudillo del siglo IX, llamado al-mallahi, que hacía referencia a su lugar de nacimiento, en la campiña de Jaén. De ambos casos hablaremos más detenidamente en las página que siguen.

Junto a estas referencias, tenemos algunos datos más sobre la existencia de salinas en territorio andalusí que nos dan la documentación cristiana, cuando tras la conquista de los distintos territorios, hacen referencia a salinas y a fuentes de agua salada ya existentes, que son repartidas entre los conquistadores o donadas por los monarcas a nobles o a la Iglesia.

También desde la lingüística hay otra línea de investigación que está por estudiar. Nos encontramos una serie de términos en la documentación cristiana bajomedieval asociada a la explotación de la sal, cuyo origen está en el árabe: «Alfolí», que son los almacenes donde se guardaba el grano y la sal, o los «Alamines», los jueves encargados de vigilar las pesas y medidas en la venta. Quizás si se rastrase el origen de toda la terminología salinera en las crónicas castellanas podríamos conocer mucha más información sobre las salinas de al-Andalus.

Desde un punto de vista arqueológico el estudio de las producción de sal es muy difícil. No hay documentados ningún caso de explotación de sal por ignición, ni existe ningún tipo cerámico directamente relacionado con la manufactura de la sal como ocurre en Centroeuropa con los «briquetage». Tampoco la sal es un elemento que se pueda constatar en el registro arqueológico. Sólo nos quedaría, por tanto, investigar los propios centros productivos, las salinas. Pero hay un problema, que es doble. Por un lado, las pequeñas explotaciones, que debieron ser las más frecuentes en al-Andalus, tienen una infraestructura mínima que además debe ser mantenida constantemente, limpiando albercas y canales, al igual que es necesario hacer con cualquier infraestructura

\footnotetext{
${ }^{127}$ VALLVÉ, Joaquín, «Una descripción de España...», p. 377.

128 LÉvi-ProvençAL, Évariste, Le Péninsule Ibérique..., p. 97 texto en árabe y pp. 119-120 de la traducción francesa.

${ }^{129}$ MALPICA CuELlO, Antonio, «El medio físico y la producción de sal...»
} 
hidráulica. Abandonado el mantenimiento de estas instalaciones, van paulatinamente desapareciendo, dejando una huella apenas imperceptible en el terreno. Cuando estas salinas constituyen grandes centros salineros, con una arquitectura mayor que hubiera perdurado en el tiempo, se han convertido en centros de «éxito», perpetuándose en el tiempo, en muchos casos hasta hoy en día. Las reformas que han sufrido han borrado prácticamente las estructuras originales, cuando no se han desmontado por completo o se ha excavado el terreno para lograr alcanzar la capa freática, como ya veremos que ha ocurrido en las salinas de Imón (Guadalajara).

Nos encontramos, por tanto, ante una enorme dificultad a la hora de estudiar los centros productores de sal por sí mismos. Ello nos obliga a encontrar nuevas estrategias de investigación. Sin poder estudiar las estructuras directamente, y siendo insuficientes tanto la toponimia, como la documentación escrita, no nos queda sino acudir a los estudios extensivos que permitan relacionar los centros de producción con los de hábitat. Es decir, acudiremos a la arqueología extensiva o del paisaje.

En este sentido, queremos traer a colación un texto de Tomás Quesada en el que expresa claramente la propuesta:

...la sal no es un producto acabado, por tanto las labores extractivas existen, pero no agotan todas las actividades posibles. Los procesos de transformación son complejos cuando se pretende conseguirla a una escala importante. Dejan una huella muy fuerte en el paisaje y se concretan en restos constructivos y de uso del medio físico. Realmente las salinas son unas estructuras complejas y un producto histórico; es decir, antes de las explotaciones salineras tal como las hallamos desde época bajomedieval, plenamente configuradas, han existido diversas formas de aprovechamiento de este elemento, que se conocen histórica y arqueológicamente. Por eso, es conveniente atender al examen de las posibilidades de obtener sal, para poder detectar las formas de uso del territorio desde una perspectiva económica. El poblamiento y las salinas, al menos como hipótesis de partida, suelen estar en una relación muy estrecha y van determinando diferentes organizaciones del territorio. Por eso, la historia de la sal es también historia del poblamiento. ${ }^{130}$

Y más adelante añade:

El control de los recursos naturales, entre ellos la sal, y los medios de producción es un elemento esencial en toda sociedad humana y, asimismo, la clave para poder definirla. Desde esta argumentación, la sal, en cuanto que producto extraído y tratado por los hombres, evoluciona a lo largo de la Historia. Esa evolución ha dejado vestigios que no sólo son materiales, sino también escritos. Éstos nos hablan primordialmente de la apropiación paulatina de esa riqueza por parte del poder político que va controlando su

${ }^{130}$ QUESADA QUESADA, Tomás, «El agua salada...», p. 76. 
producción y comercialización, hasta llegar a constituir la sal un monopolio del poder, estando, por lo tanto, también presente en la historia del poder político a través del control fiscal que de la misma hacen los distintos poderes de las diversas sociedades históricas en el proceso de su constitución y afianzamiento.

Partiendo de esta base, se ha considerado que el estudio del poblamiento, su distribución en el espacio, su jerarquización, etc., tiene que tener en cuenta el medio físico en el que se desenvuelve y los aprovechamientos que el hombre puede obtener del mismo. Es, pues, de gran importancia abordar el estudio de las sociedades históricas desde el ámbito de la producción, como base necesaria para el funcionamiento del sistema social. $^{131}$

En este sentido, lo primero que encontramos es la existencia en la práctica totalidad de las salinas, tanto en explotación como ya abandonadas, de yacimientos arqueológicos no sólo de época islámica, sino en muchos casos anteriores, romanos, protohistóricos e incluso prehistóricos, que nos permite establecer, al menos como hipótesis, la existencia de asentamientos humanos que buscaban la cercanía de los cursos de agua salada para su explotación, fuera esta de manera directa o indirecta. Hablamos de cercanía, ya que la explotación de sal no se traduce en una ocupación directa del espacio adyacente a las salinas, no encontramos en ningún caso una asentamiento estable, o al menos este no se ha documentado en ningún caso. Como ha señalado Malpica, ello se explica fundamentalmente por la necesidad de disociar el espacio de agricultura irrigada, donde las parcelas deben ser alimentadas con agua dulce, de los espacios salinos con abundancia de salmuera, que no es precisamente recomendable para los cultivos ${ }^{132}$.

Estamos, por tanto, ante toda una serie de problemas de difícil resolución, pero que, dada la importancia que debió tener la sal en al-Andalus, se convierte en un tema de gran interés histórico. Por ello ha sido necesario buscar nuevas estrategias para su investigación. Debemos a Tomás Quesada, y sobre todo a Antonio Malpica, el haber abierto nuevas formas de investigación para la salinas en al-Andalus. Ambos han señalado que como la explotación de todos los recursos naturales, dejan una huella en el paisaje y determinan, en mayor o menor medida, la organización del hábitat a su alrededor, por sí mismas y en relación con otros recursos, como la agricultura, y otras necesidades, como la defensa o las vías de comunicación. Se trata de integrar la sal dentro de los estudios que se hacen desde la arqueología espacial o la arqueología del paisaje $^{133}$, con un fuerte contenido geográfico y antropológico, y con un tiempo histórico de larga duración, ante la imposibilidad de precisar la cronología tanto como se hace desde el estudio de las fuentes escritas. Desde esta forma de estudiar las salinas,

\footnotetext{
${ }^{131}$ QUESADA QUESADA, Tomás, «El agua salada...», p. 78.

${ }^{132}$ MALPICA CUELLO, Antonio, «Techniques et aménagements des salines...», p. 436.

${ }^{133}$ Malpica Cuello, Antonio, «El medio físico y la producción de sal...»; «Análisis de las salinas medievales desde la Arqueología del Paisaje», en Morére Molinero, Nuria (Ed.), Las salinas y la sal de interior en la Historia: economía, medio ambiente y sociedad, Madrid, 2008, t. I, pp. 469-498.
} 
se integran todas las fuentes posibles, Arqueología, fuentes escritas incluso las posteriores a la conquista cristiana, toponimia etc., Se trata de poner en relación los centros de hábitat con los espacios de trabajo, agrícolas, ganaderos o pesqueros, y sobre todo relacionar a ambos con el medio físico en el que se insertan y la forma en la que el hombre se relaciona con la naturaleza.

Vamos a ver algunos ejemplos de las salinas, y como se han integrado en su estudio las distintas fuentes de información. Con todos estos datos, aunque inconexos y fragmentarios, podemos establecer a grandes rasgos un mapa de la sal en época andalusí tomando como referente la salinería tradicional hispánica, a la que alude la documentación árabe y sobre todo la cristiana, y en la que frecuentemente aparecen restos arqueológicos islámicos en sus inmediaciones.

No tenemos un mapa de los centros productores de sal en al-Andalus, trabajo que está por hacer, aunque contamos con algunos intentos para la Edad Media cristiana ${ }^{134}$ que, de alguna forma, resulta indicativo. Tampoco el trabajo sobre las distintas áreas de la península ha sido equilibrado, existiendo enormes dificultades, con grandes lagunas y zonas considerablemente mejor estudiadas, como puede ser la Andalucía oriental, sobre todo Jaén y Granada ${ }^{135}$. Esto se debe a la dificultad de estudiar una producción sobre la que no hay apenas documentación escrita del propio período, y con unas zonas productivas cuyos restos materiales o bien son difíciles de identificar, o bien han sufrido demasiadas alteraciones y reformas ya desde el momento de la conquista cristiana y hasta nuestros días.

En la campiña de Jaén, en torno a la ciudad y sobre todo al noreste hay numerosos arroyos salados y varias salinas que aparecen en la documentación escrita a partir del siglo XV, aunque se dan vagos indicios de que su explotación venía desde antiguo $^{136}$. Aún se conservan algunas de estas salinas tradicionales, siendo las más grandes la de San Carlos, San Benito y las de Bruxuelo o Albuxuelo. Es una concentración de centros productivos en un espacio relativamente pequeño. En el contacto entre dos de estos arroyos salados está el yacimiento altomedieval andalusí de Peñaflor ${ }^{137}$, con niveles de la Edad del Bronce, Islámicos y Cristianos. Vicente

\footnotetext{
${ }^{134}$ Gual Camarena, Miguel, «Para un mapa de la sal hispana en la Edad Media», Homenaje a Vicens Vives, Barcelona, 1965, t. I, pp. 483-497.

${ }^{135}$ La producción de sal en la zona oriental de Andalucía la conocemos gracias a los trabajos de Tomás Quesada Quesada y sobre todo Antonio Malpica Cuello. Por citar sólo una de las últimas publicaciones, vid. MALPICA Cuello, Antonio, «Techniques et aménagements...»

${ }^{136}$ Castellano Gutiérrez, Antonio, «Las salinas de Jaén: (Contribución al estudio de la sal en Andalucía medieval)», Cuadernos de estudios medievales, VIII-IX (1980-1981), pp. 157-166.

${ }^{137}$ Salvatierra, Vicente, AguiRre, Francisco Javier y CAStillo, Juan Carlos, «Excavaciones en el cerro del Castillo de Peñaflor (Jaén)», Anuario Arqueológico de Andalucía, 1989, vol. II, pp. 298-303; SalvatierRa, Vicente y CAStillo, Juan Carlos, «II ${ }^{\circ}$ Excavaciones en el cerro del Castillo de Peñaflor (Jaén)», Anuario Arqueológico de Andalucía, 1991, t. II, pp. 312-318; CASTILlo ARMENTEROS, Juan Carlos y SALVATIERRA CUENCA, Vicente, «El poblamiento rural: ¿histórico ó intemporal? El caso del
} 
Salvatierra ha puesto de relieve la más que probable relación entre las actividades ganaderas documentadas en la excavación arqueológica, y la explotación de sal. Se ha basado en la cita en las fuentes escritas a un caudillo rebelde al poder de Córdoba cuyo apodo, al-Mallahi, hace referencia a su lugar de nacimiento, una alquería llamada alMallaha, literalmente la salina, que debía estar en el entorno del yacimiento de Peñaflor y que pone de manifiesto la existencia de uno de estos centros de producción. Arqueología, estudio del territorio, estudios de fauna, fuentes escritas posteriores a la conquista y nombres árabes se unen para analizar una producción de sal sobre la que apenas hay noticias.

Otro ejemplo son las salinas de Mesto, en Hinojares, también en Jaén, y conocidas como las salinas de Cuenca ${ }^{138}$. Están situadas en la parte sur de la Sierra de Cazorla, en el llamado barranco Salado, y muy cerca de una alquería andalusí llamada Cuenca, que fue conquistada por Fernando III en 1230. Sabemos que a partir del siglo XIII todo este territorio tuvo una explotación ganadera de gran intensidad, con una transhumancia desde el valle del Guadalquivir y la hoya de Baza hasta las montañas de Quesada, Cazorla y Segura. Además, se trata de una zona donde la agricultura de regadío de origen andalusí se ha podido documentar, tanto asociada a la alquería de Cuenca como a otros yacimientos de la sierra ${ }^{139}$. Este espacio está asociado a Quesada, citada en el siglo XII como una pequeña ciudad por Idrisi, que funcionaba como un centro comercial para los productos ganaderos que, necesariamente, necesitan sal para su conservación y transporte. Estas salinas tienen dos partes bien diferenciadas. En la parte alta, coge el agua salada en la parte superior del barranco y mediante una conducción la llevan hasta las albercas semicirulares y dispuestas en las distintas terrazas en que se abancaló el terreno. Son las únicas albercas de esta forma que hemos documentado. Probablemente estas sean las salinas originales, sobre las cuales se ha reformado toda la parte baja, que ha diversificado las tomas de agua salada. Aunque es difícil dar cronología a todo el conjunto, por su estructura parecida a la agricultura de regadío en barranco de origen andalusí, su cercanía a la alquería de Cuenca y al

Arroyo del Salado, Jaén», Cuadernos de Madinat al-Zahra, 3 (1991), pp. 47-75; Idem, «El cerro de Peñaflor: un posible asentamiento beréber en la campiña de Jaén», Anaquel de estudios árabes, 3 (1992), pp. 153-162; Idem, «Peñaflor, un établissement rural d'époque émirale dans la Campiña de Jaén», Archéologie islamique, 5 (1995), pp. 11-24; SAlvatierra, Vicente, CAstillo, Juan Carlos y PÉreZ, Mª C., «Introducción al estudio de los materiales del despoblado del cerro del Castillo de Peñaflor», Anuario arqueológico de Andalucía, 1990, t. II, pp. 326-329; SAlvatierRA CUENCA, Vicente y CASTILLO ARMenteros, Juan Carlos, Los asentamientos emirales de Peñaflor y Miguelico. El poblamiento hispano-musulmán de Andalucía Oriental. La Campiña de Jaén (1987-1992), Jaén, 2000, pp. 33,

${ }^{138}$ Quesada QuesadA, Tomás y RodríGuez AgUILERA, Ángel, «El complejo salinero de Cuenca», El agua en la agricultura de al-Andalus, Barcelona, 1995, pp. 131-142.

${ }^{139}$ BARCEló, Miquel, KirChner, Helena, MARTí, Ramón y TORReS, José M., «Sistemas de regadío y asentamiento andalusíes en la estribación sur de la Sierra de Cazorla», El Agua en zonas áridas. I Coloquio de Historia y Medio Físico, Almería, 1989, vol. I, pp. 169-182. 
mercado de ganado de la pequeña ciudad islámica de Quesada, es probable que sean de época altomedieval.

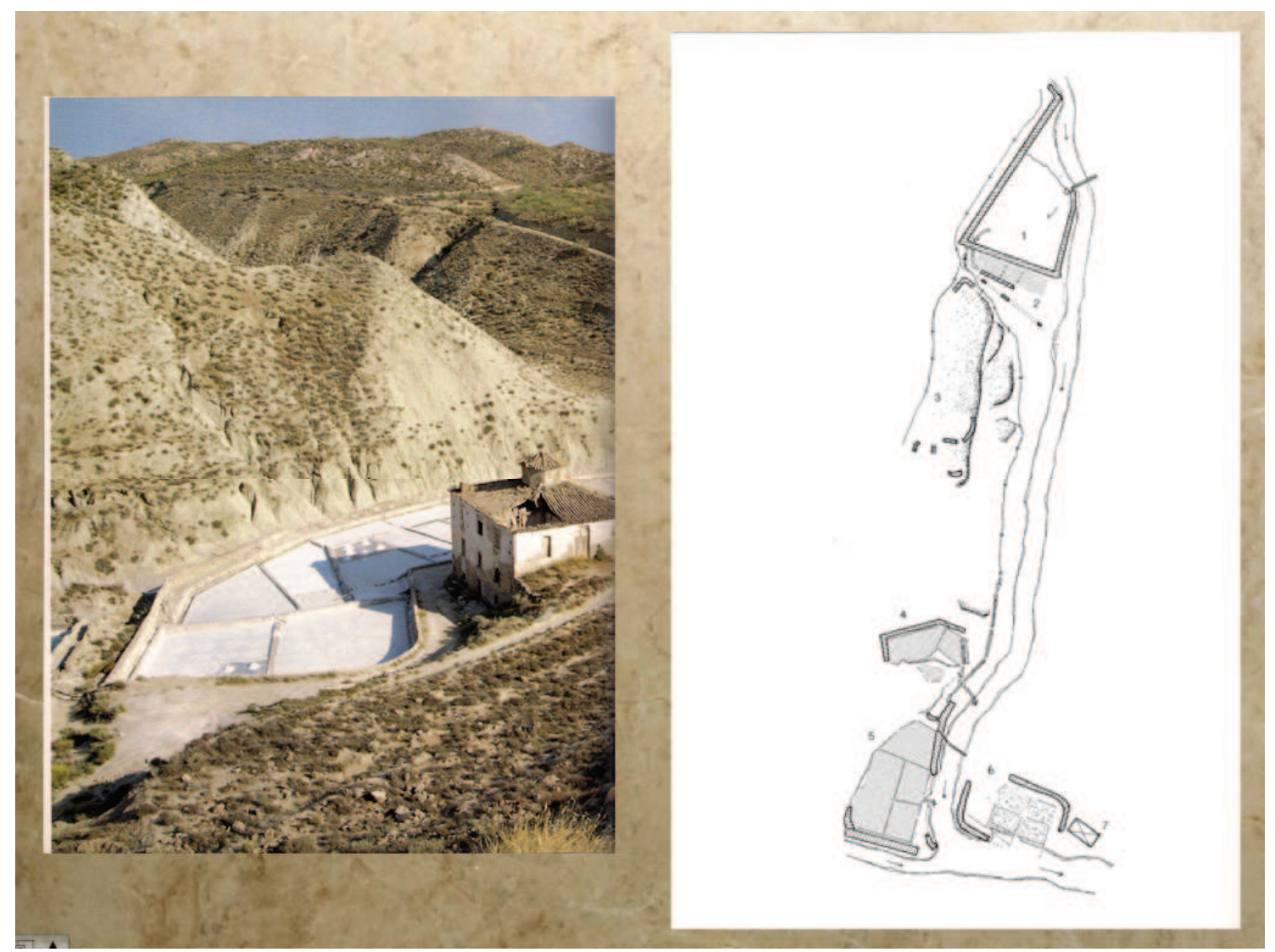

Salinas de Mesto o Cuenca, Jaén (T. Quesada Quesada y A. Rodríguez Aguilera, 1995)

Uno de los ejemplos mejor estudiados es el de las salinas de Motril, en la costa de Granada ${ }^{140}$. Son un ejemplo de salinas marítimas. Fueron las únicas del Reino de Granada que no cayeron en manos de los Reyes Católicos para la formación de un monopolio después de la conquista, sino que siguió en manos de particulares. Su nuevo dueño la adquirió de la mujer de uno de los sultanes nazaríes, y durante los primeros años de dominio cristiano siguió durante algunos años con una actividad económica similar a la de época anterior, aunque muchos aspectos como las cantidades de producción no las conocemos. Las salinas se encontraban en el extremo oriental, en lo que actualmente es Torrenueva, habiendo permanecido en explotación hasta fechas recientes. Se trata de una salina marítima, por evaporación de la salmuera en distintos estanques. Toda la costa de Granada es muy escarpada, con montañas que llegan prácticamente hasta el mar, siendo esta zona una de las pocas que permiten la instalación de una salina por su topografía. En toda la costa de Granada en época

\footnotetext{
${ }^{140}$ Malpica Cuello, Antonio, «Las salinas de Motril (aportación al estudio de la economía salinera del Reino de Granada a raíz de su conquista)», Baetica. Estudios de Arte, Geografía e Historia, 4 (1981), pp. 147-165.
} 
romana fue muy importante la producción de salazones y de garum, por ejemplo en Almuñécar, sin que se sepa con seguridad de donde se obtenía la sal. Es probable que fuera de estas salinas, aunque se duda de un origen tan antiguo. Más probable es que estuvieran ya activas en época altomedieval, en relación con el yacimiento de El Maraute, de épocas tardorromana y altomedieval andalusí, que queda muy cerca ${ }^{141}$. Con total certeza se explotaron en los siglos XIV y XV, ya en época nazarí. A pesar de estar en manos de un miembro de la dinastía real, y además por herencia de un sultán anterior, estas salinas eran arrendadas en época nazarí a pequeños productores, como sabemos por la documentación escrita posterior a la conquista. Esta documentación nos informa también de cómo la sal se transportaba por mar y se vendía, pero en un radio territorial pequeño, equivalente a lo que debió ser su volumen de producción. Su transporte se efectuaba fundamentalmente por mar, entre Albuñol y Almuñécar, que son las zonas más citadas en la documentación. También penetraba por el interior a la zona de la Alpujarra. También se vendía en el mercado que se celebraba en Motril todos los viernes, donde se intercambiaba por otros productos, por ejemplo uvas. La sal de Motril, además, entraba en relación directa con otras actividades diarias de las poblaciones rurales de la costa: la pesca y a la ganadería. La pesca se realizaría con pequeñas embarcaciones, y con un sistema de comercio similar en escala al de la sal. Las principales pesquerías de la costa corresponderían, grosso modo, con aquellos núcleos de venta de sal: Albuñol, Cautor, Jayena, Motril, Salobreña, Almulécar y Jate. El pescado salado, además, penetraba por las rutas comerciales hasta el interior del reino. Respecto a la asociación con la ganadería, podemos señalar que las los montes que llegan hasta la costa de granada era una de las principales zonas de pastos, junto con Dalías, en Almería, donde no por casualidad hay otras salinas de época nazarí.

Otro de los ejemplos estudiados es el de La Mallaha, literalmente La salina, muy cerca de la ciudad de Granada ${ }^{142}$. Con toda probabilidad estaban en funcionamiento en el siglo XII, cuando un personaje lleva en como apodo al-Mallahi, al igual que vimos para el caso de la campiña de Jaén, y el mismo pueblo es una alquería de origen andalusí. Es incluso probable que sea anterior, ya que hay una villa romana y una necrópolis tardoantigua en sus inmediaciones ${ }^{143}$. En época nazarí se detecta el mismo proceso de control por parte del Estado que en las salinas de Motril, así como

\footnotetext{
${ }^{141}$ GÓmEZ BeCERRA, Antonio, «El Maraute (Motril) y el poblamiento islámico en la costa de Granada», Trillo San José, Carmen (Ed.), Asentamientos rurales y territorio en el Mediterráneo medieval, Granada, 2002, pp. 30-62

${ }^{142}$ Ruiz JimÉnez, Ana, Las salinas de la Malaha, Proyecto de investigación inédito. Granada, 2007; Idem, «Estudio arqueológico del entorno de las salinas de la Malahá», www.arqueologiamedieval.com, (Publicado el 29/02/2008) http://arqueologiamedieval.com/articulos/articulos.asp?ref $=97$

${ }^{143}$ Fresneda PADILla, Eduardo y RodríGUez ARIZA, Maria Oliva, «El yacimiento arqueológico de Los Baños (La Malá, Granada)», Cuadernos de Prehistoria de la Universidad de Granada, 7 (1982), pp. 331338.
} 
también se ha documentado la explotación mediante el sistema de arrendamiento. Sobre estas salinas se han llevado a cabo análisis de tipo espacial que revela un uso muy interesante del territorio ${ }^{144}$ : Se trata de una alquería con un doble aprovechamiento hidráulico, tomando el agua dulce de una fuente para el espacio de tierra irrigada y el agua del arroyo salado para alimentar las salinas. Ambos quedan de forma que no se estorban entre sí, quedando el núcleo habitado en medio de ellos. Al exterior de estos dos conjuntos productivos se observa la presencia de agricultura de secano y un aprovechamiento del monte bajo para el ganado, ya que la zona también es vía de transhumancia. Vemos una ordenación del espacio para la explotación simultánea de distintos recursos naturales.

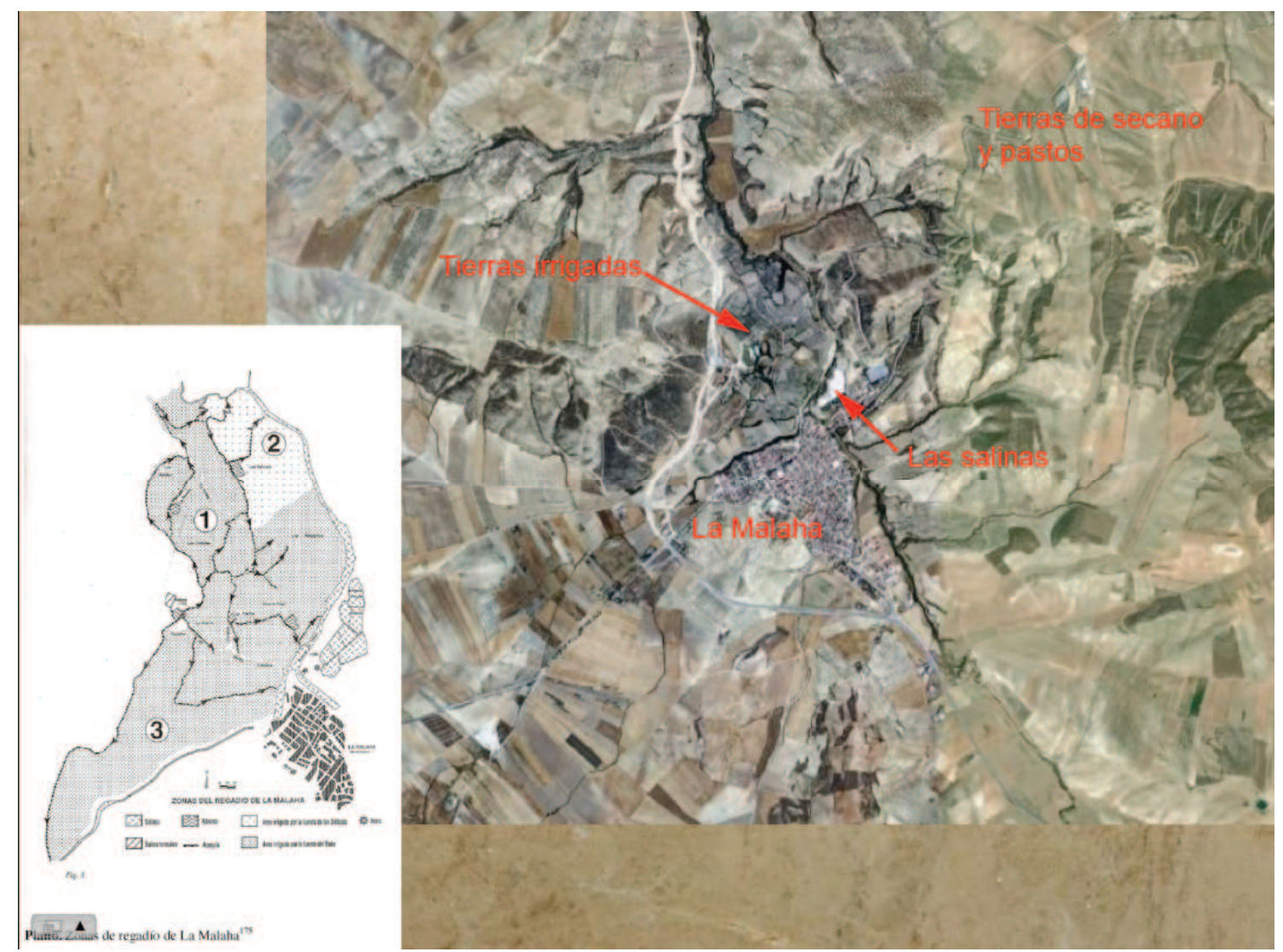

Esquema de organización del espacio en La Mallaha (C. Trillo San José 1995 y elaboración propia)

Loja, Fuente Camacho. Se hallan al sureste del principal núcleo de población, que es Loja, y que también lo fue durante gran parte de la Edad Media. Están situadas en una franja de tierra de naturaleza yesífera (el trías de Antequera), de relieve intricncado, caracerizado a nivel hidrológico por su endorreísmo, es decir numerosas lagunas de tamaño pequeño que originan una zona de escasos cultivos y donde ha

${ }^{144}$ Trillo SANJosé, Carmen, «Los diferentes aprovechamientos del agua en una alquería del reino de Granada: La Malahá, del distrito del Quempe», Agricultura y regadio en Al-Andalus, síntesis y problemas: Actas del coloquio, Almería 9 y 10 de junio de 1995, Almería, 1995, pp. 215-228. 
permanecido en gran parte una vegetación natural de tipo mediterráneo, con algunos bosques de encinas y quejigos, que se ha documentado sería muy similar en época bajomedieval. El aprovechamiento de la sal se hace a partir de esas abundantes lagunas endorreicas de pequeño tamaño. En sus proximidades hay yacimientos de época prehistórica, e incluso en las mismas salinas se documentan fragmentos de cerámica del Calcolítico y del Bronce ${ }^{145}$, así como materiales que se han adscrito al período romano y a la época de transición a la presencia de los árabes ${ }^{146}$. La ganadería juega en todo este territorio un papel preponderante, debido a las importantes masas de monte mediterráneo, agua dulce y suaves colinas, siendo el recurso salino fundamental en este sentido $^{147}$. Pero además, por referencias escritas, sabemos que la sal se debió explotar directamente, al menos durante la Baja Edad Media, pues Ibn al-Jatib indica que «Hay minas de sal y molinos de aceite» ${ }^{148}$. No se sabe con certeza a qué tipo de explotación se refiere el polígrafo granadino, ya que en el lugar hay unas salinas de albercas tradicionales. Cabe la posibilidad, no obstante, de que hiciera referencia a la obtención de la sal a partir de las conocidas como «marmotas», la sal cuajada y solidificada que se quedaba en las rocas al pasar el curso de agua, mezclada a menudo con barro, que aún en época moderna se obtenía a modo de tortas explotando las numerosas costras de sal que quedan al desecarse las lagunas endorreicas ${ }^{149}$.

Por tanto, la aproximación al estudio de las salinas debe hacerse, como en tantos otros aspectos de al-Andalus, a través del recurso a diferentes metodologías reunidas bajo la denominación común de arqueología extensiva, o más recientemente definida, de un modo más exacto, como arqueología del paisaje ${ }^{150}$. Se trata, en definitiva, de poner en relación los centros de hábitat con los espacios de trabajo, para lo cual la toponimia, los documentos escritos incluso aquellos posteriores a la conquista cristiana, y por supuesto

\footnotetext{
${ }^{145}$ Sobre el poblamiento del territorio de Loja desde el Paleolítico a la Antigüedad tardía vid. CARRASCO Rus, Javier, et alii, El poblamiento antiguo en la tierra de Loja, Granada, 1986.

146 JimÉnez Puertas, Miguel, «El poblamiento de la tierra de Loja a fines de la Edad Media», Arqueología y Territorio Medieval, 2 (1995), pp. 63-82; Idem, El poblamiento del territorio de Loja en la Edad Media, Granada, 2002.

${ }^{147}$ Malpica CuEllo, Antonio, «Fiscalidad y comercio de la sal...»; Idem, «La vida económica en la frontera nazarí-castellana. Ganadería y sal en la zona nororiental del reino de Granada», LITCHFIELD, Carol D., Palme, Rudolf y PiAseCKi, Meter (Eds.), Le monde du sel. Mélanges offerts à Jean Claude Hocquet. Journal of Salt-History, 8-9 (2000-2001), pp. 101-124; Idem, «Agriculture, livestock and salt in the Kingdom of Granada. A study of the economy and territory of the Nazari Zone» en INGENHAEFF, Wolfgang, Staudinger, Roland y EBert, Kurt, (Eds.), Festchrift Rudolf Palme, Innsbruck, 2002, pp. 337-352.

${ }^{148}$ IBN AL-JATIB, Miy'ar al-ijtiyar, ed. y traduc. CHABANA, M. K., Rabat, 1977, p. 136.

${ }^{149}$ MalpiCa Cuello, Antonio, «Fiscalidad y comercio de la sal...», p. 79.

150 BARCELÓ, Miquel, «La arqueología extensiva y el estudio de la creación del espacio rural» en BArCeló, Miquel, et alii, Arqueología Medieval. En las afueras del «medievalismo», Barcelona, 1988, pp. 195-274; MAlPICA CuEllo, Antonio, «Análisis de las salinas medievales desde la Arqueología del Paisaje», en MORÈRe Molinero, Nuria (Ed.), Las salinas y la sal de interior en la Historia: economía, medio ambiente y sociedad, Madrid, 2008, t. I, pp. 469-498; Idem, «El medio físico y la producción de sal. Propuestas para el análisis de las salinas granadinas desde una perspectiva arqueológica», en MARTíN Civantos, José María (Ed.), Medio ambiente y Arqueología Medieval, Granada, 2008, pp. 145-162.
} 
el registro arqueológico, se convierten en los instrumentos principales para investigar las salinas en al-Andalus. Recojamos para terminar las palabras de Antonio Malpica:

Ante todo, es imprescindible definir cada explotación en su ámbito físico y territorial, para lo que el concurso de la arqueología del paisaje es esencial. Sin tener clara la implantación de cada una de ellas será imposible avanzar mucho más. Por otra parte, habrá que relacionarla con el poblamiento concreto de cada área en la que estaba, no sólo en un pequeño radio, sino en una escala mayor. Por supuesto que el nivel de aproximación será distinto, pero en todos los casos es necesario atender a amas cosas. Así, si bien es obligado situar la salina concreta en el punto de su puesta en valor, valorando las opciones a tomar, no es menos aconsejable integrarla en la disposición de recursos de cada espacio. En tal sentido, las pesquerías, en el caso específico de las marítimas, son esenciales, pero también las rutas ganaderas, que para las situadas en tierras interiores cobran un especial significado. ${ }^{151}$

\section{Conclusiones}

Como señaló Malpica:

Como tantos otros productos, la sal tiene una historia en la que se distinguen claramente dos períodos. En el primero, con ser común, se explotaba en aquellos puntos en los que era posible por las condiciones naturales, que marcan mucho su desarrollo, y era objeto de un comercio limitado. En el segundo, se aprecia la existencia de un gran tráfico mercantil que la conduce desde las áreas productoras a otras consumidoras, consecuencia del agua de la navegación que transportaba de un lugar a otros grandes cantidades de sal, como de otras mercancías. Es así como surgieron o se desarrollaron las extensas salinas del Mediterráneo y del Atlántico utilizando la insolación como fuerza imprescindible para la concentración de la salmuera y la posterior cristalización. En esa segunda etapa asistimos a un paulatino y creciente control fiscal por parte de los poderes públicos. La implantación del Estado Moderno se hizo lógicamente a partir de una fiscalidad y de una burocracia. Todo ello trajo consigo un aumento de la documentación escrita y la posibilidad de conocer con bastante precisión esas explotaciones, su capacidad productiva, su radio comercial, etc.

El cambio de una etapa a otra hay que situarlo en los siglos bajomedievales, por lo que una vez más ese período histórico permite conocer lo que sucede antes y lo que va a venir más tarde. ${ }^{152}$

Resulta difícil trazar una evolución sobre la producción, venta y consumo de la sal en los ochos siglos que duró al-Andalus, toda vez que son demasiados los aspectos

\footnotetext{
${ }^{151}$ MalpiCa CuEllo, Antonio, « El medio físico y la producción de sal...», p. 161.

${ }^{152}$ MalPiCA CuEllo, Antonio, «Producción y comercio de la sal...», p. 129.
} 
parciales que no conocemos. Si que parece ser un producto de presencia cotidiana en la vida de los andalusíes, aunque en principio no cabe pensar en una producción a gran escala con fines comerciales, al menos en atención a los datos con los que contamos hoy en día. Se trataría de un consumo elemental, con una presencia habitual en los mercados. En lo que a su producción se refiere, y dejando a un lado el siempre polémico Reino Nazarí, todo apunta a que las formas de explotación serían de manera directa por los pequeños propietarios, probablemente con un sistema de arriendos a pequeña escala $^{153}$, que desembocaría, a partir de la conquista castellana, en un sistema de arriendos por dinero, sobre la base posible de un trabajo asalariado, y a la fijación de un sistema impositivo de carácter regio cuando no a un control directo por parte de la monarquía, que culminaría con la declaración de monopolio fiscal de las salinas en época de Alfonso $\mathrm{XI}^{154}$. Incluso se ha propuesto una interesante relación entre las principales salinas de la Castilla altomedieval, las de Añana y las de Pozas de la Sal, con la genealogía de las principales familias condales ${ }^{155}$.

En el caso de al-Andalus, la tímida evolución que se detecta parece desembocar en época nazarí en la mención de un centro productor de sal en el entorno de cada uno de los principales núcleos y ciudades, desde Cádiz a Almería, pasando por Loja, GuadixBaza o la misma ciudad de Granada. Esto quiere decir que, en principio, las explotaciones salineras estaban relacionadas, al menos en época nazarí, con las estructuras urbanas que organizaban gran parte de los territorios granadinos y que, aparte de funciones económicas que tenían que ver con la ganadería y el mundo campesino, se organizaban en atención a la red urbana y sus espacios de influencia ${ }^{156}$.

Tanto para la época altomedieval como para los datos que conocemos del último período nazarí, todo parece indicar que, tal y como afirma Antonio Malpica

... la sal, producto de primera necesidad, pero que tenía un radio de penetración
pequeño y no podía de una manera más o menos regular ampliarlo, se cambiaba por
otros más importantes para un comercio más estable y mucho más beneficioso, pero
que, desde luego, sólo podían realizarlo determinadas personas que sobrepasaban el
estrecho marco del mundo rural de la villa y su tierra, mientras que las unidades
campesinas, a la vez que drenaban parte de una producción que difícilmente por sí

\footnotetext{
${ }^{153}$ A hemos citado anteriormente el documento jurídico de Al-Yaziri, vid. supra

${ }^{154}$ Esta es la evolución, grosso modo, trazada por Reyna Pastor en el que sigue siendo el mejor trabajo sobre la sal en la corona de Castilla. En lo que respecta a la época altomedieval, y al menos hasta el siglo XII, y por las espigadas referencias que tenemos, todo apunta a que el sistema de explotación sería similar en al-Andalus y en Castilla. PASTOR DE TOGNERI, Reyna, «La sal en Castilla y León....». Un buen estudio sobre la evolución de la política fiscal en la España medieval a partir del siglo XIII lo encontramos en LADERO QUeSADA, Miguel Ángel, «La renta de la sal...».

${ }^{155}$ RodríGUez MARQUINA, Javier, «Las salinas de Castilla en el siglo X y la genealogía de las familias condales», Homenaje a Fray Justo Pérez de Urbel, OSB, Burgos, 1976, t. I, pp. 143-151.

${ }^{156}$ MALPICA CUELLO, Antonio, «El medio físico y la producción de sal...», p. 157.
} 
misma podían situar, obtenían una mercancía básica para ellas, la sal, la cual no conseguirían nada más que en las tiendas habilitadas para ello. ${ }^{157}$

Ello nos lleva, además, a poner la sal en relación con otras actividades, ganadería y pesca fundamentalmente.

La adaptación de esas explotaciones salineras a la vida económica nazarí, en la que ésta se integró en circuitos comerciales más amplios ${ }^{158}$, debió marcar su integración y configuración en los espacios productivos, básicamente agrícolas aunque también ganaderos, y en el territorio. En este sentido, debemos a Antonio Malpica el haber fijado varios aspectos muy importantes a tener en cuenta ${ }^{159}$. En primer lugar, la elección de un punto concreto de entre todos los posibles, e incluso con preferencia a otros utilizados con anterioridad, con el fin de establecer y fijar la instalación saliera de manera regular. $\mathrm{Y}$ en este mismo sentido, conocer la fecha exacta de la ubicación que tienen. Dilucidar esta cuestión es importante, porque podría informarnos si hubo o no acción por parte de determinados poderes, locales o estatales, en su fijación definitiva o, por el contrario, de trató de un proceso autónomo a los mismos. Sería de gran interés porque ayudaría a fijar más correctamente ante que tipo de sociedad nos encontramos en base al modo en que gestionan los recursos naturales, en este caso la sal.

No es un recurso que esté especialmente defendido, salvo en La Malaha donde se documenta una torre, en general no hay estructuras defensivas en su entorno.

Importantes yacimientos como el del Tolmo de Minateda, en los que en muchos casos se ha incidido en la importancia que tuvo que tener la ganadería, pero que no se han puesto en relación directa con la explotación de un recurso de primera necesidad como es la sal.

Pese a todo, algunas cuestiones se pueden y deben plantear. La sal, que se denomina milh en árabe, procedía en al-Andalus, por lo que sabemos, del mar y de cursos salados en el interior. Es posible que las salinas alejadas de la costa fuesen, por su organización en el territorio y su instalación topográfica, de época andalusí ${ }^{160}$, mientras que las marítimas tienen un origen anterior. Eso no quita que hubiese recogida de sal y explotaciones de la misma en algunos puntos del interior antes de la llegada de los árabes. A este respecto hay que pensar en la existencia de pozos de agua salada que se utilizasen para tal fin, como han continuado en algunos espacios hasta fechas incluso actuales, que indican, por supuesto, una explotación a pequeña escala y muy controlada

\footnotetext{
${ }^{157}$ MalpiCa Cuello, Antonio, «Las salinas de Motril...», p. 155.

158 Sobre esta cuestión vid. FÁBREGAS GARCíA, Adela, «Actividad comercial de los reyes nazaríes y su implicación con los representantes del gran comercio occidental a finales de la Edad Media», Studia Historica. Historia medieval, 25 (2007), pp. 171-190.

${ }_{159}^{159}$ MALPICA Cuello, Antonio, «Análisis de las salinas medievales...»

${ }^{160}$ Tal hipótesis se defiende en MALPICA CUELLO, Antonio, «Techniques et aménagements...».
} 
por los vecinos del entorno. Es lo que ponen de manifiesto algunas fuentes altomedievales castellano-leonesas, según en su día recogió Reyna Pastor ${ }^{161}$.

Llegados a este punto, hay que volver a recordar lo que señalaba Reyna Pastor para la sal altomedieval en Castilla y León ${ }^{162}$. La pequeña producción campesina, que era dominante también en al-Andalus, controlaba la explotación de la sal. Seguramente en aquellos momentos se utilizaban sistema menos complejos que el derivado de la organización de las salinas. El aprovechamiento de las charcas y lagunas saladas en zonas interiores es una realidad, pero también la utilización de pozos que llegaban a buscar las capas de agua saladas subterráneas y con un rudimentario sistema permitían conseguir sal suficiente para las necesidades de las comunidades campesinas. El problema se plantea cuando se establece un control feudal paulatino de los recursos naturales y su utilización. Lo señala asimismo Ladero mostrando que se produjo

desde el siglo X hasta la época de Alfonso VII [siglo XII], desaparición paulatina de los pequeños propietarios de salinas ante otros más poderoso, entre los que se encuentran los reyes, e introducción de un tributo o derecho de alvará regio sobre la compra de sal, lo que implica el reconocimiento de la regalía en última instancia ${ }^{163}$.

Seguramente hasta ese siglo X, cuando se configuró el Estado omeya cordobés en alAndalus, no se produjo un control de esos recursos, entre ellos la sal, por parte del poder del califa. De ahí que las fuentes escritas, muchas de ellas inspiradas en el registro fiscal centralizado de Córdoba, los mencionen de esas fechas en adelante.

La sal no aparece con claridad, salvo de manera excepcional, lo que nos lleva a plantear que quizás no fuese controlada por el Estado, con la posible excepción de las minas de sal gema, que se entendían que eran aprovechamientos de recursos, mientras que la creación de salinas quizás haya que pensar que comenzaron por un proceso de vivificación.

Así las cosas, la producción salinera se estableció partiendo de las necesidades de cada grupo social instalado en sus proximidades, si bien el pese creciente de la ciudad, sobre todo a partir del siglo XI, hizo que se asociara a un creciente comercio, lo que aparece con nitidez en los siglos siguientes ${ }^{164}$.

\footnotetext{
${ }^{161}$ PASTOR, Reyna, «La sal en Castilla y León...».

${ }^{162}$ PASTOR, Reyna, «La sal en Castilla y León...».

${ }^{163}$ LAdERO QUESADA, Miguel Ángel, «La renta de la sal...», p. 822.

${ }^{164}$ MalpiCA CuELlo, Antonio, «El tráfico comercial de la sal...».
} 


\subsection{EL HÁBITAT Y EL POBLAMIENTO RURAL ALTOMEDIEVAL EN LA ZONA ORIENTAL DE LA MARCA MEDIA: DE LOS BANU SALIM A LA CONQUISTA CASTELLANA.}

Pretendemos ofrecer aquí una visión sintética del conocimiento que del hábitat y el poblamiento rural altomedieval se tiene en la península Ibérica, especialmente en lo referente a su parte central y a lo que la historiografía conoce como la «Marca Media». No se trata de un estudio sistemático ni exhaustivo. Simplemente recogemos los datos existentes de diferentes lecturas con el objetivo de enmarcar el estudio que más adelante realizaremos. Somos conscientes, además, de estar dejando fuera un importante campo de estudio referente a la ciudad, o mejor dicho a las mudun, su origen y transformación. Aunque, inevitablemente, haremos distintas referencias a Guadalajara, Medinaceli y Sigüenza en época altomedieval, no nos detendremos en ellas por considerarlo, de momento, innecesario. Nos centramos, por tanto, en el mundo rural, quizás menos conocido pero de mayor importancia para el estudio que abordamos. Y ello porque, tal y como hemos señalado en otro apartado de este trabajo, es el mundo rural, el ámbito campesino, el autentico gestor de las explotaciones salineras en alAndalus, a lo que hay que añadir que además es el definidor del poblamiento que encontramos en la Sierra Norte de Guadalajara en el que se inserta el valle del Salado que nos ocupa.

No obstante, aún con todas estas pretensiones, necesitamos enmarcar históricamente aún más la región, por lo que el estado actual de los conocimientos sobre el poblamiento rural, que se conoce fundamentalmente gracias a los trabajos arqueológicos, vamos a tratar de conjugarlo con las informaciones que tenemos gracias a las fuentes escritas.

Lo primero que debemos señalar es que son muy escasas las fuentes escritas que traten directa o indirectamente el territorio que vamos a estudiar, el del valle del Salado situado al norte de la provincia de Guadalajara. De hecho, salvo la propia ciudad de Guadalajara y algo más la zona de la Alcarría, hay que espigar las referencias a la zona norte de la provincia. Dentro de estas escasas referencias, habría que destacar cómo son únicamente los principales núcleos, aquellos que controla directamente el poder, los que aparecen reflejados en las crónicas y obras geográficas, hecho que ya apuntó Eduardo Manzano ${ }^{1}$. «Esas informaciones cronísticas suelen tener siempre un carácter oficial y cortesano» $^{2}$, lo que hace que fijen su atención solamente en determinados aspectos, y a menudo no hagan sino vagas referencias que contienen información poco relevante históricamente, pero con un valor estratégico para los poderes de la época. Por ejemplo,

\footnotetext{
${ }^{1}$ MANZANO MORENO, Eduardo, «Fuentes de información andalusí y temas preferentes en la historiografía sobre al-Andalus», DE LA IGLESIA DUARTE, José Ignacio (Coord.), Cristiandad e Islam en la Edad Media hispana: XVIII Semana de Estudios Medievales, Nájera, del 30 de julio al 3 de agosto de 2007, Logroño, 2008, pp. 99-112.

${ }^{2}$ MANZANO MoRENO, Eduardo, «Fuentes de información andalusí...», p. 109.
} 
la indicación de las distancias a recorrer basándose en los principales núcleos que el poder controlaría. Tenemos algún ejemplo:

De Guadalajara a Medinaceli hay cincuenta y cinco millas (...) De Medinaceli a Atienza hay doce millas... ${ }^{3}$

Es por ello por lo que hemos decidido, para este capítulo, ampliar el marco a tratar a una región algo mayor, que incluirá todo el espacio geográfico que va desde Medinaceli a Guadalajara, con referencias, cuando los estimemos oportuno, a las tierras no sólo a la provincia de Guadalajara, sino también a parte de las de Soria, Segovia y Madrid, así como también parte de Cuenca, con el objetivo de obtener una imagen algo más completa del proceso histórico que nos es narrado en las fuentes. No es un territorio del todo caprichoso pues, como describiremos, se trata de una unidad territorial que identidad propia en las fuentes escritas, que se refieren a esta zona como «la frontera de los Banu Salim», en referencia a la familia que ejerció una cierta hegemonía y preponderancia en estas tierras durante los primeros siglos de al-Andalus.

Antes de continuar queremos dejar constancia de que este capítulo no es más que una pretensión por recoger cuantas noticias hemos considerado relevantes tanto para el período histórico como, sobre todo, para el marco geográfico en el que se centra nuestro trabajo. No es un intento de reconstrucción de todo un proceso histórico a través de las fuentes escritas, algo que, por otro lado, se nos aventura tarea imposible al ser tan escasas las referencias. Lo que pretendemos, por tanto, es realizar un marco cronológico en el que encuadrar todo el estudio cerámico y del territorio que realizaremos en las páginas siguientes.

\section{La época tardorromana}

Debemos comenzar con lo que ocurre en época tardorromana, lo que nos servirá de base para explicar los cambios que se detectan en época andalusí.

Desde época romana, el poblamiento del valle del Henares aparece encabezado por dos núcleos urbanos firmemente constituidos, Complutum y Segontia, así como otros dos de carácter algo más secundario que responderían al modelo de «mansio», Arriaca y Caesada ${ }^{4}$ En ambos casos habría un poblamiento adyacente, tanto rural como del modelo e villae, que debió permanecer hasta bien entrada la época visigoda, si bien no

\footnotetext{
${ }^{3}$ AL-IDRISI, Los caminos de al-Andalus en el siglo XII, Ed. y trad. ABID MiZAL, Jassim, Madrid, 1989, p. 98.

${ }^{4}$ Abascal Palazón, Juan Manuel, Vias romanas de la provincia de Guadalajara, Guadalajara, 1982, pp. 60 y ss.; GÓMEZ PANTOJA, J., «Notas históricas sobre la zona del Alto Henares en época romana», Valiente Malla, Jesús, (Ed.) La Celtización del Tajo Superior, Memorias del Seminario de Historia Antigua III, Alcalá de Henares 1992, pp. 116-122.
} 
es suficientemente conocido ${ }^{5}$. Cuando los visigodos entraron en la Península, ya desde mediados del siglo $\mathrm{V}$, se asentaron preferentemente en la Meseta castellana. En el entorno del valle del Henares se asentaron en los alrededores de los núcleos de población de larga tradición romana, «si bien también habría que relacionar esta elección con el hecho de que los asentamientos visigodos se caracterizaban más por su posición estratégica que por la riqueza económica del lugar, y no cabe duda de que Segontia y muy especialmente Complutum presentan esta particularidad ${ }^{6}$. En ello tuvo mucho que ver la vía de comunicación, la llamada Vía Gallica, que ya desde antiguo comunicaba desde Emerita Augusta a Caesaragusuta pasando por la misma Toletum ${ }^{7}$. El hecho de que en el siglo VII en el valle del Henares haya dos existan dos obispados, el de Segontia y el de Complutum $^{8}$, constituye un dato más que permite reafirmar la idea de que estamos ante una zona cuya importancia político-estratégica no debería ser pequeña para los monarcas visigodos. Junto a ello y como confirmación de la importancia estratégica, es preciso tomar en consideración el hecho de que la única ciudad que los monarcas visigodos fundan, la cercana Recópolis, ubicada en los campos de la actual Zorita de los Canes, esté rodeada de antiguos núcleos de población romanos y no muy lejos de la vía de comunicación antes citada ${ }^{9}$. Estos núcleos rurales, villae en origen, acabarían por dar lugar a las aldeas, del mismo modo que se ha detectado en la vecina provincia de Madrid ${ }^{10}$.

Una villae es, fundamentalmente, una explotación rural compleja, con una parte destinada a vivienda de la aristocracia (rural o urbana) propietaria de la misma (la pars urbana), un espacio dedicado a actividades productivas y/o vivienda de los trabajadores (la pars rustica), y un área de explotación de los recursos naturales adyacentes a este tipo de asentamientos (la pars fructuaria). ${ }^{11}$ Las palabras de Zozaya nos parecen acertadas en este sentido:

\footnotetext{
${ }^{5}$ VALLEJO GIRVÉS, Margarita, «Reflexiones sobre el poblamiento visigodo del valle del Henares», Actas del IV Encuentro de Historiadores del valle del Henares, Alcalá de Henares, 1994, p. 69.

${ }^{6}$ VALLEJO GIRVÉS, Margarita, «Reflexiones sobre el poblamiento visigodo...», p. 70.

7 Sobre la Via Gallica y la importancia de la misma en las comunicaciones peninsulares en época tardoantigua vid GARCíA MorenO, L. A., «La arqueología y la historia militar visigoda en la Península Ibérica» II Congreso de Arqueología Medieval Española, Madrid, 1987, pp. 332-335, poniendo de relieve el interés por mantener una «dominación militar» de esta zona para consolidar el control de esa ruta

${ }^{8}$ VALLEJO GIRVÉS, Margarita, «Nota sobre el obispado de Segontia en época visigoda», Wad-al-Hayara, 20 (1993), pp. 365-375; Idem, «La sede episcopal complutense y su relación con la toledana (400-711 d. C.) Anales Complutenses, IV-V (1992-1993); pp. 11-20.

9 Olmo EnCiSO, Lauro, «Recópolis: una ciudad en una época de transformaciones», OLMO ENCISO, Lauro, (Ed.), Recópolis y la ciudad en la época visigoda. Zona Arqueológica, 9 (2008), pp. 41-62.

${ }^{10}$ Es sobre todo Alfonso Vigil-Escalera quien más a trabajado sobre esta temática en la región madrileña: Vigil-EscAlera GuiRAdo, Alfonso, «Granjas y aldeas tardoantiguas y altomedievales de la Meseta. Configuración espacial, socioeconómica y política de un territorio rural al norte de Toledo (ss. V-X d. C.)», Archivo Español de Arqueología, 80 (2007), pp. 239-284. Hemos consultado la edición online: http://aespa.revistas.csic.es/index.php/aespa/article/download/35/35

${ }^{11}$ Sobre las villae y especialmente sobre las transformaciones y final de las mismas durante los siglos IV al VIII es mucha y muy variada la historiografía existente, con numerosos casos y ejemplos de estudio y varias reflexiones de carácter general. Citaremos únicamente dos de las más recientes y de mayor
} 
Estas villae no se limitarían a ser — strictu sensu - una casa, sino una zona amplia de residencia, en un gran predio, con su sector castral, sus casas para campesinos y otros elementos de subsistencia, controladas por señores agrarios, opuestos al dominio estatal, contra quienes, por otra parte, poco se podía hacer salvo mantenerse en un ambiente rústico y distanciador de los centros de poder político y fiscal. ${ }^{12}$

En el estudio de la evolución de las villae tardorromanas debemos tener en cuenta que estos asentamientos formaban parte de una red más amplia que incluía otras muchas formas de hábitat, como las mansio o las granjas. Eran una forma más y no la única, como generalmente se ha admitido $^{13}$. Si que serían la forma más abundante $y$ característica del hábitat rural disperso a partir de los siglos finales del período romano, conformando un paisaje determinado. Y sobre todo, eran la manifestación del poder, toda vez que las ciudades se encontraban en franco retroceso. Éste ha comenzado a ser estudiado recientemente, una vez que se ha superado el lastre que suponía la atención focalizada sobre la pars urbana, enfocándose ahora su estudio en una línea más próxima a la comprensión global del territorio ${ }^{14}$. Esta línea tiene su origen a partir de los años '90, cuando hubo una eclosión de investigaciones sobre el proceso que se ha caracterizado y definido como el final de las villae ${ }^{15}$.

Se detecta una ocupación de espacios públicos, una ocupación-reocupación de los espacios rurales y un empobrecimiento de las técnicas constructivas. Junto a ello la aparición de inhumaciones en espacios anteriormente destinados a residencia, actividades lúdicas o explotación, y la aparición de nuevos edificios y complejos dedicados a nuevas prácticas, paganas o cristianas, están igualmente en «el origen de una serie de transformaciones funcionales y estructurales en este tipo de asentamientos,

impacto, una referida a Italia pero cuyas consideraciones merecen ser tenidas en cuenta para toda la Europa mediterránea, y otra referida al caso concreto de la Península Ibérica: FRANCOVICH, Riccardo y HodGes, Richard, Villa to village. The Transformation of the Roman Countryside in Italy, c. 400-1000, Londres, 2003; Chavarria ARNAU, Alessandra, El final de las Villae en Hispania (siglos IV-VII d.C.), Bibliothèque de l'antiquité tardive, 7, (2007) Brepols, Belgium.

12 ZOZAYA, Juan, «¿Poblado? ¿ciudades? ¿campamentos? ¿recintos castrales? En la Marca Media: hacia una tipología», Al-Ándalus país de ciudades. Actas del Congreso celebrado en Oropesa (Toledo), del 12 al 14 de marzo de 2005, Madrid, 2007, p. 24.

${ }_{13}^{13}$ Francovich, Riccardo y HodGES, Richard, Villa to village..., p. 36.

14 OREJAs DEL SACO VAlle, Almudena, «Arqueología de los paisajes agrarios e historia rural», Arqueología espacial, 26 (2006), pp. 7-19; AriÑo, Enrique, GURT, José María Y PALET, Josep Maria, El pasado presente. Arqueología de los paisajes en la Hispania romana. Salamanca-Barcelona, 2004.

${ }^{15}$ Título del coloquio que de alguna forma dio carta de nacimiento a este tema específico dentro de la Antigüedad Tardía. BRogiolo, Gian Pietro, (Ed.), La fine delle ville romane: transformación nelle campagne tra tarda antichità e alto medioevo. $1^{\circ}$ Convengo Archaeologico di Garda, Mantua, 1995. Posteriormente se han celebrado otros coloquios con nuevas reflexiones y nuevos casos de estudio: Brogiolo, Gian Pietro, Chavarria, Alessandra y Valenti, Marco, (Eds), Dope le fine Della ville: le campagne del VI al IX sécolo, Mantua, 2005. 
constituyendo elementos morfogenéticos y dinámicos de cambio en el seno de los mismos» ${ }^{16}$.

Todo este proceso no ha podido ser estudiado por el momento en la región que tratamos, tanto por la falta de estudios como por las dificultades del registro arqueológico del período ${ }^{17}$. De la Sigüenza visigoda es muy poco lo que podemos decir, ya que no hay referencias en las fuentes escritas. Se ha llevado a cabo un estudio a partir de las menciones que se hacen en los concilios de la época, esencialmente los toledanos $^{18}$. Cinco obispos de la sede seguntina delatan por su onomástica un origen germánico en el siglo VII, una cifra bastante alta si consideramos que en la vecina Complutum sólo tres de los siete prelados que ocupan la silla episcopal en ese mismo siglo llevan onomástica germana. Los cinco de Sigüenza son Hildisclo, Witerico, Egica, Ella y Gunderico. Hildisclo asiste al IV, V y VI Concilio de Toledo, celebrados etre 633 y 638; Witerico al VII, VIII, IX y X de Toledo, que tienen lugar desde 646 a 656; Égica sólo acude al XI de Toledo del 675; Ella aparece como signatario de las Actas del XII, XIII y XIV Concilio de Toledo, celebrados en poco más de tres años, esto es entre 681 y 684 y por último Egica firma en el XV y XVI de Toledo, del 688 y 693 respectivamente ${ }^{19}$. Se trataría de un proceso que Orlandis califica de «germanización de la jerarquía eclesiástica» ${ }^{20}$, posterior al 589, y que básicamente habría significado la ocupación de obispados, fundamentalmente durante la segunda mitad del s. VII, por gentes cuya onomástica es germana. Ahora bien, no todos los obispados del Reino Visigodo conocieron este proceso:

...las sillas episcopales en las que predominan o abundan titulares con nombre germánico parecen ser aquellas correspondientes a ciudades cuya importancia estratégica o política era evidente para el mantenimiento del gobierno visigodo en esas zonas pero, y éste es el punto que nos interesa ahora, también en áreas donde los hallazgos arqueológicos han permitido corroborar que se trata de zonas en las que el elemento popular visigodo se habría asentado, esto es básicamente áreas de la Meseta. ${ }^{21}$

\footnotetext{
${ }^{16}$ López Quiroga, Jorge, Arqueología del hábitat rural en la Península Ibérica (siglos V-X), Madrid, 2009, p. 18 у pp. $47-57$

17 Vigil-EsCALERA GuISADO, Alfonso, «Aspectos sobre la cultura material en "Hispania" (ss. V-VII): problemas de visibilidad/invisibilidad del registro arqueológico», LÓPEZ QUIROGA, Jorge y MARTÍNEZ TEJERA, Artemio Manuel (Eds.), Gallia e Hispania en el contexto de la presencia "germánica" (ss. VVII) : balances y perspectivas, Oxford, 2006, pp. 89-108.

${ }^{18}$ VALLEJo GIRVÉS, Margarita, «Nota sobre el obispado de Segontia...»

19 VALLEJo GIRVÉS, Margarita, «Nota sobre el obispado de Segontia...», p. 73 y nota al pie 19. Sobre estos prelados en particular García Moreno, L. A., Prosopografía del Reino Visigodo de Toledo, Salamanca, 1974, p. 145, no 365-360.

${ }^{20}$ ORLANDIS, José, «El elemento germánico en la Iglesia Española del siglo VII», Anuario de Estudios Medievales, 3 (1966), pp. 27-64.

${ }^{21}$ ORLANDIS, José, «El elemento germánico...», pp. 30, 35 y 43.
} 
Teniendo en cuenta la presencia de obispos de nombre germano desde al menos el $633 \mathrm{y}$ hasta el 693, esto es, durante los dos últimos tercios del siglo VII, momento en que no existía ningún problema que hiciera temer a los monarcas visigodos la pérdida de su dominio sobre este territorio podría concluirse que el componente visigodo de la población que ocupa el Valle del Henares en aquellos siglos sería ciertamente notable.

En este sentido Orlandis aboga por una presencia de masa campesina visigoda notable en las tierras altas y pobres de Guadalajara para explicar este monopolio onomástico germánico en el episcopado seguntino del siglo VII ${ }^{22}$.

Lo cierto es que en el hinterland de Sigüenza tenemos noticias de hallazgos funerarios fechables en estos siglos en Horna, cerca de la llamada Villa de los Quintanares, en Palazuelos, en Alcolea de las Peñas, muy cercana a una posible villa romana, en Atienza y en las más lejanas Hiés, Villel de Mesa y Alarilla ${ }^{23}$.

Poco más es lo que podemos decir sobre la investigación del período tardoantiguo y visigodo en el entorno del valle del Salado, ya que en esta zona no hay investigaciones suficientes. La investigación arqueológica de este período en la provincia de Guadalajara se ha centrado en algunos asentamientos concretos, como la ciudad de Recópolis o el poblado de Gualda ${ }^{24}$. Para el entorno del valle del Salado, el único estudio que se ha realizado ha fijado la atención es la ocupación de cuevas, bien como espacios con una clara connotación religiosa de tipo eremítico o bien simplemente con un carácter habitacional dentro de los esquemas de poblamiento disperso tardorromano y altomedieval ${ }^{25}$. Como ejemplos de este tipo de ocupación se citan la cueva del Tio Grillos en Ujados, el de Morenglos en Alcolea de las Peñas y la cueva de la Merendilla o de los Corrales, que pertenece a Tordelrábano. Para estos asentamientos se da una amplia cronología, entre los siglos VI al XI, con una fase de ocupación en época andalusí adscrita a un tipo de población mozárabe. No obstante, en este tipo de trabajos encontramos una notable deficiencia: no se nos facilita de qué manera han sido fechadas las ocupaciones de estos hábitat rupestre más que con vagas analogías a lugares de la Península Ibérica. No sabemos si en el transcurso de las prospecciones se recogieron

\footnotetext{
22 ORLANDIS, José, «El elemento germánico...», p. 45.

${ }^{23}$ Morère Molinero, Nuria, Carta arqueológica de la región seguntina, Guadalajara, 1983 pp. 18,44 y 45.

${ }^{24}$ CuAdrado Prieto, Miguel Ángel, «El yacimiento hispano-visigodo de El Tesoro-Carramantiel, Gualda (Cifuentes, Guadalajara)», GARCÍA-Soto MATEOs, Ernesto y GARCÍA VALERO, Miguel Ángel (Eds.), Actas del primer Simposio de Arqueología de Guadalajara: Sigüenza, 4-7 de octubre de 2000, t. II, pp. 501-512.

${ }^{25}$ DAZA PARDO, Enrique, «Elementos para el estudio de la arqueología altomedieval en la sierra norte de Guadalajara. Monacato, edilicia y poblamiento», en LÓPEZ QUIROGA, J.; MARTíneZ TEJERA, A. M., y Morín de PABlos, J. (Eds), Monasterio e Territorio. Elites, edilicia y territorio en el Mediterráneo medieval (siglos V-XI), BAR Internacional Series S1720, 2007, pp. 399-408; Idem, «Formas de ocupación rural en la Sierra Norte de Guadalajara (siglos V-X): El despoblado de Morenglos (Alcolea de las Peñas, Guadalajara)», Cuadernos de Prehistoria y Arqueología de la Universidad Autónoma de Madrid, 31-32 (2005-2006), pp. 195-218.
} 
materiales cerámicos o numismáticos que permitan dotar de cronología, ya que ni estos han sido publicados ni se hace referencia explícita o implícita a ellos ${ }^{26}$.

\section{En la frontera de al-Andalus: el poblamiento en las fuentes escritas}

\section{Como indica Chalmeta:}

En el 711, Hispania fue ocupada por grupos humanos pertenecientes al califato omeya de Damasco. Ello implica unos cambios, ya que trajeron consigo la vigencia de ciertas novedades: 1) un grupo dominante étnicamente árabe (y subsidiariamente beréber), 2) el uso de otra era: la hégira (empieza en el 622), 3) una ideología: el islam, 4) una lengua oficial: el árabe, 5) una cultura: la musulmana. La implantación de dichos factores, nuevos en un entorno cristiano-latino, aconseja mantener el uso de términos originales árabo-musulmanes para evitar abusivas asimilaciones automáticas con conceptos europeos. $^{27}$

Tras la conquista araboberéber toda la zona norte de la provincia de Guadalajara quedó englobada durante la época andalusí en lo que las fuentes musulmanas consideran como tugur, esto es, fronteras ${ }^{28}$. Como indica Eduardo Manzano ${ }^{29}$ :

El concepto de Tagr adquirió una enorme importancia en el Islam medieval. Su relación con la idea de Yihad, o Guerra Santa, va a dotar a estas zonas no sólo de una enorme importancia estratégica, sino también de una gran relevancia de tipo ideológico. Los teóricos de la institución califal van a incluir entre las obligaciones del califa la misión de "defender las fronteras de los musulmanes", junto con otra serie de tareas tales como el mantenimiento de la religión, la práctica del Yihad o la organización de la administración fiscal.

En al-Andalus este concepto fue utilizado para designar las zonas limítrofes con los reinos del Norte. Entre los andalusíes, la conciencia de tener una frontera clara de su territorio frente al de los cristianos nace tempranamente y su constitución como tal se lleva a cabo con prontitud. No obstante, no fue un todo homogéneo, sino que los mismos geógrafos y cronistas distinguieron distintos espacios en toda esta franja fronteriza. Tres son las zonas que, grosso modo, podemos distinguir: la Marca Inferior,

\footnotetext{
${ }^{26}$ Entiéndase que la crítica no va dirigida a la investigación en sí, sino a la presentación de los resultados, ya que dificulta enormemente el desarrollo de trabajos como el presente al no poder contar con elementos suficientes de valoración y comparación.

${ }^{27}$ Chalmeta, Pedro, «Al-Andalus» en Domínguez Ortíz, Antonio (Dir.), Historia de España, Barcelona, 1989, t. III, p. 3.

${ }^{28}$ MANZANo MoRenO, Eduardo, La frontera de al-Andalus en época de los omeyas, Madrid, 1991. Sobre la palabra tagr (frontera, pl. tugur), su significado en árabe, sus diferencias con el vocablo darb, y el concepto de territorialidad, vid. cap. I «El concepto de "frontera"», pp. 23-69.

${ }^{29}$ ManZANO Moreno, Eduardo, La frontera de al-Andalus..., p. 36.
} 
cuya cabeza es Mérida, y luego Badajoz en la época de taifas; la Marca Media, con capital en Toledo, y luego en Medinaceli; y la Marca Superior, con cabeza en Zaragoza. De las tres, fue la central o Marca media, en la que se encuentra nuestro territorio y que abarca prácticamente desde Soria a Mérida, la que cargó con el peso sustancial de la defensa de al-Andalus. Es un territorio marcado geográficamente por la presencia del Sistema Central, y así lo señaló al-Idrisi, para quien al-Andalus se divide en dos partes precisamente por esa larga cordillera que el llama al-Sarrat, que se extiende desde Medinaceli hasta cerca de Coimbra. De este territorio dice el autor árabe que abundan en sus montañas las ovejas y vacas, que los tratantes y pastores llevan a los demás países y que por sus buenos pastos no hay ninguna res escasa de carnes ${ }^{30}$. De hecho, parece que al-Idrisi distingue una comarca o iqlim llamada al-Sarrat, donde se asientan los núcleos de Talavera, Toledo, Madrid, Alamín, Guadalajara, Uclés y Huete ${ }^{31}$.

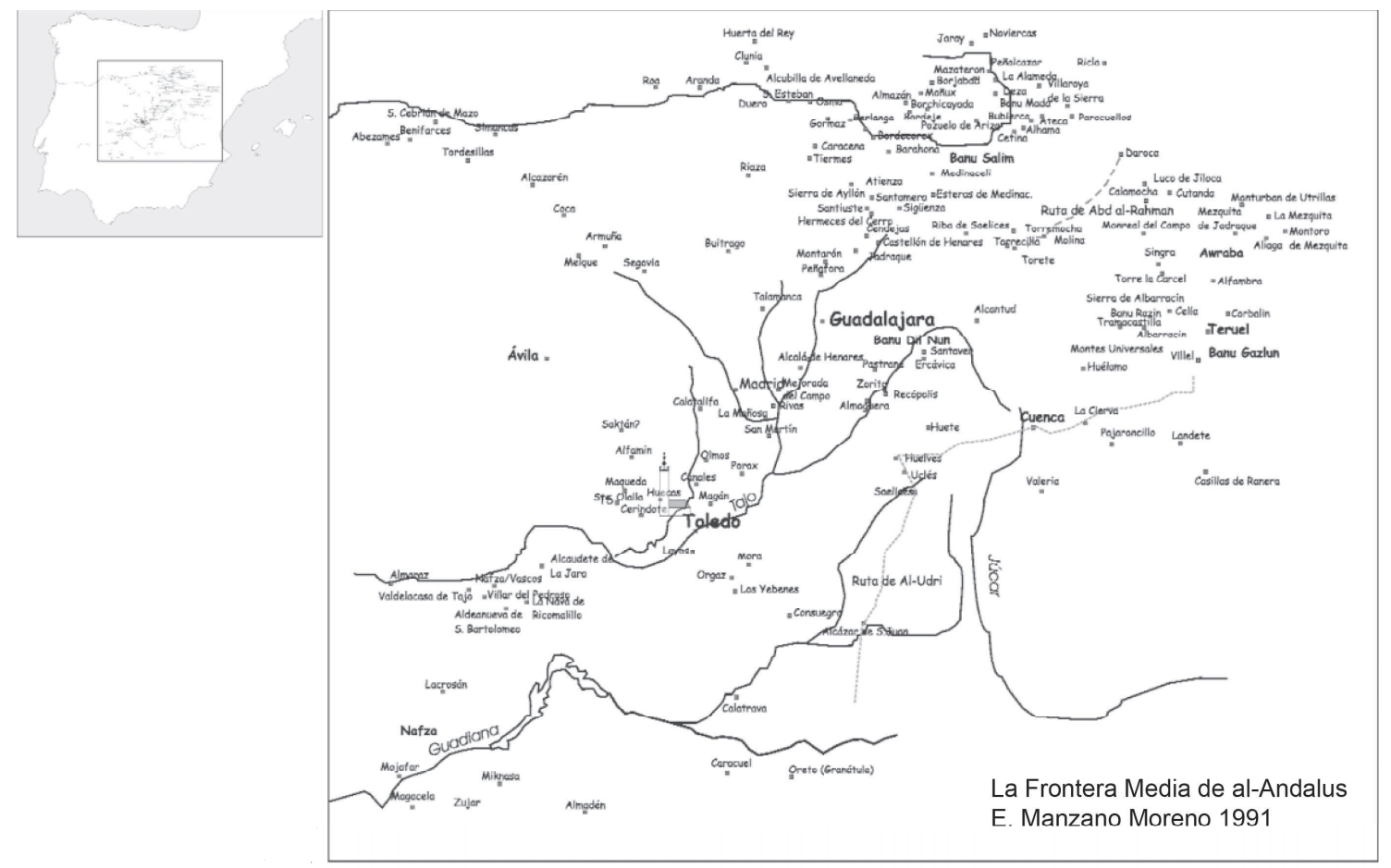

Toda la Marca Media puede considerarse, a su vez, dividida en tres sectores: el de poniente, con capital en Talavera controlando el tajo y que comprendería los núcleos de albalat, Vascos, Espegel, Gualija y Canturias; el central, dominado por Toledo, donde destacaron las poblaciones y castillos de Alamín, Maqueda, Huecas, Calatalifa, Olmos, Canales y Madrid; y finalmente el oriental, en el que se encuentra nuestro territorio del valle del Salado, y en el que destacan los núcleos de Alcalá, Talamanca, Alcolea de

\footnotetext{
${ }^{30}$ VALLVÉ, Joaquín, La división territorial de la España musulmana, Madrid, 1986, p. 120 y nota al pie 150.

${ }^{31}$ VALLVÉ, Joaquín, La división territorial..., pp. 120-121 y nota al pie 150.
} 
Torote, Hita, Castejón, Sigüenza, Atienza, Gormaz y Medinaceli entre otros muchos pequeños núcleos y puntos defensivos.

Por el contrario, lo que abunda en la historiografía es una idea generalizada acerca del poblamiento en la frontera, y que queda resumida en las palabras de Antonio Herrera:

Las marcas (en árabe «Thugur») eran totalmente distintas en cuanto a consideración territorial de las coras (en árabe «Kuwar») o provincias del interior, siempre más seguras y prósperas. Su población, sus estatutos jurídicos y sociales, sus formas de vida, eran en todo diferentes a las de zonas más meridionales. En ellas mandaba un caíd («qa'id») y estaban, eso es seguro, muy escasamente pobladas, casi desérticas en algunas partes (...) En este sentido, consideramos que la Marca Media en su distrito de Guadalajara fue siempre un territorio de escasa población, tan solo ocupado por destacamentos militares, y con ciertos núcleos de población (Guadalajara, Alcalá, Sigüenza, Medinaceli) un tanto más densos, pero siempre en grado escaso. ${ }^{32}$

Y más adelante, insiste Herrera Casado:

Una vez repasadas las ciudades, fortalezas y torreones vigías sobre la línea del Henares, hemos de terminar considerando la existencia de otros puestos de vigilancia, más aislados, sobre los valles de los ríos serrano que abocan por su orilla derecha en el Henares. Territorios éstos que, durante los tres siglos de existencia de la Marca Media, estuvieron prácticamente desiertos, tan sólo ocupados por las mínimas guarniciones militares encargadas de custodiar los diversos torreones y puntos estratégicos... ${ }^{33}$

Se trata de una idea persistente en la literatura historiográfica sobre el poblamiento del centro peninsular en época altomedieval, cuyo origen se puede rastrear en el tema del desierto en la Extremadura castellana heredera de los planteamientos de Sánchez Albornoz, y que poco a poco está siendo desmontada por distintos investigadores ${ }^{34}$. En nuestro caso, no podemos estar más en desacuerdo con las palabras de Antonio Herrera,

${ }^{32}$ Herrera CASADO, Antonio, «La Marca Media de al-Andalus en tierras de Guadalajara», Wad-alHayara, 12 (1985), p. 14.

${ }^{33}$ HerRera CASADO, Antonio, «La Marca Media...», p. 22.

${ }^{34}$ La idea se ha mantenido hasta épocas recientes. Vid. VILLAR GARCíA, Luis Miguel, La Extremadura castellana: guerreros, clérigos y campesinos (711-1252), Valladolid, 1986, donde repite el modelo de desierto y repoblación. Para la revisión historiográfica de este fenómeno, Vid. MARTín VISO, Iñaki, Poblamiento y estructuras sociales en el norte de la Península Ibérica (siglos VI-XIII), Salamanca, 2000. El mito del vacío de población en la zona de Guadalajara y especialmente en la zona de frontera ha sido también desmontado por otros: PAVÓN MALDONADO, Basilio: Guadalajara medieval. Arte y arqueología árabe y mudéjar, Madrid, 1984, y MANZANO MORENO, Eduardo, La frontera de al-Andalus en época de los Omeyas, Madrid, 1991. Interesante resulta también las propuestas realizadas por EsCALONA MONGE, J., «Poblamiento y organización territorial en el sector oriental de la cuenca del Duero en la Alta Edad Media», III Congreso de Arqueología Medieval Española, Oviedo, 1989, t. II, pp. 448-455. 
al menos en lo que al territorio del Alto Henares y especialmente el valle del Salado se refiere, ya que tanto un repaso a la bibliografía existente, como el propio proyecto de prospecciones arqueológicas, ponen de relieve una relativa densa red de asentamientos andalusíes, tanto en los castillos de Atienza, Riba de Santiuste, Baides y el área en torno a Sigüenza, como otros de menor entidad tales como los localizados en las inmediaciones de Alcolea de las Peñas, Paredes de Sigüenza, Valdelcubo, Riosalido, Imón, La Olmeda de Jadraque, o las noticias que tenemos de otros núcleos en Cutamilla, Huérmeces Guijosa etc. Quizás, las palabras de Antonio Herrera sean fruto de la falta de documentación arqueológica sobre la zona en los momentos en que emite estos juicios. O quizás, la zona que estamos tratando sea una zona diferente al resto de la Marca Media, en cuyo caso deberíamos poner el acento en el porqué, y rápidamente dirigir nuestra mirada al paso natural por el valle entre las dos submesetas, y a la cantidad de recursos agroganaderos de la zona, pero sobretodo, y fundamentalmente, a la sal. La primera opción es la que reconoce el propio Herrera Casado, si bien no deja lugar a distinta interpretación, al menos reconoce la posibilidad de nuevos hallazgos:

Esta relación de ciudades, castillos y torreones de los que ha quedado memoria o huella en la línea defensiva del sector oriental de la Marca Media, no agota, por supuesto, el tema de estudio, que sigue abierto, si no a nuevas interpretaciones, si a nuevos hallazgos, bien documentales o arqueológicos. ${ }^{35}$

Dentro de esta zona uno de los elementos en los que se insiste como definitorio para comprender el proceso histórico es la vía romana que enlazaba Zaragoza con Mérida, a la que ya hemos hecho mención anteriormente. El tramo que ahora nos interesa es el que desde Medinaceli se dirige en dirección suroeste, pasando por Segontia (Sigüenza) y desde allí seguía paralela al curso del río Henares, a través de Mandayona, Jadraque, Espinosa de Henares y Arriaca, en las proximidades de Guadalajara ${ }^{36}$. Todo apunta a que esta vía seguía funcionando tras la conquista islámica, siendo definitoria y articuladora de todo este territorio. Ya hemos citado como al-Idrisi citaba en el siglo XII las cincuenta y cinco millas que había desde Guadalajara a Medinaceli, y en el mismo sentido Ibn Hawqal, a principios del siglo X, habla de una ruta entre ambas localidades en la que se invertían dos jornadas, aunque en su caso habla de una etapa intermedia, en un lugar llamado Sar al-Qawarir, del que nos dice que se encontraba junto a una aguada, por lo que es probable que estuviera junto al río Henares ${ }^{37}$. También a

\footnotetext{
${ }^{35}$ Herrera CASAdo, Antonio, «La Marca Media...», p. 25.

${ }^{36}$ ABASCAl PAlazÓn, Juan Manuel, Vias romanas..., 1982, pp. 60 y ss

${ }^{37}$ Sobre al-Idrisi vid. supra; IBN HAWQAL, Kitab surat al-ard (Configuration de la terre),, trad. al fr. Wiet, Gaston y Kramers, J. H., Leyden, 1968, p. 117. Cit. en MANZANO MorENO, Eduardo, La frontera de al-Andalus..., p. 150 y nota al pie 43.
} 
principios del siglo $\mathrm{X}$ se cita este importante tramo en el ataque que Abd al-Rahman III lanza contra los cristianos en el año 920, lo que se conoce como la campaña de $\mathrm{Muez}^{38}$. Y aún antes, en torno al año 858, tenemos datos de la posible existencia de esta vía en el itinerario seguido por Eulogio de Córdoba cuando desde la capital omeya se dirige hasta Zaragoza pasando por Toledo, Complutum y Segontia ${ }^{39}$. Vemos por tanto como esta artería que cruza el centro peninsular en una diagonal SO-NE, en concreto el tramo que transcurre paralelo al río Henares y desde Sigüenza hasta Medinaceli, estuvo activo durante todo el período andalusí, con seguridad desde mediados del siglo IX hasta el XII, y todo apunta a que la vía romana no fue abandonada durante el período tardoantiguo.

En todo este trayecto el territorio apenas es mencionado ni son citados en las fuentes asentamientos más allá de los centros que constituyen las etapas y que equivalen a ciudades o a centros controlados por el poder, y que constituyen todos ellos centros continuadores de los establecimientos previos a la conquista musulmana. Esta continuidad en el poblamiento de los principales núcleos quizás se puede explicar por el modelo de conquista que se llevó a cabo en estos territorios.

A la llegada de los musulmanes el panorama urbano debía ser ciertamente desolador, señalándose únicamente la existencia de ruinas en los que otrora fueron los principales asentamientos de la época romana. Pero eso no quiere decir que esos centros hubieran desaparecido, y como hemos señalado para el caso de Sigüenza, aún funcionaba como silla episcopal, y por tanto como núcleo de población de cierta importancia, bien entrado el siglo VII. Se trataría de una sociedad ciertamente ruralizada, como ponen de manifiesto numerosos indicadores. Este profundo proceso de ruralización parece estar asociado a una fuerte estratificación de la sociedad y a unos modos de producción netamente feudales. Sería una de las razones que explicarían el porqué del rápido avance del Islam. El control del nuevo territorio, era imposible llevarlo a cabo sin la fijación a la tierra de los nuevos aportes humanos, que debieron situarse bien en zonas no ocupadas o bien en zonas antes habitadas mediante algún tipo de pacto con las comunidades hispanovisigodas. Ibn al-Qutiyya refiere que después de la batalla de Guadalete los enfrentamientos fueron escasos y puntuales, debiéndose hablar de un sometimiento de la población indígena mediante el sistema de capitulaciones:

Algunos sabios antiguos dicen, hablando de España, que la mayor parte de ella se
sometió por capitulación, excepto algunos lugares bien conocidos, porque después
de la derrota de Rodrigo todas las ciudades capitularon; de aquí que los cristianos

${ }^{38}$ Ibn Hayyan, Al-Muqtabas $V$. Ed. de Chalmeta, Pedro, Corriente, Federico y Sobh, M., Madrid, 1979; Trad. de Viguera, Ma Jesús y Corriente, Federico, Crónica del califa Abdarrahman III an-Nasir entre los años 912 y 942, Zaragoza, 1981, pp. 105-106

${ }^{39}$ Eulogio DE CóRdobA, «Eulogi Epistula. Epistula tertia ad Wilesindum», en Gil FernáNDEZ, Juan (Ed.), Corpus Scriptorum Mozarabicorum, Madrid, 1973, t. II, p. 500. 
que las habitaban continuaron poseyendo sus tierras y demás propiedades con el derecho de venderlas. ${ }^{40}$

Este sistema de capitulaciones para el control del territorio no es uniforme, dato que no todos los cabecillas visigodos y musulmanes adoptaron idénticas actitudes. La diferencia fundamental se basó en el tipo de oposición que se planteara desde el inicio, lo que generó dos tipos de acuerdos: a aquellos que se habían opuesto y sólo capitularon al final, se les exigió la sumisión total al Islam (suhl) y a los que se sometieron desde el principio sin ofrecer gran resistencia se les respetó en gran medida su organización política y religiosa ('ahd $)^{41}$.

La obra de Ibn al-Qutiyya permite establecer una primera valoración sobre el proceso de división del territorio y de los primeros asentamientos. Dice este autor que Musa, tras dar por finalizada la conquista, procedió a la división del territorio peninsular entre los participantes en la contienda militar, de igual manera que hiciera con los bienes procedentes del botín, pero siempre deduciendo el quinto (jums) de las tierras incultas y de los campos cultivados, esclavos y otros objetos muebles, procurando no desvincular a los individuos que explotaban los campos pertenecientes al quinto con la finalidad de mantener su productividad y con ello garantizar el tercio que debían pagar al fisco. Al margen de que esto se realizara tal como lo expone el autor árabe, lo cierto que s que se procede a un primer asentamiento y distribución de los conquistadores, en el que saldrían beneficiados los beréberes como grupo dominante tras la partida de Musa, a quien acompañaron la mayoría de los árabes que componían el grueso de su ejército.

La instalación de los nuevos pobladores se hizo por tanto respetando, en gran medida, a los conjuntos de población ya existentes en el terreno. En este sentido, conviene recordar las palabras de Chalmeta:

La primitiva conquista se propuso imponer un nuevo dominio político y sobre todo económico. No se trata de una expansión territorial y ésta fue mera consecuencia del deseo de aumentar los ingresos. Esta faceta recaudatoria es la que parece constituir la función esencial de los gobernadores (como tal la privilegia el autor de la Crónica del 754) y la que aparece siempre estipulada en los tratados de capitulación. Dado que, en la primera fase, se habla exclusivamente de botín y tributos, éstos deben ser la preocupación básica de los conquistadores o, cuando menos, de sus mandos; el interés por las tierras será posterior. La conquista no tuvo por meta establecer una colonia "de poblamiento" sino "de explotación". Característica que viene corroborada por la forma y fecha de los establecimientos árabo-musulmanes. Por tanto hubiera sido

\footnotetext{
${ }^{40}$ IBN AL-QuTIYYA, Ta'rij iftitah al-Andalus, ed. y trad. RIBERA, J., Historia de la conquista de España de Abenalcotía el cordobés, Madrid, 1926, p. 173.

${ }^{41}$ Sobre el tema vid. ChALMETA GendRón, Pedro, Invasión e Islamización. La sumisión de Hispania y la formación de al-Andalus, Jaén, 2003, passim, en espec. pp. 206-212.
} 
económicamente ruinosa la expulsión o la eliminación de la población laboral autóctona. ${ }^{42}$

La ocupación sistemática y efectiva de todo el territorio en tan corto espacio de tiempo debió conjugar el sistema de pactos con el establecimiento de asentamientos y tropas en puntos estratégicos de las principales vías de comunicación y lugares que reuniesen buenas condiciones para su explotación económica. Un ejemplo paradigmático de ello lo constituye el valle del Henares, que a su fértil vega, explotada intensamente ya desde época protohistórica, se le une la circunstancia de ser una importante vía natural de paso hacia el valle del Ebro, como ya hemos visto. Los asentamientos se irán extendiendo y concentrando en torno a las vegas de los ríos, como demuestran para el entorno del Jarama y el Henares algunas de las excavaciones realizadas ${ }^{43}$.

Pero si son escasas las referencias que tenemos en las fuentes escritas para el valle del Henares, mucho más escuetas son para los territorios que los circundan y que se adentran más allá hacia las sierras del norte y del sur. En lo que respecta a nuestro territorio del valle del Salado, salvo el caso de Atienza del que después hablaremos, apenas tenemos referencia alguna en las fuentes árabes en lo que a los núcleos de población se refiere. No así en las fuentes cristianas, en las que encontramos algo de información. En la crónica de Sampiro se narra una expedición del rey Ordoño II en el 917 en la que el monarca se habría dirigido a la tierra que llamaban Sintila, atacando y tomando en ella las fortalezas de Sarmalon, Eliph, Palmacio, Castellion y Magnancia ${ }^{44}$.

Congregato magno exercitu, jussit arma componi et in forum terram, que dicitur Sintila, strages multa fecit, terram depopulavit, etiam castella multa in ore Gladis coepit. Hec sunt Sarmaleon, Eliph, Palmacio et Castellion, et Magnancia, depraedavit.

Tradicionalmente se ha venido admitiendo que Sintila designaba las tierras comprendidas entre las actuales localizades de Cendejas de la Torre, Cendejas de en Medio y Cendejas del Padrastro, todas ellas en la cuenca del Henares, a escasa distancia de Sigüenza en dirección suroeste. A partir de ahí se ha propuesto la identificación de los otros topónimos incluidos en la crónica: Palmacio sería Palmeces y Castellion sería Castelón de Henares, al que al-Razi cita entre los castillos incluidos dentro del distrito

\footnotetext{
${ }^{42}$ Chalmeta, Pedro, «Al-Andalus...», pp. 21-22.

${ }^{43}$ Por citar algunos ejemplos: MARTíNEZ LILLO, Sergio, «Primeros materiales arqueológicos del Castillo de Olmos», I Congreso de Historia de Castilla-La Mancha, Talavera de la Reina, 1988, t. V, pp. 94-104; RetUerCe Velasco, Manuel, «Cerámica islámica de la Comunidad de Madrid», Madrid del siglo IX al XI, Madrid, 1990, pp. 145-164; BermeJo CRESPO, José Luis y MuÑoz LóPEZ-Astilleros, Katia, «Una explotación agrícola en el territorio de los Banu Salim: excavaciones en "Vereda de Sedano" o "Las Fuentecillas" (San Fernando de Henares, Madrid)», Boletín de Arqueología Medieval, 8 (1994), pp. 205225.

${ }^{44}$ PÉREZ DE URBEL, Justo, Sampiro: su crónica y la monarquía leonesa en el siglo X, Madrid, 1952, pp. 314-315.
} 
de Guadalajara ${ }^{45}$. Más problemática es la identificación de Eliph. Felix Hernández propone su identificación con Calatalifa, por la aproximación fonética Eliph-Alifa, pero esa plaza dista bastante del itinerario marcado en la crónica ${ }^{46}$. Respecto a Magnancia, Catalina García y Toribio Minguella son de la opinión de que debe hacer referencia a Atienza o a la misma Sigüenza, con el nombre alterado por los copistas ${ }^{47}$. Basilio Pavón afirma que Magnancia pudo ser el nombre de una amplia tierra comprendida entre Fragosa, Sigüenza y el valle del río Dulce ${ }^{48}$. En cualquier caso, Ordoño II atacó y se adueño de una vasta región comprendida entre los ríos Cañamares, Salado, Henares y Dulce, cuyos valles permitían adentrarse hasta la campiña entre Jadraque y Guadalajara. Lo impreciso de esta fuente, al igual que ocurre con las fuentes árabes, hace que se silencie otro importante paso que une la zona norte con el valle del Henares, y que queda comprendido también en los límites de nuestro estudio. Nos referimos al valle que desmiembra la paramera de Baides y por donde baja el río Salado tras pasar el valle del Atance hasta unirse con el propio Henares. En este espacio destacan en la actualidad los municipios de Rebollosa de Jadraque, Santiuste, Huérmeces del Cerro, Viana de

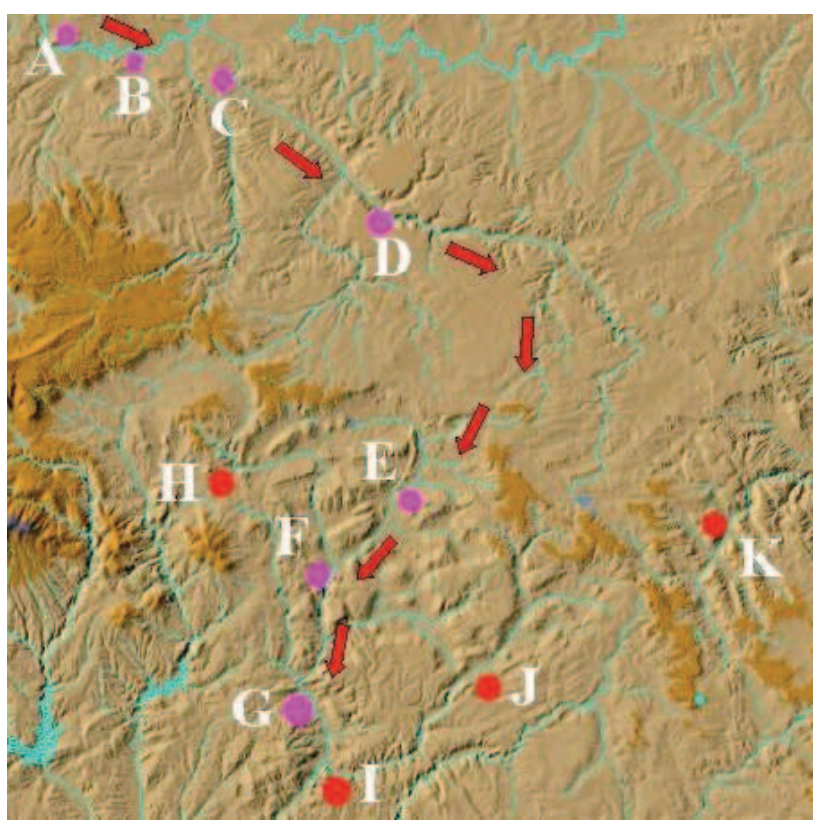
Jadraque y Baides. Junto con el acceso desde Sigüenza a través del valle del río Vadillo, es la principal conexión del valle del Henares con la zona de Atienza, que sabemos fue un importante núcleo omeya como ya veremos más adelante.

Ruta seguida por Fernando I: A castro Gormaz (castillo de Gormaz); B Aquilera (Aguilera); C ciuitatem Berlanga (Berlanga); D Hordecorex (Bordecorex); E castro quoque san iusti (castillo de la Riba de Santiuste); F Sancte Mayre municipium (Santamera); G Guermos (Huérmeces); H Atienza; I Baides; J Sigüenza; K Medinaceli

\footnotetext{
45 CATAlina GARCíA, Juan, La Alcarria en los dos primeros siglos de su reconquista, reimpr. Guadalajara, 1973, p. 17; AL-RAZI, Crónica del moro Rasis. Versión del Ajbar muluk al-Andalus de Ahmad ibn Muhammad ibn Musa al-Eazi, 889-955, Ed. y Trad. CATALÁN, Diego y AndRÉS, Ma Soledad de, Madrid, 1975, pp. 62-63. Cerca de Palmaces se encuentra una fortaleza mencionada en las «Relaciones Topográficas de Felipe II» y de la que aún quedan algunas estructuras y restos cerámicos estudiados por PAVÓN MALDONADO, Basilio, Guadalajara medieval. Arte y arqueología árabe y mudéjar, Madrid, 1984, p. 78.

${ }^{46}$ HERNÁNDEZ GIMÉNEZ, Felix, «Travesía de la Sierra de Guadarrama en el acceso a la raya musulmana (Concluirá)», Al-Andalus, 38, 1 (1967), p. 154.

47 Catalina García, Juan, La Alcarría..., p. 17; Minguella y Arnedo, Toribio, Historia de la Diócesis de Sigüenza y de sus obispos, Madrid, t. 1 (1910), p. 46.

${ }^{48}$ PAVÓN MALDONADO, Basilio, Guadalajara medieval..., p. 69.
} 
De esta ruta tenemos constancia, nuevamente, gracias a una fuente cristiana que hace referencia a otro ataque de los castellanos. En este caso es la Historia Silense, al narrar las conquistas realizadas por el rey Fernando I en torno al año 1059, quien tras apoderarse de Gormaz, Aguilera y Berlanga se hace dueño de: Rippa de Sactiuste (Riba de Santiuste), Santa Emerenciana (Santamera) y Górmices (Huérmeces), aparte de varias torres atalayas ${ }^{49}$.

$\mathrm{Si}$ a estos enclaves añadimos otros conocidos para este período como los de Jadraque, Montarrón o Peñafora ${ }^{50}$, puede concluirse que toda la cuenca del Henares, por la calzada que la atraviesa, así como las tierras de los alrededores, no por encontrarse prácticamente ausente en las fuentes tienen una menor realidad histórica.

Las escasas noticias que tenemos para esta zona referidas al siglo X/IV H, revelan una cierta frecuencia de ataques cristianos que penetran con bastante profundidad dentro de este territorio. La expedición de Ordoño II, descrita en la Crónica de Sampiro, penetra hasta los alrededores de Sigüenza. Otra incursión es recogida en el Muqtabis $V$ para el año 920, protagonizada por los que llama «enemigos de Dios» en territorio de Guadalajara, en el curso de la cual llegaron hasta un castillo llamado Alcolea ${ }^{51}$. La debilidad del sistema defensivo en esta zona se vuelve a poner de manifiesto en la noticia proporcionada por al-Razi en la que se señala que en el año 936-937 el califa Abd al-Rahman III ordenó el reforzamiento de fortalezas y atalayas comprendidas entre Atienza y Talavera, lo que viene a evidenciar, como señala Manzano, que con anterioridad a esta fecha si existía aquí algún tipo de organización fronteriza, esta era completamente ineficaz ${ }^{52}$. El hecho de que todo este tramo se encuentra expuesto a los ataques con anterioridad a mediados del siglo X revela para Eduardo Manzano que no existía ningún tipo de línea defensiva organizada para detener dichas amenazas ${ }^{53}$. El hecho de que contemos con un conjunto de asentamientos fronterizos bien organizados en el eje Medinaceli-Gormaz, atestiguado en las fuentes a partir de la segunda mitad del siglo X y comienzos del XI y no con anterioridad viene a reforzar esta idea ${ }^{54}$.

El centro más importante de este conjunto defensivo parece haber sido Medinaceli. Asentada sobre la antigua Ocilis romana, la historia de esta población es extremadamente confusa a lo largo de toda la Alta Edad Media y hasta bien entrado el

\footnotetext{
${ }^{49}$ No hemos podido consultar el original. Cit. en PAVÓn MALDONADO, Basilio, Guadalajara medieval..., p. 69 y nota al pie 209 .

${ }_{50}^{50}$ Sobre estos núcleos vid. PAVÓN MALDONADO, Basilio, Guadalajara medieval..., pp. 83, 91 y 96.

${ }^{51}$ IBN HAYYAN, Al-Muqtabas $V$..., p. 105.

${ }^{52}$ IBN Hayyan, Al-Muqtabas $V . . .$, p. 207; MANZANO Moreno, Eduardo, La frontera de al-Andalus ..., p. 152.

${ }_{53}^{15}$ Eduardo, La frontera de al-Andalus..., p. 152.

${ }^{54}$ Llul Martínez de Bedoya, Pilar, Huete, Mario y Molina Bermejo, Jesús, «Un itinerario musulmán de ataque a la frontera castellana en el siglo X: fortalezas, castillos y atalayas entre Medinaceli y San Esteban de Gormaz», Castillos de España, 93 (1987), pp. 3-13; VAliente Malla, Jesús y CuAdRAdo Prieto, Miguel Ángel, «Las torres de Atienza», Actas del primer Encuentro de Historiadores del valle del Henares, Guadalajara, 1988, pp. 631-642.
} 
siglo X. Parece que la ciudad, como todas en la época tardoantigua, había entrado en franca decadencia pues cuando los musulmanes conquistaron al-Andalus la encontraron desierta y la reconstruyeron algún tiempo después, según nos señala el cronista al$\mathrm{Razi}^{55}$, aunque es difícil precisar la fecha de la reforma. Todo apunta a que sería un miembro de la familia de los Banu Salim quien llevaría a cabo la reforma, de quien tomaría el nombre para llamarse ciudad de los Salim, Madinat Salim. Se trata de un grupo beréber de la tribu de los Masmuda, responsables también de la fundación de Guadalajara, a través de un familiar de nombre Faray, y del castillo de Alcalá, entre otros núcleos.

\section{Beréberes y Omeyas: De la dominación de los Banu Salim a la presencia del Estado Omeya}

A la Marca Media, llegaron en los momentos iniciales de al-Andalus diversas tribus bereberes que se repartieron el territorio ${ }^{56}$. Es uno de los rasgos más notorios del tagr andalusí, la existencia en él de sectores enteros descritos en las crónicas como escenarios de un asentamiento humano de origen fundamentalmente norteafricano: zonas como Albarracín, Santaver, el corredor del Henares o el curso medio y bajo del río Tajo no parecen haber recibido un aporte árabe significativo después de la conquista musulmana, mientras que, en cambio, son relativamente abundantes las referencias que nos muestran a linajes beréberes que consiguen implantar en estas zonas un control particularmente duradero que llega a sobrevivir en algunos casos al propio poder omeya, continuándose en dinastías de taifas, y en otros casos son familias que acabaron bajo su control más directo antes de la caída del califato ${ }^{57}$.

Una de estas familias fue la de los Banu Salim, un clan de Sinhaya o de Masmuda. Es muy poco lo que sabemos de este linaje beréber, aunque llegaron a dar nombre a la zona, la frontera de los Banu Salim, según recoge al-Udri ${ }^{58}$. Manzano afirma que «Seguramente, los Banu Salim se hubieran sentido algo decepcionados de haber conocido la escasa atención de que fueron objeto por parte de los cronistas omeyas». Y es que, en efecto, apenas son mencionados en las fuentes. Tan sólo algunos escuetos

\footnotetext{
55 AL-RAZI, Crónica del moro Rasis..., pp. 58-59.

56 Guichard, Pierre, Al-Andalus. Estructura antropológica de una sociedad islámica en occidente, reimpr. Granada, 1998, pp. 365-408.

${ }^{57}$ MANZANO MORENO, Eduardo, La frontera de al-Andalus..., pp. 233 y ss. y Idem, «Beréberes de alAndalus: los factores de una evolución histórica», Al-Qantara, XI-2 (1990), pp. 397-428. Sobre la distribución de los beréberes, vid. Guichard, Pierre, Al-Andalus..., p. 365 y Bosch VilÁ, Jacinto, «Establecimientos de grupos humanos norte-africanos en la Península Ibérica», Atti del Ier Congresso Internazionale di Studi Norte-Africani, Cagliari, 1965, pp. 147-165.

58 AL-UdRI, Nusus an al-Andalus min Kitab Tarsi al-ajbar, trad. parcial GRANJA, Fernando de la, «La Marca Superior en la obra de al-Udri», Estudios de la Edad Media de la Corona de Aragón, VIII (1966), p. 492.
} 
datos, como algunas filiaciones familiares ${ }^{59}$, y las citas a algunos caudillos de esta tribu entre los ejércitos omeyas ${ }^{60}$.

La preeminencia de esta familia debió continuar hasta al menos el año 920, cuando Abd al-Rahman III los destituya a su paso por Guadalajara, durante el transcurso de la campaña de Muez. Aparentemente se debió a que la población de la ciudad tenía quejas contra ellos, pero la destitución también afectó al gobernador de la ciudad de Medinaceli ${ }^{61}$, por lo que es probable que detrás de esta decisión hubiera una maniobra política, o militar, que no podemos calibrar en su justa medida.

En línea con lo que ocurre con todo este territorio del centro peninsular, es poco más lo que podemos decir. Como señaló Guichard

muy pocas cosas sabemos sobre la geografía humana de todas las regiones septentrionales, y resulta muy difícil hacerse una idea de la densidad de la población de origen norteafricano en toda esta área de la España musulmana. ${ }^{62}$

Esta escasez de datos no hace justicia a una familia cuya importancia en la región parece más que significativa. De hecho, como ya se ha señalado, una cita de al-Udri nos señala que todo este sector fronterizo era conocido bajo la denominación de «frontera de los Banu Salim» ${ }^{63}$. Apenas sabemos nada sobre la naturaleza de este dominio, pues nada en las fuentes nos proporciona la más mínima indicación sobre esta familia. Zozaya señaló como la asociación de nombres de ciudades (Madinat Salim-Medinaceli, Madinat al-Faray-Guadalajara) o fortificaciones (Qalat Rabah-Calatrava la Vieja, Qalat Abd al-Salam-Alcalá la Vieja) con nombres de personas asociadas a esta familia, podían revelar un sistema de encomiendas, que a partir de mediados del siglo $\mathrm{X}$ pasa a un sistema de control centralizado, en línea con la política general practicada por los Omeyas ${ }^{64}$. En cualquier caso es una hipótesis difícil de contrastar con las fuentes que tenemos hasta el momento. Lo que si parece claro es que, hasta que fueron

\footnotetext{
${ }^{59}$ Ibn Hayyan nos informa de la muerte en el año 832 de Faray b. Masarra b. Salim, caudilo de Guadalajara y nieto de Salim, epónimo de la dinastía. IBN HAYYAN, Al-Muqtabis min anba' ahl alAndalus, ed. Ali MaKKI, Mahmud, El Cairo, 1971, p. 79. Cit. en Manzano Moreno, Eduardo, La frontera de al-Andalus..., p. 154 y nota al pie 57.

${ }^{60}$ En el relato de Ibn al-Qutiyya en el que narra la muerte de Musa b. Musa cita a mediados del siglo IX un señor de Guadalajara de nombre Izraq b. Mantil b. Salim. IBN AL-QuTIYyA, Ta'rij iftitah alAndalus..., pp. 83 y ss. y pp. 99 y ss.

${ }^{61}$ IBN HAYYAN, Al-Muqtabas $V$..., p. 105.

${ }^{62}$ Guichard, Pierre, Al-Andalus ..., p. 405.

${ }^{63}$ AL-UdRI, Nusus an al-Andalus min Kitab Tarsi al-ajbar, trad. parcial GrANJA, Fernando de la, «La Marca Superior en la obra de al-Udri», Estudios de la Edad Media de la Corona de Aragón, VIII (1966), p. 492.

${ }^{64}$ ZoZAYA, Juan, «Recientes estudios sobre la arqueología andalusí: La Frontera Media», Aragón en la Edad Media, IX (1991), p. 377. Más recientemente, el mismo autor ha insistido en la idea de encomiendas: ««¿Poblados? ¿ciudades? ¿campamentos? ¿recintos castrales? En la Marca Media: hacia una tipología», Al-Ándalus país de ciudades. Actas del Congreso celebrado en Oropesa (Toledo), del 12 al 14 de marzo de 2005, Madrid, 2007, pp. 23-64.
} 
«destronados» por los omeyas, las dificultades del emirato para imponer su autoridad sobre los territorios fronterizos permitieron a los Banu Salim organizar este territorio frente a las agresiones de los grupos vecinos. Junto a las ya citadas Alcalá, Guadalajara y Medinaceli, debemos señalar que núcleos fortificados como Madrid, Salamanca o Peñafora estaban también bajo su control. Era un amplio territorio el que controlaban, situado en torno a los cauces de los ríos Jarama y Henares, extendiéndose por el este hasta una línea imprecisa que los separaría del territorio dominada por otro clan bereber, el de los Banu Di l-Nun establecidos entorno a Santaveria o Ercávica ${ }^{65}$. Talamanca articularía el control por el oeste sobre el Jarama, mientras que al suroeste encontramos la fortaleza de Madrid (Mayrit) como avanzada sobre el Manzanares y Calatalifa sobre el Guadarrama, controlando el acceso desde Toledo. Por último el territorio se completaría por el norte con Uceda y Peñafora. Todas estas plazas fuertes estaban orientadas a preservar el territorio de las agresiones de clanes vecinos como el de los Banu Qasi desde el norte y, fundamentalmente, de la ciudad de Toledo. Para Eduardo Manzano $^{66}$, las constantes revueltas toledanas obligaron a los omeyas, en general, y a los Banu Salim, en particular, a articular una red militar de cerco frente a las actividades de la insumisa capital visigoda, constante problema para el gobierno de Córdoba en la Marca Media, obligando a crear un "limes" interno con las plazas ya mencionadas, a lo que habría que unir Calatrava (Qalat Rabáh), Olmos (Walmus) y Canales, entre otras.

Durante la primera mitad del siglo X no contamos con información en las fuentes escritas para nuestro territorio, aunque pensamos que debieron producirse algunas modificaciones de acuerdo con el control más directo por parte de los omeyas, una vez que la familia de los Banu Salim fue desplazada.

A partir del 946 la atención de los omeyas parece bascular hacia esta parte oriental de la frontera media, cuando deciden trasladar la capitalidad de la Marca desde Toledo a Medinaceli, lo que supondrá el eclipse de Atienza como principal referencia de la zona y como plataforma de lanzamiento de las campañas hacia el norte ${ }^{67}$. La fortaleza de Gormaz, más al norte, adquirirá ahora una gran importancia ${ }^{68}$. A lo largo de la ruta entre ambos núcleos, se documentan una serie de torres y atalayas que parecen configurar un

\footnotetext{
${ }^{65}$ Almonacid Claveria, J. A., «La Kura de Santaveria: estructura político-administrativa», I Congreso de Castilla-La Mancha, Talavera de la Reina, 1988, t. V, pp. 5-20.

${ }^{66}$ MAnZAnO Moreno, Eduardo, La frontera de al-Andalus..., Idem, «Madrid en la frontera omeya de Toledo», Madrid del siglo IX al XI, Madrid, 1990, pp. 115-130.

${ }^{67}$ VALLVÉ, Joaquín, La división territorial de la España musulmana, Madrid,1986, p. 308.

${ }^{68}$ La bibliografía sobre el castillo de Gormaz es relativamente abundante. Entre los trabajos más completos destacan los siguientes: GAYA NuÑO, J. A., «Gormaz, castillo califal», Al-Andalus, VIII (1943), pp. 431-450; BANKS, P. J. y ZOZAYA, Juan, «Excavations in the capital fortress of Gormaz (Soria), 1979-1981: A summary», en BlagG, T. F. C., Jones, R. F. y KeAY, S. K. (Eds.), Papers in Iberian Archeology, British Archaeological Reports 193, Oxford, 1984, pp. 674-704; ZoZAYA, Juan, «Evolución de un yacimiento: el castillo de Gormaz (Soria)», BAZZANA, André (Ed.), Castrum 3, Madrid-Roma, 1988, pp. 173-178.
} 
sistema defensivo de vigilancia entre las fortalezas y la línea del Duero ${ }^{69}$. El mismo Abd al-Rahman habría encargado a uno de sus generales, de nombre Galib, el reforzamiento tanto de Medinaceli como de Gormaz. Como reacción al desastre de Jandaq (Alhandega) estima Chalmeta que Abd al-Rahman mandó reforzar plazas y castillos a la vez que se levantaban nuevas torres atalayas entre Atienza y Talavera de la Reina para al final terminar mudando la capital de la Frontera Media de Guadalajara a Medinaceli en $946^{70}$.

¿Habría más reformas en el territorio? ¿Debemos a estas fechas la aparición de las fortalezas que se documentan en el valle del Salado? No podemos asegurarlo todavía, aunque el avance del estudio cerámico que estamos llevando a cabo así parece sugerirlo. No sería el caso de Atienza, que como ya hemos visto, es citada con anterioridad, ya en el siglo IX, como uno de los puntos fuertes de la región. La relevante posición de Atienza como atalaya que permite ver y ser divisada desde puntos alejados comprendidos en un círculo amplísimo que pasaba por la cumbre del Ocejón y la de Alto Rey, Huérmeces, Baides, Sigüenza, Paredes de Sigüenza y Miedes. Ha sido puesto de manifiesto la importancia de este núcleo a lo largo de toda la Edad Media, especialmente a partir de la conquista cristiana ${ }^{71}$. El lugar es aludido en la Crónica de al-Razi al referirse al término musulmán de Wad-1-Hiyara, lo que prueba su interés estratégico para los andalusíes desde antiguo. Lo de plaza segura y fuerte se deduce de pasaje del Muqtabas V referido al parte de la victoria del año 939:

ordenó -el califa- se buscasen los caminos más directos hacia el hisn Antisa y los más convenientes y de trayecto seguro para el retorno de los musulmanes. ${ }^{72}$

No es ésta la única vez que las crónicas árabes mencionan Atienza, a la que curiosamente llaman indistintamente hisn y madina. Ya antes, en la campaña de Muez de 920, Abd al-Rahman III, a su regreso de tierras cristianas, pasó por Madinat Antisa ${ }^{73}$.

\footnotetext{
${ }^{69}$ ZOZAYA, Juan, «El proceso de islamicación en la provincia de Soria», Actas del I Symposium de Arqueología Soriana, Soria, 1981, pp. 483-496; Llul Martínez De BedoyA, Pilar, Huete, Mario y MOLINA BeRMEJo, Jesús, «Un itinerario musulmán...». El mismo Rodrigo Díaz de Vivar pasó por la zona, como puede leerse en el poema: «a la sierra de Miedes ellos yua posar de siniestro atiença las torres que los moros las han» o «et fue posar a la sierra de Miedes et yaziele de Siniestro Atiença, que era entonces de moros» dependiendo de la versión que se consulte. Se trata de una corrección que Menéndez Pidal hizo al texto de Per Abbat. Menéndez Pidal, Ramón, Cantar del Mio Cid, Madrid, 1964, pp. 42, 46-47, adición a la p. 379 en p. 1217 (referida al v. 397).

70 Chalmeta Gendrón, Pedro, «Simancas-Alhandega: al año siguiente», Actas de las Jornadas de Cultura Árabe e Islámica: (1978), Madrid, 1981, p. 627. Sobre la derrota de al-jandaq y sus consecuencias: Chalmeta Gendrón, Pedro, «»Simancas y Alhandega», Hispania, 36, 133 (1976), pp. 359-446; Idem, «Después de Simancas-alhandega. Año 238/938-940», Hispania, 40, 144 (1980), pp. 181199.

${ }^{71}$ Acaso el mejor estudio sobre la villa en la Edad Media siga siendo el de Francisco Layna. LAYNA SERrANO, Francisco, Historia de la villa de Atienza, Madrid, 1945, reimpr. Guadalajara, 2004.

${ }^{72}$ IBN HAYYAN, Al-Muqtabas $V . . .$, p. 300.

${ }^{73}$ IBN HAYYAN, Al-Muqtabas $V \ldots$, p. 110.
} 
Al igual que otras plazas de renombre de al-Andalus, durante el califato tuvo wali o gobernador propio, que en 930 es renovado por un tal Ismail b. Lubb, siendo renovado el cargo una vez más en el año $939^{74}$.

Siguiendo las crónicas cristianas, la primera mención de Atienza está relacionada con la expedición de Alfonso III en la segunda mitad del siglo IX, que le valió la conquista de Deza y la posesión sin resistencia de Atienza ${ }^{75}$. Y en la incursión de Ordoño II del año 917, las huestes cristianas en su avance por las tierras de Guadalajara dejaron sin ganar Atienza. También aparece citada en las expediciones de Alfonso III, como ya hemos visto, y en la de Almanzor a la tierra de Soria.

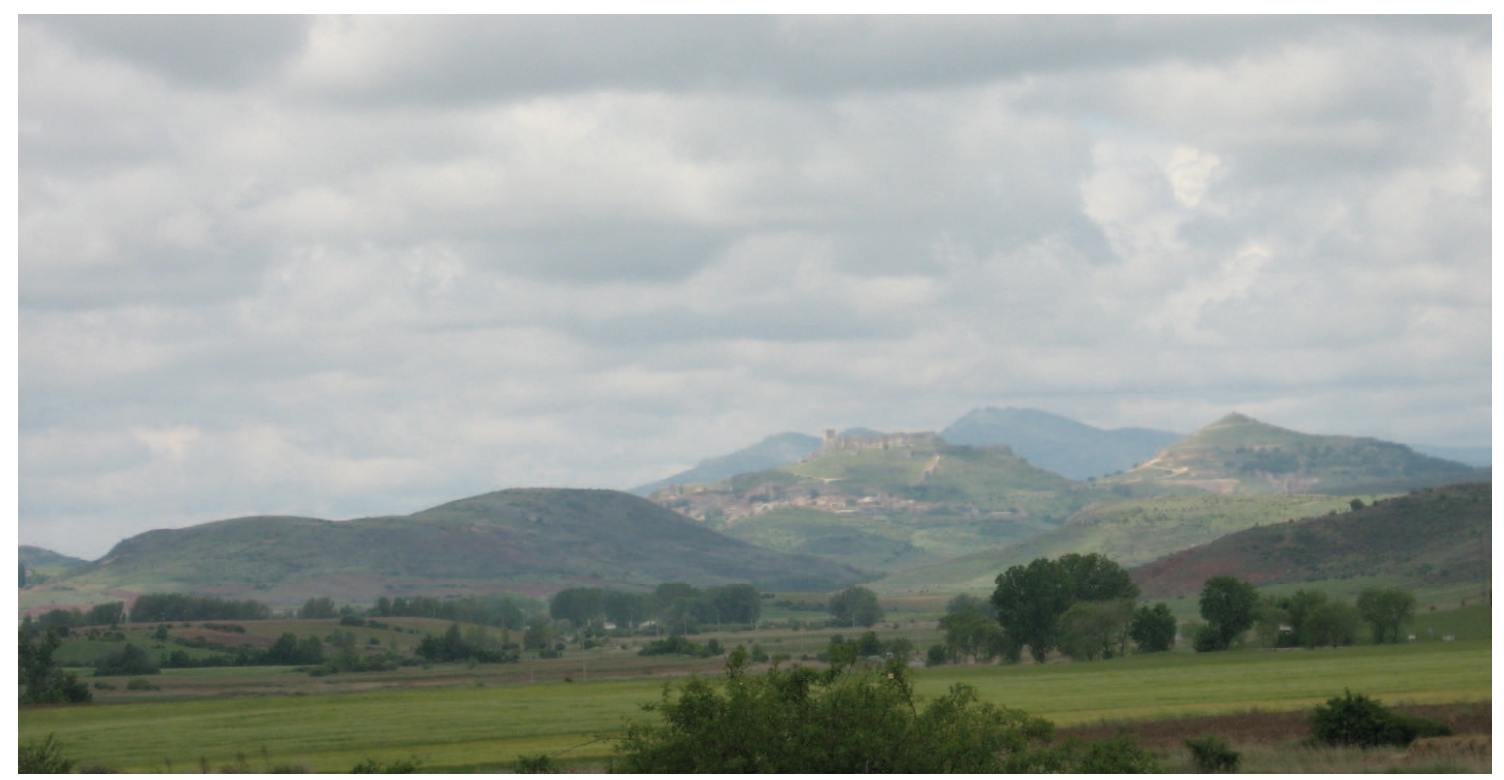

Castillo de Atienza

A lo largo de estos siglos IX y X, Atienza cayó en manos de los cristianos, bien por conquista o bien por la traición de alguno de los gobernadores de la fortaleza, como también ocurriría con la anteriormente citada Gormaz, lo que explicaría que aparezca un gobernador de nombre inequívocamente árabe, Abu l-Mundir, citado como Conde de Gormaz al servicio de las expediciones cristianas en el año $942^{76}$.

En 1078, la incursión que realizó Fernando I le permitió adueñarse de Gormaz, Berlanga, Aguilera y, como ya señalamos, entró en la tierra de Atienza por Riba de Santiuste, Santamera y Huérmeces. Teniendo todo lo dicho anteriormente en cuenta, se puede sustentar que la línea de asentamientos y fortalezas del valle del alto Henares y de sus afluentes, entre los que se encuentra el valle del río Salado, lejos de constituir una zona de retaguardia, se encontraba muy expuesta a los ataques de poblaciones asentadas en regiones contiguas, por ejemplo el valle del Riaza.

\footnotetext{
${ }^{74}$ IBN HAYYAN, Al-Muqtabas $V . . .$, p. 291.

${ }^{75}$ PÉREZ De Urbel, Justo, Sampiro: su crónica ..., p. 278.

${ }^{76}$ Cit. por MANZANO MORENO, Eduardo, La frontera de al-Andalus ..., p. 161.
} 
Estas dos expediciones cristianas le plantean a Pavón Maldonado la tentación de rehacer arqueológicamente la villa islámica de Atienza ${ }^{77}$. Rehecha sus murallas tras el paso de Almanzor por la villa, cabe pensar que los cristianos vieron una medina sólidamente fortificada con murallas y torres, posiblemente de tapial o de sillarejo, dispuesto a hiladas de pseudotizones, que aparecen en trozos de la muralla del albacar del castillo. Rehecha toda la muralla urbana por Alfonso VII con mampostería y sin torres, salvo las que flanquean dos de sus puertas, lo lógico es imaginar que las torres mencionadas en el poema del Mio $\mathrm{Cid}^{78}$ fueran militares y no torres o alminares de mezquitas que en escasa cantidad y confundidas con el caserío no se harían destacar a lo lejos.

Atienza caería en las manos de Alfonso VI, junto con otras plazas castellanas importantes del territorio, como la misma Sigüenza, en los años inmediatos a la toma de Toledo, pero volvería a ser musulmana con los almorávides que en 1109 en una arriesgada incursión por el valle del Henares lograron avanzar hasta Medinaceli, conquistada en 1104 por Alfonso VI. Ello obligaría a la definitiva recuperación de la plaza por Alfonso I el Batallador, quien consagra el templo de Santa María de la villa en el año 1112, según consta en la inscripción latina de la arquivolta de la puerta septentrional estampada junto con otra inscripción de caracteres árabes que reza «la permanencia para Allah», lo que lleva a pensar a Basilio Pavón que Santa María suplantaría a una anterior mezquita ${ }^{79}$.

Las primeras noticias de Atienza incorporada al reino cristiano son del año 1124 , cuando Alfonso VII confirma la donación a Don Bernardo de Agén, obispo de Sigüenza, de la décima de los portazgos, quintos y alcabalas reales de Atienza y Medinaceli ${ }^{80}$. Es la misma fecha en la que se constata que ya todo el territorio ha quedado en manos de los cristianos, iniciándose desde aquí la formación del Señorío episcopal de Sigüenza junto a las distintas comunidades de Villa y Tierra que permanecerán durante gran parte de la Edad Media. De ello nos ocuparemos más adelante.

\section{El poblamiento según las investigaciones arqueológicas}

Ya hemos señalado antes como ya desde el análisis de las fuentes escritas, y sobre todo a partir de las investigaciones de carácter geográfico, se está desechando la idea de un vacío poblacional en las zonas de frontera andalusíes, y particularmente en la cuenca del Henares y sus ríos tributarios, como el Salado del que nos ocupamos en este trabajo. Como en gran parte de la Península Ibérica, es la práctica de la arqueología la que

\footnotetext{
${ }^{77}$ PavÓn Maldonado, Basilio, Guadalajara Medieval ..., p. 64.

${ }^{78}$ VAliente Malla, Jesús y CuAdrado Prieto, Miguel Ángel, «Las torres de Atienza...»

${ }^{79}$ PavÓn MaldonAdo, Basilio, Guadalajara Medieval..., p. 64.

${ }^{80}$ Minguella y Arnedo, Toribio, Historia de la Diócesis de Sigüenza ..., t. I, pp. 347-348.
} 
mayores resultados está ofreciendo en el estudio del poblamiento en la Marca Media. No obstante, debemos llamar la atención también que para el área que estamos tratando las excavaciones son muy escasas, y los estudios se han limitado a recoger y describir los yacimientos conocidos ${ }^{81}$, a estudiar la cerámica ${ }^{82}$ o a plantear algunas hipótesis de evolución generales para toda la Marca Media tomando en consideración también estas tierras del Alto Henares ${ }^{83}$. Salvo el trabajo de Nuria Morère, del que en gran medida el resto de estudios son herederos, la nota dominante en todos ellos es la falta de investigación de campo en este territorio, al menos dedicados a la Edad Media. La única excepción, dejando a un lado nuestro propio proyecto, es la elaboración de un catálogo de arquitectura rupestre en el norte de Guadalajara, con un enfoque eminentemente arqueológico y que está dando resultados de diversa consideración ${ }^{84}$. Ya hemos citado como dentro de estos trabajos se mencionan una serie de asentamientos en cueva, bien con función eremética o bien simplemente hábitat dispersos, con una amplia cronología, entre los siglos $\mathrm{V}$ al XI, sin que se ofrezcan datos suficientes ni se presenten materiales que permitan saber de donde se ha obtenido esa amplia cronología ${ }^{85}$.

La falta de trabajos de campo, por un lado, y la ausencia de conjuntos cerámicos bien fechados con secuencias estratigráficas ha condicionado la interpretación del poblamiento andalusí en la medida en que salvo los castillos como Riba de Santiuste, Huérmeces o Atienza, es poco más lo que se conocía de la zona. No tanto en la provincia, donde en los últimos años una serie de yacimientos han sido excavados, contribuyendo a ampliar considerablemente el conocimiento arqueológico de la época medieval y posibilitando comenzar a construir interpretaciones de las dinámicas de transformación que en esta época se producen.

Un referente en lo que a la transición del siglo VIII se refiere es la ciudad de Recópolis, originaria del período visigodo, que va a tener continuidad durante los primeros siglos de al-Andalus, al menos en lo que a las viviendas se refiere, mientras que en el conjunto

\footnotetext{
81 Morère Molinero, Nuria, Carta arqueológica de la región seguntina, Guadalajara, 1983, especialmente cap. III «Hallazgos arqueológicos en torno al río Henares y sus afluentes» pp. 23-65; PAVÓN MALDONADO, Basilio, «II. Itinerario y villas a la derecha del río Henares» y «III. El curso alto del río Henares. Sigüenza y su tierra», en Guadalajara Medieval..., pp. 59-140 y 141-154; RETUERCE VELASCO, Manuel, «Arqueología y poblamiento en la Meseta andalusí. El referente cerámico», V Semana de estudios medievales (Nájera, 1994), Logroño, 1995, pp. 87-124.

${ }^{82}$ RetUerce Velasco, Manuel, La cerámica andalusí de la Meseta, Madrid, 1998, 2 tomos, passim.

${ }^{83}$ Olmo EnCISO, Lauro, «Arqueología medieval en Guadalajara. Un estado de la cuestión», GARCÍASoto, Ernesto y García VAlero, Miguel Ángel, Actas del primer simposio..., t. II, pp. 467-499; ZOZAYA, Juan, «¿Poblados? ¿ciudades? ¿campamentos? ¿recintos castrales? En la Marca Media: hacia una tipología», Al-Ándalus país de ciudades. Actas del Congreso celebrado en Oropesa (Toledo), del 12 al 14 de marzo de 2005, Madrid, 2007, pp. 23-64.

${ }^{84}$ Conocemos la existencia de este proyecto, coordinado por Enrique Daza Pardo y Jorge López Quiroga únicamente por una de las publicaciones que ha elaborado uno de ellos: DAZA PARDO, Enrique, «Elementos para el estudio de la arqueología altomedieval en la sierra norte de Guadalajara. Monacato, edilicia y poblamiento», en LóPez Quiroga, J.; Martínez Tejera, A. M., y Morín de PABlos, J. (Eds), Monasterio e Territorio. Elites, edilicia y territorio en el Mediterráneo medieval (siglos V-XI), BAR Internacional Series S1720, 2007, pp. 399-408, en espec. p. 399 y nota al pie 1.

${ }^{85}$ DAZA PARDO, Enrique, «Elementos para el estudio...»; Idem, «Formas de ocupación rural...».
} 
palatino se ha detectado una destrucción violenta. Esta destrucción provocaría un cambio en la fisonomía del paisaje urbano y en la funcionalidad del asentamiento, así como coincide en el tiempo con una creciente debilidad fiscal por parte de la ciudad. Ollas globulares, cuencos y producciones finas de origen visigodo también tiene continuidad durante estos primeros momentos, todas ellas realizadas a torno aunque con una presencia minoritaria de producciones a torneta, siendo muy residuales las producciones a mano. Junto a ella se van introduciendo ollas, jarras y candiles de más clara adscripción islámica. ${ }^{86}$ Para Lauro Olmo

...esta "continuidad" tipológica lo que más bien está reflejando es la debilidad de "continuar" desarrollando una realidad urbana por parte de una sociedad en conflicto y transformación. ${ }^{87}$

Este proceso de continuidad y transformación se ha detectado para los casos de Segóbriga y Arcávica, con una continuidad de su ocupación hasta bien entrado el siglo IX. Siguiendo esta intepretación se ha detectado como todos estos centros se abandonan a lo largo del siglo IX, dando lugar en el caso de Recópolis y Segóbriga a nuevas realidades urbanas en las cercanas Zorita y Uclés ${ }^{88}$.

A la vez que se constata este proceso, se está documentando para este periodo, en la actual provincia de Guadalajara, un fenómeno de creación de nuevos asentamientos que se localizan reocupando castros de la Edad del Hierro o en lugares no habitados hasta este momento. Esta aparición de nuevos asentamientos podría adscribirse a esta primera fase del siglo VIII dado que los materiales que ofrecen algunos de ellos son similares a los de esta misma época en Recópolis. Sin embargo, hay que advertir que la ausencia de secuencias estratigráficas de este período en los yacimientos obliga a ser cautos, ya que estos podrían adscribirse igualmente a la fase posterior de comienzos del siglo IX. Para Lauro Olmo lo que si es evidente es que estos asentamientos no llegan más allá de la primera mitad del siglo IX según documentan la ausencia de materiales típicos de esa cronología ${ }^{89}$. Los ejemplos más evidentes de este fenómeno proceden de la comarca de Molina de Aragón, algo más al sur de la comarca de Sigüenza. Son el yacimiento de «El Turmielo» (Aragoncillo) ${ }^{90}$ y el castro de «La Coronilla» (Chera). En el primer caso se

\footnotetext{
86 Sobre las excavaciones en Recópolis vid. OLMO ENCISO, Lauro, «Proyecto Recópolis: ciudad y territorio en época visigoda», Arqueología en Guadalajara, Toledo, 1995, pp. 211-223; Idem, «Consideraciones sobre la ciudad en época visigoda», Arqueología y territorio medieval, 5 (1998), pp. 109-118; «Ciudad y procesos de transformación social entre los siglos VI y XI: de Recópolis a Racupel», CABAllero Zoreda, Luis (Ed.), Visigodos y Omeyas: un debate entre la Antigüedad Tardia y la Alta Edad Media, Mérida, 2001, pp. 385-400.

${ }^{87}$ OLMO EnCISO, Lauro, «Arqueología medieval en Guadalajara...», p. 475.

${ }^{88}$ OLMO ENCISO, Lauro, «Ciudad y procesos de transformación...»

${ }^{89}$ OLMO ENCISO, Lauro, «Arqueología medieval en Guadalajara...», p. 475.

90 LÁzARO, Inmaculada, «Los materiales islámicos de "El Turmiello" (Aragoncillo, Guadalajara)», Kalathos, 13-14 (1995), pp. 133-141.
} 
defiende una ocupación breve del asentamiento, ya que entre las producciones cerámicas son mayoría las de tradición preislámica ${ }^{91}$, presentando además similitudes con las producciones a torneta de Recópolis, y en otros yacimientos excavados recientemente en la provincia de Guadalajara con contextos arqueológicos de la primera mitad del siglo IX, como en el Alcázar de Guadalajara o en Aguas Vivas ${ }^{92}$.

También de gran interés es «La Coronilla», un castro de época celtibérica con una fase de ocupación en época islámica definida por un habitat de viviendas rectangulares que se asocian a un conjunto de silos $^{93}$. El conjunto cerámico de este momento se relaciona con los materiales de El Turmielo o los anteriormente citados de Recópolis: predominio de formas cerradas, fundamentalmente ollas, fabricadas mayoritariamente a torno aunque con algunos ejemplos realizados a mano, que son piezas de origen y tradición visigoda, junto a la aparición de formas nuevas de adscripción andalusí, con decoraciones pintadas a la almagra o al manganeso. Nuevamente, podemos situar cronológicamente esta fase entre los siglos VIIII y la primera mitad del siglo IX.

En este mismo momento se fecha el asentamiento localizado en el Cerro Padrastro de Atienza, donde en las prospecciones arqueológicas llevadas a cabo a finales de los años '80, junto a producciones cerámicas de época andalusí apareció un dirham de Abd alRaham I fechado en el año 779-780 ${ }^{94}$. No obstante, en este caso hay que ser algo más cautos, ya que los Jesús Valiente y Miguel Ángel Cuadrado han señalado que las cerámicas que aparecen en este asentamiento no deben ser sólo adscritas a época andalusí y al siglo XI ya que hay presentes formas pintadas de época cristiana ${ }^{95}$.

En nuestra opinión, este período puede ser considerado de «transición», con una ocupación en lugares de difícil acceso con el objetivo de favorecer las funciones defensivas del asentamiento, y con una mayor preocupación por el almacenamiento de los productos, dadas las dificultades, también, de acceso a lo que serían las tradicionales zonas productivas, situadas en el llano. Esta reocupación de castros protohistóricos no es exclusiva de Guadalajara, sino que se documenta también en el valle del Jalón, en la provincia de Soria, o en zonas más alejadas como el alto valle del Ebro y el occidente Zamorano ${ }^{96}$.

\footnotetext{
${ }^{91}$ LÁZARO, Inmaculada, «Los materiales islámicos...», pp. 134-138.

92 Serrano, Elena, Torra, Mar, CAStro, Manuel y SÁnChEZ, Aurelia, «Excavaciones en Guadalajara: secuencia andalusí desde época Emiral a Taifa y presentación de un singular conjunto numismático», Arqueología y Territorio Medieval, 11.1 (2004), pp. 79-113; CuAdRADO PRIETO, Miguel Ángel, «Excavaciones arqueológicas de urgencia en Guadalajara. Aguas Vivas» en BALbín, R. de; VALIENTE, J. y Mussat, M. T. (Eds.), Arqueología en Guadalajara. Talavera de la Reina, 1995, pp. 179-191.

93 CERDEÑo, Ma Luisa y GARCía Huerta, Rosario, El Castro de la Coronilla. Chera, Guadalajara (1980-1986), Excavaciones Arqueológicas en España, 163 (1992); LÁZARO, Inmaculada, «Los materiales islámicos...», pp. 134-136.

${ }^{94}$ VAliente Malla, Jesús y CuAdrado Prieto, Miguel Ángel, «Las torres de Atienza...», p. 639, fig. 2 , lám. I

95 Ibidem, fig. 3, d, e, f y g.

96 Bueno SÁNCHEZ, Marisa, «Estrategias de supervivencia en época tardoantigua y altomedieval. Reocupación de recintos celtibéricos en el alto Jalón (Soria)» I Jornadas de Jóvenes Investigadores de
} 
Dejando a un lado esta primera fase de transición, es a partir de la primera mitad del siglo IX cuando asistimos a la consolidación de los linajes beréberes y, en cierta forma, del emirato cordobés. Se constató en las fuentes escritas, como ya señalamos anteriormente, y también a nivel arqueológico, ya que se detecta un proceso de reestructuración del sistema de asentamientos que había definido anteriormente el territorio $^{97}$. El proceso ha sido estudiado mucho mejor en el sur de la provincia de Guadalajara, siendo las familias de los Banu Di 1-Nun en Santaver y los Banu Abdus en el entorno de Recópolis y en el marco de la formación de la cora de Santabariyya, los que han recibido una mayor atención. Es el momento de fundación de nuevos centros urbanos, como Guadalajara ${ }^{98}$, Zorita — tras el abandono de Recópolis— ${ }^{99}$ o Peñafora ${ }^{100}$, así como el abandono de los centros urbanos anteriores, como Recópolis, o de los sitios de altura como El Turmielo o La Coronilla. Esta reestructuración del territorio y sus asentamientos es fundamental para entender el avance del proceso de islamización, reflejado en la aparición de esos linajes baréberes, que en el marco de la sierra norte y el valle del Henares está dominado por los Banu Salim, de los que ya hablamos anteriormente.

Todo el proceso arqueológico documentado está ligado íntimamente a las convulsiones y conflictos que se suceden en esta zona de la frontera central a lo largo del siglo VIII y primera mitad del IX. Se relaciona con el triunfo del proceso de islamización tras los conflictos de esas primeras décadas, constituyéndose a partir de entonces un modelo de sociedad hegemónica en gran parte del territorio peninsular: la andalusí. Esto tendrá su referente en la realidad urbana, con el desarrollo de centros como Guadalajara o Medinaceli, a lo largo de la segunda mitad del siglo IX y, fundamentalmente, en el siglo $\mathrm{X}$. Pero la interpretación para el resto del territorio durante este período se encuentra, por ahora, limitada debido tanto a la parquedad de fuentes escritas, como ya señalamos, como a las dificultades por contextualizar los restos arqueológicos, faltos en muchas

Arqueología: Dialogando con la Cultura Material. Madrid, 2008, Tomo 2, pp. 485-492; MARTín VISO, Iñaki, Poblamiento y estructuras sociales en el norte de la Península Ibérica, Salamanca, 2000, en espec. pp. 107-136.

${ }_{97}$ OLMO ENCISO, Lauro, «Arqueología medieval en Guadalajara...», pp. 476-480.

98 En la ciudad se detectan las primeras evidencias de ocupación en torno a mediados del siglo IX. SERrano Guerrero, Elena y Torra PÉrez, María del Mar, «La secuencia islámica en el solar de c/ Ingeniero Mariño, 27 (Guadalajara)», GARCÍA-SOTO MATEOS, Ernesto y GARCíA VALERO, Miguel Ángel (Eds.), Actas del primer Simposio..., t. II, pp. 557-567; SERrano, E., SERrano, N. Y Torra, M., «Actuaciones arqueológicas: el túnel de “Aguas Vivas” Guadalajara)», GARCÍA-SOTO MATEOs, Ernesto y García Valero, Miguel Ángel (Eds.), Actas del primer Simposio..., t. II, pp. 713-723; SERrAno, Elena, TORRA, Mar, CASTro, Manuel y SÁnchez, Aurelia, «Excavaciones en Guadalajara: secuencia andalusí desde época Emiral a Taifa y presentación de un singular conjunto numismático», Arqueología y Territorio Medieval, 11.1 (2004), pp. 79-113

99 OLMO ENCISO, Lauro, «Ciudad y procesos de transformación...»

100 JiMÉNEZ ESTEBAN, Jorge, «Aportación a la arqueología hispano-musulmana: Peñahora (Guadalajara)», Wad-al-Hayara, 16 (1989), pp. 283-292; PAvÓN MALDONADO, Basilio, Guadalajara medieval..., pp. 96101. 
ocasiones de las suficientes excavaciones. Lauro Olmo ha señalado como esto se traduce en:

\begin{abstract}
...las complicaciones que ello produce en la interpretación del proceso de transformación que se está desarrollando. Proceso que hay que interpretar desde perspectivas diferenciadas pero absolutamente interrelacionadas, por un lado el conflicto entre los diferentes grupos islamizados, o en proceso de islamización, frente a los emires cordobeses por el control del territorio; por otro la dificultad que plantean los propios procesos de cambio social y de asimilación de la islamización, que se están produciendo en el seno de los grupos recién asentados — como es el caso de las tribus beréberes, en el territorio que aquí nos ocupa; y para finalizar en la respuesta y actitud de la población indígena frente a todo este proceso $(\ldots)^{101}$
\end{abstract}

Con algo más de claridad se nos muestra la evolución del territorio y el poblamiento a partir de la época califal, cuando se produce la hegemonía de la sociedad andalusí y del Estado Califal Omeya. Los datos que conocemos sobre ciudades, alquerías y espacios productivos en este período así parecen demostrarlo. De entre todos, destacan los datos que está proporcionando la ciudad de Guadalajara, conocida como Madinat-al-Faray en este período $^{102}$, o los casos ya citados de Zorita y Peñafora. Junto a estas ciudades de época califal, la arqueología comienza a aportar datos sobre la estructuración de las alquerías en diferentes zonas de la provincia. De entre todas ellas hay que destacar la de Los Casares en Riba de Saélices ${ }^{103}$. Actualmente está en curso de excavación. Se trata

\footnotetext{
${ }^{101}$ OLMO ENCISO, Lauro, «Arqueología medieval en Guadalajara...», pp. 479-480.

${ }^{102}$ La bibliografía resulta cada vez más extensa, por lo que citaremos tan sólo algunos de los trabajos más representativos: CRESPO CANO, Ma Luisa y CUADRADO PRIETO, Miguel Ángel, «Arqueología urbana en Guadalajara. Un avance del plano arqueológico de la ciudad», Actas del III Encuentro de Historiadores del Valle del Henares, Guadalajara, 1992, pp. 17-31; CuAdrado Prieto, Miguel Ángel, Crespo CANO, $\mathrm{M}^{\mathrm{a}}$ Luisa y ARENAS ESTEBAN, J. A., «Primer avance de la excavación arqueológica en el Alcázar de Guadalajara», Actas del VI Encuentro de Historiadores del Valle del Henares, Alcalá de Henares, 1998, pp. 93-106; Serrano, Elena, Torra, Mar, CAStro, Manuel y SÁnchez, Aurelia, «Excavaciones en Guadalajara...»

${ }^{103}$ Se trata de una cueva con una ocupación prehistórica y pinturas rupestres que han recibido una mayor atención, aunque contamos con estudios específicos referidos a la época medieval. Para los primeros estudios dedicados a la época prehistórica vid. CABRÉ AgUILÓ, Juan, Las cuevas de los Casares y de la Hoz, Archivo Español de Arte y Arqueología, 30 (1934); BEltrán MARTíneZ, Antonio y BARANDiARÁN MAESTU, Ignacio, Avance al estudio de las cuevas paleolíticas de la Hoz y los Casares (Guadalajara), Excavaciones Arqueológicas en España, 64 (1968); BARANDIARÁN MAESTU, Ignacio, La cueva de los Casares (Riba de Saélices, Guadalajara), Excavaciones arqueologías en España, 76 (1971); Para los estudios sobre época medieval, vid. GARcíA-Soto MATEOs, Emilio y Ferrero Ros, Susana., «Excavaciones en el despoblado musulmán de Los Casares (Riba de Saélices, Guadalajara): Campañas de 1998, 1999 y 2000» en GARCíA-Soto MATEOS, Ernesto y GARcía VAlERO, Miguel Ángel (Eds.), Actas del primer Simposio de Arqueología de Guadalajara. Homenaje a Encarnación Cabré Herreros. Sigüenza, 4-7 de octubre de 2000, Madrid, 2002, t. 2, pp. 513-529; GARCÍA-Soto MATEOs, Emilio, FERrero Ros, Susana y Guillén Álvarez DE SOTOMAYOR, A., «Los Casares: un poblado hispanomusulmán en las serranías del norte de la provincia de Guadalajara» en ABAD CASAL, Lorenzo (ed.), Investigaciones arqueológicas en Castilla La Mancha: 1996-2002, Toledo, 2004, pp. 395-408; García-Soto Mateos, Emilio y Ferrero Ros, Susana., «Un posible barrio artesanal en el poblado hispanomusulmán de los Casares (Riba de Saélices, Guadalajara)» en MiLláN MARTínEZ, Juan Manuel y
} 
de una alquería formada por un asentamiento abierto y sin defensas, situado en una ladera dominada por una cueva, con un aljibe en su interior, y en cuya parte superior se construyó una torre de planta rectangular con un aparejo de mampostería en hiladas horizontales y mortero de yeso, rodeada por un pequeño recinto.

Más próximo al territorio que estudiamos, en la localidad de Olmedillas situada al noreste de Sigüenza se localizó un asentamiento ocupando una ladera así como parte de la Cueva Harzal ${ }^{104}$. Todo apunta a que este poblado de época califal tenía unas estructuras defensivas en la parte superior del monte donde está situada la cueva, lo cual, de confirmarse, nos reflejaría una organización el espacio similar a la descrita para Los Casares. Y similar también parece ser el esquema de la torre de Bujarrabal, también próxima a Sigüenza pero en dirección este, más al sur que la anterior, en el que se constata la existencia de un poblado con torre con una cronología del siglo $\mathrm{X}^{105}$. Se trata de una construcción de planta cuadrangular situada en la parte más alta de la población, que conserva un aparejo formado por grandes sillares sin argamada situados en posición vertical, muy parecido a los que se conservan en construcciones de la misma época en Mezquetillas (Soria) y en Guadalajara en Torresaviñán, en la misma torre de Los Casares ${ }^{106}$, o en la cercana de Barbatona.

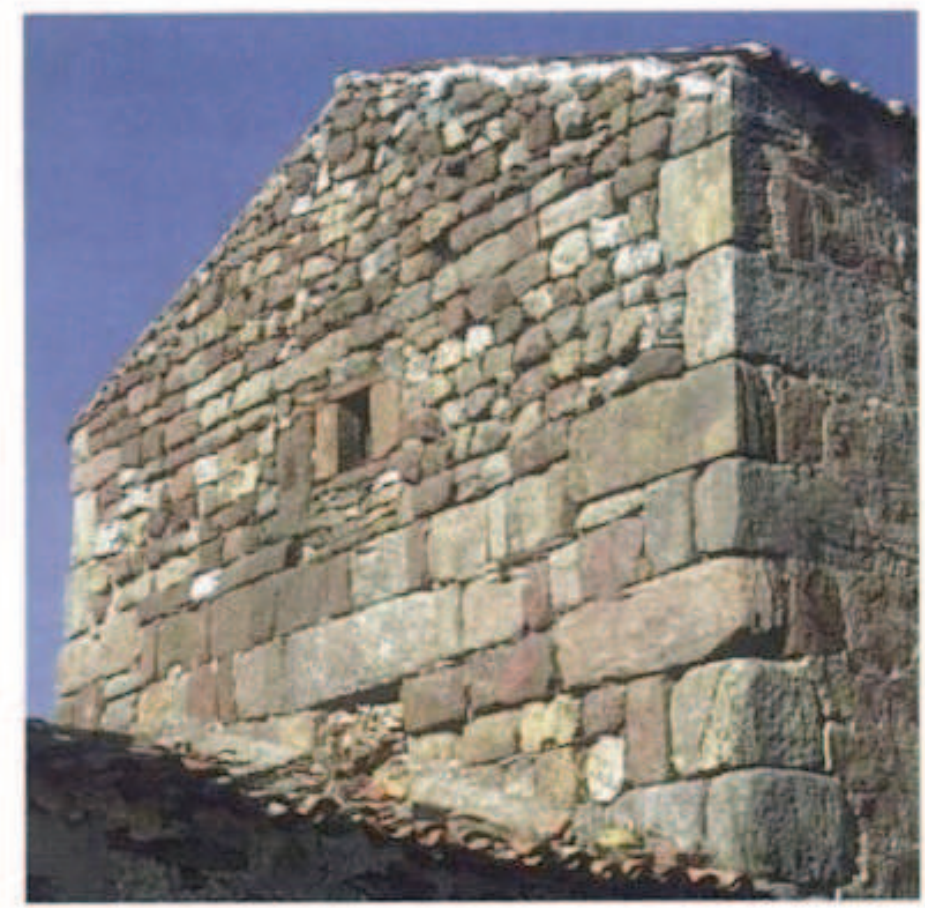

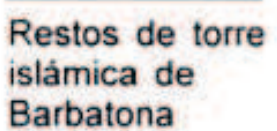

Barbatona

Rodríguez RuZA, Concepción (eds.), Arqueología de Castilla-La Mancha. I Jornadas, Cuenca 13-17 de diciembre de 2005, Cuenca, 2007, pp. 659-680.

104 Valiente Malla, Jesús y García-Gelabert Pérez, María Paz, «La cueva Harzal de Olmedillas: resultados de la prospección (Sigüenza, Guadalajara)», Wad-al-Hayara, 10 (1983), pp. 7-24.

${ }^{105}$ Herrera CASAdo, Antonio, Guía de campo de los castillos de Guadalajara, Guadalajara, 1999, pp. 66-67 y 87.

${ }^{106}$ Almagro GorbeA, Antonio, «Las torres beréberes de la Marca Media. Aportaciones a su estudio», Cuadernos de la Alhambra, 12 (1976), pp. 279-305. 
Y junto a los poblados o alquerías, el otro elemento que define el poblamiento rural en época califal son los castillos y asentamientos en altura, muchos de los cuales han sido citados ya por las referencias que tenemos de ellos en las fuentes escritas, por lo que nos ceñiremos ahora a los estudios de carácter arqueológico que se han llevado a cabo.

La importancia de estos castillos, denominados hisn en las fuentes árabes, ha hecho que algunos se pregunten si no sería la forma mayoritaria de ocupación rural en alAndalus $^{107}$. Lo cierto es que a partir de los años setenta, los trabajos desarrollados por Bazzana, Cressier y Guichard en el sur y sureste de la Península fomentaron esta visión del medio rural ${ }^{108}$, en contraposición a la historiografía dominante hasta entonces fuertemente dominada por el fenómeno urbano. En este cambio de postura tuvo mucho que ver la influencia de una práctica arqueológica muy influida por la geografía histórica y la búsqueda de modelos de poblamiento que ponía en práctica la landscape archaeology anglosajona o la teorización del site catchment analysis más propia hasta el momento de los prehistoriadores ${ }^{109}$. A partir de la práctica de esta «arqueología sin excavación» los husun se consideran los vertebradores del territorio articulado por alquerías, espacios de trabajo (fundamentalmente los de agricultura irrigada) y las ciudades $^{110}$. Para el caso del valle del Henares así se ha puesto de manifiesto:

Es aquí donde las fortificaciones, de tipo aldeano a priori, se demuestran como los principales elementos morfogenéticos del poblamiento medieval del valle del Henares, hábitat que durante los procesos de "repoblación" van a transformarse al imponerse la red parroquial. ${ }^{111}$

A partir de entonces el mismo estudio de las fortificaciones cambia radicalmente, desde una visión arraigada que se ceñía estrictamente a lo monumental-arquitectónico y al telón de fondo de los episodios bélicos y la residencia e personajes ilustres ${ }^{112}$, se pasa a

\footnotetext{
${ }^{107}$ LÓPEZ Quiroga, Jorge, Arqueología del hábitat rural..., pp. 119 y ss.

${ }^{108}$ BazZANA, André, CRessier, Patrice y Guichard, Pierre, Les châteaux ruraux d'al-Andalus. Histoire et archéologie des husun de Sud-Est de l'Espagne, Madrid, 1988.

109 BAZZAnA, André y Guichard, Pierre, «Pour une "archéologie extensive"», en BAzZANA, André y POISSON, Jean-Michel (eds.), Histoire et archéologie de l'habitat médiéval. Cinq ans de recherche dans le domaine méditerranéen et la France du Centre-Est, Lyon, 1986, pp. 175-184; BARCELÓ, Miquel, «La Arqueología extensiva y el estudio de la creación del espacio rural», en BARCELÓ, Miquel et alii, Arqueología medieval. En las afueras del «medievalismo», Barcelona, 1988, pp. 195-274.

110 AcIÉn Almansa, Manuel, «La fortificación en al-Andalus», Archeologia Medievale, XXII (1985), pp. 7-36; Idem, «Poblamiento y fortificación en el sur de al-Andalus. La formación de un país de husun», III Congreso de Arqueología Medieval Española, Oviedo, 1989, pp. 137-150.

111 DAZA PARDO, Enrique, «Los castillos olvidados. El papel de los asentamientos fortificados en altura en la génesis del poblamiento altomedieval del valle del Henares (siglos VII-XII)» Castillos de España, 148 (Diciembre 2007), p. 14.

${ }^{112}$ Un ejemplo de este tipo de estudios para el territorio que nos ocupa sería el de LAYNA SERRANO, Francisco, Castillos de Guadalajara, reed. Guadalajara, 1994. (original, 1934). En ocasiones el interés ha sido únicamente por poner en valor turístico los castillos, centrándose el estudio de los mismos en someras descripciones y datos fuera de constexto. HerRera CASADO, Antonio, Guía de campo de los castillos de Guadalajara, Guadalajara, 1999.
} 
una preocupación cada vez mayor por el contexto sociopolítico y económico. El debate pivota entre los que leen los castillos en un sentido institucional, como el poder ejercido por un representante del poder central para la captación del tributo y la dominación efectiva del espacio aunque con un sentido diferente al del castillo feudal; y los que ven en ellos una adecuación a una realidad material concreta como «refugio defensivo» con un papel central en la vertebración del territorio, en una organización social de tipo «segmentario»y de las comunidades rurales islámicas dotadas de cierta autonomía, como una sociedad sin señores. Otros autores no ven una contradicción entre ambas posturas, insistiendo en el carácter polifuncional de los husun en los que puede coexistir o predominar una $\mathrm{u}$ otra función en virtud del momento histórico al que nos refiramos $^{113}$.

Este tipo de estudios y debates no han tenido un profundo calado en el marco geográfico de la sierra norte de Guadalajara. Prácticamente toda la franja que va desde Madrid a la Marca Superior, en donde este tipo de estudios si han sido desarrollados ${ }^{114}$, no ha contado con estudios suficientes en este sentido ${ }^{115}$, salvo las notables intervenciones desarrolladas en los centros de Alcalá de Henares o Gormaz que de alguna forma han sido la base de los estudios aquí desarrollados en fechas más recientes ${ }^{116}$.

Al igual que se detectaba en la época de transición del siglo VIII, se constata como en época califal hay un fenómeno de reocupación de castros protohistóricos, como es el caso del castro de Castilviejo de Guijosa ${ }^{117}$ el de Casilla de Moros en Membrillera ${ }^{118}$ o el castillo de Nublares en Bujalaro ${ }^{119}$.

Junto a estos ejemplos se ha detectado una proliferación de edificación de otros muchos núcleos en altura, al igual que ocurre en el resto de al-Andalus. Estos asentamientos de altura en la mayor parte de las veces muestran restos suficientes como para ser considerados fortificaciones. En la mayoría encontramos una torre, ya sea circular, rectangular o cuadrada, que a menudo es el único elemento que permanece en pie, bien por su monumentalidad o bien, como se ha señalado por algún investigador, por ser

\footnotetext{
${ }^{113}$ Las tres posturas pueden quedar ejemplificadas en los siguientes autores y publicaciones: ACIÉN Almansa, Manuel, «Poblamiento y fortificación en el sur...»; BAzZAna, André, Cressier, Patrice y GUICHARD, Pierre, Les châteaux ruraux...; AzUAR RuIZ, Rafael, «Una intepretación de hisn musulmán en el ámbito rural», Revista de Estudios alicantinos, 37 (1982), pp. 33-41.

${ }^{114}$ SÉNAC, Philipe, La frontiére et les hommes (VIIIe-XIIe siécle). Le peuplement musulmana u nord de l'Ebre et les débuts de la reconquête aragonaise, París, 2000.

${ }^{115}$ Así lo ponen de relieve los trabajos que encontramos en el que se aborden los castillos del Alto Henares en época altomedieval con un intento de intepretación general: PAvÓN MALDONADO, Basilio, Guadalajara medieval ...; DAZA PARDO, Enrique, «Los castillos olvidados...» pp. 13-25.

${ }^{116}$ ZoZAYA, Juan, «Evolución de un yacimiento...», Idem, «¿Poblados? ¿ciudades? ¿campamentos? ...»; ZOZAYA, Juan y FERNÁNDEZ URIEL, Pilar, «Excavaciones en la fortaleza de Qal'at 'Abd-al-Salam...».

${ }_{117}$ DeAmos, Ma Belén, Fernández Miranda, Manuel, y Balbín Behrmann, Rodrigo, «Castilviejo de Guijosa (Sigüenza)», Wad-al-Hayara, 5 (1978), pp. 63-87.

118 Pavón Maldonado, Basilio, Guadalajara medieval..., p. 115; Valiente Malla, Jesús, Guía de la arqueología..., pp. 34-35; DAZA PARDO, Enrique, «Los castillos olvidados...» pp. 17-18.

${ }_{119}$ MORÈre Molinero, Nuria, Carta arqueológica de la región...; DAZA PARDO, Enrique, «Los castillos olvidados...»p p 18
} 
probablemente la única construcción en piedra mientras que el resto estaría edificado en materiales más perecederos, como la madera ${ }^{120}$.

Por ceñirnos únicamente al área que nos ocupa, y junto a los ya citados de Atienza o Riba de Santiuste, tenemos los castillos de Jadraque, Iñésque (Angón), Castejón de Henares, Buajalaro, Miedes de Atienza, Cendejas de la torre, Palmáces de Jadraque o Mandayona $^{121}$. La mayor parte de ellos son castillos con una reocupación en los momentos posteriores a la conquista, con una serie de remodelaciones que la mayor parte de las veces han ocultado las construcciones originales, pero que han permitido tanto su identificación como, en algunas ocasiones, la recogida de materiales cerámicos que han certificado su adscripción al período andalusí.

Relacionado con los castillos estarían los torreones y las torres de tipo vigía, para controlar los pasos de caminos y puentes y tener un control visual de las zonas a las que no llegaban los castillos. En el valle del río Salado se tiene constancia de un buen número de estas construcciones, si bien de ellas no queda en muchos casos más que el topónimo reflejado en la cartografía. Herrera Casado, a quien seguimos en este punto, nos las enumera ${ }^{122}$ : La «Torre de Alvar Díaz», en el término de Cercadillo, que debió estar situada en lo que hoy llaman el paraje de «las Torres». Más hacia el norte hubo pequeños torreones en Valdelcubo, uno de los cuales dio nombre al pueblo, y otro al lugar que llaman «Torrequebradilla». En las llanuras preserranas de Paredes de Sigüenza hubo un torreón que llegó a la época medieval cristiana con el nombre de «Torremocha». Por la orilla derecha del río Salado, llega el suave valle del arroyo de Alcolea o de los Prados. En término de Alcolea de las Peñas hubo varios torreones califales: uno de ellos sobre el lugar, dio nombre al pueblo y luego fue aprovechado como castillo de los cristianos, quedando hoy sus restos mínimos. En su término hubo otro elemento defensivo que llamaron «Tordelrey». Aún más al norte, pasado Atienza, en las faldas de la sierra hay constancia de otros tres torreones en término de Bochones: «Torrealbilla» «Torrecilla»y «Torremocha», que cumplirían su escueta misión de vigilancia. Dejando a un lado todo el norte del valle y centrándonos en la parte sur, se citan como posibles torres vigías la de Torrevaldealmendras, la «Torrecilla» en Palazuelos y la «Torre de Séñigo», aunque en el caso de esta última las prospecciones arqueológicas que hemos llevado a cabo han desechado la posibilidad de que sea de origen islámico. Sobre la meseta que por la izquierda bordea el Henares, y sobre un antiguo camino que dio luego paso al principal de Aragón situaron los árabes otras defensas, como la «Torre» que había en Torremocha el Campo, y el castillete que aún hoy luce su estampa medieval en lo alto de un cerro, en la Torresaviñan. Subiendo por

\footnotetext{
${ }^{120}$ DAZA PARDO, Enrique, «Elementos para el estudio...»; Idem «Los castillos olvidados...».

${ }^{121}$ PAvÓn MALdONADO, Basilio, Guadalajara medieval..., passim, DAZA PARDO, Enrique, «Los castillos olvidados...» pp. 19-22.

${ }^{122}$ Herrera CASAdo, Antonio, «La Marca Media de al-Andalus...», pp. 24-25.
} 
el pequeño valle que forma la zona de Alboreca o de los Algares, en término municipal de Olmedillas, y en un paso muy estrecho del río, se encuentra la «Cueva Harzal», de la que ya hemos hablado, bajo el pico de la «Atalayuela». El estudio que hace Herrera Casado es basa fundamentalmente en la toponimia, y sólo en unos pocos casos se ha contrastado un origen andalusí de estos torreones cuando se han recogido en sus inmediaciones materiales cerámicos. Mayor rigurosidad, desde un punto de vista arqueológico, tiene el estudio llevado a cabo por García-Soto y Ferrero Ros ${ }^{123}$, quienes en el año 2006 excavaron una de las torres que domina el valle del Henares, en el cerro de la Quebrada, en las inmediaciones de Sigüenza, también conocido como «Mirador del Cid». Se localizó la base de una torre circular, hoy en día ya demolida, compuesta por mampuestos calizos, que permitieron reconocer lo que serían las dimensiones d ela torre: con un diámetro total cercano a los cinco metros y un ancho del muro en la bse de $1.70 \mathrm{~m}^{124}$. No obstante, hay una total ausencia de materiales asociados a la cronología islámica de la estructura localizada, y además reconocen los autores que existen torreones cristianos de similares características. Intentan dar una cronología por el sistema constructivo y por comparación con otras construcciones similares. En cuanto al sistema constructivo, las medidas y el emplazamiento, tiene grandes similitudes con atalayas localizadas en la provincia de Soria, «La Villa Nueva» de Medinaceli y «El Castillo» de Miño de Medina, consideradas en la bibliografía como puramente islámicas y fechadas en el siglo $\mathrm{X}^{125}$. Similar también a las torres de Almarail ( $\mathrm{La}$ Turujalba), Barahona (La Torrecilla), Bliecos (Torre del Molino), Caltojar (La Ojaraca y Los Pilones), Rello (Torre Quiñón) y Velilla de los Ahos (San Millán), y aún en las inmediaciones de Sigüenza hay otras similares en Membrillera, Atienza, Horna o La Loma $^{126}$. Por todo ello, fechan esta torre dentro del conjunto de atalayas islámicas construidas a lo largo de los siglos X y XI.

Por todo ello, estos autores afirman que en Guadalajara existen para época islámica dos tipos de torreones muy bien diferenciados en sus características y funciones. Por una parte están las atalayas circulares de observación, ubicadas a gran altura, cuya función principal es controlar los caminos y los pasos principales del territorio, claramente relacionadas con la prevención de una posible agresión exterior bien desde el norte a través de los pasos montañosos de la Sierra de Pela, Altos de Barahona o Sierra Gorda, bien desde el este o el oeste a través de la vía que conectaba Mérida con Zaragoza. En

123 García-Soto Mateos, Ernesto y Ferrero Ros, Susana, «La Atalaya islámica del "Cerro de la Quebrada" o "El Mirador del Cid" de Sigüenza y algunas consideraciones sobre las fortificaciones islámicas del nordeste de la provincia de Guadalajara», en GARCÍA-SOTO MATEOS, Ernesto, GARCÍA Valero, Miguel Ángel y Martínez Naranjo, Juan Pablo (Eds.), Actas del segundo simposio de Arqueología de Guadalajara. Molina de Aragón, 20-22 de abril de 2006, Madrid, 2008, pp. 265-278.

${ }^{124}$ García-Soto MateOs, Ernesto y Ferrero Ros, Susana, «La Atalaya islámica...», p. 267 y figs. 1 y 2, láms. II, III, IV, V y VI.

${ }^{125}$ GARCÍA-SOTO MATEOS, Ernesto y FERrero Ros, Susana, «La Atalaya islámica...», p. 268

${ }^{126}$ GARCíA-Soto MAteos, Ernesto y Ferrero Ros, Susana, «La Atalaya islámica...», p. 269. 
otro trabajo, García-Soto habla de la existencia de una amplia red de torres cuadrangulares o rectangulares, situadas a nivel de altitud muy inferior al de las atalayas mencionadas, cuya principal función no es prevenir una agresión exterior sino el control interno del territorio por el que se extienden a través de una tupida red de la que forman parte, entre otras, las localizadas en el castillo de Riba de Santiuste, enmascarada por paramentos posteriores, Los Altos de Señigo, Mojares, La Villavieja de Sigüenza, Barbatona, Bujarrabal, La Torrecilla de Estriégala, Torresabiñán y tantas otras que sería prolijo referir $^{127}$. Evidentemente también servirían llegado el caso para atajar un posible ataque exterior, aunque se señala que no debería ser esta su principal función ${ }^{128}$. Por último como es lógico todo este conjunto de fortificaciones se apoyaría en las grandes fortalezas de la zona como Medinaceli, Atienza o Riba de Santiuste, de las que ya hemos hablado.

\section{Restos de torre islámica de Bujarrabal}

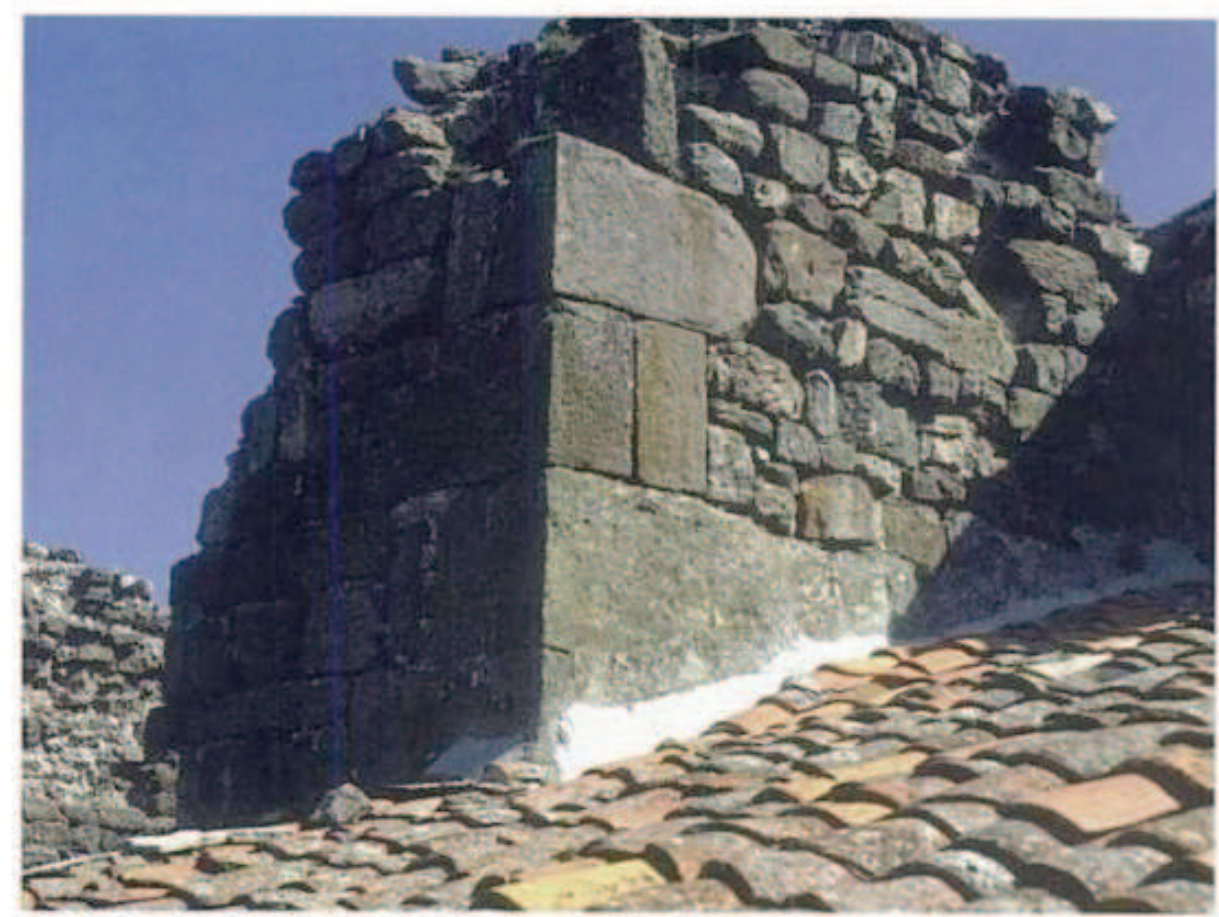

No obstante, con todo lo dicho hasta aquí, y aunque se detecta una cada vez mayor preocupación por el estudio de la red de poblamiento andalusí en esta zona, es mucho lo que queda aún por hacer. La falta de trabajo de campo y de excavaciones con seriaciones estratigráficas dificulta la correcta comprensión de la evolución de los núcleos conocidos, así como son muchos los asentamientos que no se conocen, sobre

\footnotetext{
127 García-Soto MAteOs, Ernesto «La comarca seguntina en época islámica, siglos VIII-XII», Anales seguntinos, 21 (2005), pp. 20-22.

${ }^{128}$ GARCíA-Soto MAteos, Ernesto y Ferrero Ros, Susana, «La Atalaya islámica...», pp. 269-270.
} 
todo los de pequeño y mediano tamaño que podemos considerar alquerías ${ }^{129}$. Ello impide que toda esta región del norte de Guadalajara entre a formar parte de los debates que se mantienen sobre el poblamiento y el hábitat rural de época andalusí en la Península Ibérica.

Un último aspecto del que se debe ocupar la arqueología, dejando a un lado el tema del hábitat y los asentamientos, es de estudiar los espacios de trabajo, las zonas productivas tanto agrícolas, como ganaderas o mineras. Se trata, en definitiva, de estudiar la gestión de los recursos naturales con una metodología que ha sido denominada Arqueología del Paisaje. Aunque en gran parte de al-Andalus se está avanzando muchos en estos aspectos, esencialmente en lo que se refiere a la agricultura de regadío ${ }^{130}$, en la serranía norte de Guadalajara es, una vez más, mucho lo que queda por hacer, aunque algo más se ha avanzado para otras zonas de la provincia de Guadalajara. Por ejemplo, como señala Lauro Olmo para este período la investigación arqueológica nos ofrece la posibilidad de investigar las actividades productivas gracias a la localización de una serie de yacimientos en zonas destinadas a la producción de sal, o relacionados con actividades de extracción y transformación de mineral de hierro. En el señorío de Molina, y concretamente en el valle del río Bullones se sitúa una zona de salinas ya activa en la producción de sal desde el siglo XII, tal y como refleja la documentación escrita, pero con asentamientos fechados en época califal - El Castillo, Fuente Jimena (Tezaga), El Castillejo_- y claramente relacionados con estas salinas, a lo que hay que añadir algunos de los topónimos cristianos como es el caso de Almalla, que deriva de la palabra árabe al Mallah = la salina, y que denotan su origen islámico. Fundamentales para el entendimiento de la actividad minera son los yacimientos relacionados con la sierra Menera, como Fuente del Moro y otros en el término municipal de Setiles, cuya prospección dio como resultado su adscripción a esta época califal ${ }^{131}$.

\section{El fin del período andalusí y la conquista castellana}

Aunque desde la conquista de Toledo en 1085 todo esta área cae en la órbita de los castellanos, no se puede afirmar con rotundidad el fin del período andalusí en estas

\footnotetext{
${ }^{129}$ En los trabajos de prospección arqueológica que hemos llevado a cabo en el valle del Salado hemos localizado más de diez asentamientos de pequeño tamaño con materiales andalusíes que no se conocían anteriormente. Serán descritos y localizados en el capítulo correspondiente de este mismo trabajo.

${ }^{130}$ Los fundamentos de la llamada arqueología hidráulica han sido desarrollados por el equipo de Miquel Barceló y han sido desarrollados en distintos ámbitos peninsulares: BARCELÓ, Miquel, KIRCHNER, Helena, NAVArro, Carmen, El agua que no duerme. Fundamentos de la arqueología hidráulica andalusí, Granada, 1996; MALPICA CUELLO, Antonio, «El agua en al-Andalus. Un debate historiográfico y una propuesta de análisis», V Semana de Estudios Medievales (Nájera, 1994), Logroño, 1995, pp. 6585.

${ }^{131}$ OLMO ENCISO, Lauro, «Arqueología medieval en Guadalajara...», p. 483.
} 
tierras hasta la efectiva conquista de Sigüenza, que se produjo el 22 de enero de $1124^{132}$. E incluso con posterioridad habría que tener en cuenta la posible perduración de la población musulmana en el territorio, convertida en mudéjar pero con una cultura material muy similar a la que tenían con anterioridad, como se ha detectado tanto en otras regiones de la provincia como del conjunto de la Marca Media ${ }^{133}$.

Tras la conquista se formó un señorío episcopal, con sede central en Sigüenza, y se reordenó todo el territorio respondiendo a las necesidades y exigencias de una sociedad muy diferente a la que anteriormente ocupó estas tierras, que además estaba en plena transformación, con distintos sectores sociales enfrentados entre sí por ejercer el dominio efectivo ${ }^{134}$. Todo ello ha generado una abundante documentación escrita ${ }^{135}$, aunque lo que nos interesa recoger aquí son las transformaciones que se detectan a nivel arqueológico en los distintos asentamientos y la reordenación del espacio que se produce a partir del siglo XII, en relación a lo que ocurre en el resto de la provincia.

No conocemos apenas nada sobre lo que ocurre en los momentos finales del período andalusí, en lo que conocemos como época taifa, siendo la menos documentada desde todo punto de vista. Sabemos que nuestro territorio cayó en la órbita de la taifa de Toledo ${ }^{136}$. Para esta época, los recientes estudios numismáticos están ofreciendo datos sobre las características fiscales del período, en un panorama de circulación relativamente local que muestra una desarticulación del modelo fiscal omeya así como la implantación de una fiscalidad más gravosa y coercitiva como consecuencia de las necesidades de mantenimiento de una nueva burocracia, de una militarización del estado, de la rapiña de los propios monarcas, así como de la necesidad de hacer frente a la imposición de las parias por parte del reino de Castilla ${ }^{137}$. Creemos que que debió producirse una contracción en el hábitat hacia las fortificaciones y núcleos más grandes, en paralelo al avance de los cristianos.

\footnotetext{
${ }^{132}$ BLÁZquez GARBAJOSA, Adrian, «La reconquista de Sigüenza y su significación geopolítica regional», Wad-al-Hayara, 12 (1985), pp. 35-42

133 CORTÉs, Ruiz, M $M^{\text {a }}$ Elena y LÁzAro Molinero, Inmaculada, «¿Continuidad o ruptura entre musulmanes y mudéjares?: el ejemplo de Molina de Aragón (Guadalajara)», Wad-al-Hayara, 22 (1995), pp. 177-214; Martínez Lillo, Sergio y Matesanz Vera, Pablo, « Cerámicas cristianas y musulmanas de la Marca Media Central: siglos X, XI y XII », A Cerâmica medieval no Mediterrâneo ocidental, Mértola 1991, pp. 273-284.

${ }^{134}$ BLÁZQUeZ GARBAJOSA, Adrián, «Obispo, cabildo y concejo: tres entidades en lucha por el poder en Sigüenza, capital del señorío episcopal seguntino», SERRAno MarTín, Eliseo (Ed.), Señorío y feudalismo en la Peninsula Ibérica (ss. XII-XIX), Zaragoza, 1993, t. 4, pp. 51-66; Idem, El Señorío episcopal de Sigüenza economía y sociedad (1123-1805), Guadalajara, 1988.

${ }_{135}$ Recogida por Minguella y ARNEDO, Toribio, Historia de la diócesis de Sigüenza...,

${ }^{136}$ Boloix Gallardo, Bárbara, «La taifa de Toledo en el siglo XI. Aproximación a sus límites y extensión territorial», Tulaytula, 8 (2001), pp. 23-57.

${ }^{137}$ CAStro Priego, Manuel, «Hallazgos numismáticos de época islámica en Guadalajara: El tesorillo taifa de Aranzueque», en García-Soto Mateos, Ernesto y García VAlero, Miguel Ángel (eds.), Actas del primer Simposio de Arqueología de Guadalajara. Homenaje a Encarnación Cabré Herreros. Sigüenza, 4-7 de octubre de 2000, Madrid, 2002, t. 2, pp. 569-578.
} 
A partir de la conquista castellana, con la implantación de una formación social feudal, se produce una reordenación del territorio a partir de lo que se conoce como la repoblación. En los primeros años del siglo XII las labores de repoblación recaen en tres facciones, por un lado Alvar Fáñez en la zona de Hita y Guadalajara, por otro lado la familia Lara en Atienza, Medinaceli y Molina y finalmente en el Señorío de Sigüenza el obispo D. Bernardo de Agén y sus sucesores en la cátedra episcopal ${ }^{138}$. El proceso de refundación de las diócesis es el que en gran medida va a articular y a formular los esquemas de concentración de la población y la generación aldeana en torno a la red parroquial, como puso en su día de manifiesto García de Cortazar ${ }^{139}$.

En cuanto a los esquemas e poblamiento, una de las características de este momento es la desaparición de las torres aldeanas y las alquerías y el inicio del «castillo feudal», en muchos casos en los mismos emplazamientos en los que se situaban los castillos islámicos, pero con profundas readaptaciones, como es el caso de Atienza, Riba de Santiuste o Baides. Se implanta ahora una red parroquial, en ocasiones en torno a los mismos espacios y valles ocupados anteriormente, aunque desplazándose la población hacia el llano, surgiendo así nuevas poblaciones generalmente en torno a las iglesias de nueva construcción. El es caso de Castejón, donde la iglesia se construye en la parte alta del cerro donde se asentaba la aldea islámica, o en el caso de Bujalaro donde la iglesia está ubicada más lejos del cerro. En uno y otro caso no hay una superposición ni solapamiento del asentamiento.

Los primeros siglos de la dominación castellana son el período en el que toda la zona que antes se conocía como la «Marca Media» pasa a denominarse la «Extremadura castellana». Hay una enorme dificultad para definir con precisión la extensión de la Extremadura castellana por la ambigüedad con que se empleara el término en la Edad Media $^{140}$. En cualquier caso, tienen varias cosas que lo definen: la existencia de un derecho común, el «Derecho de Extremadura»; la organización del espacio rural en «Comunidades de Villa y Tierra»; y su disposición en el reborde montañoso que une las dos mesetas Cordillera Central y Sistema Ibérico. La topografía abrupta y montañosa, la

\footnotetext{
${ }^{138}$ SÁNCheZ DE MORA, Antonio, La nobleza castellana en la plena Edad Media: el linaje de Lara (s. XIXII), Tésis Doctoral, Universidad de Sevilla, 2003, Inédita (edición online: http://fondosdigitales.us.es/tesis/tesis/204/la-nobleza-castellana-en-la-plena-edad-media-el-linaje-de-laras-xi-xiii/); ÁvILA SEOANE, Nicolas, El proceso de señorialización de la Extremadura castellana: el ejemplo de la provincia de Guadalajara (siglos XII-XVIII), Tesis Doctoral, Universidad Complutense de Madrid, 2005, Inédita (edición online: http://eprints.ucm.es/tesis/ghi/ucm-t28752.pdf).

${ }^{139}$ GARCÍA DE CORTAZAR y RuIZ DE AgUiRre, José Ángel, «La Extremadura castellano-leonesa: hacia la construcción de un modelo», Revista de Historia Económica, 2 (1987), pp. 365-370; y los estudios recogidos en Sociedad y organización del espacio en la España medieval, Granada, 2004.

${ }^{140}$ Distintas opiniones pueden verse en GONZÁLEZ, J., «La Extremadura castellana al mediar el siglo XIII», Hispania, 127 (1974); VILlAR GARCíA, L. M., La Extremadura castellano-leonesa. Guerreros, clérigos y campesinos (711-1252), Valladolid, 1986, en espec. pp. 21-39; MARTínEZ DíEZ, G., Las Comunidades de Villa y Tierra de la Extremadura castellana, Madrid, 1983 y su crítica en BARRIOS GARCÍA, Ángel, «Sobre el poblamiento medieval de la Extremadura castellana. Crítica de una descripción estática e incompleta», Studia Historica, II (1984), pp. 201-206.
} 
elevada altitud media, las condiciones climatológicas rigurosas, los suelos pobres, el dominio del bosque, los pastos de baja calidad, la agricultura reducida a los fondos margosos de los valles y el hábitat disperso, son otros tantos factores que influyeron en la organización económica y social de la región ${ }^{141}$.

Todo el proceso de expansión y consolidación de la nueva formación social parece concentrarse entre los siglos XII y XIII, conociéndose mucho peor los siglos XIV y XV desde un punto de vista arqueológico, no así desde las fuentes escritas ${ }^{142}$.

En cualquier caso, en lo que a nosotros nos interesa, el proceso de abandono de la mayor parte de los asentamientos andalusíes se producirá ya desde el momento de la conquista, aunque no toda la población abandonará el territorio ya que tenemos distintas evidencias de la presencia de mudéjares durante la Baja Edad Media.

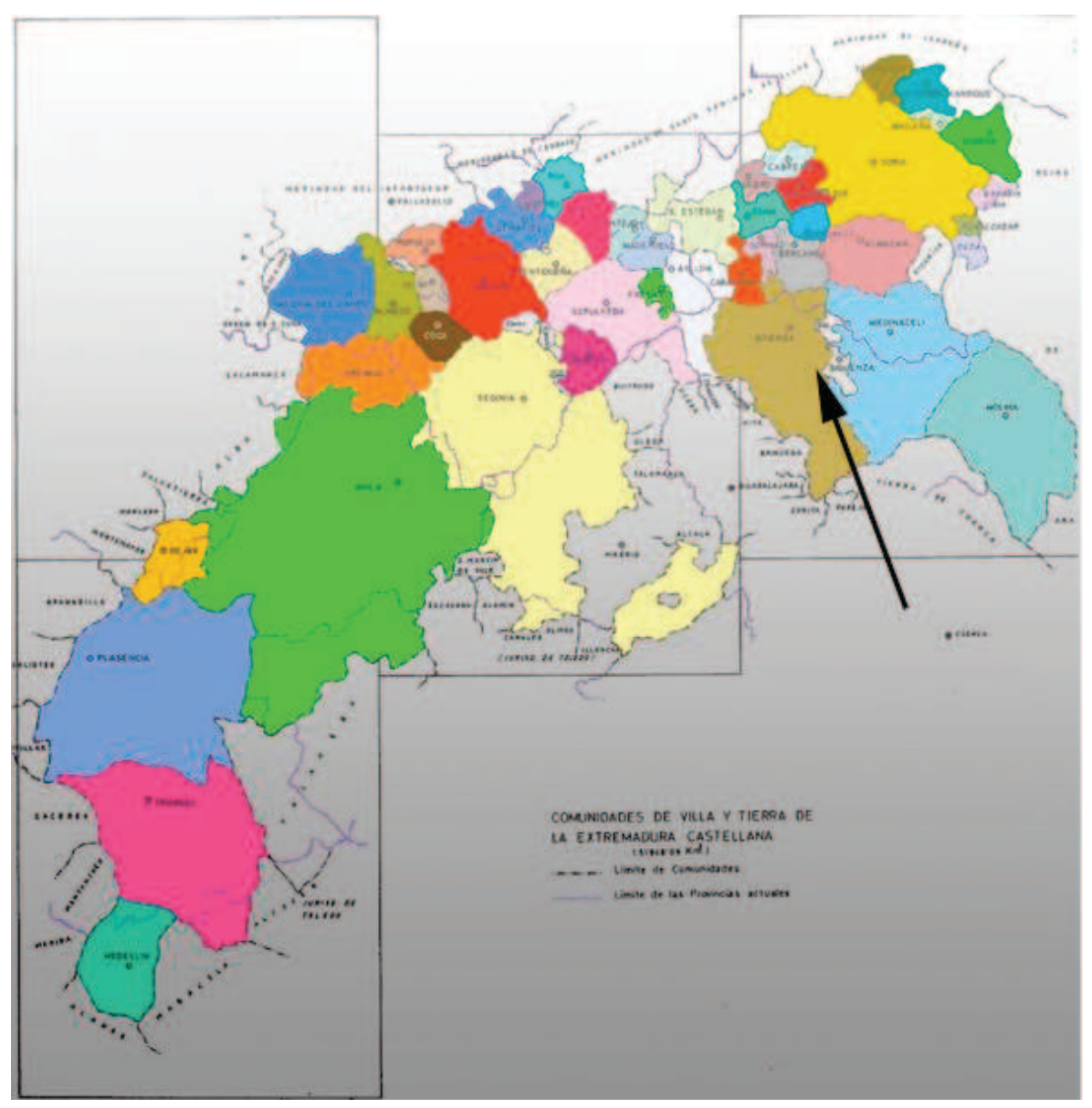

Mapa de las Comunidades de Villa y Tierra en la Extremadura castellana indicando las de Atienza y Sigüenza de las que el valle del Salado formaría parte tras la conquista

\footnotetext{
${ }^{141}$ LÓPEZ RODRÍGUEZ, Carlos, «La organización del espacio rural en los fueros de la Extremadura castellana», En la España Medieval, 12 (1989), pp. 63-64.

${ }^{142}$ Sigue siendo imprescindible la consulta de Layna Serrano, Francisco, Historia de Guadalajara y sus Mendoza. Siglos XV-XVI, Madrid, 1942, 4 tomos.
} 
III. EL VALLE DEL SALADO EN ÉPOCA ALTOMEDIEVAL

3.1. Marco físico y contexto Geográfico: una tierra ligada a la sal

3.2. Resultados de la prospección: catálogo y descripción de yacimientos

3.3. Sal, salinas, agua salada y prados halófilos en el valle del Salado 


\subsection{MARCO FÍSICO Y CONTEXTO GEOGRÁFICO: UNA TIERRA LIGADA}

\section{A LA SAL}

El valle del Salado constituye una depresión situada en la Sierra Norte de Guadalajara, en el punto en donde se encuentran el Sistema Central y el Sistema Ibérico. Forma parte de una región natural más amplia que podemos llamar «El Alto Henares». El valle del Salado se caracteriza por su red hidráulica con vertiente noreste-sureste, del que el río Salado, tributario del Henares, es el principal curso; por una edafología de margas, arcillas, yesos y calizas, y por un manto vegetal compuesto por un característico monte mediterráneo en las zonas altas y por el cultivo del cereal en la zona baja del valle. Y sobre todo ello, el rasgo que marca profundamente a toda la región es la abundancia de sal, bien disuelta en los cursos de agua y lagunas endorreicas o bien formando parte de la composición mineral de los suelos. Todo ello da lugar a una vegetación halófila característica en el fondo del valle, mientras que en las sierras que los rodean está presente el bosque aclarado del centro peninsular.

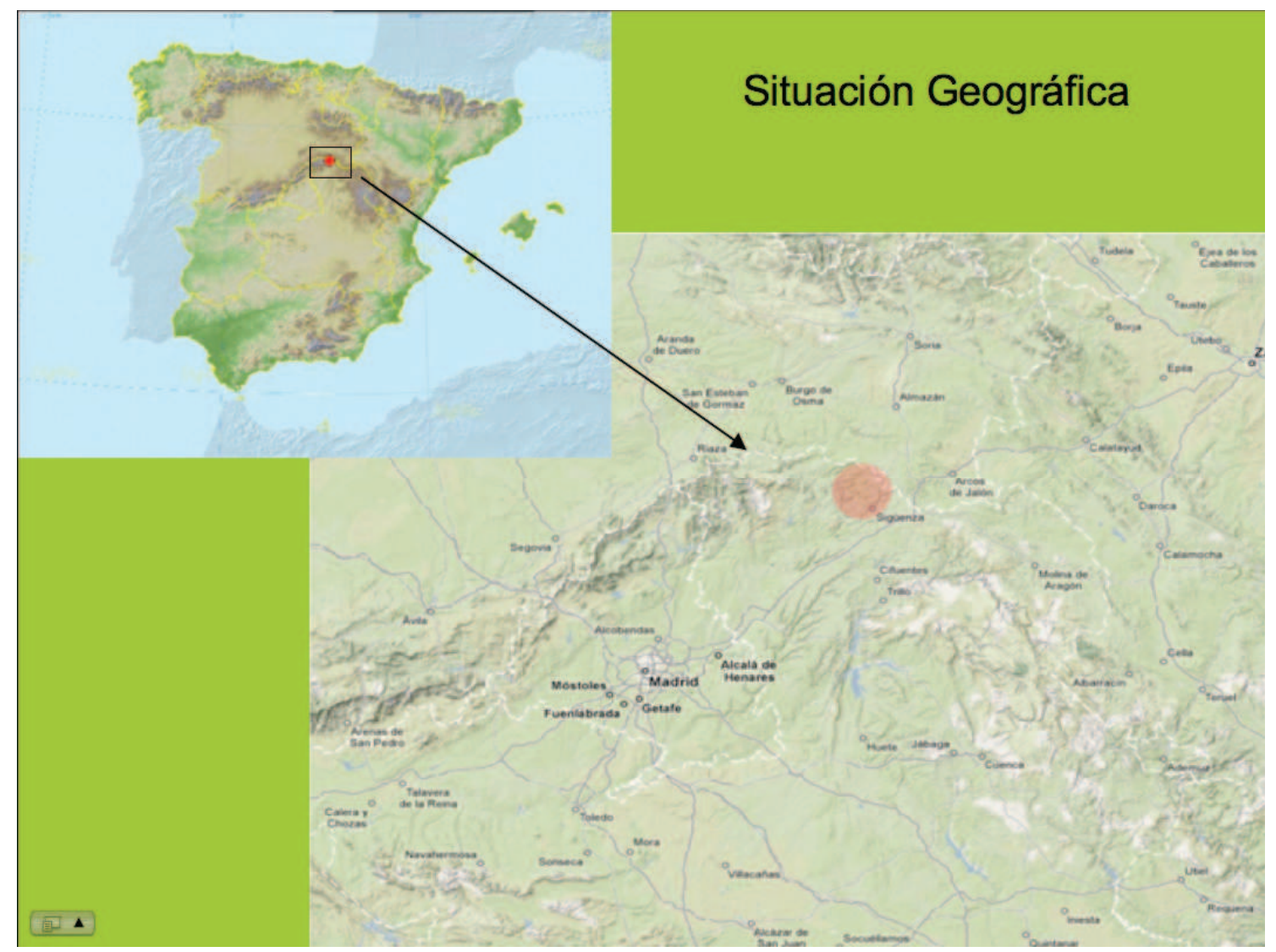

Vamos a exponer todo esto atendiendo a distintos niveles de análisis geográfico, centrando nuestra atención únicamente en aquellos aspectos que deben haber influído más directamente en el poblamiento altomedieval, como son la base base 
geomorfológico, la red hidrográfica, la edafología y el origen de la sal y por último algunos aspectos relacionados con la vegetación. Pero antes, queremos transcribir una interesante descripción de todo este territorio realizada en el siglo XVII, que creemos resume a la perfección lo que el valle del Salado, situado en la comarca de Sigüenza, ha sido históricamente:

El Obispado de Siguença (que comprehende gran parte de los Pueblos, que los Antiguos llamaron Celtibericos, Arèuacos, Verones, i Carpetanos) se termina al Oriente por el Reyno de Aragon, con la Diócesis de Zaragoza, Taraçona, y Albarracin, por el Occidente, con el Arzobispado de Toledo: tiene al medio dia el Rio Tajo, linde entre su Diocesis, y la de Cuenca: y al septentrión parte terminos con el Obispado de Osma, y alguna parte de los de Taraçona, y Segouia, alcanzando en latitud, y en longitud veinte leguas, y mas por algunas partes. Compone este Territorio vna de las mas dilatadas Diócesis de España, abundante de Trigo, Ceuada, Centeno, Auena, finas lanas, ganados mayores, y menores, miel, cera, cañamo, frutas y hortalizas: buena parte de vino, y azeyte; copiosas fabricas de sal, y de hierro, de que ay ricas minas en el Señorio de Molina, como tambien de otros metales de mas vtilidad en otros siglos, que en este. La Region es en gran parte montañosa, y llena de excelentes arboles silvestres: algo fria, fecunda de todas caças, y proueida de quantos alimentos necesita la vida humana, vtiles a la salud, y sabrosos al gusto. Abunda de Fuentes de famosas aguas, y riegan sus Campos los Rios Tajo, Duero, Henares, Tajuña, Salón, Gallo, Cabrilla, Mesa, y otros de menos nombre, que provecho. ${ }^{1}$

\section{Geomorfología}

El territorio que estudiamos resulta fácil de localizar al constituir el área de enlace de dos de los sistemas montañosos más importantes de la Península Ibérica, ya que constituye a la vez el extremo oriental del Sistema Central y la terminación noroeste de la rama occidental de la Cordillera Ibérica. Todo esta área, de difícil denominación geográfica, ha sido definida como la «paramera de Sigüenza» ${ }^{2}$. Su situación entre dos sistemas montañosos dota a este territorio de un carácter poco definido y algo ambivalente en cuanto al sistema montañoso al que cabría encuadrarlo, por lo que el geógrafo Vázquez Hoehne optó en su día por definir el área atendiendo al conjunto geomorfológico más extendido, el conjunto de páramos, y al principal núcleo de población, el de Sigüenza.

\footnotetext{
${ }^{1}$ SÁnchez Portocarrero, Diego, Nuevo catálogo de Obispos de la Santa Iglesia de Sigüenza, Madrid, 1646, p. 1.

2 VÁzQuez Hoenne, Antonio, La paramera de Sigüenza: estudio geomorfológico, Tesis Doctoral, Universidad Complutense de Madrid, 1994 (Inédita). Hemos consultado la edición online: http://eprints.ucm.es/tesis/19911996/H/0/H0019001.pdf
} 
Nuestro valle forma parte de este conjunto. Si ampliamos el marco, todo el espacio definido como la paramera de Sigüenza adquiere una forma romboidal, limitando sus bordes no serranos con las depresiones del Tajo y el Duero, esta última en su sector oriental, diferenciada como Cuenca de Almazán. La Depresión del Tajo ocupa el ángulo menor, interior, mientras que la Depresión del Duero bordea el ángulo exterior, de mayor recorrido, realizando una inflexión desde la dirección noreste a la oeste-este y finalmente a la dirección noroeste, ya plenamente ibérica. Todo el conjunto constituye una superficie elevada respecto a las cuencas del Tajo, Duero y Jalón, a la vez que una depresión relativa entre los sistemas Central e Ibérico.

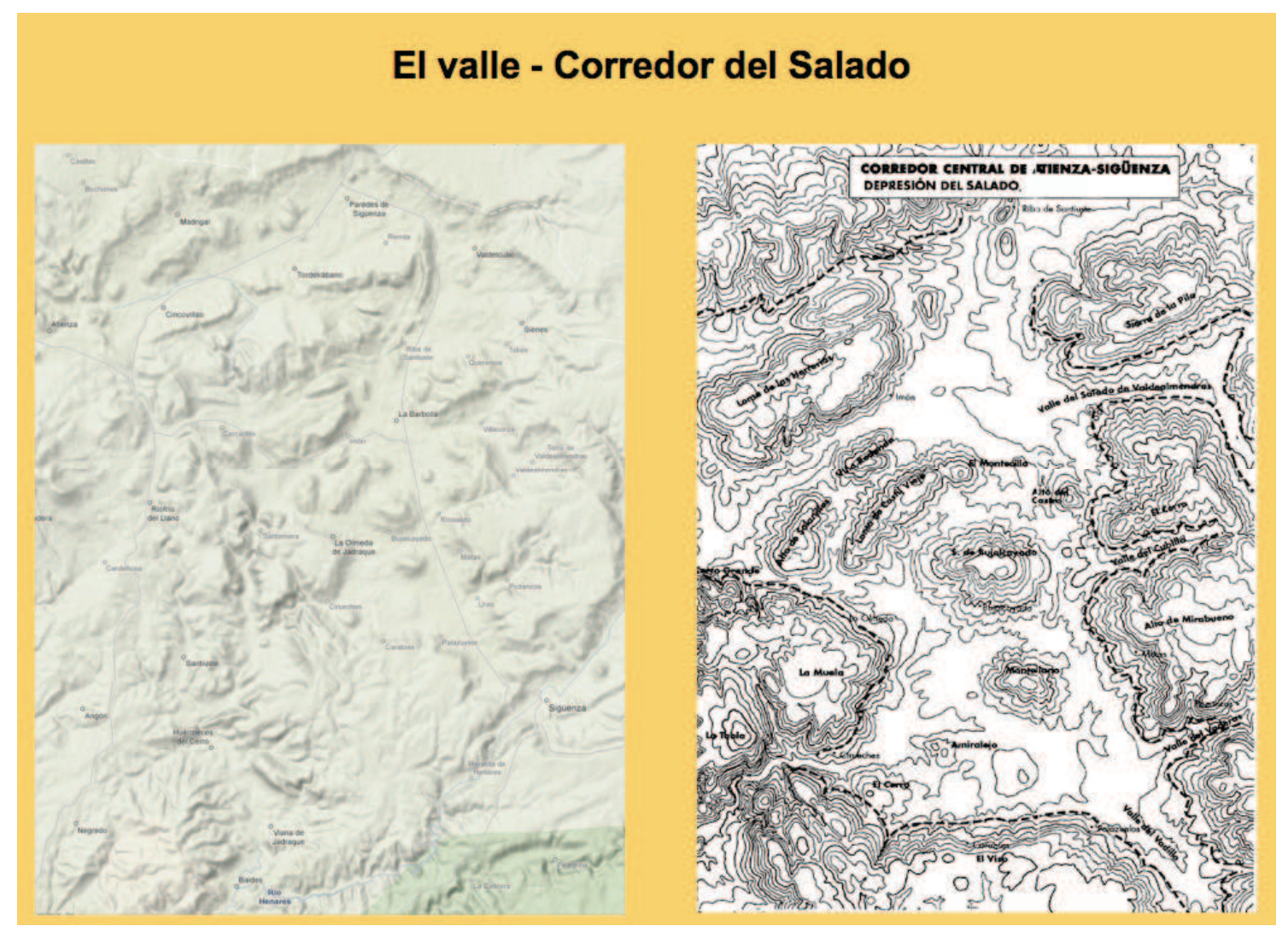

Vázquez Hoehne diferencia dos espacios dentro de la Paramera de Sigüenza: el sector occidental, que ocupa desde Caracena a la Depresión de Tiermes y hasta la Depresión de Miedes; y el sector oriental, en el que se incluye el valle del Salado sobre el que estamos trabajando, que se caracteriza por su morfología más masiva y diversamente orientada, esto es, menos alineada que la occidental ${ }^{3}$.

En este sector oriental la morfología predominante es de culminación aplanada; sin embargo, en el centro de dispone una franja quebrada y movida, el «Cinturón»o «Corredor Central de Atienza-Sigüenza», que se define, ante todo, por no ser paramera, a diferencia de los terrenos que lo circundan. En sí, este cinturón es complejo, pues

\footnotetext{
${ }^{3}$ VÁZQUez HoEHNE, Antonio, La paramera de Sigüenza ..., p. 26.
} 
comprende serrotas, depresiones y áreas de montículos aislados. En cualquier caso, rompe y desmiembra al conjunto de la Paramera, que de esta forma se individualiza en unidades aisladas: al Norte, la Paramera de Barahona; al Este, la Paramera de Medinaceli y Sierra Ministra (que de hecho es otra Paramera) y, cerrando al Sur y al Oeste, la Paramera de Baides ${ }^{4}$.

El «valle del Salado», nombre con el que nosotros preferimos referirnos al corredor de Atienza-Sigüenza, se puede definir como un eje alargado que se ensancha y estrecha a modo de rosario, con sus diferentes valles a modo de cuentas. Constituye un área compleja, quebrada y movida, integrada por serrotas, largos valles y una serie de muelas, colinas y peñones aislados. Dentro de nuestro estudio, no obstante, debemos tener en cuenta también el conjunto de sierras que limitan con el valle, que en esencia son páramelas también. Son cuatro:

- La Paramera de Barahona, que es un altiplano (de más de 30 por $20 \mathrm{Km}$ ), masivo y con una altitud entre 1100 y 1250 metros.

- La Paramera de Medinaceli, que en planta presenta una característica disposición de espolones recortados, articulados por la cabecera del Jalón

- Sierra Ministra, que constituye un sector autónomo del conjunto, elevado hasta 1300 metros, siendo el punto más elevado entre las cabeceras del Jalón y del Henares

- La Paramera de Baides, altiplano hendido por las gargantes de los ríos Salado, Henares y Dulce, que la seccionan y fragmentan.

De todas estas sierras tan sólo nos interesa la Paramera de Baides, que incluímos en nuestro estudio geográfico e histórico. El resto de las parameras no serán tomadas en consideración más que como los límites de nuestro marco geográfico.

Vamos a centrarnos en el valle. En conjunto, las altitudes relativas en el valle no son excesivas, aproximadamente entre 150 y 300 metros sobre el nivel del mar en el fondo, mientras que las culminaciones, con una notable uniformidad, se sitúan en cotas similares a las de las vecinas parameras, entre los 1000 y los 1200 metros de altura.

Ya señalábamos anteriormente algunas de las características que lo definen, que vamos a pasar a resumir agrupando sus componentes en tres grupos ${ }^{5}$ :

- Las «depresiones», valles planos y alargados, enlazados por sus extremos a modo de rosario o cadena, como decíamos anteriormente, muy compartimentados desde el punto de vista hidrográfico como ya veremos

\footnotetext{
${ }^{4}$ VÁZQUez HoeHne, Antonio, La paramera de Sigüenza..., p. 28.

${ }^{5}$ Recogemos los nombres y descripciones dadas por VÁzQuez Hoenne, Antonio, La paramera de Sigüenza..., pp. 91 y ss.
} 
- Los «poyatos», muelas, serrezuelas redondeadas en mayor o menor grado, que salpican frecuentemente los distintos valles a modo de islas

- Las «serrotas» alargadas, a veces con una nítida y prolongada orientación, que ocupan una posición marginal en nuestro estudio.

Vamos a ver de forma algo más detenida todos estos elementos. Comenzaremos por los valles o depresiones ${ }^{6}$, con un peculiar trazado en zig-zag conformado por cuatro tramos principales con varias unidades gemorfológicas individualizadas; al que añadimos en nuestro trabajo un quinto, con un sentido no tan geográfico pero si histórico como explicamos en otro apartado. Estos valles son:

1.- El estrecho valle de Bochones está drenado por el curso alto del río Alcolea $\left(20^{\circ} \mathrm{E}\right)$, de $8 \mathrm{~km}$ de longitud. En sus extremos presenta un modelado peculiar, ya que en su cabecera enlaza por un doble collado poco pronunciado con el Escalote y Cañamanes y sin embargo el tramo final se perfila estrecho y encajado en una corta pero pronunciada hoz.

2.- El valle de Los Prados, también llamado valle de Atienza, que se extiende en quiebro brusco hacia el noreste. No presenta unidad, diferenciándose tres depresiones nítidamente definidas en el sector occidental, una serie de relieves dispuestos longitudinalmente que permiten distinguir al Norte la Depresión del Madrigal, que albergaba la laguna de salobre en la que nace el río, y al Sur la Depresión de Cincovillas, con un dispositivo longitudinal de drenaje que abandona la depresión por su centro, en la hoz de Alcolea. En el extremo oriental se individualiza asimismo la Cuenca de Paredes perteneciente ya a lo que podemos llamar el valle del Alto Salado, que constituye una depresión de aspecto cerrado, de gran unidad desde el punto de vista paisajístico, donde el curso del Salado abandona la depresión constreñida por los relieves del Sur. En esta cuenca de Paredes también existen también una serie de lagunas endorreicas de fuerte salinidad.

3.- El valle de la Riba de alineación $20^{\circ}$ E y $5 \mathrm{~km}$ de recorrido, es disimétrico, ya que el río Salado que lo drena se encuentra desplazado hacia su sector occidental, hasta que finalmente abandona la depresión lateralmente, encajado entre montículos, donde se localiza la propia localidad de La Riba y su castillo. En su sector septentrional aparece subdiferenciado el pequeño valle de Valdecubo, que se adentra hacia el este con una identidad propia y casi $4 \mathrm{~km}$ de longitud.

4.- El valle del Salado/Vadillo, tramo de $15 \mathrm{~km}$, relativamente ancho, está drenado por afluentes del Salado dispuestos perpendicularmente a la depresión. Se dibuja una malla de valles e interfluvios montuosos muy característica con multitud de collados intermedios poco pronunciados. Los primeros se prolongan en su cabecera de

\footnotetext{
${ }^{6}$ VÁzQUez HoeHne, Antonio, La paramera de Sigüenza ..., pp. 93-100.
} 
forma lineal y nítida, adentrándose en la paramera contigua dando lugar a los valles del Salado de Valdealmendras o de Villacorza, al Valle del Cubillo, al valle de Vaderas y finalmente en sentido longitudinal al valle del Vadillo, todos ellos a modo de prolongaciones de la depresión central.

5.- La vega del alto Henares, que como señalábamos antes, es un añadido no tanto con carácter geográfico como con carácter histórico, tal y como expondremos en su momento. Lo que incluimos aquí son aproximadamente $15 \mathrm{~km}$ del recorrido del río Henares, que cuenta con un primer tramo de orientación $40^{\circ} \mathrm{E}$ y otro de $60^{\circ} \mathrm{E}$. E1 Henares nace a cota relativamente baja, en un manantial conocido como "Jardín de la Horna".

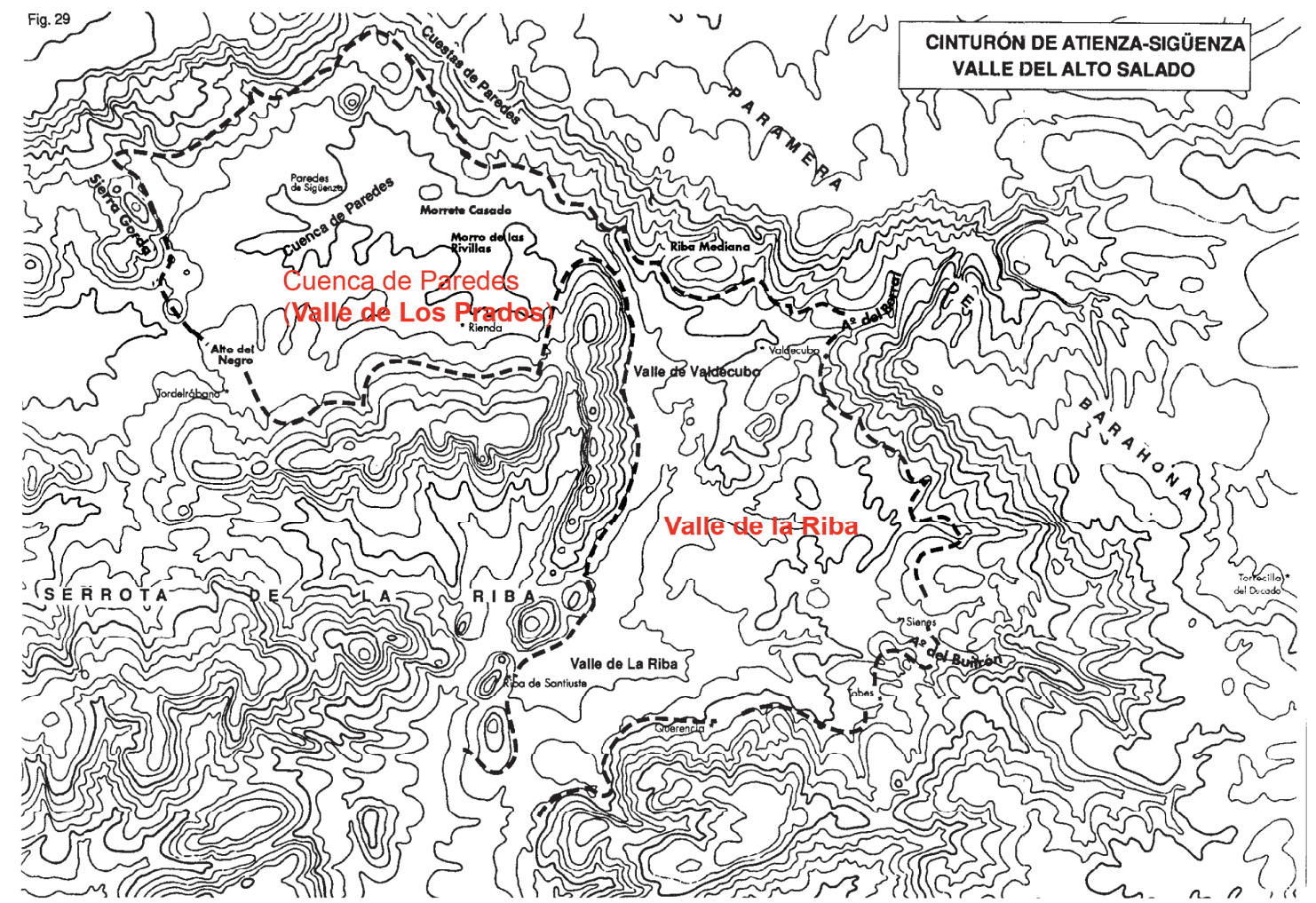

Ejemplo de la delimitación de los distintos valles

En estos valles, formando parte de ellos pero como elementos diferenciados y diferenciadores, nos encontramos con lo que popularmente llaman en Guadalajara los «poyatos», esto es, una profusión de montículos intermedios, que constituye una característica notable y específica de este cinturón o corredor. Se encuentran muelas o mesas de cumbre plana y forma redondeada, cerros o cerrajones, espinados alargados, lomos y serrezuelas y también elevaciones aisladas de perfil coniforme, dispuestos con frecuencia en hilera. 
Esta diversidad de elevaciones aisladas se puede referir con el término representativo de poyatos, aumentativo de pueyo, empleado localmente aunque no de forma general como sinónimo «lugar en lo alto, otero o atalaya».

Vázquez Hoehne diferencia cuatro sectores fundamentales ${ }^{7}$ :

- Al oeste de Atienza se individualiza el sector que puede ser designado como los «Poyatos de Atienza» por la profusión de relieves aislados individualizados. Se diferencian dos tipos fundamentalmente: los cerros abruptos, de perfil troncocónico, como la alineación de Peña Negra, el cerro Padrastro y el propio cerro del castillo de Atienza. Sin embargo, son mayoritarios los anchos cerros redondeados de culminación aplanada, como Los Picozos, que aparecen articulados entre valles laterales, a través de collados planos, de navas. Unos y otros compartimentan el terreno en depresiones menores: valle de Alpedroches, de Cañamanes, de Tordelloso, de la Bragadera y de los Barraganes. En el resto de las zonas diferenciadas, los montículos se insertan, salpicándolos, en los valles ya considerados.

- En el valle de Los Prados (Alcolea de las Peñas) se establece un esquema muy diferente al de los Poyatos de Atienza, pues los relieves son mesas alineadas, paralelas al borde de la Paramera circundante: ante todo la Sierra de Cincovillas de $4 \mathrm{~km}$ y su prolongación, solo ligeramente desplazada hacia el SE, de la Sierra Mediana y la Sierra Gorda.

- Un tercer sector es el correspondiente a los valles del Salado y Vadillo, donde predominan las mesas redondeadas, dispuestas a modo de islas, entre un esquema reticular de depresiones. Las elevaciones más importantes son de Norte a Sur:

- El monte de Imón, de $4 \mathrm{~km}$

- Viña Redonda, también llamada La Matilla y Alto de Solanillas

- La Loma de Castilviejo, de $3 \mathrm{~km}$ de longitud

- La Sierra de Bujalcayado, de 2 km, que es la más elevada

- Montellano, de $1 \mathrm{Km}$ de diámetro aproximadamente.

- Finalmente, en el valle del alto Henares, se disponen de nuevo lomas alargadas, como La Loma de El Mirón, en contacto con el río Vadillo y El Calar, paralelo al rio de casi $5 \mathrm{~km}$ de longitud total, aunque algo curvado en su extremo NE. También destaca la elevación aislada y redondeada de El Otero.

Por último nos queda hablar de las serrotas del corredor Atienza-Sigüenza ${ }^{8}$, que constituyen la tercera unidad característica dentro del valle. Son, concretamente, las serrotas de La Riba y de Guijarrosa. Se trata de las mayores unidades del cinturón de

\footnotetext{
${ }^{7}$ VÁZQUez HoEHne, Antonio, La paramera de Sigüenza ..., pp. 101-104.

${ }^{8}$ VÁzQuez Hoehne, Antonio, La paramera de Sigüenza ..., pp. 105-108.
} 
Atienza-Sigüenza, de unos $12 \mathrm{~km}$ de longitud y una anchura de 4 a $5 \mathrm{~km}$. En conjunto conforman un relieve a la vez masivo y quebrado de laderas irregulares y abruptas, en vez de regladas y continuas, con culminaciones irregulares, disecadas y articuladas en anchos nudos, entre collados pandos, todo lo cual contrasta con la planitud de las parameras circundantes. La tonalidad oscura, por la roca rojiza y la vegetación arbórea, destaca vivamente en la claridad del entorno.

Es notable la isoaltitud de cumbres, que alcanza la máxima expresión en los Altos de la Guijarrosa, donde las tres culminaciones, separadas 4,5 km, una de otra, presentan las siguientes altitudes: 1200, 1201 y $1201 \mathrm{~m}$.

En ambas serrotas se diferencian dos alineaciones fundamentales de dirección en: la principal es la meridional, ancha masiva y elevada; la septentrional, más recortada presenta un frente disimétrico encarado hacia el Sur, mientras que la vertiente Norte, amplia y tendida, ofrece un aspecto grandioso.

Una vez que hemos descrito lo que en sentido estricto constituye el valle del Salado, vamos a describir la paramera de Baides $^{9}$, ya que parte de ella, junto con el valle del Henares, forma parte del área de estudio que nos hemos marcado como explicábamos anteriormente.

Al Sur del Cinturón central de Atienza-Sigüenza se extiende un sector de la Paramera que se caracteriza por las gargantas y valles profundamente incididos de los ríos Salado, Henares y Dulce que tajan y recortan una típica culminación aplanada, con una altura de entre 1050 y $1180 \mathrm{~m}$, a veces reducida a estrechos espolones.

De esta forma la compartimentación del relieve es grande, y las unidades perceptibles se estructuran a un nivel espacial inferior. No obstante es posible reconocer una unidad morfográfica donde se recogen toda esta serie de relieve, que presentando las características básicas de la Paramera, se interponen entre el Cinturón Central de Atienza-Sigüenza al Norte y los relieves del Valle del Henares Medio y de la Alcarría que quedan al Sur. Todo este conjunto es lo que se define como «Paramera de Baides», que forma a su vez una parte importante del conjunto más amplio que es la Paramera de Sigüenza.

La variedad de incisión y de disposición de relieve permite diferenciar tres sectores:

- sector noroeste, de cortos congostos que alternan con largas y anchas muelas en los interfluvios

- sector suroeste, de valles y ejes montañosos transversales al principal

- sector este, de marcadas, largas y profundas gargantas hendidas en la superficie culminante de la Paramera

\footnotetext{
${ }^{9}$ VÁzQUEz HoEHNE, Antonio, La paramera de Sigüenza ..., pp. 122-129.
} 
De todos estos sectores, solo nos interesan el NW y el SW, donde se combinan los congostos escarpados, las hoyas, los valles relativamente anchos y las muelas. Son las hoyas de El Atance, hoy convertida en pantano, Santiuste y la de la confluencia del Regacho y el Salado. Son pequeñas, cerradas y de gran unidad paisajística. En ella las muela y cabezos están separados por pequeñas incisiones: Muela de la Virgen, La Dehesa, Muela Vieja, Valdehierro, Cerro Grande, Alto del Cuerno, La Tabla. Los congostos escarpados de roca desnuda corresponden al de Santamera y al de Huérmeces del Cerro en el Salado y al de Cirueches en el Rio de la Hoz o Vadillo.

En el sector SW se erige como elemento fundamental del relieve el valle del Salado, relativamente ancho y con orientación N-S. Este valle presenta más méritos morfográficos que el vecino alto Henares para considerarse como cabecera del curso resultante aguas abajo, ya que además de ser más amplio se encuentra alineado con él.

El valle del Salado se prolonga hacia el Este por ramificaciones transversales de los valles de Huérmeces, de Viana y la embocadura de la mencionada garganta del Henares, que seccionan y delimitan entre medias reductos de la paramera recortados como espolones: La Muela de Viana y el Llanazo ante todo.

Hacia el Oeste la Sierrezuela presenta una culminación aplanada en progresivo descenso hacia el Norte y sucesivos ramales laterales en disposición transversal.

Las gargantas de los ríos Henares y Dulce constituyen el elemento más significativo del sector oriental de la Paramera de Baides. Sin embargo, todo este espacio lo dejamos fuera de nuestros límites de trabajo.

\section{Hidrografía}

Uno de los marco de referencia espacial más nítidos para nuestro estudio son las cuencas hidrográficas. Todo el conjunto del territorio ocupa una posición especial en la divisoria de las tres grandes cuencas del Duero, del Tajo y del Ebro. Entre estos tres se sitúan los cauces que marcan, de alguna forma, el poblamiento histórico de todo este marco geográfico. Destacan el Henares en el centro, al norte el Salado y al sur el Dulce. Vamos a centrarnos en el río Salado, en su transcurso por el valle y en los cursos de agua que le son tributarios.

El río Salado nace en la Laguna de «El Madrigal», en el término municipal de Paredes de Sigüenza, aproximadamente a $1,5 \mathrm{~km}$ al suroeste de la localidad de ese nombre, a los pies de la Sierra Gorda, que tiene una altura máxima de $1123 \mathrm{~m}$. Esta laguna se encuentra a $1007 \mathrm{~m}$ de altura, en una zona amesetada que podemos considerar como paramera.

Las diferencias de cotas en el valle no son excesivas, entre $150 \mathrm{~m}$ y $200 \mathrm{~m}$, pero el relieve, muy fragmentado y compartimentado, resulta movido. Las culminaciones de las 
zonas elevadas, con una notable uniformidad, se sitúan a cotas similares a las de las vecinas parameras $(1050-1200 \mathrm{~m})$.

Todo el conjunto de este valle presenta un peculiar trazado en zig-zag, al que se adapta el propio río, conformado por varios tramos que podemos individualizar de norte a sur: el valle de Bochones, el valle de Los Prados o de Atienza, el valle de Paredes, el valle de Valdelcubo, el valle de la Riba, el valle del Salado-Vadillo, el valle del Atance y el valle de la Paramera de Baides.

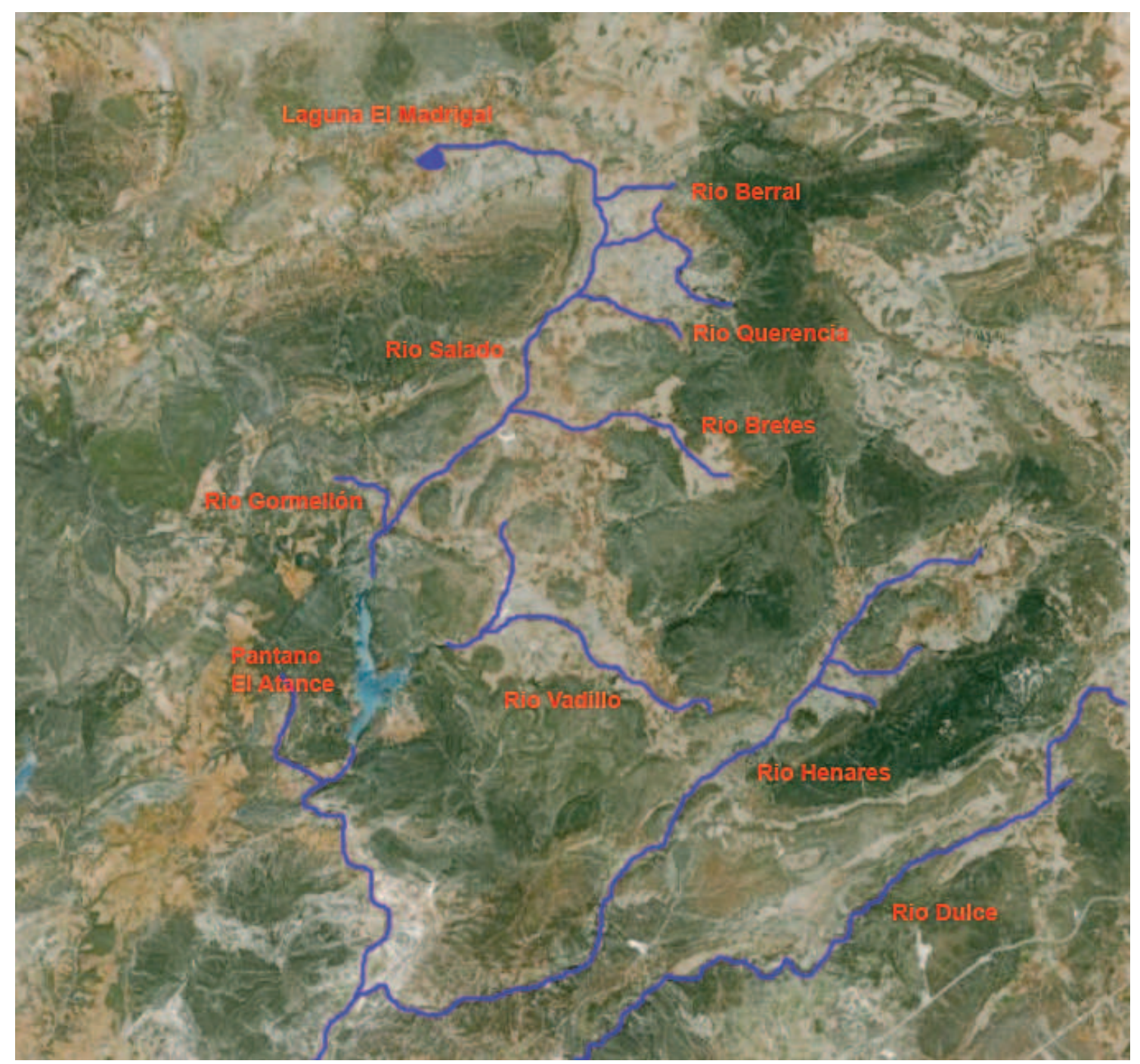

A lo largo de su curso el citado río Salado, antes de llegar al embalse del Atance, que ha modificado el espacio, recibe aguas de varios afluentes. Los principales, todos ellos por la margen izquierda, ya que sólo el Gormellón le es tributario por la derecha, son los siguientes: Berral, Querencia, Bretes y el Vadillo. Este último hoy en día vierte las aguas en el pantano del Atance directamente.

Al llegar a Imón, en el primer tercio de su recorrido, el río Salado da un giro hacia el oeste, para entrar por Santamera, donde se encajona en un estrecho paso, donde en el 
año 1996 se construyó el embalse de el Atance, inaugurado en el año 2000. Aunque el curso de agua se encajone hacia el oeste, el valle propiamente tiene continuidad en dirección sur hasta llegar casi al límite de la ciudad de Sigüenza, separado en este punto el valle del salado del valle del Henares por la loma del Mirón. La continuación del valle se debe a la existencia del río Vadillo, tributario del Salado como hemos dicho.

El Salado, salvado el embalse de Atance, deja de ir tan encajonado, abriéndose un poco el valle al llegar a la zona de Huermeces. Discurre en un espacio algo más abierto, aunque no tanto como el primer valle, formando distintas vegas en las que se asientan los principales núcleos de población (Huermeces y Viana de Jadraque). Finalmente, a los pies del municipio de Baides, el Salado se une al Henares, que nace en Horna, hacia el noreste de aquel punto, y pasa por Sigüenza y Moratilla de Henares. Un solo caudal discurre desde este punto en dirección hacia Guadalajara conformando el característico valle del Henares que marca en gran parte la geografía de la provincia alcarreña.

\section{Edafología: El origen de la sal en la comarca}

Toda esta comarca también puede describirse desde un punto de vista edafológico ${ }^{10}$. En el valle dominado por el río aparece una apófisis del macizo antiguo de la serranía de Atienza, en dirección SO-NE, rodeado de terrenos mesozoicos suacemente plegados en la misma dirección. La erosión ha desventrado los anticlinales, dejando en saliente el eje del paleozoico (Valdejudios 1147) y dando lugar a valles en ambos flancos; al Norte, el de Atienza-Paredes, a unos 1000 m. de altitud, y al Sur, los de Imón y Cercadillo a 950 $\mathrm{m}$ de altitud, labrados en los materiales triásicos por el río Salado y otras corrientes menores.

Al exterior están limitados por suaves sinclinales colgados de carniolas ${ }^{11}$, que forman en los límites con Soria los páramos llamados Altos de Barahona. Hacia el SE, en la zona de contacto con las sierras Ibéricas, aparecen pliegues muy suaves, de dirección NO-SE, cortados por la superficie de erosión de Sigüenza, también en forma de páramos en las carniolas, con valles abiertos en el Keuper por los afluentes del Salado; por ejemplo, el que dibuja una Y de Imón a Sigüenza y otros menores como el de Valdealmendras.

En dichos valles, sobre las areniscas rojas de Buntsadstein y delgados lechos de Muschelkalk, está bien desarrollad el Keuper con arcillas irisadas, margas grises o verdes con pequeños bancos de caliza y dolomía y una potente zona superior de margas rojas. En varios horizontes se encuentran yesos rojos, sobre todo en el primer tercio del

\footnotetext{
${ }^{10}$ GonzÁlez Ponce, J., Rodríguez Señas, J. y Serrano Comino, F, Principales suelos agrícolas de la provincia de Guadalajara. Su fertilidad y posibilidades de mejora. Madrid, 1987.

${ }^{11}$ Las carniolas o carneolas son un tipo de roca sedimentaria evaporítica carbonatada, que suelen presentarse carcomidas, con vacuolas y brechas. Su color es amarillo, pardo o herrumbroso. Forma masas poco estratificadas de aspecto ruiniformes. Su composición es habitualmente un $70 \%$ calcárea (calcita), un $20 \%$ dolomítica, hidróxidos de hierro, y a veces también algo de composición yesífera. FoUCAULT, Alain y RAOULT, Jean-Franðcois Diccionario de Geología, Barcelona, 1988.
} 
piso, y hay también sal, de la cual se cargan las aguas aprovechadas en las salinas y forma a veces eflorescencias o pequeños depósitos en los fondos mal avenados.

El origen de estos yacimientos de sal, hay que buscarlo unos doscientos millones de años atrás cuando el mar cubría aún buena parte de la Península Ibérica. Al sucederse los movimientos tectónicos del Terciario, que convulsionaron el relieve, ese mar interior quedó reducido a un conjunto de lagos poco profundos, pero muy ricos en sal. La evaporación hizo desaparecer con los tiempos esos lagos, quedando tan sólo el lecho cristalizado de sal gema en depósitos que incluso superan los $200 \mathrm{~m}$. de espesor.

De esta forma, el discurrir de las corrientes subterráneas en contacto con estos estratos es el origen de las numerosas fuentes y manantiales de naturaleza salobre que salpican, no solo el mapa alcarreño, sino numerosos enclaves distribuidos por los más diversos rincones de la Península.
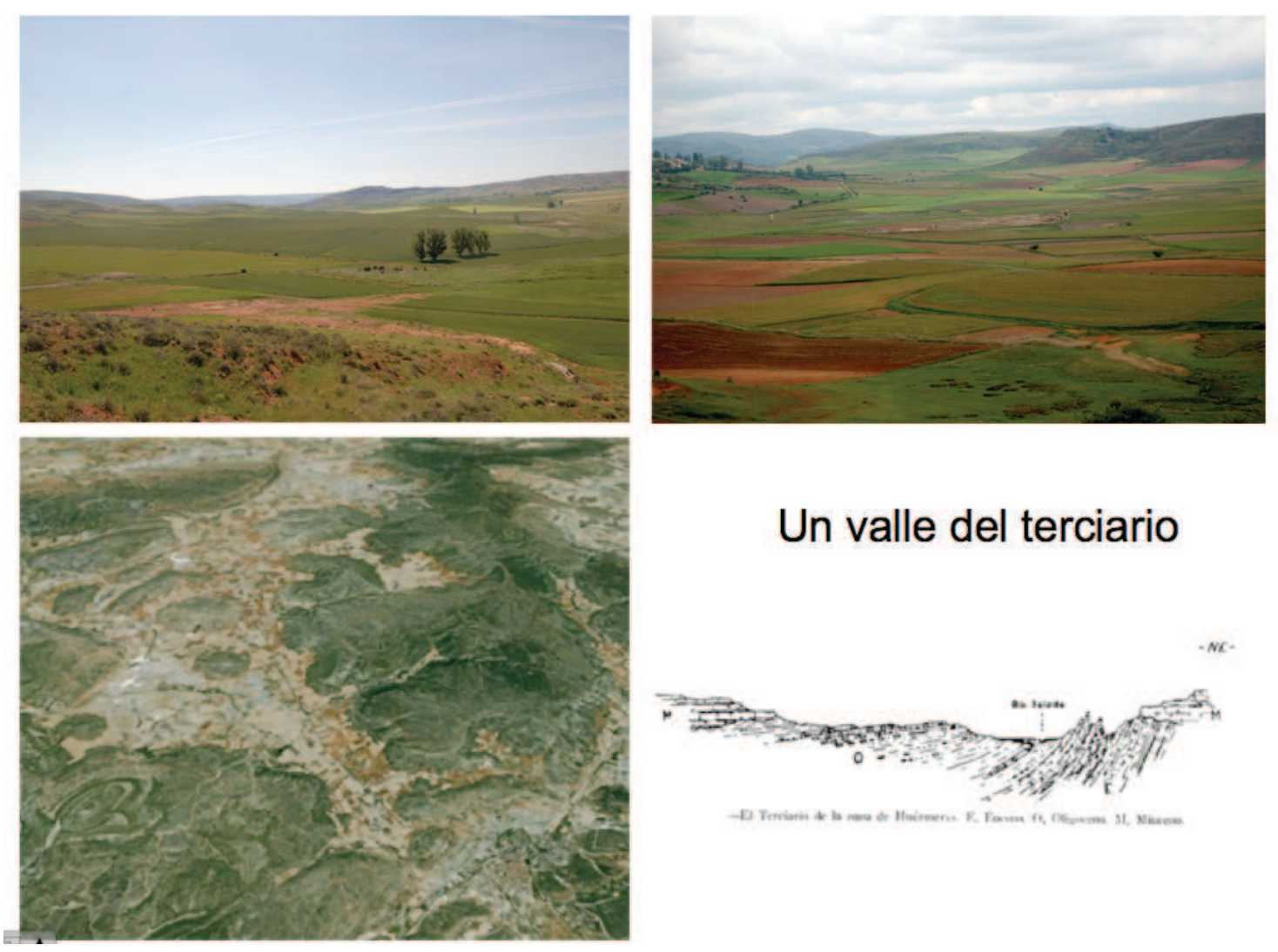

Los materiales anteriores a la Era Secundaria (más de 600 millones de años) no afloran en los alrededores de la zona de Jadraque, aunque sí aparecen en zonas próximas, donde los diversos plegamientos y cortes han dado lugar a las sierras que bordean el Sistema Central. Estos materiales son en dichas zonas sobre todo pizarras y gneises, característicos de esta Era.

Los plegamientos del ciclo Hercínico (que provocan cortes paralelos y desplazamientos verticales en el suelo) elevaron estos materiales haciendo de las zonas próximas a 
Sigüenza una región deprimida, una cuenca entre dos macizos: la Meseta Central y el Macizo del Ebro hoy hundido y configurando el valle del Ebro.

Para entonces, el relieve de la corteza permitía suficiente acumulación permanente de agua dulce procedente de precipitaciones, y se trazaron los cauces primitivos de algunos ríos, comenzando así el proceso de erosión y sedimentación fluvial.

El estudio de las cuencas sedimentarias permite conocer las diferentes situaciones que han sufrido las zonas erosionadas y receptoras, según sean los sedimentos de tipo químico, detrítico u orgánico, y dentro de estos su procedencia continental y oceánica. A esta región llegaron sedimentos transportados por los ríos y arroyadas, procedentes de los macizos más elevados.

Más tarde, en la primera parte del Triásico (200 millones de años) el mar llegó a invadir estas tierras, provocando depositos netríticos (materiales acumulados en un fondo marino poco profundo).

Las orillas sufrieron sucesivas transgresiones y regresiones, provocando la aparición de rocas de deposición costero-continental (areniscas y conglomerados) y rocas de deposición marina (calizas). Las regresiones también explican la presencia de lagunas sedimentarias, provocadas por la desecación de lagunas de agua salada que quedaron aisladas al retirarse el mar.

Del período Triásico proceden materiales acumulados en capas relativamente altas, que presentan los tres pisos típicos de este sistema en condiciones desiguales:

- El Triásico Inferior (Buntsandstein), y el Medio (Muschelkalk) presentan a lo largo de la hoja cambios de facies y de potencia: de Este a Oeste disminuyen de espesor y se hacen más detríticos. Se caracterizan, respectivamente por conglomerados, arcillas, areniscas, y por calizas.

- El Triásico Superior (Keuper), está compuesto por arcillas y yesos rojizos, muy característicos de esta zona. Se trata de una roca evaporítica formada por sedimentos continentales en zonas palustres, encharcadas, donde la evaporación fue muy intensa, y favoreció la precipitación de sales y sulfatos. La presencia del Keuper en estratos de considerable potencia y uniformidad indica que en el momento de su deposición el mar ya se había retirado. Durante la Orogenia Alpina (que provocó fuertes plegamientos desiguales durante ese período) el comportamiento plástico de yesos y arcillas ha permitido el despegue entre el rígido zócalo paleozoico y los estratos posteriores del Jurásico y Cretácico. Las arcillas de este período se explotan en Sigüenza y Atienza para cerámica y los yesos al norte de Saúca.

Los procesos erosivos del Cuaternario han afectado fácilmente a estos materiales, y han excavado amplios valles sobre el roqueado. Durante el Jurásico sedimentaron sobre el Keuper los materiales carbonatados del Secundario (margas, calizas y arenas), propios 
de ámbitos marinos poco profundos, lo que indica una nueva y marcada transgresión del mar. Son rocas de transición entre los depósitos hipersalinos del Keuper y los carbonatados superiores, formando extensas planicies que protegen los niveles arcillosos del Keuper, manteniendo la impermeabilidad de esta capa.

Durante el Cretácico terminal, se produc una rápida regresión, y la sedimentación se hace definitivamente continental, aunque debido a la fuerte erosión sufrida en los alrededores de Jadraque, no aparecen materiales de este período en la zona. Este proceso es general en todo el Sistema Ibérico. Son muy escasos los afloramientos de rocas del Terciario en la zona. Las tierras emergieron, pasando de ser cuenca de recepción a exportar sedimentos, provocándose procesos de deformación y erosión muy marcados hasta los albores del Cuaternario. Con los materiales detríticos procedentes del desmantelamiento de las zonas altas próximas, se rellenan las zonas deprimidas adyacentes (cuencas del Almazán y del Tajo).

A principios del Cuaternario, 1 millón de años, se empieza a configurar la red hidrográfica actual, que sufrirá cambios hasta llegar al estado que hoy conocemos. En las zonas próximas aparece un roqueado organizado por 1 cruce de los sistemas Central e Ibérico, formado por dos anticlinales: el de Sigüenza y el de Sierra Ministra. El pliegue de Sigüenza está desventrado: la charnela ha sido barrida por la erosión y asoman los materiales del Triásico Inferior: areniscas y conglomerados.

Los materiales de la edad Cuaternaria se encuentran en el fondo de los valles, consistiendo en elementos detríticos sueltos, gravas y arenas transportadas por los ríos, y formando terrazas en la margen derecha del Henares y depósitos de menor potencia en el resto de las cuencas fluviales. También aparecen tobas, que ha sido usadas ampliamente en la construcción rural.

Como se aprecia, toda la zona hacia el Norte y el Este de Sigüenza ha sufrido una enorme erosión durante largos períodos, dejando en superficie materiales relativamente antiguos.

En la zona Oeste de la hoja afloran materiales más jóvenes, allí donde se localizan los relieves correspondientes a la sierra de Ayllón y el inicio del Sistema Central. Esta configuración ha dado lugar a un área hidrológica en los estratos del Mesozoico de techo y suelo poco permeables, con series calcáreas de buena permeabilidad, que se recargan por la infiltración de agua de lluvia, dado lugar a fuentes y surgencias de gran volumen de aportación a las cuencas fluviales próximas.

Además, por su textura y profundidad, estos suelos poseen gran poder de retención de agua y una lenta permeabilidad, lo que facilita el encharcamiento y la escasa aireación 
En este contexto edafológico es en el que se han formado las sales ${ }^{12}$. Los mares primitivos se formaron en una atmósfera caliente y rica en elementos marinos, carbonato cálcico, cloruro sódico. Cuando la atmósfera se enfrió y permitió precipitaciones en forma de aguas más puras, las superficies terrestres eran aún muy planas e insuficientes como para regenerarlas y crear cuencas dulces. Todos los restos de suelos hasta el carbonífero son marinos, y no hay constancia de aguas dulces permanentes en la superficie de la tierra hasta entonces.

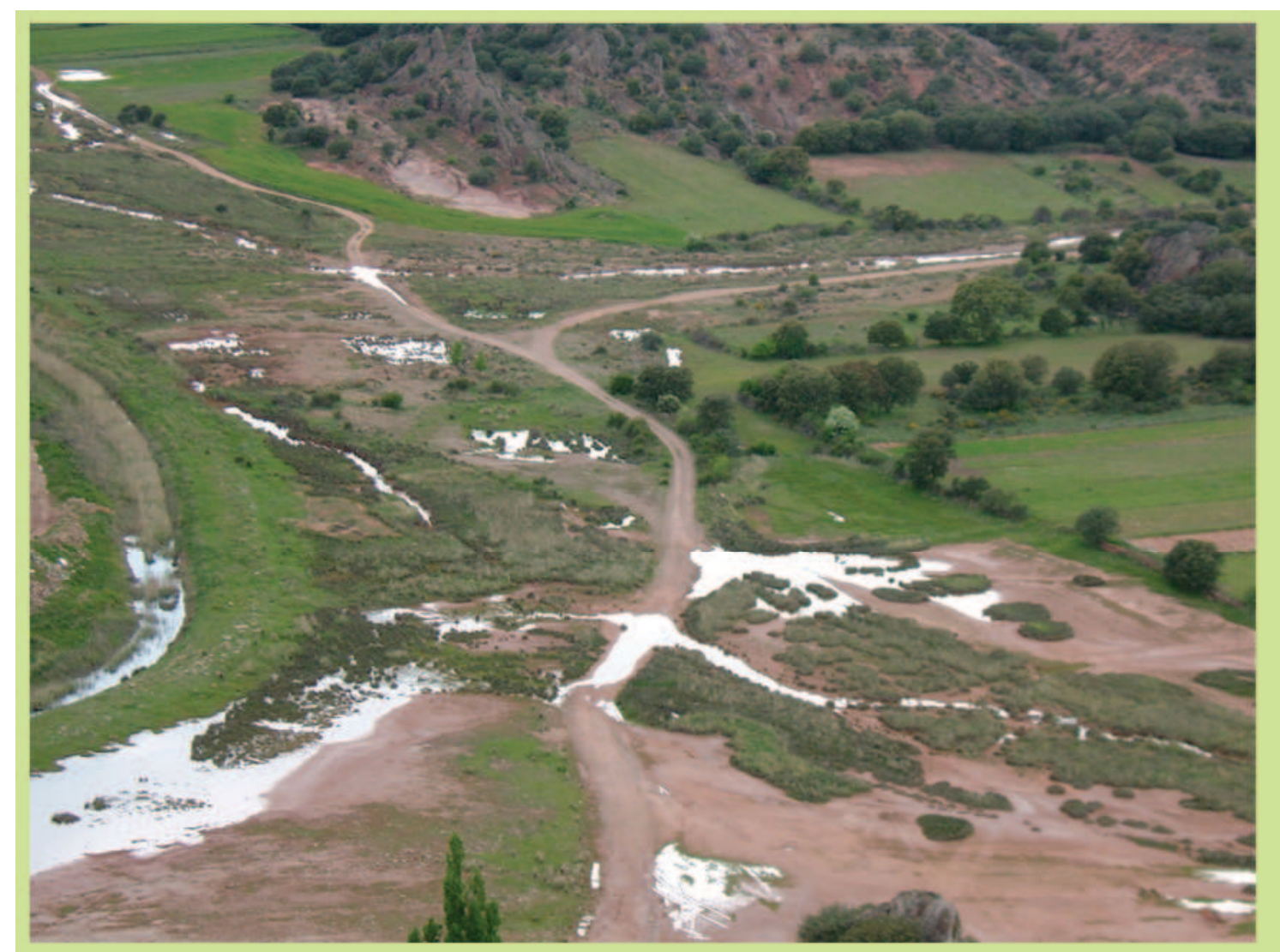

Salobrales en el entorno de Riba de Santiuste

Los yacimientos de sal se forman por la evaporación de lagunas mantenidas en contacto con el mar por un estrecho canal, lo que permitía la renovación del agua marina y acumulación de la sal por depósito en el fondo de dichas lagunas.

Los plegamientos y dislocaciones que desplazaron el agua de la superficie de los continentes provocaron estas situaciones y favorecieron la aparición de estos yacimientos. El depósito de sal está precedido por un depósito de yesos, que es inmediato a la evaporación del agua del mar. Por esta razón encontramos yacimientos de los dos materiales siempre juntos. Además, esta descomposición de la sal interviene en parte en la formación de hidrocarburos y puede ser un indicio de la existencia de yacimientos petrolíferos.

\footnotetext{
12 Trallero SAnZ, Antonio, Arroyo SAn José, Joaquín y Martínez SEÑor, Vanesa, Las salinas de la Comarca de Atienza, Guadalajara, 2003, pp. 17-18.
} 
Los manantiales termales toman la sal de las capas que atraviesan, llevándolas hasta la superficie. En algunos casos, corrientes subterráneas disuelven las sales y transportan a puntos de fácil acceso que permitan su explotación.

En la zona próxima a Jadraque (que es una extensión de la zona salinífera del Sur de Aragón) se sucedieron los depósitos marinos y la acumulación de sal durante varios períodos geológicos, pero también la aportación de materiales de variada permeabilidad y una posterior en diferentes grados, que hacen más o menos inaccesible la sal, sobre todo para las primitivas explotaciones como las de Guadalajara.

En este caso la formación de depósitos arcillosos durante el Triásico, aún cuando no estaban las tierras cubiertas por el mar, propició la acumulación de sal que provocó un nuevo movimiento del mar. Las corrientes de agua amparadas en este sustrato, transportan la sal disuelta hasta zonas especialmente erosionadas, donde se hacen fácilmente accesibles a través de pozos de 4 a $5 \mathrm{~m}$. de profundidad. Otras veces la sal crea depósitos como las minas de Santamera, donde la explotación se realiza por procedimientos industriales más complejos.

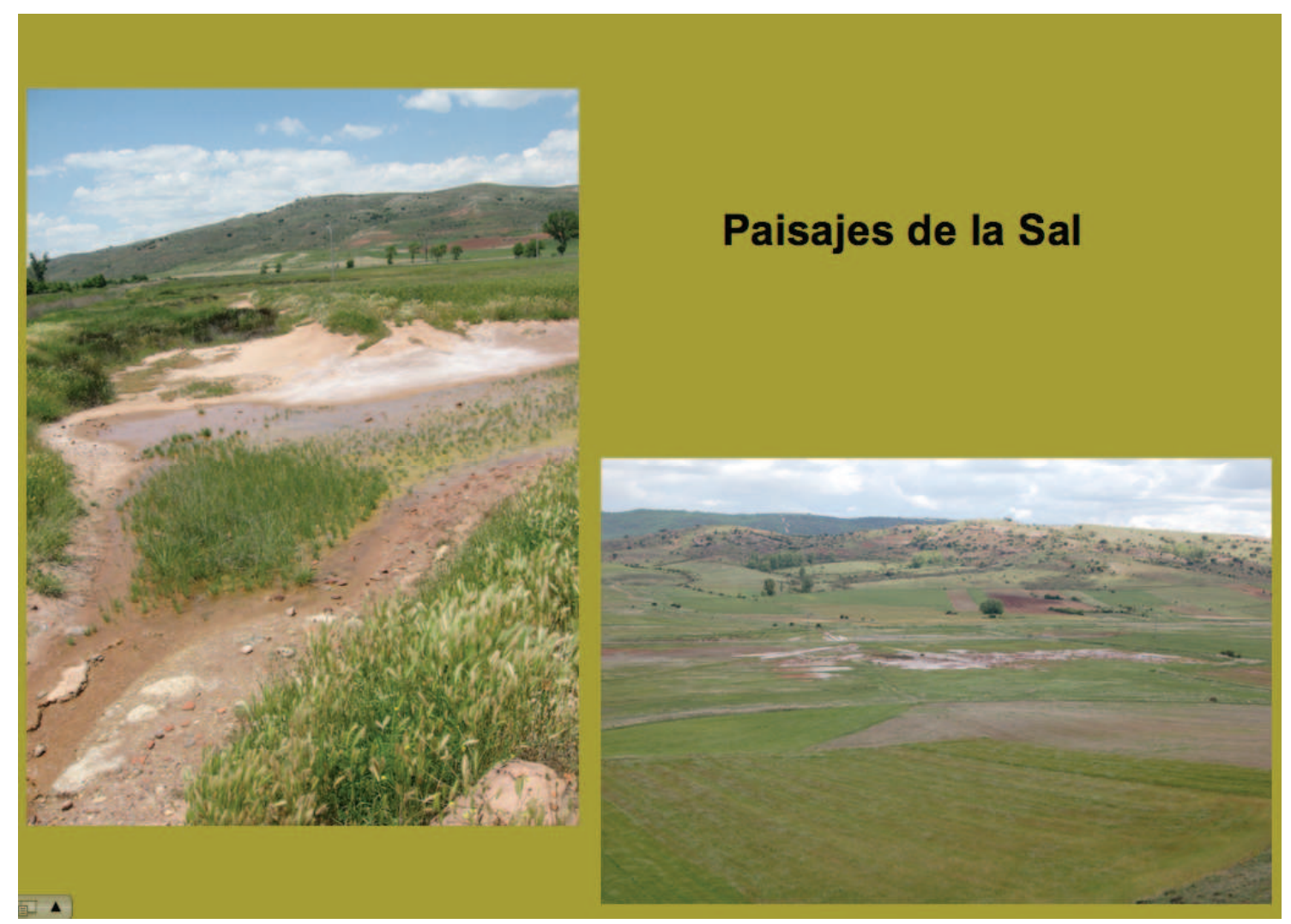

\section{La vegetación}

Dada la pobreza del medio, suelos en general poco productivos, duras condiciones climáticas asociadas a la altitud, etc., permiten la aparición de una vegetación de carácter xerófilo, que unido a una población sobredimensionada en un territorio de 
escasos recursos, con un pastoreo excesivo, han dado como resultado la deforestación y la sustitución del bosque primitivo por el predominio del monte bajo y el matorral de especies aromáticas; solamente algunos bosques residuales de pinos, encinas y robles cubren exiguas extensiones en las zonas montañosas. ${ }^{13}$

En la actualidad y por los procesos de emigración masiva de los últimos años se está detectado en las áreas montañosas, un avance progresivo de los matorrales y el bosque en detrimento de los pastizales antaño ocupados por la oveha. El clima, en bastantes áreas, es potencialmente favorable a esta reforestación, que en definitiva sólo requiere un equilibrio entre las variables hombre, pastoreo-agricultura y el medio natural ${ }^{14}$.

La principal especie árborea de la zona es el roble (Quercus robur) también conocido como rebollo o melojo. La importancia ecológica de este árbol es enorme, al ejercer sobre el suelo genéticamente ácido una acción basificante producida por la exfoliación otoñal que permite la retención de la humedad edáfica. El roble del mismo modo produce mediante la fuerza de sus raíces una compactación y densificación del suelo, evitando de este modo la erosión en los suelos que antes de su aparición eran ya de por sí erosivos. Su límite altitudinal es de $1500 \mathrm{~m}$. a $1600 \mathrm{~m}$. apareciendo a partir de esta altitud el estrato arbustivo.

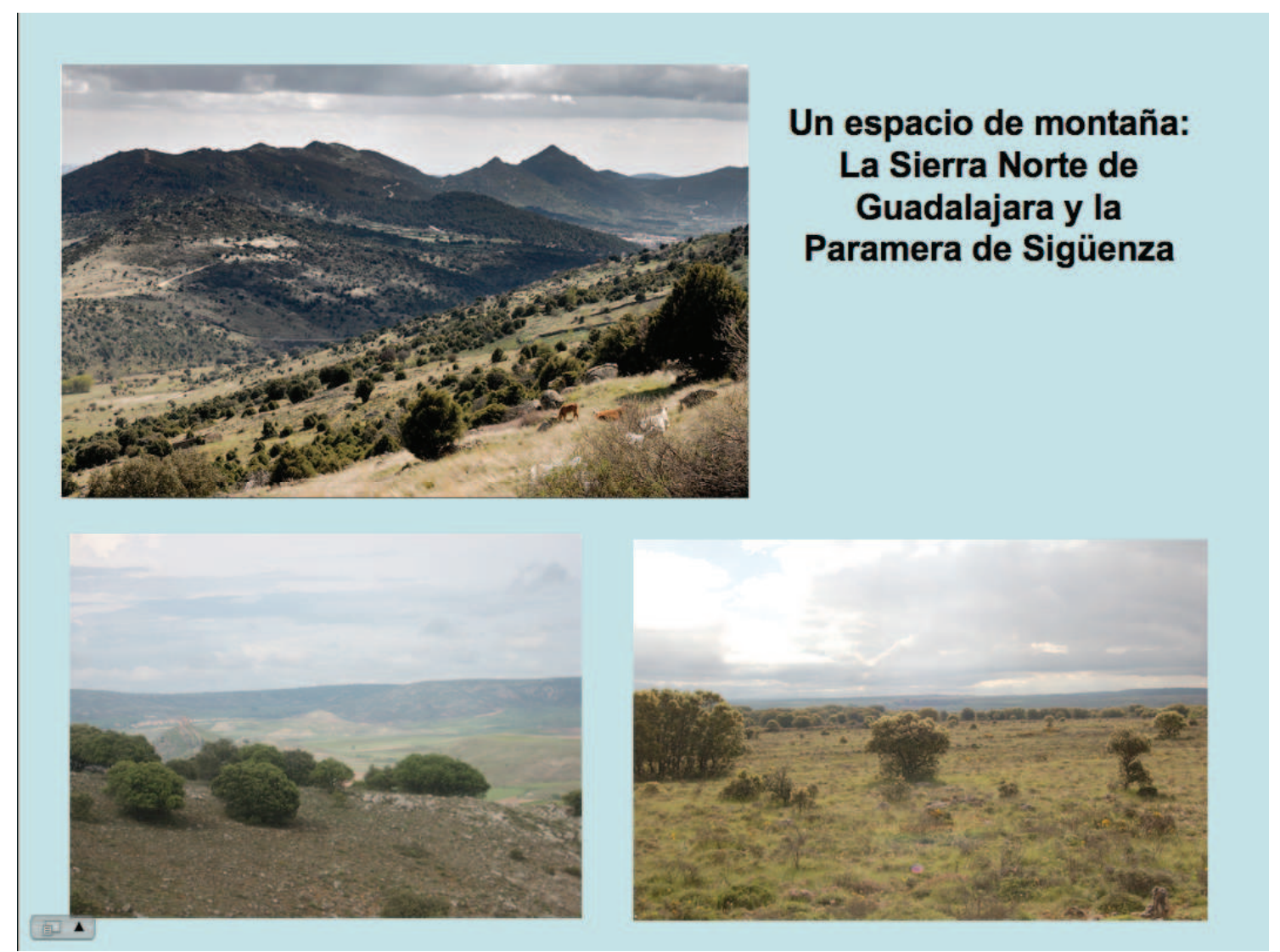

\footnotetext{
${ }_{13}^{13}$ Alonso FernándeZ, J., Guadalajara. El Territorio y los Hombres, Madrid, 1976, p. 35.

${ }^{14}$ MuÑoz MuÑoz, Jesús, Archilla AldeAnueva, Rafael y Rey ArNaiz, José María, «El clima de la provincia de Guadalajara», Anales de geografia de la Universidad Complutense, 12 (1992), pp. 13-14.
} 
El aprovechamiento del roble era máximo, se utilizaba como alimento del ganado, como robusto material de construcción y como carbón vegetal, una actividad para la que su madera es propicia. Esta multiplicidad de usos elevó progresivamente la población, hecho este que motivó un desequilibrio ecológico al producirse una importante regresión del robledal, que pasó a convertir la zona en un estrato arbustivo.

Al desaparecer el roble, desaparece también la industria primaria del carbón vegetal, el ganado encuentra menos alimento y el suelo aumenta su acidez que hace imposible su cultivo, a la vez que aumenta la erosión del mismo.

Todo lo anterior lleva a un empobrecimiento de la tierra y a una escasez de recursos naturales, que unido al aislamiento y la falta de comunicación origina la despoblación y el consiguiente deterioro progresivo de la edificación hasta llegar, en algunos casos, a la ruina total como ha ocurrido en las salinas de Valdealmendras, Rienda etc. por citar únicamente dos ejemplos.

La segunda especie principal de la zona es el enebro (juniperos oxycedrus). Es un árbol de bajo porte, a veces no pasa de arbusto, pero que puede alcanzar una altura entre $3 \mathrm{~m}$. y $5 \mathrm{~m}$. Su aprovechamiento fundamental se basa en la alimentación del ganado. Este árbol-arbusto presenta una fuerte resistencia, tanto a la sequía como a las bajas temperaturas, lo que significa una adaptación total al medio que estudiamos, aunque su carácter elifolio le permite únicamente situarse en las vertientes de solera. El enebro marca la frontera entre el robledad y el arbusto, pues a partir de los $1600 \mathrm{~m}$. la vegetación se compone fundamentalmente de brezal mixto y diferentes tipos de genista, el piorno y la gayuba.

Otro estrato arbustivo de la zona es el que viene asociado al robledal y está compuesto fundamentalmente por escoba negra, retama blanca y helechos en las zonas con microclimas húmedos (arroyos, manantiales...). Todos ellos constituyen un conjunto de materiales acidifólios plenamente adaptados a la sequía estival y a la litología existente de pizarras negras con contenido en sílice.

Un hecho significativo, es que a pesar de existir en la zona especies arbóreas muy aptas en construcción, se haya elegido el pino como madera fundamental del proceso constructivo. Este hecho se justifica debido a las necesidades constructivas, ya que la estructura de los almacenes requiere pilares de elevada longitud, característica que no poseen las especies de la zona.

Y junto a todas estas especies, debemos detenernos también en lo que a la vegetación halófila se refiere, es decir, aquella característica de los suelos salinos tan abundantes en nuestra región. Podemos destacar la vegetación anual pionera con Salicornia y otras especies de zonas fangosas y arenosas en las inmediaciones de las salinas, los pastizales salinos mediterráneos más tradicionales (Juncetalia maritimae), los matorrales halófilos mediterráneos y termoatlánticos (Sarcocornetea fruticosa), los matorrales halonitrófilos 
(Pegano-Salsoletea) y las estepas salinas mediterráneas (Limonetalia). Entre toda esta diversidad de flora, destacan dos especies, la Scorzonera parviflora y Glaux maritima. Ambas se encuentran representadas tan sólo en Guadalajara, y están consideradas como vulnerables. Junto con la abundante hierba salada (Salicornia ramossisima), la sosa fina (Suaeda vera) y algo más escaso el taray (Tamarix canariensis) conforman una microreserva muy característica que ha motivado su protección como «Saladares de la Cuenca del río Salado» y como parte de la red europea de conservación de la naturaleza Natura 2000, como Lugar de Importancia Comunitaria y Zona Especial para la Protección ${ }^{15}$.

\footnotetext{
${ }^{15}$ Sobre todas estas consideraciones referentes a la vegetación halófila y al espacio natural protegido vid. HUESO KORTEKAAS, Katia y CARRASCO VAYÁ, Jesús-F., Las salinas de los espacios naturales protegidos de la provincia de Guadalajara, Madrid, 2008.
} 


\subsection{RESULTADOS DE LA PROSPECCIÓN: CATÁLOGO Y DESCRIPCIÓN DE YACIMIENTOS}

\section{Consideraciones sobre la prospección}

Como ya se indicó, el proyecto de investigación en el que se enmarca este trabajo ${ }^{1}$ es un intento de analizar el poblamiento y su relación con un recurso natural de gran importancia a lo largo de la historia como es la sal. Para centrar la atención en esa relación cobra una vital importancia la arqueología, especialmente a la del paisaje, para determinar hasta qué punto la sal y el poblamiento están unidos ${ }^{2}$. Aunque es un problema de amplia discusión, la base de este análisis debe ser la localización de los asentamientos, su evolución y cronología de los cambios que se detecten así como establecer qué tipo de relación tienen con el medio físico en el que se insertan, y sobre todo con las fuentes de sal. Se ha elegido en la primera fase del proyecto un espacio reducido con vistas a realizar una prospección minuciosa que permitiese establecer una primeras pautas.

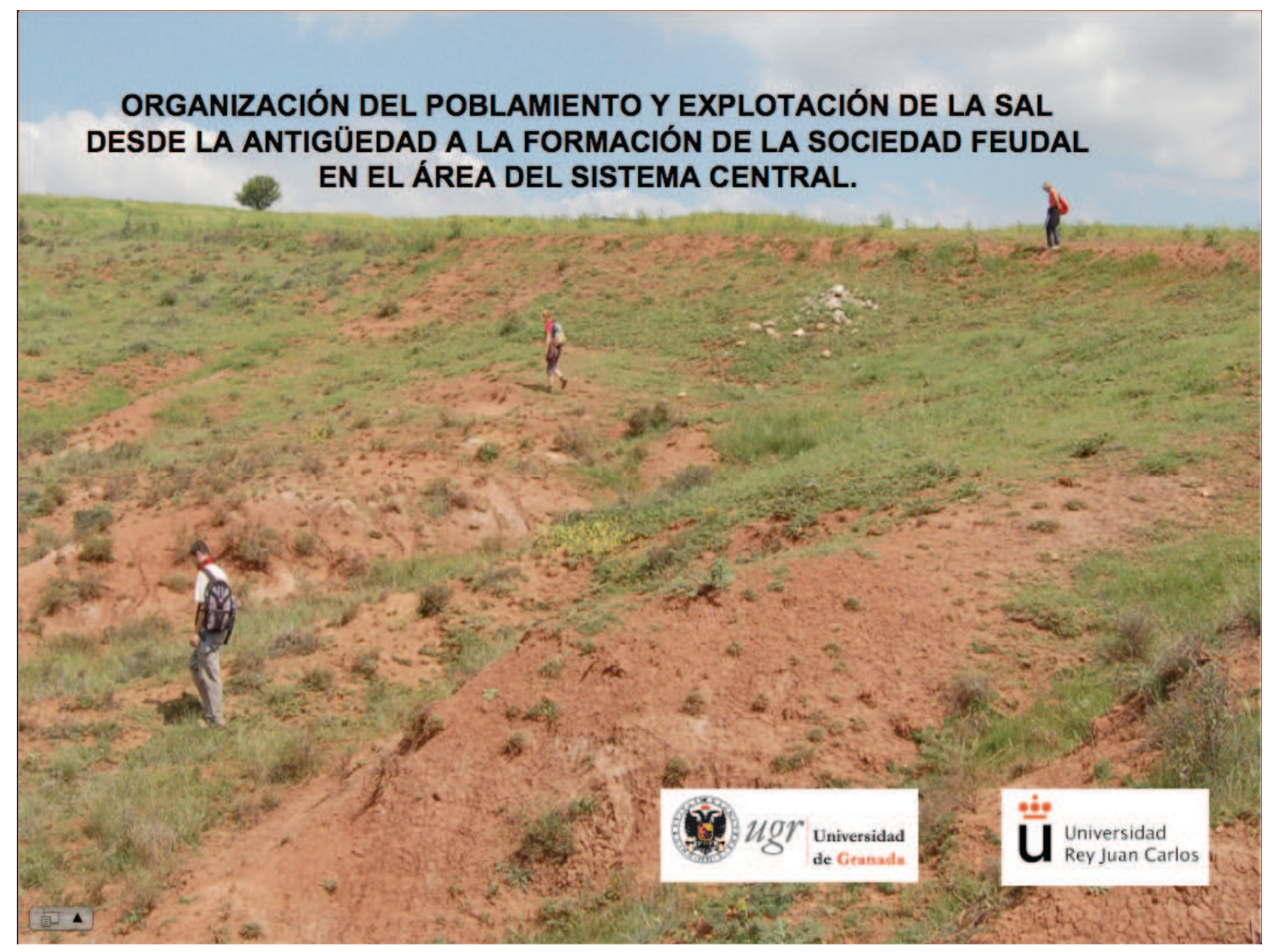

\footnotetext{
${ }^{1}$ Proyecto de investigación I+D titulado «Organización del territorio y explotación de la sal desde la Tardía Antigüedad a la formación de la sociedad feudal en el área del Sistema Central: zonas de Guadalajara y Madrid» (HUM 2007-66118/HIST), dirigido por Antonio Malpica Cuello.

2 MalpiCA Cuello, Antonio, «Análisis de las salinas medievales desde la Arqueología del Paisaje» en MorÈre Molinero, Nuria (ed.) (2008) Las salinas y la sal de interior ..., pp. 469-498.
} 
Entre junio y octubre se han llevado a cabo estudios en el valle del río Salado $^{3}$ y un reconocimiento general del territorio en que se enmarca ${ }^{4}$. La prospección arqueológica llevada a cabo en 2008 es la primera fase del proyecto. Se ha seleccionado el tramo completo del río desde sus orígenes (en torno a La Laguna como dijimos) hasta la confluencia y derivación en las aguas del Henares, en la localidad de Baides, tras el paso por los vericuetos cársticos de la región de Santamera, donde afloran, masivas, las calizas terciarias que dieron cobijo a algunas de las más antiguas ocupaciones humanas del valle ${ }^{5}$. Decidimos marcar, además, todo un territorio natural que implicase igualmente a las principales corrientes tributarias del río Salado por sus dos orillas, algunas saladas también, puesto que el territorio debe configurarse no sólo ante la aparente explotación de los esteros salinos, sino también alrededor de las fuentes dulces que garantizan la continuidad del poblamiento. De esta manera el sector considerado para los trabajos de prospección arqueológica durante el año 2008 se situó básicamente en el municipio de Sigüenza (Guadalajara) y en 17 de sus pedanías, así como en municipios como La Olmeda, Paredes, o el mismo Baides, como confluencia final.

En un área en el que este recurso es tan abundante, la explotación salinera ha debido generar, sin duda, mecanismos de organización del territorio y también de los asentamientos. Pero no es fácil discernir esa relación, ya que si observamos, al menos en el estado actual de nuestra investigación, la existencia de yacimientos arqueológicos, que, lógicamente, representan una ocupación humana en ese espacio, el grado de intervención en los recursos salineros estaría por determinar. En cualquier caso, consideramos que este debe ser el primer paso, el de relacionar los asentamientos con las salinas.

No fijamos nuestra atención en todos los recursos disponibles, sino fundamentalmente en la sal. Qué duda cabe que hay otros que deberíamos introducir, y lo hacemos, aunque no de manera principal, sino de forma secundaria. En tal sentido, sin salir siquiera del tema de la sal, introducimos, sobre todo teniendo en cuenta la peculiaridad que imprimen a su paisaje, el tema de la existencia de prados halófilos, al igual que hablamos de la disponibilidad de agua dulce, esencial para los seres vivos. No nos vamos a detener, sin embargo, en el estudio de toda la infraestructura hidráulica que está por hacer. Quedan otros muchos recursos que tratar (minería, por ejemplo), pero en el estado actual en que se haya nuestro proyecto y contando con los puntos de partida no se ha considerado aconsejable incluirlos.

\footnotetext{
${ }^{3}$ Las dos campañas de prospección arqueológica se han llevado a cabo en junio y en octubre del año 2008, bajo la dirección de Nuria Morère Molinero y Jesús Jiménez Guijarro, y con la participación de Alberto García Porras, Guillermo García-Contreras Ruiz, Ángel González Escudero, Teresa Koffler Urbano y Pilar Sánchez Duarte.

${ }^{4}$ Se llevó a cabo en septiembre de 2008 por Antonio Malpica Cuello.

${ }^{5}$ Valiente Malla, Jesús, «El Abrigo de Peña Corva en Santamera, Riofrío del Llano, Guadalajara», Wad Al Hayara, 11 (1984), pp. 289-312.
} 
Vamos a describir ahora los distintos asentamientos que han sido hallados en el curso de las prospecciones arqueológicas. Hemos decidido en el presente caso, atendiendo a la dinámica del proyecto y a los primeros resultados que ya se han presentado ${ }^{6}$, limitarnos a la Alta Edad Media, más específicamente al período que va desde el siglo VIII al XI, ya que para los momentos anteriores aún no tenemos datos certeros. Aún no podemos valorar suficientemente la organización de los asentamientos de época visigoda, ya que apenas se han localizado evidencias directamente relacionadas con este período, salvo la posible existencia de algunas necrópolis ${ }^{7}$ y cierta tradición formal en algunas ermitas e iglesias de la zona, hábitats rupestres cuyo prototipo puede ser el de Torre Morenglos, Tordelrábano $^{8}$, y pensamos que en ese sentido una parte del registro arqueológico cristiano de más compleja caracterización podría asociarse a este momento. En ese sentido, se produciría un desplazamiento espacial del hábitat, de la vega, característico de la época romana, hacia algunas zonas elevaciones del llano en su conexión ya con la media ladera, con continuidad en la Alta Edad Media. Algunas noticias más tenemos a partir de las fuentes escritas, aunque se ciñe al listado de obispos que ocuparon la sede seguntina y que aparecen citados en los concilios toledanos ${ }^{9}$. Desconocemos por tanto si en este espacio concreto hay una continuidad en los lugares de hábitat o no. Lo cierto es que en aquellos espacios en los que hemos identificado ocupación del siglo VIII en adelante, no hemos documentado cerámicas de épocas anteriores. El proceso de feudalización posterior a la conquista del territorio seguntino, que tiene como fecha inicial 1124, ha dejado una organización espacial muy distinta y una reordenación de los núcleos habitados que requieren un tratamiento aparte y que queda para otra ocasión. Por lo tanto, aún no estamos en condiciones de poder realizar una valoración global sobre el poblamiento en época medieval, ya que el proyecto que estamos llevando a cabo aún se encuentra en un estadio inicial. No obstante, si que podemos

\footnotetext{
${ }^{6}$ Malpica Cuello, Antonio, Morère Molinero, Nuria, FÁBregas García, Adela y JimÉnez GUIJARRO, Jesús, «Organización del territorio y explotación de la sal en el área del Río Salado (Sigüenza, Guadalajara, España): Antigüedad y Edad Media. Resultados de la I Campaña 2008», Actas del XI Encuentro de Historiadores del valle del Henares, Guadalajara, 2008, pp. 49-62; Malpica Cuello, Antonio, Morère Molinero, Nuria, Jiménez Guijarro, Jesús y García-Contreras Ruiz, Guillermo, «Paisajes de la sal en la Meseta castellana desde la Prehistoria a la Edad Media», X Jornadas de Arqueología Medieval: Paisajes históricos y Arqueología Medieval, Granada, 2009 (En prensa).

${ }^{7}$ Sobre este tema vid. MoRĖRE Molinero, Nuria, Carta Arqueológica de la provincia segutina. Madrid, 1984. Referente a la necrópolis visigoda de «El Altillo de la Horca» en Palazuelos, fechada por sus materiales en el siglo VII p. 45; en cuanto a la necrópolis de «Los Casares» en Garbajosa p. 18; y la del «Cerrillo de los Moros» en Horna p. 44.

${ }^{8}$ DAZA PARDO, Enrique, «Formas de ocupación rural en la Sierra Norte de Guadalajara (siglos V-X). E1 despoblado de Morenglos (Alcolea de las Peñas, Guadalajara)», Cuadernos de Prehistoria y Arqueología de la Universidad Autónoma de Madrid, 31-32 (2005-2006); pp. 195-218; Idem, «Elementos para el estudio de la Arqueología altomedieval en la Sierra Norte de Guadalajara. Monacato, edilicia y poblamiento», en lópez Quiroga, J.; Martínez Tejera, A. M., y Morín de Pablos, J. (Eds), Monasterio e Territorio. Elites, edilicia y territorio en el Mediterráneo medieval (siglos V-XI), BAR Internacional Series S1720, 2007, pp. 399-408.

9 Olea Álvarez, Pedro, «Presencia de Sigüenza en los concilios ecuménicos medievales», Análes Seguntinos, 1-3 (1986), pp. 45-65; VALLEJo GIRVÉs, Margarita, «Notas sobre el obispado de Segontia en época visigoda», Wad-al-Hayara, 20 (1993), pp. 365-375.
} 
señalar varias cuestiones que nos parecen importantes a la hora de valorar la evolución del paisaje histórico de la sal en esta región.

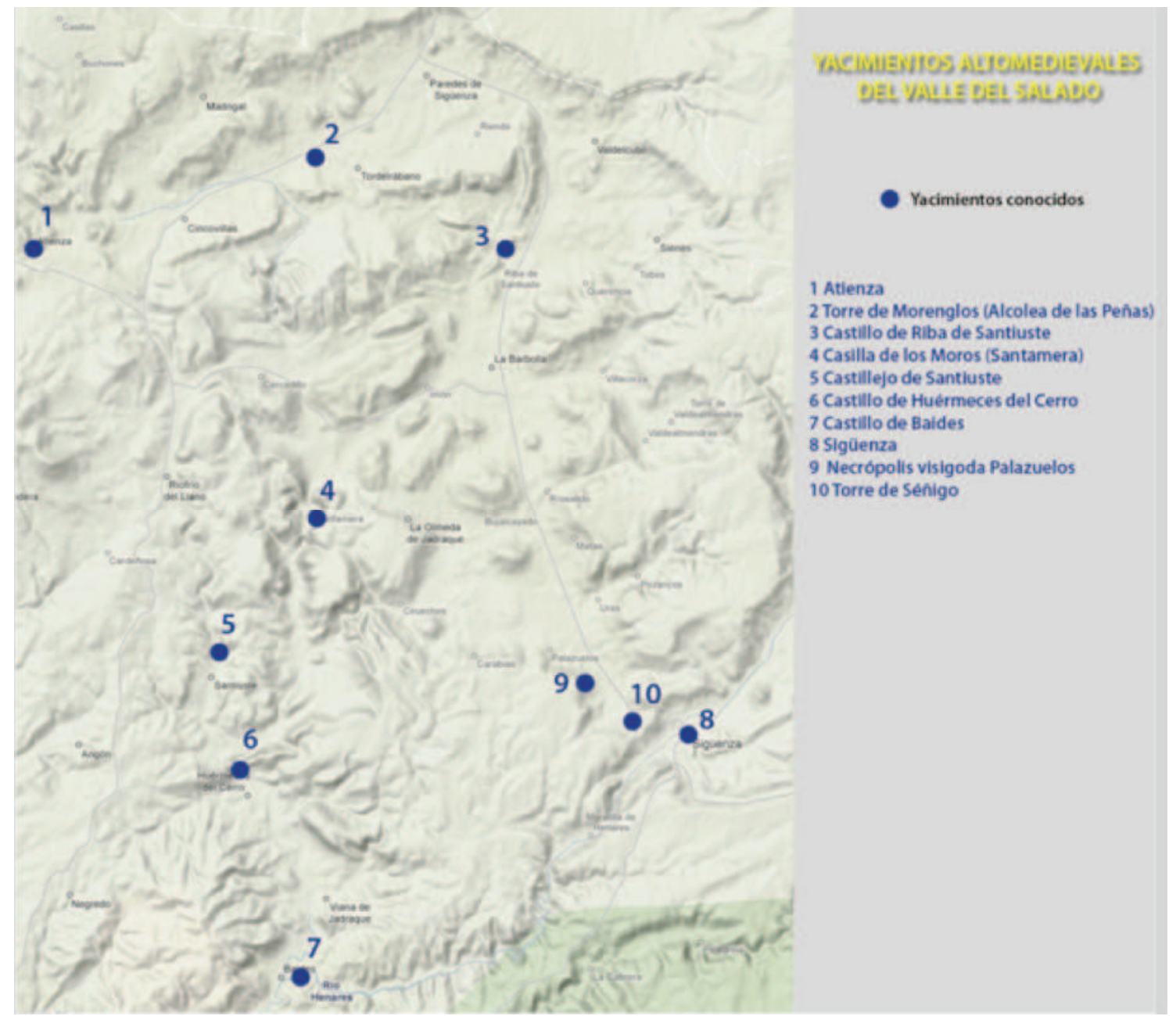

Yacimientos citados en la bibliografía como pertenecientes al período andalusí

En primer lugar, hemos de señalar que somos conscientes de estar ofreciendo una imagen un tanto estática de lo que debió ser un poblamiento mucho más dinámico. No obstante, el estado actual de nuestros conocimientos, fruto del trabajo de prospecciones arqueológicas y el estudio del material cerámico, no nos permite llegar más allá por el momento.

En el momento islámico que ahora nos interesa, hemos detectado una cierta proliferación de asentamientos, con hábitat situado en zonas de media ladera junto a los cursos hídricos dulces, principalmente manantiales, y próximo también a surgencias salinas, con las que parecen guardar una cierta relación. El estudio que se está llevando a cabo a partir de los materiales cerámicos parece fijar el origen de estos asentamientos en torno a mediados del siglo IX, como ya expondremos más adelante ${ }^{10}$. En este

${ }^{10}$ GARCÍA-CONTRERAS RUIZ, Guillermo «Primera aproximación a la cerámica altomedieval del valle del Salado (Sigüenza, Guadalajara)» en GARCÍA PORRAS, Alberto (ed.), Actas del II Taller de cerámica: Cerámica medieval e Historia económica y social: problemas de método y casos de estudio, Granada, 
momento parece establecerse y consolidarse el poblamiento andalusí basado en pequeñas explotaciones asociadas a un modelo político caracterizado por la notable ausencia de un fuerte poder central. El poder, no obstante, se hace visible a través de la presencia de distintos castillos y una densa red de torreones. El hábitat militar, del que podemos poner como ejemplos los castillos de Riba de Santiuste y Baides, aparece situado en altozanos con un gran valor defensivo y sentido estratégico y de control de amplios territorios a cuyos pies, normalmente, se desarrolla una suerte de arrabal en el que se debía concentrar, a tenor de los vestigios recuperados, el sistema principal de producción.

Vamos a ir viendo todo esto de manera más detallada mediante la descripción de cada uno de los yacimientos arqueológicos localizados. El catálogo que presentamos es el resultado del trabajo de campo que hemos desarrollado. No hemos tomado en consideración aquellos yacimientos que son mencionados en la bibliografía como adscritos a este período a menos que tengamos seguridad, por la rigurosidad de su estudio o por una comprobación por nuestra parte, de que estos yacimientos pertenecen a este período. Antes de iniciar la campaña de prospecciones, se citaban en nuestro territorio una decena de yacimientos fechados en esta época, bien por referencias documentales o bien por ciertos trabajos arqueológicos que se habían efectuado ${ }^{11}$. De éstos, hemos descartado algunos asentamientos como los de Alcolea de las Peñas ${ }^{12}$, Torre Morenglos ${ }^{13}$ o el poblado de «Casuto de los Moros» de Santamera ${ }^{14}$, ya que en

2009 (en prensa); y «Aportación al estudio de la cerámica andalusí en la Marca Media: el valle del Salado (Sigüenza, Guadalajara)» en Jornada Internacional sobre metodología de análisis de la cerámica tardoantigua y medieval, León, 2009 (en prensa).

${ }^{11}$ Morère Molinero, Nuria, Carta arqueológica... cap. III «Hallazgos arqueológicos en torno al río Henares y sus afluentes», pp. 23-65, Idem, «Dos conjuntos de tumbas antropomorfas de la Meseta Sur: Provincias de Guadalajara y Madrid», Actas del I Congreso de Arqueología Medieval Española. Zaragoza, 1986, t. V, pp. 276-288; Retuerce Velasco, Manuel, «Carta arqueológica de la Meseta andalusí según el referente cerámico» Boletín de Arqueología Medieval, 8 (1994); pp. 7-110; Idem, «Arqueología y poblamiento en la Meseta andalusí. El referente cerámico», V Semana de estudios Medievales. Nájera, 1 al 5 de agosto de 1994. Logroño, 1995, pp. 87-124; DAZA PARdo, Enrique, «Formas de ocupación rural...»; Idem, «Elementos para el estudio...», Idem, «Los castillos olvidados. El papel de los asentamientos fortificados en altura en la génesis del poblamiento altomedieval del valle del Henares (siglos VII-XII)» Castillos de España, 148 (Diciembre 2007), pp. 13-25.

${ }^{12}$ El yacimiento conocido como «La carcel» o simplemente el castillo de Alcolea de las Peñas es citado como de época islámica, sin que hasta el momento haya constancia de ninguna intervención arqueológica o cita en la documentación escrita que así lo certifique. Se trata de una peña arenisca horadada en su interior con galerías y cámaras, que exteriormente presenta abundantes rebajes y rozas de cimentación para la colocación de muros y estructuras en madera. En la parte baja de la roca, además, se localizan abundantes restos de viviendas semi-excavadas en la roca, rozas de cimentación etc. Aunque tanto la toponimia del municipio, «Alcolea», como la ubicación, que podría relacionarse con uno de los asentamientos en el llano que después mencionaremos, puede hacernos sospechar un origen andalusí, no tenemos datos certeros para incluirlo como uno de los asentamientos en cueva de la época, por lo que no será tenido en consideración. Sobre su mención como fortificación altomedieval, vid. DAZA PARDO, Enrique, «Los castillos olvidados. El papel de los asentamientos fortificados en altura en la génesis del poblamiento altomedieval del valle del Henares (siglos VII-XII)» Castillos de España, 148 (Diciembre 2007), pp. 22-23.

${ }^{13}$ DAZA PARDO, Enrique, «Formas de ocupación rural...»

${ }^{14}$ Valiente Malla, Jesús, Guía de la Arqueología en Guadalajara, Guadalajara, 1997, p. 66. 
uno y otro caso no tenemos seguridad de su adscripción al período andalusí al no haberse publicado materiales, ni cerámicos ni de otro tipo, que nos aseguren su adscripción al período.. Otro de los asentamientos tradicionalmente adscrito a la Alta Edad Media en el valle es el de la Torre de Séñigo, conocida popularmente como un asentamiento visigodo. El reconocimiento que hicimos de este yacimiento, así como las referencias que encontramos en las fuentes escritas, nos indican que se trata de un modelo de aldea con fortificación propio de la Baja Edad Media, por lo que no forma parte de nuestro catálogo de yacimientos ${ }^{15}$. También hemos dejado fuera otros yacimientos situados en el marco geográfico del valle del Salado en el catálogo que presentamos, si bien éstos, entre los que se encuentran los castillos de Huérmeces o Santiuste, si serán tomados en consideración en las valoraciones que hagamos sobre la organización del poblamiento

Finalmente indicar que en esta ocasión no hemos querido entrar a valorar y contrastar todo el estudio de la documentación escrita que, dentro del proyecto, se ha llevado a cabo $^{16}$, aunque inevitablemente hagamos mención a las fuentes de archivo cuando lo creamos necesario. A priori, la contrastación entre la documentación escrita generada tras la conquista castellana y los resultados de la prospección arqueológica parece un problema de difícil resolución que merece un tratamiento individualizado y que debe ser abordado como un trabajo distinto a éste.

Para la elaboración de este catálogo seguimos las siguientes pautas:

- Nombre: Nombre que se le ha dado al yacimiento en virtud de la toponimia que se refleje en la cartografía. En los casos en los que no hay ningún nombre, se le ha asignado uno atendiendo a su caracterización topográfica y al municipio al que pertenece.

- Localización: Término municipal al que pertenece, ubicación geográfica y vías de acceso que tiene el yacimiento.

- Siglas: Las iniciales con las que el yacimiento ha sido identificado en el conjunto de la prospección arqueológica, que sirven además para identificar los materiales recogidos. Llevan el prefijo asignado a la actividad por el servicio territorial de arqueología de Guadalajara, MG08/069, seguido de las iniciales del término municipal y un número de yacimiento. En ocasiones un mismo lugar se ha identificado con distintas siglas ya que se ha optado por diferenciar diversas áreas en la prospección.

\footnotetext{
${ }^{15}$ El primer documento en el que se cita la Aldea de Séñigo es de 1180, por lo que es probable también un origen anterior al siglo XII, de época altomedieval. Vid. Minguella, Toribio, Historia de la diócesis de Sigüenza y sus obispos, Madrid, 1910, t. 1, p. 442. No obstante, en las prospecciones llevadas a cabo, no se ha hallado material anterior al siglo XII, por lo que no podemos asegurar que sea un núcleo de población anterior. No será, como decimos, tenido en cuenta en nuestro análisis.

${ }^{16}$ El estudio de la documentación de archivo, sobre todo del archivo episcopal de Sigüenza, dentro del citado proyecto lo está realizando Adela Fábregas García.
} 
- Coordenadas: Coordenadas UTM del yacimiento. Se tomaron en el trabajo de campo eligiendo un punto central del asentamiento o aquel más significativo por una mayor concentración de materiales o por alguna estructura de mayor envergadura.

- Tipo de yacimiento: Para clasificar los yacimientos se ha seguido una pauta sencilla, atendiendo a su topografía y a las características físicas del mismo. Se individualizan así: asentamientos en el llano, asentamientos de altura, asentamientos en media ladera y cuevas $^{17}$. También se designó como categoría para los asentamientos la torre, si bien no hemos encontrado ninguna en las prospecciones arqueológicas.

- Estado actual: Situación del asentamiento en el momento de su prospección, si el lugar ha sido reocupado con posterioridad por otro tipo de estructuras, que procesos se pueden detectar en él, como remociones o actuación de expoliadores, y que grado de conocimiento se tenía del mismo antes de su identificación en el trabajo de campo que hemos llevado a cabo.

- Descripción del yacimiento: Somera descripción del yacimiento a partir de los datos tomados durante las campañas de investigación arqueológica, haciendo referencia a estudios anteriores que hayamos encontrado en la bibliografía.

- Relación con el medio físico y el recurso salino: También de una manera breve, tratamos de relacionar el asentamiento con el medio físico más inmediato en el que se inserta, que potenciales recursos naturales han podido ser utilizados y que tipo de asociación se puede establecer entre él y los recursos salinos de su entorno.

- Propuesta de interpretación: Como resultado de todo lo anterior, se trata de establecer finalmente una hipótesis de funcionamiento del asentamiento dentro de la red de poblamiento de todo el valle.

Finalmente indicar que el orden que se ha seguido para la descripción de los distintos asentamientos es básicamente el eje de norte a sur que sigue el propio curso del río Salado.

\footnotetext{
${ }^{17}$ Se trata, grosso modo, de la misma división adoptada en la Carta Arqueológica de la Región. MORÉRE Molinero, Nuria, Carta Arqueológica ... pp. 23-61.
} 
CATÁLOGO de YACIMIENTOS ARQUEOLÓGICOS ALTOMEDIEVALES DEL VALLE Del SAlado (ATIENZA-SigüENZA) 


\section{Nombre LLANO DE LOS PERICALES}

Localización Alcolea de las Peñas. Acceso a pie desde la carretera que se adentra en el pueblo de Alcolea de las Peñas en el km 91 de la CM-101

Siglas MG08/069/ALPE-05

Coordenadas 3005180664562719

Tipo de yacimiento Asentamiento en el llano

Estado actual Amplia zona de cultivo que ha enterrado el yacimiento. Los materiales afloran en las zonas en barbecho donde la tierra se ha roturado. En la parte sur se detectan varias líneas de muros de mampostería. El lugar queda rodeado por dos carreteras, al norte la CM-101, en el km 91 aproximadamente, y al oeste la carretera que permite acceder al pueblo de Alcolea de las Peñas.

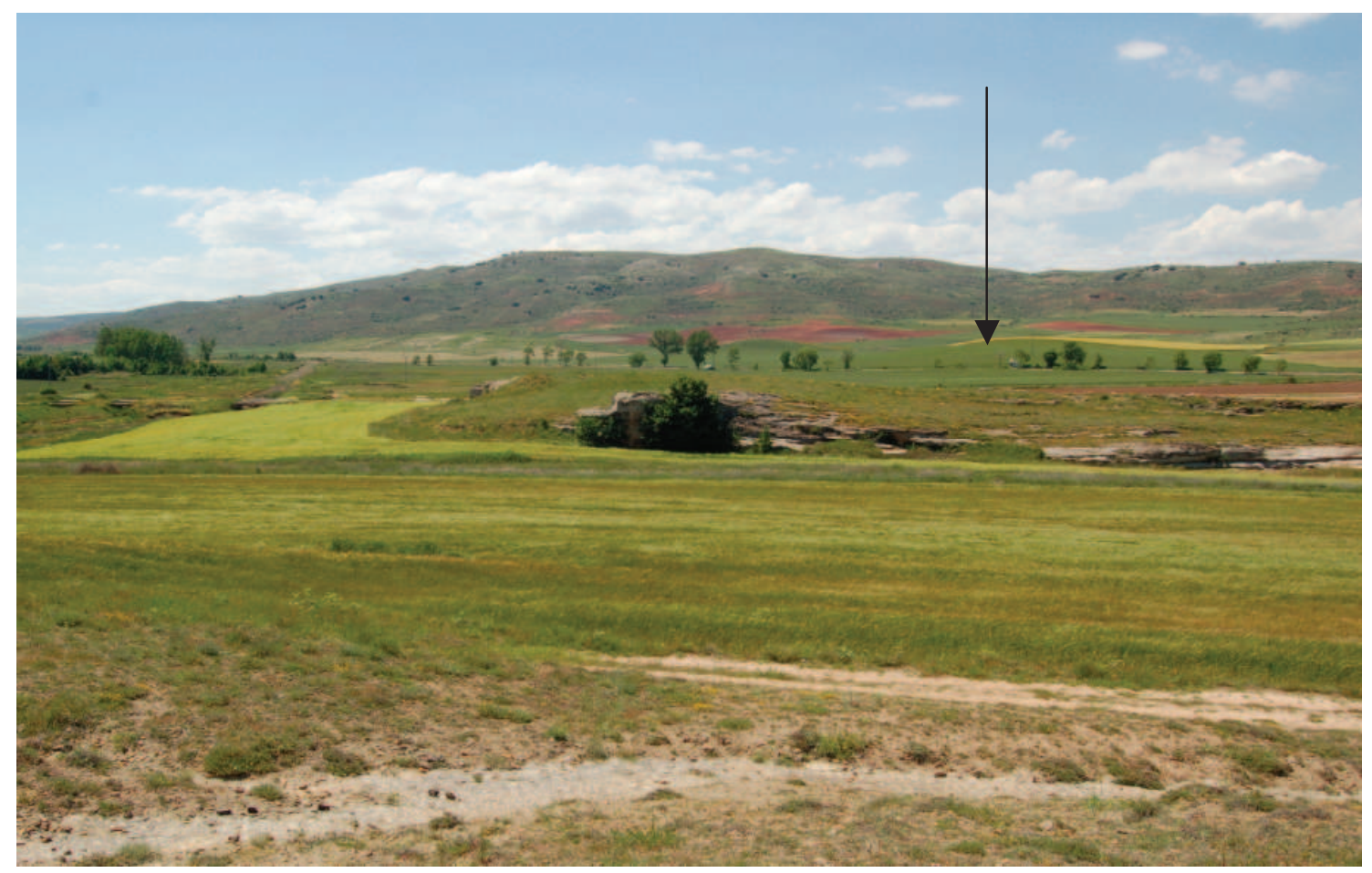

Imagen de la zona prospectada indicando la elevación donde se halla el asentamiento

Descripción del yacimiento En dirección Oeste, aproximadamente a unos $700 \mathrm{~m}$ del yacimiento de Torre de Morenglos se identificó una zona elevada y amesetada, con una pendiente suave hacia el norte y un fuerte corte en la roca hacia el Oeste, quedando el Sur también cortado de forma abrupta por el afloramiento rocoso. Tiene una altitud aproximada de 1000 metros.

En este espacio se identificaron dos núcleos diferenciados. Por un lado Los Pericales-1 (GU-ALPE-05) que corresponde a la parte superior y prominente, donde se encontró un elevado volumen de cerámicas de época altomedieval y del Bronce, especialmente en la parte Sur de la zona amesetada y en un segundo nivel algo más bajo que también quedaba al sur, separado de la parte superior por un corte en el terreno. En este corte se 
pueden observar varias líneas de muros de mampostería muy arrasados con algunos recrecimientos que sirven hoy día para retener las tierras de cultivo, y que probablemente hayan sido reaprovechados.
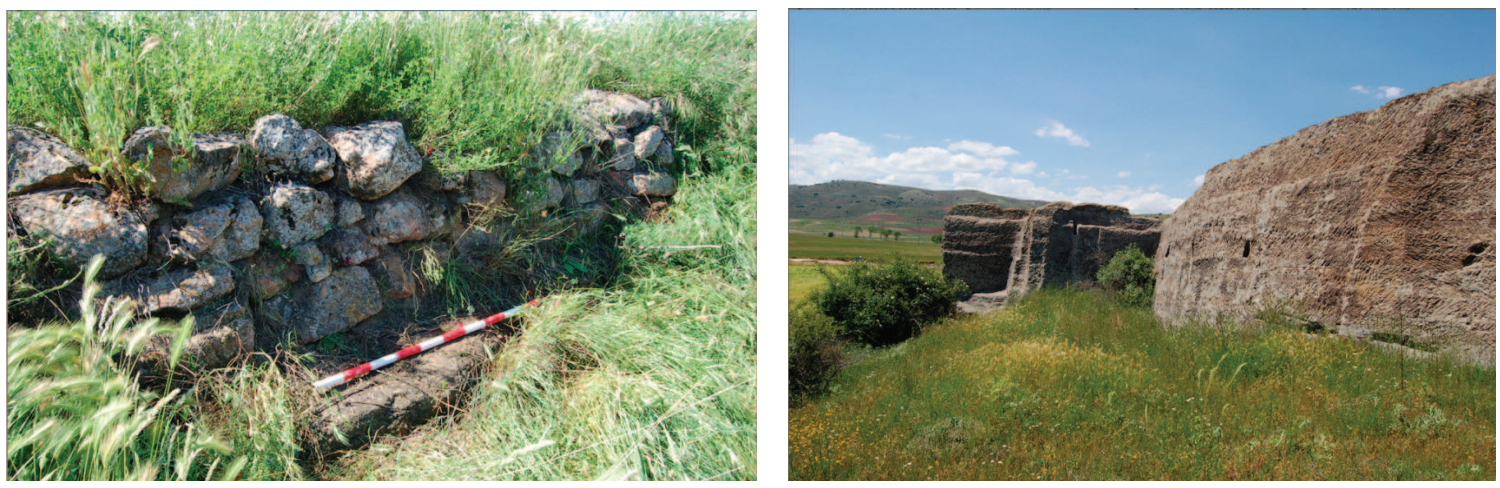

Restos de los muros hallados y de la cantera de piedra

En la parte oeste del promontorio amesetado hay restos de una cantera de piedra de grandes dimensiones. Se ha identificado como un núcleo distinto (GU-ALPE-06) Varios tramos de paredes rectas con abundantes huellas del picado de la roca, así como huecos en la parte superior probablemente de cuñas de madera para hacer saltar los bloques. También hay que llamar la atención sobre una serie de huecos en la parte superior, casi en el límite de la cantera, que pudieran corresponder a tumbas rupestres o a cubetas de decantación.

Relación con el medio físico y el recurso salino El yacimiento se encuentra en la parte llana, en una zona óptima para el cultivo, y con una cierta elevación que le permite un buen control visual del valle. En su entorno se detectaron varias fuentes de agua dulce, sobre todo en el pie de monte que queda al sur; pero el principal recurso hídrico es el del río Alcolea, que pasa entre el propio afloramiento y la sierra de El Perical que queda al sur antes de encajonarse por el estrecho paso de Alcolea de las Peñas. Se han detectado algunas obras de embalsamiento de este río en el entorno del yacimiento, sin que se pueda fechar el momento de su construcción.

Aproximadamente a 200 metros al norte de la superficie amesetada en la que se encuentra el asentamiento se localizan los restos de una explotación salina, de la que sólo quedan los restos visibles de lo que debieron ser las albercas de evaporación y los canales de derivación, pero sin que se observe ninguna construcción en el entorno. Tan sólo queda la huella en el paisaje ante la abundante vegetación halófila y las zonas embarradas en las que aún hoy se pueden recoger costras saladas. 
Propuesta de interpretación Dejando a un lado la fase de ocupación prehistórica que se detecta ${ }^{18}$, el asentamiento parece corresponder a una época muy temprana de la Edad Media, siendo quizás el único ejemplo de asentamiento visigodo que hemos encontrado. De ser así, y de confirmarse la datación tardorromana-altomedieval del asentamiento de Torre de Morenglos, el llano de los Pericales formaría parte de la ocupación en el llano de esta época, con una explotación agrícola del entorno del valle y ganadera del pie de monte de la serranía que queda al sur, que se mantendría durante el período andalusí, que es cuando se tiene una certeza mayor de la ocupación del lugar por el estudio cerámico que hemos elaborado. En la fase de ocupación andalusí habría que relacionar este asentamiento en el llano con la cueva fortificada de Alcolea de las Peñas, en el caso de que, al igual que Torre de Morenglos, pudiese certificase su adscripción cronológica a este período ${ }^{19}$. En cualquier caso, este asentamiento se abandonaría, no obstante, en un momento temprano de la ocupación andalusí, ya que no aparecen formas que con claridad podamos fechar del siglo $\mathrm{X}$ en adelante.

\footnotetext{
${ }^{18}$ Esta fase prehistórica está relacionada con el yacimiento de los Pericales, inmediatamente por encima del nuestro y excavado en los años '70, así como con la necrópolis de Valdenovillos y el cerro Otero excavados por el Marqués de Cerralbo a principios del siglo XX CERdeño SERRANO, M ${ }^{a}$ Luisa, «Notas sobre algunas cerámicas campaniformes de Alcolea de las Peñas (Guadalajara)», Wad-al-Hayara, 5 (1978), pp. 35-47.

${ }^{19}$ DAZA PARDO, Enrique, «Los castillos olvidados...», pp. 22-23.
} 


\section{Nombre CUEVAS DE LOS POYATOS Y LAS CONEJERAS}

Localización Paredes de Sigüenza. El primero está a 400 metros y el segundo a 700 metros en dirección norte entre los kilómetros 10 y 11 de la Carretera comarcal Sigüenza-Atienza (C-110)

Siglas MG08/069/PAS-16, MG08/069/PAS-17 y MG08/069/PAS-18

Coordenadas 3005239534565948 y 3005240564566303 Precisión 4 m

Tipo de yacimiento Cuevas

Estado actual Zona de monte con cultivos en los alrededores, las cuevas han sido usadas por pastores y por animales hasta el momento reciente. Se han removido algunas zonas para acondicionar el interior de las cuevas y hay indicios de hogueras.

Descripción del yacimiento Ambas cuevas se sitúan en sendos cerros amesetados, separados entre sí 200 metros por una vaguada, y con unas alturas respectivas de 1033 y 1025 m. En ambos casos, las cuevas están abiertas en dirección sur-sureste. Se han diferenciado tres zonas en la prospección, por un lado el pie de monte y media ladera del cerro que queda más al sur, por otro la cueva de los Poyaros y en tercer lugar todo el cerro de Las Conejeras que es el que queda más al norte de los dos.

En la ladera oeste del primer cerro había un bancal y por debajo fragmentos de teja y cerámica vidriada, tal vez moderna (alguna puede ser de arrastre) Se ven grandes bloques calizos. También se incluye en esta unidad de prospección la terraza en la ladera SE, entre afloramientos rocosos, donde se recogió algo más de cerámica y teja de similar adscripción.

En cuanto a Las Conejeras es un cerro amesetado de roca caliza, en cuya ladera hay varias cuevas horadadas en la roca caliza o aprovechando oquedades de ésta. Destaca una de ellas de gran tamaño, perfectamente acondicionada, con dos estancias, mampuestos para tapiar los huecos que dan al exterior, y una estructura para recepción y almacenaje de agua de lluvia. Control visual del valle, la cueva está orientada al sur.

Hay cerámica vidriada a media ladera, y cerámica grisácea a torneta, tal vez altomedieval.

Entre GU-PAS-16/GU-PAS-17 y GU-PAS-18 se recogió cerámica de cronología algo más moderna Entre los dos cerros hay un camino fosilizado delimitado por mampuestos, del que no queda más que este tramo, que no parece conducir a ningún sitio. 


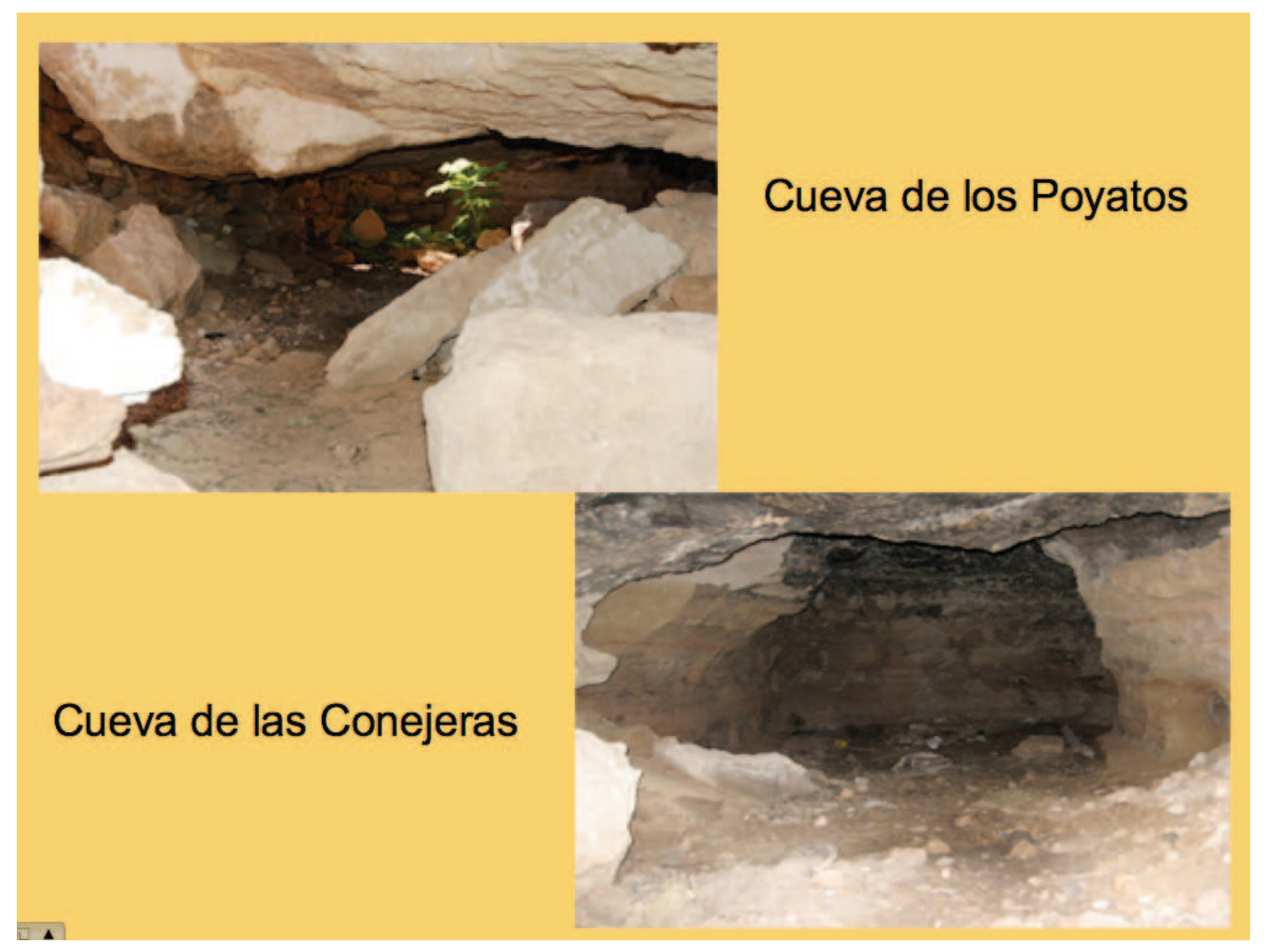

Relación con el medio físico y el recurso salino Las cuevas se sitúan en la entrada al valle del río Salado, justo donde el terreno se estrecha, en la parte baja de los Altos de Barahona. Las estribaciones de estos altos dan lugar a pequeños y estrechos valles de alguna forma independientes entre sí, que se abren hacia el valle principal del río Salado por el sur. Como toda la zona, guarda unas relaciones óptimas para la práctica de la agricultura de secano, y se pueden aprovechar diferentes torrenteras que se forman en la pendiente del monte. Toda la zona más al sur de este conjunto de montes es un área relativamente pantanosa con abundancia de pequeñas lagunas endorreicas con una alta concentración salina. De hecho en dirección sureste, a 1,5 km y a 2,4 km se sitúan respectivamente las salinas de Paredes de Sigüenza y de Rienda, ambas abandonadas en la actualidad.

Propuesta de interpretación Junto con la cueva de las Calzadizas forma el conjunto de habitat rupestre que se ha identificado como adscrito al período altomedieval en esta zona norte del valle, conjunto al que se podría añadir la cueva de Valdelcubo, aunque queda algo más alejada. Aprovechan la oquedades de la roca caliza para acondionarlas aún más, algo especialmente notable en el caso de la cueva del cerro de Las Conejeras, en el que se ha documentado incluso un ingenioso sistema para la captación y almacenamiento del agua de lluvia. También en el interior de las cuevas aparecen estructuras excavadas en la roca, a modo de estantes. No es extraño pensar en un uso fundamentalmente ganadero de este tipo de espacios, si bien en el ámbito de la Sierra 
Norte de Guadalajara, una serie de investigaciones han puesto el acento en su probable relación con fenómenos eremíticos ${ }^{20}$. Es difícil asegurarlo en el caso de las localizadas por nosotros en la prospección arqueológica. No obstante, es probable que se trate de centros asociados a actividades ganaderas en línea con lo que ocurría en el período altomedieval en los primeros monasterios castellano-leoneses ${ }^{21}$.

\footnotetext{
${ }^{20}$ DAZA PARDO, Enrique, «Elementos para el estudio...», p. 400.

${ }^{21}$ Acerca de la propiedad ganadera y su relación con instituciones religiosas, como los monasterios, vid. MíngueZ FernánDEZ, José Domingo, El monasterio de Sahagún en el siglo X. Paisajes agrarios, producción y expansión económica, Salamanca, 1980.
} 


\section{Nombre CUEVA DE LAS CALZADIZAS O DE LAS VIÑAS}

Localización Paredes de Sigüenza. Se accede por un camino rural que parte desde el $\mathrm{km}$ 9,5 de la carretera comarcal Sigüenza-Atienza (C-110) en dirección norte. El camino está prácticamente borrado, pero es fácil de identificar ya que lleva directamente a un cortijo situado en las faldas de los Altos de Barahona

Siglas MG08/069/PAS-16

Coordenadas 3005248524566229 Precisión $4 \mathrm{~m}$

\section{Tipo de yacimiento Cueva}

Estado actual Relacionada con el cortijo que queda apenas unos metros al norte, la cueva ha sido usada hasta fechas muy recientes como corral para el ganado. Para tal fin, se ha acondicionado toda la entrada mediante una serie de muros de mampostería, aprovechando también las diversas oquedades del promontorio rocoso.

Descripción del yacimiento Cueva de importantes dimensiones excavada en la roca caliza, donde se observan las huellas de la talla. La cueva está abierta hacia el sur, como las de Los Poyatos y Las Conejeras. Una serie de estructuras rodean la boca de la cueva, conformando un conjunto algo mas complejo que la sola cueva. Algunas zonas están cubiertas de tejas, aunque estas han caído y todo el conjunto presenta un estado ruinoso. Hay mampostería a hueso hasta los 2,5 m de altura.

La cueva se ve trabajada, observándose restos de talla para hacerla más grande y para suavizar las aristas. Hay agujeros artificiales tanto en la entrada como a mitad de la cueva, quizás para fijar en ellos una puerta a modo de quicialera. Hay también restos de su uso más reciente. Aparece cerámica bastante moderna, salvo en una zona en la parte alta y amesetada del promontorio calizo, sobre la cueva, donde se hallaron algunas piezas grises a torneta y otras de pastas algo más claras, que nos permiten aventurar una ocupación en época andalusí.

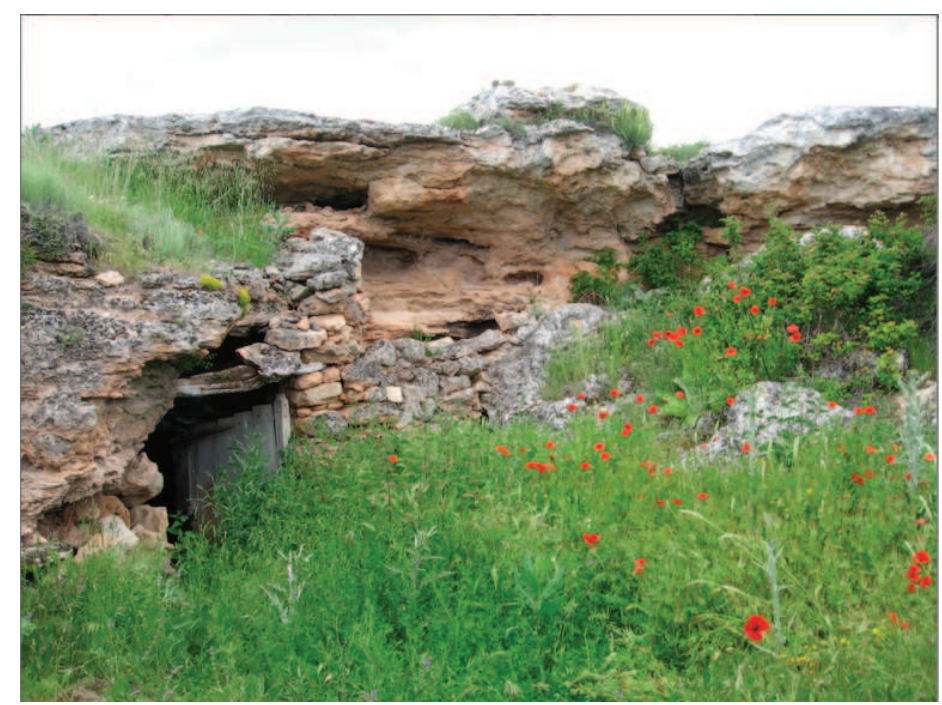

Entrada a la cueva y estructuras en las inmediaciones. En la parte superior se recogieron las cerámicas 
Relación con el medio físico y el recurso salino Al igual que en el caso de las cuevas de Los Poyatos y Las Conejeras, se sitúa en un pequeño valle formado por las estribaciones de los Altos de Barahona, abierto por el sur hacia el valle del Salado. La zona presenta, no obstante, peores condiciones para la agricultura por el elevado número de pequeñas elevaciones, si bien hay mejores condiciones hídricas debido a la existencia de dos fuentes en el pie de monte: la de La Zapata, al este del cortijo, y otra sin nombre situada algo más al norte. Llamar la atención sobre la existencia del topónimo «Las Viñas» en la cartografía, aunque en la actualidad no existe este tipo de explotación en el entorno. Al igual que el conjunto de cuevas anterior, del que dista apenas un centenar de metros, se encuentra en una de las áreas de mayor concentración salina, siendo más abundantes en esta zona los prados halófilos que las zonas endorreicas.

Propuesta de interpretación Al igual que en el caso anterior, se trata de una cueva con un uso ganadero probado hasta fechas muy recientes, pero que presenta una serie de obras de cierta envergadura que nos hacen pensar que originalmente no estaba destinado únicamente para tal fin. La recogida de material cerámico que se puede adscribir al período altomedieval en la amplia zona amesetada que queda por encima del promontorio rocoso donde está la cueva nos indica su probable origen andalusí. 


\section{Nombre CUEVA DE VALDELCUBO}

Localización Al norte del actual municipio de Valdelcubo, prácticamente integrado en la actualidad dentro del urbanismo del mismo.

Siglas MG08/069/VA-08

Coordenadas 3005276844564478 Precisión 4 m

Tipo de yacimiento Cueva

Estado actual: Uso como corral de ganado hasta fechas recientes. La cueva y todo el entorno está muy alterado por quedar en las inmediaciones del pueblo actual.

Descripción del yacimiento Al Noreste del pueblo de Valdelcubo, donde se halla el topónimo los palomares, se localizó una cueva hoy abandonada pero que ha debido estar ocupada hasta fechas recientes a juzgar por los materiales que en ella se encontraron (botellas etc.) La cueva está perfectamente adaptada, con al menos dos espacios diferenciados, los huecos al exterior se han cerrado con mampuestos, y en el interior tiene una especie de barra tallada en la roca para colocar objetos.

En la parte superior de la cueva se localizaron también algunas estructuras talladas en la roca, así como material cerámico de época altomedieval (piezas grises)

Relación con el medio físico y el recurso salino Una vez más, se trata de una cueva abierta en un promontorio rocoso, mirando hacia el sur, aunque en este caso no está en un pequeño valle como ocurría con las anteriormente descritas. Se sitúa en el llano del valle de Valdelcubo, que está surcado por el río del Berral, el río de Valdelcubo y distintos arroyos que bajan desde los altos de Barahona, todos ellos tributarios en última instancia del río Salado. Es una zona de menor concentración salina que las anteriores, sin ningún conjunto salinero próximo

Propuesta de interpretación Debido al alto grado de afectación de esta cueva y su entorno por la existencia del núcleo de Valdelcubo, resulta difícil reconocer en el paisaje indicios suficientes para interpretar correctamente este yacimiento, del que, por otro lado, son muy pocos los materiales cerámicos que se han podido recuperar. Consideramos que debe tratarse de un pequeño centro agroganadero, al igual que los anteriormente descritos. 


\section{Nombre CORRALES EL PUENTE}

Localización Pertenece al término municipal de Valdelcubo, aunque queda algo alejado de él. Situado en la media ladera este de la Loma de la Sierra, inmediatamente por encima del encuentro entre las carreteras comarcales GU-170 (entre los kilómetros 7 y 8) y GU-139.

Siglas MG08/069/VA-07

Coordenadas 300525753 4563970. Precisión de 4 m.

Tipo de yacimiento Media ladera

Estado actual Todo el entorno es ocupado por una granja de ganado de fábrica actual. También se documentan parideras y corrales de época moderna que han alterado el conjunto.

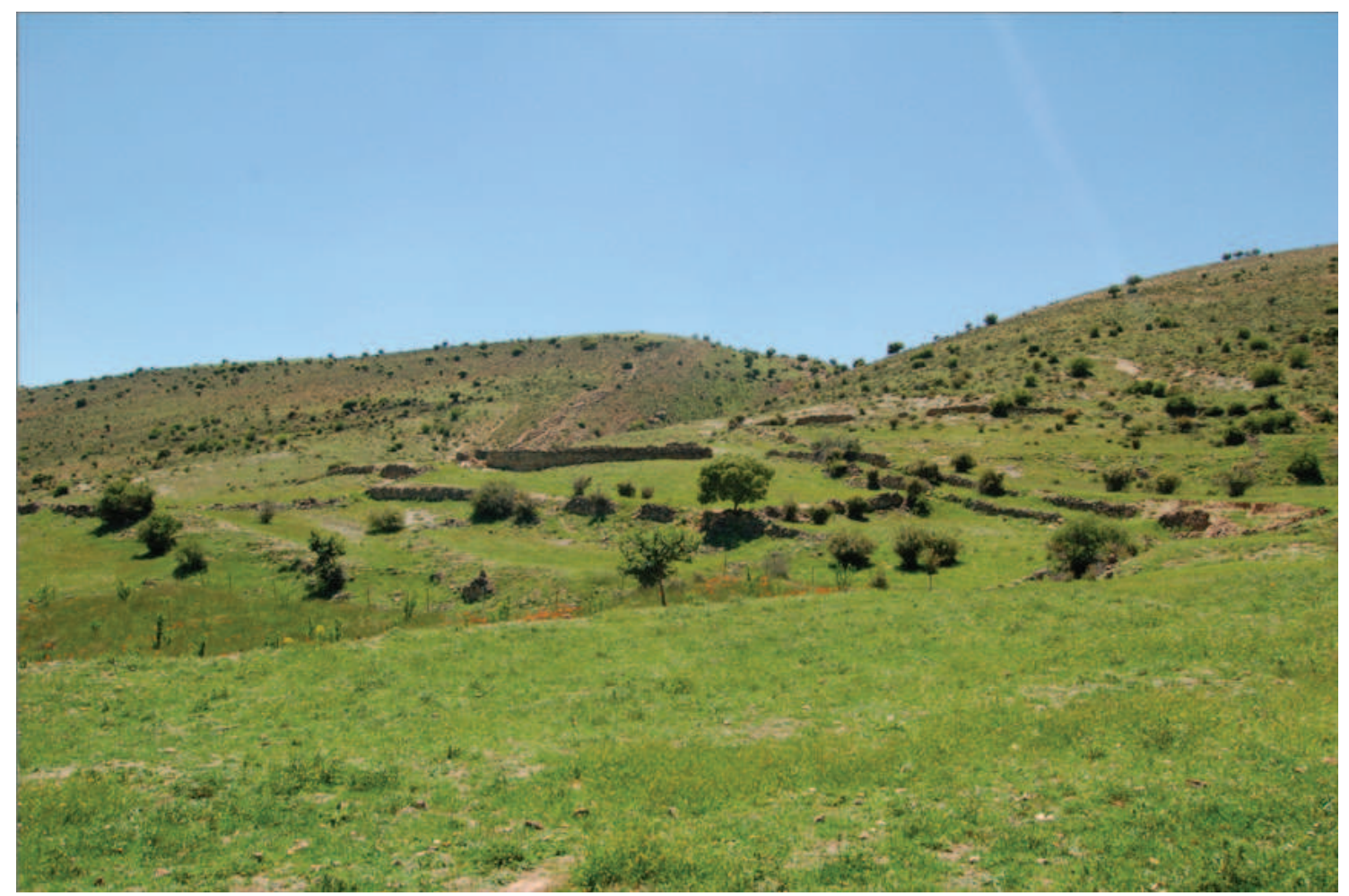

Descripción del yacimiento Enfrente del pueblo de Valdelcubo, a media ladera sobre la sierra hay una serie de parideras y una nave más moderna que están sobre restos que parecen más antiguos, de época islámica a juzgar por la cerámica. Se trata de un conjunto de grandes dimensiones, el mayor de los localizados, dejando a un lado el caso de los castillos. En total, sus dimensiones son de 300 x 200 metros, un total de $500 \mathrm{~m}^{2}$ aproximadamente. Aunque arrasados prácticamente a nivel de suelo, pueden identificarse numerosas estructuras en mampostería y en sillarejo. Se han documentado calles, edificios de planta rectangular y alguna construcción de paredes circulares. Lo alterado del entorno hace difícil distinguir aquellas construcciones originales de los corrales posteriores, por lo que se hace necesario un análisis más minucioso. De todo el conjunto, llaman la atención tres estructuras: una gran construcción con contrafuertes, al menos tres, que queda en el extremo más al sur del conjunto; un edificio aún en pie 
construido con sillares bien escuadrados del que se conserva un alzado de más de un metro de altura, que está en la parte más elevada, hacia el oeste; y los restos de un puente que salvan una de las torrenteras en el extremo sur, y que probablemente de nombre al yacimiento.

También destacar que junto a los restos de cerámica, también se recogieron algunos metales y restos óseos humanos.
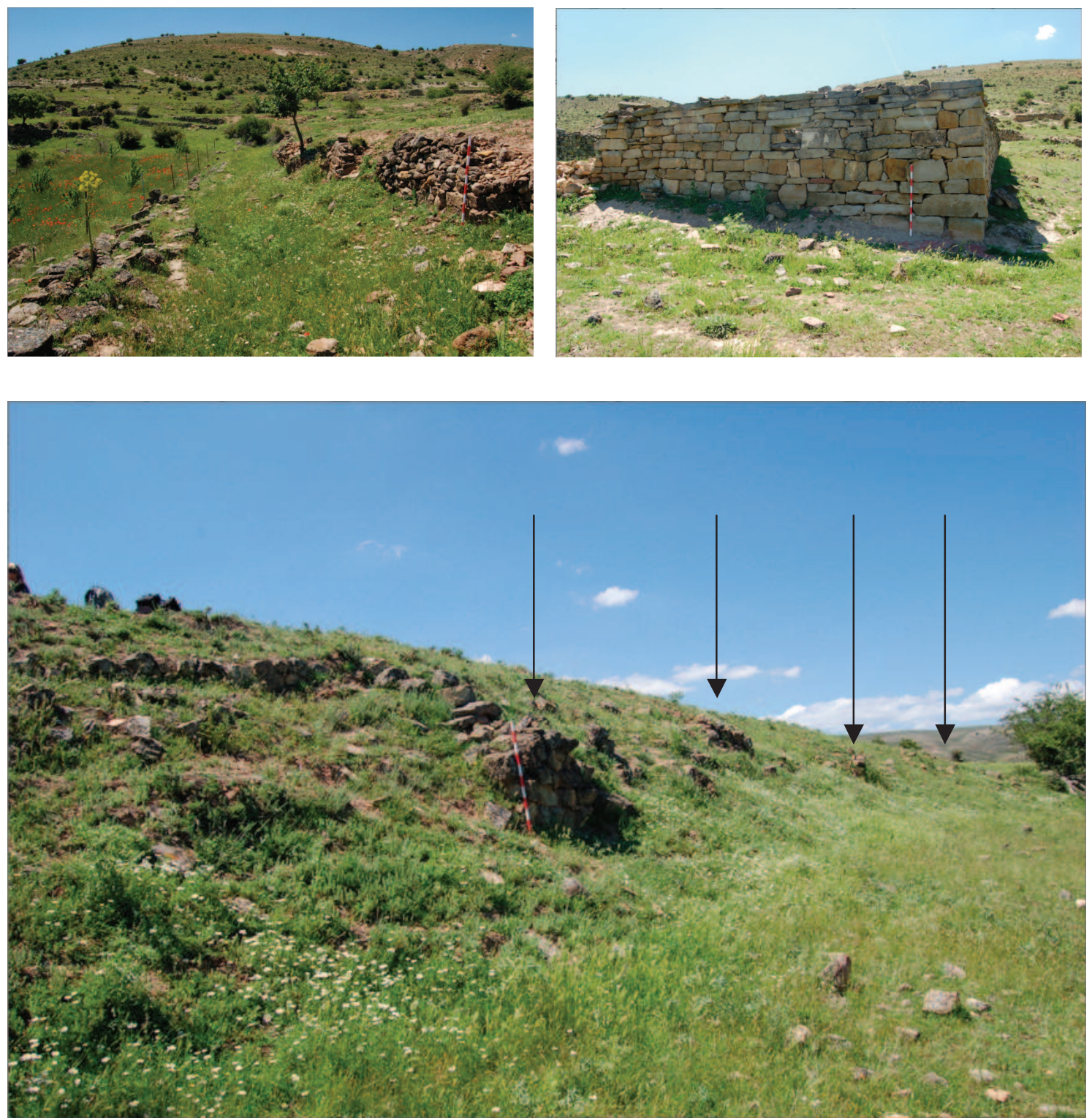

Relación con el medio físico y el recurso salino El yacimiento está situado en una elevación amesetada en la media ladera de La Loma de la Sierra. Inmediatamente por debajo de él pasa el río Salado, al que se le une el río de Valdelcubo unos metros más al sur del yacimiento. En este punto se ha generado un espacio de huerta que aprovecha el agua de ambos cursos. Desde el yacimiento parte un camino que se dirige hacia este espacio, del que forma parte el puente que hemos mencionado anteriormente, y que 
sirve para salvar una de las torrenteras. Todo indica que el yacimiento aprovecharía las dos torrenteras que lo limitan al sur y al norte, pues en la parte baja de ambas se documentan estructuras para el embalsamiento del agua, si bien también pueden datar del momento en el que el espacio es usado como para acorralar el ganado. También parece que tiene relación directa con una fuente que se localiza apenas $250 \mathrm{~m}$ en dirección SE.

Esta zona no es especialmente rica en lo que al recurso salino se refiere, distando las salinas más próximas, las de Rienda al norte y las de Riba al sur, más de 1,5 km y $3 \mathrm{~km}$ respectivamente. No obstante, en el extremo norte de la Loma de la Sierra, a unos 800 metros en línea recta del yacimiento, se sitúa una gran laguna endorreica en lo que se conoce como la fuente de las Praderas. También en este extremo hay una cantera de piedra caliza de tonalidad oscura, que es la misma piedra que se documenta en el yacimiento, auque no podemos asegurar por el momento que el lugar de extracción fuera esta cantera.

Propuesta de interpretación Se trata del yacimiento de mayor envergadura de todos los hallados en el curso de las prospecciones, dejando a un lado los castillos que ya se conocían. Aunque todo apunta a que debe tratarse de una alquería, creemos que debió jugar un papel central y aglutinador de esta zona, siendo la cabecera del valle del Salado una vez que abandona la amplia paramera desde donde nace. Es probable que se trate de un poblado con una cierta fortificación, sino en la totalidad del núcleo si en parte, por la construcción con contrafuertes que se ha documentado. 


\section{Nombre CERRO DE LA HORCA}

Localización En la parte norte del municipio de Riba de Santiuste, a dos Kilómetros al norte del desvío hacia el pueblo de la CM-110.

Siglas MG08/069/RI-01

Coordenadas 3005252114561245 precisión $4 \mathrm{~m}$

Tipo de yacimiento Llano

Estado actual Pequeño cerro en mitad del llano ocupado en la actualidad por tierras de cultivo

Descripción del yacimiento Pequeño cerro totalmente exento, junto a la carretera, que presenta un doble aterrazamiento; el más bajo de cultivo, y el más alto que parece corresponder a un amurallamiento. La cabecera del cerro está arrasada. Al Oeste, una posible muralla que presenta un recodo con acceso. El yacimiento ha sido fechado en época protohistórica, pero entre los materiales que se recogieron hay un pequeño volumen de cerámicas de época andalusí. Aunque el volumen es escaso, hemos decidido tomarlo en consideración en los estudios de cerámica, pero el asentamiento no se relaciona en el estudio sobre el poblamiento. En cualquier caso, sería un pequeño núcleo asociado al castillo de la Riba de Santiuste.

Relación con el medio físico y el recurso salino Se sitúa en el entorno de una zona fácilmente anegable debido a las características litológicas. El río Salado pasa por sus inmediaciones antes de hacer el brusco giro en Riba de Santiuste. En las inmediaciones hay una fuente de agua dulce, llamada «Fuente Nueva» situada en el punto de contacto entre un cerro redondeado que queda al norte y el llano donde se sitúa el área prospectada.

Propuesta de interpretación Probablemente se trate de un núcleo más de los que formaban el conjunto de Riba de Santiuste antes de la conquista, tal y como menciona la documentación castellana. Habría que ponerlo en relación con el de La Alquería que describimos a continuación. 


\section{Nombre LA ALQUERÍA}

Localización Riba de Santiuste, en la pequeña explanada de la cara norte del cerro donde se sitúa el castillo

Siglas MG08/069/RI-02

Coordenadas 3005245654561102 precisión $4 \mathrm{~m}$

\section{Tipo de yacimiento Llano}

Estado actual Tierras de cultivo y pequeñas huertas. Los materiales se han recuperado en las tierras roturadas. Es una zona fácilmente inundable y con una litología muy arcillosa.

Descripción del yacimiento Al norte del monte donde se ubica el Castillo, donde se sitúa el topónimo de «La Alquería», hay una serie de barbechos. En uno de ellos, de los más próximos al pie de monte, se localizó un conjunto de cerámicas realizadas a mano que parecen de factura prehistórica o protohistórica diferentes a las que se han localizado en el resto de la zona prospectada, por lo que se decidió diferenciarlo. Se han recogido también un buen número de cerámicas de factura andalusí, aunque cabe la posibilidad de que tengan origen en la ladera del cerro donde se sitúa el castillos. Al haber localizado diferentes líneas de muros de mampostería en esta zona llana, algunos con un claro uso agrícola y otros semienterrados que pudieran corresponder a estructuras habitacionales, se ha optado por diferenciar como un núcleo autónomo este espacio.

Relación con el medio físico y el recurso salino Ya se ha señalado que se sitúa en una zona fácilmente anegable debido a las características litológicas y al brusco giro que hace el río Salado para encajonarse entre e cerro del castillo y la sierra que queda al oeste. Hay una fuente de agua dulce, llamada «Fuente Nueva» situada en el punto de contacto entre un cerro redondeado que queda al norte y el llano donde se sitúa el área prospectada.

Propuesta de interpretación Aunque resulta difícil diferenciar este espacio del propio del castillo, ya que mucho de los materiales probablemente provengan por rodamiento de la zona alta del cerro, la existencia del topónimo y de muros de mampostería creemos que son argumentos suficientes para individualizarlo. Probablemente se trate de un núcleo más de los que formaban el conjunto de Riba de Santiuste antes de la conquista, tal y como menciona la documentación castellana ${ }^{22}$. Habría que ponerlo en relación con el del cerro de la Horca antes descrito.

\footnotetext{
${ }^{22}$ Varias veces se cita la existencia del castillo de la Riba y sus aldeas. MinguELla, Toribio, Historia de la diócesis de Sigüenza y sus obispos, Madrid, 1910, Vol. I, pp. 348.-349.
} 


\section{Nombre CASTILLO DE RIBA DE SANTIUSTE}

Localización En lo alto de un monte homónimo, dominando todo el término municipal de Riba de Santiuste

Siglas MG08/069/RI-03, MG08/069/RI-05

Coordenadas 305246544560789

Tipo de yacimiento En altura

Estado actual El castillo fue ocupado y reformado en época castellana, tanto en la Edad Media como en gran parte de la Edad Moderna ${ }^{23}$, sufriendo distintas reformas, restauraciones e invenciones arquitectónicas en los tiempos más recientes. Por todo ello, la estructura altomedieval ha sido enormemente modificada y es en la actualidad prácticamente irreconocible, salvo en la parte norte del cerro donde se asienta el castillo en el que se conservan una serie de estructuras y una mayor concentración de material andalusí.

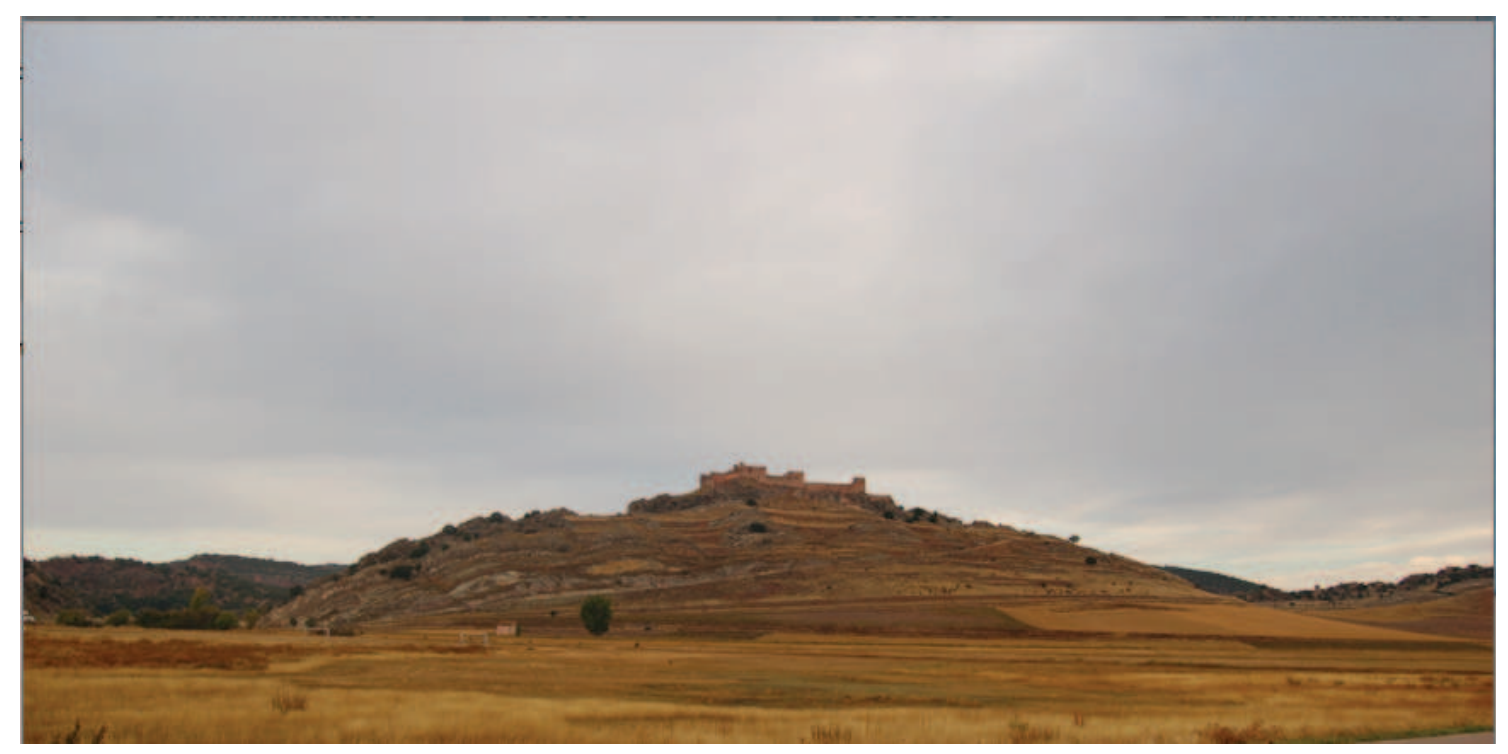

Descripción del yacimiento Se trata de un característico castillo roquero que se adapta a los afloramientos rocosos del cerro en el que se asienta. El lugar es mencionado en la documentación escrita aludiendo a su ocupación en época andalusi ${ }^{24}$, y es uno de los pocos centros de nuestra región en el que los materiales islámicos han sido estudiados ${ }^{25}$. El castillo actual, remodelado sucesivas veces incluso en época muy reciente, tiene una planta alargada impuesta por la morfología del cerro rocoso. Mide 90 metros de longitud y 12 de altura, quedando en la totalidad construido en piedra y ladrillo hueco.

\footnotetext{
${ }^{23}$ Minguella, Toribio, Historia de la diócesis ..., pp. 83, 119, 352

${ }^{24}$ La Historia Silense, al narrar las conquistas realizadas por el rey Fernando I en torno al año 1059, quien tras apoderarse de Gormaz, Aguilera y Berlanga, describe como el monarca se hace dueño de: Rippa de Sactiuste (Riba de Santiuste), Santa Emerenciana (Santamera) y Górmices (Huérmeces). No hemos podido consultar el original. Cit. en PAVÓn MALdonado, Basilio, Guadalajara medieval. Arte y Arqueología árabe y mudéjar, Madrid, 1984, p. 69 y nota al pie 209.

${ }^{25}$ RetUerce Velasco, Manuel, La cerámica andalusí de la Meseta, Madrid, 1998, 2 tomos, passim.
} 
Layna Serrano, no obstante, describió paredes de tapial y paramentos de piedras irregulares que podrían ser los del castillo original ${ }^{26}$, sin que podamos precisar mucho más sobre él. De 1 que hoy se puede reconocer como parte del castillo castellano original, hay que mencionar un primer recinto en el extremo más meridional del cerro, con dos torres redondas en la delantera que datan del siglo XIII y un segundo recinto que arranca de dos pequeñas torres rectangulares, dibujando un angosto rectángulo dividido en tres compartimentos cuyos muros de los costados quedan en ángulo. En el primero de esos compartimentos hay restos de lo que debió ser un aljibe. El tercer recinto, en forma triangular, remata hacia el extremo posterior en una torre pentagonal, también de época cristiana, situándose por esa parte la entrada principal de la fortaleza. También en esta parte se detectan los restos de otro aljibe. Basilio Pavón afirma que salvo las torres redondas y la pentagonal, el resto del recinto central sería el castillo árabe, al que habría que añadir en la parte septentrional un albacar ${ }^{27}$.

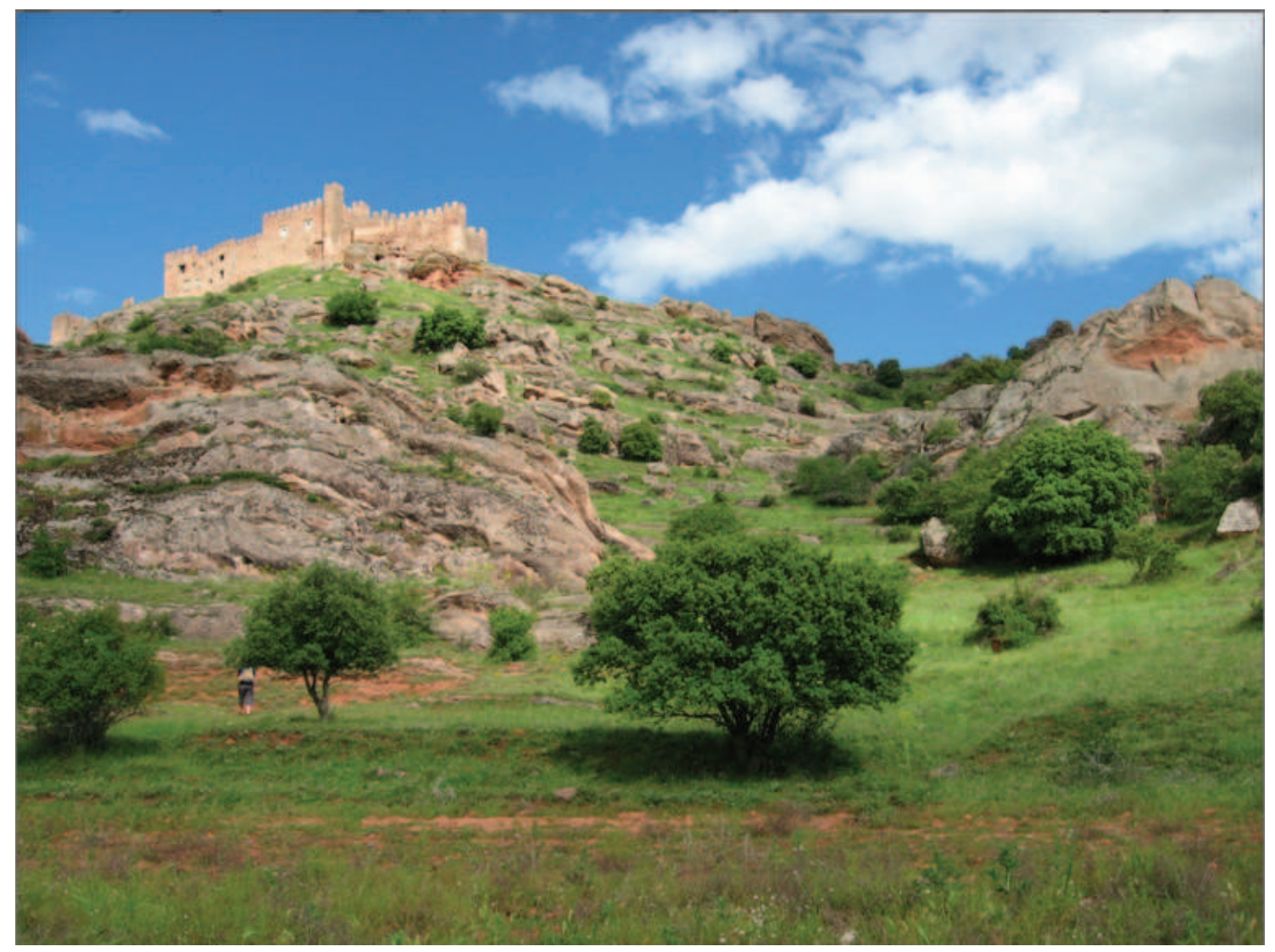

En la investigación de campo que hemos llevado a cabo se han individualizado tres partes, dejando de lado las laderas sur y oeste debido a que son prácticamente

\footnotetext{
${ }^{26}$ Layna Serrano, Francisco, Castillos de Guadalajara, reed. Guadalajara, 1994 (original, 1934), pp. 34-45. Otras descripciones del castillo en Herrera CASAdo, Antonio, Castillos y Fortalezas de CastillaLa Mancha, Guadalajara, 2003, p. 205; Idem, Guía de campo de los castillos de Guadalajara, Guadalajara, 1999, pp. 71-72 y 85; y PAVÓN MALDONADO, Basilio, Guadalajara medieval..., pp. 70-73.

${ }^{27}$ Pavón MALdonAdo, Basilio, Guadalajara medieval..., p. 73.
} 
inaccesibles dado lo escarpado del terreno. La primera, que correspondería a la zona donde el castillo se levanta y sus aledaños más inmediatos no es tomada en consideración, ya que el grado de afección de esta zona es tan alto que desechamos la posibilidad de que ofreciera información sin un estudio mucho más minuciosos. En la zona que se sitúa más al norte del alto del escarpado cerro, donde Pavón Maldonado sitúa el albacar, se individualizó la zona MG08/069/RI-05. Aquí se documentaron restos de toda una serie de estructuras, así como aterrazamientos artificiales, a lo que añadir la presencia de abundantes tejas y material cerámico. Junto a las estructuras de mampostería, también se documentaron actuaciones en la misma roca para acondicionar espacios probablemente de habitación, así como una técnica mixta en la que junto al tallado de la roca se daba la presencia de mampostería. En todo este espacio, aproximadamente la parte alta de la ladera Norte, y toda la parte alta de la ladera Este se recogieron abundantes materiales cerámicos que se pueden adscribir a distintos períodos, y por supuesto al andalusí. La otra zona diferenciada, en la que también se han recogido materiales, ha sido denominada MG08/069/RI-03. Esta unidad de prospección corresponde a la cara norte del cerro donde se sitúa el castillo de Riba de Santiuste. Se decidió prospectar esta zona por ser de más difícil acceso y no haber sufrido alteraciones ni expolios (aunque alguno se encontró). Se documentaron distintos muros de mampostería, algunos para aterrazar y crear suelo agrícola y otros que deben corresponder a estructuras habitacionales. Es una ladera escarpada, con constantes afloramientos de roca, algunos de los cuales parece haber sido tallado y usado para construir habitaciones. Se localizó una buena cantidad de material cerámica de época andalusí y cristiana medieval.

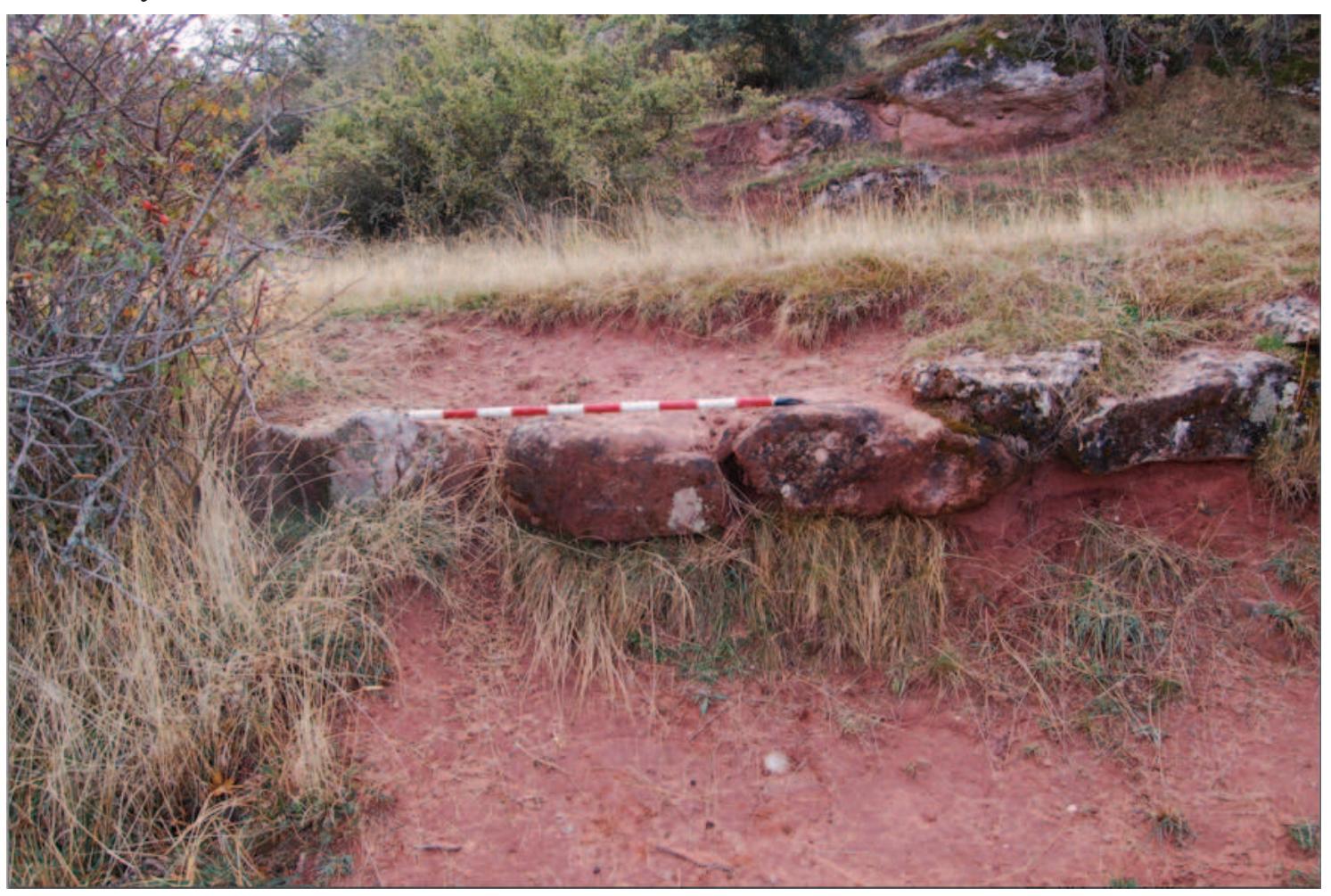


Relación con el medio físico y el recurso salino El elemento más sobresaliente de la ubicación del castillo es el control visual que establece, no solo con su entorno más inmediato, sino en un amplio radio de varios kilómetros que hace que en días claros pueda divisarse hasta Atienza por el norte, y hasta la zona de Palazuelos por el sur, teniendo contacto visual con otras zonas elevadas como los altos de Barahona y gran parte de la serranía norte de Guadalajara. En su entorno más inmediato, que es lo que ahora nos interesa, controla el paso del río Salado así como el estrechamiento que el valle tiene al encajonarse entre la Sierra de la Pila y las estribaciones de la Serranía por el oeste. En lo que se refiere a los recursos hídricos, además del propio río Salado, el río Querencia vierte sus aguas en el anterior prácticamente a los pies el cerro. También hay distintas fuentes de agua dulce en sus alrededores, y arroyos y torrenteras que bajan por las faldas de los montes.

Respecto a la sal, en la documentación cristiana inmediatamente posterior a la conquista castellana se menciona la donación del castillo junto a las salinas. No sabemos si habría más de una explotación en el entorno o que el castillo encabezaba, de algún modo, las distintas explotaciones del valle, ya que en la actualidad en sus inmediaciones sólo se pueden reconocer los restos, hoy abandonados, de las salinas de la Riba, aproximadamente a unos 900 metros en línea recta del castillo.

Propuesta de interpretación Además de su papel como hisn, del que parece no haber duda, lo que nos interesa aquí es llamar la atención sobre su papel como sitio principal y cabeza del territorio por parte de los castellanos en el momento de la conquista. Así se entiende la donación que se hace del castillo de Sancti Justi y de sus aldeas, entre las que habría que incluir la ya citada de «La Alquería». Este papel central dentro de un distrito, aunque aún no podemos establecer que consideración tendría desde un punto de vista administrativo y en lo que se refiere a su extensión territorial, si que tendría un valor económico, ya en las citadas donaciones el castillo y las villas se reparten junto a salinas, molinos, prados etc. que dependían del castillo:

\begin{abstract}
...facio cartam donationis sancti Mariae seguntine ecclesie et tibi venerabile ejusdem sedis episcopo domino Bernardo tuisque succesoribus ibi deo canonice servientibus de castro sancti justi cum omnibus suis hereditatibus, et cum illa villa de la Riba cum toto suo directo videlicet cum salinis, portaticis, pratis, turribus, molendinis, montibus, fontibus, exitibus et regressibus, et cum omnibus terminis qui ad illud castellum pertinent jure hereditario pro ut regale jus exigit. ${ }^{28}$
\end{abstract}

Se trata de una concesión de Alfonso VII al obispo don Bernardo y al cabildo en 13 de julio de 1124, tan sólo seis meses después de la conquista castellana, y que ofrece la

\footnotetext{
28 Minguella, Toribio, Historia de la diócesis de Sigüenza y sus obispos, Madrid, 1910, Vol. I, Colección diplomática ${ }^{\circ}$ II, p. 348.
} 
imagen de un territorio bien conformado y estructurado en el que se identifican una serie de elementos, como molinos y fuentes, así como una serie de espacios, como montes y prados, y lo que más nos interesa, se dona el castillo y la villa con sus salinas. 


\section{Nombre CASTILLEJO DE LA RIBA}

Localización Cerro a las espaldas del pueblo de Riba de Santiuste.

Siglas MG08/069/RI-06

Coordenadas 305244414560533

\section{Tipo de yacimiento}

\section{Estado actual}

Descripción del yacimiento En el monte en cuya ladera se encuentra el pueblo de Riba de Santiuste, en el cerro que queda frente al castillo, se encuentra otro de los yacimientos. Es un lugar llamado «El Alto»o «El Castillejo» Designado como GU-RI06 , era un espacio en el que se había postulado podría haber un poblamiento anterior y coetáneo al del castillo, según referencias bibliográfica que hacían referencia a la existencia de tumbas antropomorfas de forma trapezoidal con encaje para la cabeza ${ }^{29}$, así como a la existencia de construcciones que podían datar de época altomedieval ${ }^{30}$. Efectivamente, se pudieron recoger algunos fragmentos cerámicos, y se reconocieron algunas estructuras y restos constructivos, sobre todo en la cara oeste del cerro. Lo más destacado son dos construcciones de mampostería con mortero fuerte de cal que se elevan casi en el centro de la cima del cerro. Junto a ello, en el lado norte del cerro hay afloramientos de estructuras con mechinales. También es de destacar una pequeña estructura circular de mampostería que queda a los pies del cerro en la cara Este, muy cercano al puente que cruza hacia el castillo, y que se incluye dentro de esta unidad de prospección.

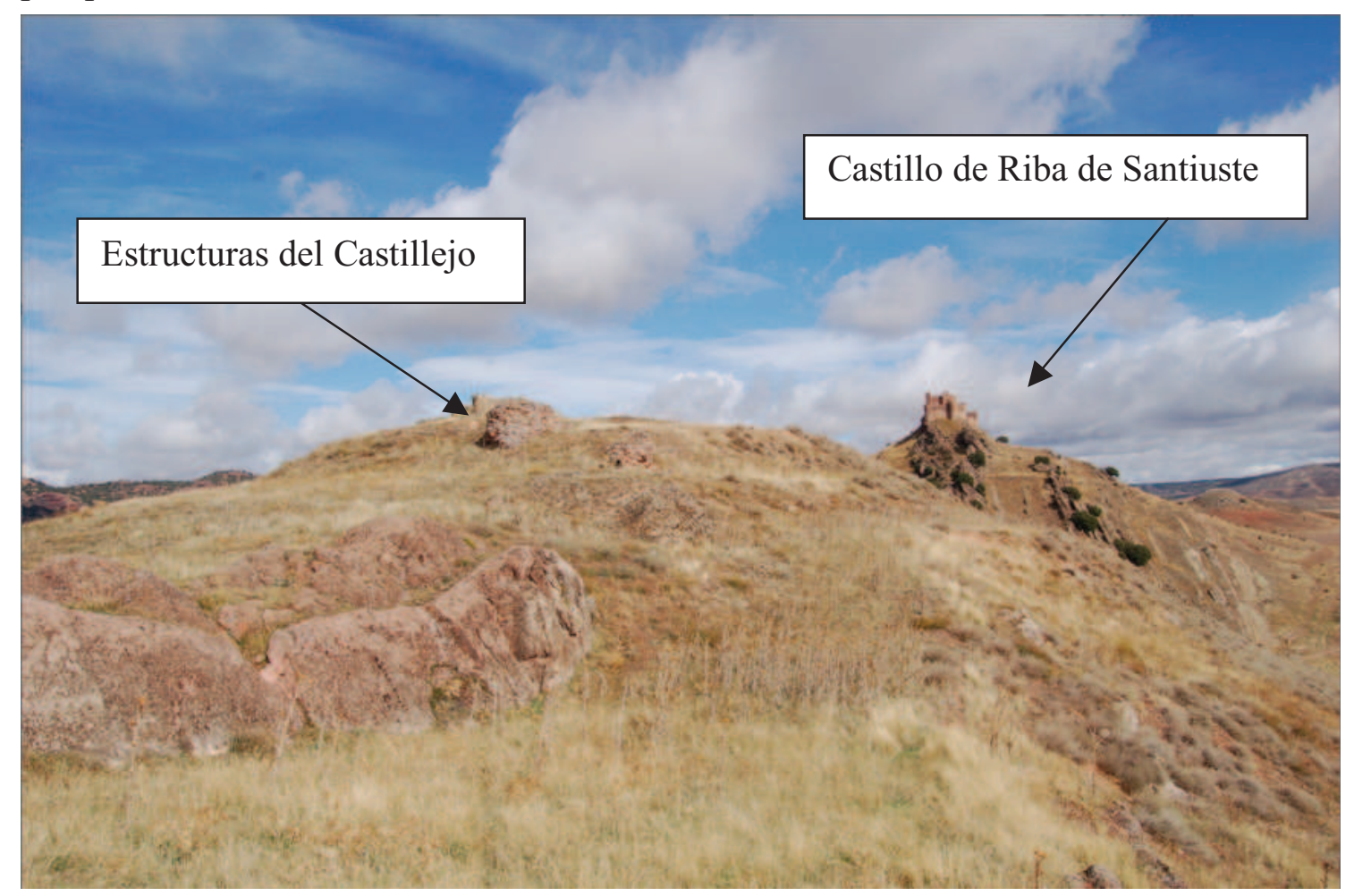

\footnotetext{
${ }^{29}$ Morère Molinero, Nuria, Carta arqueológica ..., p. 46, Idem, «Dos conjuntos de tumbas...»»

${ }^{30}$ DAZA PARDO, Enrique, «Los castillos olvidados...», p. 20.
} 
Relación con el medio físico y el recurso salino Está a muy pocos metros en dirección sur de castillo de Riba de Santiuste, por lo que las condiciones físicas y su relación con los recursos naturales es la misma que hemos descrito allí.

Propuesta de interpretación La existencia de dos fortificaciones tan próximas entre si y con una cronología de ocupación tan similar resulta algo extraña. No cabe duda que es el castillo de Riba el que tiene el papel preponderante, como se desprende de su mención en las fuentes escritas y de la envergadura de sus construcciones, así como el mayor volumen de cerámica recuperado. Además, en el caso de el castillejo nos encontramos con la existencia de un conjunto de tumbas antropomorfas, que han sido fechadas por analogía, en el siglo XIV, después de la conquista castellana. Aunque sólo es una hipótesis, y en todo caso muy difícil de verificar, cabe la posibilidad de que se trate de un asentamiento en altura más temprano que el del castillo de la Riba que estuviera ocupado por una población cristiana, esto es, mozárabe, lo que se corroboraría si se revisara la cronología de las tumbas halladas. Lo que no cabe duda es que la construcción de las que quedan pocos restos debió tener una cierta envergadura.

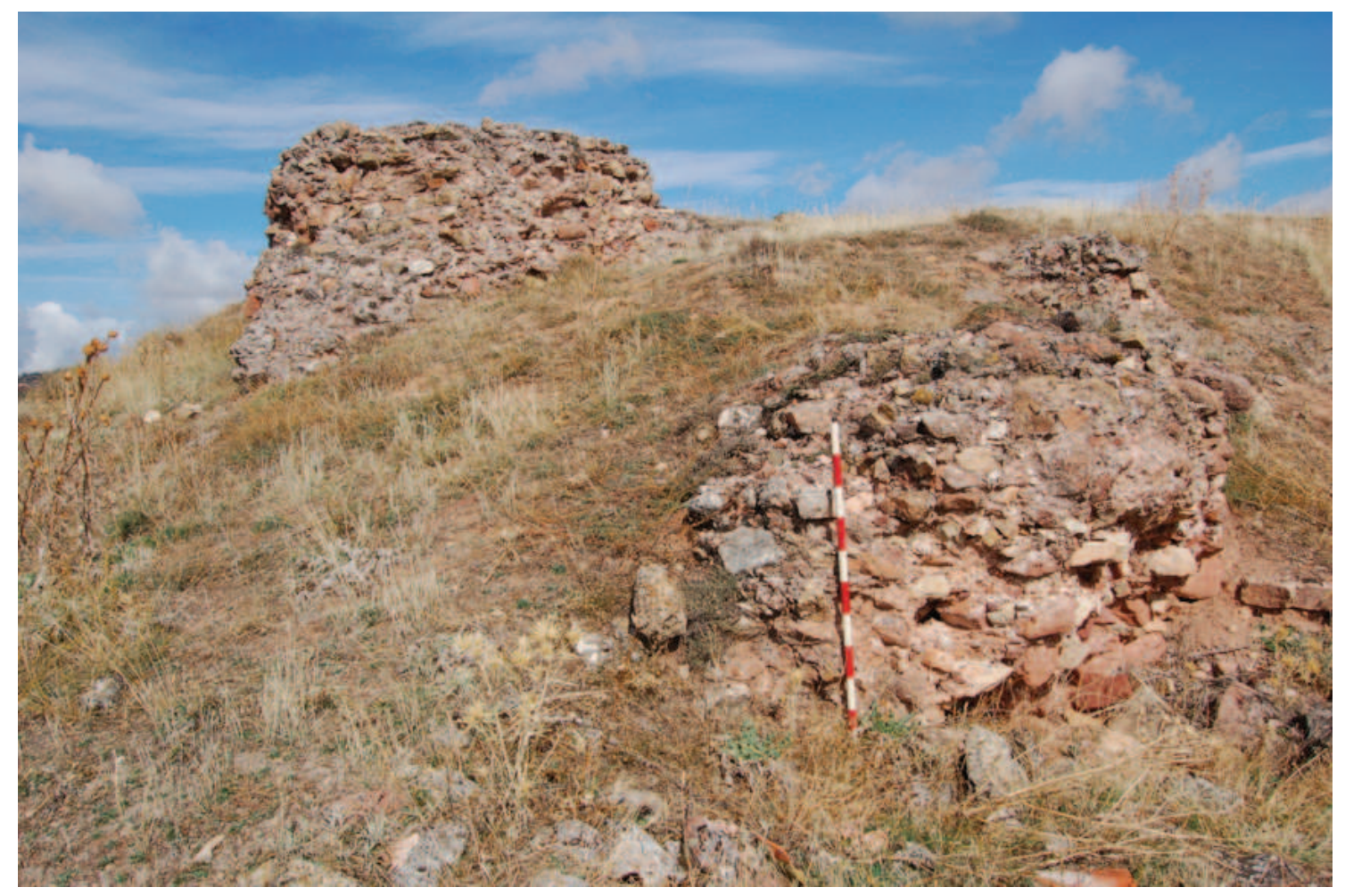

Restos de las construcciones que se han hallado en el castillejo de la Riba 


\section{Nombre CERRO DE VILLACORZA}

Localización Un promontorio en el pie de monte antes de llegar a Villacorza, en la carretera que se dirige hacia Torrevaldealmendras, aproximadamente en el km 2.

Siglas MG08/069/VIL-01

Coordenadas 30525941455724

Tipo de yacimiento Asentamiento a media ladera

Estado actual Enterrado. Ha sido usado como recinto para el ganado y la torre ha sido alterada para servir de refugio a los pastores, pero el conjunto se conserva sin grandes alteraciones

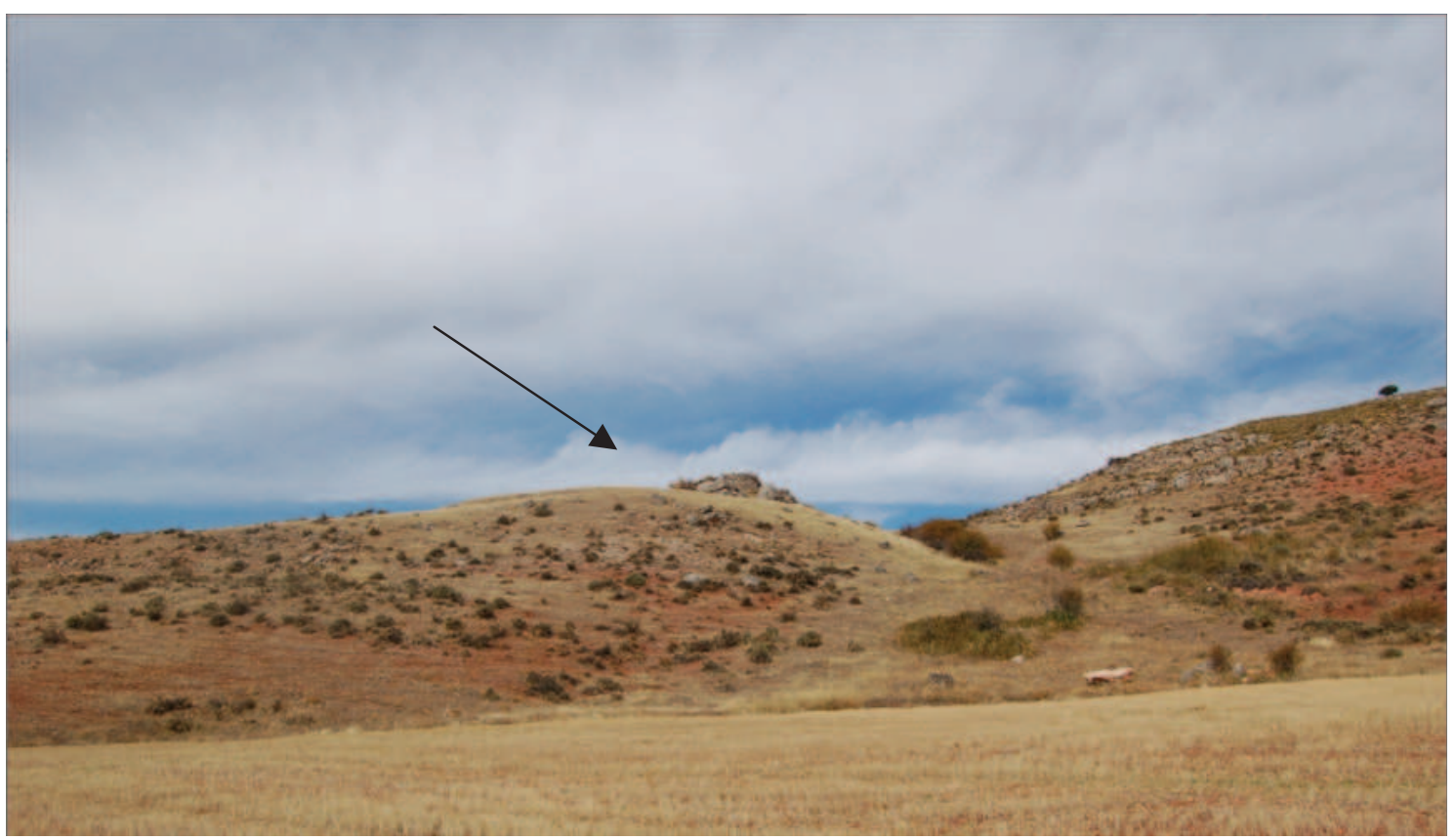

Descripción del yacimiento Un pequeño promontorio amesetado antes de llegar a Villacorza, en las faldas de la sierra que queda al Norte, fue el siguiente espacio en el que se encontró un yacimiento. Se trata de un pequeño yacimiento altomedieval constituido por una pequeña torre en mampostería aprovechando la roca en el extremo oriental y un espacio anexo que se extiende hacia el oeste con un muro de mampostería que lo circunda. Se recogieron bastantes fragmentos cerámicos, fundamentalmente dentro del recinto.

Relación con el medio físico y el recurso salino Controla toda la entrada al valle de Valdealmendras al estar situado a bastante altura, siendo un sitio de difícil acceso y fácil defensa. Su entorno es uno de los prados halófilos más extensos de todo el valle del Salado. No obstante, salvo el curso salado que discurre por el llano, la única agua dulce a la que tiene acceso es un pequeño arroyo que baja por el monte en la parte oriental del asentamiento.

Propuesta de interpretación Por su configuración y tamaño, no parece que estemos ante un lugar de habitación tipo aldea o alquería, sino más bien ante un refugio o 
pequeño otero de carácter defensivo, con un redil para proteger bienes como el ganado. Su control del acceso al valle de Valdealmendras así como un buen dominio visual de parte del propio valle del Salado parecen apoyar esta hipótesis. Respecto a la cronología de su ocupación, por el estudio cerámico que hemos llevado a cabo, parece no llegar hasta la época final andalusí, pudiendo abandonarse aproximadamente en el siglo X.

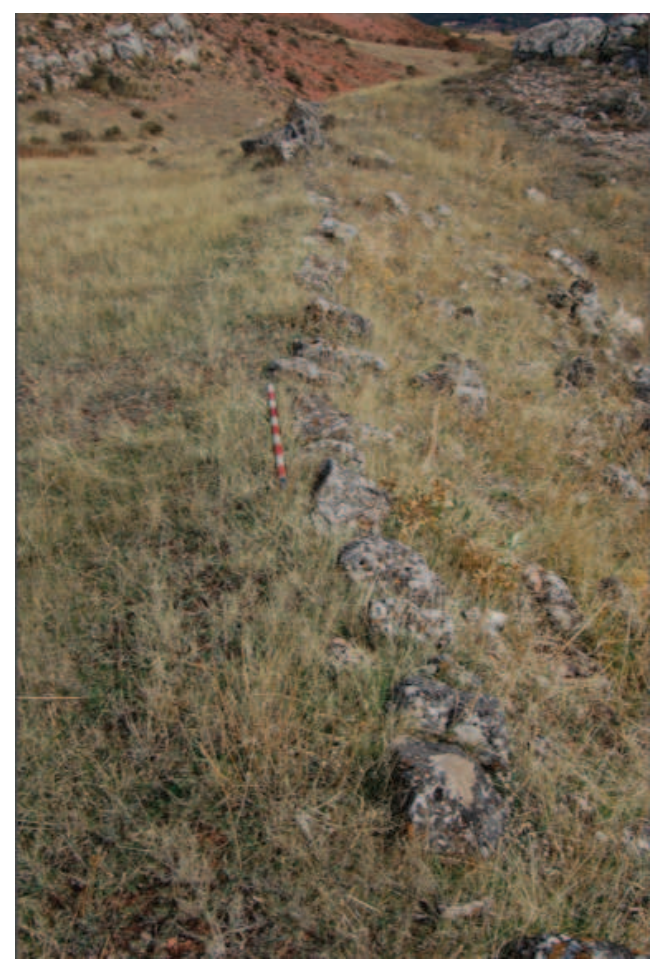

Restos que se evidencian en superficie de la cerca que engloba el yacimiento 


\section{Nombre LA ASOMADILLA}

Localización: Media ladera que queda en el cerro al sur de las salinas de Imón, de nombre «Viña Redonda». Se accede desde la carretera CM114 en el Km 37

Siglas MG08/069/IM-01

Coordenadas 305222854556344

Tipo de yacimiento Asentamiento a media ladera

Estado actual Sepultado. Hay estructuras para el ganado en la parte superior del cerro que parecen haber aprovechado los mampuestos, ya que presentan un aspecto más trabajado de lo normal.

Descripción del yacimiento Cerro que queda al Sur de las salinas, situado el asentamiento en la media ladera que da hacia el norte, aproximadamente a $1057 \mathrm{~m}$ de altura. El topónimo que aparece en la cartografía en esta zona es el de «Asomadilla». En este espacio se recogieron cerámicas, aunque son algo escasas, siendo sin embargo muy abundantes los mampuestos y las tejas, y en lo alto del cerro, además de una gran paridera, se pudieron ver algunos otros restos que podrían corresponder a estructuras antiguas. La paridera o estructura para el ganado estaba construida con mampuestos medianamente bien trabajados, por lo que no se descarta que sean reaprovechados de las construcciones más antiguas que hubiera.

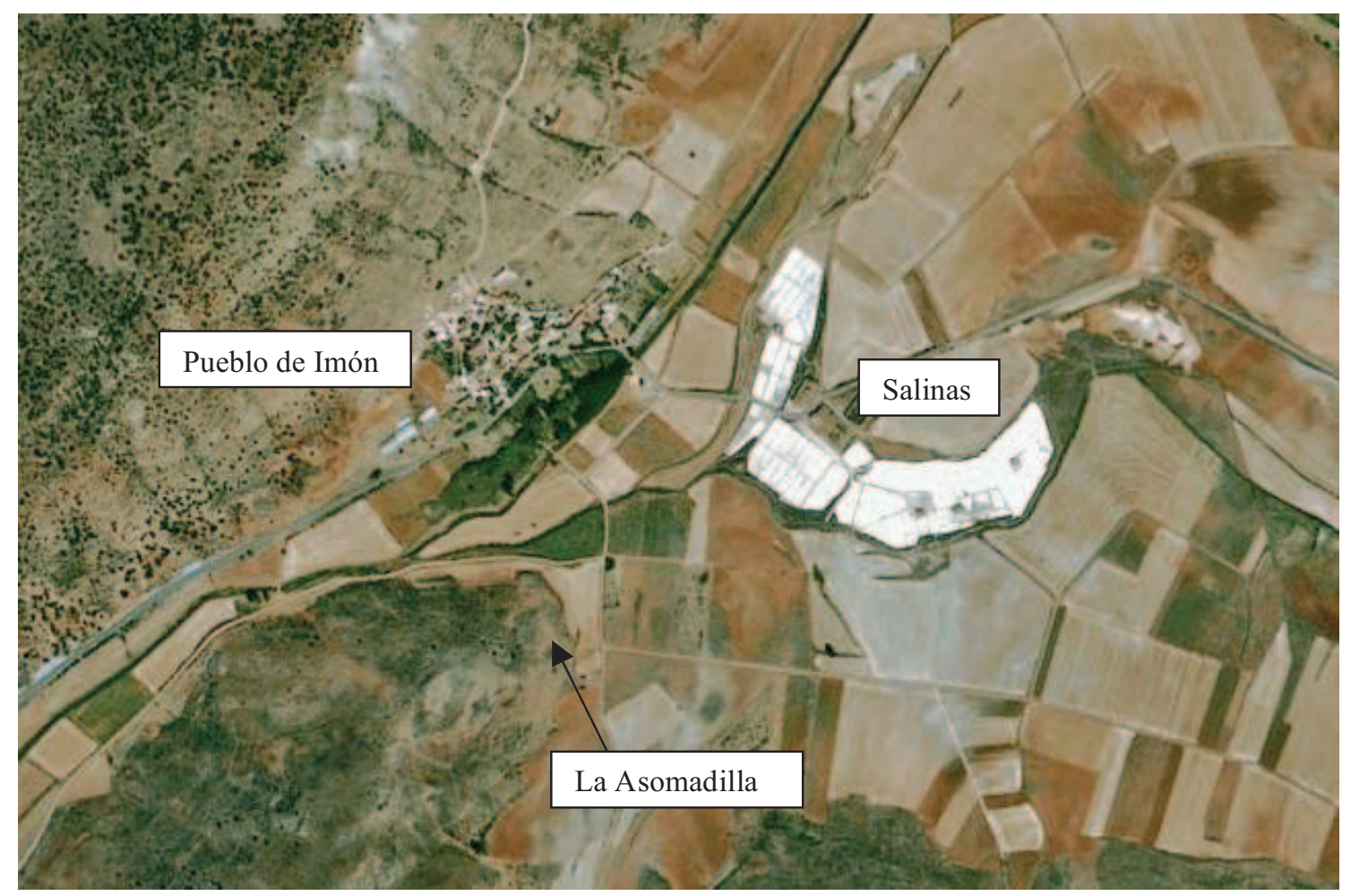

Relación con el medio físico y el recurso salino El cerro se sitúa inmediatamente por encima del núcleo de salinas más grande de todo el valle, el de las salinas de Imón. Todo el entorno está conformado por abundantes arroyos cargados de sales disueltas y 
prados halófilos. Por la toponimia que se ha conservado en la cartografía, la zona debía contar además con lagunas endorreicas, como lo ponen de manifiesto los nombres de «laguna» o «salobral». Tampoco faltan los arroyos de agua dulce, sobre todo a partir de surgencias naturales, como la fuente de «La muda», la de «La Solana o la de «Las viñas», todas ellas en los pie de montes cercanos, aunque ninguna directamente en la Viña Redonda. También hay bastantes arroyos de agua dulce.

Propuesta de interpretación Se tiene constancia por las fuentes escritas de la existencia de un núcleo de población de nombre aimon o aymon en el entorno de una salinas, y tradicionalmente se ha relacionado con el del actual pueblo de Imón. Aún sin descartar esta posibilidad, la existencia de este asentamiento a tan sólo 300 metros del pueblo actual nos hace pensar que, o bien este era el Imón andalusí, o toda el área tenía un poblamiento más disperso, que acabó por concentrarse tras la conquista en el actual núcleo, aglutinándose las construcciones en el entorno de la iglesia que data de época románica. El lo que ocurre en otros casos de la provincia, como el de Castejón, donde la iglesia se construye en la parte alta del cerro donde se asentaba la aldea islámica, o en el caso de Bujalaro donde la iglesia está ubicada más lejos del cerro. En uno y otro caso no hay una superposición ni solapamiento del asentamiento. También ocurre en Mandayona y Cendejas de la torre, donde la iglesia se instala en la base del cerro y desde aquí crece el núcleo cristiano.

En época islámica, este núcleo quedaría relacionado visualmente con el castillo de Riba de Santiuste y con el asentamiento en altura del Castro de Riosalido. Además, pensamos que debe guardar relación también con el asentamiento del Cerrillo de las Monjas, pues un camino hoy prácticamente desaparecido une estos dos puntos hoy abandonados, pasando por un estrecho paso entre la Loma de Castilviejo y el Montecillo, que lleva por nombre «El portillo». 


\section{Nombre CASTRO DE RIOSALIDO}

Localización En el alto del Castro, a poco más de un kilómetro en línea recta del pueblo de Riosalido. 1047 metros de altura en su punto más alto.

\section{Siglas MG08/069/RIO-01}

Coordenadas 305255974555175 Precisión $4 \mathrm{~m}$

Tipo de yacimiento En altura

Estado actual Hay varias construcciones en la ladera oriental, entre las que destacan dos cortijos, y toda la parte alta del cerro ha sido acondicionada para ser usada como redil para el ganado, aunque en la actualidad todo ello está abandonado.

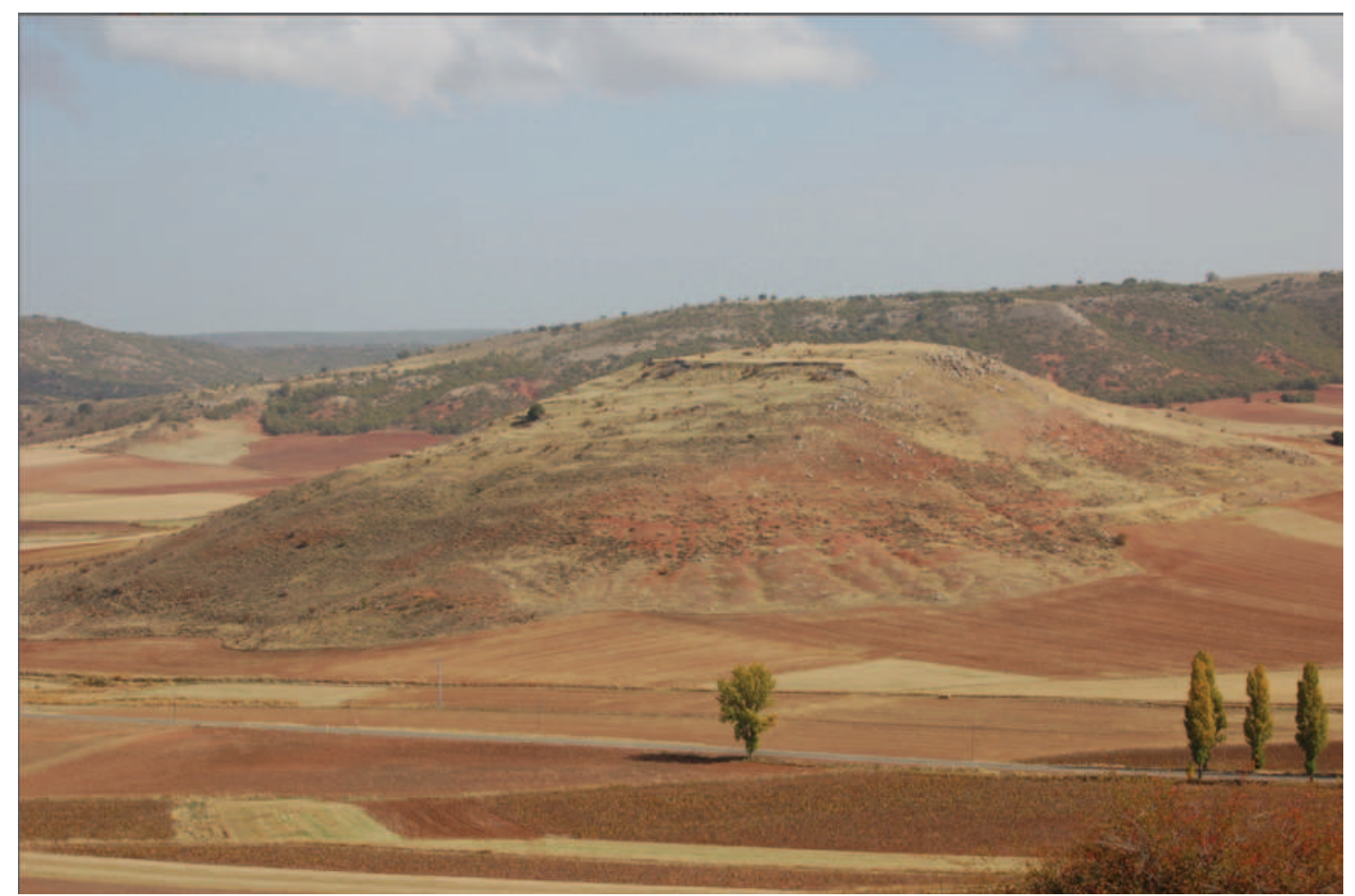

Descripción del yacimiento Se trata de un yacimiento conocido para la época protohistórica $^{31}$, en el que además de haberse confirmado la existencia de un imponente castro se ha detectado una reocupación en época andalusí. El material cerámico, presente por todo el cerro, era especialmente abundante en una zona amesetada en la ladera oeste. En la parte alta, sobre todo en la ladera Norte, se ha documentado la existencia de un muro de mampostería quizá asociado a la práctica ganadera, cuyos mampuestos han podido ser reutilizados por la buena factura que presentan. También hay uno muros algo más altos en la ladera este, quizás pertenecientes a alguna tenada,

\footnotetext{
${ }^{31}$ Morère Molinero, Nuria, Carta arqueológica ..., pp. 35-36; FernÁndez GAliAno, Dimas, «Notas de prehistoria seguntina»Wad-al-Hayara, 6 (1979), pp. 9-48; VALIENTE MALLA, Jesús, «La facies Riosalido y los Campos de urnas en el Tajo Superior» en ArenAS, J. A. y PALACios, M. V., (eds.), El origen del mundo celtibérico. Actas de los encuentros sobre el origen del mundo celtibérico (Molina de Aragón, 1-3 de octubre de 1998), Molina de Aragón, 1999, pp. 88-95.
} 
hoy casi enterrada. Pero la estructura más imponente es la muralla ciclópea, que hoy está en parte al descubierto, con sillares bien trabajados de un metro de lado, aproximadamente. Hay varios tramos en los que esta muralla ha sido reparada o recrecida con mampuestos de peor factura. Aunque no es posible fechar estas remodelaciones, cabe la posibilidad de que sean del momento altomedieval, toda vez que son piedras tomadas con mortero de cal, una construcción bien trabajada para ser únicamente destinada a contener al ganado.

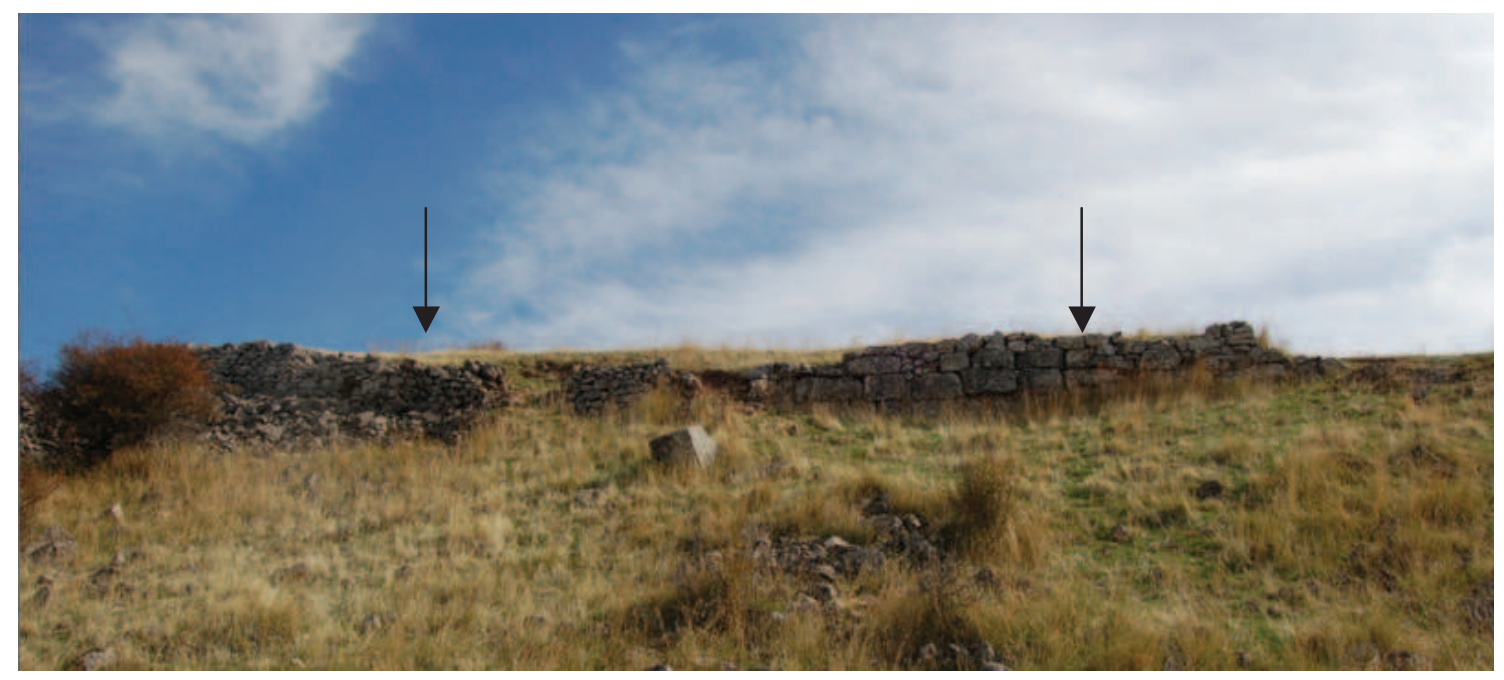

Relación con el medio físico y el recurso salino El asentamiento domina visualmente gran parte del valle del Salado, situándose en el tercio sur del mismo en el punto en el que el río abandona el propio valle antes de encajonarse por Santamera en dirección al Atance y en donde el valle es surcado por cursos de agua de menor entidad, como los ríos Cubillo y Vadillo. Domina una de las vegas más fértiles del valle por la menor presencia de salinidad en su entorno más inmediato, así como por la abundancia de agua dulce en un radio de 500 metros a su alrededor, gracias a los arroyos de «Aguanales», «El Chorrón» o «Los Arbollones», y a las fuentes como «Fuente del Torrejón» y la «Fuente de Estebanico». No obstante, también hay que destacar el control visual que tiene de las dos zonas de mayor concentración salina, las de Imón en dirección noroeste, y las de Bujalcayado-La Olmeda en dirección suroeste, distando en ambos casos no más de $3 \mathrm{~km}$.

Propuesta de interpretación Se trata de un castro de la edad del Hierro reocupado en época altomedieval, un proceso que se detecta en otras zonas de Guadalajara o en la vecina provincia de Soria ${ }^{32}$. En época andalusí es probable que funcionara como hisn,

\footnotetext{
${ }^{32}$ Para el caso de Guadalajara vid. Olmo EnCISO, Lauro, «Arqueología medieval en Guadalajara. Un estado de la cuestión» en GARCíA-Soto MATEOS, Ernesto y GARCíA VALERO, Miguel Ángel (eds.), Actas del primer Simposio de Arqueología de Guadalajara. Homenaje a Encarnación Cabré Herreros. Sigüenza, 4-7 de octubre de 2000, Madrid, 2002, pp. 467-500 especialmente p. 475. Para el caso soriano, vid. Bueno SÁNCHEZ, Marisa, «Estrategias de supervivencia en época tardoantigua y altomedieval.
} 
dominando y controlando toda la parte del valle que queda fuera del control directo del castillo de Riba de Santiuste, ya que su campo de visibilidad abarca desde el final del valle por el sur, donde la Loma de El Mirón separa éste del valle del Henares y la ciudad de Sigüenza, hasta las mismas estribaciones del castillo de Riba de Santiuste.

Reocupación de recintos celtibéricos en el Alto Jalón (Soria)»I Jornadas de Jóvenes en Investigación Arqueológica: Dialogando con la cultura material, Madrid, 2008, tomo 2, pp. 485-492. Hemos consultado la edición on-line en formato pdf: http://www.ajhiscam.com/Documentacion/I\%20JORNADAS\%20EN\%20INVESTIGACION\%20ARQU EOLOGICA.pdf 


\section{Nombre CERRILLO DE LAS MONJAS}

Localización En la falda noroeste de la Sierra de Bujalcayado, aprovechando un conjunto de cerros que se levantan sobre el llano, aproximadamente a unos 1000 metros de altura. Se accede por un camino rural que sale de la CM-110 en el Km 30 hacia el Oeste, y que finalmente se dirige hacia la Olmeda de Jadraque, tras girar precisamente frente al Cerrillo de las Monjas

Siglas MG08/069/BU-09, MG08/069/BU-10, MG08/069/BU-11, MG08/069/BU-12

Coordenadas 305240924554734

Tipo de yacimiento Asentamiento a media ladera

Estado actual Abandonado y enterrado

Descripción del yacimiento Situado en el sector NO de la parte baja de la Sierra de Bujalcayado, donde se localiza el topónimo "Cerrillo de las Monjas". Aquí se localizan cuatro pequeños cerretes en el pie de monte, dos más adelantados hacia el llano y otros dos más atrás, en el ascenso a la sierra. Los dos primeros, GU-BU-09 y GU-BU-10 parecen constituir en conjunto un mismo asentamiento, probablemente islámico. Los cerros parecen tener rampa de acceso y una cerca que los engloba, así como algunas otras estructuras de mampostería que se pueden observar en superficie. Especialmente interesante resulta el primero de ellos, GU-BU-09, que es el que queda más al NO de los cuatro. En él se pudieron documentar un elevadísimo número de fragmentos de tejas, así como lascas de pizarra, y también algunas de las estructuras que se apreciaban en superficie parecen estar compuestas por mampuestos de un tamaño mayor. GU-BU10 es el cerrete que queda más al NE del conjunto. En él se recogió algo menos de material y se documentaron menos tejas que en GU-BU-09, aunque desde este punto la visibilidad era bastante major hacia el conjunto del valle.

En lo que respecta a los otros dos ceros, GU-BU-11 es el cerro que queda más hacia el $\mathrm{SO}$ de los cuatro. En él se asienta un complejo ganadero constituido

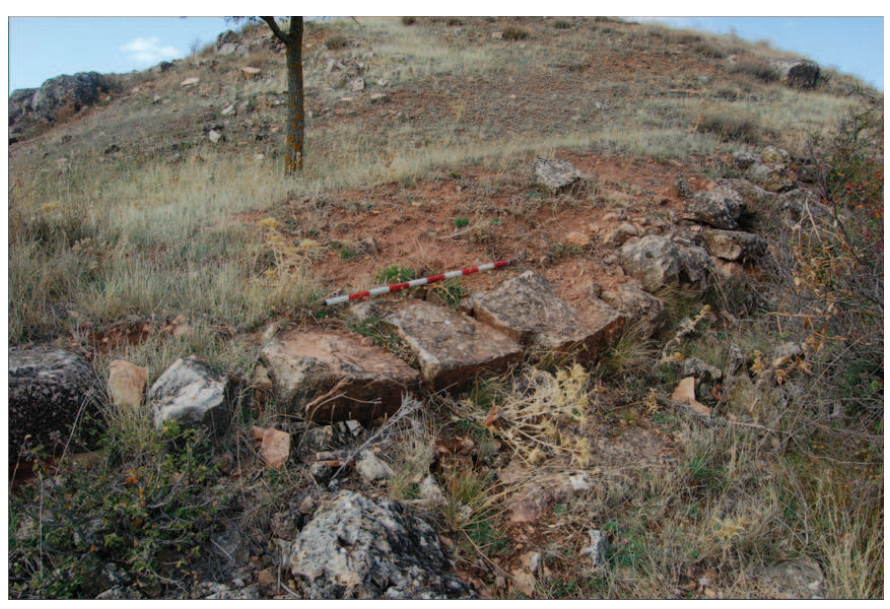
por dos hogares de mampostería y algunos corrales, siendo este espacio el único más alterado de todo el conjunto. Finalmente, GU-BU-12, es el cerrete que queda más al SE, y que casi forma parte de la ladera de GU-BU-11. En él no se han documentado ni estructuras, y apenas cerámica, pero nos llamó la atención que es el único de los cuatro constituido por arcillas y margas y en el que además afloraban algunas piedras de color blanco que quizás pueda tratarse de silex. También se recogió una pequeña lasca de silex. 
Relación con el medio físico y el recurso salino Situado en una posición dominante sobre un pequeño valle que se crea entre la Loma de Castilviejo, la Sierra de Bujalcayado y el Montecillo, en el que varios cursos de agua lo surcan: arroyo de los Arbollones, arroyo de los Aguanales etc. Dos son las fuentes de agua dulce que podría explotar: la fuente de las Almijeras, que queda al este y la Fuente de las Zarzas, en el pie de monte de la Loma de Castilviejo, a 900 metros hacia el oeste. Esta última surgencia natural nace cargada de sales, como hemos podido comprobar en las prospecciones, creando a su paso una especie de ribera halófila, el conocido como arroyo de las Cañadas, que acaba por suministrar agua a las salinas de Bujalcayado y La Olmeda.

Propuesta de interpretación Por su tamaño, disposición y volumen de materiales, consideramos que estamos ante un poblado de pequeñas dimensione situado a media ladera, con un control directo de una amplia zona probable de explotación. Como de la mayoría de los asentamientos que hemos localizado, no tenemos constancia alguna en las fuentes escritas acerca de este asentamiento, si bien queremos dejar constancia aquí de la posible identificación con el topónimo «Las Almijeras», que se documenta en la Estadística de $1353^{33}$ y después no aparecen más noticias de este lugar, según Ranz Yubero $^{34}$. Es probable que estemos ante un caso de corrupción lingüística y de desplazamiento del topónimo en la cartografía ya que en el extremo noreste de la Sierra de Bujalcayado no hemos localizado restos de la existencia de ningún yacimiento de época medieval, y en este espacio sólo hemos encontrado éste del cerrillo de las Monjas.

Finalmente insistir en que queda dentro del espacio controlado más directamente por el yacimiento del Castro de Riosalido, así como también está en relación visual con el castillo de Riba de Santiuste.

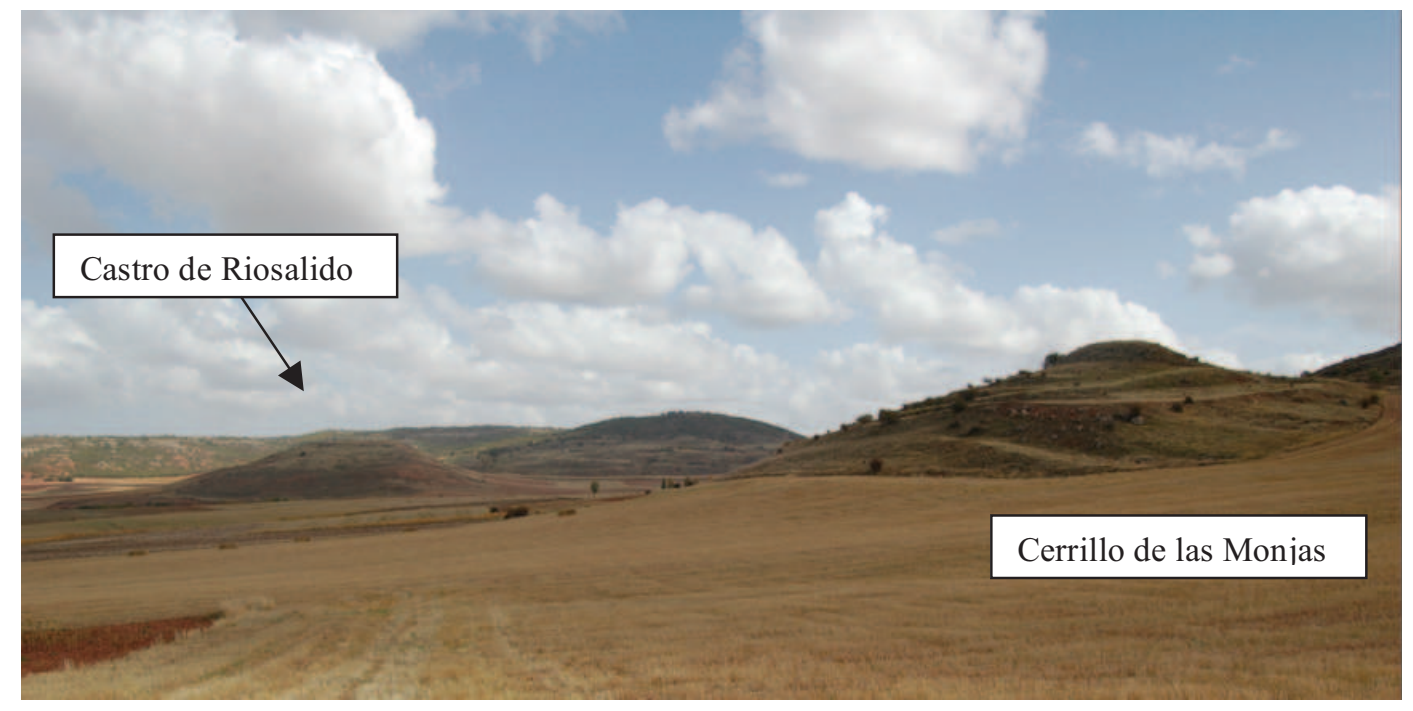

\footnotetext{
${ }^{33}$ Minguella, Toribio, Historia de la diócesis ... t. II, p. 320

${ }^{34}$ RANZ Yubero, José Antonio, «El nombre de los despoblados en el Señorío Episcopal de Sigüenza», Anales Seguntinos, 9 (1993), p. 142.
} 


\section{Nombre BUJALCAYADO}

Localización Barbecho situado inmediatamente por debajo del pueblo de Bujalcayado. Se accede por la carretera comarcal 114, que se dirige hacia La Olmeda, en el desvío hacia Bujalcayado

Siglas MG08/069/BU-01

Coordenadas 3005242134552902

Tipo de yacimiento Asentamiento en media ladera

Estado actual Tierra de cultivo en la parte baja del pueblo, ha sufrido aportes de tierras y remociones a causa de la roturación

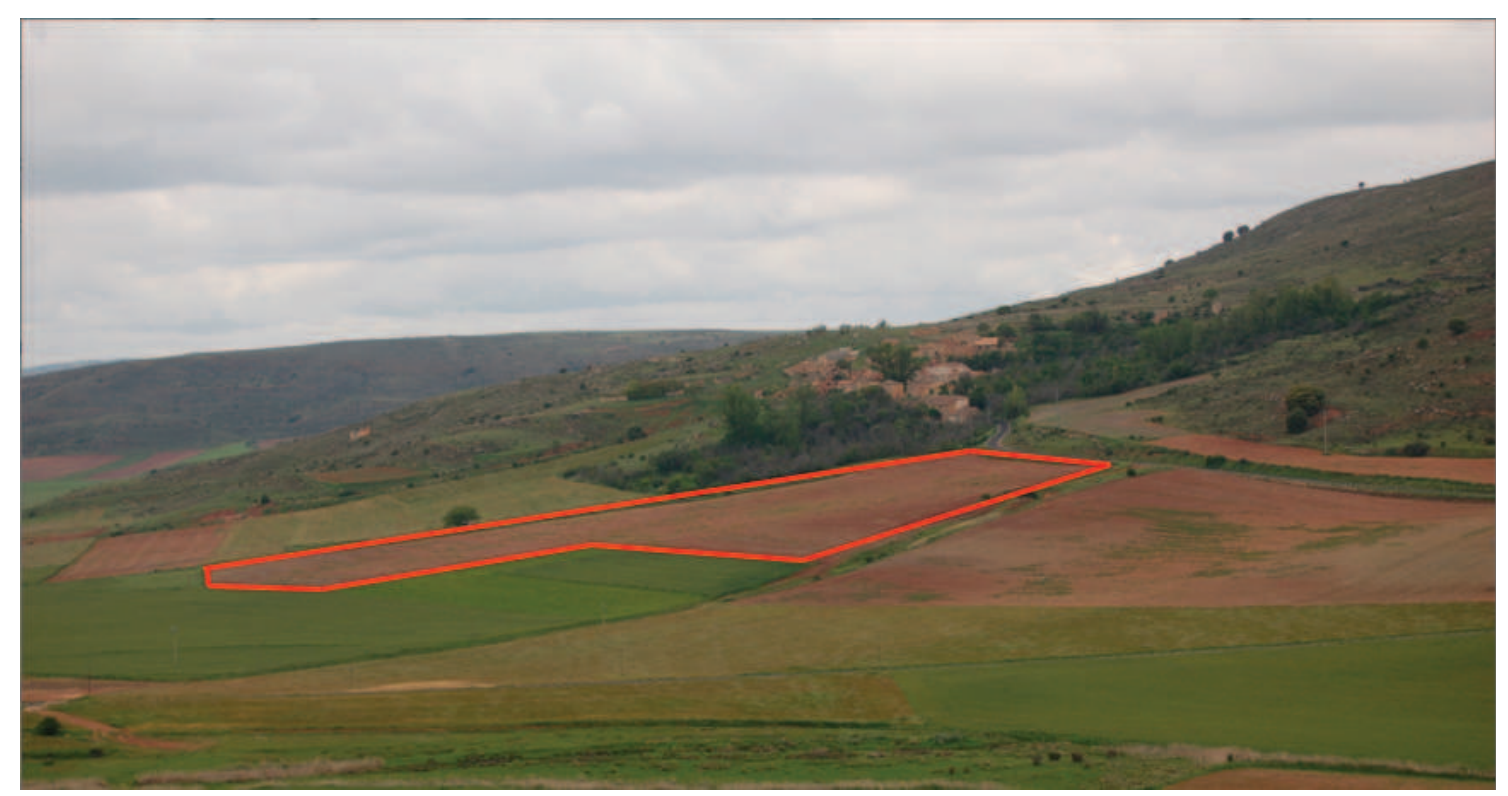

Delimitación del barbecho que fue prospectado y su relación con el pueblo de Bujalcayado

Descripción del yacimiento En la ladera sur de la sierra se sitúa el pueblo de Bujalcayado, topónimo ya de por sí sugerente ${ }^{35}$, aunque insuficiente para asegurar la presencia de un asentamiento islámico en él. No obstante, la prospección efectuada en un amplio espacio de cultivo que estaba en barbecho, permitió recoger un volumen de cerámica bastante amplio, conjunto en el que también se ha podido identificar abundante material de época islámica, lo que nos permitiría hablar, con algo más de seguridad, de un asentamiento altomedieval en este espacio. Se ha recorrido la totalidad del pueblo, hoy prácticamente abandonado, pero no se ha identificado ninguna estructura que remita a construcciones de el período andalusí. Cabe la posibilidad de que, en el caso de existir, estén camufladas por las construcciones en mampostería más modernas.

\footnotetext{
${ }^{35}$ Podría proceder del árabe burŷ (= torre), si bien la segunda parte del topónimo no parece árabe. En la zona encontramos algunos topónimos con prefijos similares como Bujalaro o Bujalance que son indicativos de la existencia de torreones de origen islámico.
} 
Relación con el medio físico y el recurso salino El yacimiento se encuentra en un lugar privilegiado para el desarrollo de la agricultura, así como también cuenta con un buen número de fuentes de agua dulce, tanto diversos arroyos como surgencias, como la fuente que hay en el centro del pueblo, como otras en un radio de no más de $500 \mathrm{~m}$ : Fuente de San Sebastián, Fuente de Montelllano, Fuente de los cerrillos etc. Además, este asentamiento, junto con el de Bonilla que ahora pasaremos a describir, se sitúa en una de las zonas con mayor presencia de sal, donde destacan las tres salinas de Bujalcayado, La Olmeda y Malpica o Carabias, así como los restos de otras a las que de momento no podemos poner nombre. Pero, más que en las estructuras salineras en sí mismas, lo que llama la atención es el elevado número de cursos salinos de este entorno, creando una zona de amplios prados halófilos que plantean la posibilidad de que los asentamientos que estamos citando deban tener algún tipo de relación con la sal, aunque no seamos de momento capaces de establecer cual es la relación entre ambos.

Propuesta de interpretación En el caso de confirmarse la existencia en Bujalcayado de un asentamiento de época altomedieval, estaríamos ante un nuevo caso de asentamiento en la media ladera, aprovechando los recursos de agua dulce de las inmediaciones y en relación directa con la zona llana, que sería la productiva, tanto para la explotación agrícola como para del recurso salado. Está en relación visual directa con el asentamiento de Bonilla, del que dista $1,74 \mathrm{~km}$ en línea recta. 


\section{Nombre BONILLA}

Localización Situado en la ladera de la sierra que queda inmediatamente por encima de las salinas de La Olmeda, a una altura de $945 \mathrm{~m}$. Se accede por el desvío que hay en la carretera de Sigüenza a La Olmeda, CM 114, en el punto desde el que parte el desvió hacia Cirueches.

Siglas MG08/069/BU-01

Coordenadas 3005242134552902

Tipo de yacimiento Asentamiento a media ladera

Estado actual Enterrado, pero prácticamente inalterado, salvo por unas estructuras para el ganado que quedan en el extremo septentrional del yacimiento, aunque la afección parece ser mínima.

Descripción del yacimiento Está en una superficie aplanada situada a media ladera, con una práctica ausencia de vegetación que revela una notable anomalía en el subsuelo frente al espacio que lo circunda en el que abunda la vegetación propia del monte bajo. Aquí se documentó y se recogieron un considerable volumen de cerámicas y tejas en superficie, así como también se han documentado algunos alineamientos de piedras soterradas que tal vez correspondiesen a muros. En concreto, llama la atención un alineamiento de mayor longitud que cierra la casi totalidad del cerro y que pudiera ser algún tipo de cerca o muralla perimetral.

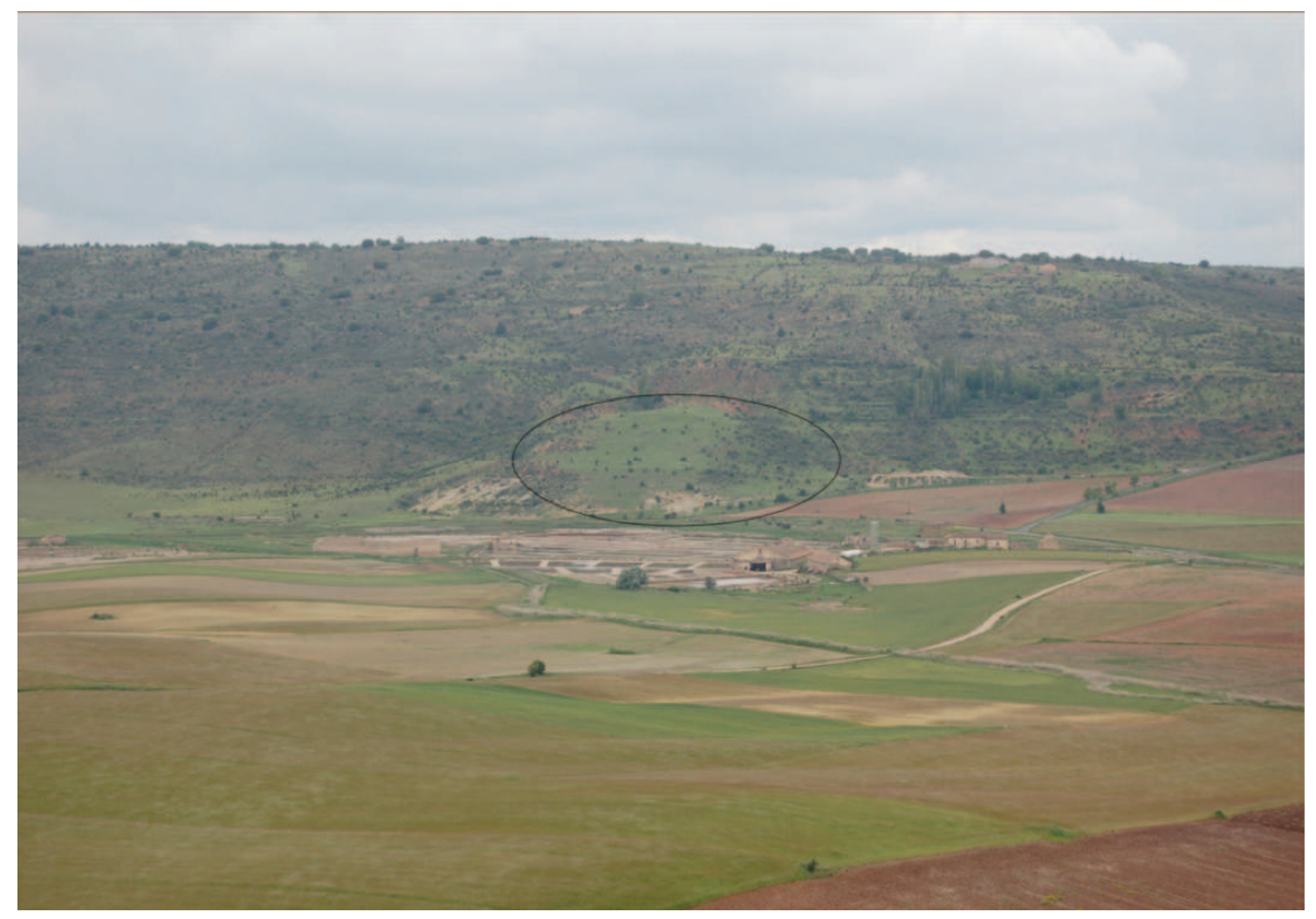


Relación con el medio físico y el recurso salino Es un asentamiento situado en una amplia explanada a media ladera por el este del «Alto de Valdeabejas», inmediatamente por encima de las salinas de La Olmeda. Aparece asociado a dos fuentes de agua dulce, «La fuente del Piojo» y la «Fuente de Juana Llana». La abundancia de salinas en este espacio —Las de Bujalcayado, la Olmeda, Los Berrales, Malpica, Caravias más los restos de otras de las que no tenemos constancia alguna- se combina con un volumen de prados halófilos que fueron explotados, y aún lo son en la actualidad, para la ganadería, dejando constancia en la toponimia: Los pradejones, Las praderillas, Prado de las Carretas, Prado Largo, Prado Cañizar etc. Junto a ello, toda la sierra en cuya ladera se asienta ofrece también unas muy buenas condiciones para la explotación ganadera.

Propuesta de interpretación Se ha optado por poner este nombre al yacimiento debido a que los documentos de la Colección Diplomática de Sigüenza presentada por Minguella aparecen citadas junto a las salinas de Imón las de «Bonela» o «Boniella», que necesariamente deben hacer referencia a las posteriormente conocidas como salinas de La Olmeda sobre las que se sitúa este asentamiento ${ }^{36}$.

Estamos, de nuevo, ante un asentamiento a media ladera, en este caso de medianas dimensiones, situado en una de las zonas más ricas en lo que al recurso salino se refiere. 36 Minguella Y ARnedo, Toribio, Historia de la diócesis de Sigüenza..., Colección Diplomática
XXXIX, 24 de septiembre de 1154,pp. 393-394. 


\section{Nombre VILLAVIEJA}

Localización Se sitúa en el extremo oriental de la Loma del Mirón, en un cerro homónimo, al que se accede por un camino rural que parte desde la misma Sigüenza, o bien desde el Km 2 de la carretera Gu-127.

Siglas MG08/069/SI-08, MG08/069/SI-12

Coordenadas 305310834547926

Tipo de yacimiento En altura

Estado actual El yacimiento al estar tan próximo a Sigüenza es bastante conocido, sobre todo por su adscripción a la Edad del Hierro, y ha sido expoliado en numerosas ocasiones, de lo que han quedado huellas en el yacimiento. Un pequeño cortijo en la media ladera, asociado a actividades ganaderas, también ha alterado esta parte del yacimiento.

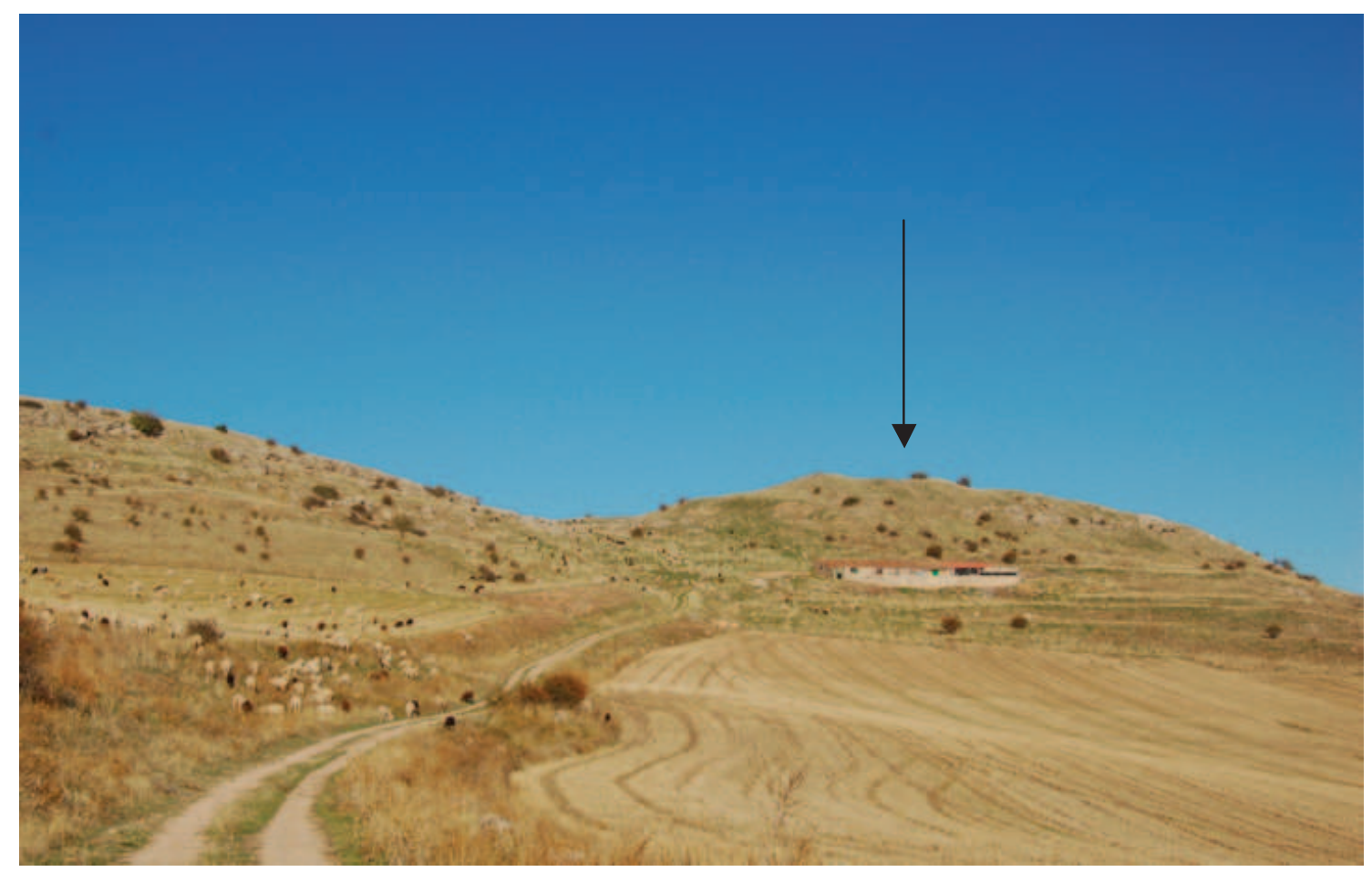

Descripción del yacimiento Aquí se reconoció la totalidad de un yacimiento conocido, fechado en época del hierro e identificado como uno de los castros celtibéricos de la región $^{37}$, dato que se corroboró, añadiendo ahora una posible reocupación del espacio en época islámica a juzgar por algunos de los fragmentos cerámicos recogidos. También se vieron y documentaron bastantes estructuras, como los dos torreones semicirculares que flanquean una rampa de acceso al asentamiento; la muralla que lo circunda de la que queda el vestigio topográfico, y distintas habitaciones en el interior levantadas en mampostería y tapial, algunas de las cuales conserva parte de enlucidos con almagra.

\footnotetext{
${ }^{37}$ FERNÁNDEZ-GALIANO, Dimas «Notas de prehistoria Seguntina...»
} 
Las dos áreas diferenciadas en la prospección corresponden al propio yacimiento y la parte alta del cerro por un lado (GU-BU-08), y por otro lado a la parte llana y los alrededores del cerro en los que se recogieron materiales que probablemente provengan rodados del cerro (GU-BU-12). En este último caso, no descartamos la posibilidad de que en la parte llana se ubicara también una población más o menos estable.

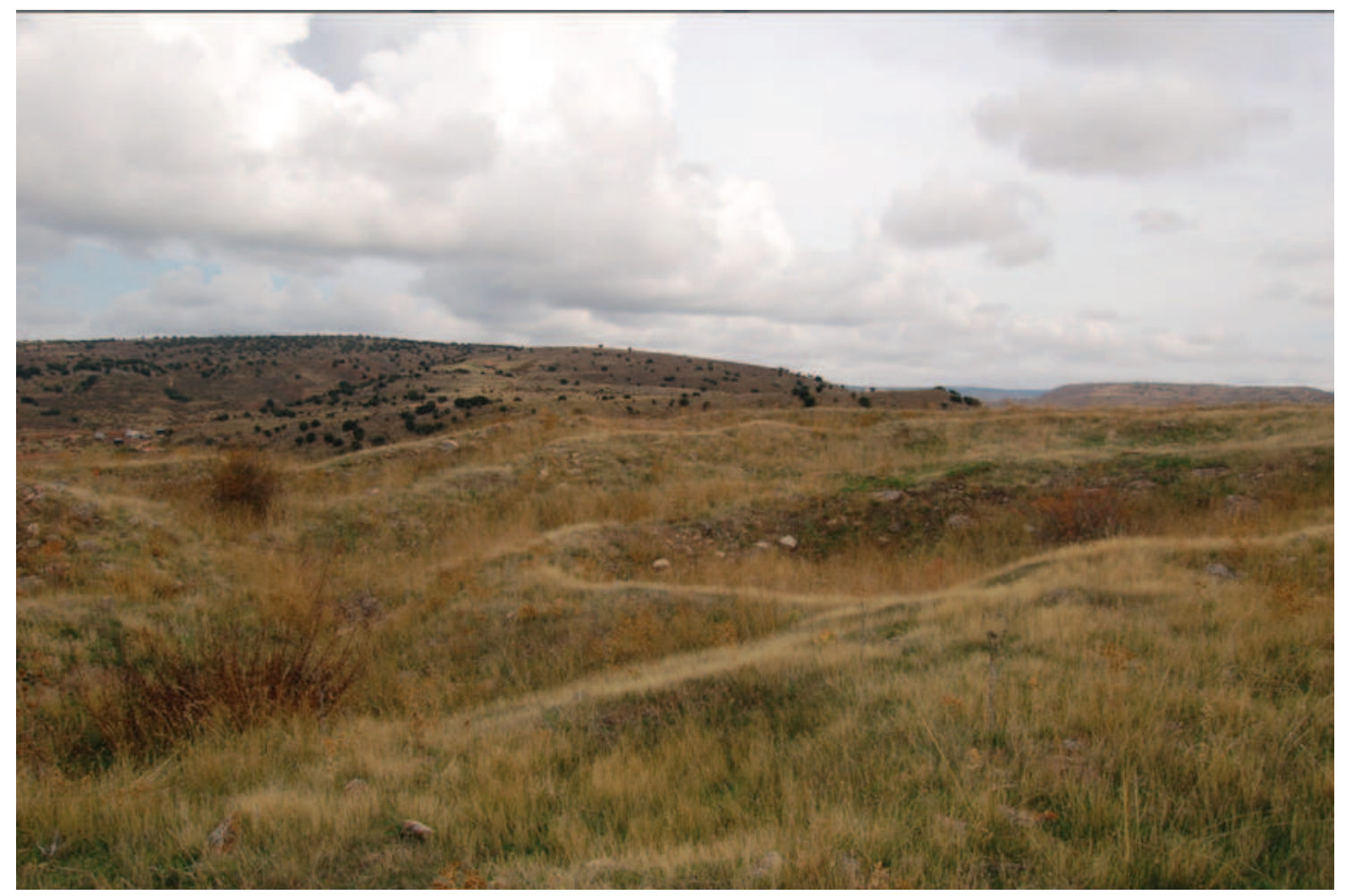

Aspecto de la cumbre del cerro con las marcas topográficas de las estructuras

Relación con el medio físico y el recurso salino Lejos de las áreas de explotación salina, este yacimiento se sitúa en la fértil vega del Alto Henares, en un promontorio elevado da fácil defensa y difícil acceso, lo crea unas condiciones óptimas para el control tanto del valle del Henares como del vecino valle del Vadillo. Hay varias fuentes de agua dulce en las inmediaciones, pero lo alterado del paisaje por la expansión urbana del núcleo seguntino hace difícil determinar cuales serían las condiciones de partida del yacimiento.

Propuesta de interpretación Para época andalusí, probablemente podamos estar ante un hisn que domine tanto la vía de comunicación que supone el valle del Henares, como el valle del Vadillo y que termina de comunicar con el propio valle del Salado, y por supuesto, con toda la fértil vega seguntina. Resulta interesante señalar, en este sentido, que el papel de nudo de comunicaciones que juega Sigüenza, y concretamente el cerro de Villavieja, ya ha sido señalado ${ }^{38}$, cruzándose en este punto los itinerarios de Mérida a

\footnotetext{
38 Abascal Palazón, Juan Manuel, Vias de comunicación romanas de la provincia de Guadalajara, Guadalajara, 1982, p. 50 .
} 
Caesaragusta con los que se dirigían desde la Segontia romana hacia Termancia y Arcóbriga. Este papel permanecería en época altomedieval, si bien aún no se puede señalar su verdadera dimensión. El papel del cerro de Villavieja cobra más fuerza si cabe teniendo en cuenta que la vía romana hacia Termancia nace a los pies del cerro, cruzando por el valle del Vadillo y no por las proximidades de la Loma del Mirón, como hasta ahora se había señalado ${ }^{39}$, ya que las prospecciones arqueológicas que hemos llevado a cabo así lo han puesto de relieve.

${ }^{39}$ Abascal Palazón, Juan Manuel, Vias de comunicación romanas ..., pp. 100-102 y plano p. 123. 


\section{Nombre LA QUEBRADA}

Localización En la carretera que va desde Sigüenza a Moratilla de Henares, en la ladera norte de la sierra de «La Quebrada» también llamada Canto Blanco, a las espaldas de unas naves industriales y unos almacenes hoy en funcionamiento

Siglas MG08/069/SI-11

Coordenadas 305209654545932

Tipo de yacimiento A media ladera

Estado actual Alterado por distintas naves industriales que se sitúan en las afueras de Sigüenza y por canteras de extracción de tierra

Descripción del yacimiento Se identificaron algunos sillares bien trabajados, amontonados junto a otros materiales de construcción más modernos, que llamaron nuestra atención. Al recorrer todo este espacio, se pudo recoger cerámica y reconocer en el terreno algunos saltos topográficos que pudieran tener su origen en estructuras hoy enterradas, algo más arriba y a unos metros hacia el oeste hay una estructura circular enterrada, en cuyo entorno se recogieron también cerámicas altomedievales.

En la parte alta del cerro en el que se sitúa este yacimiento se ha excavado un torreón de época islámica, con el que necesariamente debe guardar relación este yacimiento ${ }^{40}$.

Relación con el medio físico y el recurso salino En este caso no aparece relacionado a ninguna fuente de agua dulce, pero está a escasos metros del curso del Henares, situándose justo donde el valle del Henares se estrecha. Como ya señalamos, no queda este asentamiento en el valle del Salado, y por lo tanto tampoco en relación directa con la explotación de la sal, pero al igual que aquel probable hisn de Villavieja, se sitúa en el curso de una vía de comunicación histórica, datada ya desde época romana, cual es el propio curso del Henares.

Propuesta de interpretación Aunque debamos plantearlo también a nivel de hipótesis, este yacimiento, junto con aquel de Villavieja, nos aproxima a cuál debería ser la realidad del hábitat seguntino en época altomedieval. La ausencia de restos islámicos de envergadura en el propio municipio de Sigüenza, ni en el Parador ni en la parte llana de la ciudad ${ }^{41}$, al menos que se hayan documentado y publicado hasta el momento, salvo

\footnotetext{
40 García-Soto mateos, Ernesto y Ferrero ros, Susana, «La Atalaya islámica del "Cerro de la Quebrada" o "El Mirador del Cid" de Sigüenza y algunas consideraciones sobre las fortificaciones islámicas del nordeste de la provincia de Guadalajara» en GARCÍA-SOTO MATEOS, Ernesto, GARCÍA Valero, Miguel Ángel y Martínez Naranjo, Juan Pablo (Eds.), Actas del segundo simposio de Arqueología de Guadalajara. Molina de Aragón, 20-22 de abril de 2006, Madrid, 2008, pp. 265-278.

${ }^{41}$ En ninguna de las excavaciones modernas que se han publicado hay referencias a la existencia de materiales de época andalusí, ni siquiera en posición secundaria. Vid. FERRERO Ros, Susana y GARCÍASoto MAteos, Ernesto, «Excavaciones arqueológicas en el Atrio de la Iglesia de Nuestra Señora de los Huertos (Sigüenza, Guadalajara)» en Millán Martínez, Juan Manuel y Rodríguez RuzA, Concepció (Eds.), Arqueología de Castilla-La Mancha. Actas de las I Jornadas (Cuenca 13-17 de diciembre de 2005), Cuenca, 2007, pp. 615-640; VEGA RIVAS, Elena, DAZA PARDO, Enrique, LÓPEZ-MuÑIZ Moragas, Gonzalo y MArtínez RAmos, M $\mathrm{M}^{\mathrm{a}}$ Piedad, «Nuevas aportaciones a la investigación de las necrópolis medievales de Sigüenza (Guadalajara): Hallazgos realizados en la Casa del Pintor, calle San Roque, $17 »$ en García-Soto Mateos, Ernesto, GArcía VAlero, Miguel Ángel y Martínez NarAnJo,
} 
algún arco en el interior de algunas viviendas, más propiamente de estilo mudéjar ${ }^{42}$, hacen dudar de una ciudad bien estructurada en el lugar que ocupara la Segontia romana. Quizás debamos pensar más bien en una dispersión de núcleos que explotaran la fértil vega del Henares, encabezados por el hisn de Villavieja que queda en posición preeminente controlando todo el valle.

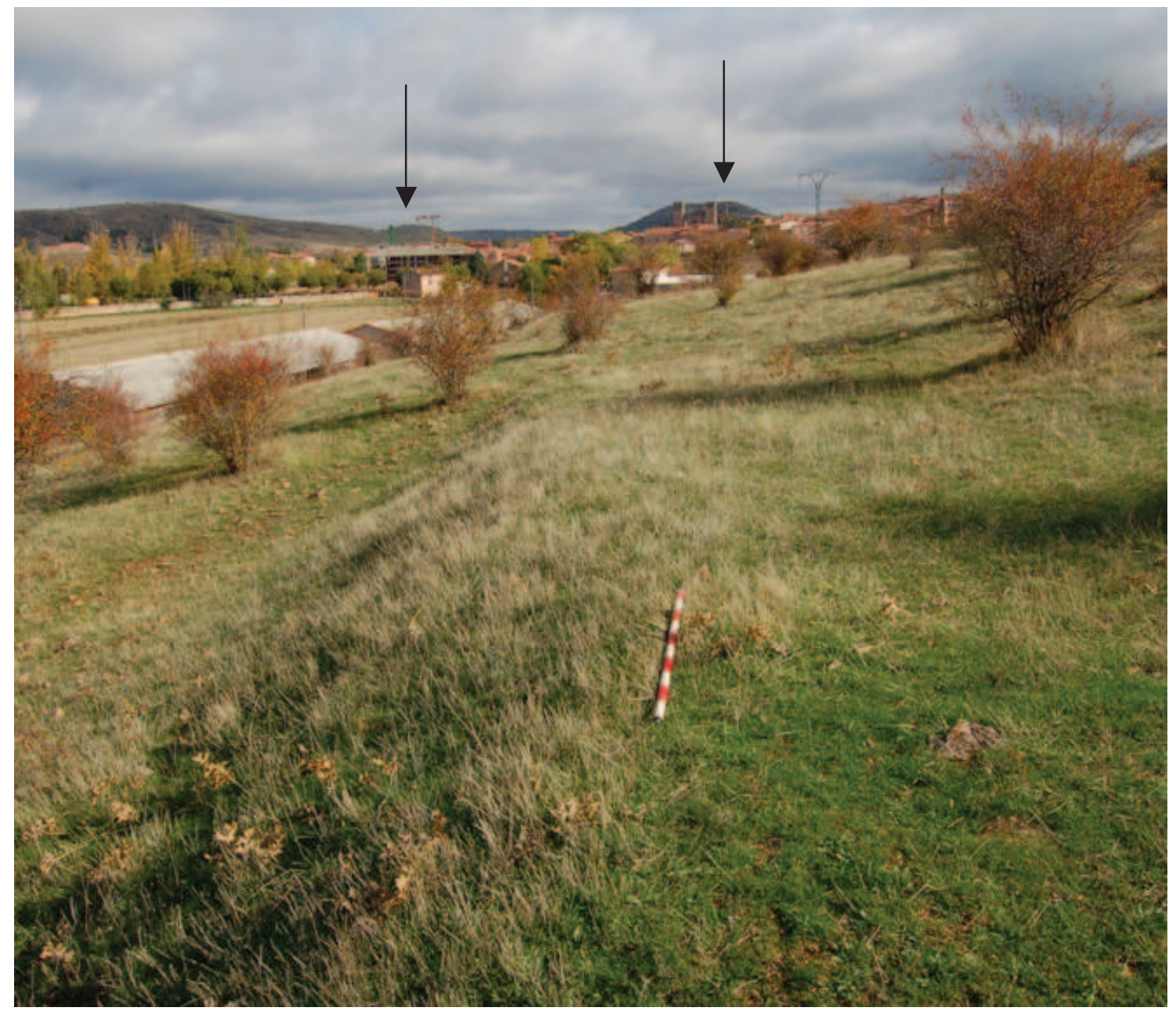

El yacimiento en primer plano con la marca en el terreno de una de las estructuras, y al fondo el yacimiento de Villavieja (izquierda) y la ciudad de Sigüenza (derecha)

Juan Pablo (Eds.), Actas del segundo simposio de Arqueología de Guadalajara. Molina de Aragón, 20-22 de abril de 2006, Madrid, 2008, pp. 299-312; Vela Cossio, Fernando, DAZA PARdo, Enrique, VeGA RIVAS, Elena y VILlAFruEla ARRANZ, Esther, «Noticias de las excavaciones arqueológicas en el claustro de la Catedral de Sigüenza (Guadalajara)» en GARCÍA-SOTO MATEOS, Ernesto, GARCíA VALERO, Miguel Ángel y Martínez Naranjo, Juan Pablo (Eds.), Actas del segundo simposio..., pp. 325-340; Martínez SECO, Paz y Ruiz TreviÑo, Carmen, «Hallazgos más destacados aparecidos en las intervenciones arqueológicas realizadas durante los últimos años en Sigüenza» en GARCíA-Soto Mateos, Ernesto, García Valero, Miguel Ángel y Martínez Naranjo, Juan Pablo (Eds.), Actas del segundo simposio..., pp. 383-400.

42 Pavón Maldonado, Basilio, Guadalajara medieval..., pp. 143-150. 
Cabría citar algunos de estos pequeños núcleos agrícolas que conocemos por la bibliografía, como es Alboreca ${ }^{43}$, o por una topónimia que nos remite a época andalusí, como Alcuneza o Bujarrabal. Incluso, de haber algún tipo de núcleo en el lugar que hoy ocupa la propia ciudad seguntina, quizás hubiera que pensar en otro más de estos pequeños núcleos rurales. Esta densidad de ocupación, que puede verse justificada por el nudo de comunicaciones que es la comarca seguntina ${ }^{44}$, nos hace pensar también en la no existencia de un núcleo de más envergadura que pueda ser considerado como madina, siendo Villavieja el núcleo central. Este hisn se vería apoyado por las torres que debería haber a lo largo del curso del Henares, alguna de las cuales ha podido documentarse como es el caso de la atalaya del «cerro de la Quebrada» ${ }^{45}$ o las más conocidas de Barbatona y la ya citada de Bujarrabal ${ }^{46}$.

\footnotetext{
${ }^{43}$ Alboreca, situado en un estrecho valle que desemboca en el del Henares, es el lugar donde tuvo lugar una de las batallas citadas en las fuentes escritas: en el año 974 el conde de Castilla García Fernández va a ir primero contra la plaza de Deza para intentar posteriormente el ataque a Medinaceli y en su retirada va a asolar las tierras del Alto Henares, momento en el que obtiene una resonada victoria en Alboreca sobre los musulmanes que pretendían cortarle el paso. ZAMORA LUCAS, F., «Batallas de Deza y Almenar en el año 974», Celtiberia, 22 (1981), pp. 261-265.

${ }^{44}$ GARCÍA-Soto MATEOS, Ernesto, «La comarca seguntina en época islámica, siglos VIII a XII», Anales Seguntinos, 21 (2005), p. 35.

${ }^{45}$ GARCÍA-SOTO MATEOS, Ernesto y FerRero Ros, Susana, «La Atalaya islámica...»

${ }^{46}$ Valiente Malla, Jesús, Guía de la Arqueología... pp. 54-55; PavÓn Maldonado, Basilio, Guadalajara medieval..., pp. 151-152; HeRrerA CASADO, Antonio «La Marca Media de al-Andalus en tierras de Guadalajara», Wad-al-Hayara, 12 (1985), pp. 24-25.
} 


\section{Nombre CASTILLO DE BAIDES}

Localización En la sierra que se sitúa a las espaldas del actual pueblo de Baides. Se accede por una pista rural que parte de la iglesia del pueblo.

Siglas MG08/069/BA-05

Coordenadas 305188634539418

Tipo de yacimiento En altura

Estado actual En la actualidad es propiedad privada. El dueño de los terrenos ha construido un puesto de caza en el punto más alto del yacimiento, directamente sobre los restos de una de las torres. Salvo por esta afección, el yacimiento no parece haber sido alterado más que por los agentes naturales.

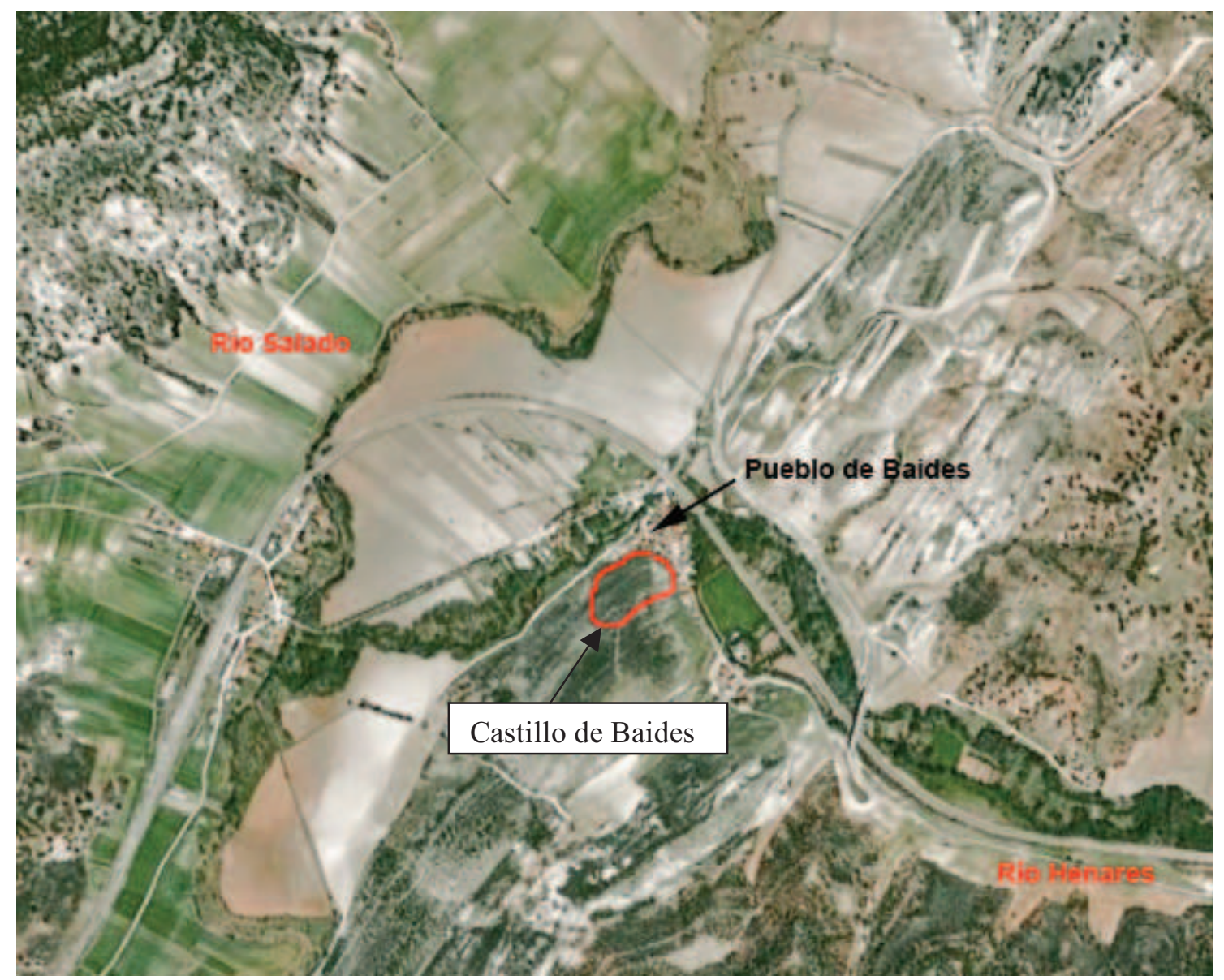

Descripción del yacimiento Castillo de Baides (GU-BA-05) situado en la montaña que queda al Sur del actual pueblo de Baides y al Este del municipio que ha surgido en torno a la estación de tren del mismo municipio. Junto al abundante material cerámico, se reconocieron bastantes estructuras, líneas de muros, saltos topográficos que revelan más estructuras (muros y hoyos), y una especie de torreón de tapial de calicanto en el centro del monte. 
El Castillo es conocido, y ha sido descrito por varios investigadores ${ }^{47}$. El castillo que hoy puede verse, resultado de las reformas que se documentan en el siglo $\mathrm{XV}$, tiene planta cuadrada con torres de igual forma en los ángulos; ese recinto torreado, de 100 metros cuadrados, se encontraba precedido del lado del pueblo por una especie de albacar de más de 150 metros cuadrados, aparte de la amplia explanada de acampadas con más de 40 metro de longitud en la parte opuesta ${ }^{48}$.

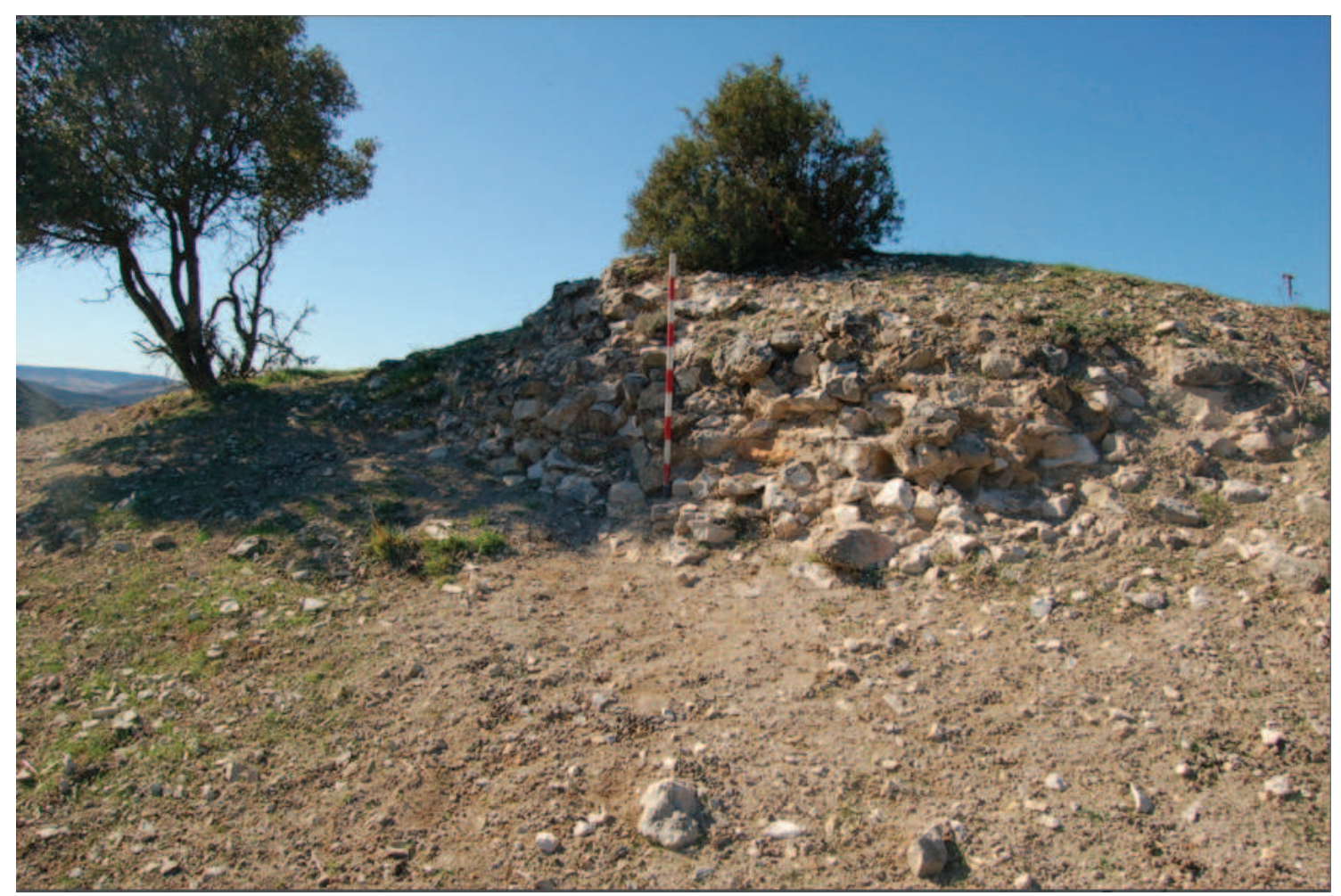

Relación con el medio físico y el recurso salino Se sitúa en un elevado cerro a cuyos pies los ríos Salado y Henares se unen, en una posición estratégica que le permite controlar todo el transcurso del Salado desde que abandona el valle del Atance, donde en la actualidad hay un pantano. Precisamente es a partir de ese punto de El Atance donde el río pierde su característica salinidad, y desde aquí hasta que vierte sus aguas bajo el castillo de Baides no se vuelve a documentar explotaciones salineras alguna. Por el contrario, todo el valle que ahora forma ha generado unas zonas de amplias vegas, especialmente notables en el entorno del castillo que ahora nos ocupa. Además, Baides se encuentra rodeado de montes que forman parte de la Sierra de la Muela, quedando algo encajonado en el estrecho valle que se abre en la comarca de las Serranías de Guadalajara.

\footnotetext{
${ }^{47}$ Layna Serrano, Francisco, Castillos de Guadalajara ..., pp. 33 y 103; PAVOn Maldonado, Basilio, Guadalajara Medieval..., pp. 73 y ss. y planta p. 78

${ }^{48}$ PaVON MALDONADO, Basilio, Guadalajara Medieval..., pp. 73 y ss. y planta p. 78.
} 
Propuesta de interpretación Como señala Pavón Maldonado, Baides probablemente derive de al-bayda - la blanca - si se tiene en cuenta que allí han existido de siempre tierras yesosas actualmente en explotación, si es que no era la enigmática Eliph mencionada en la Primera Crónica General de la que ya hablamos en otro capítulo ${ }^{49}$. En cualquier caso, se trata de una de las más destacadas fortalezas de toda el área, tanto por sus dimensiones, como por su control visual y sobre todo por su dominio de los dos valles de los ríos Salado y Henares y de las vías de comunicación que ambos establecían.

\footnotetext{
${ }^{49}$ Pavon Maldonado, Basilio, Guadalajara Medieval..., p. 73.
} 


\section{ASENTAMIENTOS ALTOMEDIEVALES DEL VALLE DEL SALADO Y SU RELACIÓN CON LAS EXPLOTACIONES SALINERAS}

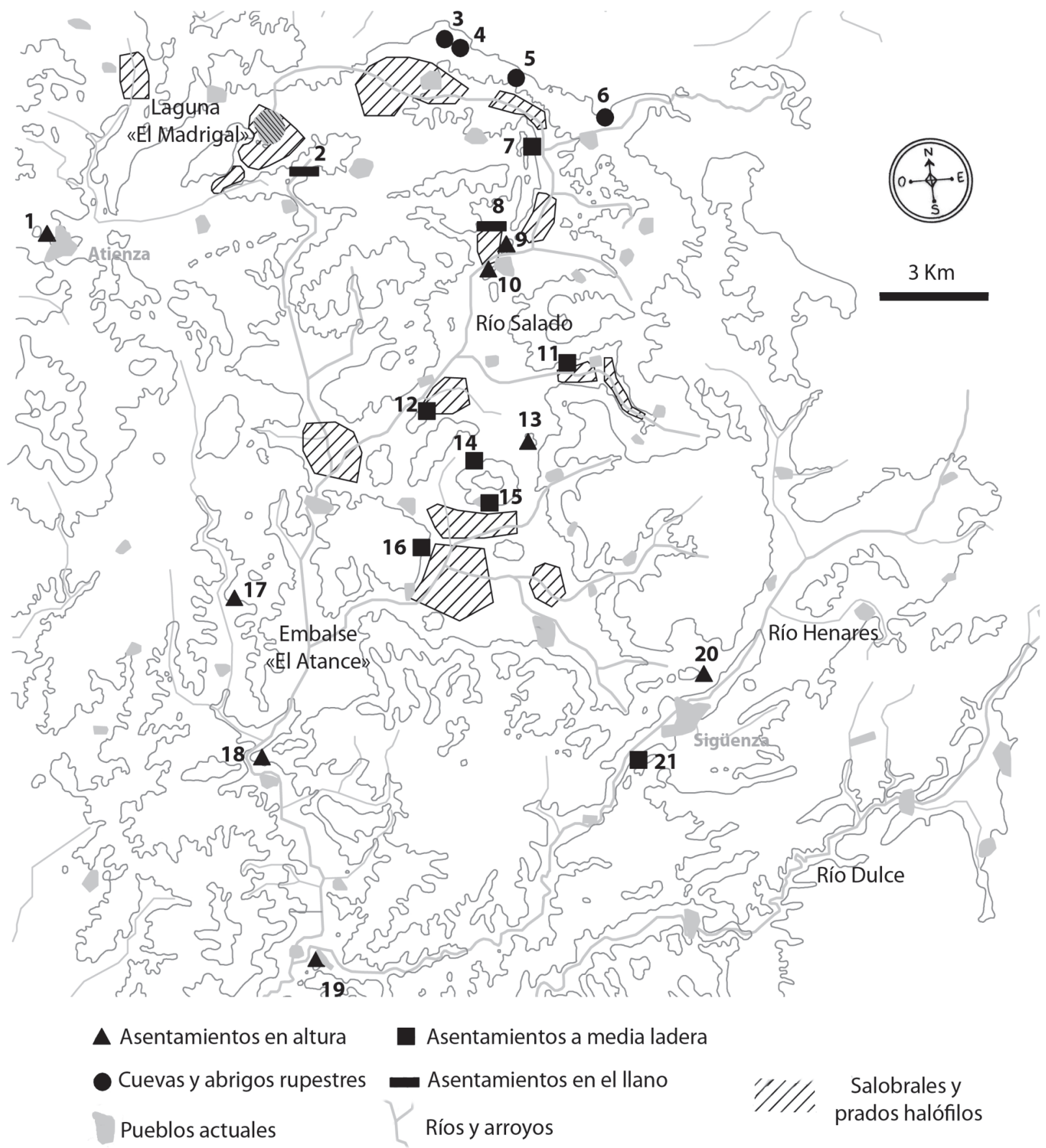

1.- Atienza 2.- asentamiento en el Ilano de Alcolea de las Peñas 3.- Los Poyatos 4.- Las Conejeras 5.- Las Calzadizas 6.- Cueva de Valdelcubo 7.- Corrales de El puente 8.- La Alquería 9.- Castillo de Riba de Santiuste 10.- Castillejo frente a la Riba 11.- Yacimiento de Villacorza 12.- Imón 13.- Castro de Riosalido 14.- Cerrillo de Las Monjas 15.- Bujalcayado 16.- Bonilla 17.- Castillo de Santiuste 18.- Castillo de Huérmeces del Rio 19.- Castillo de Baides 20.- Yacimiento de Villavieja (Sigüenza) 21.- La Quebrada 


\subsection{SAL, SALINAS, AGUAS SALADAS Y PRADOS HALÓFILOS EN EL VALLE DEL SALADO}

Uno de los principales aspectos que caracterizan y dan personalidad propia al valle del Salado es la abundancia de sal que encontramos tanto en los suelos arcillosos y yesíferos de la región, como disuelta en los diferentes cursos de agua.

El aprovechamiento de este recurso salino ha dado lugar a un buen número de construcciones para su explotación: las salinas. Responden al modelo tradicional, y en cierta forma endémico, que encontramos en la Península Ibérica: una serie de albercas de grandes dimensiones y poco fondo, realizadas en materiales muy básicas como adobe y mampostería, que sirven para almacenar el agua y provocar su evaporación con el objetivo de obtener la precipitación y concentración de la salmuera hasta que quede en grano, permitiendo una «cosecha» de la sal ${ }^{1}$. Toda esta área ha generado unos paisajes particulares que, afortunadamente, han sido protegidos, si bien se presta más atención a los aspectos físicos y biológicos que a los patrimoniales.

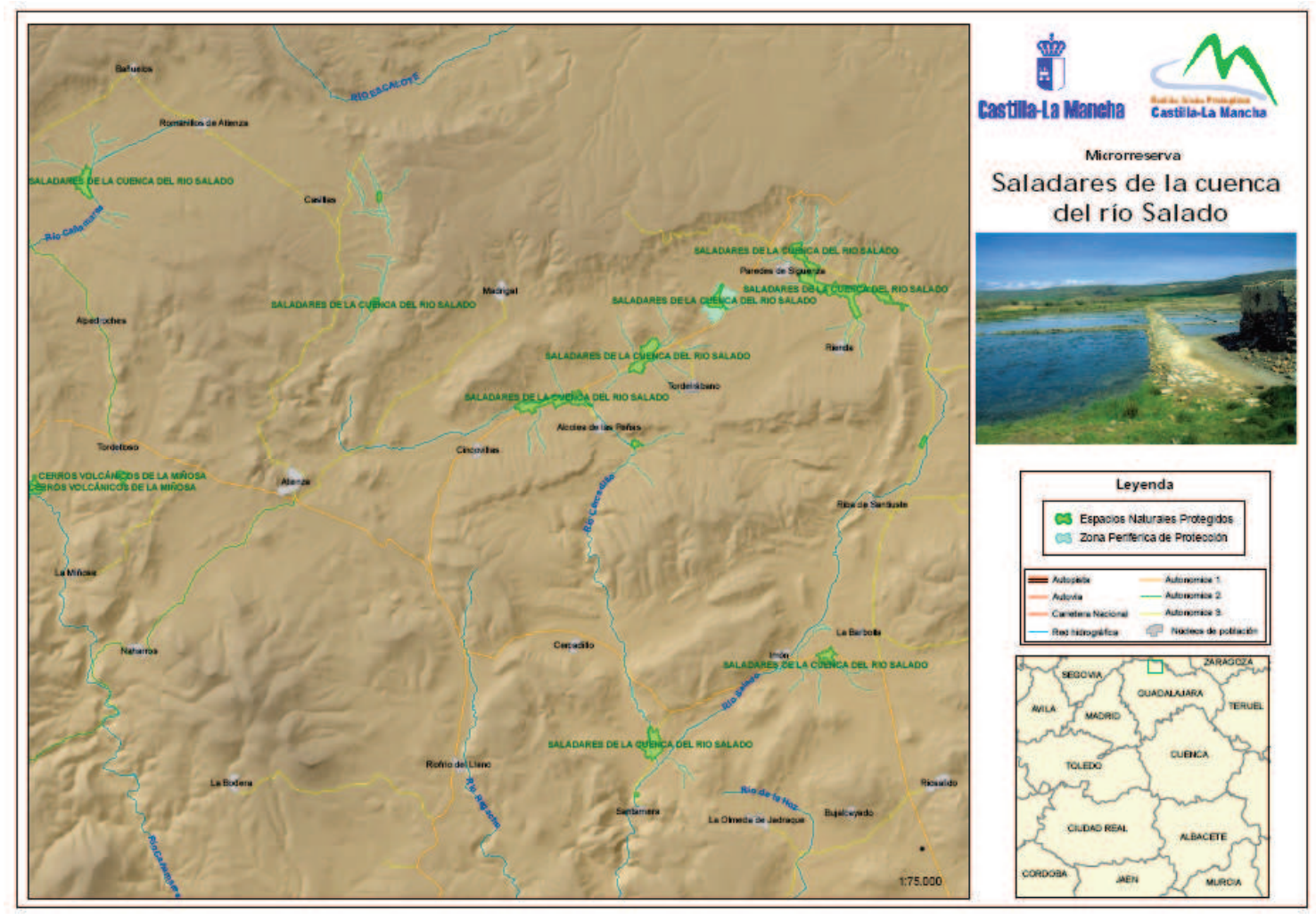

Es nuestra intención en este capítulo ofrecer algunas reflexiones sobre la posible explotación de las distintas salinas que encontramos en el valle del Salado durante el período que nos interesa. Muchas de ellas tienen un origen medieval posterior a la llegada de los castellanos, como queda contrastado a través de la documentación escrita,

\footnotetext{
${ }^{1}$ Todo el proceso ha sido explicado en otro apartado de este mismo trabajo.
} 
aunque no podemos precisar nada más atrás del siglo XII. Es precisamente a raíz de la conquista cristiana cuando varios de estos centros salineros aparecen en la documentación, en distintas donaciones que los monarcas hacen a los obispos o al cabildo catedralicio de Sigüenza, y con posterioridad irán apareciendo también en documentación privada o incluso en otras fuentes menos habituales ${ }^{2}$.

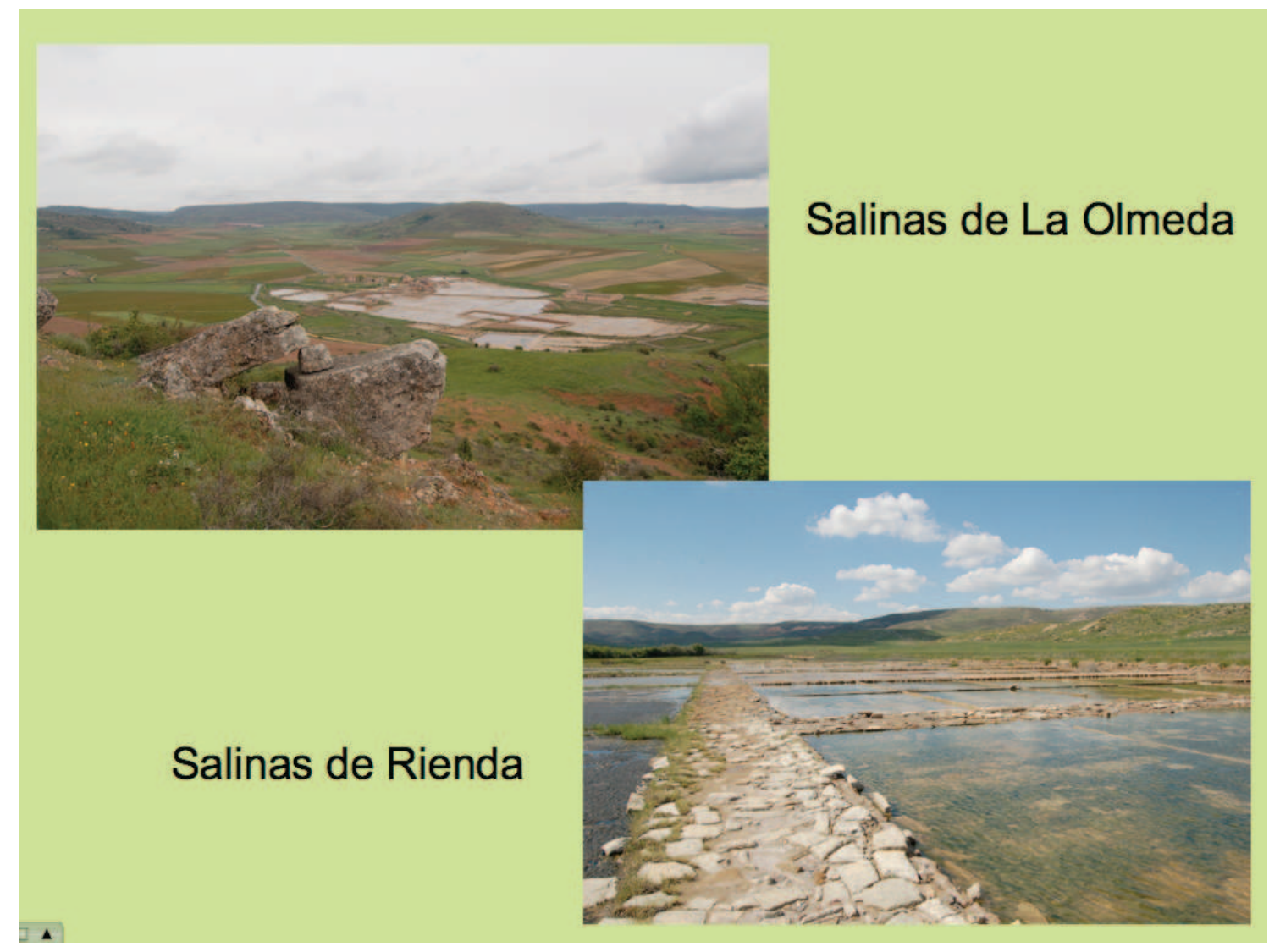

Hay constancia documental y material de cómo todo este valle ha estado volcado hacia la producción de sal, al menos con seguridad indiscutible desde la Baja Edad Media. Las salinas de estas tierras aparecen citadas desde el siglo XII prácticamente en todos los documentos que guardan relación con la comarca, especialmente en relación al señorío episcopal de Sigüenza. Se debió a sus especificas condiciones geológicas, dando lugar a una de las regiones salineras de interior más importantes de la Península Ibérica. El área norte de Guadalajara es una de las zonas más significativa en producción de sal, como queda patente si observamos los datos cuantitativos desde el siglo XV: En el 1482 la región producía 1.600.000 maravedíes de renta de sal, frente al 1.060.00 de las salinas de Espartinas, o los $500.000 \mathrm{mrs}$ que se cifran para toda la provincia de Granada algunos años después, en 1494. En los primeros años del siglo XVI, en 1503-1504

\footnotetext{
${ }^{2}$ Por ejemplo, hay referencias en el Libro de Caza de Don Juan Manuel. Llanos MARTínez CARRILlo, María de los, «El obispado de Sigüenza en el Libro de caza: un itinerario geográfico», Don Juan Manuel VII centenario, Murcia, 1982, pp. 187-198.
} 
nuestra región ya producía 3.860.000 mrs., mientras que Espartinas, la siguiente de la lista, situada en la parte sur del Jarama, en el término de Ciempozuelos, en la zona meridional de Madrid, no llegaba al millón y medio, quedándose en 1.414.000 mrs., seguida de Avilés con 1.161.000 mrs. y la región granadina con 985.000 mrs. Hacia 1532, las salinas de Atienza producían $6.384 .000 \mathrm{mrs}^{3}$. Y todo ello antes de que se produjese el estanco real. Entre 1565 y 1566 los cargos líquidos al distrito de Atienza de la renta de salinas alcanzó la cifra de 27.839 .873 mrs., seguidas por toda Castilla la Vieja con 13.362.769 mrs., Galicia con 11.698.936 mrs., y las salinas de Espartinas con 9.092.600 mrs. ${ }^{4}$. Estas cifras dan una idea de la importante producción de sal en la comarca, que abastecía a todas las extremaduras entre el Duero y el Sistema Central, e incluso algunos puntos al sur, y desde la frontera de Aragón hasta Portugal ${ }^{5}$.

Fruto de esta intensa actividad, que se acelera entre finales de la Edad Media y principios de la Edad Moderna aunque tiene notables precedentes anteriores, nos encontramos ante unos «paisajes de la sal» muy característicos, que encuentra en las salinas y los entornos de Imón y de La Olmeda sus principales referentes, aunque no sólo, ya que hay salinas al menos otras diez salinas que estuvieron en funcionamiento en la zona en distintas épocas: Alcuneza, El Atance, Bujalcayado, Carabias o Malpica, Paredes de Sigüenza, Riba de Santiuste, Rienda, Santamera o Gormellón, Tordelrábano y Valdealmendras ${ }^{6}$.

\footnotetext{
${ }^{3}$ Datos ofrecidos por UlloA, Modesto, La Hacienda real de Castilla en el reinado de Felipe II, Madrid, 1977, p. 383.

${ }^{4}$ UlloA, Modesto, La Hacienda real..., p. 397. Esta superioridad en cifras se mantendrá a lo largo de la Edad Moderna y durante todo el siglo XIX. Vid. Plata MonTERO, Alberto, El ciclo productivo de la sal y las salinas reales a mediados del siglo XIX, Vitoria-Gasteiz, 2006, passim.

5 LADERo QueSADA, Miguel Ángel «La renta de la sal en la Corona de Castilla (siglos XIII-XVI)», Homenaje al Profesor Juan Torres Fontes, Murcia, 1987, p. 828.

${ }^{6}$ García-Soto Mateos, Emilio y Ferrero Ros, Susana, «Estudios de algunos complejos salineros contemporáneos de las comarcas de Atienza y Sigüenza: Cercadillo, Santamera, Bujalcayado-La Olmeda de Jadraque, El Atance y Cirueches», Wad Al Hayara, 23 (2007), pp. 85-120.
} 


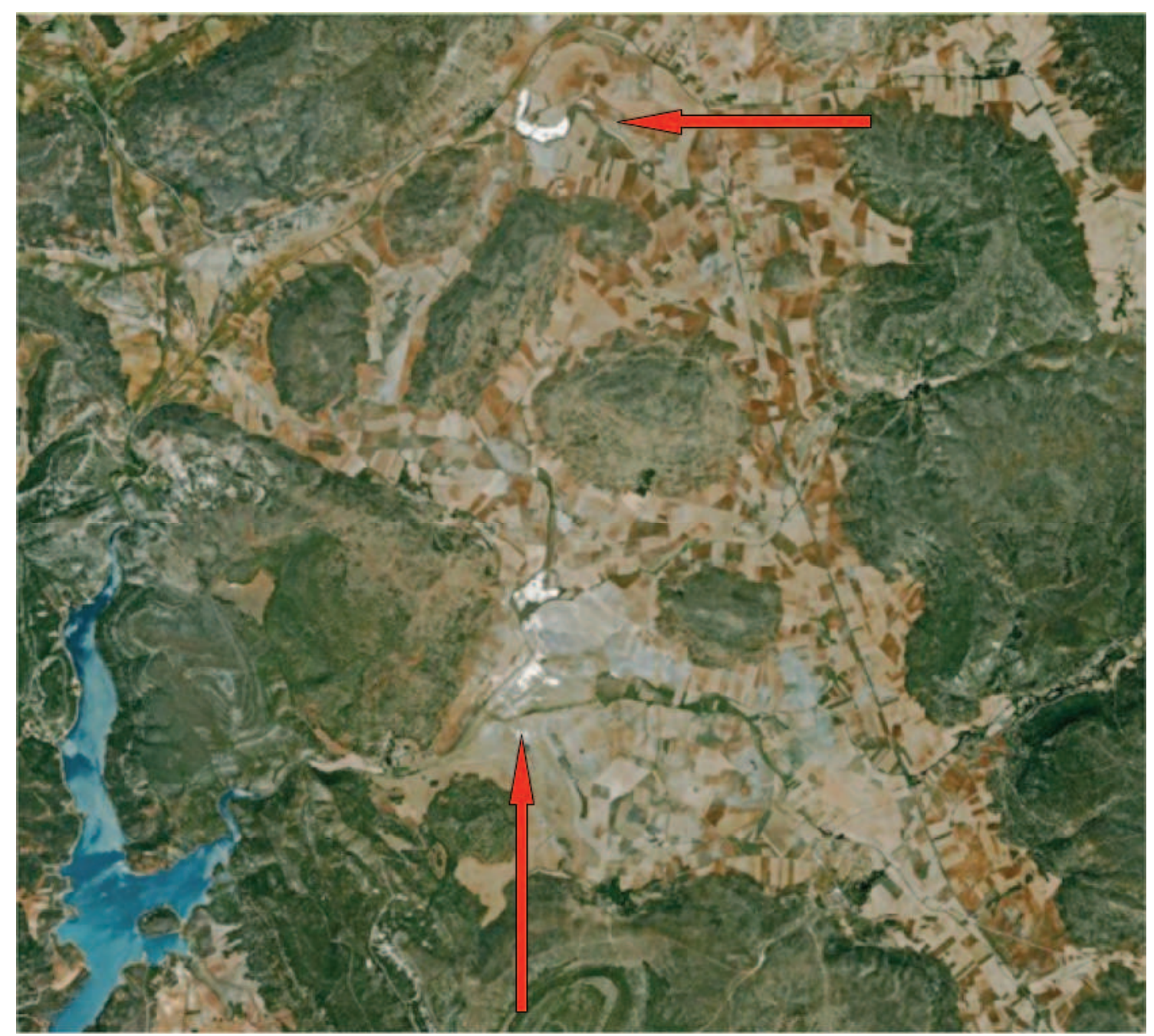

Conjuntos de salinas de Imón (arriba) y La Olmeda (abajo)

Dentro de estos paisajes, dos han sido los municipios que han capitalizado el protagonismo de toda esta región salinera desde un punto de vista jurídico y administrativo a lo largo de la Historia: Atienza y Sigüenza, situadas en los dos extremos últimos del propio valle del Salado, y ambas en la intersección de importantes vías y ejes de comunicación que facilitarían además el almacenamiento y la salida comercial de la sal. Especialmente importante en tal sentido es el caso de la ciudad seguntina, quien emerge a partir del siglo XII como capital del Señorío Episcopal ubicándose en la vía natural suroeste-noreste recorrida por el río Henares. Parece quedar clara la importancia de este núcleo y su territorio en relación con la explotación de la sal desde época protohistórica y en época romana ${ }^{7}$, y más aún si cabe desde el momento de la conquista castellana y a lo largo de toda la Baja Edad Media y la Edad Moderna, como se deduce del examen de la documentación conservada en los archivos de

\footnotetext{
${ }^{7}$ Morère Molinero, Nuria, «L'exploitation romaine du sel dans la région de Sigüenza» Gerion, 3 (1991), pp. 223-235; MorÈre Molinero, Nuria, «La sal en el desarrollo histórico de Sigüenza. Los primeros siglos» en MoRère, Nuria (ed), Las salinas y la sal de interior..., t. 1, pp. 3-30; TALAVERA CostA, Julián, «La sal en la comarca de la Sigüenza arévaca: ¿riqueza natural-riqueza social?», en MORĖRE, Nuria (ed), Las salinas y la sal de interior..., t. 1, pp. 241-262.
} 
Sigüenza ${ }^{8}$. La Colección diplomática que presentó hace ya un siglo Toribio Minguella recoge un gran volumen de documentación en el que las referencias a las salinas en la comarca de Sigüenza y Atienza y los impuestos y conflictos que generan son constantes entre los siglos XII al XIII ${ }^{9}$. No obstante, queda la duda respecto a la época altomedieval, es decir, aquella comprendida entre la desintegración del sistema político y económico de Roma y el cambio de milenio, lo que en nuestro caso concreto se traduce en un período cronológico que abarca desde el siglo IV hasta el siglo XII aproximadamente.

Para este período no podemos asegurar con total seguridad que estas instalaciones existieran, aunque tenemos algunos indicios que así nos lo hacen sospechar.

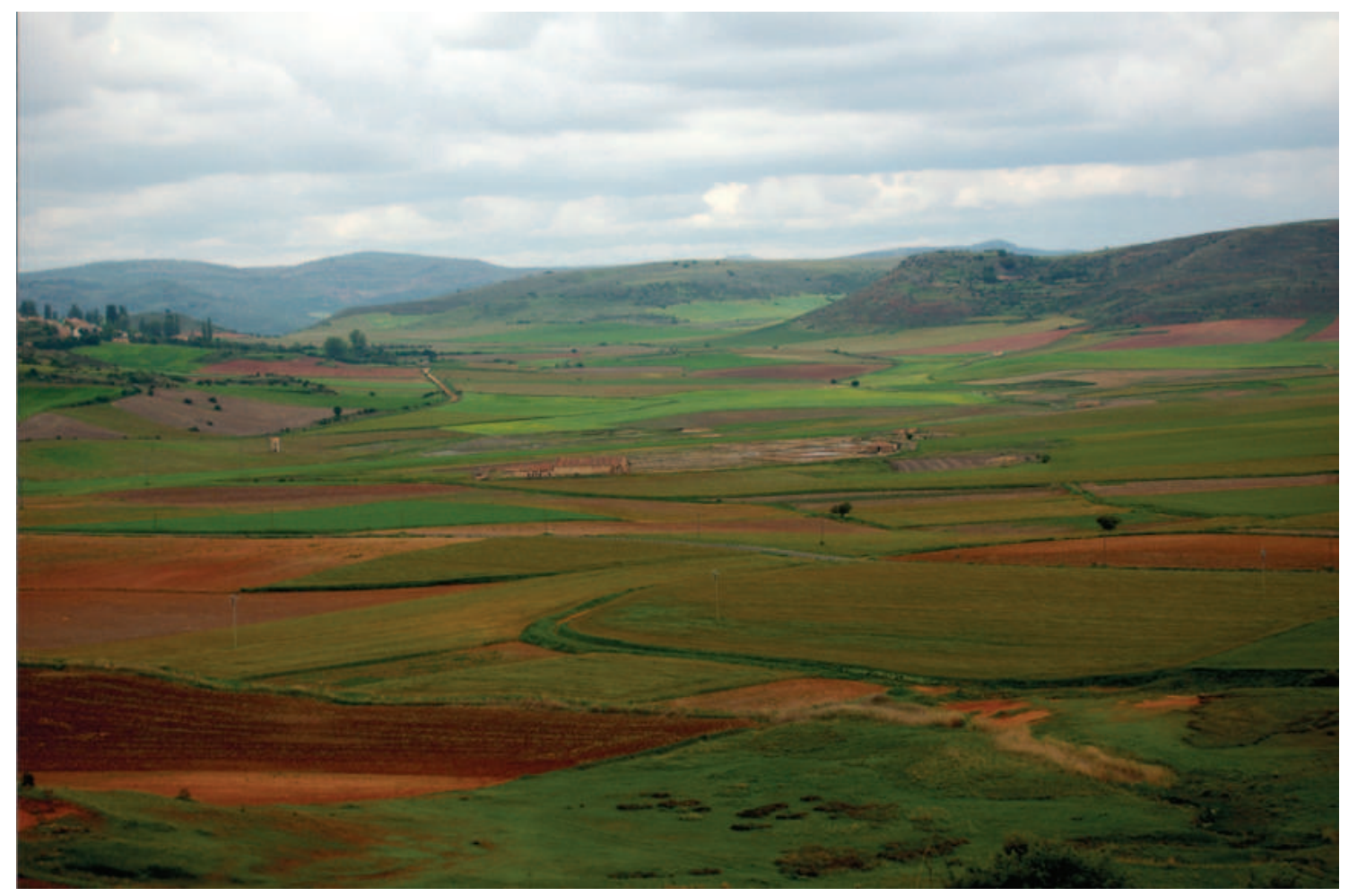

Salinas de Bujalcayado rodeadas de prados halófilos

Estos indicios son triples. Por un lado, el volumen y distribución del poblamiento que podemos fechar en época andalusí a lo largo del valle y las sierras de alrededor. La proliferación de centros de pequeño tamaño en relación directa a las regiones más prolíficas en recursos salinos, allí donde precisamente se constata la existencia de salinas o bien donde abundan los prados halófilos, nos hace pensar que en la ubicación

\footnotetext{
${ }^{8}$ DONDERIS GUASTAVINO, Amparo, «Historia de la sal y las salinas: fuentes para su estudio en el archivo municipal de Sigüenza» en MORÈre MOlinero, Nuria (ed), Las salinas y la sal de interior..., pp. 31-44. ${ }_{9}^{9}$ Minguella, Toribio, Historia de la diócesis de Sigüenza..., Vol. I, Colección diplomática, pp. $345-$ 651.
} 
de éstos hay una lógica económica, en la que la sal está presente, aunque no sólo ${ }^{10}$. En segundo lugar, la propia infraestructura hidráulica de las salinas que nos aproxima a las prácticas hidráulicas de la agricultura de regadío en la que se basó, en gran medida, el modo de vida campesino de los andalusíes ${ }^{11}$. Incluso, algún autor ha querido ver en la técnica de extracción de la salmuera para las salinas un origen en la tradición musulmana $^{12}$. En tercer lugar, en la documentación cristiana inmediatamente posterior a la conquista se cita la existencia de salinas en los repartimientos que se llevaron a cabo. Valga como ejemplo los siguientes:

«...facio cartam donationis sancti Mariae seguntine ecclesie et tibi venerabile ejusdem sedis episcopo domino Bernardo tuisque succesoribus ibi deo canonice servientibus de castro sancti justi cum omnibus suis hereditatibus, et cum illa villa de la Riba cum toto suo directo videlicet cum salinis, portaticis, pratis, turribus, molendinis, montibus, fontibus, exitibus et regressibus, et cum omnibus terminis qui ad illud castellum pertinent jure hereditario pro ut regale jus exigit.» ${ }^{13}$

Se trata de una concesión de Alfonso VII al obispo don Bernardo y al cabildo en 13 de julio de 1124, tan sólo seis meses después de la conquista castellana, y que ofrece la imagen de un territorio bien conformado y estructurado en el que se identifican una serie de elementos, como molinos y fuentes, así como una serie de espacios, como montes y prados, y lo que más nos interesa, se dona el castillo y la villa con sus salinas. Valga también como ejemplo la donación del mismo monarca al obispo y la iglesia de Sigüenza de ciertos derechos reales en noviembre del mismo año 1124, entre los que se encuentran tanto la décima sobre el pan, el vino y la sal como también la tenencia en servidumbre de moros y judíos:

\footnotetext{
${ }^{10}$ Es la misma lógica de ocupación del espacio y uso de los recursos inmediatos, tanto del agua dulce como del agua salada y de las zonas de cultivo y de pastos, que se detecta en otras zonas de la Península en las que la sal está presente, como por ejemplo las salinas de La Malaha, en Granada. TriLlo SANJosÉ, Carmen, «Los diferentes aprovechamientos del agua en una alquería del reino de Granada: La Malahá, del distrito del Quempe», Agricultura y regadio en Al-Andalus, sintesis y problemas: Actas del coloquio, Almería 9 y 10 de junio de 1995, Almería, 1995, pp. 215-228; RUIZ JiMÉNEZ, Ana, Las salinas de la Malaha, Proyecto de investigación inédito. Granada, 2007; Idem, «Estudio arqueológico del entorno de las salinas de la Malahá», Edicicón online http://arqueologiamedieval.com/articulos/articulos.asp?ref=97; MALPICA CUELLO, Antonio, «Análisis de las salinas medievales desde la Arqueología del Paisaje», en MorÉre Molinero, Nuria (Ed.), Las salinas y la sal de interior en la Historia: economía, medio ambiente y sociedad, Madrid, 2008, t. I, pp. 469-498; Idem, «El medio físico y la producción de sal. Propuestas para el análisis de las salinas granadinas desde una perspectiva arqueológica», Martín Civantos, José María (Ed.), Medio ambiente y Arqueología Medieval, Granada, 2008, pp. 145-162.

${ }^{11}$ Barceló, Miquel, Kirchner, Helena, NAVArRo, Carmen, El agua que no duerme. Fundamentos de la arqueología hidráulica andalusí, Granada, 1996.

${ }^{12}$ CRUZ García, Oscar, «Norias de tradición mudéjar en las salinas de Imón (Guadalajara)», Revista de Folklore, 107 (1989), pp. 147-166.

${ }^{13}$ Minguella, Toribio, Historia de la diócesis de Sigüenza y sus obispos, Madrid, 1910, Vol. I, Colección diplomática n ${ }^{\circ}$ II, p. 348.
} 
«...Totam decimam partem omnium regalium et forum omnium videlicet redituum qui regalis juris ad preseas esse videntur vel in antea adquiri poterir in atencia in medina et in sancto justo et in aldeis forum decimam scilicet partem panis et vidis et salis et tocius portatici (...) Concedo etiam illi ut christiani mauri sive Judea quicumque ejes servitia tenuerint ut ipsius sint et ejes pendant judicium et nullum alium dominum habeant.» ${ }^{14}$

Estas breves citas, si bien hay que tomarlas con cautela ya que estas fórmulas son generales por lo común, pueden indicarnos que el recurso salino ya debía ser explotado con anterioridad, pues no parece posible que toda la infraestructura necesaria para su explotación, y por consiguiente, para su identificación como uno de los elementos dignos de mención en la concesión real, se realizara en los escasos seis meses que transcurren desde la conquista, tal y como se menciona en el primero de los textos. Aunque sean tan sólo sugerencias, creemos que deben ser tenidas en cuenta a la hora de considerar la explotación de sal por parte de los andalusíes en los momentos previos a la conquista castellana.

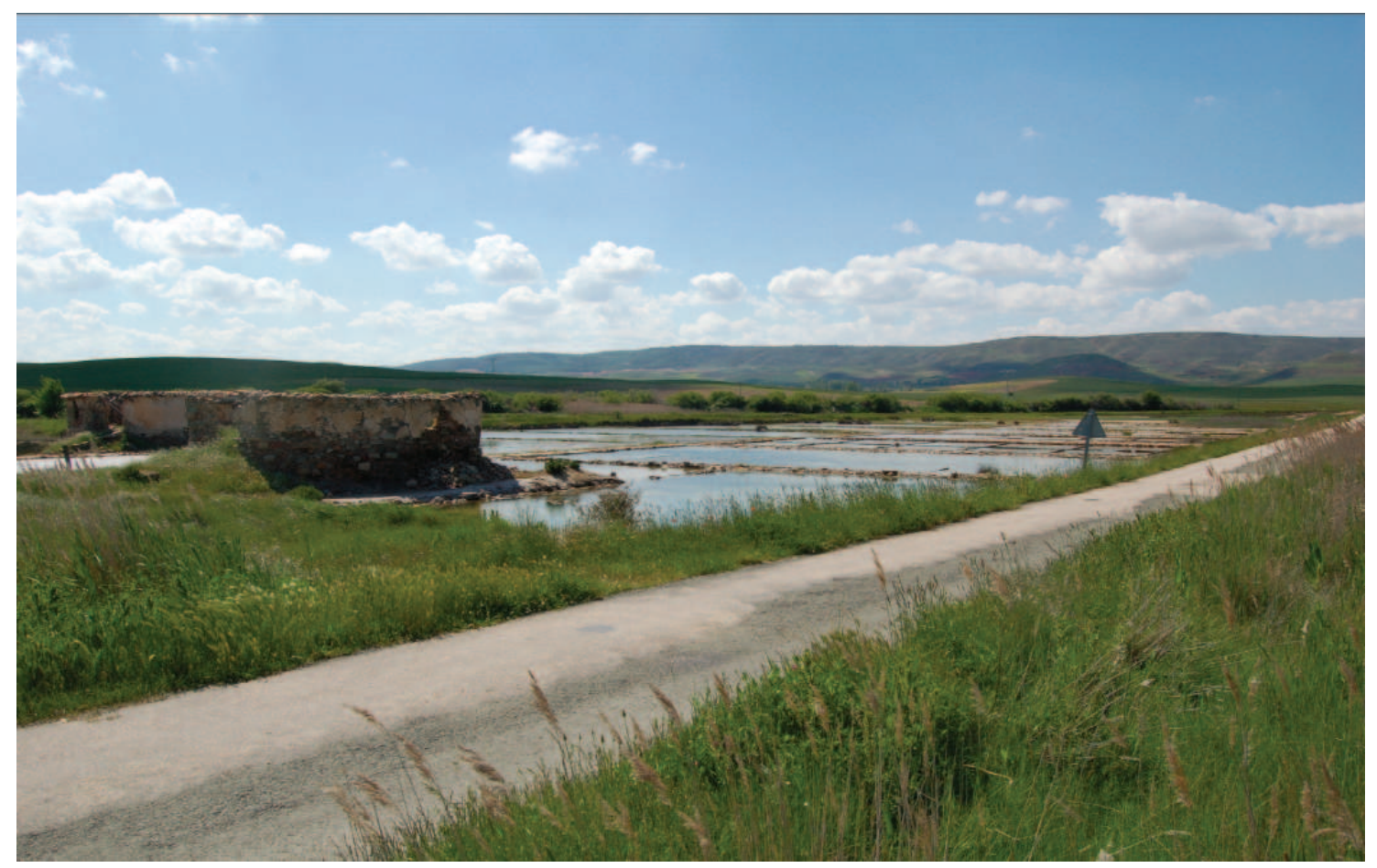

Salinas de Rienda, con la estructura de la noria a la izquierda y las balsas a la derecha

El estudio directo de los centros salineros de la comarca con una metodología arqueológica está aún por hacer, aunque su descripción más o menos minuciosa,

\footnotetext{
${ }^{14}$ Minguella, Toribio, Historia de la diócesis ..., p. 349.
} 
atendiendo sobre todo a os vestigios de su arquitectura industrial, ha sido abordado por distintos investigadores ${ }^{15}$.

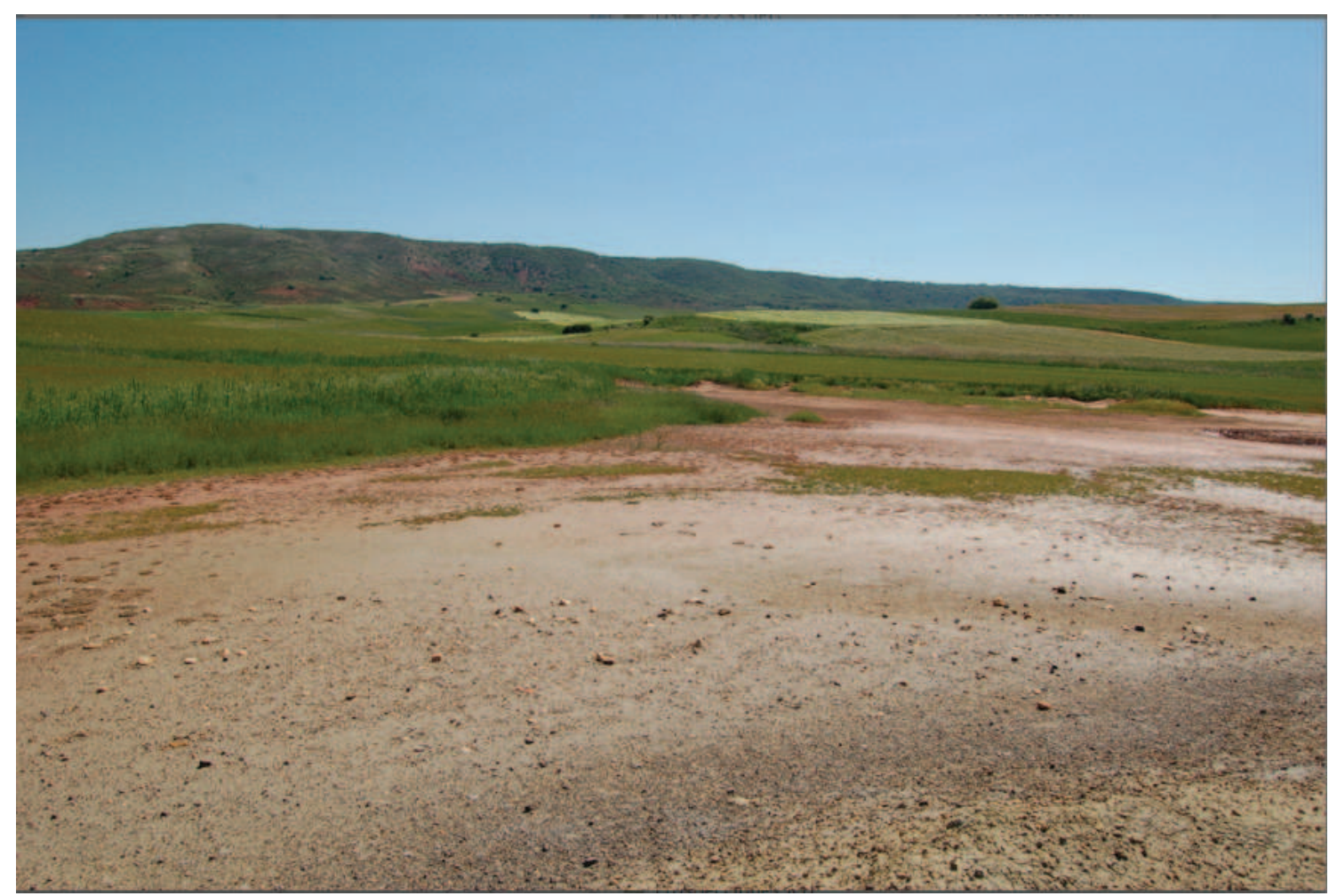

Huellas en el terreno de la antigua existencia de las salinas de los Rivachos

Desde un punto de vista arqueológico el estudio de las producción de sal es muy difícil. No hay documentados en ningún caso, ni siquiera en los yacimientos prehistóricos del valle, de explotación de sal por ignición, ni existe ningún tipo cerámico directamente relacionado con la manufactura de la sal como ocurre en Centroeuropa con los «briquetage». Tampoco la sal es un elemento que se pueda constatar en el registro arqueológico, por lo que la excavación arqueológica de alguno de los yacimientos localizados, tampoco arrojaría una solución directa a esta cuestión. Sólo nos quedaría, por tanto, investigar los propios centros productivos. Pero hay un problema, que es doble. Por un lado, las pequeñas explotaciones, que debieron ser las más frecuentes y de las que hemos encontrado un buen número en distintas zonas, por ejemplo junto a

\footnotetext{
${ }^{15}$ Además de nuestras observaciones de campo como resultado de las prospecciones arqueológicas que hemos llevado a cabo, nos basamos para la descripción de las distintas salinas en LÓPEZ GÓMEZ, A., «Salinas de la comarca de Imón (Guadalajara)», Revista de Estudios Geográficos, 122 (1970), pp. 371394; GARCIA GRINDA, José Luis, «Las salinas de Imón, en Guadalajara: parte de un conjunto salinero», Q. Revista del Consejo Superior de los Colegios de Arquitectos, 64 (1984), pp. 28-35; Trallero SANZ, Antonio, Arroyo SAn José, Joaquín y Martínez SeÑor, Vanesa, Las salinas de la Comarca de Atienza, Guadalajara, 2003; Hueso KortekAas, Katia y CARrasco VAyÁ, Jesús-F., «Las salinas de Imón y de La Olmeda (Guadalajara): historia de la creación de un paisaje de la sal», RIVERA BLANCO, J. J. (Coord.), Actas del V Congreso Internacional "Restaurar la Memoria" patrimonio y territorio Valladolid, 2006, Valladolid, 2007, vol. 1, pp. 507-510.
} 
Alcolea de las Peñas o en la zona entre Valdelcubo y Sienes, tienen una infraestructura mínima que además debe ser mantenida constantemente, limpiando albercas y canales, al igual que es necesario hacer con cualquier infraestructura hidráulica. Abandonado el mantenimiento de estas instalaciones, van paulatinamente desapareciendo, dejando una huella apenas imperceptible en el terreno, como hemos podido documentar. En muchas ocasiones sólo se detecta una serie plataformas llenas de barro a las que llegan o desde las que parten canales de agua, hoy ya secos y en el entorno una abundante vegetación halófila.

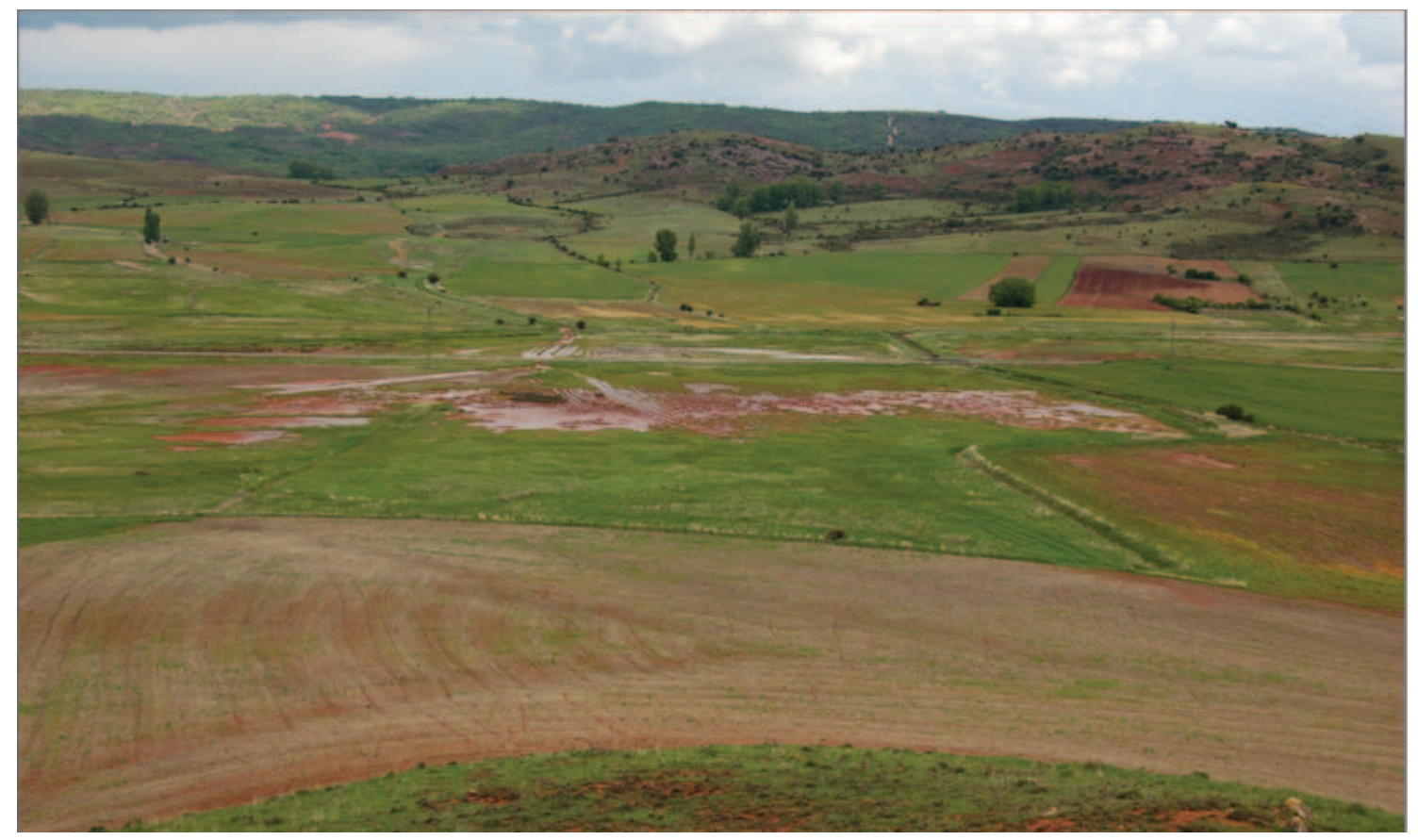

Evidencias en el paisaje de la existencia de unas salinas en el municipio de Tordelrábano

En cambio, cuando estas salinas constituyen grandes centros salineros, con una arquitectura mayor que ha perdurado en el tiempo, por ejemplo Imón, Bujalcayado o La Olmeda, se han convertido en centros de «éxito», perpetuándose en el tiempo, en muchos casos hasta hoy en día. Las reformas que han sufrido han borrado prácticamente las estructuras originales, cuando no se han desmontado por completo o se ha excavado el terreno para lograr alcanzar la capa freática, como ocurre en alguno de los centros del valle del Salado. Estas reformas de las salinas, con sus rebajes de cota que probablemente puedan fecharse en época de Carlos III ya que es en el siglo XVIII cuando hay un auge de su explotación, han acabado por camuflar o desaparecer los vestigios de las construcciones originales que pudiéramos datar en época andalusí. A pesar de todos estos problemas, encontramos una serie de indicios de carácter indirecto en la propia evolución de los centros productivos, como es su propia distribución. En las salinas de Imón, el mayor centro de toda la región, hay aproximadamente unas mil albercas, varios recocederos y cinco norias para la extracción del agua salada desde la 
capa freática. Las salinas están divididas por el clásico método de partidos, en los que cada uno de ellos recibe un nombre diferente. En la actualidad, entre los nombres que se pueden rastrear, algunos dos llaman la atención por su nombre y por su ubicación: «Las torres», que forma un conjunto de noria y recocederos prácticamente independiente, situado más al norte del resto del conjunto, y con su propio canal para el abastecimiento y recogida del agua salada que forma parte del reguero madre; y el partido de «La alcalá» situado en una posición central del conjunto de albercas, a modo de centro sobre el cual se ha generado todo el conjunto. ${ }^{16}$

Al igual que ocurre en Imón, en las salinas más grande de la región seguntina también se rastrea, aún de manera muy superficial, la existencia de un conjunto complejo y con distintas fases de evolución. Nos referimos a La Olmeda. En su entorno no sólo los prados halófilos son extremadamente abundantes, sino que además, junto a otra salinas aún en pie como las de Bujalcayado o las de Carabias, se detectan albercas y canales de lo que debieron ser otros centros productivos, quedando en algún caso los restos arquitectónicos de norias para la extracción del agua salada diseminadas por la zona sin relación, en el presente, con ninguna alberca. Son datos indicativos de que una evolución de los centros productivos, aunque aún no seamos capaces de proponer fechas a todo ello.

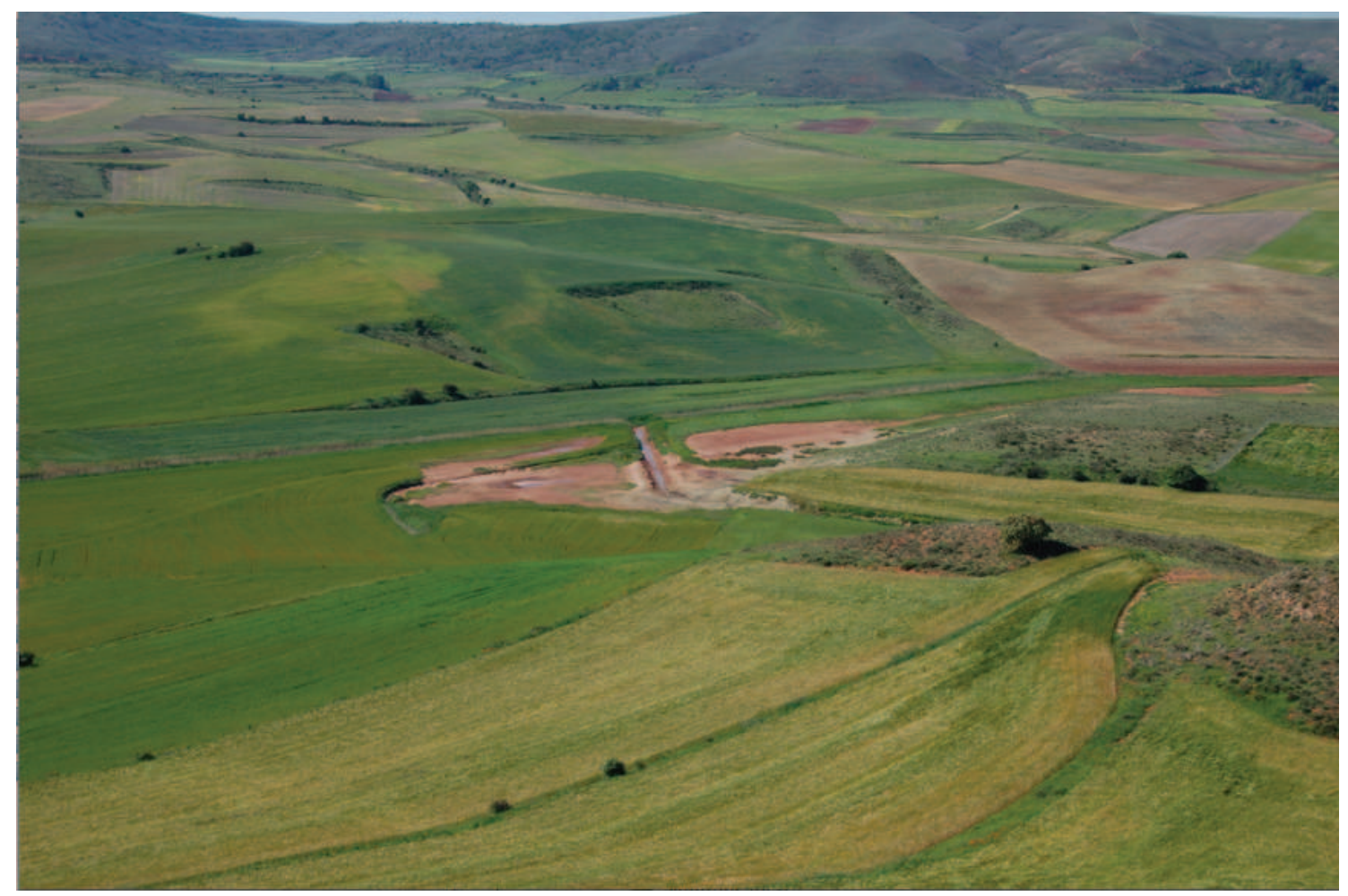

Evidencia de la existencia de una antigua salina al sur de Valdelcubo

\footnotetext{
16 Trallero SanZ, Antonio, Arroyo SAn José, Joaquín y MArtínez SEÑOR, Vanesa, Las salinas de la Comarca..., pp. 47-122.
} 
El estudio detallado y exhaustivo de la evolución de las salinas de Imón y de la Olmeda, como de los partidos que se detectan en otras de mayor tamaño de la región como las de Bujalcayado o Valdealmendras, ofrece unas perspectivas para la investigación que deben ser abordadas para una correcta comprensión del problema aquí planteado.

Pero dejando a un lado este análisis de carácter microespacial, la propuesta para el estudio de la explotación salina pasa necesariamente por el estudio del poblamiento y el paisaje con un foco macroespacial, como ya explicamos en otra parte de este trabajo siguiendo las propuestas de Antonio Malpica ${ }^{17}$. En otras zonas de la provincia de Guadalajara también se ha propuesto una asociación entre los yacimientos andalusíes localizados y la producción de sal. Así lo indica Lauro Olmo, quien señala que en el señorío de Molina, y concretamente en el valle del río Bullones se sitúa una zona de salinas ya activa en la producción de sal desde el siglo XII, tal y como refleja la documentación escrita, pero con asentamientos fechados en época califal - El Castillo, Fuente Jimena (Tezaga), El Castillejo_-, y claramente relacionados con estas salinas, a lo que hay que añadir algunos de los topónimos cristianos como es el caso de Almalla, que deriva de la palabra árabe al Mallah = la salina, y que denotan su origen islámico ${ }^{18}$. Más cerca aún de nuestra zona de estudio hayamos uno de los pocos asentamientos andalusíes excavados con método arqueológico en fechas recientes. Se trata de la cueva de los Casares, en Riba de Saélices ${ }^{19}$. Queda algo más al sur de nuestro territorio, en el valle del río Linares que transcurre por la Sierra del Ducado, limite entre las altiplanicies de la Alta Alcarria, en la Meseta, y las del Señorío de Molina de Aragón, en el Sistema Ibérico. Esta cueva y su poblado asociado de época altomedieval incluyendo la torre de la cima, se inserta en otra de las regiones salineras de la provincia

17 Malpica Cuello, Antonio, «Análisis de las salinas medievales...»; «El medio físico y la producción...»

${ }^{18}$ OLMO ENCISO, Lauro, «Arqueología medieval en Guadalajara. Un estado de la cuestión» en GARCÍASoto Mateos, Ernesto y García VAlero, Miguel Ángel (eds.), Actas del primer Simposio de Arqueología de Guadalajara. Homenaje a Encarnación Cabré Herreros. Sigüenza, 4-7 de octubre de 2000, Madrid, 2002, t. 2, p. 483.

${ }^{19}$ Se trata de una cueva con una ocupación prehistórica y pinturas rupestres que han recibido una mayor atención, aunque contamos con estudios específicos referidos a la época medieval. Para los primeros estudios dedicados a la época prehistórica vid. CABRÉ AguiLÓ, Juan, Las cuevas de los Casares y de la Hoz, Archivo Español de Arte y Arqueología, 30 (1934); Beltrán MARTíneZ, Antonio y BARANDIARÁN MAEStu, Ignacio, Avance al estudio de las cuevas paleolíticas de la Hoz y los Casares (Guadalajara), Excavaciones Arqueológicas en España, 64 (1968); BARANDIARÁn MAESTU, Ignacio, La cueva de los Casares (Riba de Saélices, Guadalajara), Excavaciones arqueologías en España, 76 (1971); Para los estudios sobre época medieval, vid. GARcíA-Soto MATEOS, Emilio y Ferrero Ros, Susana., «Excavaciones en el despoblado musulmán de Los Casares (Riba de Saélices, Guadalajara): Campañas de 1998, 1999 y 2000» en GARCÍA-Soto MATEOS, Ernesto (ed.), Actas del primer Simposio de Arqueología de Guadalajara: Sigüenza, 4-7 de octubre de 2000, Sigüenza, 2002, Vol. 2, pp. 513-529; GARCíA-SOTO Mateos, Emilio, Ferrero Ros, Susana y Guillén Álvarez de sotomayor, A., «Los Casares: un poblado hispanomusulmán en las serranías del norte de la provincia de Guadalajara» en ABAD CASAL, Lorenzo (ed.), Investigaciones arqueológicas en Castilla La Mancha: 1996-2002, Toledo, 2004, pp. 395408; GArcíA-Soto MAteos, Emilio y Ferrero Ros, Susana., «Un posible barrio artesanal en el poblado hispanomusulmán de los Casares (Riba de Saélices, Guadalajara)» en MiLlán MARTínEZ, Juan Manuel y Rodríguez RuZA, Concepción (eds.), Arqueología de Castilla-La Mancha. I Jornadas, Cuenca 13-17 de diciembre de 2005, Cuenca, 2007, pp. 659-680. 
de Guadalajara, la de Saélices de la Sal. Aunque entre el centro salinero en sí y el yacimiento existe una distancia considerable, superior a los $4 \mathrm{~km}$, lo que dificulta establecer una relación directa entre el asentamiento y la zona productiva. No obstante, es probable que nos encontremos ante otro caso de poblado asociado al hábitat rupestre en una clara relación con los recursos ganaderos transhumantes, y por tanto, también al recurso salino aunque queda algo alejado, siendo el mismo proceso que se detecta en varios de los asentamientos que localizamos en el valle del Salado y que describimos en otra parte de nuestro trabajo.

Volviendo al valle del Salado que nos ocupa, el trabajo de prospección desarrollado ha permitido contabilizar un buen número de salinas bien porque aún están en pie o bien porque se evidencia en el terreno los restos de su existencia. Y junto a las salinas en sí, se detectan un notable conjunto de fuentes salobres y lagunas endorreicas que podrían haber sido explotadas. En una primera aproximación se ha realizado una propuesta de categorización ${ }^{20}$, diferenciando entre

1- Manantiales y surgencias salinos, como El Salobral.

2- Lagunas endorreicas con rico aporte en sales, como La Laguna o la Fuente de las Praderas.

3- Espacios salinos alterados y antropizados, entendidos como tales las explotaciones salineras basadas en los sistemas de extracción de sal mediante pozos artesianos y creación de recocederos, eras y secaderos de sal por medio de la evaporación solar como Santamera, Riba de Santiuste, Imón o La Olmeda, todas ellas asociadas a las denominadas 'salinas históricas' y sobre las que existe una importante bibliografía, que ya hemos citado.

Ya hemos visto como los asentamientos de época altomedieval localizados en el valle se localizan, fundamentalmente, en el entorno más inmediato de las zonas salinas y por lo general a una cierta altura en la media ladera de los cerros y sierras. Los asentamientos en altura, no obstante, quedan fuera de esta relación tan inmediata, e incluso en el caso de la Riba de Santiuste, el castillo que parece los cristianos en el momento de la conquista consideraron como centro rector desde un punto administrativo de las salinas, se sitúa en un espacio en el que este tipo de centros no es abundante en absoluto.

Encontrándonos en un estado inicial de la investigación, únicamente podemos esbozar algunas cuestiones que deben quedarse a modo de hipótesis sobre las que trabajar en un futuro. elementales. La abundante presencia de explotaciones salineras y prados

\footnotetext{
20 Malpica Cuello, Antonio, Morère Molinero, Nuria, FÁbregas García, Adela y JimÉnEZ GUIJARRO, Jesús, «Organización del territorio y explotación de la sal en el área del Río Salado (Sigüenza, Guadalajara, España): Antigüedad y Edad Media. Resultados de la I Campaña 2008», Actas del XI Encuentro de Historiadores del valle del Henares, Guadalajara, 2008, p. 54.
} 
halófilos aparece relacionada con los asentamientos hallados, sin que podamos determinar con certeza ni la cronología de los segundos, ni el grado exacto de relación, aunque parece evidente que debió haber algún tipo de explotación. Queda a duda de si este aprovechamiento fue directo, con la explotación o incluso producción del recurso salino para su posterior consumo y comercialización, o si debemos pensar en un uso de carácter algo más indirecto y vinculado a la explotación ganadera. Lo que si parece claro es que son los centros situados en el llano o en la media ladera, aquellos identificados como alquerías o aldeas, los que debieron explotar las salinas, a la vez que debieron explotar agrícolamente las tierras, a partir de las numerosas fuentes y arroyos de agua dulce, ya que en todos los casos examinados son abundante este tipo de recurso en el entorno de los asentamientos. En lo que respecta a los asentamientos en altura (Riba de Santiuste, Riosalido, Villavieja), no están tan claramente relacionados con este recurso, sino que, junto al control visual entre sí y de la práctica totalidad del valle, parecen estar dominando las vías de comunicación y los pasos por el valle.

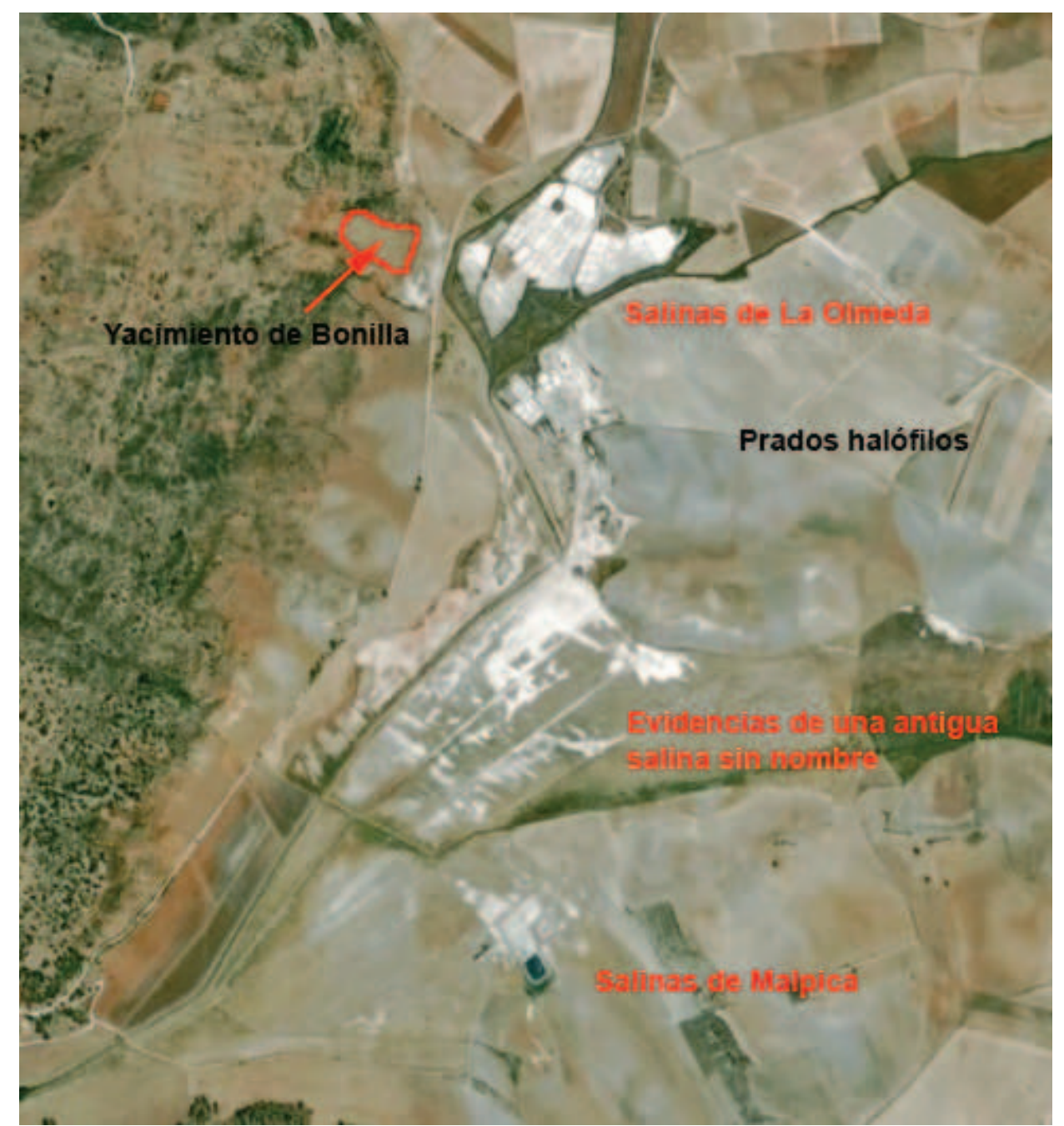




\section{ESTUDIO CERÁMICO}

4.1. Historiografía de los estudios de cerámica altomedieval andalusí en la Marca Media

4.2. Objetivos y metodología de nuestro estudio

4.3. Resultados del análisis cerámico. 


\subsection{HISTORIOGRAFÍA DE LOS ESTUDIOS DE CERÁMICA ALTOMEDIEVAL ANDALUSÍ EN LA MARCA MEDIA}

\section{La cerámica altomedieval: mitos y problemas}

Los estudios cerámicos en la Marca Media son herederos, en gran medida, de los trabajos de campo, excavaciones y prospecciones, que se han llevado a cabo en estos territorios y de los que hablamos en otro apartado de nuestro trabajo. Otros estudios han sido fruto de sistematizaciones y clasificaciones de colecciones privadas y de museos, aunque se han centrado fundamentalmente en sus aspectos decorativos y morfológicos. Este capítulo va a centrarse en el examen historiográfico de la cerámica andalusí en la Marca Media, cómo se ha estudiado y cuales son los referentes que hemos tomado en consideración en nuestro trabajo.

La caída del Imperio Romano trajo consigo un retroceso técnico en la fabricación de la cerámica y una progresiva desaparición de las formas de distribución y uso que permitían las producciones estandarizadas y de gran número de piezas, como fueron las sigillatas. Los talleres de fabricación concebidos para abastecer esta demanda, desaparecieron y, junto con otras tantas otras formas de producción de manufacturas, la producción de cerámica pasó a hacerse de forma mucho más modesta en cantidad y con una red de distribución también más limitada.

En este contexto, vuelven a tomar fuerza las producciones domésticas - no nos atrevemos a decir que resurgieron porque no estamos seguros de que hubieran desaparecido del todo-, cuyo proceso técnico de fabricación se simplifico notablemente, y se redujo a lo más indispensable. La cronología y los ritmos de ambos procesos, por un lado la desaparición de las producciones comerciales de tradición romana y por otro su sustitución por las producciones de tipo doméstico y local, son muy diversos cronológicamente y según las zonas, habiéndose documentado determinados momentos de convivencia entre ambos tipos de producciones.

Este cierto retroceso técnico no se debe a una simple pérdida de habilidades técnicas por parte de los alfareros. Debemos contextualizarlo dentro de un momento concreto, en el que las condiciones de fabricación de objetos muebles e inmuebles sufre la desaparición de unas condiciones de producción, distribución y uso que, de alguna forma, desactivan los mecanismos de especialización. Sin especialistas, entendidos como tales en las redes de producción y distribución anteriores, desaparecen también las infraestructuras artesanales a ellos asociados ${ }^{1}$.

\footnotetext{
${ }^{1}$ Es algo que se detecta también en la construcción, donde aparecen edificios construidos en materiales perecederos como la madera o el reaprovechamiento de espacios públicos y estancias de construcciones anteriores, mientras que la cantería y el tallado de la piedra llegan incluso a desaparecen en buena parte de Europa y el Mediterráneo occidental. Vid. Quiros CASTILLO, Juan Antonio, «La sillería en la
} 
En efecto, al desaparecer el Estado desaparecen muchos de los aspectos que generaba, como los mecanismos de producción y consumo de amplio rango, y otros que promovía, como los intercambios a largas distancias y una vida urbana indispensables para las condiciones de producción estandarizadas y especializadas, así como los capas sociales que los consumían. En este contexto, la producción tiende, de alguna forma, a la autarquía, lo cual no quiere decir que las sociedades altomedievales sean autosuficientes ni que el comercio se haya derrumbado, ni mucho menos ${ }^{2}$. Pero si que se potencian las unidades de producción y consumo locales, y en mucho caso incluso domésticas.

En el caso de la cerámica, las producciones de los siglos $\mathrm{V}$ al X, e incluso en algunos casos el XI, parecen ser mayoritariamente realizadas en el seno de la unidad doméstica, para uso propio, o en pequeños talleres con un radio de distribución local o regional. En ambos casos se generarían un modesto número de objetos para abastecer las necesidades más inmediatas, es decir, para satisfacer las funciones más insustituibles, que en el caso de la cerámica serían la cocción de alimentos y su almacenamiento. Necesidades más complejas, o incluso algunas que hoy nos parecen indispensables, como el servicio de mesa, quedarían relegadas a un segundo plano, al meno en los ámbitos rurales y domésticos. Otra cuestión serían los ámbitos del poder, donde estas producciones marcaban además las diferencias sociales con el resto.

En estas condiciones de producción, la variedad de formas sería limitada, si bien los tipos se multiplicarían al no contar con referentes estandarizados. Las diversas piezas de una misma forma, esto es para solucionar una misma necesidad, adquirirían rasgos distintos. Pequeños detalles como el grosor de las paredes, el tamaño o inclinación de los bordes, o la distribución y forma de las asas pueden ser indicadores de producciones diferentes, debido al escaso grado de especialización que tendrían quienes fabricaran la cerámica.

En definitiva, se trataría de repertorios cerámicos poco variados formalmente y con escaso volumen de piezas, adquiridos y usados como ajuares a su vez compuestos por un número reducido de piezas, con escasa variedad de formas y fundamentalmente con funciones imprescindibles, como la cocción y el almacenamiento, que en la práctica se convertirían en recipientes plurifuncionales.

arquitectura altomedieval en el Mediterráneo occidental», Actas del V Congreso de Arqueología Medieval Española, Valladolid, 2001, t. I, pp. 281-291.

2 MCCORMICK, Michael, Origenes de la economía europea: viajeros y comerciantes en la Alta Edad Media, Barcelona, 2005. Esta obra critica en gran medida los modelos derivados de la tesis de Perenne (PIRENNE, Henri, Mahoma y Carlomagno, Madrid, 1978), afirmando que en la Alta Edad Media Europa y el Mediterráneo no se aislan como consecuencia de la expansión musulmana, sino que, al contrario, la conexión entre Europa y los ámbitos bizantino y musulmanes, con sus propias conexiones orientales, crea un conjunto de relaciones geográficas muy complejo, y de mayor rango que el de época tardorromana. 
Estas producciones parecen encajar con el primero de los tipos de organización de la producción cerámica islámica definida por N.L. Benco ${ }^{3}$, tal como la describe $\mathrm{H}$. Kirchner:

La mayor parte de la producción especializada tiene lugar en talleres pequeños o independientes que efectuarían directamente la venta a los consumidores en el mismo taller o en mercados urbanos o rurales próximos. Producen fundamentalmente para las necesidades de los consumidores locales y, por ello, son particularmente sensibles a los cambios en la economía local o en la población. Así, en respuesta a un cambio en el tamaño, el estatus socio-económico o la etnia de la población local, el número de estos pequeños talleres puede crecer o disminuir, pueden introducirse nuevas técnicas o productos para satisfacer nuevos consumidores. La unidad básica de producción y su organización, sin embargo, permanece, probablemente, invariable a través del tiempo. ${ }^{4}$

Estos mercados de distribución inmediata pueden coincidir con los ambulantes semanales que ha descrito Chalmeta ${ }^{5}$.

Respecto a la comercialización de estas producciones locales o regionales, hay que destacar las reflexiones de $\mathrm{H}$. Kirchner relativas a las redes de intercambios en la primera época islámica, partiendo de los planteamientos de otro autor:

J. Torras ha descrito con precisión este proceso de formación de redes de mercados rurales y urbanos en la alta Edad Media: la organización de mercados periódicos campesinos asegura la existencia de contactos e intercambios que de otra forma serían excesivamente aleatorios. Este tipo de mercados permite la circulación de bienes en ámbitos regionales y la aparición de especialistas en su frecuentación. Algunos de estos mercados llegan a añadir la función complementaria al conectar redes de mercados regionales, diversificando los intercambios. Los nudos de estas redes de mercados eran mayoritariamente las aglomeraciones rurales habitadas sobre todo por campesinos. A medida que se densifica la red, en los nudos donde más niveles de intercambio se concentran, la proporción de habitantes que vivían de trabajos que creaba la actividad mercantil era más importante. Estos nudos eran las ciudades. ${ }^{6}$

Pero por otra parte es evidente que deben existir otros centros productivos más lejanos, según hemos visto al analizar el caso de los vidriados. En este caso cabría pensar en importantes centros urbanos como Pechina o Córdoba. Estos centros productivos deben

\footnotetext{
3 Benco, N. L., The early medieval pottery at al-Basra, Morocco, BAR, Internacional Series, 341, Oxford, 1987, pp. 13-15.

${ }^{4}$ KirCHNER, Helena, «Las técnicas y los conjuntos documentales. I La cerámica», en BARCELÓ, Miquel, et alii, Arqueología Medieval. En las afueras del «medievalismo», Barcelona, 1988, p. 97.

5 Chalmeta, Pedro, «Formation, structures et contrôle du marché arabo.musulman» en Mercati e mercanti nell'alto Medioevo:l'area auroasiatica e l'area mediterranea, Settimana di Spoleto 1992, Spoleto, 1993, pp. 677-680.

${ }^{6}$ KIRCHNER, Helena, «Indígenas y extranjeros. Cerámica y etnicidad en la formación de al-Andalus», Arqueología Espacial, 21 (1999), p 157.
} 
relacionarse con los descritos por N.L. Benco en segundo lugar, siguiendo nuevamente las palabras de H. Kirchner:

Una parte menos importante de la producción artesanal se hace en talleres de gran escala o industrias nucleadas (talleres agrupados) situados cerca de los grandes mercados urbanos o de formas eficientes de transporte para una comercialización a través de intermediarios que distribuyen los productos a distancias bastante importantes. A causa de esta comercialización lejana, son centros vulnerables a los trastornos regionales políticos o económicos que puedan romper o dislocar las rutas de comercio. Ello puede conllevar cambios bruscos en la dirección de la comercialización o bien fragmentaciones de los talleres que, a su vez, comportarían la dispersión de conocimientos técnicos en toda una región concreta. ${ }^{7}$

\section{Los estudios de cerámica medieval en la Marca Media}

Con anterioridad a los años '70 muy pocos son los trabajos dedicados a la cerámica andalusí de la zona central de la Península, salvo el trabajo de Mélida sobre Medinaceli y algún otro más ${ }^{8}$. Valga a título indicativo las cifras que ofreció hace ya algunos años Zozaya: antes de la Guerra Civil se publicaron únicamente 15 trabajos, 21 desde 1939 a 1970 y 86 desde 1971 hasta principios de los años ' $90^{9}$. Es decir, en 20 años ya se había cuadruplicado lo publicado en los cuarenta años anteriores.

A principios de los años '70 se publica el catálogo de las cerámicas medievales del Museo de Soria ${ }^{10}$. Eran las primeras aproximaciones tipológicas a las cerámicas de esta parte de al-Andalus, coincidiendo además con la publicación de los trabajos que sirvieron de despegue definitivo a los estudios de cerámica medieval islámica que, aunque no estaban dedicados a esta zona, sirvieron para articular y ordenar los conjuntos de la cerámica andalusí ${ }^{11}$. En 1979 comienzan a publicarse los resultados de la investigación de los importantes yacimiento de Vascos y Melque ${ }^{12}$ con sendos corpus

\footnotetext{
${ }^{7}$ KIRCHNER, Helena, «Las técnicas y los conjuntos...», p. 97.

8 Mélida y Alinari, José Ramón, «Ocilis (Medinaceli)», Memoria de la Junta de Excavaciones y Antigüedades, 82 (1926); CASAMAR PÉREZ, Manuel, «Cerámica musulmana de la fortaleza de Alcalá la Vieja», Al-Andalus, 23 (1958), pp. 406-407.

9 ZOZAYA, Juan, «Recientes estudios sobre la arqueología andalusí: La Frontera Media», Aragón en la Edad Media, IX (1991), pp. 371-372.

${ }^{10}$ ZozAYA, Juan, «Cerámicas medievales del Museo Provincial de Soria», Celtiberia, 42 (1971), pp. 211222; Idem, "Cerámicas islámicas del Museo de Soria», Boletón de la Asociación Española de Orientalistas, XI (1975), pp. 135-148.

${ }^{11}$ Rosselló Bordoy, Guillermo, Ensayo de sistematización de la cerámica árabe en Mallorca, Palma de Mallorca, 1978; ZOZAYA, Juan, «Aperçu general sur la céramique espagnole (Séme-XVème siècles)» y «Essai de chronologie pour certains types de céramique caliphale andalouse» en I Congreso de Cerámica Medieval en el Mediterráneo Occidental, Paris, 1980, pp. 265-296 y 322-325.

12 IZQUIERDO BENITO, Ricardo, «Excavaciones en la ciudad hispano-musulmana de Vascos», Noticiario Arqueológico Hispánico, 7 (1979), pp. 249-392; Idem, «La ciudad hispano-musulmana de Vascos (Navalmoralejo, Toledo). Campaña 1979-1980», Noticiario Arqueológico Hispánico, 16 (1982), pp. 291380; CABAllero ZoredA, Luis y LATOrRe MaCARrón, José Ignacio, «La iglesia y el Monasterio de Santa María de Melque (Toledo). Arqueología y arquitectura. San Pedro de la Mata (Toledo) y Santa Comba de Bande (Orense)», Excavaciones Arqueológicas en España, 109 (1988)
} 
de cerámica andalusí tratados con una excelente rigurosidad, y que aún hoy sirven de referente indiscutible. La celebración del II Congreso de Cerámica Medieval en el Mediterráneo Occidental, que tuvo lugar en Toledo en 1980, fue otro elemento que impulsó estos estudios, con diversos trabajos que tuvieron una gran relevancia referidos a centros de producción, técnicas y tipologías e influencias culturales (Izquierdo 1986, Turina, 1986).

De manera paralela al estudio de estos conjuntos, empezaron a desarrollarse los trabajos de excavación arqueológica con método estratigráfico, lo que incrementó y permitió afianzar las cronologías de muchos de estos materiales. La excavación del castillo de Alcalá de Henares ${ }^{13}$ aportó, además, una amplia tipología, centrada fundamentalmente en las características morfológicas de los bordes y en menor medida de las bases o fondos. Este tipo de estudios tardaron en afianzarse y en convertirse en referentes para los estudios que se desarrollaban en la zona, ya que las monografías sobre Alcalá de

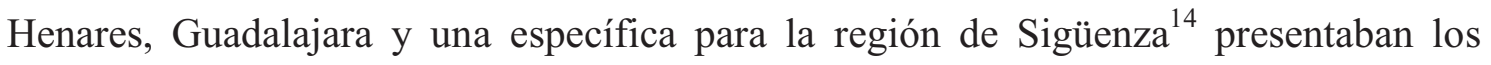
materiales sin la rigurosidad exigida y plasmada en los trabajos que se estaban desarrollando en otras zonas de la Península a partir de la influencia de los arqueólogos franceses y de la tradición tipológica de los prehistoriadores ${ }^{15}$, aunque suponían ya todo un avance y un acicate para el medievalismo más apegado a los documentos escritos. Bazzana proponía una metodología para el análisis morfológico de la cerámica en un extenso estudio en el que incluía tanto una propuesta para la construcción de la clasificación como una propuesta tipológica completa. En el caso de Rosselló, aunque limitado cronológica y geográficamente, su propuesta de clasificación y su terminología han servido de precedente obligatorio para todos los estudios posteriores. El mallorquín organiza por formas, técnicas y motivos todos los fragmentos encontrados $\mathrm{y}$ catalogados, proponiendo, al mimo tiempo, un estudio de funciones, una correcta denominación de las formas cerámicas y un cuadro cronológico que abarca toda la presencia islámica en la isla. La validez de su trabajo viene determinada porque en la medida en la que se ha ido ampliando la investigación al territoio peninsular se ha comprobado que su clasificación es válida por el alto gran de estandarización del ajuar cerámico en época medieval, al menos a partir de los siglos X-XI.

Por otro lado, y aunque alejado también de la metodología más estrictament arqueológica, a principio de los ' 80 se publico el trabajo de Aguado sobre los alfares de

\footnotetext{
13 ZozayA, Juan y Fernández URIEL, Pilar, «Excavaciones en la fortaleza de Qal'at 'Abd-al-Salam (Alcalá de Henares, Madrid», Noticiario Arqueológico Hispánico. Serie Nueva, 17 (1983), pp. 411-529.

14 Pavón MaldonAdo, Basilio, Alcalá de Henares. Islámico y mudéjar, Madrid, 1983; Idem, Guadalajara medieval. Arte y arqueología árabe y mudejar, Madrid, 1984; MorÈre Molinero, Nuria, Carta Arqueológica de la región seguntina, Guadalajara, 1983.

${ }^{15}$ BAZZANA, André, «Ceramiques médievales: les méthodes de la description analitiques apliquées aux productions de 1'Espagne Orientale I» Melanges de la Casa Velázquez, XV (1979), pp. 135-186; RosSELló BORDOY, Guillermo, Ensayo de sistematización...
} 
Toledo $^{16}$ en el que junto al corpus de materiales que presentaba, desarrollaba una preocupación por los aspectos más tecnológicos de la cerámica. Aguado puso de manifiesto las bases para el estudio del contexto de la producción, partiendo de los restos encontrados en un testar de la ciudad de Toledo, identificando algunas claves de las técnicas de fabricación mediante las huellas que los procesos imprimen sobre el objeto. De este modo pudo avanzar algunos datos en cuento al combustible utilizado, ya que era habitual la presencia de huellas de la retama, o las interesantes observaciones que hace sobre la fabricación de la cuerda seca parcial gracias al hallazgo de pequeños fragmentos que no completaron la cocción. La influencia de Aguado, menor en los estudios cerámicos andalusíes más afines a la tipología y la funcionalidad, puede rastrearse no obstante hasta trabajos mucho más recientes en los que vuelve a ponerse el acento en las cuestiones tecnológicas ${ }^{17}$.

Junto a los conjuntos cerámicos de Toledo, Madrid ve sus primeras excavaciones urbanas con sus correspondientes ajuares cerámicos (Caballero et alii 1983, 1984). Pero son los trabajos sobre Calatalifa los que dieron lugar a los estudios más estructurados sobre las cerámicas de la Marca Media, luego completados con los de otros asentamientos como Torete, en Guadalajara ${ }^{18}$.

Como se aprecia, hay una gran actividad de publicaciones en la primera mitad de los ochenta, que se va a intensificar como consecuencia de la celebración de los primeros Congresos de Arqueología Medieval Española. A partir de entonces los análisis cerámicos no sólo crecen en número, sino también en variedad de enfoques: estadístico $^{19}$, iconográfico ${ }^{20}$, tipológico ${ }^{21}$, en los que a las técnicas de acabado y decoración se refiere ${ }^{22}$ y otros varios que sería prolijo enumerar aquí ${ }^{23}$.

Pero el trabajo que sirvió de auténtico renovador para los estudios de cerámica en la Marca Media fue la Tesis Doctoral de Manuel Retuerce, publicada ya a finales de los

\footnotetext{
${ }^{16}$ Aguado Villalba, José, La cerámica hispanomusulmana de Toledo, Madrid, 1983.

17 FERnÁndez NAVARRO, Esteban, Tradición tecnológica de la cerámica de cocina almohade-nazarí, Granada, 2008.

18 Retuerce Velasco, Manuel, «La cerámica islámica de Calatalifa. Apuntes sobre los grupos cerámicos de la Marca Media» Boletín del Museo Arqueológico Nacional, II (1984), pp. 117-136; Idem, «Cerámicas islámicas procedentes de Torete (Guadalajara). Nuevos datos sobre los grupos cerámicos de la Marca Media», Boletín de la Asociación Española de Orientalistas, 20 (1984), pp. 338-357.

${ }^{19}$ IZQUIERDO BENITO, Ricardo, «Tipología de la cerámica hispano-musulmana de Vascos (Toledo)», II Congreso Internacional de Cerámica Medieval en el Mediterráneo Occidental, 1986, pp. 113-125; Idem, «La cerámica común de Vascos (Navalmoralejo, Toledo», II Congreso de Arqueología Medieval Española, Huesca, 1987, t. 2, pp. 712-718.

20 IzQUIERDO BENITO, Ricardo, «La cerámica hispano-musulmana decorada de Vascos (Toledo)», Homenaje al profesor Martín Almagro Basch, (1983), t. 4, pp. 107-115; MARTínez LiLlo, Sergio, «Plato con motivo zoomorfo de Layos (Toledo)», Al-Qantara, 6 (1985), pp. 491-502.

${ }^{21}$ RetUerce Velasco, Manuel y LOZANO GARCíA, Isidoro, «Calatrava la Vieja: primeros resultados arqueológicos», I Congreso de Arqueología Medieval Española, Huesca, 1986, t. 3, pp. 57-75

22 RetUerCe Velasco, Manuel y ZoZAYA, Juan, «Variantes geográficas de la cerámica omeya andalusí: los temas decorativos»,, III Congreso Internacional de Cerámica Medieval en el Mediterráneo Occidental, Siena, 1986, pp. 69-128.

${ }^{23}$ Son recogidos con un carácter más minucioso en ZOZAYA, Juan, «Recientes estudios...»
} 
años 90 aunque con algunas publicaciones anteriores ${ }^{24}$. Supuso una nueva visión de la cerámica medieval de la Frontera Media y de las relaciones de producción y la sociedad que las generaron, pero sobre todo, una muy importante aportación de orden tipológico con pretensiones de abarcar toda la zona central de la Península. Su base es la tipología cerámica de las excavaciones de Calatalifa, Torete, Madrid y la de Calatrava la Vieja, algo más al sur y posterior en el tiempo. Mediante el estudio de distintas colecciones privadas, fondos de museos y algunas excavaciones, y sirviéndose de la analogía, recoge más de 200 yacimientos con material arqueológico comprobado de época islámica en la zona central de la al-Andalus. A su vez establece toda una serie de relaciones entre las distintas regiones de la meseta y las zonas del Levante y el sur peninsular. Junto con el impulso definitivo que el estudio de Retuerce ha tenido, los estudios de cerámica se han multiplicado a partir del creciente desarrollo de la arqueología desde los años '90 a nuestros días en estrecha relación con el desarrollo urbanístico, la masificación de la construcción y una cada vez más completa legislación en materia de bienes culturales. En lo que a nuestro territorio se refiere hay otra serie de estudios que nos han sido de enorme importancia: por un lado las referencias a los excavaciones urbanas y los alfares de Guadalajara ${ }^{25}$, y por otro lado otra serie de estudios realizados en distintos asentamientos andalusíes, como son los de Toledo, Calatalifa, Olmos, Peñafora, Madrid, Vereda de Sedano, Oreja y Ercávica ${ }^{26}$, así como

\footnotetext{
24 Retuerce Velasco, Manuel, La cerámica islámica de la Meseta, Madrid, 1998, 2 tomos; Idem, «Carta arqueológica de la Meseta andalusí según el referente cerámico» Boletín de Arqueología Medieval, 8 (1994); pp. 7-110; Idem, «Arqueología y poblamiento en la Meseta Andalusí. El referente cerámico» en V Semana de Estudios Medievales (Nájera, 1994), Logroño, 1995, pp. 87-124.

${ }^{25}$ Barroso Bermejo, R. M. y Jiménez, P. J., «Arqueología de la iglesia de los Remedios», Actas del III Encuentro de historiadores del valle del Henares, Guadalajara, 1992, pp. 93-102; CUADRADO PRIETO, Miguel Ángel, «Un hogar hispanomusulmán en el solar del Palacio de los Guzmán», Actas del III Encuentro de historiadores del valle del Henares, Guadalajara, 1992, pp. 79-92; Idem, «Excavaciones arqueológicas de urgencia en Guadalajara. Aguas Vivas», Balbín, R. De, VAliente, J. y Mussat, M. T. (Eds.), Arqueología en Guadalajara, Talavera de la Reina, 1995, pp. 179-191; CUADRADO PRIETO, Miguel Ángel y CRESPO CANO, María Luisa, «Un alfar hispanomusulmán en la Plaza de la Antigua. Guadalajara», Wad-al-Hayara, 19 (1992), pp. 9-38.

${ }^{26}$ Martínez Lillo, Sergio y MAtesanz Vera, Pedro, «Cerámicas cristianas y musulmanas de la Marca Media Central: siglos X, XI y XII», A Cerâmica medieval no Mediterr Âneo occidental, Mértola, 1991, pp. 273-284; LARREN IZQUIERDO, H., «Apuntes para el estudio del sistema defensivo del Tajo: Oreja, Alarilla y Alboer», Boletín de Arqueología Medieval, 2 (1988), pp. 87-96; MARTínez LiLlo, Sergio, «Primeros materiales arqueológicos del Castillo de Olmos» en I Congreso de Historia de Castilla-La Mancha, Talavera de la Reina, 1988, tomo V, pp. 95-104; Álvarez DELGADO, Y. «Cerámicas del siglo IX de Arcávica (Cuenca)», Boletín de Arqueología Medieval, 3 (1989), pp. 109-122; JIMÉNEZ ESTEBAN, J. «Aportación a la arqueología hispano-musulmana: Peñahora (Guadalajara)», Wad-al-Hayara, 16 (1989), pp. 283-292; GARCíA MuÑoz, M., «Excavaciones arqueológicas en el solar de la Plaza de la Morería c/v Plaza del Granado», en Madrid del siglo IX al XI, Madrid, 1990, pp. 217-222; PÉREZ ViCENTE, D. «Excavaciones arqueológicas en el solar $n^{\circ} 21$ de la Calle Segovia» en Madrid del siglo IX al XI, Madrid, 1990, pp. 261-266; PrIEGO FERnÁNDEZ DEL CAMPO, M. C., «Origen y evolución urbana de la Plaza de los Carros» en Madrid del siglo IX al XI, Madrid, 1990, p. 267-275; SÁnChEZ PALENCIA, F. J.; Sainz Pascual, M. J., Martínez Lillo, S. y JuAn S. de, «El circo romano de Toledo», Actas del Primero Congreso de Arqueología de la Provincia de Toledo. Talavera de la Reina, 1990, pp. 351-369, Soler, A. y TurinA, A., «Excavaciones arqueológicas en el solar de la Cava Baja, 22» en Madrid del siglo IX al XI, Madrid, 1990, pp. 283-285; Vallespin, O., Serrano, E., LópeZ, M. A. y Marín, F. J. «Excavaciones en el solar Calle de San Isidro», en Madrid del siglo IX al XI, Madrid, 1990, pp. 287-296;
} 
algunos otros estudios de la provincia de Soria y Zaragoza, siendo especialmente importantes para nosotros, por la proximidad del asentamiento, los que se han elaborado en Medinaceli ${ }^{27}$. En todos ellos se han recuperado materiales entre los que destacan algunas formas cerámicas que se han considerado características de la Marca Media, como determinados tipos de ollas, jarras y redomas, a torno, con ausencia de vedríos y presencia de decoración — cuando la hay- poco elaborada, destinados fundamentalmente a un uso cotidiano. Vamos a pasar a ver la caracterización de las cerámicas de la Marca Media más detenidamente.

\title{
Caracterización de la cerámica de la Marca Media
}

En casi todos los estudios de cerámica reseñados anteriormente se analiza, la forma general cerámica, la morfología formal de la pieza, la función, la denominación semántica, la tecnología, el contexto de los hallazgos, la comparación etnológica y la que resulta de la conjunción del acabado y la decoración - aunque en realidad, estos dos caracteres normalmente se consideran agrupados como si fuera uno sólo: el decorativo- - A partir de varios de estos aspectos se ha hecho el esfuerzo por agrupar la cerámica en categorías mayores, con el objetivo de evaluar la distribución geográfica de las producciones cerámicas. Es lo que Retuerce llama «Grupos cerámicos», que para él

\begin{abstract}
se trata de un criterio de análisis cerámico en el que se tiene en cuenta la contingencia -a través de la existencia o ausencia y la correlación de diversas variables o «atributos»de todos los caracteres internos de la cerámica: desde los tecnológicos hasta los decorativo. $^{28}$
\end{abstract}

Estos «atributos» a los que se refiere son los siguientes:

\footnotetext{
Barrio Aldea, C. y Maquedano CARrasco, B. «Desechos de un alfar musulmán en la c/ Honda 46» en SÁnchez Palencia, F. J. et alii, (Coords.), Toledo; Arqueologia en la ciudad, Talavera de la Reina, 1996, pp. 159-170; Bermejo CRESPO, J. L. y MuÑoz LóPEZ-Astilleros, K., «El yacimiento medieval de Vereda de Sedano o Las Fuentecillas (San Fernando de Henares, Madrid: Campañas de excavación de 1989 y 1990» Estudios de Prehistoria y Arqueología Madrileñas, 10 (1995-1996), pp. 111-120; BERMEJO CReSPO, J. L. y MUÑoz LóPEZ-Astilleros, K., «Una explotación agrícola en el territorio de los Banu Salim: excavaciones en "Vereda de Sedano" o "Las Fuentecillas" (San Fernando de Henares, Madrid)», Boletín de Arqueología Medieval, 8 (1994), pp. 205-225.

${ }^{27}$ MARTínez GARCÍA. Francisco José, «El otero del Cid o cerro Torrecid: enclave militar del Campeador en el valle del Jalón» Simposio Internacional El Cid en el valle del Jalón, Calatayud, 1991, pp. 49-95; Gómez Martínez, Susana, «Cerámica islámica de Medinaceli», Boletín de Arqueología Medieval, 10 (1996), pp. 123-182; BuENo SÁnCHEZ, Marisa, « Cerámica islámica en Medinaceli villa. Excavaciones de urgencia e investigación (1975-2009)», en Jornada Internacional sobre metodología de análisis de la cerámica tardoantigua y medieval, León, 2009 (en prensa).

${ }^{28}$ RetUerce Velasco, Manuel, La cerámica andalusí..., t. I, p. 39. La propuesta de grupos cerámicos ha sido abordada y desarrollada por el mismo investigador en distintas publicaciones: «La cerámica islámica de Calatalifa...»; «Cerámicas islámicas procedentes de Torete...»; «Cerámica islámica en la Comunidad de Madrid...»
} 
- Clase de componentes mineralógicos

- Tamaños de los componentes mineralógicos

- Clase de cocción

- Color de la pasta

- Tipo cerámico concreto

- Tipo de acabado y de decoración

Según señala Retuerce de momento y mientras no se tenga más elementos de comparación y más materiales pertenecientes al período africano posterior, esta clasificación sólo conviene a la cerámica del período omeya, en sus diversas fases: paleo-andalusí, califal, post-califal y epi-omeya o taifa.

Cinco son los grupos cerámicos que distingue el investigador en la Meseta durante el período omeya, divididos a su vez en otros subgrupos. Vamos a señalarlo tal cual él lo expone:

GRUPO 1 (G1): se trata de un grupo cerámico en el que, en cuanto a su tecnología, se agrupan aquellas piezas realizadas a torno, que presentan pequeñas intrusiones minerales de cuarzo y mica y que poseen unas pastas de color claro (blanca, amarilla, roja o pajiza). Formalmente, la mayoría de las piezas son cerradas y en cuanto al acabado, no presentan vedrío. Pueden o no estar decoradas. Es de esta circunstancia de la que depende en mayor grado la diferenciación de los siguientes tres subgrupos:

- SUBGRUPO 1A (G1A): en él se presentan con mayor frecuencia las pastas de color blanca o amarilla. No posee ninguna clase de acabado ni de decoración.

- SUBGRUPO 1B (G1B): en él se presentan con mayor frecuencia las pastas de color rojo o pajizo. Cubriendo toda la superficie exterior, se presenta una engalba de color rojo -con una mayor frecuencia- o negro

- SUBGRUPO 1C (G1C): en él se presentan con mayor frecuencia las pastas de color rojizo o pajizo. Sobre el fondo claro, se presenta siempre una decoración pintada de trazos gruesos de color negro o rojo

GRUPO 2 (G2): es un grupo cerámico en el que, en cuanto a su tecnología, se agrupan aquellas piezas realizadas a torno que presentan medianas y gruesas intrusiones minerales de cuarzo y mica y que poseen unas pastas de color oscuro (pardo o grisnegro). Formalmente, aunque existen también algunas piezas abiertas la mayoría de ellas son cerradas. Pueden o no estar decoradas. Como en el Grupo 1, de la posesión o carencia de decoración deriva la distinción de los siguientes tres subgrupos:

- SUBGRUPO 2A (G2A): no posee ninguna clase de acabado ni de decoración.

- SUBGRUPO 2B (G2B): en él, toda la superficie exterior de las piezas se presenta cubierta de una engalba de color rojo

- SUBGRUPO 2C (G2C): sobre el fondo oscuro de todas las piezas siempre se presenta una decoración pintada de trazos gruesos de color rojo 
- SUBGRUPO 2D (G2D): en él, toda la superficie interior de las piezas se presenta vidriada.

GRUPO 3 (cerámica escarlata): se trata de un grupo del que se tienen muy pocas piezas o ejemplos. Sin embargo, por las especiales características que tienen, considero que estos pocos ejemplares deben ser encuadrados dentro de un grupo particular.

Llama la atención que las pocas piezas conocidas aparecen, más que fragmentadas, casi machacadas, rotas en múltiples y pequeñísimos trozos, que sólo en algunos casos superan los 2 o $3 \mathrm{~cm}$, sobre todo en la totalidad de los ejemplos encontrados en la Meseta. Pienso que esta gran pequeñez de los hallazgos, unida a su escaso número, ha podido dificultar su identificación y, por consiguiente, su estudio

Las pastas son muy compactas, rojas, pardas o pajizas oscuras, con pequeñas intrusiones de cuarzo y mica. Pero más que en este aspecto, su verdadera tipicidad reside en su factura, acabado y decoración. Por lo que hasta ahora se conoce, no sólo en el ámbito regional meseteño sino también en el resto de al-Andalus, parece que se trata de piezas que, continuando con una posible tradición técnica de períodos muy anteriores, intenten conseguir, con mejor o peor resultado, algo a lo que fue la cerámica sigillata romana (...) cerámicas sin vedrío, monócromas y moldeadas (...) Por otro lado, este intento de imitación de la sigillata romana se produce en los tres aspectos mencionados con anterioridad (factura, acabado y decoración). En este sentido, por el momento, no conozco ningún ejemplar de cerámica escarlata lisa y sin decoración a mole, como sucede en muchas piezas de cerámica sigillata romana, que se pretende imitar.

(...) Con un grosor de entre 3 y $4 \mathrm{~mm}$., todas las piezas se han realizado primero a torno para posteriormente, con el fin de realizar la decoración, y con el barro aún más fresco, se terminadas mediante un molde colocado en la pared exterior. Mediante presiones manuales -se aprecian las marcas de los dedos- realizadas desde el interior de la pieza, se iba materializando la decoración. Ésta es totalmente clásica, con variados motivos (...) En cuanto al acabado, todas las piezas, menos la alcalaína, se encuentran engobadas en rojo, con peor o mejor resultado y con un mejor o peor estado de conservación, por ambas superficies. (...)

Es por ello que a toda esta escasísima producción del Grupo 3, que, como se puede ver, no es exclusiva de la Marca Media, sino que parece ser labor de un taller muy localizado -de momento no sé si peninsular o extrapeninsular-, la vengo denominando desde hace algún tiempo como "cerámica escarlata», aunque es ahora cuando por primera vez lo hago por escrito.(...). Dentro de este grupo cerámico, distingo a su vez tres subgrupos

- SUBGRUPO 3A (G3A): realizadas y decoradas a molde, todas las piezas o fragmentos presentan al exterior una engalba de color rojo

- SUBGRUPO 3B (G3B): realizadas y decoradas a molde, todas la superficie exterior se presenta con una cubierta vítrea $(. .$.

- SUBGRUPO 3C (G3C): realizadas y decoradas a molde, todas las piezas o fragmentos presentan al exterior una engalba de color rojo; además de ello, 
poseen una decoración pintada de trazos finos grises (...)

GRUPO 4 (G4): si se exceptúan las tan características piezas que se acaban de encuadrar en el grupo G3b, dentro de grupo 4 se han incluido todas aquellas piezas que se presentan vidriadas, generalmente por ambas superficies. Son piezas realizadas a torno, con intrusiones minerales finas y medias de cuarzo y mica. Las pastas suelen ser pajiza o roja. Se trata tanto de piezas de forma abierta como cerrada, aunque son mayoritarias las segundas. Por sus especiales características y variantes de cromáticas, se podrían establecer múltiples subgrupos; es por este motivo que prefiero estudiarlas dentro del apartado de acabados y decoraciones. A pesar de ello, sigo manteniendo el Grupo 4 como un instrumento que posibilita la integración -con unos fines estadísticos, primordialmente- de las cerámicas vidriadas dentro del conjunto cerámico de la Meseta.

GRUPO 5 (G5): Es un grupo cerámico en el que, en cuanto a su tecnología, se agrupan aquellas piezas realizadas a torno, que presentan pequeñas y medianas intrusiones minerales de caliza y que poseen unas pastas de color claro (blanco, rosado o pajizo). Suelen presentarse con un alisamiento exterior. Formalmente, se presentan tanto piezas abiertas como cerradas. En cuanto al acabado, no presentan vedrío. Pueden o no estar decoradas. Es por esta circunstancia por la que se diferencian los siguientes dos subgrupos:

- SUBGRUPO 5A (G5A): No posee ninguna clase de acabado ni de decoración

- SUBGRUPO 5B (G5B): Sobre el fondo claro de todas las piezas siempre se presenta una decoración pintada de trazos finos de color rojo o castaño. ${ }^{29}$

Esta clasificación ha servido de base a numerosas investigaciones posteriores, si bien no ha recibido modificaciones prácticamente desde su creación. Como veremos, nuestro estudio cerámico es también, en gran medida, deudor de las propuestas de Retuerce.

Pero no sólo en la caracterización de las pastas cerámicas, también en lo que se refiere a la tipología y a la dotación de cronología a las cerámicas andalusíes, las propuestas del investigador madrileño han sido para toda la Marca Media el principal referente.

En este sentido, y para terminar este apartado dedicado a la historiografía de la cerámica andalusí, queremos dejar constancia aquí de un estudio que trata de identificar unos tipos cerámicos con la distribución de la familia de los Banu Salim ${ }^{30}$. La propuesta parte de la investigación en el yacimiento de Vereda del Sedano ${ }^{31}$. Los investigadores afirman que

\footnotetext{
${ }^{29}$ Retuerce Velasco, Manuel, La cerámica andalusí..., pp. 66-69.

${ }^{30}$ Bermejo CRESPO, José Luis y MuÑoz LóPEZ-Astilleros, Kenia, «La producción cerámica en el entorno del Henares durante los siglos IX y X» en Actas del V Encuentro de Historiadores del Valle del Henares, Guadalajara, 1996, pp. 79-86, ampliando algunas ideas ya propuestas por Manuel Retuerce.

${ }^{31}$ Bermejo Crespo, José Luis y MuÑoz LóPEZ-Astilleros, Kenia, «Una explotación agrícola en el territorio de los Banu Salim: excavaciones en "Vereda de Sedano" o "Las Fuentecillas" (San Fernando de Henares, Madrid», Boletín de Arqueología Medieval, 8 (1994), pp. 205-225; Idem, «El yacimiento medieval de Vereda de Sedano o Las Fuentecillas (San Fernando de Henares, Madrid: Campañas de
} 
dos de las formas identificadas por Retuerce como características de la Marca Media presentan un área de distribución aún más concreta que coincidiría con el ámbito geográfico de los Banu Salim. Nos referimos a sendos tipos de olla, una correspondiente al denominado grupo G1c y otra encuadrable en el grupo G2c de la sistematización de Retuerce. $^{32}$

La primera pieza a la que se refieren es una olla con cuerpo globular y decoración «de goterones» en grupos de a tres del mismo color, que no suele presentar signos de exposición al fuego y que parece, por tanto, destinada a contener o servir alimentos en la mesa. Se ha documentado en el caso urbano de Madrid y en algunos yacimientos como Alcalá de Henares, Vereda de Sedano y Calatalifa ${ }^{33}$, haciéndose más escasas hacia el occidente — según señaló el propio Retuerce—, y faltando en otros puntos más meridionales de la Marca Media como la ciudad de Toledo ${ }^{34}$.

El segundo ejemplo es la denominada «olla en escotadura o con carena en el hombro», que si suele presentar evidencias de haber sido destinada a la cocción de alimentos, se documenta en un área geográfica muy similar, aunque puede encontrarse alguna pieza de parecidas características algo más al sur.

Bermejo y Muñoz indican que

La dispersión concreta de ambas formas permite pensar, por tanto, en la existencia de alfares locales, que, si bien en el primer caso repiten un motivo como la decoración "de goterones", muy extendido en todo el ámbito de al-Andalus, dotan a ambos tipos de recipientes de unos perfiles característicos que parecen vinculados a un grupo humano concreto. Por otra parte, el inicio de la producción de estas ollas puede remontarse al siglo IX, perviviendo la forma G2c hasta casi el siglo XI, pero ya con vedrío.Por tanto, la presencia más antigua de las piezas citadas correspondería al momento de dominio de los Banu-Salim en el entorno del Jarama-Henares (...) La desaparición en la documentación escrita a partir del siglo X de las referencias a miembros del linaje de los Banu Salim y de su preponderancia política en el territorio sobre el que aparecen asentados al menos desde el siglo IX no implica, sin embargo, la desaparición de estas

excavación de 1989 y 1990», Estudios de Prehistoria y Arqueología Madrileñas, 10 (1995-1996), pp. 111-120

32 Bermejo Crespo, José Luis y MuÑoz LóPEZ-Astilleros, Kenia, «La producción cerámica en el entorno...», p. 82.

33 Turina Gómez, A. y Retuerce Velasco, M., «Arqueología más reciente...»; García MuÑoz, M., «Excavaciones arqueológicas en el solar...»; VAllespin, O., SERrAnO, E., LÓPEZ, M. A. y MARÍN, F. J., «Excavaciones en el solar...»; ZOZAYA, Juan y FERNÁNDEZ URIEL, Pilar, «Excavaciones en la fortaleza...»; BERMEJO CRESPO, José Luis y MuÑoz LóPEZ-Astilleros, Kenia, «El yacimiento medieval...»; Idem, «Una explotación agrícola...», RETUERCE VELASCO, Manuel, «La cerámica islámica de Calatalifa...»

34 Sánchez Palencia, F. J., Sainz Pascual, M. J., Martínez Lillo, S. y Juan, S., «El circo romano...»; BARRio AldEA, C. Y MAQUEDANO CARRASCO, B. «Desechos de un alfar...»; Idem, «El corralillo...» 
formas, que continuarán en uso hasta ser sustituidas por otras nuevas o adoptar avances técnicos como el vedrío ${ }^{35}$

Un fenómeno similar se ha documentado en el Sharq al-Andalus, donde la presencia de una serie de piezas cerámicas — en este caso las ollas de cuello alto- y un determinado grupo humano, significativamente también beréber, son sincrónicas ${ }^{36}$.

No obstante debemos realizar una puntualización a la propuesta de identificación de un tipo cerámico con un territorio concreto y único. En el caso de las ollas con decoración de «goterones», por lo que conocemos, no es un caso exclusivo y único de este territorio, presentándose en otras zonas bastante más alejadas como es el caso de Medina Elvira, en donde en cambio es considerada una jarrita y no una olla ${ }^{37}$.

Como conclusión a este repaso a la historiografía y caracterización de la cerámica en la Marca Media de al-Andalus, podemos afirmar que durante las últimas décadas se ha avanzado notablemente en el conocimiento de los procesos históricos de este territorio, uniéndose a un considerable aumento de las intervenciones arqueológicas en yacimientos de época islámica como hemos expuesto en otra parte de este mismo trabajo. Ello ha permitido desarrollar nuevas líneas de investigación en las que ambas vías de estudio confluyen y se complementan. Por ejemplo, se ha propuesto la existencia de una posible asociación en el mismo espacio geográfico, el entorno del valle del Henares, y durante un período de tiempo concreto, siglos IX y X, del establecimiento de un nuevo grupo humano de origen extrapeninsular como es el de los Banu Salim, mencionado en las fuentes, con dos determinadas formas cerámicas características -las ollas de «carena en hombro o en escotadura» y las «ollas de decoración "de goterones"»-. Esta última aseveración, no obstante, debe ser contrastada con las últimas investigaciones que se están llevando a cabo en el resto de al-Andalus, pues si el primer caso si parece más exclusivo del área oriental de la Marca Media, no lo tenemos tan claro en lo que a las ollas con decoración de goterones se refiere.

\footnotetext{
${ }^{35}$ Bermejo Crespo, José Luis y MuÑoz LóPEZ-Astilleros, Kenia, «La producción cerámica en el entorno...», p. 83.

${ }^{36}$ ACIEN ALMANSA, Manuel, «La cultura material en la época emiral en el sur de al-Andalus. Nuevas perspectivas», Malpica Cuello, Antonio (ed.), La cerámica altomedieval en el sur de al-Andalus, Granada, 1993, pp. 153-172.

${ }^{37}$ Carvajal López, José Cristóbal, La cerámica de Madinat Ilbira (Atarfe) y el poblamiento altomedieval de la vega de Granada, Granada, 2008, en espec. p. 478.
} 


\subsection{OBJETIVOS Y METODOLOGÍA DE NUESTRO ESTUDIO}

\section{Consideraciones previas}

La metodología que hemos empleado para el análisis de las piezas cerámicas procedentes de la prospección arqueológica del valle del Salado encuentra su justificación en la necesidad de caracterizar las producciones cerámicas de un área de al-Andalus que no ha sido aún suficientemente bien estudiada. Junto a ello, los objetivos que nos marcamos desde un principio fueron cuatro:

- Dotar de cronología a los yacimientos localizados

- Tratar de establecer diferencias y similitudes entre los distintos asentamientos

- Evaluar la posible circulación de cerámica en el valle del Salado como indicador de la circulación de otros productos, como pudiera ser la sal.

- Evaluar, a través de la cerámica recuperada en superficie, los posibles procesos posdeposicionales que hayan afectado a los yacimientos.

Si bien son todos ellos objetivos de carácter muy general, y casi básicos en cualquier estudio arqueológico ${ }^{1}$, nos encontramos con una serie de inconvenientes que han dificultado enormemente el estudio. En primer lugar, debemos considerar que se trata de conjuntos cerámicos procedentes de la prospección arqueológica con recogida superficial de materiales. Son cerámicas muy fragmentadas, con formas en algunos casos irreconocibles, y en la mayoría de difícil adscripción tipológica. Junto a ello, son piezas faltas totalmente de cronologías fiables, dado lo escaso de la documentación escrita para los distintos yacimientos, y en muchos casos con secuencias de ocupación anteriores y posteriores. A ello hay que sumar la escasez de estudios arqueológicos en el entorno más inmediato, debido a la práctica inexistencia de excavaciones y a la escasez de clasificaciones de colecciones que pudieran servirnos de referencia, salvo algunas excepciones que luego trataremos. El primer problema con el que nos enfrentamos es por tanto el desconocimiento sobre el material, y la constante dificultad para abordar toda la problemática en torno a las cronologías y los orígenes. Además, los estudios que se han llevado a cabo en los espacios más próximos a nuestro valle, y nos referimos a distancias que superan el centenar de kilómetros, son por lo general anticuados o insuficientes, o se limitan a realizar estudios tipológicos y decorativos, que no terminaban de satisfacer los objetivos que nos habíamos marcado para nuestro trabajo.

\footnotetext{
${ }^{1}$ Se pueden considerar las «tres grandes» evidencias que aporta la cerámica. MoLINARI, Alessandra, «Cerámica» en Francovich, Riccardo y Manacorda, Daniele (Eds.), Diccionario de Arqueología, Barcelona, 2001, pp. 53-61.
} 
Por todo ello, recurrimos a una metodología de trabajo que permitiera no sólo el análisis de aquellas piezas más completas que permitieran averiguar el tipo de pieza de la que formaban parte, o que contuvieran algún tipo de decoración característica. Nos centramos en el estudio de la cerámica como objeto resultante de una larga y compleja cadena de operaciones que incluyen desde la captación y extracción de la arcilla hasta la fractura de la pieza, pasando por la adicción de desgrasantes, el modelado de la pieza, la inclusión de decoración, la cocción etc.

En definitiva, dentro de la línea de estudios arqueológicos más próxima a la Historia y la Antropología, perseguimos un sistema de análisis del material cerámico del que se puedan obtener la mayor cantidad de datos significativos y necesarios tanto para fijar la cronología, como para conocer los sistemas de producción e intercambio de las cerámicas, así como su función, todo ello con la intención de dotar a la cerámica de todo su potencial explicativo.

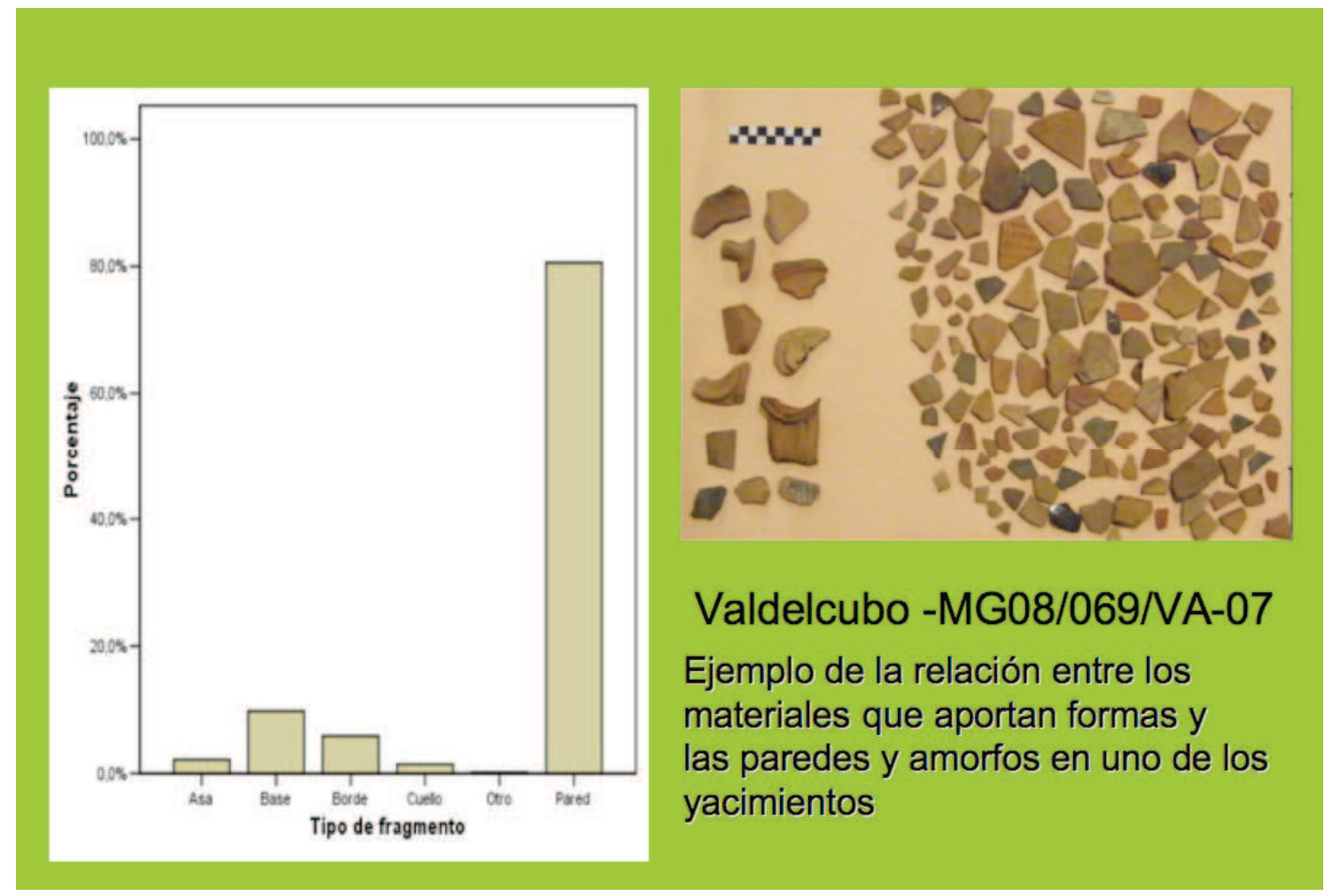

Teniendo en cuenta que el material proveniente de las prospecciones arqueológicos se halla bastante fragmentado, como ya hemos señalado, hemos considerado que los análisis formales y decorativos ofrecían unas limitadas posibilidades frente al estudio de las pastas y de los procesos tecnológicos seguidos en su configuración. 
De alguna forma, nuestra intención es aproximarnos al concepto de «tradición tecnológica» aplicado a los estudios cerámicos ${ }^{2}$. Supone un método de análisis destinado a la descripción y estudio de las técnicas de fabricación de la cerámica, mediante el cual se pretende identificar los elementos tecnológicos que conforman el proceso de fabricación de las vajillas definiendo la tradición tecnológica correspondiente. Es un concepto «por el que se reconoce una alta correlación entre procesos productivos, mediante los cuales se puede establecer una relación con su contexto cultural, de modo que este concepto puede ser sinónimo de cultura» ${ }^{3}$, aunque con una base más material, más cercana a la materialidad. Quizás las palabras de Retuerce sean también indicativas, aunque este investigador no use el concepto de tradición tecnológica y prefiera hablar de «grupos cerámicos», como exponemos en otro lugar de este trabajo:

[La tecnología de la cerámica] se trata de una característica interna, base del análisis tipológico (...) el aspecto tecnológico de una pieza cerámica es su característica más primaria. Según ello, el criterio de análisis tecnológico sería también el primero que se debería realizar. Toda cerámica para llegar a ser un artefacto ha de pasar por este nivel «formativo». Por lo tanto, el análisis de las características de su formación vendría a ser el primer estadio de una clasificación. Una vez hecho este análisis, podrían ser realizados los restantes. ${ }^{4}$

Aunque la correcta y estricta aplicación del concepto de «tradición tecnológica» debe desembocar, de manera casi inevitable, en el análisis de las pastas cerámicas desde un punto de vista químico y físico, mediante la aplicación de técnicas arqueométricas, para el trabajo que pretendemos llevar a cabo nos ceñiremos solamente a la primera fase de este tipo de estudios, aquella que se centra en el análisis visual de la cerámica a partir de una serie de cuestionamientos que tienen que ver con su tecnología.

El análisis visual de las pastas se basa en tomar una serie de parámetros que es posible observar en cualquier fragmento cerámico, con lo que el problema de la alta fragmentariedad de las cerámicas de prospección al que antes aludíamos queda resulto en gran medida. Además, este tipo de estudios permite tanto estudiar los materiales provenientes de excavaciones en un futuro, como incluir los estudios referentes a tipologías y decoraciones.

\footnotetext{
${ }^{2}$ La aplicación de estas consideraciones a la cerámica medieval ha sido realizada por Esteban Fernández, quien a su vez recoge las aportaciones de Rye Owens. Vid. FERnÁNDEZ NAVARRo, Esteban, Tradición tecnológica de la cerámica de cocina almohade-nazarí, Granada, 2008; RYE OWENS, S., «Pottery technology. Principles and reconstruction», Manuals on archaeology 4, Washington, 1988.

${ }^{3}$ FERNÁNDEZ NAVARRo, Esteban, Tradición tecnológica de la cerámica de cocina almohade-nazarí, Granada, 2008, p. 27.

${ }^{4}$ RetUerCe Velasco, Manuel, La cerámica andalusí de la Meseta, Madrid, 1998, t. 1, p. 28.
} 
Tratamos, en definitiva, de elaborar un sistema de análisis abierto y compatible, que permita extraer conclusiones tanto dentro del propio método de trabajo, como al comparar este registro arqueológico con otros estudiados de formas distintas.

Además, la forma en que estos datos se han tomado pretenden seguir el mismo proceso de producción de la cerámica. Así, desde los elementos relativos a la composición de las pastas, que debe relacionarse con la captación y elaboración de los barros, hasta el tratamiento último de las superficies, en el que se incluirán también las decoraciones.

Nuestro estudio cerámico pretende seguir los mismos pasos que el proceso de producción seguido por el alfarero, fases por las que la cerámica ha debido pasar antes de llegar a su primer uso. Después, veremos las huellas de uso, y finalmente las huellas de los procesos postdeposicionales.

Respecto al proceso de producción, Esteban Fernández resalta la necesidad de distinguir entre las fases esenciales de las que no lo son. Las primeras serían la localización y extracción de la materia prima, el transporte al lugar de fabricación, a preparación para el uso, el modelado, el secado, la cocción y la distribución para su uso. La ultima será el miso uso, o usos. Respecto a los procesos no esenciales, se incluyen aquí el tratamiento de las superficies, las formas decorativas empleadas y las pequeñas variaciones formales dentro de un mismo estándar. Son no esenciales por no afectar a la utilidad del producto. $^{5}$

El análisis de las materias primas se hará siempre sobre la pasta cerámica, si bien debemos recordar que no habrá resultados seguros sin la aplicación de métodos de análisis químicos y mineralógicos y petrográficos, esto es, arqueométricos, que lo pongan en relación con las formaciones geológicas del entorno y que detecten variables tales como la temperatura de cocción, que el análisis visual no permite ${ }^{6}$.

Con todas estas consideraciones, que justifican la metodología del análisis cerámico empleado, vamos a exponer los parámetros concretos que hemos definido en nuestro estudio. Como ya se ha señalado, la secuencia de análisis, esto es, las preguntas que le formulamos a la cerámica, pretende respetar en gran medida la propia secuencia de vida de la cerámica desde el mismo momento en el que se extrae la arcilla.

Antes de entrar en detalle, queremos dejar constancia de algo. Toda la metodología para el análisis cerámica que aquí exponemos tiene diferentes referentes bibliográficos que iremos citando en su debido momento, pero por encima de todos ellos tiene un punto de partida fruto de la experiencia en el seno de un grupo de trabajo y un proyecto de investigación. Nos referimos al proyecto La ciudad de Madinat Ilbira (Atarfe-Pinos

\footnotetext{
${ }^{5}$ FERNÁNDEZ NAVARRO, Esteban, «Estudio tecnológico de la cerámica nazarí de Granada», Transfertana, Monografias 4: Estudios de cerámica nazarí y meriní, Ceuta, 2000, pp. 46-49. La idea de operaciones esenciales y otras secundarias está inspirada también en la obra de RYE OWENS, S., «Pottery technology. Principles and reconstruction», Manuals on archaeology 4, Washington, 1988.

${ }^{6}$ Sobre los tipos de análisis arqueométricos que pueden aplicarse sobre la cerámica resulta útil la lectura de CAPEl Fernández, Josefa, «Ciencias de la tierra y Arqueología», en CARTA, Raffaela, (Ed.), Arqueometría y Arqueología medieval, Granada, 2005, y las referencias bibliográficas que se incluyen.
} 
Puente, Granada), y al grupo de investigación «Toponimia, Historia y Arqueología del Reino de Granada», ambos dirigidos por el profesor Antonio Malpica Cuello ${ }^{7}$ El método de trabajo con la cerámica desarrollado en el seno de este proyecto es la referencia fundamental de nuestro trabajo ${ }^{8}$.

\section{Indicadores referentes a la pasta, el modelado del alfarero y la cocción}

El análisis de la pasta consiste en el estudio y la clasificación de la cerámica a partir de las características de la arcilla de la que está hecha. Podemos dividir estas características en tres clases:

- las que están en función del tipo de arcilla empleado

- las que son una consecuencia de las inclusiones que se añaden

- las que son producto de la temperatura y las condiciones de cocción.

El análisis visual de las pastas se basa en tomar una serie de parámetros observables en cualquier fragmento cerámico. Estos criterios, que denominamos primarios, permiten establecer grupos tecnológicos, ya que son datos que informan sobre los distintos momentos del proceso de producción. En el caso de que coincidan todos estos rasgos se puede presuponer que dos fragmentos pertenecen a un mismo grupo tecnológico, aunque no podrá ser verificado hasta usar otras técnicas más complejas.

Todos estos indicadores pueden ser examinados de manera visual, aunque los resultados nunca serán tan exactos como lo es el análisis mediante técnicas arqueométricas, si que es un tratamiento útil y que proporciona respuestas satisfactorias en un primer nivel de estudio arqueológico como es el que pretendemos llevar a cabo.

Los distintos indicadores que permiten el análisis visual de las pastas cerámicas son descritos por Orton, Tyers y Vince en una obra que se ha convertido en el auténtico referente para este tipo de estudios ${ }^{9}$. Aunque es un método de análisis de la cerámica en el mundo anglosajón, es bastante menos utilizado en la Península Ibérica, donde los

\footnotetext{
${ }^{7}$ Vaya desde aquí nuestro más sentido agradecimiento a todos los investigadores que hacen posible este proyecto, y especialmente a Alberto García Porras, Esteban Fernández Navarro, Miguel Jiménez Puertas y José Cristóbal Carvajal López, dedicados al estudio de la cerámica todos ellos, entre otros muchos temas, por haber compartido con nosotros algunas de sus reflexiones y habernos hecho notables puntualizaciones, correcciones y aportaciones a nuestro método de trabajo.

${ }^{8}$ La metodología a la que nos referimos ha sido expuesta en diferentes publicaciones. Vid. CARVAJAL LóPEZ, José Cristóbal, La cerámica de Madinat Ilbira (Atarfe) y el poblamiento altomedieval de la vega de Granada, Granada, 2008, pp. 211-222; JIMÉNEZ PUERTAS, Miguel, «Cerámica tardoantigua y emiral de la Vega de Granada. Cerro del Molino del Tercio (Salar)» en MalPiCa Cuello, Antonio y CARVAJal LÓPEZ, José Cristóbal (Eds.), Estudios de cerámica tardorromana y altomedieval, Granada, 2008, pp. 163-219.

${ }^{9}$ Orton, Clive, Tyers, Paul y Vince, Alan, La cerámica en Arqueología, Barcelona, 1997. Todo el capítulo $5^{\circ}$ está dedicado al análisis de las pastas (pp. 83-93), siendo la base fundamental de la metodología que aquí aplicamos.
} 
análisis cerámicos siguen muy apegados a los criterios taxonómicos y funcionalistas. Aún así, son varios los trabajos que en España siguen este método ${ }^{10}$.

No obstante, debemos señalar que, en nuestro caso, el exhaustivo análisis que se propone por los tres autores británicos ha sido simplificado en el transcurso de la propia investigación, ya que determinados campos como aquellos referentes a la dureza o el tamaño y rodamiento de las inclusiones resultaba en exceso detallista, pudiendo simplificarse sin que se alteraran por ello los resultados en exceso, como veremos más adelante $^{11}$.

1.- El color de la pasta depende de varios factores. Fundamentalmente, del tipo de arcilla utilizada, el contenido de hierro que presente, y de las condiciones de cocción. Aunque lo ideal es trabajar con un catálogo estándar, como por ejemplo la Tabla de Munsell, lo cierto es que en la mayoría de las investigaciones se impone un tratamiento del color más simplificado, atendiendo a cuatro o cinco colores básicos para referirse a las pastas cerámicas. Hemos optado por distinguir cinco gamas o tonalidades de color:

- muy clara, que incluye colores amarillos y rosáceos

- parda, con gamas de colores entre los beige y los anaranjados

- rojiza, que incluye desde el naranja al marrón

- oscura, para aquellas tonalidades de pastas más oscuras, marrones y negras

- gris, una categoría definida por la propia experiencia de trabajo con los materiales, ya que hay un grupo de cerámicas con esta tonalidad en la pasta que muy probablemente tiene que ver con los procesos de cocción.

El color se ha definido atendiendo a cinco zonas básicas: el núcleo, los márgenes y el color de la superficie. Se ha tomado en cuenta el color predominante, desechando aquellas variaciones que se han considerado producto de alteraciones en la cocción de la pieza o por huellas de uso.

\footnotetext{
${ }^{10}$ Junto a los ya mencionados trabajos sobre Madinat Ilbira que han sido ya reseñados, citaremos tan sólo uno de los últimos trabajos publicados dedicados al período altomedieval en el ámbito leones: MARTínEZ Peñín, Raquel, Estudio de la cerámica medieval del Castro de los judios, Puente Castro (León): campaña de 1999, León, 2007; Idem, «La producción cerámica medieval del Castrum Iudeorum (Puente Castro, León: análisis de los materiales de la campaña de 1999», Arqueología y Territorio Medieval, 14 (2007), pp. 163-207. Hay que señalar que es precisamente en el período altomedieval donde este tipo de estudios se han implantado y difundido con mayor celeridad. No obstante, a pesar de la preocupación que muchos investigadores muestran por los aspectos tecnológicos de la cerámica, éstos indicadores no son luego tomados en consideración a la hora de las conclusiones o propuestas de evolución de las cerámicas. Como ejemplo PÉrez Alvarado, Sonia, Un indicador arqueológico del proceso de islamización. Las cerámicas omeyas de Marroquies bajos, Jaén, 2003, trabajo que, por otra parte, nos parece excelente en todo su planteamiento teórico y metodológico, y con unos resultados excepcionales.

${ }^{11}$ Esta tendencia a la simplificación de las propuestas de los investigadores anglosajones, pero sin descartar las líneas principales de sus propuestas, se detecta en los más recientes estudios sobre cerámica altomedieval en la Península Ibérica. Vid. supra
} 
2.- Respecto a las inclusiones se ha tenido en cuenta tanto la cantidad y frecuencia observada, como su perfil redondeado o anguloso, con el objetivo de aclarar algunos aspectos sobre la matriz usada en la conformación de la pieza cerámica. Esta categoría supone, por tanto, la identificación de la cantidad de inclusiones, su tamaño y la erosión que presentan. Con estos indicadores pretendemos establecer grupos en los que las pastas tengan los mismos valores de frecuencia, tamaño $-\mathrm{y}$ también la naturaleza que después veremos - de las inclusiones que se observan a simple vista, ayudados tan solo por una lupa binocular de 30 aumentos. El objetivo de esta clasificación es determinar si la inclusión se encontraba naturalmente en la pasta o fue añadida por el alfarero, suponiendo que como tales serán las machacadas de arista afilada.

Para medir la frecuencia de las inclusiones usamos el gráfico de estimación de porcentajes presentado en el apéndice de la obra de Orton, Tyers y Vince ${ }^{12}$, considerando los valores inferiores al $5 \%$ como escasez, entre 5 y $10 \%$ moderado y los superiores al $10 \%$ como abundancia.

Con respecto al tamaño, nos basamos en una simple clasificación aproximada a partir del tipo de inclusión más abundante, considerando los siguientes valores:

- Inclusiones finas entre 0,1 y $0,5 \mathrm{~mm}$

- Inclusiones medias entre 0,5 y $1,5 \mathrm{~mm}$

— Inclusiones groseras mayores a $1,5 \mathrm{~mm}$

Finalmente, para el grado de erosión de las inclusiones, hemos optado también por simplificar las propuestas de Orton et alii, que incluían hasta cinco grupos ${ }^{13}$, y hemos usado solamente dos valores para medir el grado de desgaste: redondeado o anguloso.

Fruto de la experiencia con el trabajo de la cerámica, y tras varias pruebas, hemos optado finalmente por establecer siete rangos a la hora de analizar las inclusiones en la cerámica, que quedan de la siguiente manera:

- Muy depuradas, cuando apenas es posible distinguir las inclusiones, debido a su diminuto tamaño, y se presentan de forma homogénea y bien distribuida por toda la pasta.

- Pocas y pequeñas, cuando en las inclusiones puede distinguirse su naturaleza, aunque aún son de pequeño tamaño y es difícil establecer el grado de erosión

- Bastantes y pequeñas, igual que el anterior, pero cuando su número se multiplica por toda la pasta, con una estimación del porcentaje superior al $10 \%$

- Pocas, medianas y angulosas, cuando el tamaño es superior a los 0,5 mm y presentan un perfil de arista quebrada, no redondeada

\footnotetext{
${ }^{12}$ ORTON, Clive, TYERs, Paul y VINCE, Alan, La cerámica en Arqueología, Barcelona, 1997, p. 267.

${ }^{13}$ Angular, subangular, redondeado, irregular y plano, ORTON, Clive, TYERS, Paul y VINCE, Alan, La cerámica en Arqueología, Barcelona, 1997, p. 269.
} 
- Pocas, medianas y redondeadas, cuando las inclusiones aparecen en su mayoría rodadas y $\sin$ aristas vivas

- Bastantes, medianas y angulosas, cuando el porcentaje estimado es superior al 5$10 \%$ y el tamaño es superior a los $0,5 \mathrm{~mm}$, presentando además un aspecto no rodado

- Bastantes, medianas y redondeadas, cuando, al igual que en el caso anterior, son frecuentes y de tamaño medio las inclusiones, pero con un aspecto rodado $\mathrm{y}$ redondeado en este caso

- Presencia de grandes inclusiones, que define al tipo de pasta más grosera, con inclusiones que superan los 1,5 mm, y que por lo general aparecen en las piezas grandes como tinajas y tejas.

3.- Ha sido posible también identificar los minerales a partir de la guía que se presenta en la obra que usamos de referencia ${ }^{14}$, y usando también el simple análisis visual con apoyo de una lupa binocular de 30 aumentos. En nuestro caso, los minerales fundamentales han sido mica, cuarzo, calcita, caliches y una serie de poros redondeados y alargados que pueden ser indicativos de la presencia de inclusiones de tipo orgánico, bien vegetal o bien animal como pequeñas conchas. También se ha destinado un apartado dedicado a otro tipo de inclusiones cuyo origen mineral no ha sido posible identificar, y que suelen presentar un color muy oscuro o rojizo. Es probable que sean hierro, silex o chamota (grog), pero hemos preferido dejarlo en un campo indeterminado.

4.- Respecto a las acciones del alfarero a la hora de tratar las piezas, y dejando de momento a un lado el tema de la tipología, se ha tenido en cuenta varios aspectos. En primer lugar, si el moldeado se ha realizado a torno o a mano, dejando un campo para las elaboraciones a torneta o torno lento que en algunas piezas hemos podido identificar debido a la irregularidad de las marcas del torno o a ciertas diferencias en el grosor de las paredes ${ }^{15}$. Dentro de las operaciones de modelado del alfarero habría que consignar también la forma dada a la pieza, así como el grosor, el diámetro y el acabado de la superficie, campos todos ellos que son tratados de forma autónoma.

\footnotetext{
${ }^{14}$ Orton, Clive, Tyers, Paul y Vince, Alan, La cerámica en Arqueología, Barcelona, 1997, pp. 264265, basada, según reconocen en p. 88, en la obra de PEACOCK, D. P. S., «Ceramics in Roman and medieval archaeology» en PEACOCK, D. P. S., (Ed.), Pottery and early commerce, Londres, 1977, pp. 2134.

15 Sobre la identificación del uso de la torneta en época altomedieval en espacios andalusíes vid. KIRCHNER, Helena, «Torneta y torno. Formas de producción, distribución y uso de la cerámica andalusí. El caso de Yâbisa», en MAlPICA Cuello, Antonio y CARVAJAl LóPEZ, José Cristóbal (Eds.), Estudios de cerámica tardorromana y altomedieval, Granada, 2007, pp. 221-245.
} 
5.- El siguiente aspecto considerado ha sido el del acabado de la superficie de la cerámica. A grandes rasgos, nos permite distinguir entre las piezas que son tratadas de alguna forma, de aquellas que presentan el mismo aspecto que recién modeladas, y por último un grupo a las que se le aplica algún tipo de cobertura superficial, bien engobes o bien vidriados. De esta forma, se han podido distinguir varios tipos de acabado, elaborando una lista que incluye: alisada, artilada, áspera, bruñida, con presencia de engobe, raspada, vidriada o con suaves marcas de torno.

La experiencia del trabajo nos ha permite demostrar que este tipo de indicador es más fiáble que aquel propuesto por Orton et alii $^{16}$ en el que se consignaba el tacto que presentaba la pieza, ya que los términos «áspero», «grosero» o «suave» resultan demasiados subjetivos y poco operativos, cuando en una misma pieza se identifican texturas diferentes en según que zonas. Es por ello por lo que hemos dejado a un lado este indicador.

6.- Dentro de la misma concepción del acabado de la superficie como rasgo diferenciador de grupos tecnológicos dentro de la cerámica, y con el mismo objetivo de definir diferencias y semejanzas en la conformación de piezas que aparentemente pertenecen a una misma familia tipológica o morfofuncional, se ha optado por dedicar un apartado para los acabados de las bases y de los bordes. Se han señalado como indicadores cóncava, convexa, plana alisada, plana rugosa, con huellas del torzal, raspada, retorneada, y espatulada para las bases, y en ala, recto y redondeado, recto y apuntado, exvasado y redondeado o exvasado y apuntado para los bordes.

Como ha señalado Fernández Navarro, el acabado de la base es fundamental para entender una tradición tecnológica ${ }^{17}$. Sin embargo, la imposibilidad de asignar una base a todos los tipos de pasta, debido a la alta fragmentariedad del registro con el que trabajamos, hace que no deba considerarse un elemento determinante en este análisis.

7.- El siguiente aspecto que se ha consignado ha sido el del grosor del fragmento, para lo cual se han establecido 6 rangos de tamaño: $<30 \mathrm{~mm}, 30-70 \mathrm{~mm}, 70 \mathrm{~mm}-1 \mathrm{~cm}$, $1-1,5 \mathrm{~cm}, 1,5-2 \mathrm{~cm}$ y $>$ a $2 \mathrm{~cm}$. La idea a la hora de consignar este valor es la de establer diferencias en la morfometría de pieza que, en principio, responden a una misma tipología y caracterización de la pasta, con el objetivo de indagar acerca de una posible diferenciación en los centros de producción. Aunque no es del todo fiable, en conjunto con el resto de indicadores creemos que puede ser de gran utilidad.

\footnotetext{
${ }^{16}$ Orton, Clive, Tyers, Paul y VInCE, Alan, La cerámica en Arqueología, Barcelona, 1997, p. 220.

${ }^{17}$ FERnÁNDEZ NAVARRO, Esteban, Tradición tecnológica de la cerámica de cocina almohade-nazarí, Granada, 2008, pp. 110-119.
} 
8.- También se ha tenido en consideración el diámetro que originalmente debía tener la pieza, para lo cual se ha tomado la medida únicamente en los bordes y bases, así como en las tapaderas o fragmentos de cerámica cuyo diámetro podía ser muy indicativo como es el caso de los cuellos. En otras piezas, como las paredes, amorfos o materiales de construcción como las tejas no hemos tomado esta medida. El diámetro se ha establecido con ayuda de escalímetros y gráficos de bordes, y siempre que ha sido posible, a partir de la reproducción gráfica del perfil que originalmente debía tener la pieza.

9.- Los siguientes indicadores tenidos en cuenta se refieren más específicamente al proceso de cocción de la cerámica. En primer lugar, se determina si la cocción ha sido oxidante, reductora, alterna o ha dejado una pasta tipo sandwich o sandwich inverso. Esta caracterización se determina por la presencia de una coloración distintiva en la pasta cerámica, ya que dependiendo de la entrada o no de oxígeno en el horno, así como del mantenimiento de unas condiciones más o menos estables tanto en el momento de calentamiento como en el de enfriamiento, la pasta adquiere una coloración distintiva y unas huellas que son de relativamente fácil distinción.

10.- En segundo lugar, en lo que se refiere a la dureza hay que señalar que es un parámetro que nos da una indicación aproximada de la temperatura de cocción, y puede sernos útil en la clasificación. Existen diferentes medios para determinar la resistencia al rayado, como la escala de dureza de Mohs. En nuestro caso, hemos optado también por simplificarla, distinguiendo únicamente las piezas muy frágiles, de aquellas que pueden rayarse con la uña, con acero o que no pueden rayarse.

Todos estos indicadores son lo que hemos tenido en cuenta para tratar de establecer una clasificación referente a las pastas de la cerámica.

\section{Tipología}

Aunque lo ideal en cualquier análisis cerámico, de alguna forma aquello a lo que cada especialista aspira, es crear una clasificación novedosa que permita resolver las cuestiones y preguntas específicas planteadas para cada estudio, ello no siempre es posible y, a veces, ni siquiera recomendable. Al crear una nueva clasificación se pierde una de sus principales utilidades, la de permitir la comparación entre distintos conjuntos cerámicos procedentes bien de distintos espacios, bien de distintas cronologías. Y en cualquier caso, si se elabora una nueva clasificación cerámica, o un catálogo distinto, lo ideal es crear una «tabla de traducción» respecto a las colecciones de referencia ya existentes en la zona y el período. En cualquier caso, como señalan Orton, Tyers y 
Vince, lo ideal es trabajar con catálogos y clasificaciones ya existentes e intentar mejorarlas o criticarlas $^{18}$. En nuestro caso concreto de estudio, tenemos la suerte de contar con un minucioso estudio de carácter muy amplio, puesto que incluye toda la Meseta, y que realiza además el esfuerzo tanto de elaborar una tipología propia, como de establecer detalladas comparaciones con otros puntos de la Península Ibérica ${ }^{19}$.

Junto a éste y otros trabajos de Retuerce ${ }^{20}$, base fundamental de todo la tipología y cronología que aquí presentamos, hay otra serie de estudios que nos han sido de enorme importancia: por un lado las referencias a los excavaciones urbanas y los alfares de Guadalajara $^{21}$, y por otro lado otra serie de estudios realizados en distintos asentamientos andalusíes, como son los de Toledo, Calatalifa, Olmos, Peñafora, Madrid, Vereda de Sedano, Oreja y Ercávica ${ }^{22}$, así como algunos otros estudios de la

18 Orton, Clive, Tyers, Paul y VINCE, Alan, La cerámica en Arqueología, Barcelona, 1997, p. 89.
${ }^{19}$ RETUERCE VELASCO, Manuel, La cerámica andalusí de la Meseta, Madrid, 1998, 2 tomos.
20 RetUerCe VelasCO, Manuel, «La cerámica islámica de Calatalifa. Apuntes sobre los grupos
cerámicos de la Marca Media» Boletín del Museo Arqueológico Nacional, 2.1. (1984), pp. 117-136; Idem,
«Cerámica islámica en la Comunidad de Madrid» en Madrid del siglo IX al XI, Madrid, 1990, pp. 145-
164; Id. «Arqueología y poblamiento en la Meseta Andalusí. El referente cerámico» en V Semana de Estudios Medievales (Nájera, 1994), Logroño, 1995, pp. 87-124.

${ }^{21}$ Barroso Bermejo, R. M. y Jiménez, P. J., «Arqueología de la iglesia de los Remedios», Actas del III Encuentro de historiadores del valle del Henares, Guadalajara, 1992, pp. 93-102; CUADRADO PRIETO, Miguel Ángel, «Un hogar hispanomusulmán en el solar del Palacio de los Guzmán», Actas del III Encuentro de historiadores del valle del Henares, Guadalajara, 1992, pp. 79-92; Idem, «Excavaciones arqueológicas de urgencia en Guadalajara. Aguas Vivas», Balbín, R. De, VAliente, J. y Mussat, M. T. (Eds.), Arqueología en Guadalajara, Talavera de la Reina, 1995, pp. 179-191; CUADRADO PRIETO, Miguel Ángel y CRESPO CANO, María Luisa, «Un alfar hispanomusulmán en la Plaza de la Antigua. Guadalajara», Wad-al-Hayara, 19 (1992), pp. 9-38.

22 Aguado Villalba, José, La cerámica hispano-musulmana de Toledo, Madrid, 1983; LARREN IZQUIERDO, H., «Apuntes para el estudio del sistema defensivo del Tajo: Oreja, Alarilla y Alboer», Boletín de Arqueología Medieval, 2 (1988), pp. 87-96; MARTínEz LiLlo, Sergio, «Primeros materiales arqueológicos del Castillo de Olmos» en I Congreso de Historia de Castilla-La Mancha, Talavera de la Reina, 1988, tomo V, pp. 95-104; Álvarez Delgado, Y. «Cerámicas del siglo IX de Arcávica (Cuenca)», Boletín de Arqueología Medieval, 3 (1989), pp. 109-122; JiMÉNEZ EsTEBAN, J. «Aportación a la arqueología hispano-musulmana: Peñahora (Guadalajara)», Wad-al-Hayara, 16 (1989), pp. 283-292; García MuÑoz, M., «Excavaciones arqueológicas en el solar de la Plaza de la Morería c/v Plaza del Granado», en Madrid del siglo IX al XI, Madrid, 1990, pp. 217-222; PÉREZ VICENTE, D. «Excavaciones arqueológicas en el solar n ${ }^{\circ} 21$ de la Calle Segovia» en Madrid del siglo IX al XI, Madrid, 1990, pp. 261266; Priego FERnÁndeZ del CAMPO, M. C., «Origen y evolución urbana de la Plaza de los Carros» en Madrid del siglo IX al XI, Madrid, 1990, p. 267-275; SÁnChez Palencia, F. J.; SAinz PAscuAL, M. J., Martínez Lillo, S. y JuAn S. de, «El circo romano de Toledo», Actas del Primero Congreso de Arqueología de la Provincia de Toledo. Talavera de la Reina, 1990, pp. 351-369, SOLER, A. y TURINA, A., «Excavaciones arqueológicas en el solar de la Cava Baja, 22» en Madrid del siglo IX al XI, Madrid, 1990, pp. 283-285; VAllespin, O., Serrano, E., López, M. A. y Marín, F. J. «Excavaciones en el solar Calle de San Isidro», en Madrid del siglo IX al XI, Madrid, 1990, pp. 287-296; BARRIO AldEA, C. y Maquedano CARrasco, B. «Desechos de un alfar musulmán en la c/ Honda 46» en SÁNCHEZ Palencia, F. J. et alii, (Coords.), Toledo; Arqueologia en la ciudad, Talavera de la Reina, 1996, pp. 159170; Bermejo Crespo, J. L. y Muñoz López-Astilleros, K., «El yacimiento medieval de Vereda de Sedano o Las Fuentecillas (San Fernando de Henares, Madrid: Campañas de excavación de 1989 y 1990» Estudios de Prehistoria y Arqueología Madrileñas, 10 (1995-1996), pp. 111-120; BERMEJO CRESPO, J. L. y MuÑoz LóPEZ-Astilleros, K., «Una explotación agrícola en el territorio de los Banu Salim: excavaciones en "Vereda de Sedano" o "Las Fuentecillas" (San Fernando de Henares, Madrid)», Boletín de Arqueología Medieval, 8 (1994), pp. 205-225. 
provincia de Soria y Zaragoza ${ }^{23}$. En todos ellos se han recuperado materiales entre los que destacan algunas formas cerámicas que se han considerado características de la Marca Media, como determinados tipos de ollas, jarras y redomas, a torno, con ausencia de vedríos y presencia de decoración — cuando la hay- poco elaborada, destinados fundamentalmente a un uso cotidiano.

Todos los trabajos que anteriormente hemos citado, de manera más o menos directa, han servido de base a nuestro estudio en tanto que se trata de las excavaciones y asentamientos andalusíes más próximos al valle del Salado en el que se centra nuestra investigación. Junto a todos ellos debemos citar otro que ha sido de gran importancia por varios motivos. Se trata del único trabajo, al menos que publicado y accesible, sobre la cerámica islámica de Medinaceli en el que los materiales son tratados desde un punto de vista alejado de la mera tipología y más próximo a preocupaciones tecnológicas, en el que el estudio de las pastas y las inclusiones juega un papel importante ${ }^{24}$. Además, este estudio se sustenta en toda una serie de estadísticas presentadas de forma gráfica. Al ser un estudio muy similar al que nosotros hemos querido realizar, y al tratar sobre el más importante centro de todo este espacio geográfico, al menos según nos citan las fuentes escritas, que debió funcionar casi como una ciudad, las comparaciones con este estudio han sido fundamentales a la hora de tratar la cerámica del valle del Salado.

De acuerdo con todos estos principios, y con los estudios antes citados que nos han servido de referencia, la clasificación tipológica que hemos realizado ha quedado estructurada de la siguiente forma. En primer lugar, el grupo morfofuncional, es decir, la adscripción funcional pretendida para la pieza desde su origen ${ }^{25}$. Aquí distinguimos entre piezas destinadas a Almacenamiento y transporte, de las de Servicio de mesa, cocina, construcción, iluminación, y usos múltiples.

En cuanto a la serie tratamos de aproximarnos a las clasificaciones más habituales de la cerámica andalusí, derivadas de las propuestas de Rosselló ${ }^{26}$.

\footnotetext{
${ }^{23}$ MARTínez GarCía. Francisco José, «El otero del Cid o cerro Torrecid: enclave militar del Campeador en el valle del Jalón» Simposio Internacional El Cid en el valle del Jalón, Calatayud, 1991, pp. 49-95

${ }^{24}$ GómeZ MartíneZ, Susana, «Cerámica islámica de Medinaceli», Boletín de Arqueología Medieval, 10 (1996), pp. 123-182.

${ }^{25}$ Aunque tenemos muy presente en todo momento la más que posible plurifuncionalidad de toda la vajilla cerámica en época altomedieval, no nos cabe duda que determinada morofología tiene necesariamente que estar adscrita a una función, al menos pretendida originalmente.

${ }^{26}$ Seguimos el ejemplo de Rosselló Bordoy, Guillermo, El nombre de las cosas en al-Andalus. Una propuesta de terminología cerámica, Palma de Mallorca, 1991; quien a su vez lo ha tomado en gran medida de las propuestas de BAZZANA, André «Ceramiques médievales: les méthodes de la description analitiques apliquées aux productions de l'Espagne Orientale I» Melanges de la Casa Velázquez, XV (1979), pp. 135-186.
} 


\section{Decoración}

Ya anteriormente indicábamos como, aunque seguimos grosso modo los trabajos de Manuel Retuerce para la clasificación tipológica de la cerámica, hay determinados aspectos que hemos preferido dejar fuera por considerarlos innecesarios en el estado actual de nuestra investigación. Entre estos descartes debemos mencionar también el prolijo sistema de clasificación de las decoraciones cerámicas de Retuerce, también planteado por Zozaya ${ }^{27}$, ya que el volumen de cerámicas decoradas con el que vamos a trabajar es realmente exiguo. No obstante, en este último caso debemos reconocer su valía a la hora de aportar cronologías, por lo que acudiremos a él hasta donde nos sea necesario.

En nuestro caso, para la elaboración de este estudio, nos hemos limitado a consignar el tipo de decoración que hemos documentado en las diversas piezas cerámicas a partir de distintas variables:

En primer lugar la técnica, con la que nos referimos al tipo de decoración que presente, distinguiendo entre Digitaciones, Incisiones, Punciones, Pintada en blanco, Pintada en negro, Pintada en rojo, Restos de pintura imprecisos, Ungulaciones, Vidriado monócromo, Vidriado bícromo, Vidriado en tres colores. También se ha preparado la base de datos para incluir, en un futuro, otros campos como Engobe, Cuerda Seca o Estampillado, si bien no tenemos ningún ejemplo de estos entre el registro cerámico con el que hemos trabajado.

En segundo lugar prestamos atención al motivo, esto es, la forma decorativa que adopta la técnica elegida. En este campo ocurre igual que en el anterior: aunque la base de datos se ha preparado para incluir campos como Motivos vegetales, Motivos zoomorfos, Epigrafía etc., son solo los siguientes campos los que se han identificado: Vidriado solo interior, Vidriado por las dos caras, Vidriado solo al exterior, Reticulado, A peine, Geométrico, Goterones, Lineas onduladas, Lineas rectas horizontales y Líneas rectas verticales.

El último campo está dedicado únicamente al vidriado, y tiene por objeto consignar el color o la combinación de colores del vidriado: Amarillento, Blanco, Trazos negros sobre fondo blanco, Melado, Exterior melado e interior verde $y$ manganeso, Marrón, Verde, Verde blanco y negro y Verde y manganeso son los colores que se han identificado, aunque como en los campos anteriores, la base de datos queda abierta para su ampliación.

\footnotetext{
27 Sobre la decoración cerámica, Vid. RetUERCE VelAsco, Manuel y ZozAYA, Juan, «Variantes geográficas de la cerámica omeya andalusí: los temas decorativos» en La ceramica medievale nel Mediterraneo Occidentale, (Siena-Faenza, 1984), Florencia, 1986, pp. 69-128. El sistema de registro de la decoracióne s ampliamente descrito por el primero de los autores en RETUERCE VELASCO, Manuel, La cerámica andalusí de la Meseta, Madrid, 1998, t. I, pp. 403-429.
} 


\title{
Huellas de uso y procesos posdeposicionales
}

La idea de este tipo de análisis la hemos tomado del estudio de las tejas que se ha llevado a cabo en el yacimiento arqueológico de Madinat Ilbira ${ }^{28}$.

En lo que a las huellas de uso se refiere únicamente se ha detectado la aplicación directa de Fuego a las piezas, lo que resultaría indicativo de su uso culinario, o la presencia de Restos de mortero y cal, que podría indicar su utilización como parte de los elementos constructivos del yacimiento.

Algo más interesante ha resultado el estudio de los procesos posdeposicionales a partir del grado de rodamiento que presenta la cerámica. El objetivo es evaluar, mediante una gradación, los daños que presenta cada pieza tanto en su superficie como en las aristas de fractura. Pretende ser un elemento indicativo de los procesos posdeposicionales que haya podido sufrir el yacimiento, en el caso de los daños en la superficie por las alteraciones y remociones del suelo con fines agrícolas o de otro tipo, y en el caso de las aristas para indicar el rodamiento que las piezas han tenido y que indicarían alteraciones de tipo sedimentario o por transporte debido a causas, fundamentalmente, naturales. Así, tomando en consideración estos aspectos, las gradaciones que hemos establecido son las siguientes:

\author{
Superficie \\ 1. Intacta \\ 2. Buen estado \\ 3. Desgastada \\ 4. Muy desgastada \\ 5. Irreconocible
}

Arista

1. Arista viva

2. Arista difusa

3. Arista redondeada

4. Arista muy rodada

5. Irreconocible

Consideramos que lo normal en la recogida de materiales en prospección debe ser un grado de alteración $3 / 3$, esto es una superficie gastada y una arista redondeada. Cuanto

\footnotetext{
${ }^{28}$ CARVAJAl López, José Cristóbal y Moreno RuedA, Gregorio, «Estudio de tejas extraídas en Madinat Ilbira en la campaña de 2005», en MALPICA CUELLO, Antonio (Dir.), Informe de la campaña de estudio de materiales de Madinat Ilbira (2006), Granada, 2006. Informe depósitado en la Delegación de la Consejería de Cultura de la Junta de Andalucía en Granada, Inédito.
} 
más próximo al contexto de uso de la cerámica el grado de alteración más próximo debe ser al 1/1, aún estando fragmentada como es normal en la cerámica arqueológica. En yacimientos enormemente alterados este valor sería más próximo a 5/5. La idea es evaluar el conjunto total de la cerámica recuperada en el yacimiento. Lo normal será una preponderancia del valor 3/3, como ya se ha indicado, pero las pequeñas variaciones en conjuntos cerámicos tan grandes, tanto en el caso de que muestren una cerámica más rodada como si está más intacta, puede ser un referente a tomar en consideración a la hora de evaluar los propios procesos posdeposicionales que haya sufrido el asentamiento. Insistimos en que en ningún caso pretende ser un valor único, pero si uno más a tener en consideración junto con el grado de pendiente, la presencia o no de estructuras en superficie, el tipo de suelo ante el que nos encontremos etc.

\section{Estadística y Base de datos}

Ninguno de los resultados de las técnicas de análisis y de los distintos indicadores que hemos estimado como importantes en el estudio de la cerámica, permiten una interpretación por sí mismos, como hemos visto. Es una mera descripción, que necesita de una interpretación. Ésta surge, fundamentalmente, de la comparación de los datos resultantes. Esto exige la intervención de los métodos de análisis de los datos, tanto del propio registro cerámico que trabajamos, como de este conjunto con otros. En este sentido, el análisis estadístico resulta indispensable.

Uno de los problemas que ha acarreado la excesiva atención a la morfología y decoración de las piezas cerámicas es el descuido de aspectos fundamentales en el registro arqueológico como es la cuantificación de los materiales, y especialmente de las cerámicas. Es cierto que esta preocupación estadística ha estado presente a la hora de relacionar cuantitativamente diferentes tipologías por ámbitos de un mismo yacimiento o entre yacimientos ${ }^{29}$. Pero hay varios puntos débiles en esta concepción de la cuantificación. En primer lugar, se cuenta por tipologías o series, no por tipos, lo que impide contemplar la evolución de los mismos desde el punto de vista cuantitativo para poder realizar una propuesta de producciones e importaciones en cualquier yacimiento o región. En segundo lugar, el cálculo se hace muy a menudo sobre selecciones por número mínimo de individuos, dejando de lado grandes cantidades de fragmentos que no son estudiados debido a la falta de morfología o a criterios de selección del material no suficientemente bien explicitados o por motivos poco convincentes, como es la

\footnotetext{
${ }^{29}$ Los ejemplos son muy numerosos, nos limitaremos a exponer algunos de los más recurrentes para época altomedieval: Motos GuIRAo, Encarnación, El poblado medieval de «El Castillón» (Montefrío, Granada), Granada, 1991, pp. 21-118; CASTILlo GALDEANO, Francisco y MARTínez MAdRID, Rafael, «Producciones cerámicas en Bayyana», en MALPICA Cuello, Antonio (Ed.), La cerámica altomedieval en el sur de al-Andalus, Granada, 1993, pp. 67-116.
} 
presencia o no de decoración ${ }^{30}$. Esto limita la representatividad del conjunto estudiado, como ha sido demostrado por Orton, Tyers y Vince, quienes además presentan alternativas teniendo en cuenta el peso de los conjuntos y los equivalentes de vasija estimados o EVE, ${ }^{31}$. Esto permite hacer comparaciones cuantitativas muy efectivas entre distintos conjuntos ${ }^{32}$. El EVE sirve para medir el porcentaje de pieza que tenemos a partir de un fragmento de borde, siempre que podamos establecer el diámetro de la vasija. Los porcentajes se calculan, para facilitar el cómputo, a partir de un valor mínimo del $5 \%$, en múltiplos de cinco.

El problema ante el que nos encontramos a la hora de aplicar el EVE es que el conjunto cerámico con el que trabajamos se encuentra enormemente fragmentado, no siendo siempre posible calcular el porcentaje de vasija estimado de las piezas al no poder conocer su diámetros. Siempre que ha sido posible lo hemos considerado, pero los resultados que presentamos no siempre lo tienen en consideración.

Dejando a un lado la cuestión del EVE, hemos de señalar finalmente que en nuestro caso, el análisis estadístico ha sido posible elaborarlo a partir de la propia base de datos que hemos elaborado con los distintos indicadores que hemos expuesto anteriormente. Para ello hemos recurrido a un software específico, el conocido como SPSS ${ }^{33}$. Las distintas variables han sido consignadas de manera independiente, lo que nos ha permitido establecer distintas gráficas y cuantificaciones porcentuales a partir de las cuales valorar todo el conjunto cerámico ante el que nos encontramos.

Antes de pasar a valorar los resultados del estudio tipológico y estadístico, queremos dejar constancia de los números reales con los que hemos trabajado, esto es, cuantos yacimientos y cuantos fragmentos cerámicos han sido analizados.

\footnotetext{
${ }^{30}$ Valga como ejemplo el cálculo de varianza realizado sobre los materiales seleccionados de Qal'at 'Abd-al-Salam (Alcalá de Henares) en ZoZAYA, Juan y FernÁNDEZ URIEL, Pilar, «Excavaciones en la fortaleza de Qal'at 'Abd-al-Salam (Alcalá de Henares, Madrid», Noticiario Arqueológico Hispánico. Serie Nueva, 17 (1983), pp. 411-529, en espec. p. 507. Sobre el cálculo de varianza, vid. SHENNAN, Stephen, Arqueología cuantitativa, Barcelona, 1992, pp. 54-57.

31 Del inglés «Estimated Vessel Equivalent», que ha sido traducido al español como «Equivalente de Vasija Estimado». Orton, Clive, Tyers, Paul y Vince, Alan, La cerámica en Arqueología, Barcelona, 1997, pp. 191-197; para el EVE en concreto pp. 35-36, y también ORTON, Clive, Matemáticas para arqueólogos, Barcelona, 1988, pp. 174-177. Posteriormente se realizaron mejoras a este sistema. Vid. Tyers, Paul A. y OrTON, Clive F., «Statistical analisis of ceramic assemblages» en LOCKYEAR, K. y RAHTZ, S. P. Q. (Eds.), Computer applications and quantitative methods in archaeology 1990, BAR International Series 565, Oxford, 1991, pp. 117-120, aunque su uso requiere de conocimientos avanzados de matemática estadística, y no serán usados en este trabajo.

32 Son muy escasas las aplicaciones de este sistema, que sin embargo es de fácil aplicación y ofrece muy buenos resultados. Está siendo usado en el análisis de la cerámica del proyecto La ciudad de Madinat Ilbira. Vid. Jiménez Puertas, Miguel y CARVAJAl LóPeZ, José Cristóbal «La cerámica del Pago de los Tejoletes 2006 (Madinat Ilbira Granada)» en http://www.arqueologiamedieval.com/docs/080428JIMENEZ2008.pdf

33 Como se sabe Statistical Package for the Social Sciences (SPSS) es un programa estadístico informático muy usado en las ciencias sociales y las empresas de investigación de mercado. Nosotros usamos la versión 17 (2008) para Microsoft Windows XP.
} 
La propuesta que hacemos de fijarnos en los aspectos tecnológicos (grupos tecnológicos o grupos cerámicos) nos ha permitido trabajar con un volumen cerámico mucho mayor que si sólo nos hubiéramos fijado en las cuestiones topologías, ya que para ello es necesario fragmentos cerámicos «diagnósticos», esto es, con características morfológicas suficientes para ser indicativos de la forma a la que pertenecen. En resumen, lo que queremos decir es que en lugar de contabilizar únicamente bordes y bases, como generalmente se hace, hemos considerado todos los fragmentos, incluso aquellos cuya alta fragmentariedad o gran erosión dificultan distinguir nada más allá de una masa de barro cocido. Hasta estas «masas informes» contienen parte de la información que necesitamos, como el color de la arcilla, los minerales presentes como inclusiones o los procesos de cocción a los que se les ha sometido.

Así, teniendo todo esto en consideración, hemos podido valorar 1113 fragmentos de cerámica de un total de $\mathbf{1 6}$ yacimientos, repartidos de la siguiente forma:

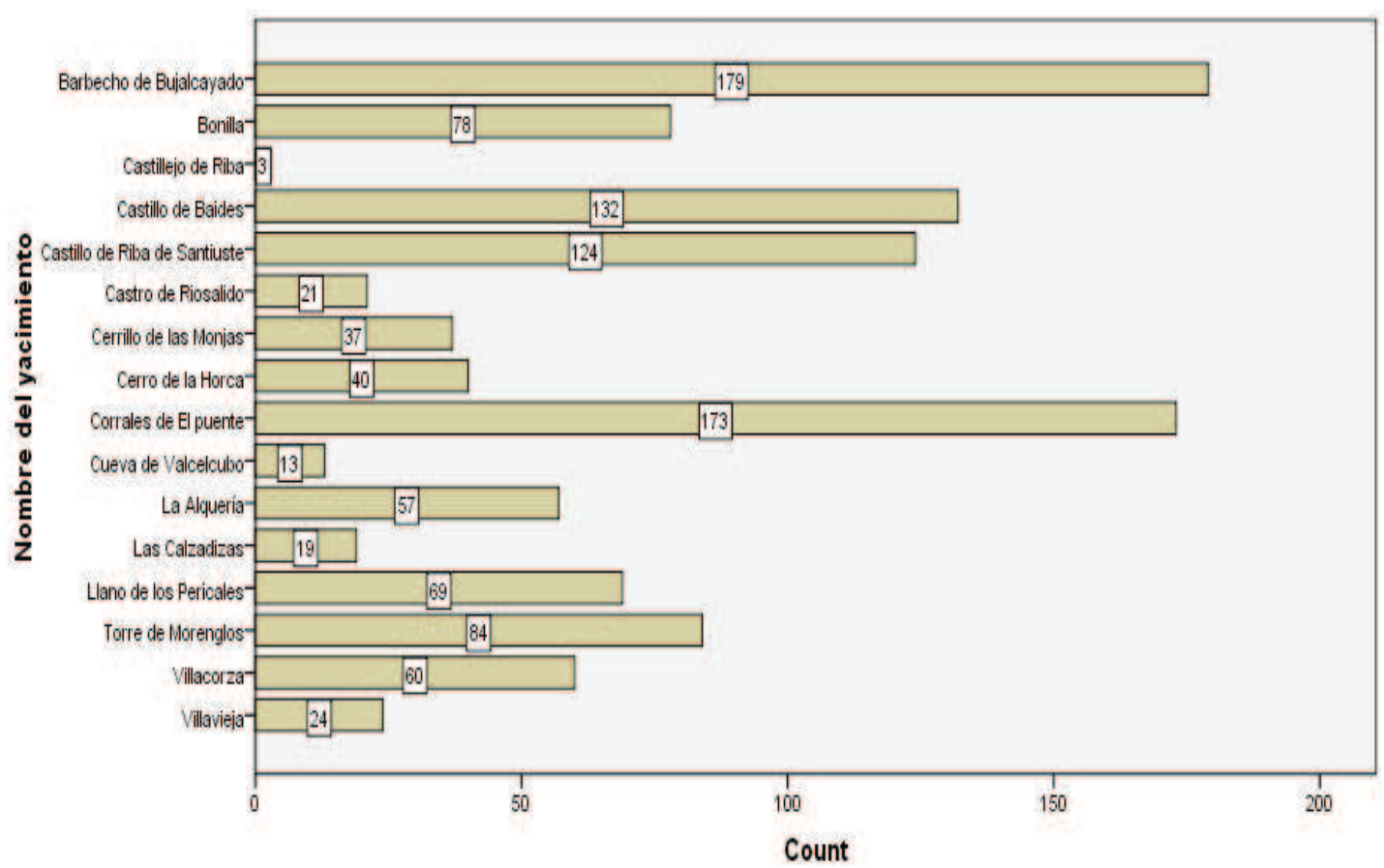




\title{
4.3. RESULTADOS DEL ANÁLISIS CERÁMICO
}

A partir de todas las consideraciones que hemos hecho anteriormente, vamos a pasar a exponer los que han sido los principales resultados del estudio cerámico que hemos elaborado. Para ello, vamos a centrarnos en primer lugar en todos aquellos indicadores referentes a la pasta y a los procesos de modelado y cocción, para posteriormente centrarnos en los aspectos decorativos y, de manera más extensa, detenernos en las series tipológicas que hemos podido identificar y en los tipos concretos caracterizados, atendiendo a la información cronológica que nos proporcionan y a las variables funcionales. Finalmente expondremos unas consideraciones acerca de los grupos cerámicos que hemos podido individualizar como consecuencia del estudio de todas las variantes e indicadores que hemos tenido en cuenta.

\section{Procesos tecnológicos}

De manera resumida, podemos afirmar que las cerámicas altomedievales del valle del Salado están bien depuradas, con predominio de cocciones oxidantes o tipo sandwich y acabados en los que el alisado es lo más frecuente, seguido por una textura áspera y las suaves marcas de torno. Junto a estas pastas, que son las más frecuentes, encontramos también como notables un conjunto de pastas pardas y grises, con procesos de cocción alternos cuando no directamente reductores, que son especialmente significativas en algunos yacimientos. Vamos a ir describiendo todo ello detenidamente En primer lugar, en lo que a los colores de las pastas se refiere nos encontramos con lo siguiente:

\author{
Muy claras: $1,8 \%$ \\ Clara: $37,7 \%$ \\ Parda: $12,7 \%$ \\ Gris: $12,6 \%$ \\ Oscura: $7,6 \%$ \\ Rojiza: $27,6 \%$
}

\begin{abstract}
Abundan las pastas claras y rojizas, esto es, toda la gama que va desde el rosáceo hasta el rojo pasando por el naranja. Es lo propio de un contexto edafológico en el que abundan las arcillas y las margas y no tanto las tierras calcáreas. Las tonalidades pardas, gris y oscura, consecuencias en la mayor parte de los casos no tanto de la matriz como de los procesos de cocción, suman en total un 32,9 \%. Si atendemos a la distribución de colores de las pastas por asentamientos, observamos lo siguiente:
\end{abstract}




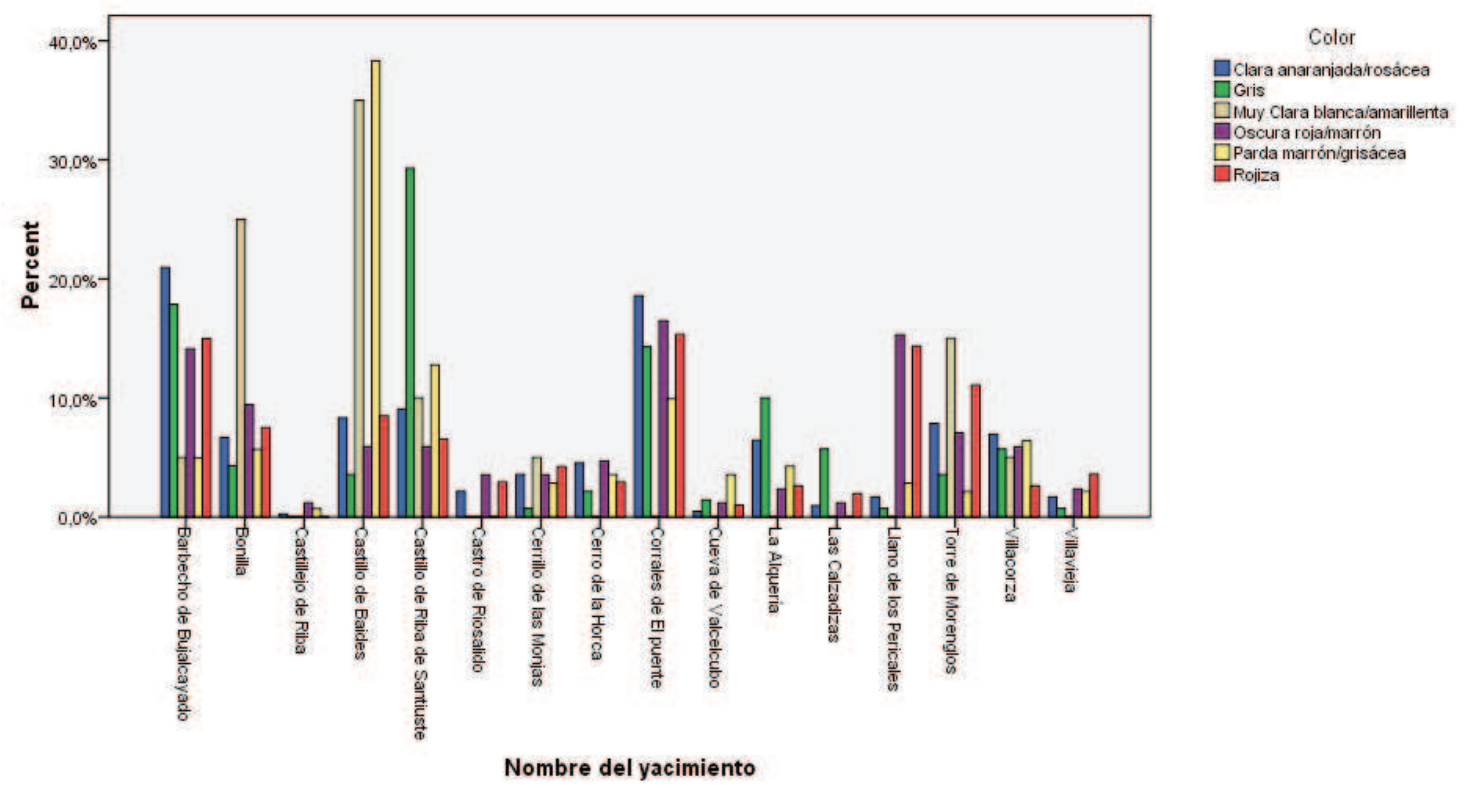

Los porcentajes son más o menos similares para todos los yacimientos salvo algunos casos. Por ejemplo, el porcentaje de pastas pardas y muy claras es muy elevado en el Castillo de Baides, que aglutina más del $30 \%$ del total de ambos colores. Teniendo en cuenta que es el yacimiento que dista más de la zona donde se concentran las arcillas salitrosas, quedando en una zona donde predominan las calizas, cabe pensar que tanto en una como en otra zona las zonas de extracción y los tratamientos de la matriz antes de la elaboración de las piezas cerámicas debieron ser diferentes. Éstas serían más o menos las mismas para los yacimientos que se concentran en la zona de alto y medio valle del Salado, mientras que pasado la zona de El Atance, estaríamos ante condiciones distintas, aunque aún no podamos definir con mayor precisión todo esto.

Si estas consideraciones sobre los colores de las pastas las realizamos agrupando los asentamientos por el tipo al que pertenecen (en altura, a media ladera, cueva o en el llano) los resultados son también significativos: 


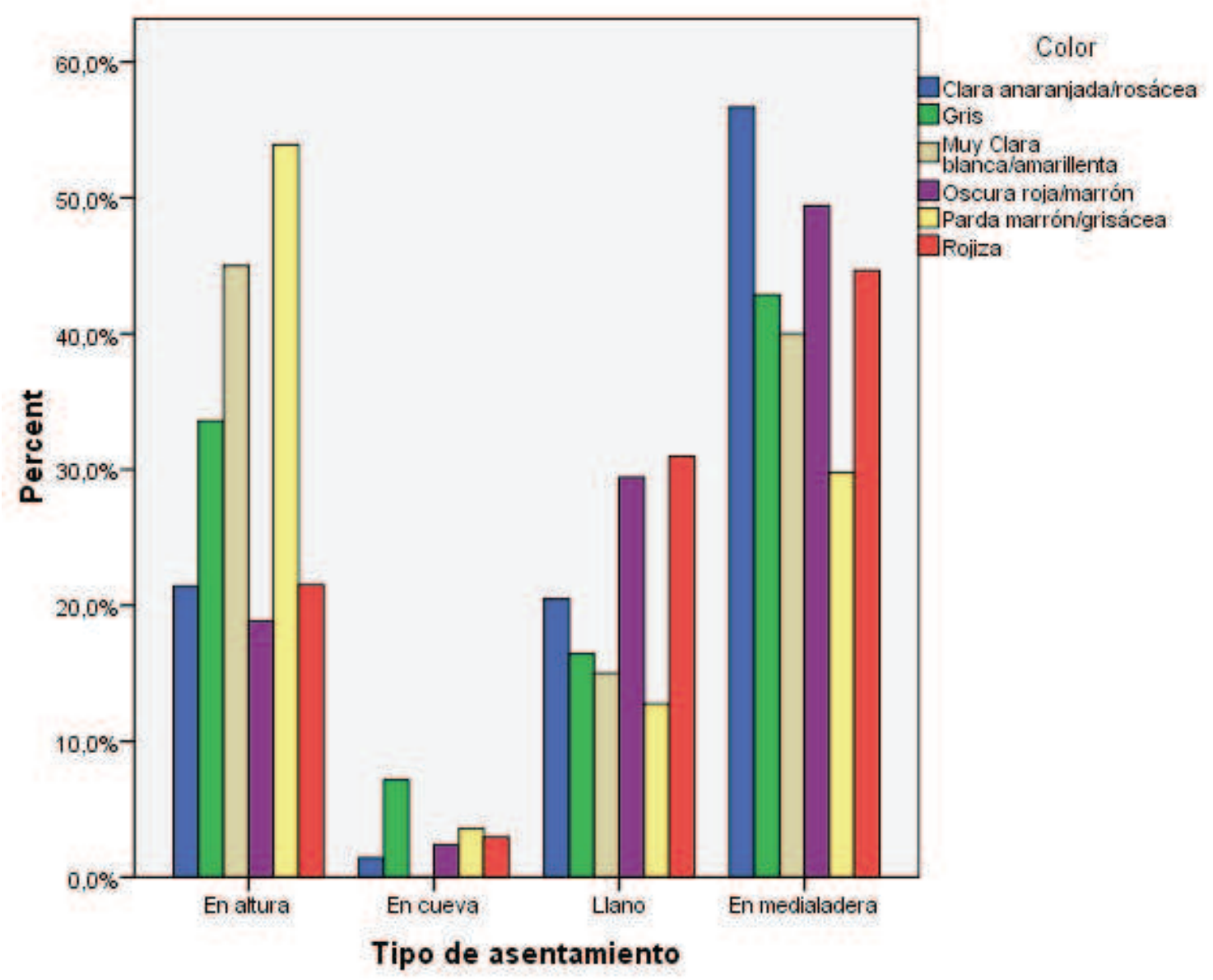

Los porcentajes de pastas rojizas y claras son más o menos similares para todos los asentamientos, salvo en los de altura donde desciende notablemente, al igual que las pastas oscuras, siendo más abundantes las pastas pardas que en el resto de los tipos de asentamientos. También hay una sensible variación en los porcentajes de las cuevas, en donde las pastas grises son las más abundantes, aunque la escasez de fragmentos cerámicos hallados en las inmediaciones de este tipo de asentamientos tampoco permite hacer otro tipo de consideraciones. Como veremos más adelante, estas variaciones, tanto en el caso de los asentamientos en altura como en se detectan también en los tipos de cocción. Cabe la posibilidad de que estas variaciones respondan, de alguna forma, a los tipos de población que ocupan unos y otros sitios.

Ya señalábamos que, en general, las pastas presentaban un aspecto bien depurado, siendo mayoría absoluta las inclusiones de pequeño tamaño y redondeadas, con más de un $40 \%$ cuando estas son escasas, que suman el 75,3\% si tomamos en consideración también cuando éstas son bastante abundantes. Sólo en muy pocos casos aparecen inclusiones de mayor tamaño o de formas angulosas. Tampoco se detectan variaciones sensibles si el análisis lo hacemos según el tipo de asentamiento, salvo la mayor presencia de inclusiones angulosas en los asentamientos de altura. 

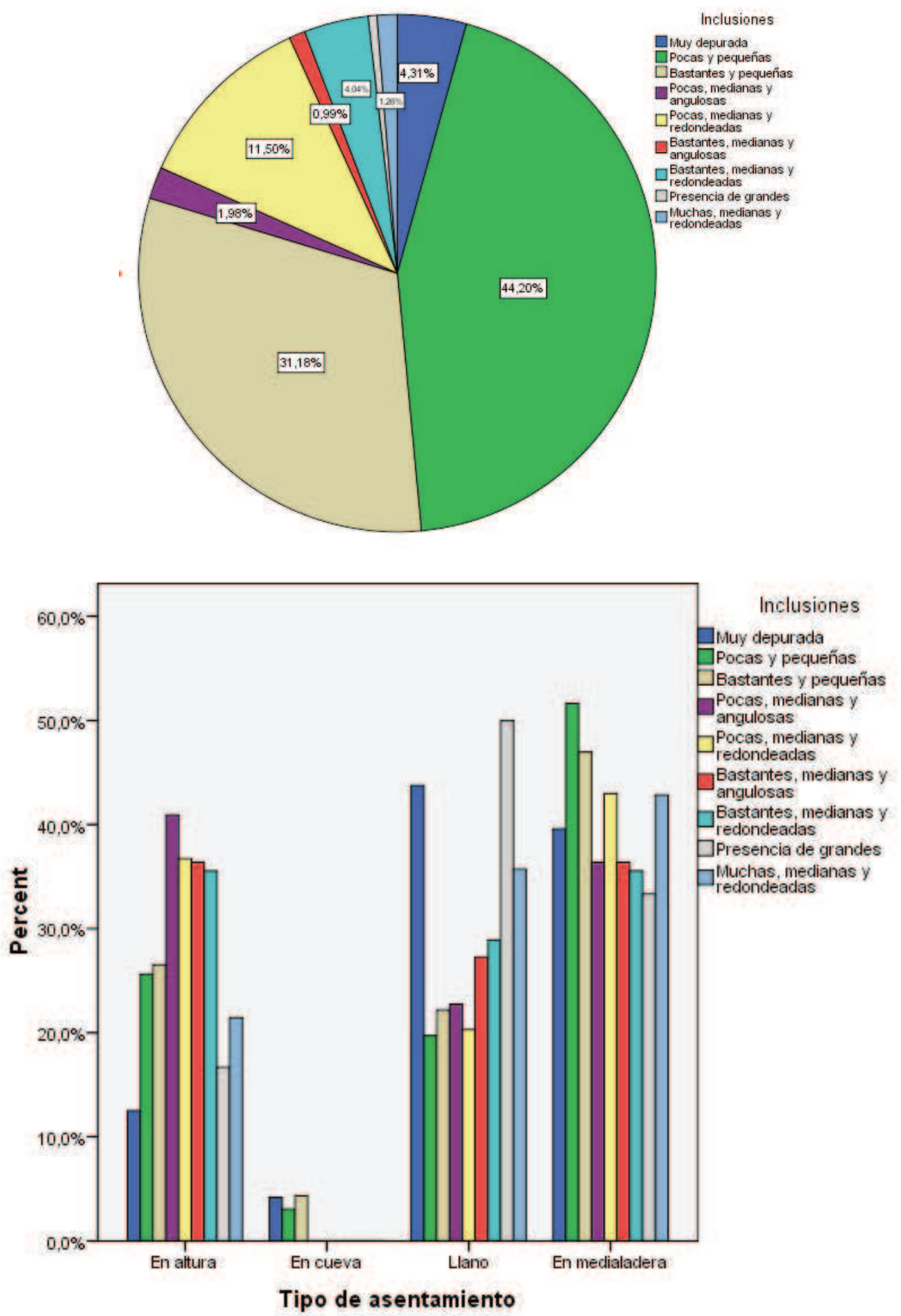

En lo que se refiere a los tipos de minerales, hemos detectado que la mica es el elemento más abundante en todo el conjunto cerámico, apareciendo sola o en combinación con el cuarzo y la calcita. Este último elemento, la calcita, es sin embargo 
el mineral más abundante por sí mismo, o al menos el que más hemos podido identificar con el análisis visual, ya que en muchos casos lo depurado de las cerámicas no permitía observar otro tipo de inclusión. Si nos fijamos solo en los porcentajes más altos que se detectan en el análisis de los minerales, los resultados son los que siguen:

\author{
Mica y calcita, $28,84 \%$ \\ Calcita $21,65 \%$ \\ Mica $12,85 \%$ \\ Mica y cuarzo $11,95 \%$ \\ Mica, cuarzo y calcita $9,07 \%$
}

Esta relación quizás sea mucho más clara si comparamos el grado de depuración de la pasta con los minerales que presenta:
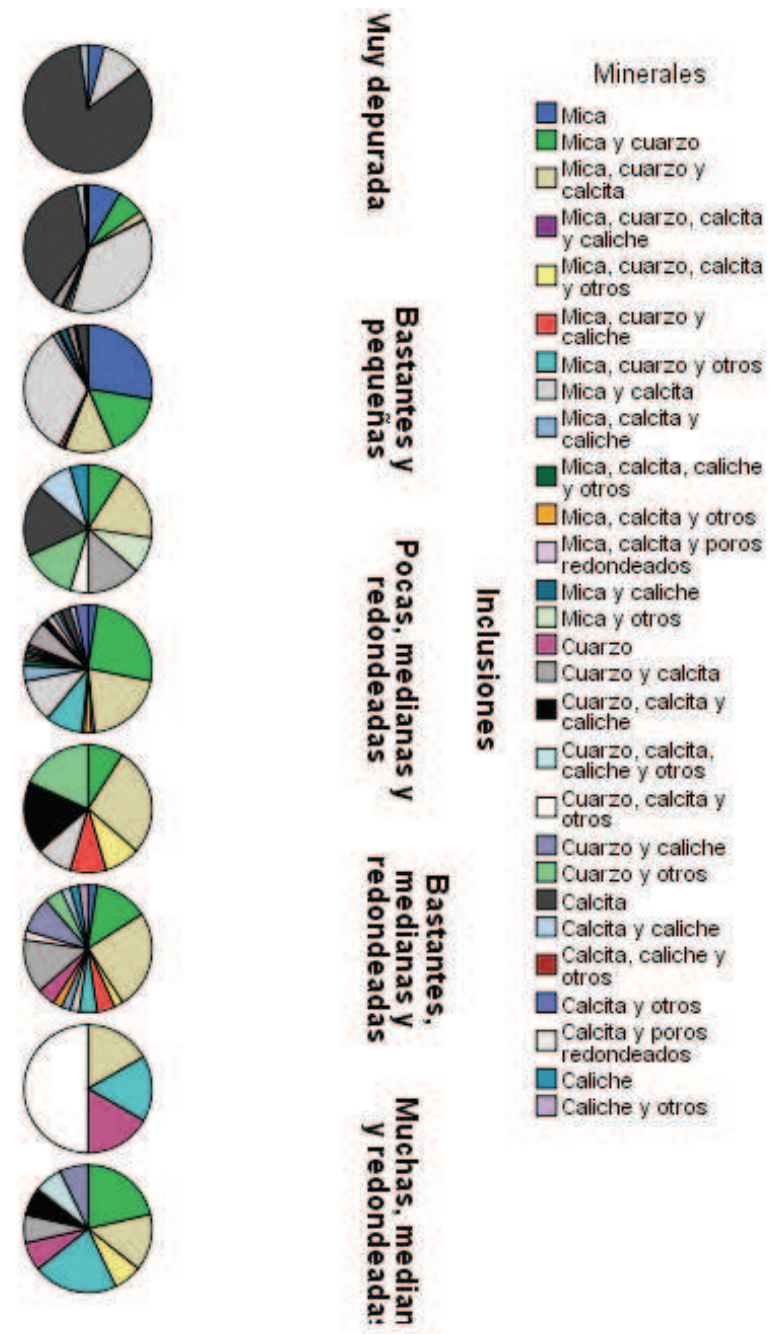
El resto de los minerales o combinación de minerales aparecen en un porcentaje inferior al $9 \%$, por lo que apenas si podemos tomarlos en consideración. En lo que respecta al porcentaje de minerales por yacimientos o por tipos de asentamientos, no se detecta ninguna anomalía, siendo la distribución más o menos similar en todos los casos.

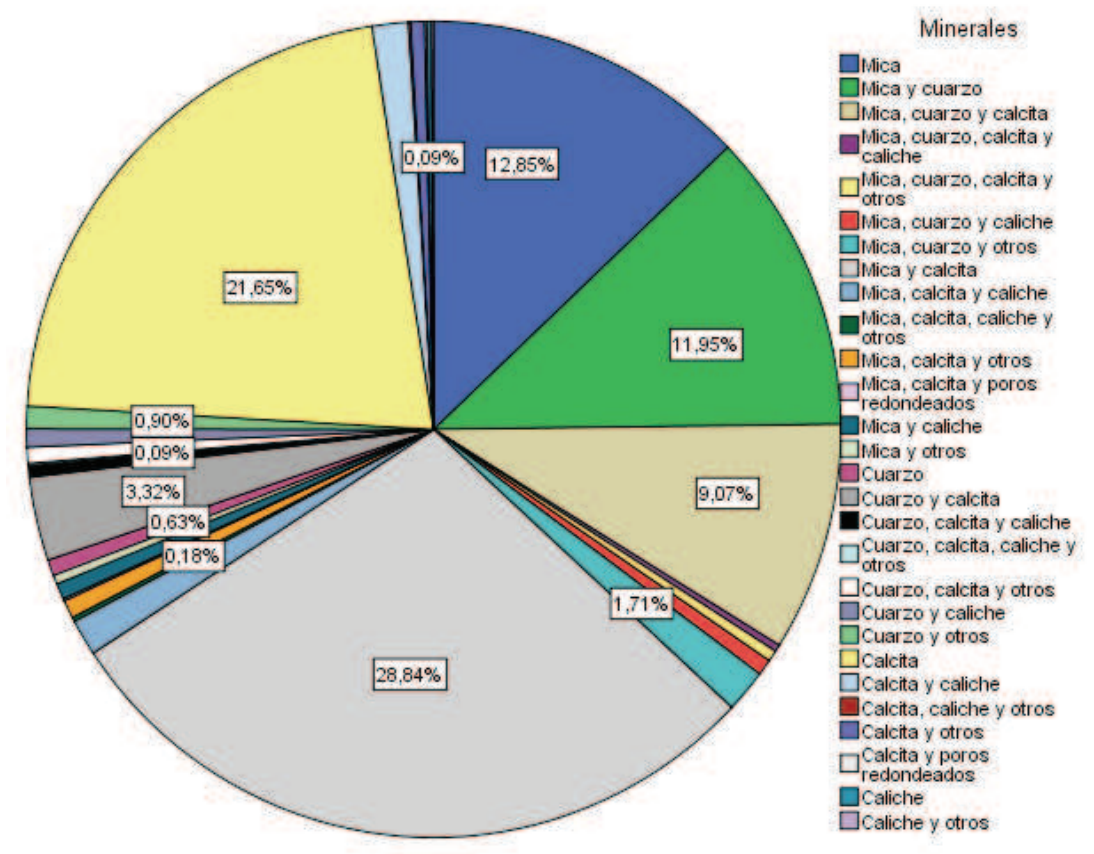

Los tipos de cocciones presentan unos porcentajes previsibles, con una abundancia de las cocciones oxidantes $(63,79 \%)$, seguidas de las tipo «sandwich» (15,09\%) y en menor porcentaje las alternas y reductoras $(10,78 \%$ y $10,15 \%)$. Sólo en un caso se ha detectado una cocción de tipo «sandwich inverso». Nos encontramos, por tanto, ante una producción cerámica de una alta calidad, con cocciones controladas en la mayor parte de los casos. Junto con lo depurado de las pastas, estamos ante unas condiciones técnicas bastante elevadas, lo que nos alejaría de un modelo de producción campesino fundamentalmente autosuficiente, y nos da indicios de una más que probable circulación de las cerámicas entre unos centros productores algo más especializados y los centros de consumo. No hay que descartar, por tanto, que el intercambio de mercancías se produjese también en el otro sentido. Si tomamos en consideración las cocciones por yacimientos y por tipos de asentamientos, nos encontramos con que los porcentajes son más o menos similares, destacando únicamente el número de cocciones de tipo «sandwich» que hay en el asentamiento de «Los Corrales de el Puente» y en general en todos los de media ladera. 


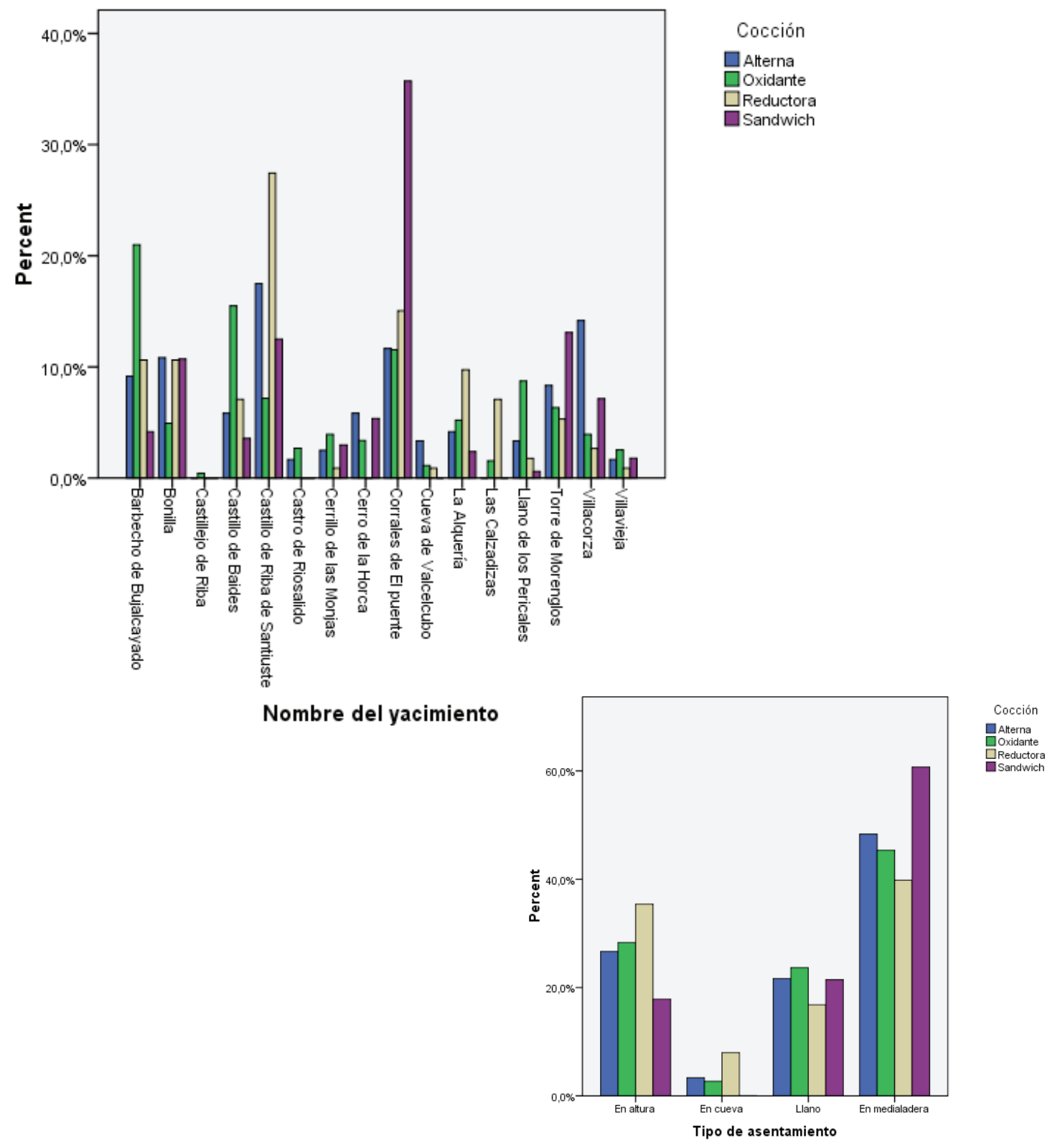

En lo que respecta al modelado del alfarero, prácticamente la totalidad de las piezas están modeladas a torno, sin que hayamos sido capaces de identificar en ningún caso el uso de torneta o torno lento. La distribución entre cerámica a torno y a mano es del respectivamente $89,76 \%$ y $10,24 \%$, si tenemos en cuenta las tejas, y $94,15 \%$ y $6,65 \%$ si no las consideramos. Si observamos la distribución de la relación torno/a mano entre los distintos tipos de asentamientos, vemos como hay un alto porcentaje en los asentamientos en el llano (dejando fuera del análisis las tejas). Los asentamientos del llano de los Pericales, en Alcolea de las Peñas, y de «La Alquería», en Riba de Santiuste han ofrecido un conjunto de cerámicas a mano que corresponden todas ellas a tinajas y en algún caso alcadafes, series tipológicas ausentes o muy poco representadas en el resto de los asentamientos. 

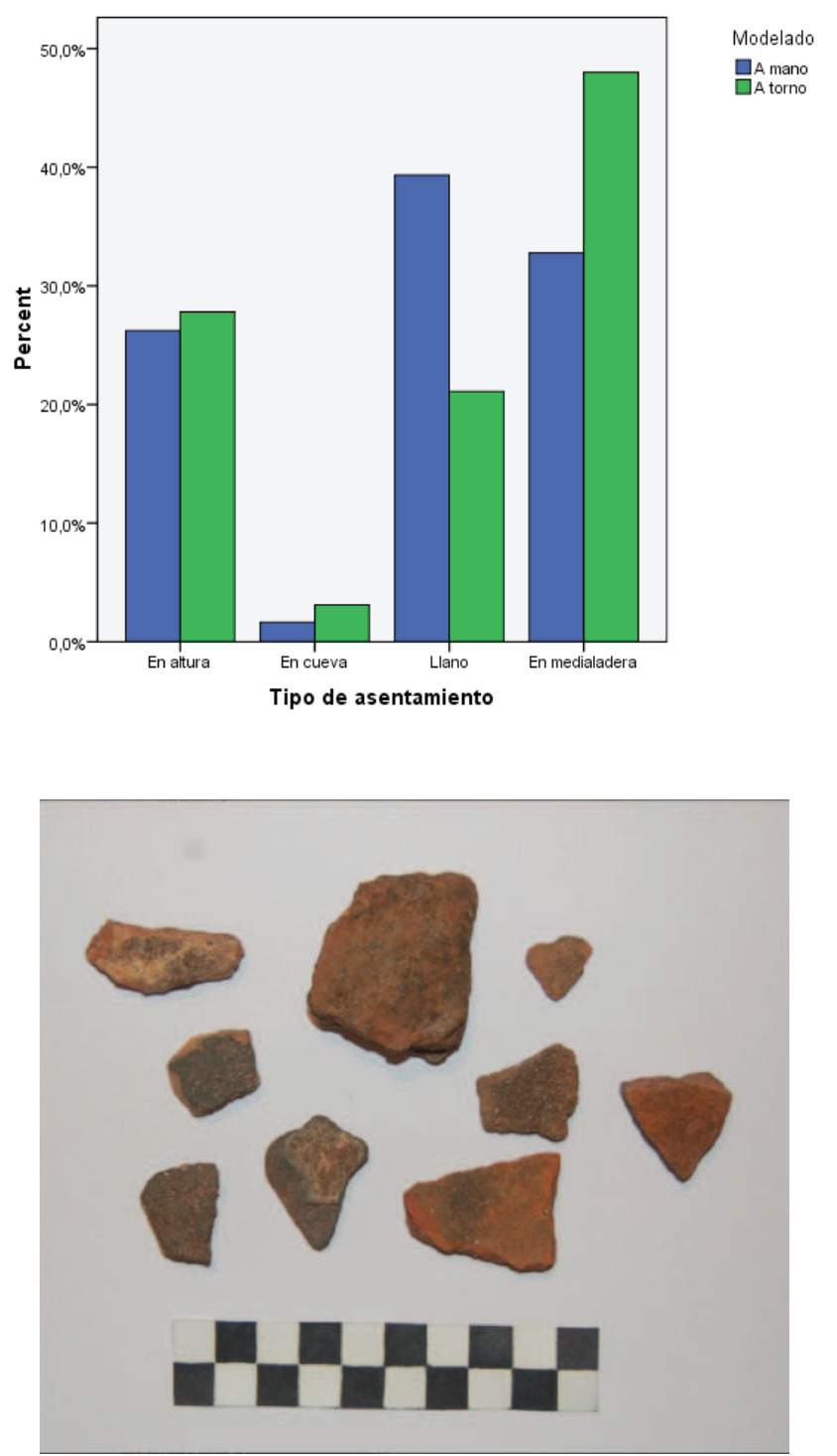

Fragmentos de cerámica a mano del yacimiento de La Alquería

Dentro de las operaciones de modelado, otra de las variables que debemos tener en cuenta es la referente al grosor de las piezas. Resulta evidente que este indicador está estrechamente relacionado con la funcionalidad a la que vaya destinada la pieza, pero también es cierto que en determinadas piezas, como las jarras o las ollas, es un indicador de calidad técnica cuanto más delgadas sean sus paredes. En general, más de la mitad de las piezas tienen un grosor de entre 30 y $70 \mathrm{~mm}$, el estándar en la mayoría de los conjuntos cerámicos andalusíes. Lo que si llama la atención es el escaso porcentaje de piezas anchas, de más de un centímetro de grosor, que apenas llega al 7\% del total. Se corresponde al escaso volumen de piezas destinadas al almacenaje y trasporte que hemos localizado. En general, los porcentajes son los siguientes: 
Menos de $30 \mathrm{~mm}: 10,4 \%$

Entre 30 y $70 \mathrm{~mm}: 52,9 \%$

Entre $70 \mathrm{~mm}$ y $1 \mathrm{~cm}: 29,1 \%$

Entre 1 y $1,5 \mathrm{~cm}: 6,8 \%$

Entre 2 y $3 \mathrm{~cm}: 0,3 \%$

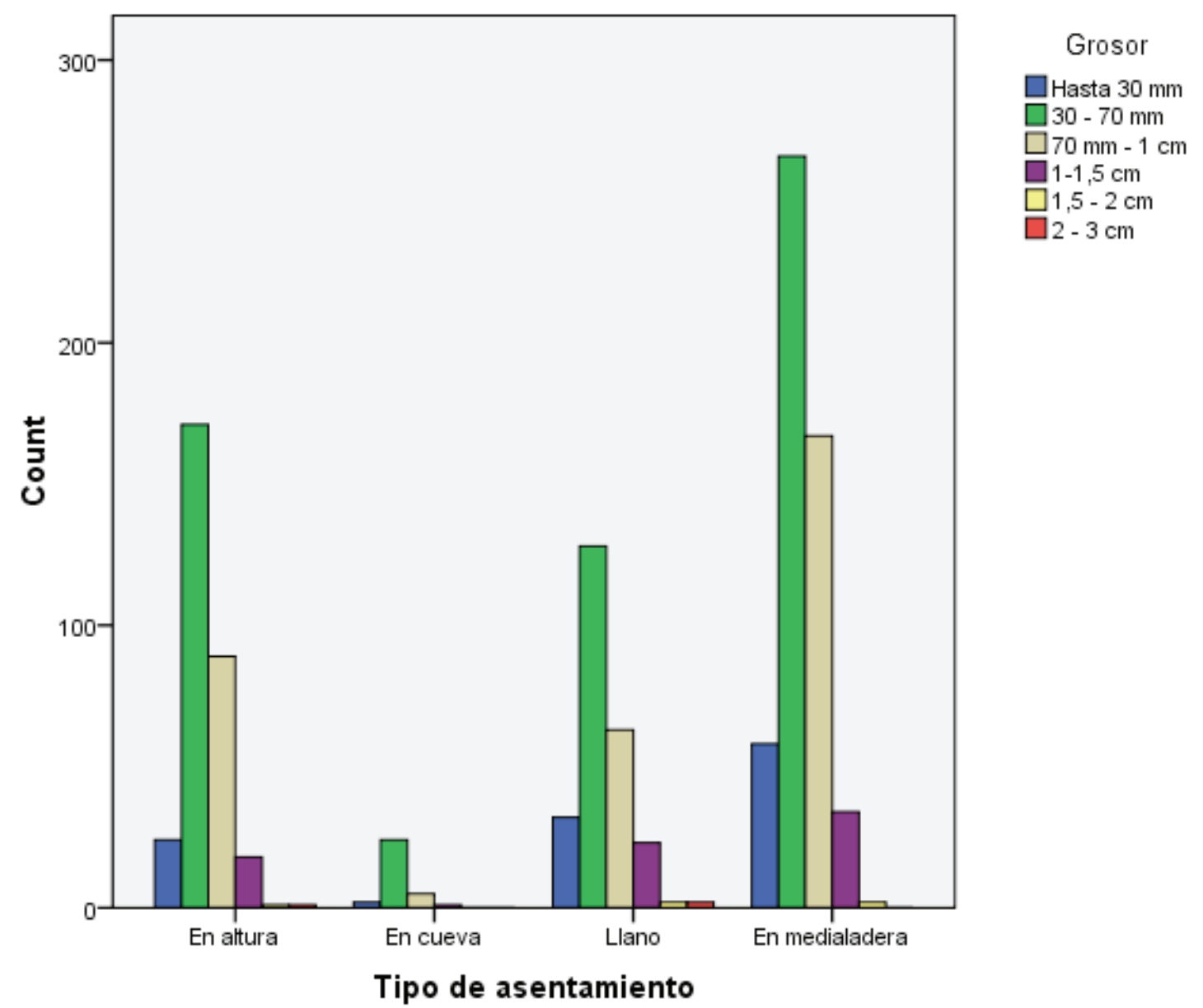

Si nos fijamos en la distribución de las dimensiones de la cerámica atendiendo al tipo de asentamiento vemos como es prácticamente similar en todos ellos, despuntando únicamente las categorías mayores a $1,5 \mathrm{~cm}$ en los asentamientos en el 1lano, debido a los fragmentos de tinajas y alcadafes allí localizados.

En cuanto a los acabados de la superficie, los resultados obtenidos han sido: un 47,35\% de las piezas presentaban huellas de haber sido alisadas intencionadamente, mientras que un $31 \%$ tenían una textura áspera de la superficie. Son los dos conjuntos mayoritarios de acabados, seguidos por un $11,77 \%$ de piezas con suaves marcas de torno, un $3,05 \%$ de piezas estaban artiladas y sólo un caso $(0,18 \%)$ presentaba un engobe en su superficie. El otro 6,65\% de las piezas aparecían vidriadas, categoría en la que sólo se incluyen aquellas piezas cuya superficie está totalmente vidriadas, mientras 
que en las que sólo uno de los dos lados está vidriado se ha optado por consignar el acabado de la superficie que no contenía el vedrío.

En cuanto a la distribución de los acabados por el tipo de asentamiento, las cifras son similares. El único rango a destacar es la práctica ausencia de piezas vidriadas por ambas superficies en los asentamientos en cuevas, aunque dada la escasez de materiales recuperados en este tipo de asentamientos no estamos seguros de que sea un indicador a tomar en consideración.

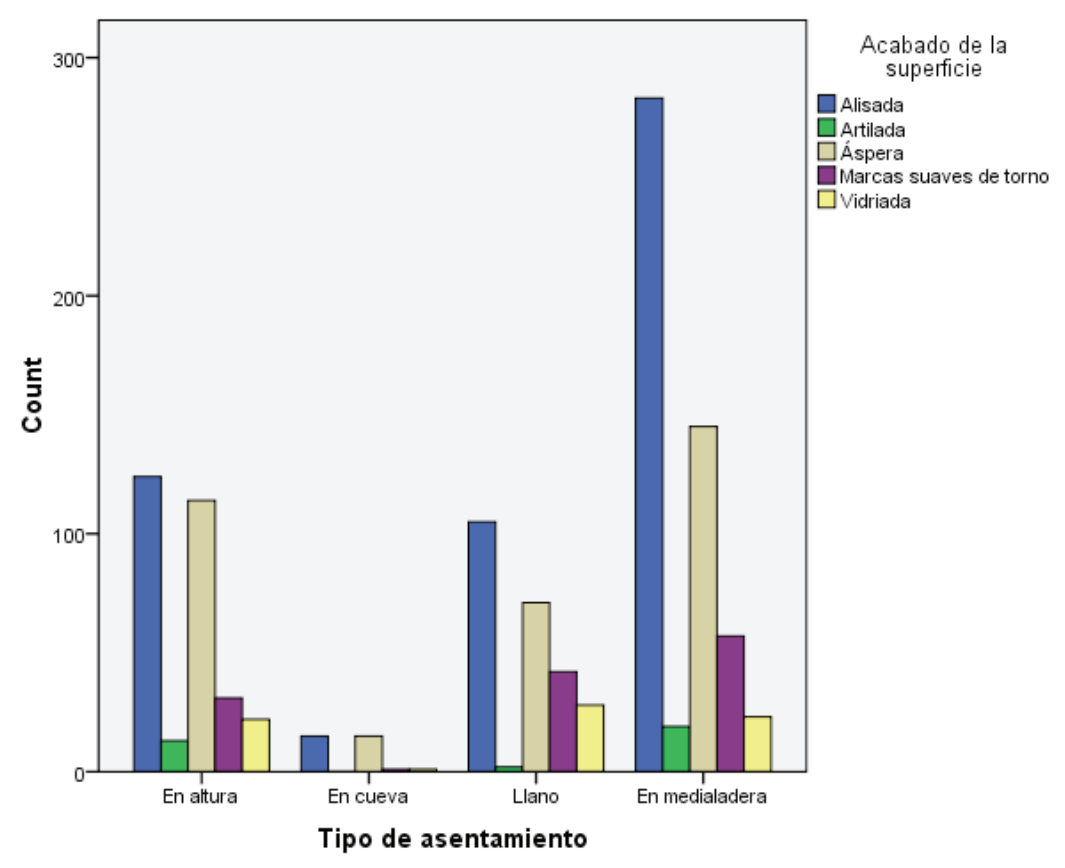

\section{Decoración}

En lo que se refiere a la decoración tenemos que comenzar señalando que el 78,5\% de las piezas analizadas, esto es 874 fragmentos, no presentaban restos de decoración alguna, aunque en algunos casos lo erosionado de su superficie ha podido hacer desaparecer los restos de pintura o vidriado que pudiera tener. Dejando a un lado este alto porcentaje de piezas no decoradas, entre las que si lo están decoradas, un total de 239 piezas que suponen el 21,5\% del total, encontramos la siguiente distribución: 


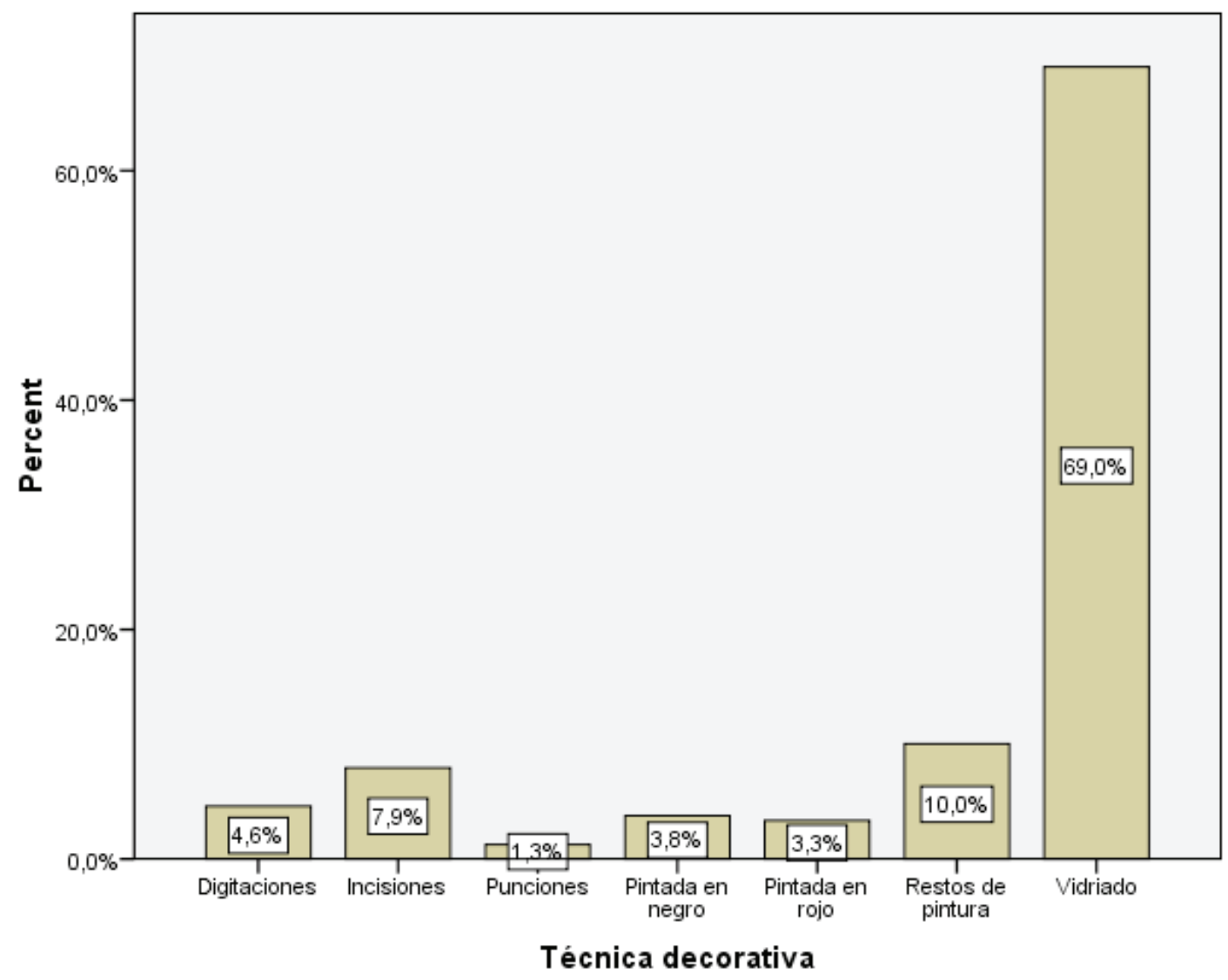

Las digitaciones, representadas en un 4,6\%, normalmente las encontramos en las tejas, siendo de hecho el rasgo diferencial para distinguir uno de los tipos como ya veremos. Tan sólo en algunas asas y paredes aparece la impresión de uno o varios dedos marcados.

En lo que respecta a las incisiones, el 7,9\% del total de piezas decoradas, prácticamente la mayoría (11 fragmentos) pertenecen a los grupos cerámicos 4 y 10. En su mayoría son incisiones realizadas a peine (8 fragmentos), seguidas de las líneas rectas horizontales (6 piezas) y las líneas onduladas (4 cerámicas).

Las punciones sólo se han detectado en dos asas pertenecientes a jarras de mediano tamaño, y aparecen en la parte de unión de éstas con el cuerpo.

\section{ALPE0511}

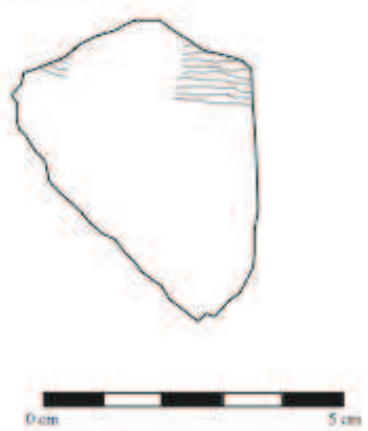


Más interesantes son las cerámicas decoradas con pintura, bien en trazos negros o rojos o bien simplemente restos de pintura que aparecen de forma dispersa por la superficie de la cerámica. Ya hemos señalado como el grupo cerámico en el que este tipo de decoraciones se ha documentado con mayor frecuencia es el de las «pastas suaves», aunque también tenemos varios ejemplos de aplicaciones de pinturas en pastas grises y pardas, sobre todo en color negro.

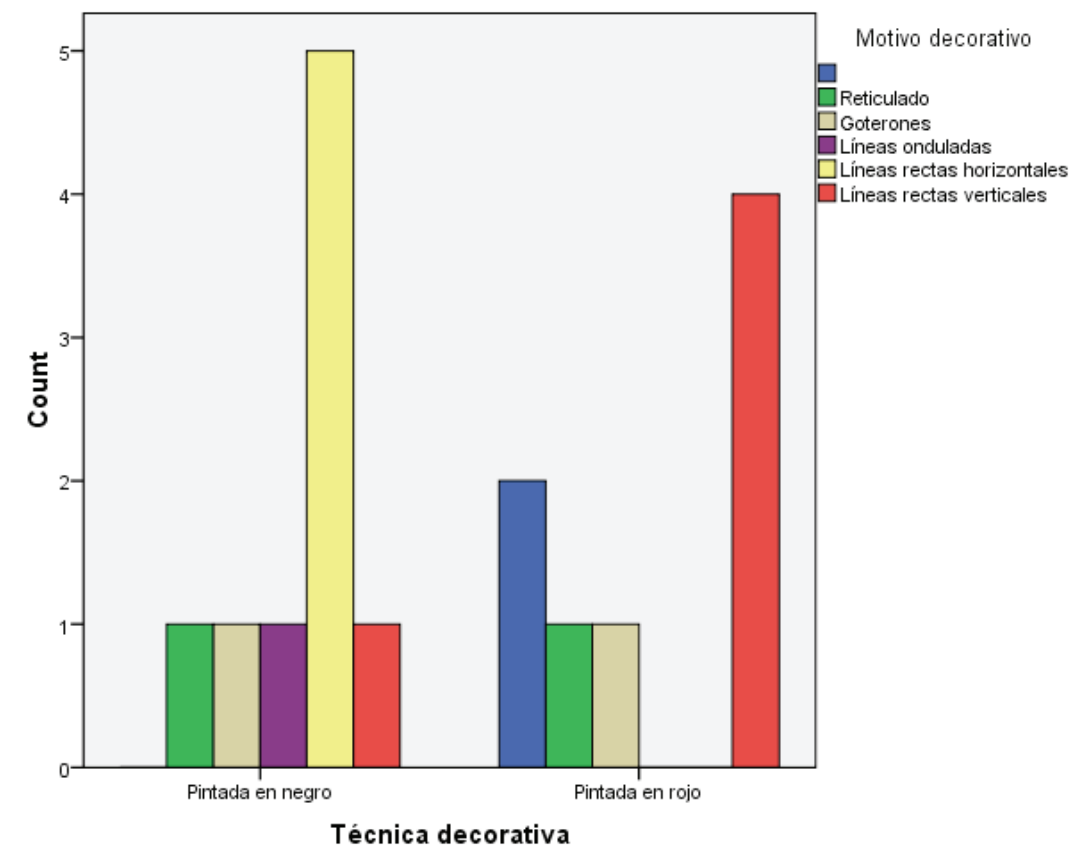

Como puede verse en el anterior gráfico, hay una preferencia por usar uno u otro color en función de si las líneas son horizontales o verticales, que se usan respectivamente el negro y el rojo, si bien también tenemos un ejemplo de línea vertical en el color del manganeso. También hay que llamar la atención, aunque no se ha reflejado en la estadística, que por lo general las pintadas en rojo presentan varios trazos, mientras que el trazo en pintura negra suele ser único. 
Pintura roja: Trazos paralelos
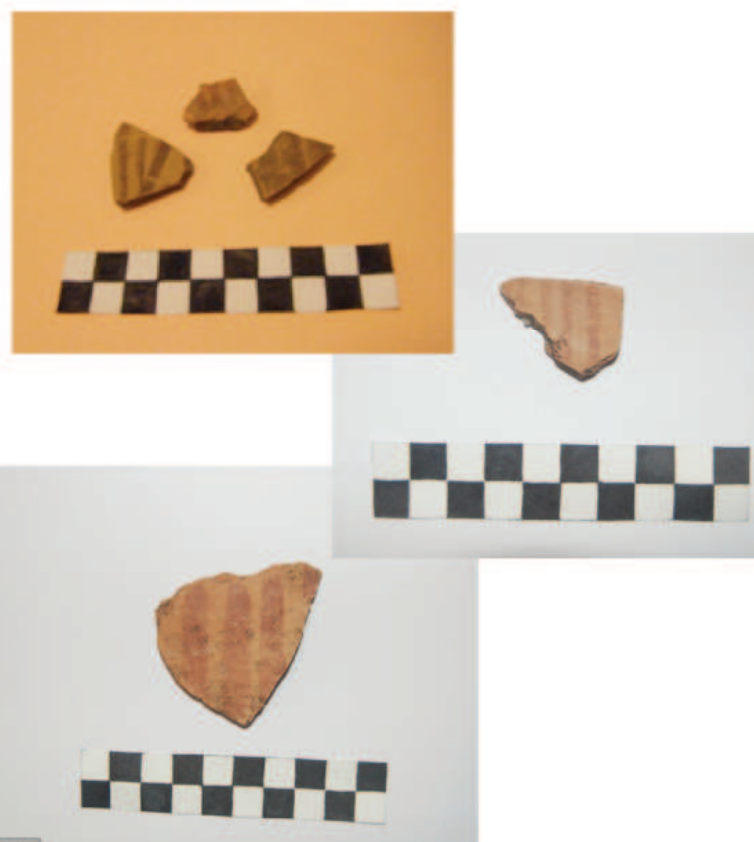

4

ALPE0513

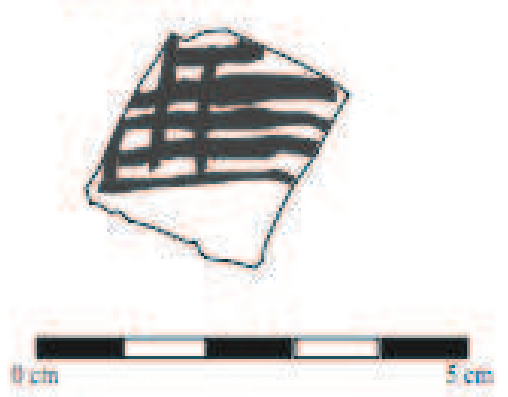

Pintura negra: Trazo único

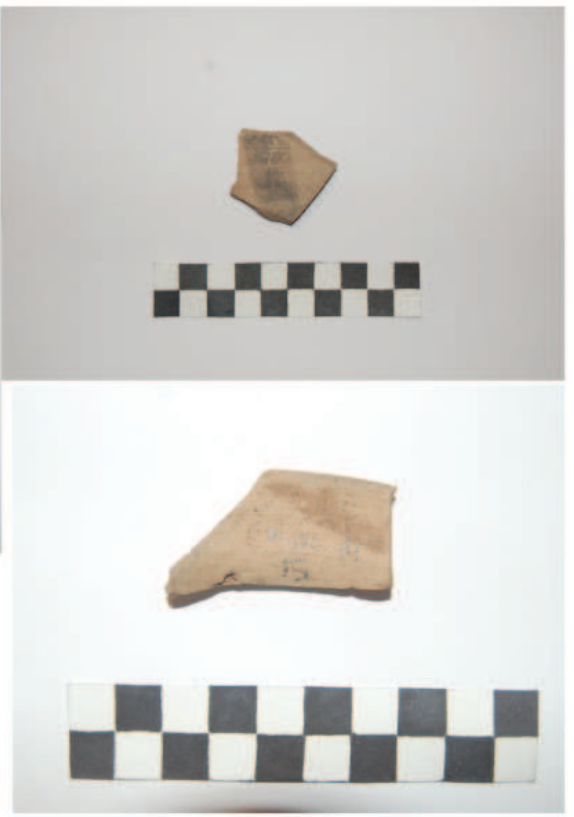

ALPE0111

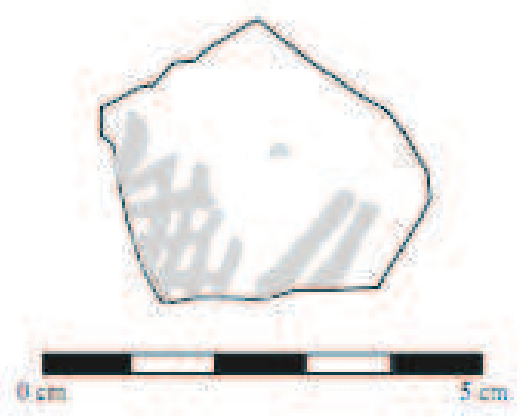

Fragmentos con decoración pintada en cuadriculas en negro (izquierda) y en rojo (derecha)

Pero el conjunto más abundante dentro de las cerámicas decoradas es el de las cerámicas vidriadas, que representan el $69 \%$ de entre las piezas decoradas y un 14,8\% de la totalidad de los fragmentos estudiados - 165 de 1113 fragmentos-. Dentro de estas piezas vidriadas no hemos documentado ningún caso en el que sea únicamente la cara externa la que presenta el vedrío, siendo siempre la cara interior $(58,79 \%)$ o ambas partes $(39,39 \%)$ las que aparecen vidriadas. 


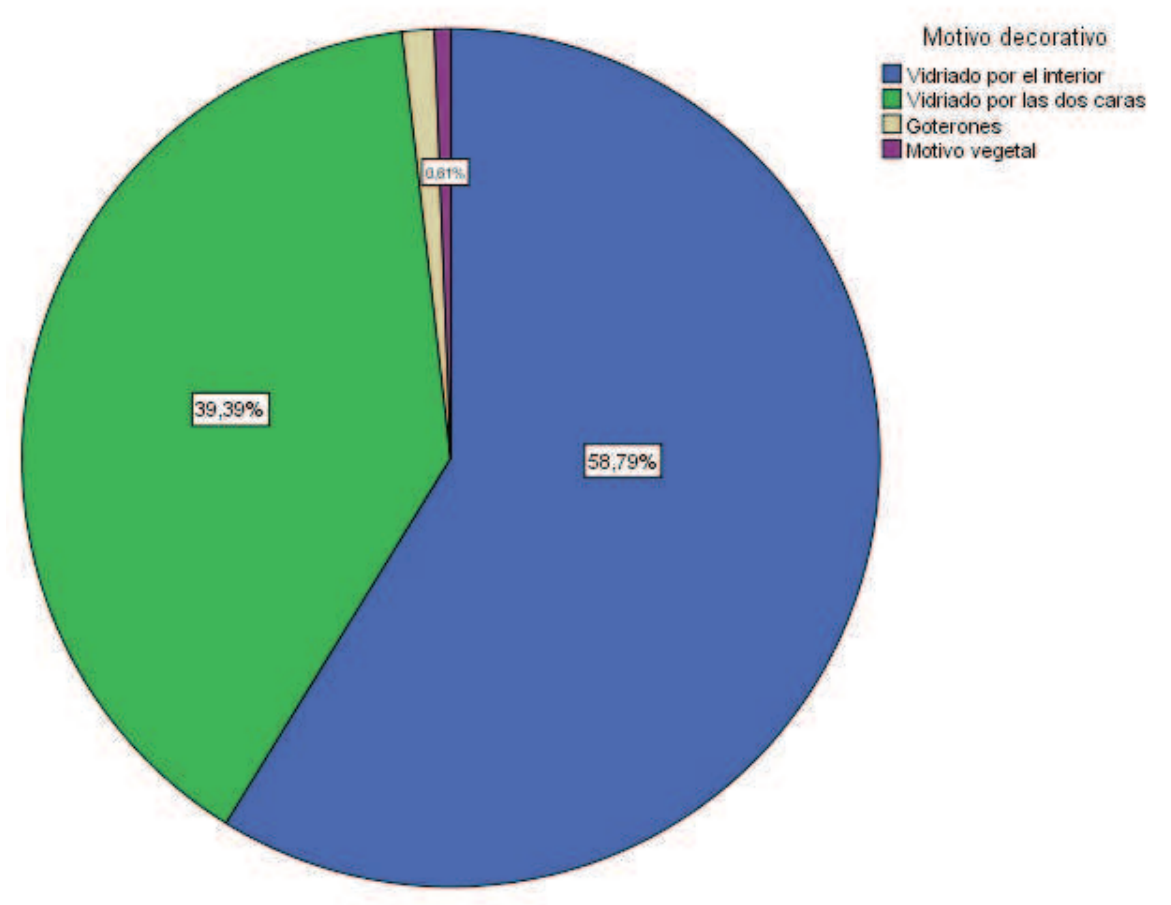

En el gráfico anterior puede observarse la distribución del vidriado por una o por las dos caras. Hay algunos ejemplos especiales que se han consignado aparte, aunque representan sólo uno o dos casos, con un porcentaje inferior al 1\% del total. Se trata de algunos casos en los que el vedrío aparece a modo de goterones sin ocupar la totalidad de la pieza, que en ambos casos se trata de asas, y una singular pieza que presenta un estampillado con motivo vegetal por debajo del vidriado.

En cuanto a los colores, hay una mayoría absoluta de melados $(51,4 \%)$ y tonos verdosos $(39,9 \%)$. También contamos con algunos casos sueltos de vidriados en verde y manganeso, verde, blanco y negro, trazos negros sobre fondo blanco y vidriados blancos, y algo más numerosos son los fragmentos vidriados amarillentos y melados y manganeso.

Otra cuestión sobre la que queremos llamar la atención en referencia al vidriado, y a la que ya hemos aludido más arriba, es que por lo general esta decoración se presenta siempre en el mismo tipo de pasta de colores rojizos y bien depurada, que hemos definido como grupo 9 o simplemente «pasta roja vidriada» 


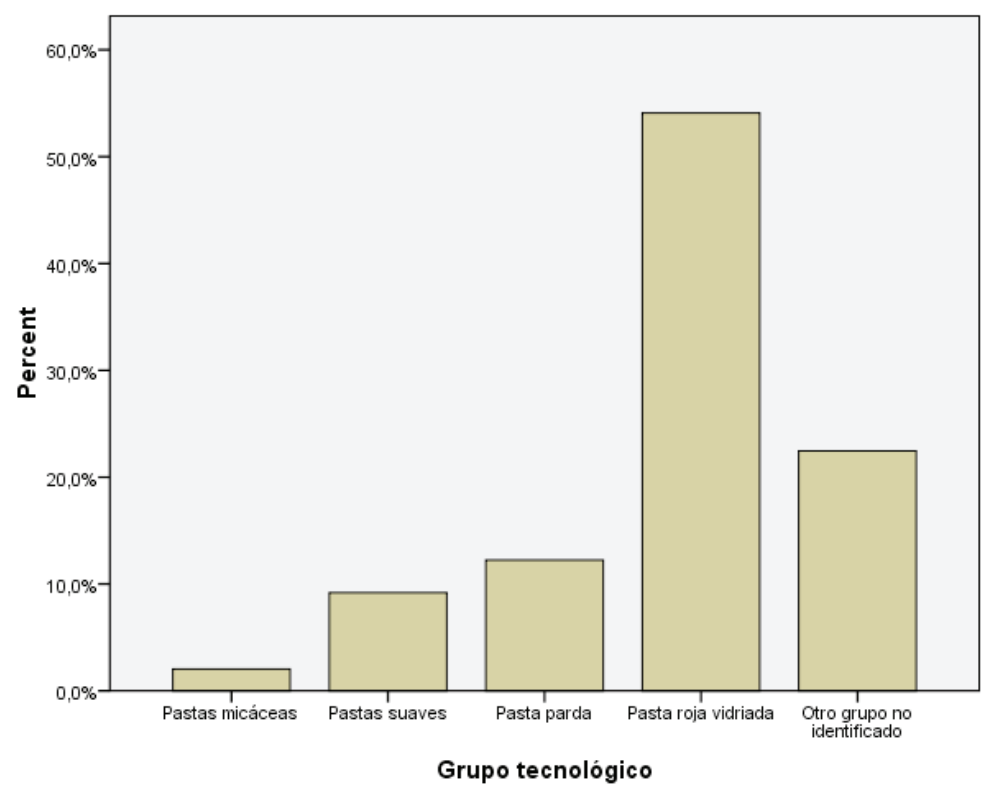

En cuanto a la distribución geográfica de las piezas vidriadas, éstas aparecen prácticamente en todos los asentamientos, aunque no en igual número. Son muy abundantes en el llano de los Perícales, en los «Corrales de El Puente», en el Barbecho de Bujalcayado y en los castillos de Baides y de Riba de Santiuste, estando por el contrario escasamente presentes en las cuevas.

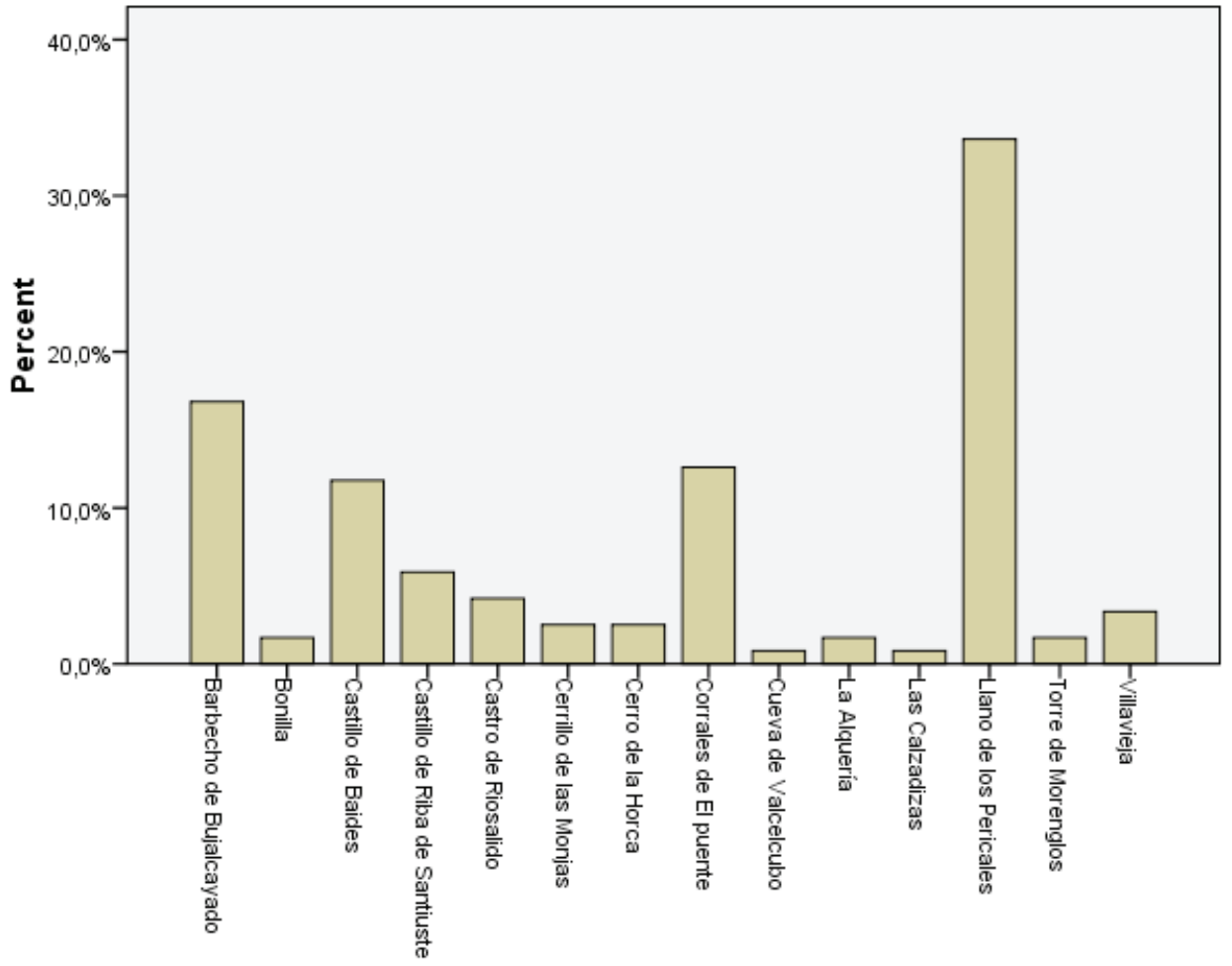

Nombre del yacimiento 


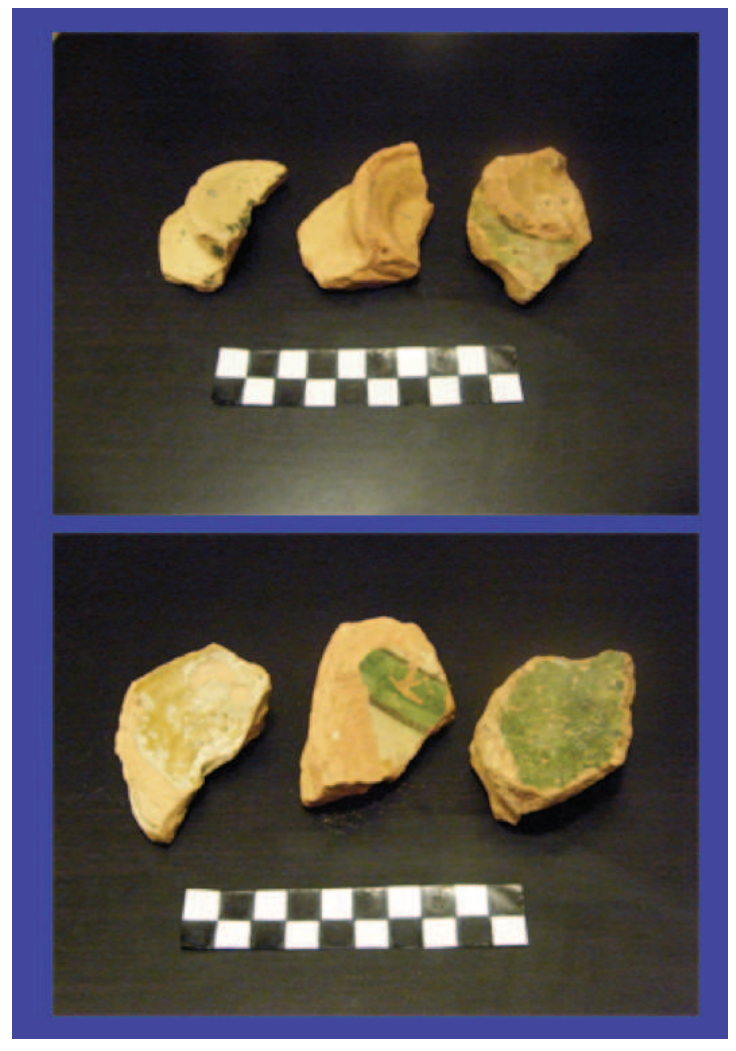

Ataifores vidriados

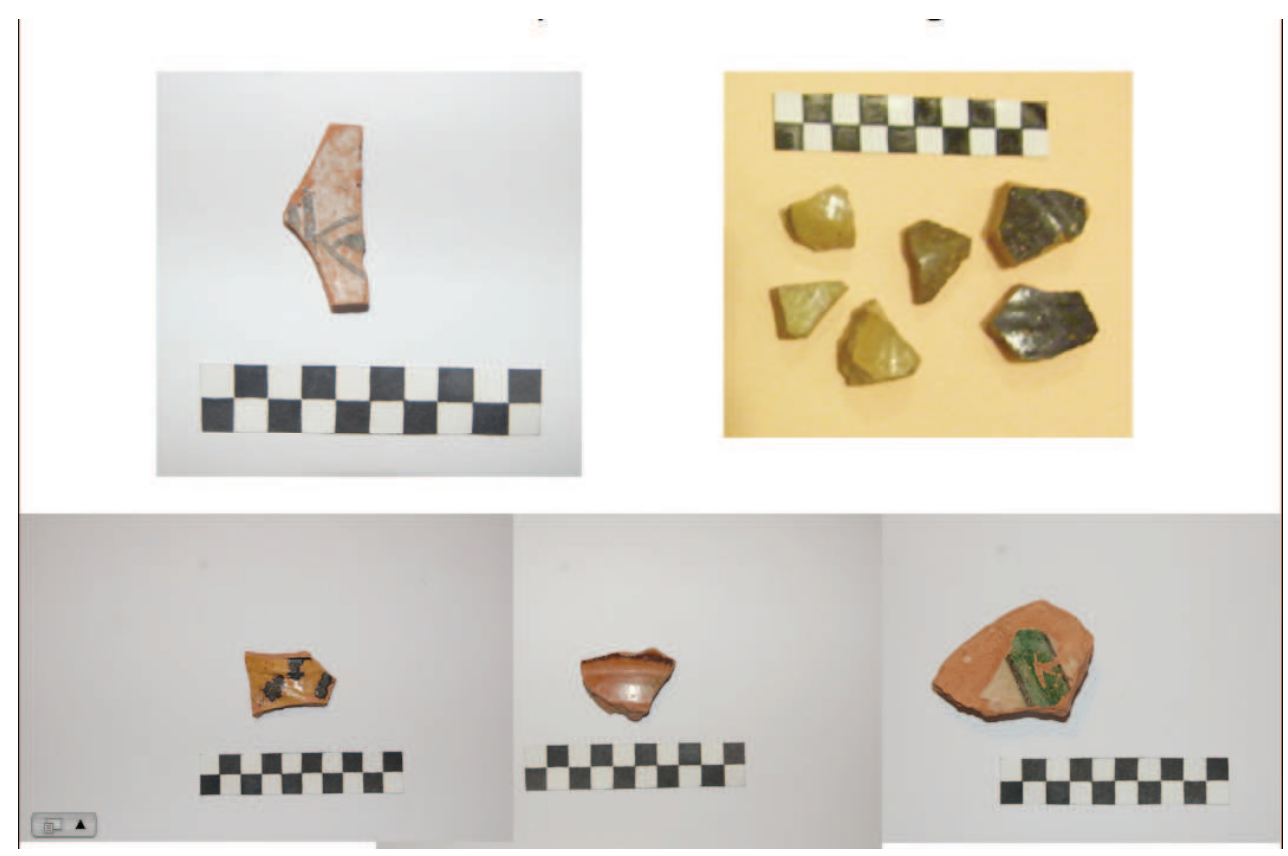




\section{Tipología y cronología}

Ya hemos expuesto en páginas anteriores cuales son los referentes que hemos utilizado para caracterizar desde un punto de vista morfológico y funcional las piezas cerámicas. Recordar ahora tan sólo que básicamente tomamos como referente el estudio cerámico elaborado por Manuel Retuerce, ya que en él se recogen, clasifican y comparan más de 200 yacimientos arqueológicos de la Meseta, y el estudio más reciente que tenemos sobre la cerámica islámica de Medinaceli, la ciudad andalusí más cercana a nuestro territorio $^{1}$. Cuando este estudio ha sido insuficiente, hemos recurrido a otra bibliografía específica, especialmente en el caso de los ataifores y la cerámica más tardía ${ }^{2}$.

Debido a la alta fragmentariedad de la cerámica, y al escaso volumen de bordes, bases $\mathrm{y}$ otras partes que sirvieran como diagnóstico para establecer diferencias y semejanzas en la cerámica, el catálogo que ahora presentamos no es más que una primera aproximación, que forzosamente tendrá que ser revisada y ampliada en un futuro, pero que creemos suficiente en este momento.

Si nos fijamos en los grupos funcionales, la categoría más general y quizás la más sencilla de establecer, considerando incluso muchas de las paredes, obtenemos que el $65,7 \%$ de las piezas no han podido ser identificadas, mientras que el 19,4\% pertenecen al servicio de mesa, el $5 \%$ a recipientes para el almacenaje y transporte, el 4,8\% son fragmentos cerámicos para la construcción, esencialmente tejas aunque hay también algún adobe, un 4,5\% son piezas destinadas a la cocina y sólo un $0,6 \%$ se pueden adscribir a la categoría de usos múltiples. Llama la atención es escasísimo porcentaje de piezas destinadas a la cocina, aunque hay que tener en cuenta que probablemente la mayor parte de los fragmentos no encuadrados en ninguna de las categorías pertenecen a ollas y marmitas destinadas a la preparación de elementos.

Siguiendo con los grupos funcionales, su distribución por tipos de asentamientos, sin tomar en consideración los fragmentos no identificados, nos revela como hay un volumen más alto de tejas en los asentamientos en media ladera, y como es en el llano donde las piezas destinadas a usos múltiples, como los alcadafes o las tapaderas son más abundantes, en relación con el resto de los conjuntos. El resto de los grupos siguen

\footnotetext{
1 Retuerce Velasco, Manuel, La cerámica andalusi de la Meseta, Madrid, 1998, 2 tomos; GómeZ Martínez, Susana, «Cerámica islámica de Medinaceli», Boletín de Arqueología Medieval, 10 (1996), pp. 123-182. Sobre Medinaceli tenemos referencias de un estudio más reciente que no hemos podido consultar por estar aún en prensa: BUENO SÁNCHEZ, Marisa, «Cerámica islámica en Medinaceli villa. Excavaciones de urgencia e investigación (1975-2009)», en Jornada Internacional sobre metodología de análisis de la cerámica tardoantigua y medieval, León, 2009 (en prensa)

${ }^{2}$ Martínez Lillo, Sergio y Matesanz Vera, Pablo, « Cerámicas cristianas y musulmanas de la Marca Media Central: siglos X, XI y XII », A Cerâmica medieval no Mediterrâneo ocidental, Mértola 1991, pp. 273-284; CORTÉS, RuIZ, Ma Elena y LÁZARo Molinero, Inmaculada, «¿Continuidad o ruptura entre musulmanes y mudéjares?: el ejemplo de Molina de Aragón (Guadalajara)», Wad-al-Hayara, 22 (1995), pp. 177-214.
} 
una distribución más o menos similar, salvo en las cuevas donde los grupos de construcción están ausentes, como es lógico.

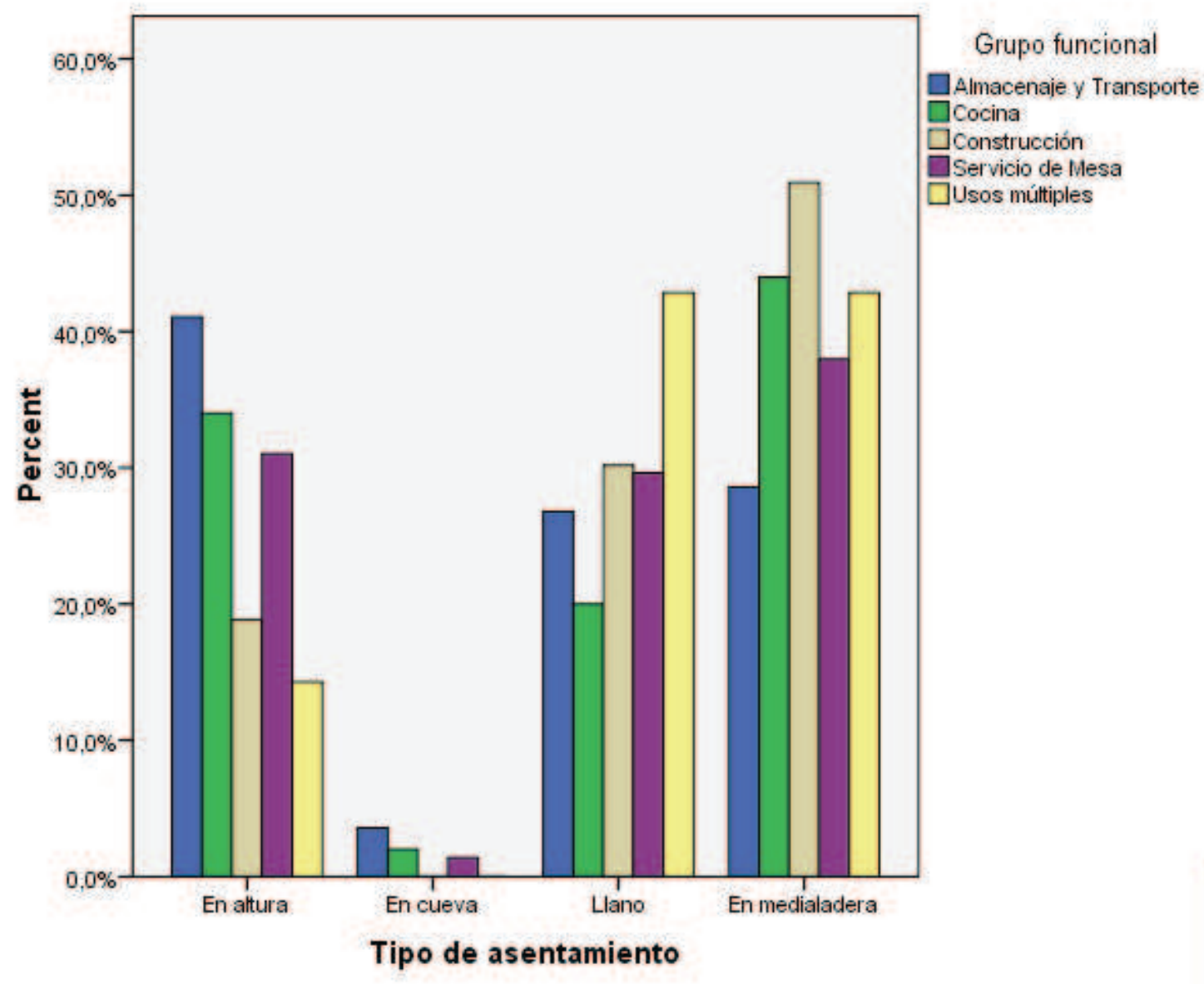

En lo que se refiere a las series tipológicas, hemos podido identificar sólo el 29,5\% (328 fragmentos) mientras que un 70,5 \% (785 piezas) pertenece al grupo de «no identificado». De entre los identificados, la distribución es la siguiente

Jarro/a/ito/ita 45,4\% (149)

Ataifor $18,8 \%(55)$

Teja $16,5 \%(54)$

Olla/marmita $12,8 \%(42)$

Redoma/botella 2,4\%(8)

Tapadera $2,4 \%(8)$

Tinaja $1,8 \%(6)$

Otros (cazuelas, alcadafes...) 1,8 \% (6) 
En cuanto a la distribución por el tipo de asentamiento, vemos que resulta bastante homogénea, salvo una vez más en el caso de las cuevas, en las que las tejas están ausentes, así como la mayor parte de los grupos, identificándose únicamente jarras y ollas. En los asentamientos en el llano es significativo también el escaso porcentaje de ollas y marmitas que encontramos

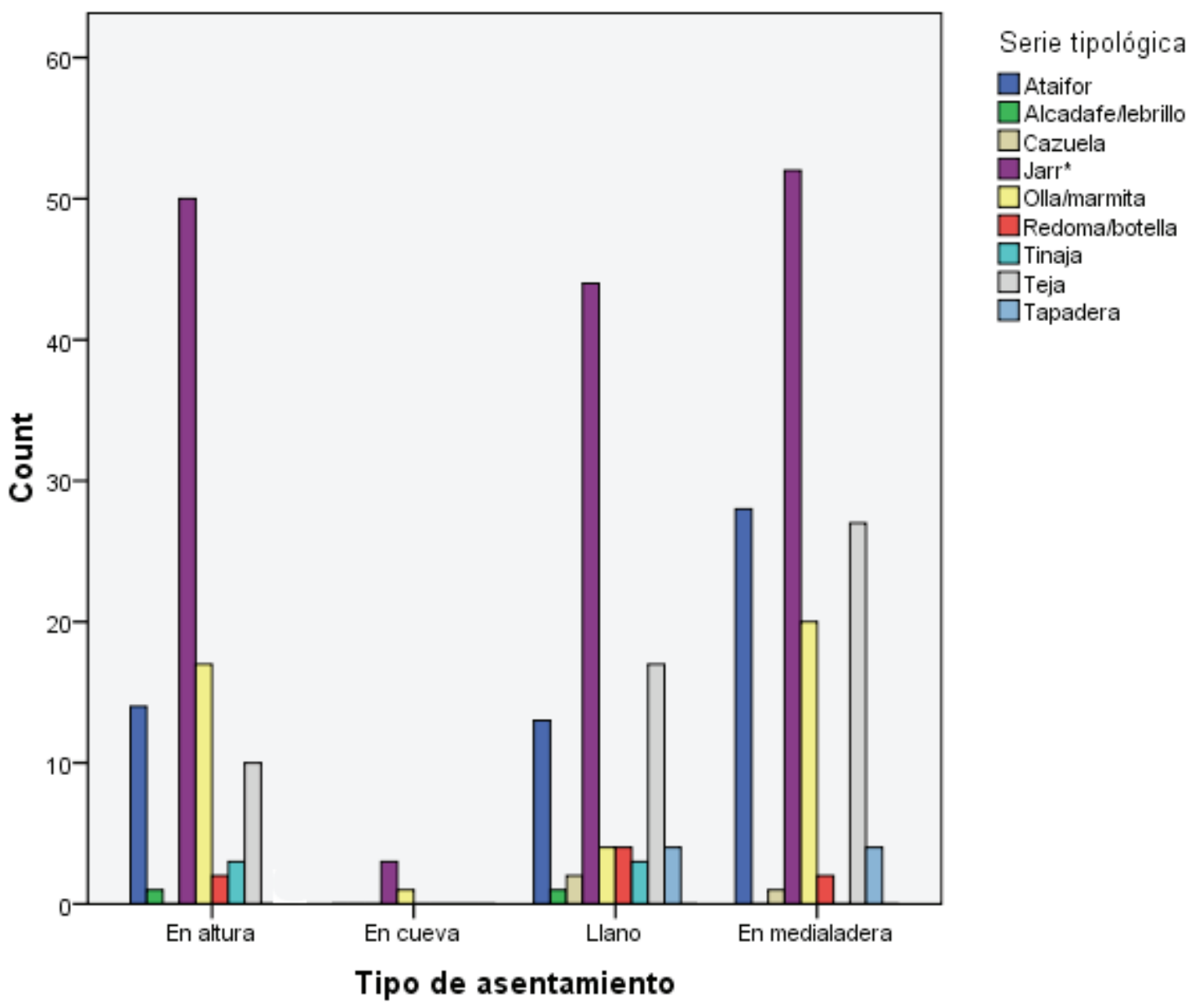

Queda por ver los tipos que hemos definido a partir de las características morfológicas que los individualizan. En primer lugar hay que señalar que sólo el 13,8 \% del conjunto ha podido ser adscrito a alguno de los tipos que hemos identificado, frente a un $86,2 \%$ de piezas que no lo han sido. Vemos como este grupo de no identificados es mucho más alto que en los grupos funcionales y la series tipológicas.

Vamos a describir los distintos tipos antes de pasar a ver las distribuciones cuantitativas que presentan. Seguiremos un orden alfabético en su descripción: alcadafes, ataifores, cazuelas, jarr*, ollas/marmitas, redomas/botellas, tapaderas, tejas y tinajas

Alcadafes Son recipientes de gran tamaño, pastas burdas y a menudo modelado a mano, que presentan siempre un mayor diámetro en el borde que en el fondo, y que no 
suelen tener una gran altura. Sus funciones no han sido identificadas con claridad, aunque por su forma pueden ser usados tanto en la preparación de alimentos como en el lavado de textiles etc. Es por ello por lo que se consideran en la serie funcional de usos múltiples.

Sólo se ha identificado un tipo de alcadafe, el Al-1, con únicamente dos casos. Ambos son de pasta rojiza-oscura, con intrusiones medianas redondeadas y un aspecto alisado al exterior, que presentaba una cocción alterna en uno de los casos, mientras que en el otro era oxidante. El diámetro de las piezas es en ambos casos de $26 \mathrm{~cm}$, con una forma troncocónica invertida, con el fondo plano y paredes muy gruesas, rectas y exvasadas y molduradas al interior. Este tipo de piezas puede corresponder al tipo I.01 establecido por Retuerce, y con el tipo A de la serie $9^{\circ}$ «Alcadafe» definido por Roselló. Es una pieza a la que es muy difícil encontrar un encuadre geográfico, ya que está representada por gran parte de la península, y tampoco es fácil definir su cronología, que en muchos casos rebasa incluso el período altomedieval aquí estudiado.

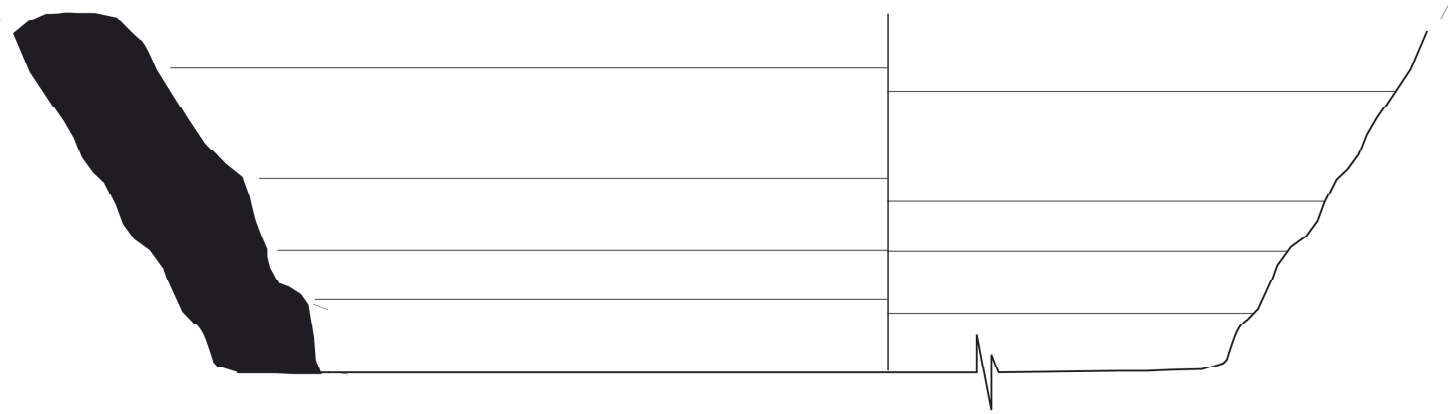

Ataifores Son probablemente, junto con los candiles, las piezas más características de la vajilla andalusí, aunque también una de las más discutidas en su denominación, pues atendiendo al diámetro de la pieza se las ha llamado plato, jofaina, cuenco o escudilla. Los tipos identificados en todo el territorio peninsular son muchos y variados, aunque por lo general se suele distinguir entre aquellos de base recta y los que presentan un anillo de solero, siendo también significativa la presencia o no de vedrío u otro tipo de decoraciones.

Entre el conjunto que henos examinado podemos distinguir ocho tipos. El primero de ellos, A-1, se caracteriza por unas paredes gruesas de tonalidades rojiza y medianamente bien depuradas, que ascienden rectas. Presentan un vedrío de color verde al interior y un alisado por su cara externa. La base es plana, ligeramente cóncava y alisada, pero no conocemos ningún borde adscrito a este grupo. Retuerce no ofrece 
ningún paralelo para este tipo, mientras que en el estudio sobre Medinaceli podría equivaler al tipo $5^{3}$.

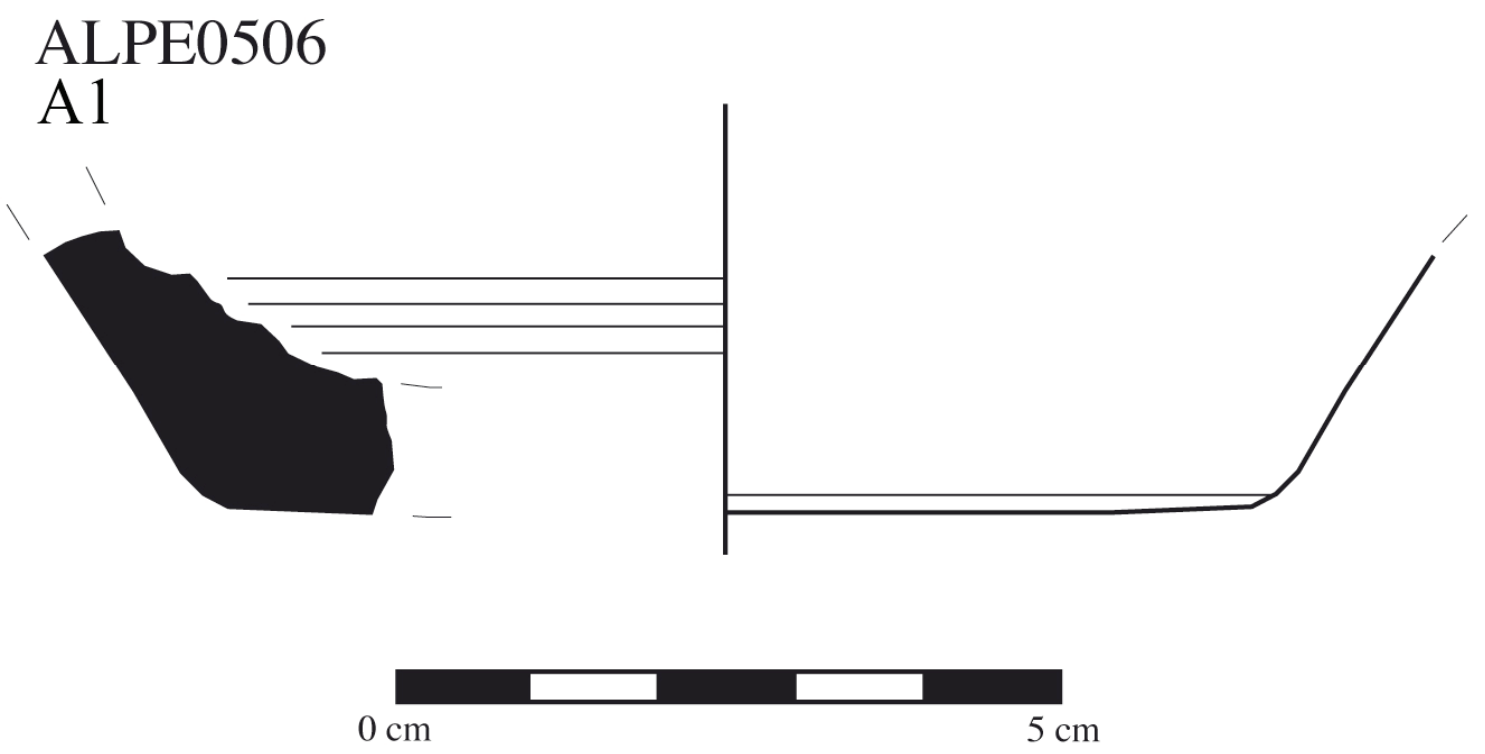

El segundo tipo es el A-2 que caracterizamos por el borde y el vidriado que presenta. Se trata de una pieza de paredes no muy gruesas y proyectadas que terminan en un borde recto y redondeado, de pastas rojizas bien depuradas, que presentan un vidriado melado con trazos de manganeso al interior y sólo melado al exterior. Sólo uno de los ejemplos nos ha permitido medir el diámetro del borde: $19 \mathrm{~cm}$. Podría corresponderse con el tipo A33 de Retuerce ${ }^{4}$, en cuyo caso tendría una cronología de entre el siglo XI y el XII, es decir del final del período andalusí en nuestras tierras.

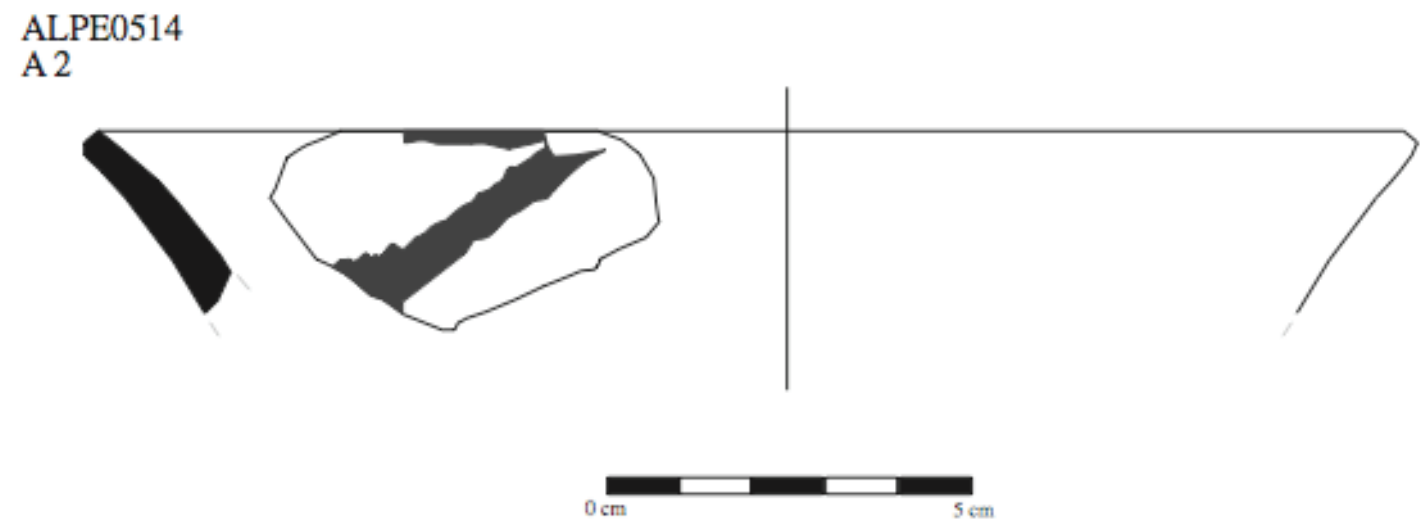

El tipo A-3 se caracteriza por un borde exvasado en ángulo recto, a modo de ala, bien horizontal o bien ligeramente caída. Presenta un vidriado melado únicamente al interior, mientras que el exterior aparece alisado o con suaves marcas de torno. Se corresponde al tipo A14 de Retuerce, fechado en el siglo X, y que aparece prácticamente en todo alAndalus. Tiene un diámetro de $22 \mathrm{~cm}$.

\footnotetext{
${ }^{3}$ Gómez MartíneZ, Susana, «Cerámica islámica de Medinaceli...», pp. 152-153.

${ }^{4}$ RetUerCe Velasco, Manuel, La cerámica andalusí... pp. 140-141
} 
El cuarto tipo identificado, A-4, es el más abundante, con seis piezas adscritas. Se caracteriza por un grosor superior a los $70 \mathrm{~mm}$, una pasta bien depurada de colores claros o anaranjados, con presencia de mica y calcita, y sobre todo por un anillo de solero de sección rectangular y ascenso vertical, con $7 \mathrm{~cm}$ de diámetro aproximadamente, y unas paredes exvasadas y rectas o ligeramente curvadas. Junto a ello, los otros rasgos distintivo son que la pared interior del anillo es más alta que la exterior, quedando en el centro del ataifor una pared mucho más fina, y que el vidriado se presenta únicamente al interior, siendo éste de color verde o de combinaciones de colores blanco y manganeso o blanco y verde. Se corresponde con el tipo A12 de Retuerce, que aparece prácticamente en toda la Marca Media y el valle del Ebro y en menor número en el litoral levantino. Se ha fechado como propio de finales del siglo $\mathrm{X}$.

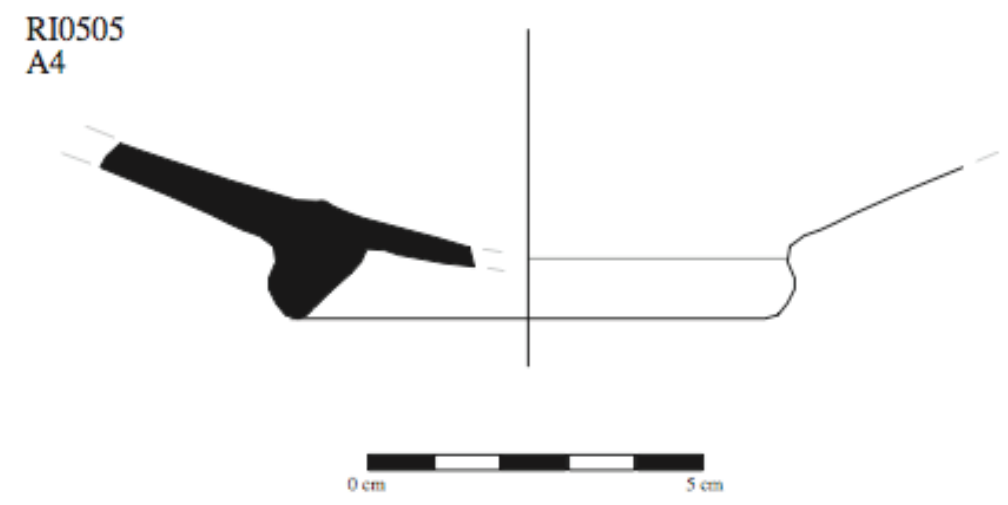

VA0708

A4

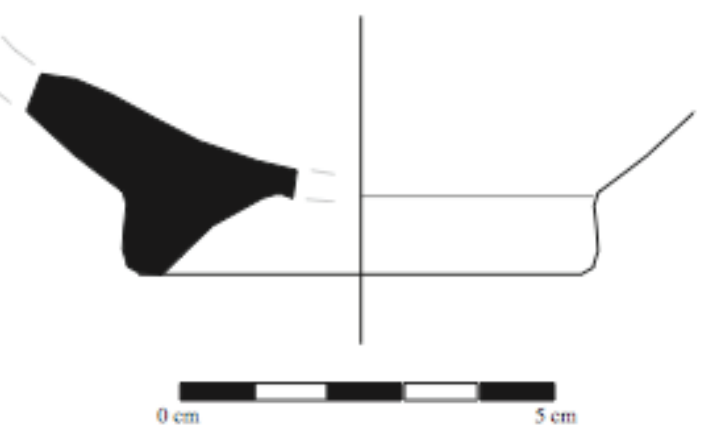

El quinto tipo, A-5 es el único caso de piezas sin vidriar que tenemos. Se presenta en pastas claras o pardas con abundante mica, y tiene un borde recto y redondeado con un diámetro de $16 \mathrm{~cm}$ aproximadamente. Se corresponde con el tipo A01A de Retuerce, quien lo fecha como propio de una época temprana en al-Andalus, y lo sitúa 
fundamentalmente en la región oriental de la Marca Media, desde Madrid a Medinaceli, donde también está presente.

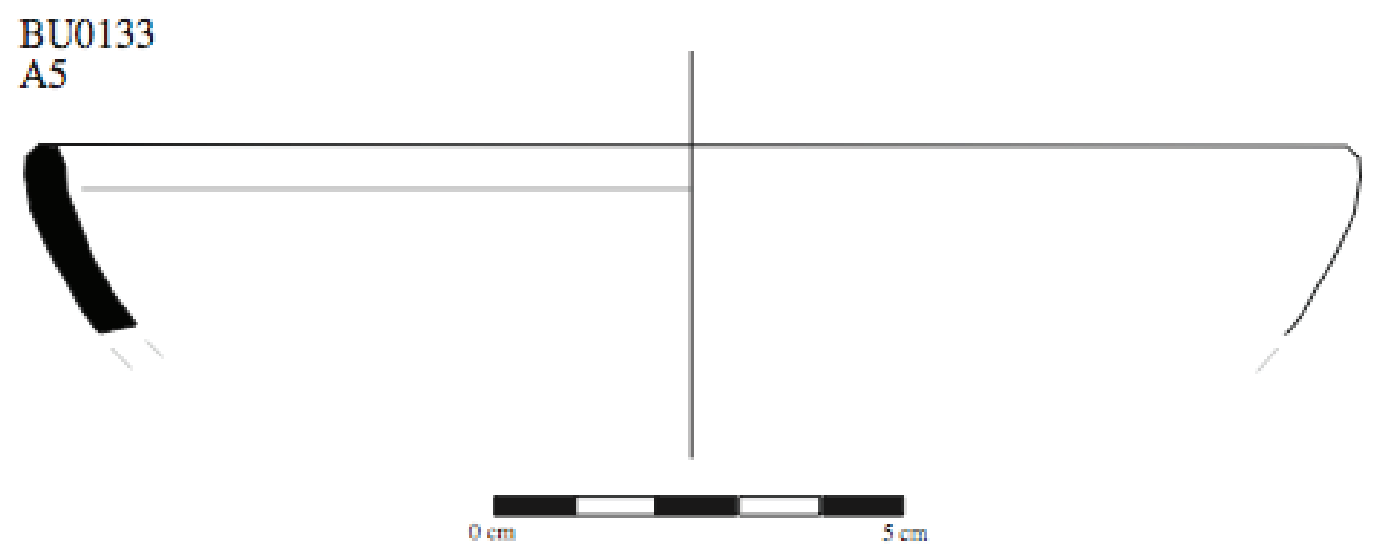

El sexto tipo, A-6, se caracteriza por una pasta rojiza muy depurada, de paredes relativamente gruesas, y un vidriado de color verde o melado que aparece por las dos caras. Tiene anillo de solero de ascenso recto. Se corresponde al tipo A.08 de Retuerce, y tendría una adscripción cronológica de entre los siglos X-XI.

Hay un grupo de paredes de ataifores que presentan una cuidada decoración, con combinaciones de colores verde y manganeso sobre fondo blanco en el interior en unas paredes bien depuradas y muy finas, en algún caso inferiores a los $30 \mathrm{~mm}$ de grosor. El exterior puede variar, en unos casos es liso y en otros presenta un vidriado melado. Todas estas piezas las hemos adscritas al grupo A-7. El único borde que tenemos de este grupo tiene una pequeña moldura triangular hacia el exterior.

Finalmente, el último tipo identificado es el A-8, de pastas grises con abundante mica, de textura áspera o alisada, que no presenta ningún tipo de vidriado ni decoración. Se caracteriza, además, por un borde redondeado y engrosado que destaca del resto del cuerpo, y que al exterior tiene un recorrido algo desigual. Es similar al tipo A.02 de Retuerce.

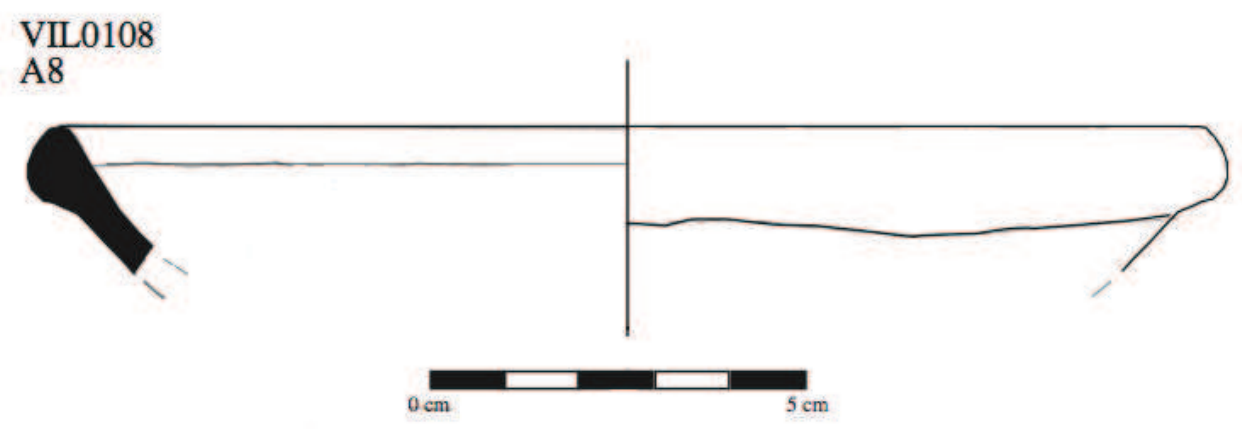


Cazuelas Sólo tenemos un caso de cazuela, C1, de borde envasado y redondeado con un vidriado melado en ambas caras sobre una pasta roja medianamente depurada y no muy gruesa, que tiene un diámetro de entre 15 y $20 \mathrm{~cm}$. No estamos seguros de su adscripción al período andalusí, ya que no hemos encontrado paralelos formales.

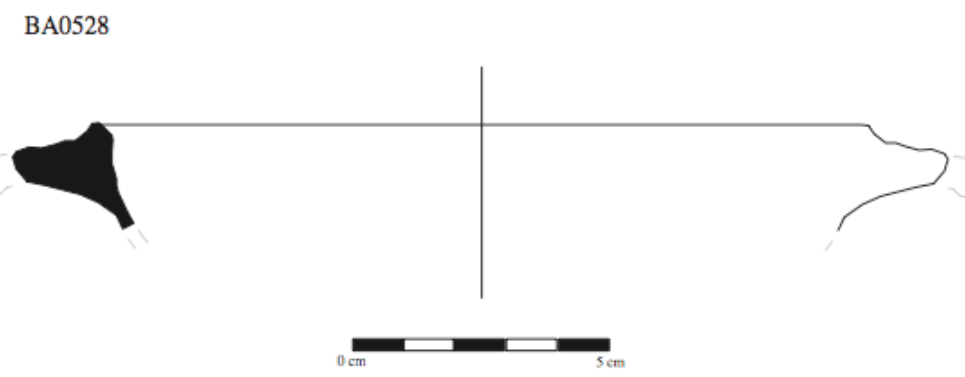

Jarr* La serie de jarros, jarras, jarritos y jarritas, que englobamos bajo el nombre de jarr ${ }^{5}$, se corresponde a recipientes cerrados en los que se puede diferenciar, con mayor o menor claridad, el cuerpo globular del cuello alargado. Su funcionalidad es amplia, desde el almacenaje en los casos más grandes, hasta el servicio de mesa en los más pequeños y decorados. Ya hemos señalado que son las piezas que más profusión de decoración con pintura presentan. Hemos distinguido ocho tipos. El primero, J-1, se caracteriza por un borde con moldura triangular y una base convexa, con unas paredes no muy gruesas y unas pastas de tonalidades oscuras, rojizas o pardas.. La base y el borde suelen presentar aproximadamente el mismo diámetro, de entorno a los 10-12 cm. Se corresponde al tipo C04 de Retuerce, para quien es un tipo que sólo aparece en la Meseta y con mayor abundancia en el entorno de los ríos Manzanares y Jarama. Su datación se situaría entre los siglos IX y X sin una aparente prolongación posterior.

\footnotetext{
${ }^{5}$ Tomamos la idea de CARVAJAl LóPEZ, José Cristóbal, La cerámica de Madinat Ilbira (Atarfe) y el poblamiento altomedieval de la vega de Granada, Granada, 2008.
} 
BA0545

J1
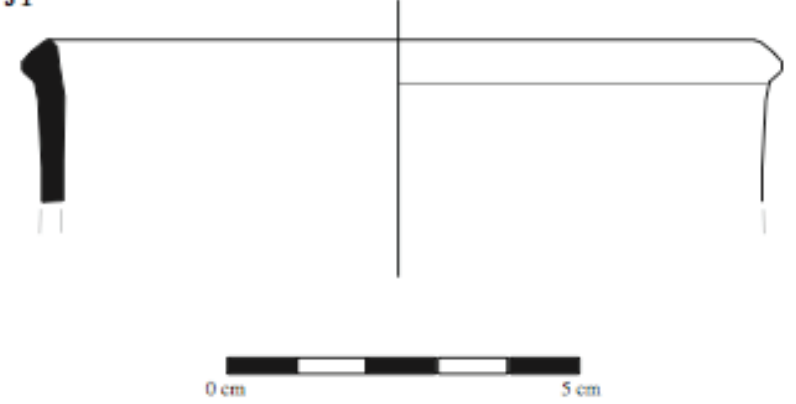

BA0546

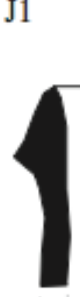
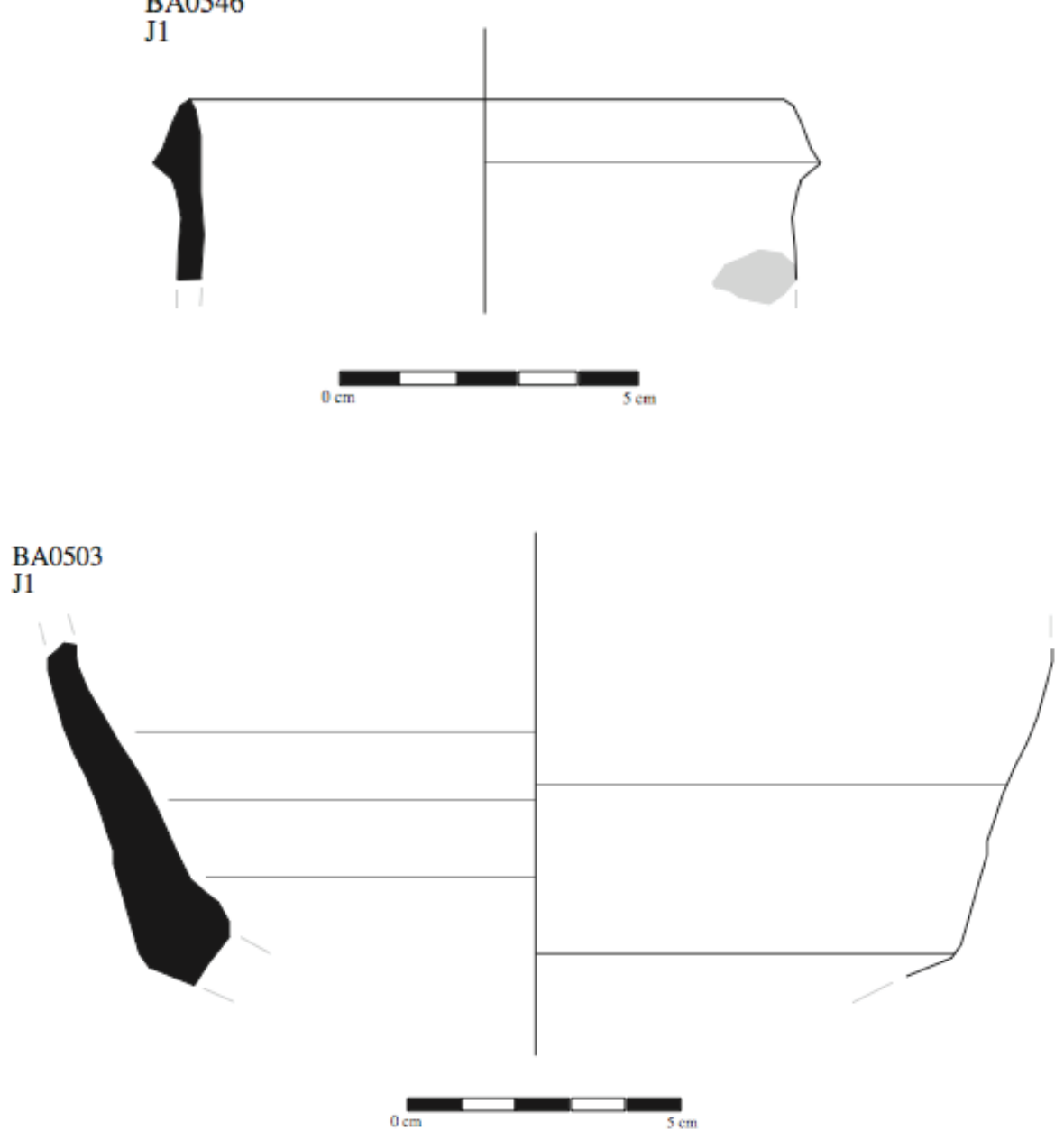
BA 05135

J1

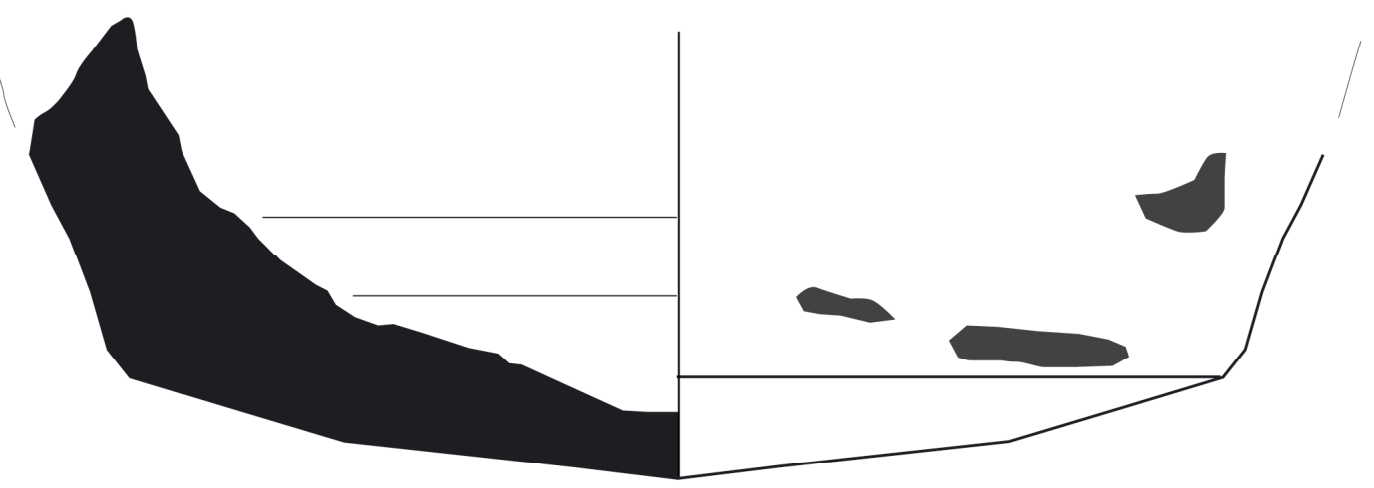

El segundo tipo, J-2, corresponde a recipientes de pequeño tamaño, de pastas pardas y claras bastante depuradas, con vidriados verdosos y melados al interior. Presentan una característica moldura en la unión del cuerpo con la base, y en todos los casos se aprecia la huella del torzal. Tienen un diámetro pequeño, de entre los $5 \mathrm{y} \operatorname{los} 10 \mathrm{~cm}$. No tenemos constancia de paralelos, por lo que tampoco podemos darle una cronología a estas piezas.

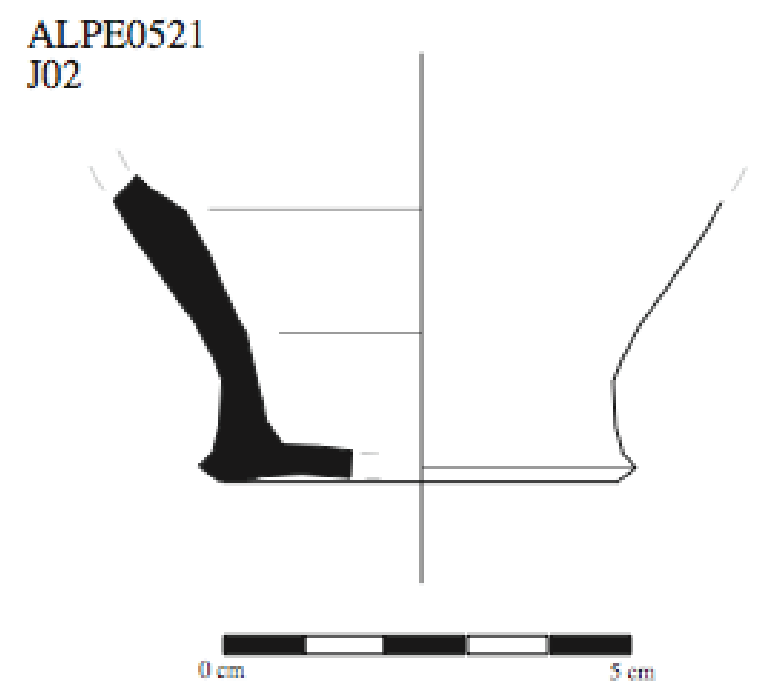




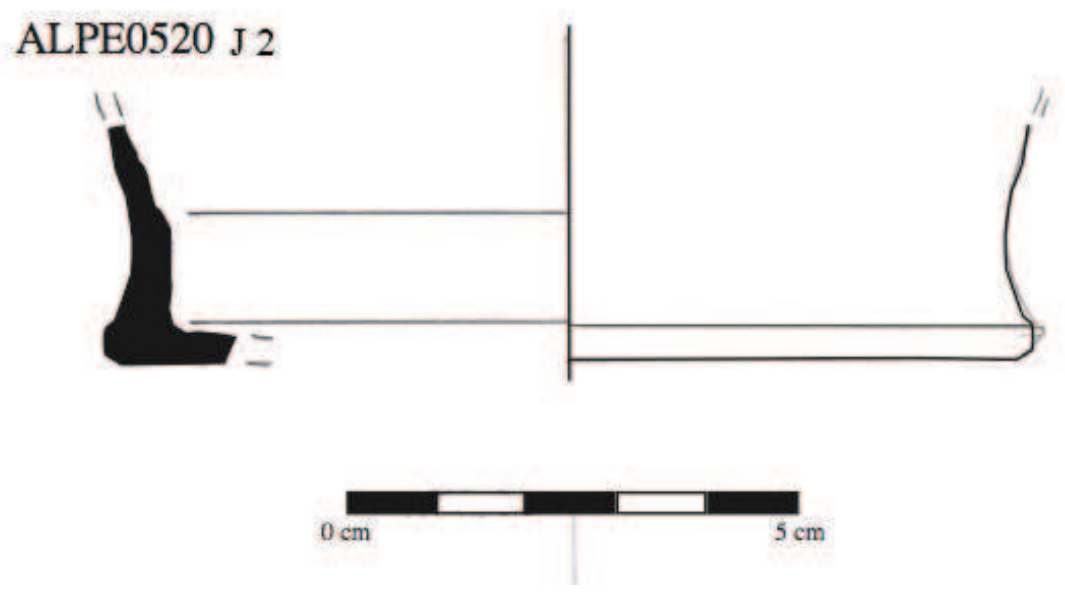

El tercer grupo, $\mathbf{J}-\mathbf{3}$, es muy característico por el artilado o sucesión de molduras que presenta tanto en el tercio inferior como en el superior. Las pastas suelen ser claras o pardas, con mica y cuarzo, y normalmente no son pastas muy depuradas, presentando algunos desgrasantes de mediano tamaño. También hay algunos ejemplos con pastas muy depuradas y muy claras, con abundante calcita y caliches. La base es recta y plana. Puede corresponderse con dos de los tipos definidos por Retuerce, el C01 y el C02, pero al no haber encontrado ningún borde adscrito a este tipo no podemos fijar más la comparación. En cualquier caso, su cronología oscila entre los siglos X y XI.

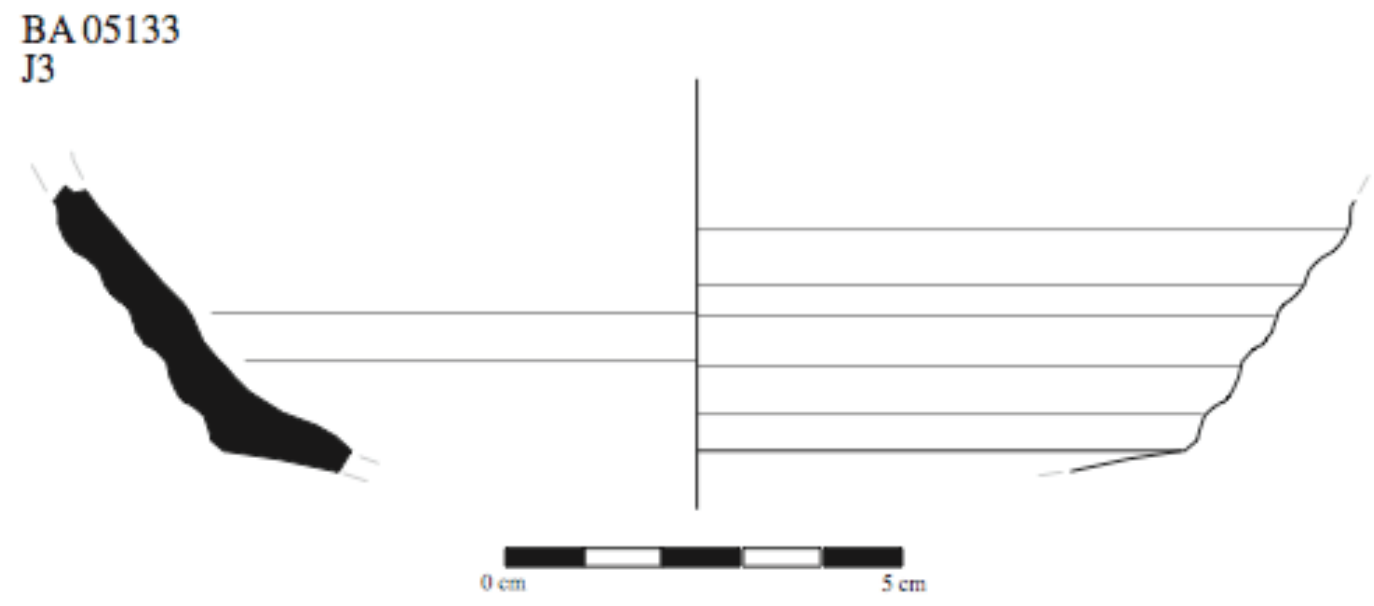

Hay un tipo de jarra de grandes dimensiones, de pastas pardas, claras y grises, con abundante mica, que presentan un fondo convexo y espatulado, y a menudo restos de una decoración con pintura en la superficie externa, que por lo demás se presenta alisada, áspera o con marcas de torno Se trata del tipo $\mathbf{J}-\mathbf{4}$, que puede equivaler al tipo C04 de Retuerce al igual que nuestro grupo J-1, por lo que tendría una cronología relativamente temprana.

El quinto grupo, J-5, se caracteriza por unas paredes gruesas, a veces de más de $1 \mathrm{~cm}$, pastas anaranjadas y ausencia de vidriado. Tiene un fondo recto sin huellas de haber 
sido alisado, y presenta unas paredes molduradas al interior. Al exterior, las paredes están alisadas y en la unión del cuerpo con la base hay dos incisiones paralelas que recorren todo el diámetro de la pieza. Tienen un diámetro de entre 10 y $12 \mathrm{~cm}$. Puede corresponder al tipo C12 de Retuerce, aunque no tenemos bordes ni asas que nos lo certifiquen.

El sexto grupo es morfológicamente muy parecido al anterior, pero con la diferencia de no presentar ni las incisiones exteriores ni las molduras interiores, ascendiendo las paredes rectas y con tendencia vertical. Este tipo $\mathbf{J}-\mathbf{6}$ presenta una textura áspera y a menudo los desgrasantes son de mediano tamaño, entre los que cabría citar la mica y el cuarzo. Las cocciones son siempre oxidantes o tipo sandwich, y el diámetro oscila entre los 10-12 cm. Es un tipo muy representado en el conjunto cerámico del valle del Salado, el 7,14 del total de las piezas adscritas a algún tipo pertenecen a este tipo de jarras. Sin embargo, al no presentar ninguna característica especial, los paralelos son difíciles de establecer y puede equivaler a muchos de los tipos presentados por Retuerce.
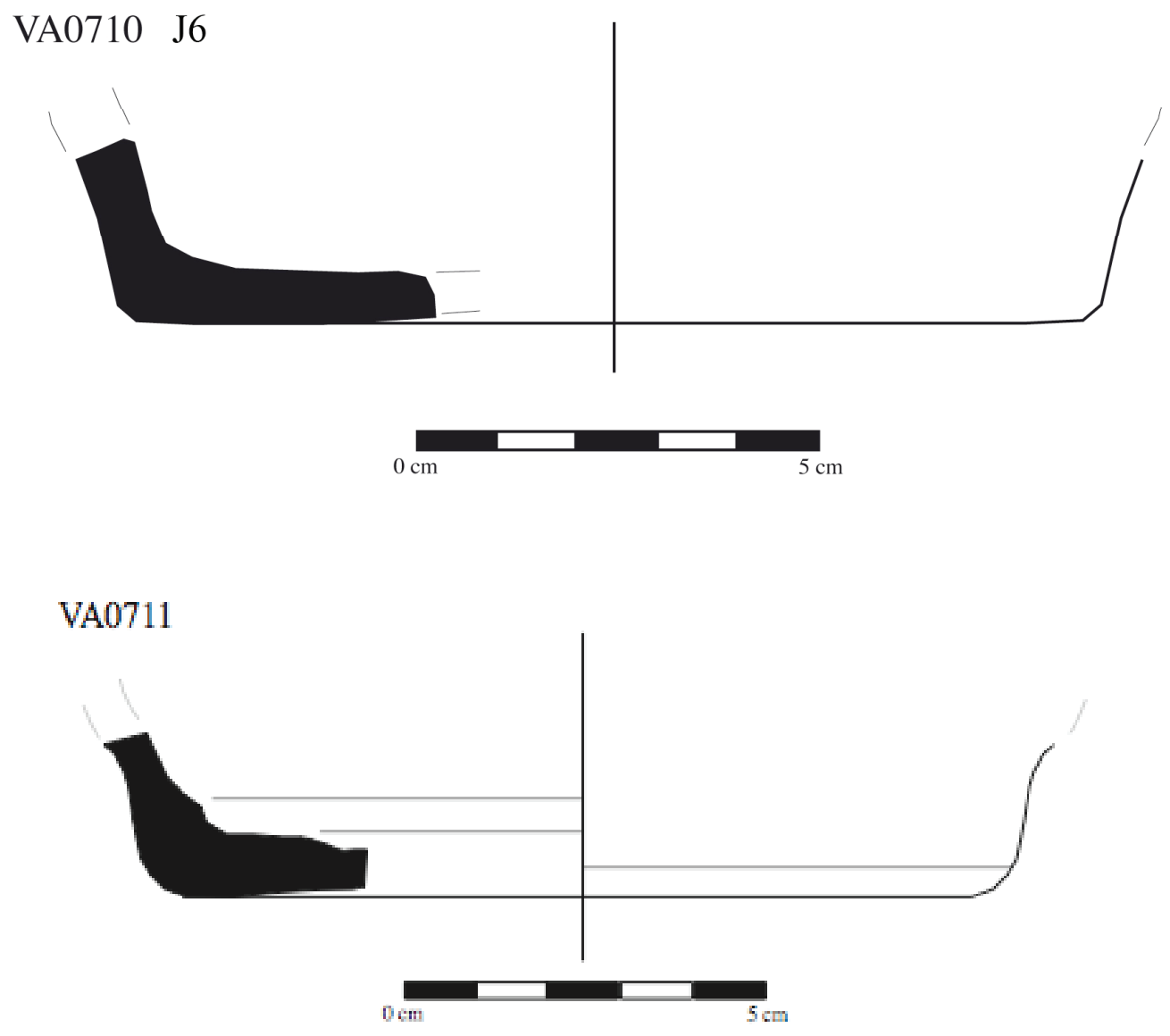

El siguiente grupo, J-7, está escasamente representado, con tan sólo dos fragmentos. Son piezas muy finas, inferiores a los $30 \mathrm{~mm}$ de grosor, de pastas grises o pardas. Tiene un borde sinuoso, casi en forma de "S", que acaba en un extremo redondeado. Quizás lo más característico de las piezas sean los restos de pintura que aparecen en el borde y 
caen como goterones hacia el interior. Tienen un diámetro de aproximadamente $7 \mathrm{~cm}$. No hemos encontrado paralelos para esta forma.

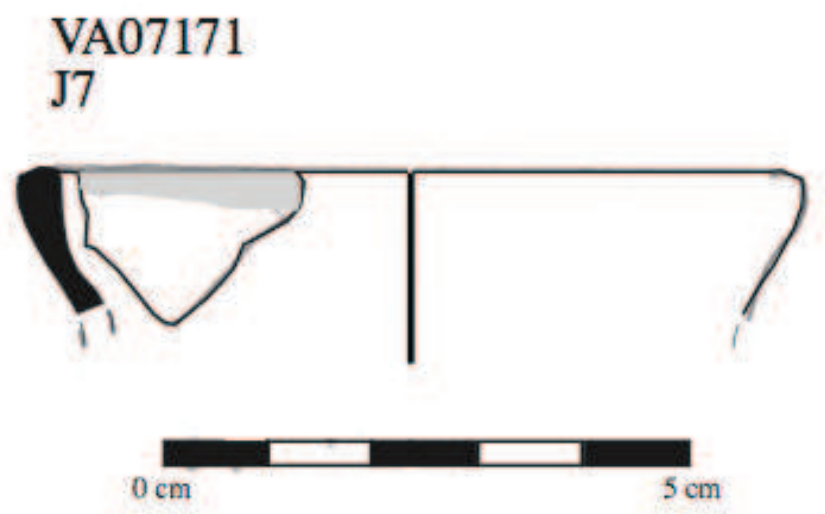

El último tipo, J-8, también está representado únicamente por dos piezas, aunque ambas son de considerables dimensiones y presentan el arranque del asa. Son jarras de gran porte, con paredes relativamente gruesas de entre los $70 \mathrm{~mm}$ y $1 \mathrm{~cm}$ de anchura, que tienen un aspecto alisado. Las asas tienen un perfil sinuoso, con dos partes hendidas y el centro levantado, y en uno de los fragmentos hay una serie de punciones en la parte en la que el asa se une al cuerpo. Aparte de esas punciones, las piezas no presentan decoración. Esa unión entre el asa y el cuerpo se produce en una parte de diámetro estrecho, que corresponde a un cuello cilíndrico y alto de ascenso vertical. Este tipo se corresponde con la forma C.38 de Retuerce, quien le otorga una cronología tardía, del siglo XII en adelante.

Ollas/marmitas Son las formas cerámicas generalmente destinadas a la cocción de alimentos. Tienen formas cerradas, troncocónicas o globulares, con escaso desarrollo del cuello. Hemos distinguido tres grupos. El primero, O-1, se ha definido por la base convexa y espatulaza que presentan, que es el rasgo más definitorio. Aparece representado en pastas pardas, rojizas y oscuras, con bastantes inclusiones entre las que abunda la mica y la calcita. El diámetro de la base, en el punto en el que aparece el quiebro hacia la base convexa, oscila entre los 10 y los $14 \mathrm{~cm}$. Resulta difícil determinar tanto la cronología de estas piezas como compararlas con otras, ya que las ollas de base convexa suelen ser muy frecuentes, estableciéndose la distinción a partir de los bordes. Los otros dos tipos si que han sido caracterizados a partir del tipo de borde que presentan. 

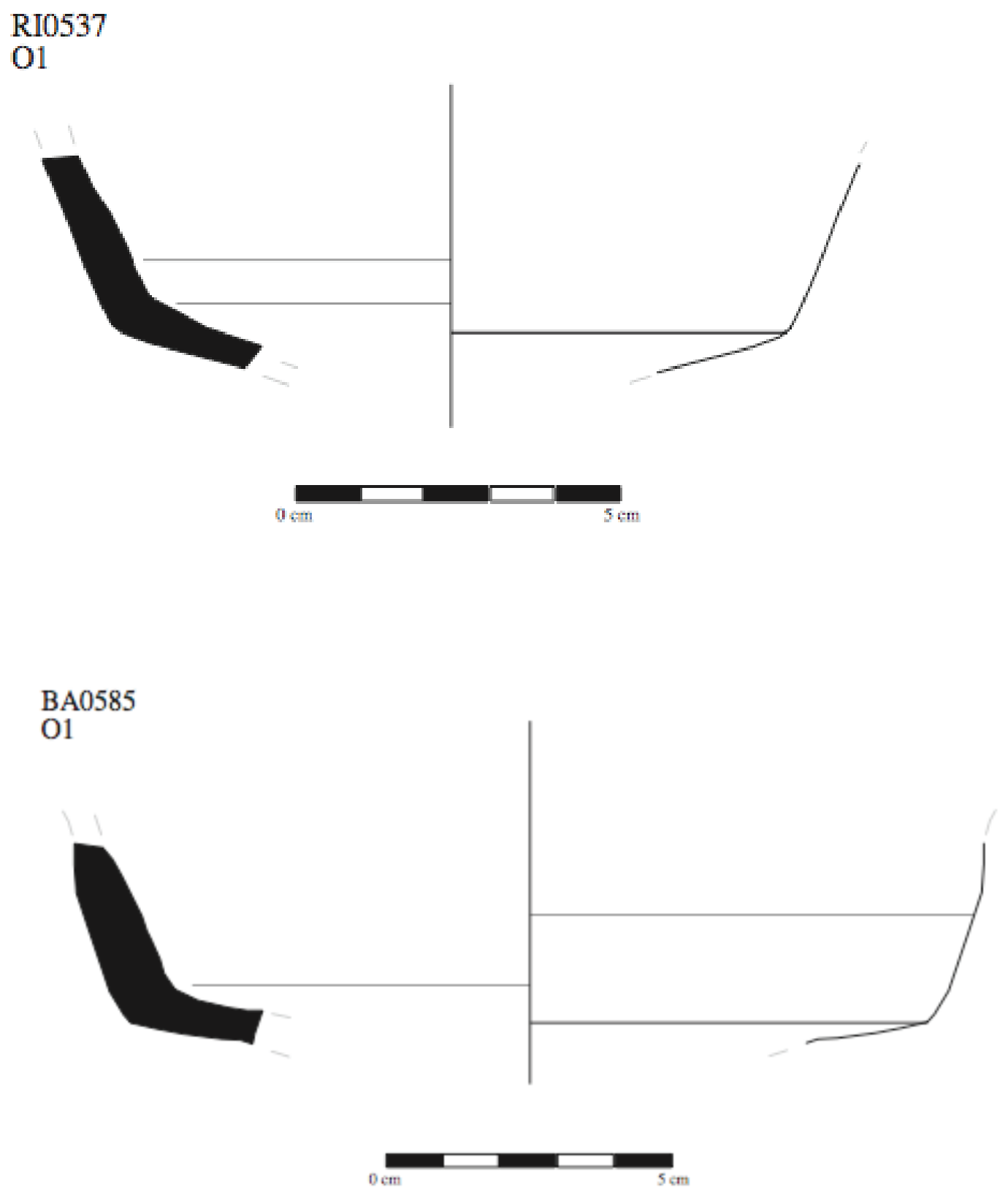

El tipo O-2 presenta un borde recto y vertical, con diferentes desarrollos ya que tenemos tanto ejemplos en los que éste apenas se insinúa como otros en los que alcanza más de un centímetro de altura. A veces en la parte interior del borde hay una pequeña incisión que recorre todo el diámetro de la pieza. No presentan ningún tipo de vidriado ni acabado superficial, salvo un alisado, aunque también son frecuentes los casos en los que se observan las líneas del torno. Este tipo equivale a los denominados F.01 y F.05 establecidos por Retuerce, quien los distingue, entre otras cosas, por el desarrollo de su cuello, aunque nosotros lo hemos considerado como el mismo. Parece ser un tipo propio del centro de la península donde únicamente aparece representado, sobre todo en las zonas de Madrid y Calatalifa. 

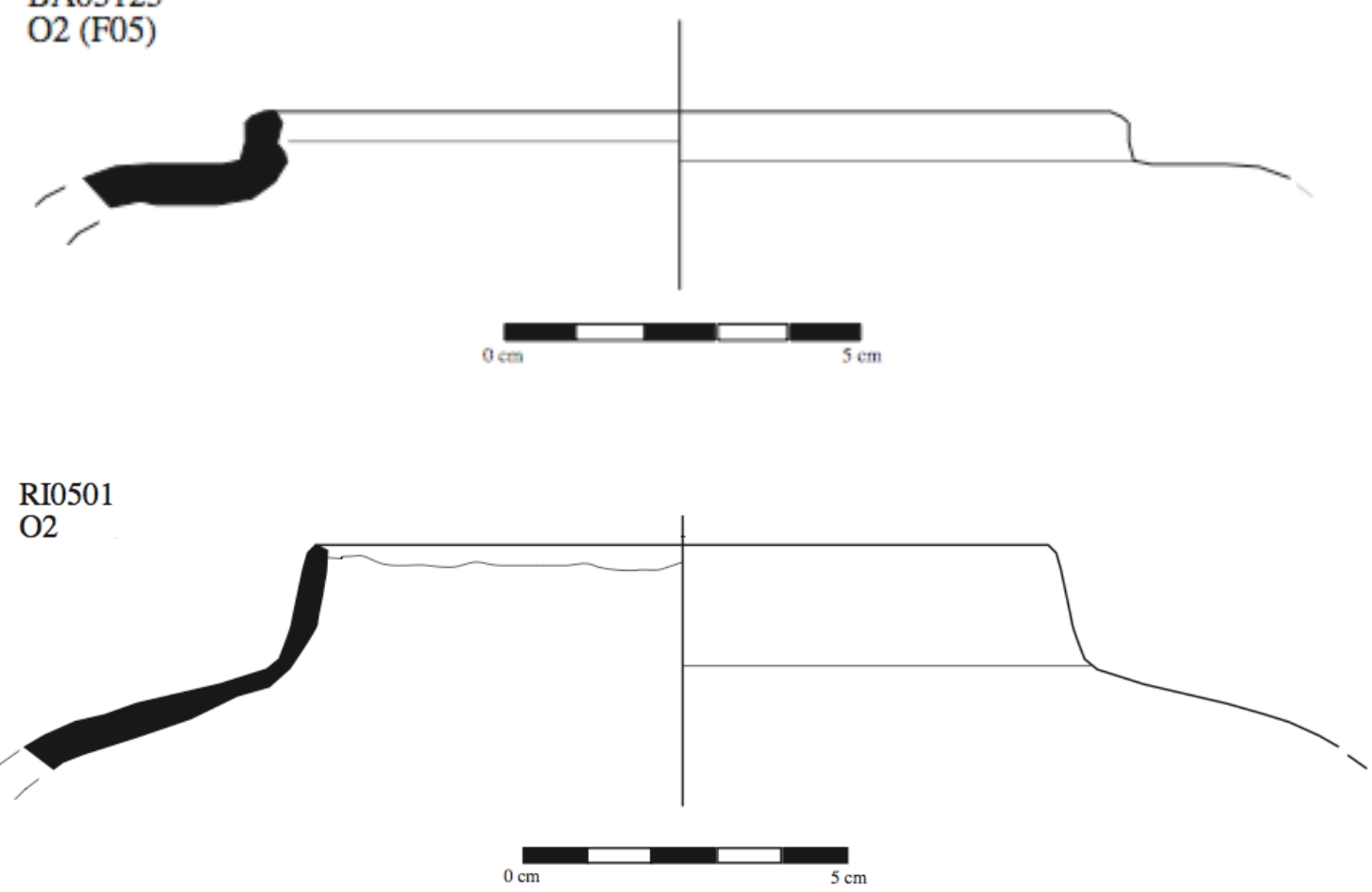

El último tipo de olla identificado es la $\mathbf{O - 3}$, que es, probablemente, la pieza más significativa de la ocupación andalusí de toda la zona de Guadalajara y gran parte de la Marca Media. Son recipientes de forma cerrada y variados tamaños y diseños formales que tienen como principal característica el poseer una «escotadura» en la parte alta del cuerpo, justo antes del inicio de un borde siempre curvado. Es el ejemplo más representado y mejor caracterizado de todos los encontrados en el valle del Salado, siendo el 10,39 \% del total de piezas identificadas y adscritas a uno de los tipos. Este atributo de la «escotadura» es el elemento morfológico que da el verdadero carácter definitorio al tipo, ya que por lo demás aparece en distintos tipos de pastas, con cocciones oxidantes, alternas y reductoras, con diferentes grados de depuración en las pastas y en ocasiones con algún tipo de decoración, aunque no es muy frecuente. Este tipo se corresponde con el F-02 de Retuerce, quien distingue a su vez numerosos subgrupos dependiento de algunas variaciones, lo que va a marcar también algunas precisiones en la cronología. No obstante, en nuestro caso, ya que todos los fragmentos aparecen tan fragmentados, hemos optado por considerarlos pertenecientes todos ellos al grupo O-3 en general, con lo que su cronología abarca todo el período andalusí. 


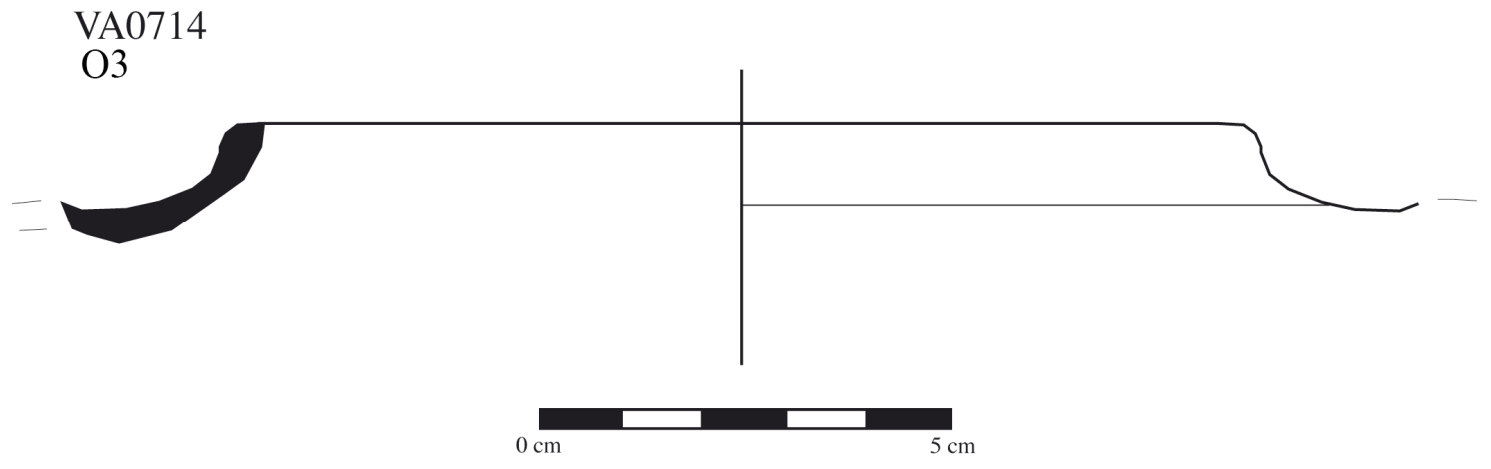

$\mathrm{O} 3$

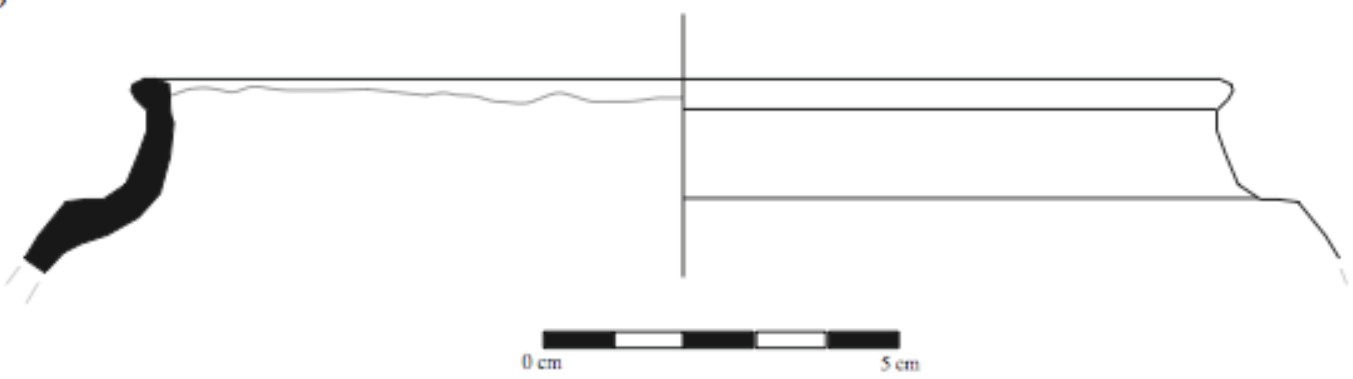

Redomas/botellas Son recipientes cerrados de cuello estrecho, largo y corto y cuerpo globular, que por lo general tienen unas paredes estrechas. Las diferencias de tipos dentro de este grupo las hemos establecido a partir del tipo de borde, ya que por lo general todas las redomas identificadas tienen pastas depuradas de colores claros o anaranjados, con abundancia de mica y calcita. Dos son los tipos que hemos podido distinguir: R-1, con un borde con moldura triangular, y el tipo R-2, un borde exvasado y recto. En ambos casos, los diámetros de la boca no superaban los 5 centímetros.

\section{VIL0163 \\ R2}

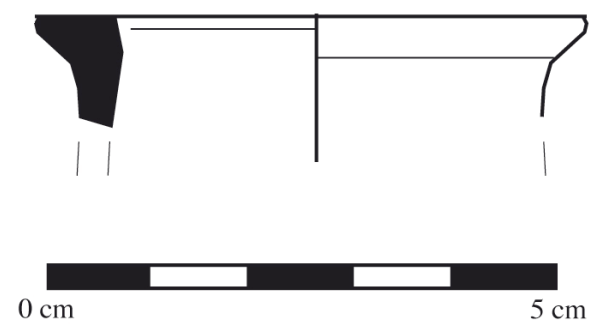


Tapaderas En lo que respecta a las tapaderas, están mal representadas debido a su escasísimo número, a pesar de lo cual hemos clasificado tres grupos. No conocemos, para ninguno de los tres, cual sería el sistema de asidero. El primero, Tp-1, corresponde a piezas planas de un grosor medio, entre los $30 \mathrm{y}$ los $70 \mathrm{~mm}$, cuyo rasgo diferenciador es la presencia de una carnea aproximadamente hacia la mitad del diámetro de las piezas, sin que hasta el momento podamos saber cual es la finalidad de este elemento. Los ejemplos encontrados tienen un diámetro superior a los $25 \mathrm{~cm}$. En el tipo Tp-2 incluimos todas aquellas piezas que se caracterizan por la abundancia de mica en sus pastas y por ser piezas muy delgadas, en el que quedan marcadas suavemente las líneas del torno en su superficie. Los bordes son redondeados y ligeramente apuntados hacia abajo. Son piezas de menor tamaño que las anteriores, con un diámetro de aproximadamente $15 \mathrm{~cm}$. El último grupo individualizado, Tp-3, corresponde también a piezas finas, aunque en este caso las pastas son muy depuradas y de colores claros. Se caracterizan por no ser planas como las dos anteriores, sino que presentan un suave ascenso hacia el centro. Al igual que en el caso anterior, el borde aparece levemente apuntado hacia abajo, pero no se ha podido determinar el diámetro de estas piezas.

Tejas El alto volumen de tejas encontradas en los distintos yacimientos nos ha permitido establecer una tipología muy general, sin que podamos indicar de ella prácticamente nada aparte de los rasgos morfológicos que los distinguen, ya que todos los tipos aparecen en la mayor pare de los asentamientos y no conocemos paralelos ni estudios sobre este tipo de materiales que nos den indicios de posibles cronologías. El primer tipo, $\mathbf{T j} \mathbf{j} \mathbf{1}$, se caracteriza por poseer una pasta roja medianamente depurada, en la que sobresalen los granos de cuarzo y calcita. Tiene muy poca curvatura, siendo piezas casi planas, y la superficie exterior aparece alisada y en todos los casos con decoración a base de digitaciones en líneas rectas verticales. El segundo grupo, $\mathbf{T j} \mathbf{j} \mathbf{2}$ corresponde a ejemplos mucho más curvados, con un característico borde redondeado y apuntado hacia abajo. En este caso las pastas suelen ser más claras, pardas, amarillentas y anaranjadas, con abundante presencia de mica. Por último, en el tipo Tj-3 incluimos las tejas de pastas burdas, cocciones alternas, con grandes y abundantes inclusiones de cuarzo y mica, que por lo general son piezas mucho más gruesas que en los dos tipos anteriores. 


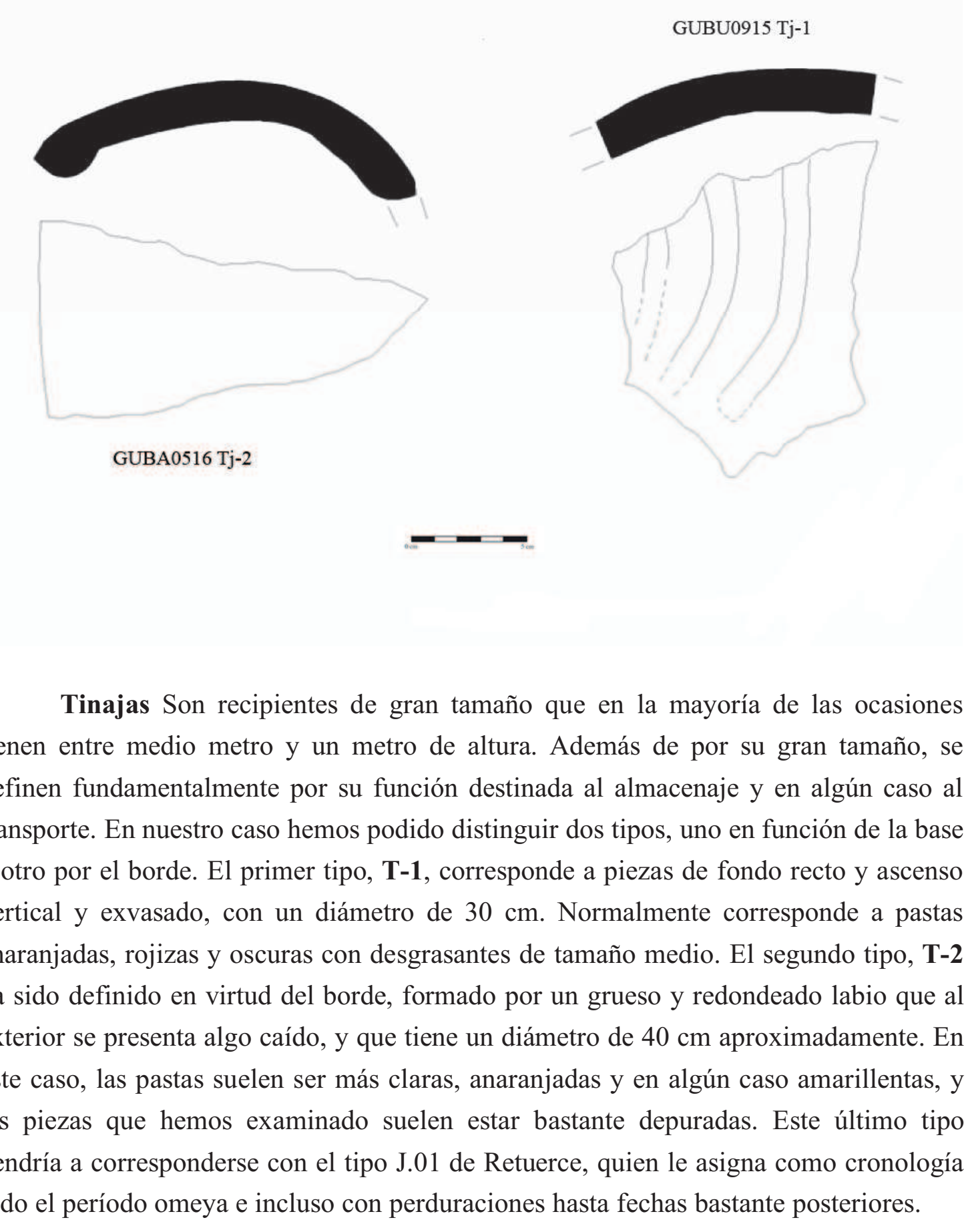

. 

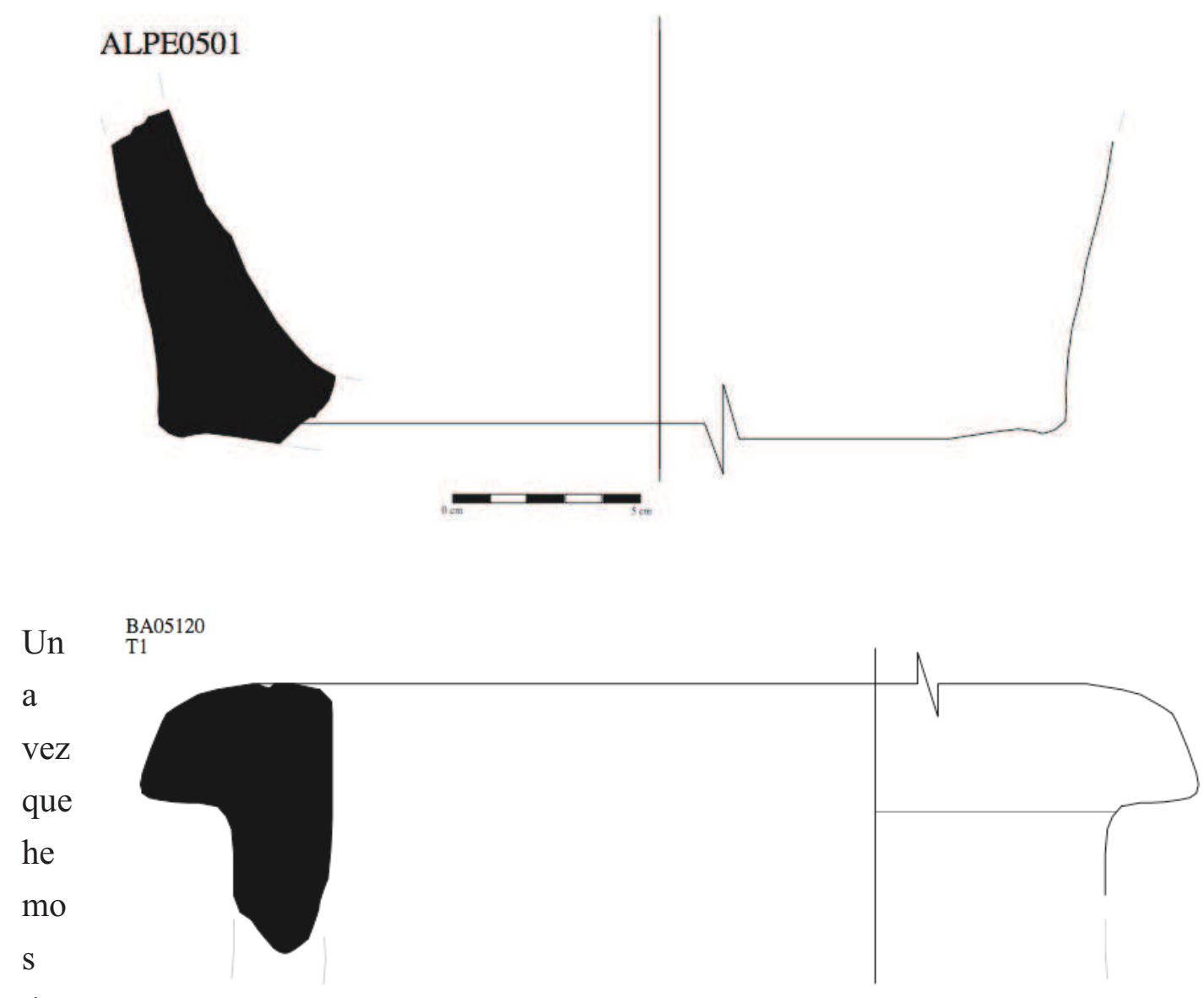

des

crit

o

los distintos tipos identificados, vamos a pasar a ver su distribución en el valle.

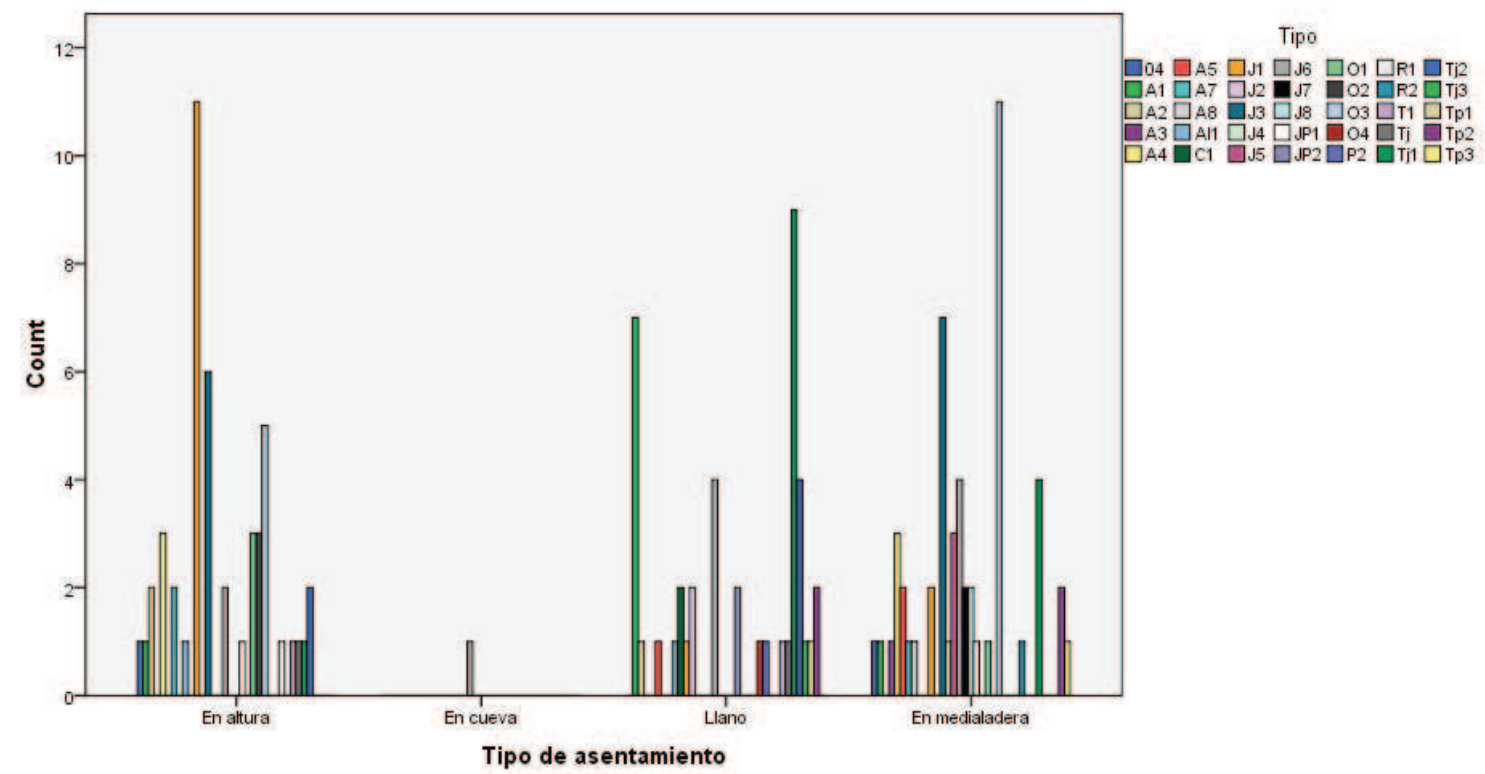

Dos tipos de jarras, las formas $\mathbf{J}-\mathbf{1}$ y $\mathbf{J}-\mathbf{2}$, son las más abundantes, siendo su distribución significativa ya que en el primer caso aparecen con más frecuencia en los asentamientos en altura, mientras que la segunda forma está distribuida por igual en todos los 
yacimientos, siendo la única forma identificada con claridad en las cuevas. También es significativa la presencia de la olla con escotadura, el tipo $\mathbf{0 - 3}$, abundante tanto en los asentamientos en altura y media ladera, pero que prácticamente no tiene representación en el llano.

Por último, una última consideración respecto a las tejas: el tipo T-1 aparece tanto en media ladera como en altura, mientras que los tipos $\mathbf{T j} \mathbf{- 2} \mathbf{T} \mathbf{T}-\mathbf{3}$ son las tejas dominantes en el llano.

Por último, vamos a tomar en consideración algunos aspectos sobre la cronología que arrojan estos materiales. La mayor parte de las piezas se pueden adscribir al período que abarca entre los siglos $\mathrm{X}$ al XI, seguido por otros materiales que se pueden fechar en toda la etapa andalusí. Apenas si contamos con materiales con fechas anteriores al siglo IX.

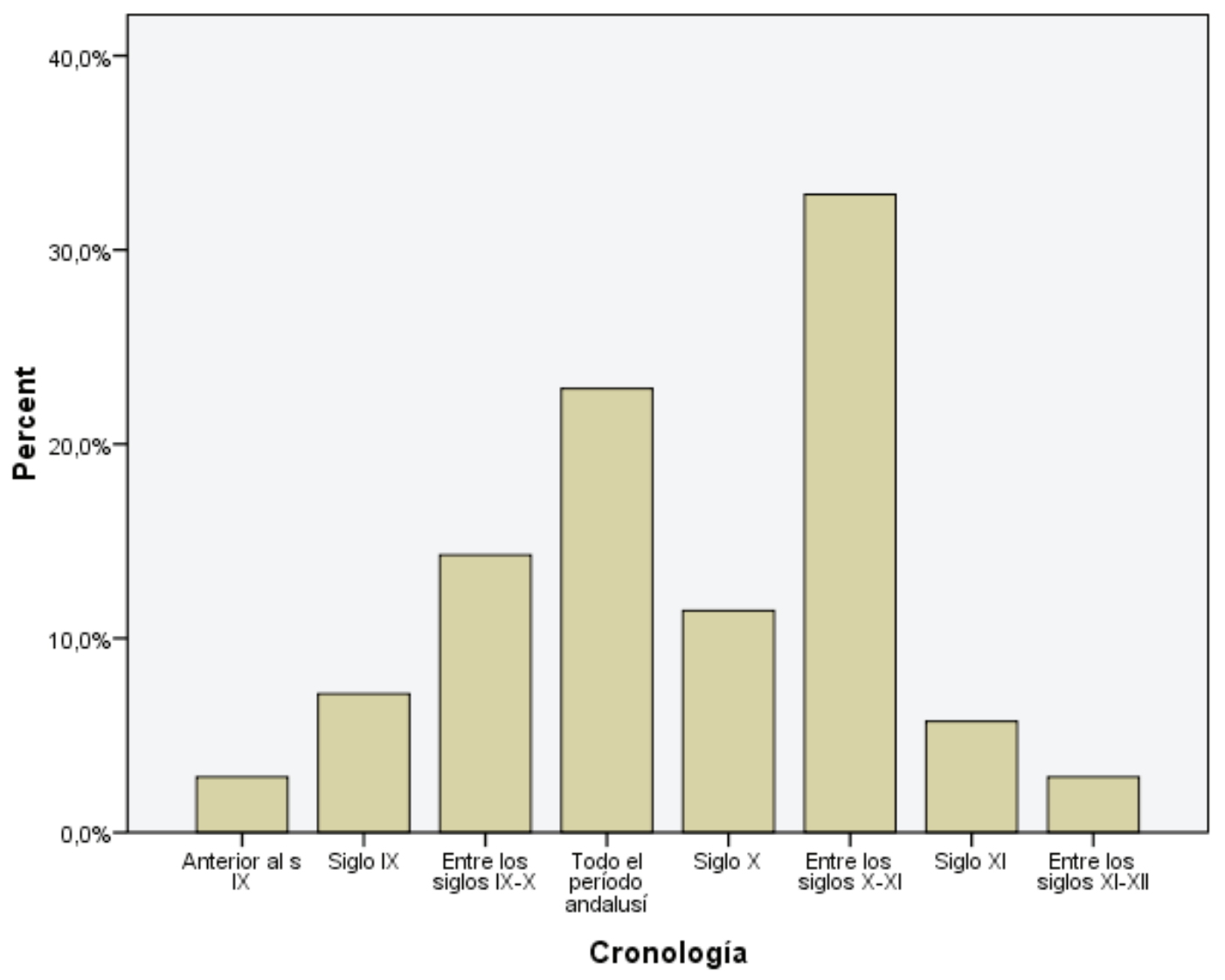




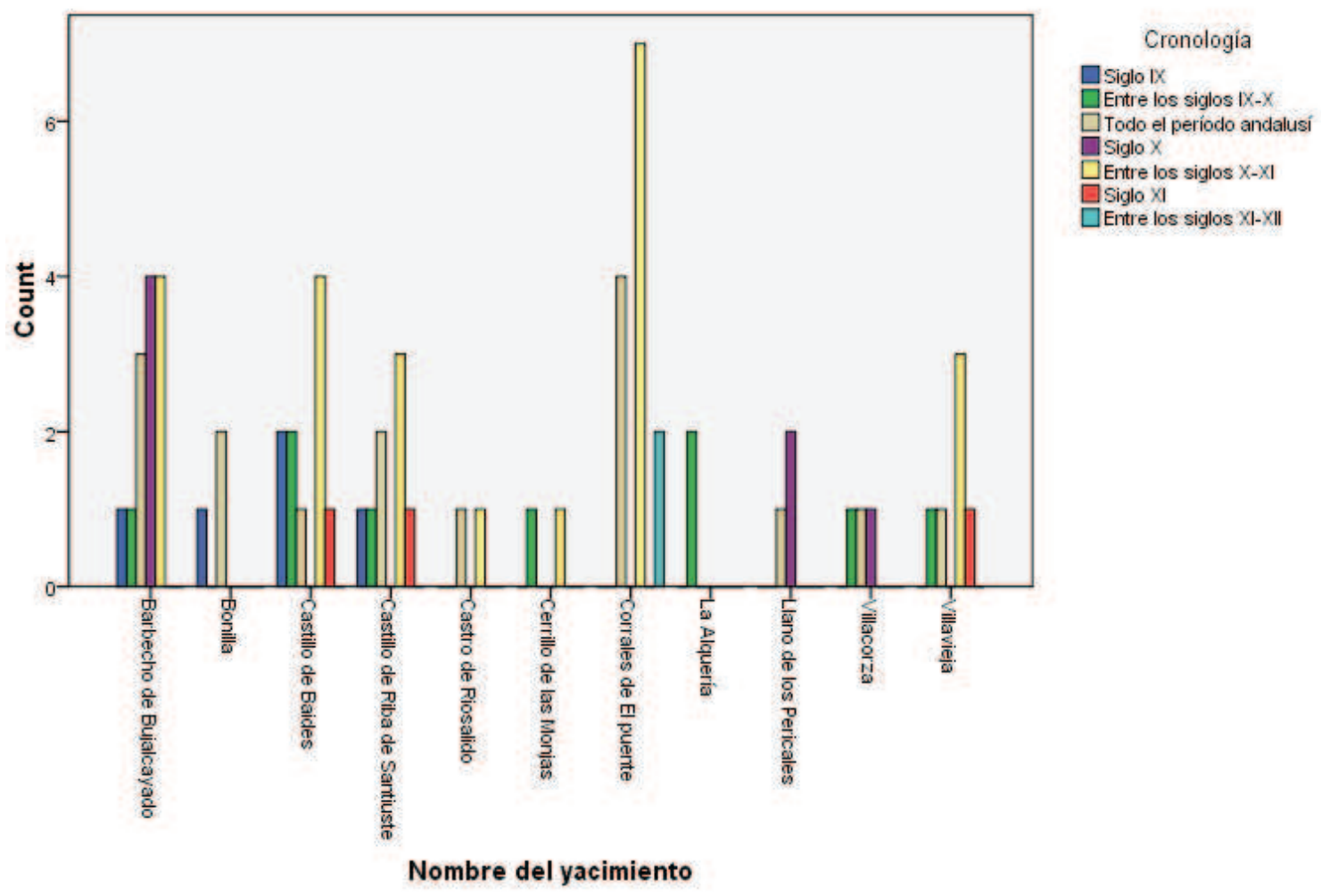

Al examinar esta distribución cronológica según el tipo de asentamiento, nos encontramos con que únicamente Bujalcayado, Bonilla y los castillos de Baides y Riba de Santiuste pueden documentarse con anterioridad al siglo IX, mientras que la mayor parte de los asentamientos tiene un origen que no se puede llevar más atrás del siglo X y con una perduración durante el siglo XI. Es el momento en el que otros asentamientos parecen abandonarse, o al menos, no aparecen materiales que con mayor o menor claridad puedan fecharse del siglo X en adelante. Nos referimos a los de Villacorza y el llano de los Pericales. El último dato cronológico que queremos destacar es como apenas si hay materiales que se puedan fechar más allá del siglo XII, momento en el que se produce la conquista castellana, salvo en el lugar de los corrales de El Puente, en Valdelcubo, que como ya describimos en otro apartado de este trabajo era el único asentamiento a media ladera de un tamaño más grande que el resto. Cabe la posibilidad, de momento solo establecida como hipótesis, que la población andalusí se concentrara en esta alquería, que crecería de tamaño al albergar ahora a una población mudéjar.

\section{Grupos cerámicos}

Los análisis que hemos realizado sobre las cerámicas nos han permitido establecer unos grandes conjuntos cerámicos o «tradiciones tecnológicas» que presentan similares características, objetivo que perseguíamos como ya dijimos en otra parte de este trabajo, 
ya que nos permitiría otro tipo de comparaciones con lo que Retuerce denomina «grupos cerámicos» ${ }^{6}$. Básicamente consiste en, mediante una serie de análisis multivariantes a los que hemos sometido el registro cerámico, tratar de establecer conjuntos que presentan unas características similares, prácticamente las mismas, en lo que a los indicadores de la pasta, el modelado, el acabado y la cocción se refiere. En este sentido, hemos sido bastante flexibles a la hora de considerar como pertenecientes a un mismo grupo piezas que podían presentar sólo un indicador distinto, por ejemplo, la aparición de algún tipo de mineral que no presenta el grupo básico, o rastros de una cocción alterna cuando claramente el resto de características son las mismas. El método que hemos seguido a constado de dos fases: en primer lugar, tras el volcado de información en la base de datos, se realizaron análisis comparativos entre las distintas variables para ver que tendencias se detectaban a grandes rasgos. En un segundo momento, se volvió a examinar todas las piezas con el objetivo de ir clasificando, siempre que fuera posible, en alguno de los grupos.

Esta clasificación que presentamos no es más que un intento por hacer un análisis que lleve al máximo de sus posibilidades el análisis visual de la cerámica sin apoyo de la microscopía, como ya hemos explicado en otra parte de este trabajo. Futuras investigaciones de carácter arqueométrico ayudarían a revisar estos grupos, así como ayudar a clasificar todo el material que no ha sido adscrito a ningún conjunto.

Los grupos identificados son un total de 10, con la siguiente cuantificación

\footnotetext{
${ }^{6}$ RetUerce Velasco, Manuel, La cerámica andalusí..., t. 1, pp. 66-69.
} 


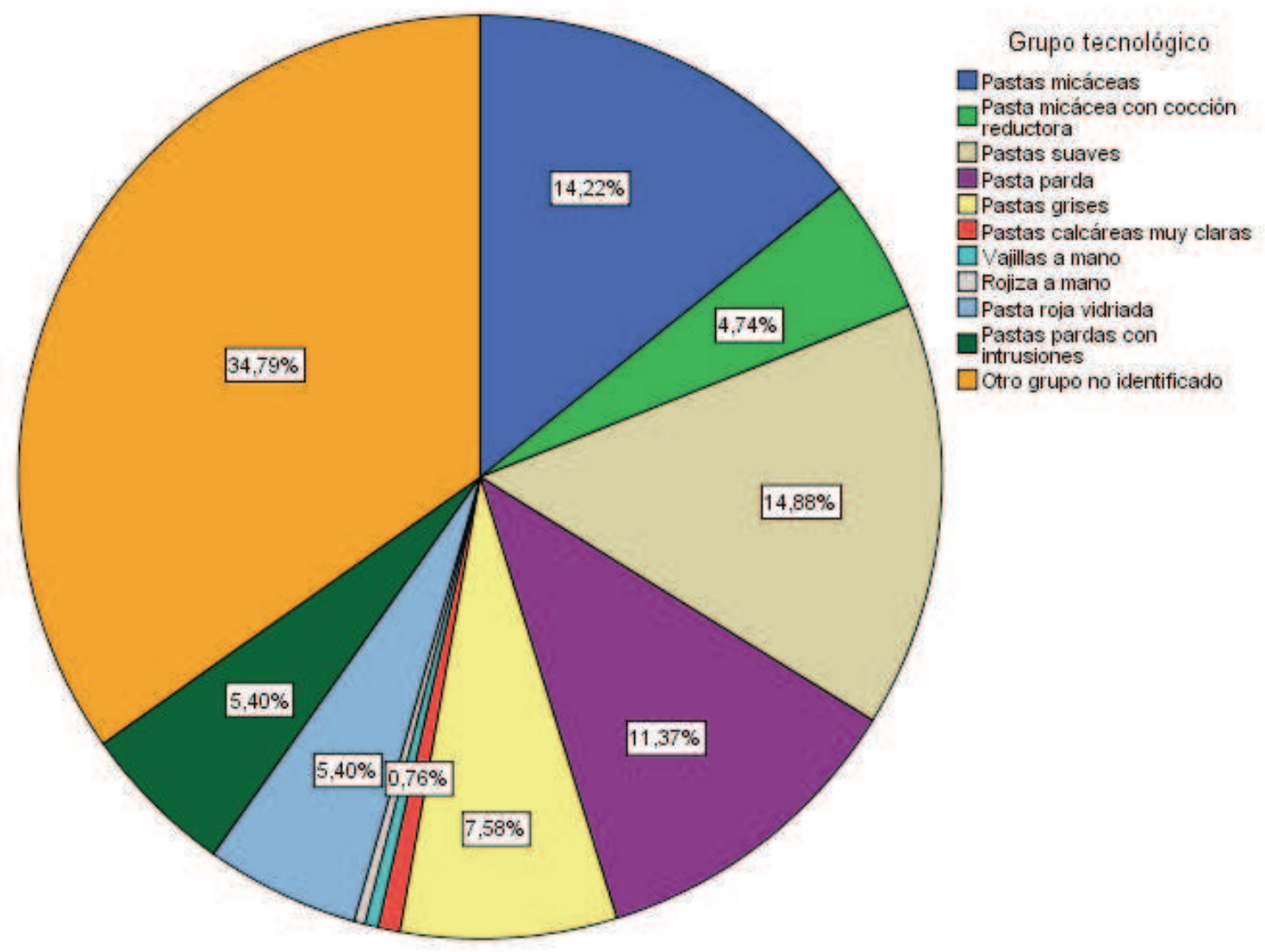

Como puede verse en la gráfica, más del 34\% del material no ha podido ser adscrito a ninguno de estos grupos tecnológicos que hemos establecido. De los nueve, el más numeroso es el que hemos denominado «Pastas micáceas» $(14,22 \%)$, seguido por las «Pastas suaves» $(14,88 \%)$ y las pastas pardas $(11,37 \%)$. El resto de grupos representan unos valores inferiores al 10\%.

Vamos a pasar a describir cada uno de estos grupos

1. Pastas micáceas. Se trata del grupo más numeroso, representado en un $14,22 \%$. Se trata de cerámicas de colores claros o rojizos, con abundantes inclusiones pero de pequeño tamaño y formas redondeadas, entre las que abunda la mica, sola o en combinación con la calcita o el cuarzo. Esta abundancia de la mica le da un aspecto brillante al acabado de las piezas, que por otra parte presentan una superficie áspera en todos los casos. Las cocciones son oxidantes, salvo algunos ejemplos de cocciones alternas que hemos admitido como pertenecientes a este grupo. La dureza es de grado 3 (se raya con el acero). Por lo general no hay en este grupo cerámicas de menos de 30 $\mathrm{mm}$ de grosor ni superiores a los $70 \mathrm{~mm}$, quedando todas en ese rango intermedio. A este grupo pertenecen formas cerradas y globulares, que se pueden adscribir a ollas o jarras, siendo los únicos tipos claramente identificados las ollas con escotadura (O3) y las jarras de base convexa y borde con moldura triangular (J1). También hay algún 
ejemplo de jarras con tercio inferior artilado (J3) que se adscribe a este grupo. Por el momento, no podemos certificar ninguna cronología para este grupo, ya que se da en todo el período andalusí. También aparecen en todos los asentamientos, sin que en su distribución haya diferencias notables.

Este grupo podría corresponder al tipo G1 definido por Retuerce ${ }^{7}$.

2. Pastas micáceas con cocción reductora. Presentan las mismas características que el grupo anterior, con la única salvedad de tener en todos los casos una cocción reductora. Suponen el 4,74 \% del total. Tan sólo aparecen en la serie de ollas o marmitas, pero sin que se pueda adscribir a ningún tipo concreto. Su distribución nos indica que es fundamentalmente en el área de Riba de Santiuste, tanto en el propio castillo como en el asentamiento en el llano de «La Alquería», donde aparece representado, como se puede ver en el siguiente gráfico:

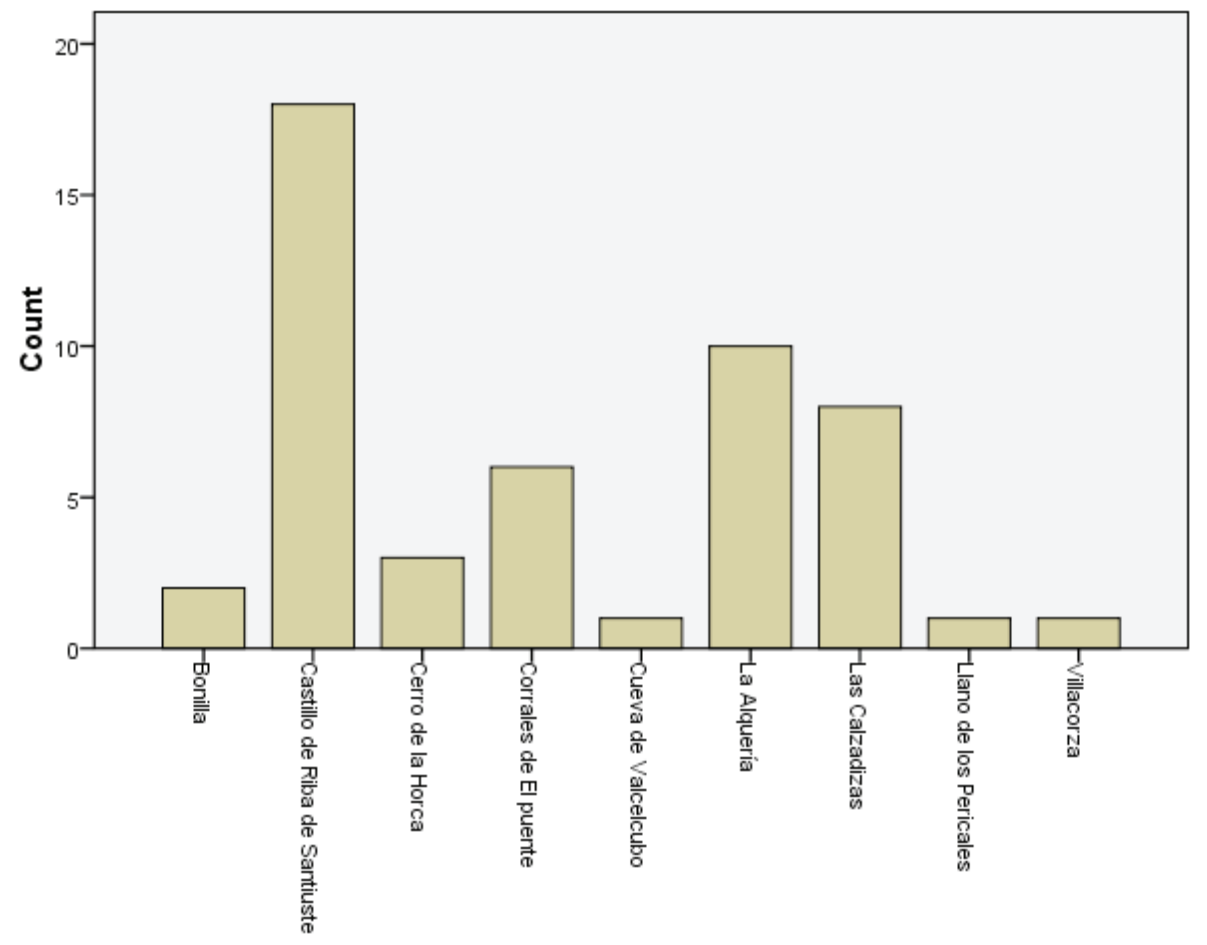

3. Pastas suaves. Con este nombre nos referimos a un grupo tecnológico en el que todas las cerámicas son de arcillas claras, con pastas bastante depuradas o con pocas y pequeñas inclusiones, entre las que únicamente puede identificarse como mineral la calcita, a veces en combinación con mica pero ésta última en poca cantidad. Todas tienen un modelado a mano, y su acabado superficial es siempre alisado o con marcas de artilado. El grosor de estas piezas es mayoritariamente entre 30 y $70 \mathrm{~mm}$, aunque hay bastantes piezas de paredes muy finas, inferiores a los $30 \mathrm{~mm}$. Una nota dominante en este grupo es la cocción tipo «sandwich», la más frecuente, apareciendo la cocción

\footnotetext{
${ }^{7}$ RetUerce Velasco, Manuel, La cerámica andalusí..., pp. 66-69.
} 
oxidante únicamente en las piezas más finas. También se ha admitido en este grupo algunas piezas que presentaban una cocción alterna cuando la reducción se había producido en la parte interior de piezas cerradas.

En los casos en los que ha podido identificarse, prácticamente la totalidad de las piezas forman parte del servicio de mesa, y fundamentalmente jarras, que suponen más del $20 \%$ de los casos incluyendo aquellas piezas que no han sido identificadas, y algunos casos de ataifores (el 7\%). Los tipos concretos más representados son las jarritas de paredes artiladas (J3) y los ataifores que la pared interior del anillo más alta que la exterior (A4). Este grupo, junto con el siguiente, es en el que la decoración pintada se da con mayor frecuencia, sobre todo en tonos ocres y rojos.

Este grupo podría corresponder al grupo definido por Retuerce como G5, subgrupo $3^{8}$

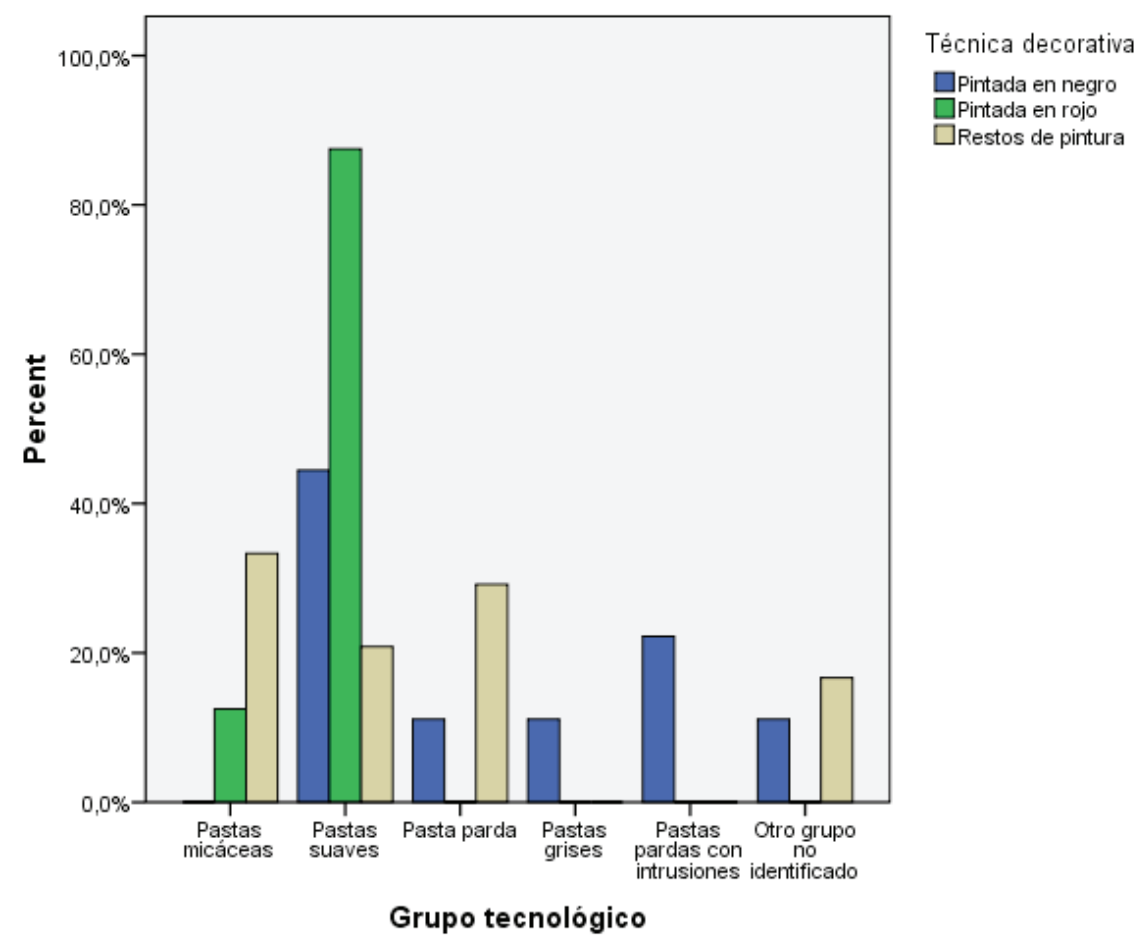

4. Pastas pardas. Aunque su denominación original es la de «pastas pardas», sería más correcto hablar de pastas claras, ya que recogen toda una gama de colores que van desde el anaranjado al marrón claro. Representa el 11,37\% del total. Contiene bastantes y abundantes inclusiones siempre de tamaño pequeño y formas redondeadas, $\mathrm{y}$ los acabados de las superficies son únicamente alisados, aunque se han admitido como pertenecientes a este grupo algunos casos en los que pueden verse las marcas del torno marcadas en la superficie. Aunque lo más abundante son los ejemplos de entre 30 y 70

\footnotetext{
${ }^{8}$ RetUerce Velasco, Manuel, La cerámica andalusí..., pp. 66-69.
} 
mm (el 53,3 \% de las piezas adscritas a este grupo) hay un buen número de piezas de un grosor mayor, sobre todo de entre $70 \mathrm{~mm} \mathrm{y} 1 \mathrm{~cm}$ (36,7\% del total del grupo). En todos los casos las cocciones son oxidantes, aunque en aquellas más anchas se han incluido algunas que presentaban una cocción tipo «sandwich» (el 23,3\%, el resto son oxidantes). Es un grupo repartido por igual entre todos los asentamientos.

5. Pastas grises. En este grupo incluimos todas aquellas cerámicas que presentan una cocción por reducción, lo que les da una coloración grisácea y en algún caso oscura, pero cuyas pastas están bastante depuradas, identificándose sólo calcita y en algún caso, pocos, mica como minerales. Otro de los elementos distintivos es su superficie alisada, lo que, junto a un grosor que no supera $\operatorname{los} 70 \mathrm{~mm}$, dota a las piezas de un aspecto muy parecido al segundo de los grupos salvo por la coloración. Aunque aparece en todos los asentamientos es especialmente abundante en Bujalcayado, el castillo de Riba de Santiuste y la alquería de los corrales de El Puente, en Valdelcubo. Es una cerámica muy fragmentada y apenas está representada por ningún grupo tipológico, salvo por un tipo de ataifor de borde engrosado y redondeado (A8).

6. Pastas calcáreas muy claras. Es un grupo escasamente representado, prácticamente ausente en la totalidad de los asentamientos salvo en el castillo de Baides. Presenta una pasta muy depurada, en la que sólo se puede reconocer la calcita y en algún ejemplo granos de cuarzo, siendo la mica la gran ausente. No son piezas muy gruesas, y los pocos ejemplos que tenemos tienen unos característicos acabados artilados, salvo en el caso de las asas, de las que también hay varios ejemplos. La serie tipológica más representada son las jarras, sobre todo el tipo J3.

7. Vajilla mano. Con este grupo hacemos referencia al conjunto de cerámicas poco representadas, que teniendo un modelado a mano no forman parte de los elementos destinados a la construcción, sino a formas cerámicas globulares que muy probablemente sean ollas o cazuelas, aunque no se ha identificado ninguna forma con total seguridad. Tienen pastas oscuras y grises, con bastantes inclusiones a menudo de tamaño medio, y en la combinación de minerales siempre está presente el cuarzo, junto a la mica y la calcita. Solo están presentes en dos de los yacimientos: el castillo de Baides y el llano de los Perícales

8. Rojiza a mano. Son un conjunto de cerámicas también escasamente representadas, que se diferencian de las anteriores por unas pastas de color rojizo en las que la mica si está presente. Los únicos ejemplos que tenemos de este tipo aparecen en el castillo de Baides y en el llano de los Pericales, en Alcolea de las Peñas, al igual que ocurría con el caso anterior. En ninguno de los fragmentos ha sido posible reconocer la 
forma a la que pertenece, pero tienden a ser formas cerradas y globulares con marcas de fuego, por lo que es probable que pertenezcan a vajillas de cocina.

9. Pasta roja vidriada. La mayor parte de las piezas vidriadas que se han estudiado pertenecen a este grupo. Se trata de una pasta bastante bien depurada, en la que se reconoce mayoritariamente la calcita como inclusión, con unos grosores bastante variados, desde inferiores a los $30 \mathrm{~mm}$ hasta $1 \mathrm{~cm}$. Por lo general se ha adscrito este grupo a formas abiertas, sobre todo ataifores, entre los que se incluyen casi todos los tipos de ataifores que hemos identificado. Los vidriados suelen ser melados $(49,1 \%)$ y verdes $(38,6 \%)$. Este grupo está distribuido de forma homogénea por todos los yacimientos prospectados. Podríamos considerar a este grupo como el mismo G4 que define Retuerce 9 .

10. Pastas pardas con intrusiones. Con una gama de colores que abarcan desde el marrón oscuro al gris, lo que caracteriza a este grupo es la presencia de inclusiones de tamaño mediano y en una cantidad considerable, sobre todo de mica, cuarzo, calcita y en algún caso otros minerales que no han podido ser identificados. Podría tratarse del grupo G2 establecido por Retuerce ${ }^{10}$. En lo que se refiere a sus acabados superficiales, hay variedad: predominan las alisadas $(54,4 \%)$, seguidas de las ásperas $(31,6 \%)$, y en menor cuantía hay algunos ejemplos con suaves marcas de torno $(10,5 \%)$ o incluso artiladas (3,5\%). Son piezas por lo general bastante gruesas, superando en más del $30 \%$ de los casos los $70 \mathrm{~mm}$ de anchura. La mayoría responde a cocciones de tipo oxidante, salvo un $28,1 \%$ en los que la cocción es alterna, generalmente aquellas piezas de forma globular.

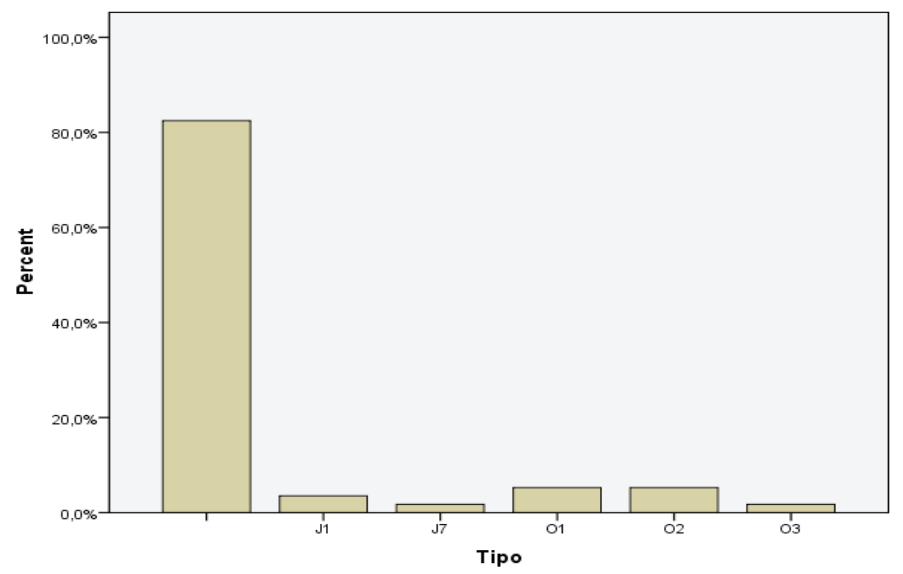

\footnotetext{
${ }^{9}$ RetUerCe Velasco, Manuel, La cerámica andalusí..., pp. 66-69.

${ }^{10}$ RetUerCe Velasco, Manuel, La cerámica andalusí..., pp. 66-69.
} 
Como se puede ver en la gráfica anterior, entre las series tipológicas a las que se ha adscrito este grupo, son todas ollas y pertenecientes a la serie de jarros/as. Los tipos más representados son los tres tipos de ollas $(01,02$ y 03$)$ y las jarras de base convexa y borde con moldura triangular (J1), o las de borde exvasado con restos de pintura (J7).

Respecto a este grupo, señalar finalmente que aunque se documenta en todos los yacimientos prospectados, es más abundante en los castillos de Baides y Riba de Santiuste, donde se concentran casi el $45,6 \%$ el total de los fragmentos adscritos a este grupo. 


\section{CONCLUSIONES}

5.1. Síntesis y perspectivas de estudio 


\subsection{SÍNTESIS Y PERSPECTIVAS DE ESTUDIO}

Hemos tratado de movilizar el mayor volumen de información para acercarnos al territorio del valle del Salado en época andalusí, tomando en consideración algunos datos de las fuentes escritas árabes y cristianas, así como algunas referencias espigadas posteriores a la conquista. Junto a ello, el estudio territorial a partir de la prospección y la descripción de cada uno de los asentamientos tratando de relacionarlos en el medio físico en el que se insertan en combinación con el análisis geográfico de la zona, pone en evidencia estrecha relación entre éstos y la explotación de la sal.

El examen de la documentación de origen andalusí pone de relieve como la sal era un producto cotidiano presente en multitud de recetas de cocina, tratados farmacológicos, prácticas médicas o relacionadas con la higiene, e incluso es citada en los tratados agrícolas como parte de algunos compuestos para el abono de los campos. Y sobre todo, es un producto que aparece estrechamente relacionado con la ganadería, tanto en sus rutas trashumantes como en la conservación posterior de las carnes. No hay evidencia ninguna de que la sal fuese un producto escaso en al-Andalus y todo apunta a que la producción era fundamentalmente local, bien en los centros de la costa cuyo origen se puede rastrear hasta época romana sino anterior, o bien en las salinas de interior, de probable origen andalusí por sus características próximas a la agricultura de regadío o por la presencia de topónimos de origen árabe. Las dificultades de todo tipo que encontramos a la hora de abordar el estudio directo de las salinas para la época andalusí, se ha solventado con el recurso a la arqueología del paisaje y el examen del poblamiento que se organiza en torno a su producción. Ejemplos estudiados tenemos en varios puntos de la Península Ibérica, pero son especialmente notables en las áreas de Jaén y Granada.

La misma metodología es la que hemos aplicado al caso concreto del valle del Salado, situado en la sierras del norte de Guadalajara. Se trata de una región históricamente volcada hacia la sal, producto que ha explotado desde épocas remotas lo que ha motivado una serie de transformaciones en el paisaje e incluso la misma organización del hábitat. No hay datos certeros de la producción de sal en esta área en época andalusí. De hecho, apenas si se conocían asentamientos en esta zona, salvo algunos castillos y torres, que pudieran datar de estos momentos. Las prospecciones arqueológicas llevadas a cabo a lo largo del año 2008 han permitido localizar un buen número de estos asentamientos, aproximadamente una veintena, diferentes todos ellos, aunque comparten una serie de rasgos. Estos asentamientos han sido analizados de manera individual, relacionándolos entre sí y con el medio físico en el que se insertan, tratando en todo momento de ponerlos en relación con las aguas saladas y los prados halófilos. De los cuatro tipo de asentamientos que se han distinguido, son las cuevas y los situados a media ladera los que parecen guardar una relación más estrecha con el recurso salado, 
mientras que los de altura, que probablemente representan la manifestación material del poder omeya en la región, parecen estar más relacionados con las vías de comunicación y el control del territorio, y no tanto con la explotación directa de sus recursos. En cuanto a los asentamientos en el llano, son pocos los datos con los que contamos, ya que ha sido la zona que menor atención ha recibido por nuestra parte, algo que pretendemos solventar en futuras campañas de investigación.

Las citadas prospecciones permitieron recoger un volumen cerámico considerable, aunque se trata de un material muy fragmentado en el que las piezas diagnósticas, esto es, aquellas que presentan rasgos morfológicos suficientes para adscribirlas a tipos y funciones, son muy escasas. Por ello hemos decidido abordar su estudio desde una óptica que tuviera en cuenta los rasgos tecnológicos, aquellos referentes a las pastas, sus desgrasantes, el tipo de modelado al que se ven sometidos y el acabado de las superficies, con el objetivo de analizar el grado tecnológico de los grupos humanos asentados en el valle del Salado en época altomedieval. Nos encontramos, por tanto, ante una producción cerámica de una alta calidad, con cocciones controladas en la mayor parte de los casos, pastas bastante depuradas, homogeneidad en los colores de las arcillas en prácticamente todo el valle, y una cierta estandarización tipológica. Estamos ante unas condiciones técnicas bastante elevadas, lo que nos alejaría de un modelo de producción campesino fundamentalmente autosuficiente, y nos da indicios de una más que probable circulación de las cerámicas entre unos centros productores algo más especializados y los centros de consumo. No hay que descartar, por tanto, que el intercambio de mercancías se produjese también en el otro sentido, sin que hasta el momento podamos establecer cuales son los centros productivos y que relación guardan con los centros urbanos de mayor tamaño de la región, como son Guadalajara y sobre todo Medinaceli. Este será otro de los aspectos que habremos de tratar en el futuro con mayor detalle, toda vez que la circulación o no de las cerámicas puede estar revelando la circulación a su vez de otros productos, como por ejemplo la sal.

El análisis de los 1113 fragmentos cerámicos a partir de análisis estadísticos nos ha permitido individualizar diez grupos tecnológicos con características similares, sin que hasta el momento sepamos con qué debemos relacionar estas agrupaciones: ¿centros productores distintos? ¿grupos consumidores diversos? Quedan aún muchos aspectos por afinar en este sentido, y además es necesario ponerlo en relación con lo que ocurre en el resto de la provincia de Guadalajara y, en grado mayor, con todo el sector oriental de la Marca Media. Algunas investigaciones anteriores a la nuestra ya apuntaban como es probable identificar una serie de producciones cerámicas adscritas a los Banu Salim, el grupo beréber que ocupó y dominó estas tierras durante gran parte del periodo andalusí. Será necesario en posteriores investigaciones analizar bajo la misma metodología que hemos propuesto, los conjuntos cerámicos de otros yacimientos de la 
región que se puedan encontrar entre los fondos de museos arqueológicos o colecciones privadas.

Junto al estudio de las características tecnológicas de la cerámica, no hemos desechado el estudio decorativo y tipológico. En este último caso, hemos propuesto un primer catálogo de formas y tipos de la cerámica andalusí en el valle del Salado. Aunque incompleto, ya que muchos grupos no están representados, y falto de más y mejores comparativas con otros conjuntos de al-Andalus, sobre todo con los provenientes de las excavaciones arqueológicas más cercanas, este estudio tipológico nos ha permitido además comenzar a fechar los yacimientos, y establecer unas primeras pautas de evolución del poblamiento.

Si bien no conocemos, por no tener datos certeros, lo que ocurre en el período tardorromano y visigodo, si que podemos asegurar que la mayor parte de los asentamientos localizados en las prospecciones arqueológicas no tienen parecen tener un origen anterior a la segunda mitad del siglo IX y sobre todo al siglo X. Tan sólo en cuatro casos, dos castillos (Baides y Riba de Santiuste) y dos asentamientos en la media ladera (Bujalcayado y Bonilla) hay materiales que nos remitan a fechas anteriores al siglo IX. El cambio en el patrón de poblamiento del siglo X se detecta no sólo por la aparición de los nuevos asentamientos, sino también por el abandono de otros. Es el caso del llano de los Perícales y del cerro de Villacorza, cuyos materiales no permiten fechar más allá de este siglo X. Son, no creemos que por casualidad, dos de los asentamientos situados en las regiones más periféricas del valle del Salado, donde la concentración de salinas es menor, no así la de los prados halófilos.

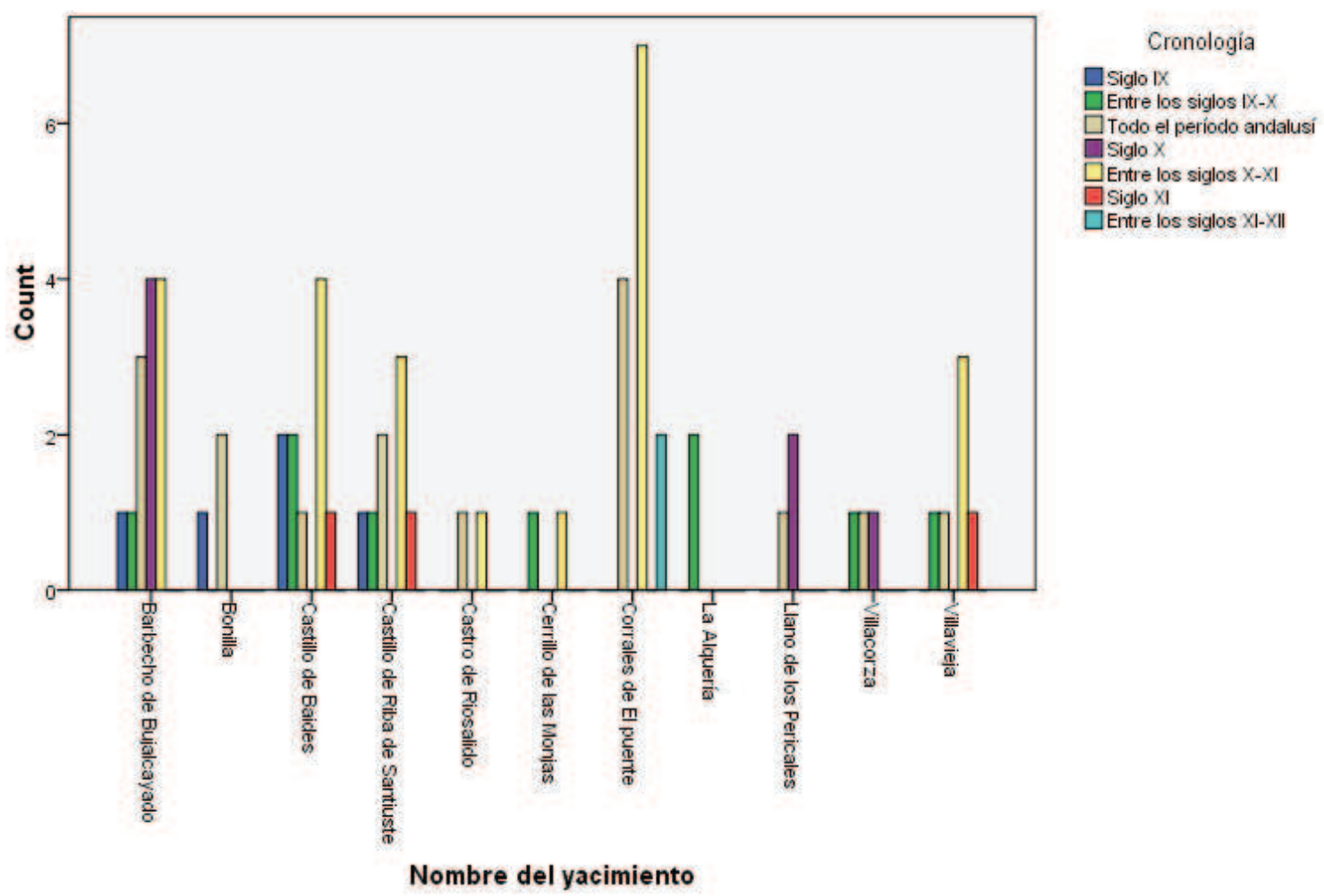


El abandono de estos centros coincide con el surgimiento y desarrollo, con mayor claridad, de la gran mayoría de los poblados de pequeño y mediano tamaño situados en las medias laderas de los cerros, y en algún caso directamente en el llano: cerrillo de las Monjas, Corrales de El Puente, la Alquería o el Cerro de la Horca. También se observa un repunte en el volumen de cerámicas de estas fechas en otros ocupados con anterioridad, como Bujalcayado o Bonilla. Son precisamente todos estos asentamientos los que se sitúan en las inmediaciones de los grandes conjuntos de salinas. ¿Cabe pensar, por tanto, en una explotación más directa o más intensa a partir del siglo X del recurso salado? Aún es pronto para asegurarlo, pero a la vista de los resultados que tenemos por ahora si que podemos, al menos, escribirlo como hipótesis.

Estos cambios en el poblamiento podrían guardar relación con los procesos de refortificación que llevan a cabo los omeyas en estas fechas, cuando el Estado de Córdoba pasa a controlar más directamente esta zona fronteriza desplazando del poder a los Banu Salim, y trasladando la capitalidad de la Marca Media de Toledo a Medinaceli en el año 945. En este sentido, hay que llamar la atención de cómo es también éste el momento en el que el volumen cerámico es mayor en dos asentamientos de altura, el de Riosalido y el de Villavieja, ambos antiguos castros de la Edad del Hierro ahora reocupados. Ambos, junto con el castillo de Riba de Santiuste, parecen no guardar una relación tan estrecha con el recurso salino, y creemos que deben entenderse conectados con las principales vías de comunicación de la región, heredera del sistema viario romano que ahora parece pervivir.

También somos capaces ya de apuntar algunas cuestiones acerca del aprovechamiento del medio físico. La proliferación de asentamientos que hemos detectado se sitúa mayoritariamente en las zonas de media ladera, junto a los cursos hídricos dulces, principalmente manantiales, y próximo también a surgencias salinas con las que parecen guardar una cierta relación. A partir de estos elementos, el espacio aparece estructurado de la siguiente forma:

- En la media ladera el poblado, en el punto en el que los dos pisos edafológicos, las arcillas y las calizas se encuentran. La zona de media ladera era más óptima para el hábitat, debido a que prácticamente la totalidad de las zonas llanas eran fácilmente inundables con aguas procedentes del subsuelo, a menudo saladas

- En las inmediaciones de los asentamientos las surgencias de agua dulce o del encauzamiento y embalsamiento de las torrenteras. Las fuentes, por 1o general, aparecen en el contacto entre los dos niveles litológicos, las arcillas y margas del llano y las calizas y areniscas de las zonas más elevadas. Normalmente hay más de uno por cada yacimiento encontrado 
- Por encima del asentamiento se sitúa la zona de monte, con tierras no roturadas pero muy probablemente aprovechadas para la ganadería, en las que es el monte bajo y los encinares los que dominan el paisaje

- Inmediatamente por debajo del poblado, en las estribaciones finales de esta parte de la media ladera y en la parte superior del llano se sitúan los espacios de cultivo, que en la actualidad son mayoritariamente cereales sin que podamos conocer aún qué tipo de explotación habría en época andalusí

- En el fondo del valle, más allá de la zona de cultivo, y aprovechando en unos casos el propio curso del río Salado y en otro las lagunas endorreicas, se localizan las modernas salinas en los lugares en los que muy probablemente se explotara el recurso, aunque aún no sepamos capaces de dilucidar con claridad de qué modo se hacía.

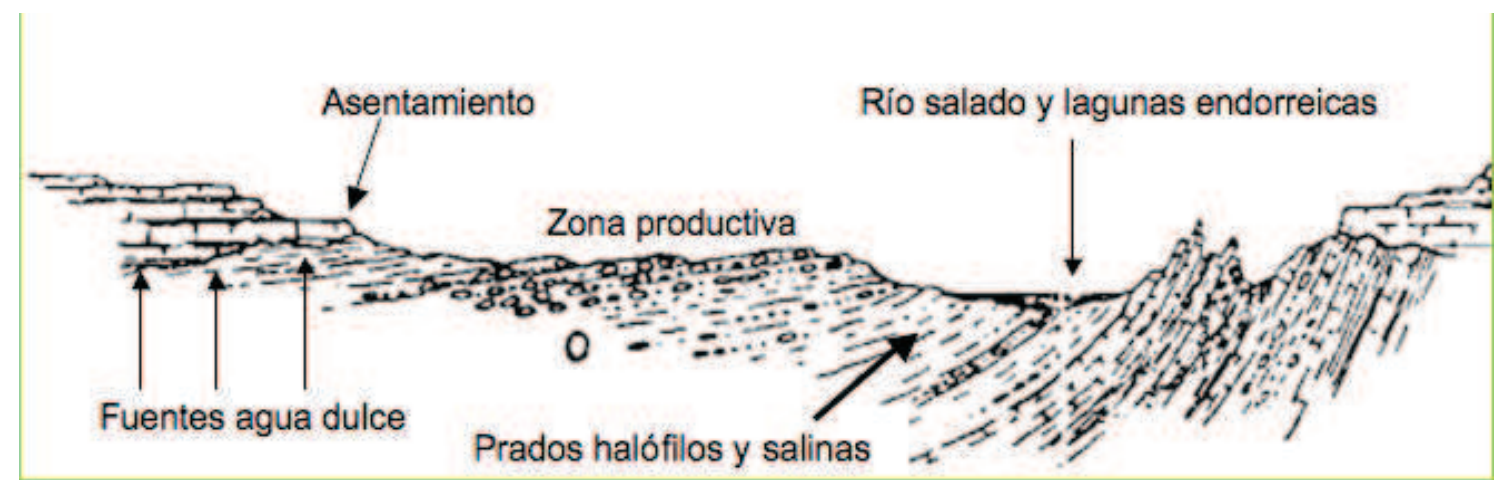

Este esquema de explotación del medio físico no es único, sino que se imbrica con modelos de aprovechamiento de carácter esencialmente ganadero en lo alto de las sierras y parameras, y con los asentamientos en altura, de carácter más militar. Queda aún mucho que estudiar en este sentido, ya que las cuevas y los lugares en el llano que han revelado una ocupación para el período central andalusí no se ajustan plenamente con este esquema, sin que por el momento podamos apuntar más que vagas reflexiones: ¿corresponden a poblados más antiguos, con esquemas de explotación diferentes, que se mantienen ocupados ahora? ¿responden a poblaciones singulares con actividades específicas, como por ejemplo eremitas, tal y como se ha propuesto para las cuevas? ¿o es un modelo de explotación y asentamiento que se complementa con el anterior, dedicado a actividades específicas a las que no se dedican los otros poblados, tales como vigilancia y control de las zonas en las que se estrecha el valle?

A partir del siglo XI, coincidiendo con el avance de los cristianos, el poblamiento parece que se vuelve a modificar. La no aparición de conjuntos cerámicos claramente fechables en la segunda mitad del siglo XI en muchos de los asentamientos anteriores coincide con la concentración de los mismos en los castillos: Villavieja, Riba de Santiuste y Baides. Tan sólo uno de los asentamientos en media ladera parece que 
pervive, incluso, hasta bien entrado el siglo XII: el de los Corrales de El Puente, en Valdelcubo, que arroja un volumen de materiales de esta fecha que se podría considerar ya como mudéjar. De nuevo, aunque solo sea a nivel de hipótesis, planteamos una probable concentración de la población en los lugares de altura y en este yacimiento, lo que explicaría sus mayores dimensiones y alguno de los elementos defensivos que se han podido documentar en él.

Estamos aún en una fase muy inicial de un proyecto de estudio que necesariamente debe continuar, siendo muchos y muy variados los caminos que recorrer. Somos conscientes de que todos los datos expuestos deben ser tomados con cautela, ya que ni mucho menos es una investigación cerrada, quedando mucho por hacer. Junto a un más exhaustivo estudio de la cerámica, y sobre todo a partir de las comparaciones y analogías con conjuntos excavados estratigráficamente que den mayor fiabilidad a la cronología, el estudio microespacial de las salinas se revela como indispensable, toda vez que se detecta en su configuración la existencia de agrupaciones de centros menores en unos casos, y de la segregación y abandono de partes de ellos en otros. Finalmente, las prospecciones deben continuar con el objetivo de afianzar aún más la visión que tenemos del poblamiento, especialmente en el llano en donde se ha trabajado menos. No descartamos encontrar más asentamientos que apuntalen, o cambien radicalmente, los planteamientos aquí expuestos, como tampoco descartamos la posibilidad de intervenir mediante excavación arqueológica en alguno de ellos. 


\section{FUENTES Y BIBLIOGRAFÍA}

6.1. Fuentes

6.2. Bibliografía 


\subsection{FUENTES}

\section{ABU I-JAYR}

- Kitãb al-Filãha. Tratado de agricultura, Ed. y trad. CARABAZA, Julia Ma, Madrid, 1991.

\section{Abu Marwan}

- Abu Marwan Abd al-Malik b. Sur (,. 557/1162), Kitab al-Agdiya (Tratado de los alimentos), Ed. y trad. GARCíA SÁNCHEZ, Expiración, Madrid, 1992.

\section{Al-Arbuli}

- Un tratado nazarí sobre alimentos: Al-Kalam Ala al-Addiya, Edición, traducción y estudio de DíAz GARCíA, Amador, Almería, 2000.

\section{AL-IDRISI}

- Los caminos de al-Andalus en el siglo XII, Ed. y trad. ABID Mizal, Jassim, Madrid, 1989.

\section{AL-RAZI}

- Crónica del moro Rasis. Versión del Ajbar muluk al-Andalus de Ahmad ibn Muhammad ibn Musa al-Eazi, 889-955, Ed. y Trad. CATALÁN, Diego y ANDRÉS, Mª Soledad de, Madrid, 1975.

\section{AL-YAZIRI}

- Ali b. Yahya, Al-Maqsad al-Mahmud fi Tal his al-'Uqud (Proyecto plausible de compendio de fórmulas notariales), estudio y edición crítica FERRERAS, Asunción, Madrid, 1998.

\section{AL-UDRI}

- Nusus an al-Andalus min Kitab Tarsi al-ajbar, trad. parcial GRANJA, Fernando de la, «La Marca Superior en la obra de al-Udri», Estudios de la Edad Media de la Corona de Aragón, VIII (1966).

\section{Álvarez de Morales y Ruiz-Matas, Camilo}

- «El libro de la Almohada» de ibn Wafid de Toledo (Recetario médico árabe del siglo XI), Toledo, 1980.

\section{AVERroes}

- El libro de las generalidades de la Medicina [Kitan al-Kulliyyat fil-tibb], Abu-lWalid ibn Rusd (Averroes), Trad. de VÁZQUEZ DE BENITO, $\mathrm{M}^{\mathrm{a}}$ de la Concepción y Álvarez Morales, Camilo, Madrid, 2003. 


\section{Chalmeta Gendrón, Pedro}

- «El "Kitab fi adab al-hisba (libro del buen gobierno del zoco) de al-Saqati. (Continuará)», Al-Andalus, XXXII (1967), pp. 125-162 y 359-397.

- «El "Kitab fi adab al-hisba (libro del buen gobierno del zoco) de al-Saqati. (continuación)», Al-Andalus, XXXIII (1968), pp. 143-196 y 367-434.

\section{Eulogio de Córdoba}

- «Eulogi Epistula. Epistula tertia ad Wilesindum», en Gil FernÁNDEZ, Juan (Ed.), Corpus Scriptorum Mozarabicorum, Madrid, 1973, t. II, p. 500.

\section{IBN AL-JATIB}

- Miy'ar al-ijtiyar, ed. y traduc. ChaBAnA, M. K., Rabat, 1977.

\section{IBN AL-QUTIYYA}

- Ta'rij iftitah al-Andalus, ed. y trad. RIBERA, J., Historia de la conquista de España de Abenalcotía el cordobés, Madrid, 1926.

\section{IBN BASSÃL}

- Libro de agricultura, editado, traducido y anotado por Millás VAlLicrosa, José Ma . y AzIMAN, Mohamed, Tetuán, 1955.

\section{IBN HAWQAL}

- Kitab surat al-ard (Configuration de la terre), trad. al fr. WIET, Gaston y KRAMERS, J. H., Leyden, 1968, 2 vols.

\section{IBN HAYYAN}

- Al-Muqtabas V. Ed. de Chalmeta, Pedro, Corriente, Federico y SoBH, M., Madrid, 1979; Trad. de Viguera, Ma Jesús y Corriente, Federico, Crónica del califa Abdarrahman III an-Nasir entre los años 912 y 942, Zaragoza, 1981.

\section{Diaz García, Amador}

— «Un tratado nazarí sobre alimentos: Al-Kalâm 'Alà l-Agdiya de Al-Arbuli. Edición, traducción y estudios, con glosNOarios (I)», Cuadernos de estudios medievales, VI-VII (1978-1979).

- «Un tratado nazarí sobre alimentos: Al-Kalâm 'Alà l-Agdiya de Al-Arbuli. Edición, traducción y estudios, con glosarios (II)», Cuadernos de estudios medievales, X-XI (1982-1983). 


\section{Huici Miranda, Ambrosio}

- Traducción española de un manuscrito anónimo del siglo XIII sobre la cocina hispano-magribí, Madrid, 1966.

\section{IBN AL-`AWWÂM}

- Libro de Agricultura, Madrid, 1802 (reed. 1988), 2 tomos.

\section{IBN AL-BAYTÂR,}

— Traité des simples, trad. de LECLERC, L., Paris, 1883.

IBN AL-JATIB,

- Mi'yâr al-ijityâr fì dikr al-ma'âhid wa-l-diyâr, Ed. y trad. por KAMAL Chabana, Mohammed, S.L., 1977.

\section{IBN AL-QUTIYYA}

- Ta'rij iftitah al-Andalus, ed. y trad. RiBerA, J., Historia de la conquista de España de Abenalcotía el cordobés, Madrid, 1926.

\section{LÉvi-ProvenÇAL, Évariste}

- Le Péninsule Ibérique aun Moyen-âge d'après le Kitab ar-rawd, Leiden, 1938.

\section{LÉvi-ProvenÇAL, Évariste y García Gómez, Emilio}

- (Eds.), Una crónica anónima de 'Abd al-Rahman III al-Nasir, Madrid, 1950.

\section{NAVARro, Ma Ángeles}

- (Ed. y trad.) Risala fi awqat al-Sana. Un calendario anónimo andalusí, Madrid, 1990.

\section{Pérez de Urbel, Justo}

- Sampiro: su crónica y la monarquía leonesa en el siglo X, Madrid, 1952.

\section{VALLVÉ BERMEJO, Joaquín}

— «Una descripción de España de Ibn Gâlib», Anuario de Filología de la Universidad de Barcelona, I (1975), pp. 369-384. 


\subsection{BIBLIOGRAFÍA}

\section{Abascal Palazón, Juan Manuel}

- Vias romanas de la provincia de Guadalajara, Guadalajara, 1982.

\section{Abellán Pérez, Juan}

- «Poblamiento y sociedad en al-Andalus» en García SANJuÁn, Alejandro, (Ed.), Saber y sociedad en al-Andalus. IV-V Jornadas de cultura islámica Almonaster la Real (Huelva), Huelva, 2006, pp. 13-36.

\section{Acién Almansa, Manuel}

— «La fortificación en al-Andalus», Archeologia Medievale, XXII (1985), pp. 7-36

- «Poblamiento y fortificación en el sur de al-Andalus. La formación de un país de husun», III Congreso de Arqueología Medieval Española, Oviedo, 1989, pp. 137-150.

- «De nuevo sobre la fortificación del emirato» en Ferreira Fernández, I. C. (Ed.), Mil anos de fortificaçôes na Peninsula Ibérica e no Magreb (500-1500), Palmela, 2002, pp. 59-75.

\section{Aguado Villalba, José}

- La cerámica hispano-musulmana de Toledo, Madrid, 1983.

\section{Almagro Gorbea, Antonio}

- «Las torres beréberes de la Marca Media. Aportaciones a su estudio», Cuadernos de la Alhambra, 12 (1976), pp. 279-305.

\section{Alonso Fernández, J.}

- Guadalajara. El Territorio y los Hombres, Madrid, 1976.

\section{Alonso Villalobos, Carlos, Gracia Prieto, F. Javier y Ménanteau, Loïc}

— «Las salinas de la bahía de Cádiz durante la Antigüedad: visión geoarqueológica de un problema histórico», SPAL: Revista de prehistoria y arqueología de la Universidad de Sevilla, 12 (2003), pp. 317-332.

\section{AMIN, Samir}

— Sobre el desarrollo desigual de las formaciones sociales, Barcelona, 1974.

\section{Ariño, Enrique, GurT, José María y PALet, Josep Maria}

- El pasado presente. Arqueología de los paisajes en la Hispania romana. Salamanca-Barcelona, 2004. 


\section{ARroyo ILERA, Rafael}

— «La sal en Aragón y Valencia durante el reinado de Jaime I»; Saitabi, XI (1961), pp. 253-261.

\section{Asin Palacios, Miguel}

- Contribución a la toponimia árabe de España, Madrid-Granada, 1944.

\section{Ávila Seoane, Nicolas}

- El proceso de señorialización de la Extremadura castellana: el ejemplo de la provincia de Guadalajara (siglos XII-XVIII), Tesis Doctoral, Universidad Complutense de Madrid, 2005, Inédita (edición online: http://eprints.ucm.es/tesis/ghi/ucm-t28752.pdf)

\section{AzUar Ruiz, Rafael}

- «Una intepretación de hisn musulmán en el ámbito rural», Revista de Estudios alicantinos, 37 (1982), pp. 33-41.

\section{BARANDiARán MAESTU, Ignacio}

- La cueva de los Casares (Riba de Saélices, Guadalajara), Excavaciones arqueologías en España, 76 (1971).

\section{Barceló Perelló, Miquel}

— «Los límites de la información documental escrita», Miquel, et alii, Arqueología Medieval. En las afueras del «medievalismo», Barcelona, 1988, pp. 73-87.

- «La arqueología extensiva y el estudio de la creación del espacio rural» en BARCEló, Miquel, et alii, Arqueología Medieval. En las afueras del «medievalismo», Barcelona, 1988, pp. 195-274.

- «Víspera de feudales. La sociedad de Sharq al-Andalus justo antes de la conquista castellana» Maíllo, Felipe (Ed.), España. Al-Andalus. Sefarad: síntesis y nuevas perspectivas, Salamanca, 1988, pp. 99-112.

- «Quina arqueología per al-Andalus?» Coloquio hispano-italiano de Arqueología medieval, Granada, 1992, pp. 243-252.

- «¿Qué arqueología para al-Andalus», MalPiCA Cuello, Antonio y Quesada QUESADA, Tomás, (Eds.), Los orígenes del feudalismo en el mundo mediterráneo, Granada, 1994, pp. 69-99.

- «¿Por qué los historiadores académicos prefieren hablar de islamización en lugar de hablar de campesinos?», La prospección arqueológica, Granada, 1997, pp. 133-144.

- El sol que salió por Occidente. Estudios sobre el estado omeya de al-Andalus, Jaén, 1997.

Barceló Perelló, Miquel, Kirchner, Helena, Lluró, Josep M., MArtí, Ramón y TORRES, José M. 
- Arqueología Medieval. En las afueras del «medievalismo», Barcelona, 1988.

\section{Barceló, Miquel, Kirchner, Helena, NaVArro, Carmen}

- El agua que no duerme. Fundamentos de la arqueología hidráulica andalusí, Granada, 1996.

${ }_{\text {AZZANA, André }}^{\text {B }}$

_ «Ceramiques médievales: les méthodes de la description analitiques apliquées aux productions de 1'Espagne Orientale I Melanges de la Casa Velázquez XV (1979), pp. 135-186.

\section{Bazzana, André, Cressier, Patrice y Guichard, Pierre}

- Les châteaux ruraux d'al-Andalus. Histoire et archéologie des husun de Sud-Est de l'Espagne, Madrid, 1988.

\section{Bazzana, André y Guichard, Pierre}

— «Pour une "archéologie extensive"», en BAZZANA, André y PoIsson, JeanMichel (eds.), Histoire et archéologie de l'habitat médiéval. Cinq ans de recherche dans le domaine méditerranéen et la France du Centre-Est, Lyon, 1986, pp. 175-184.

\section{Beltrán Martínez, Antonio y Barandiarán Maestu, Ignacio}

- Avance al estudio de las cuevas paleolíticas de la Hoz y los Casares (Guadalajara), Excavaciones Arqueológicas en España, 64 (1968).

\section{Bermejo Crespo, José Luis, MuÑoz LóPEz, Kenia.}

- «Una explotación agrícola en el territorio de los Banu Salim: excavaciones en "Vereda de Sedano" o "Las Fuentecillas" (San Fernando de Henares, Madrid», Boletín de Arqueología Medieval, 8 (1994), pp. 205-225.

- «El yacimiento medieval de Vereda de Sedano o Las Fuentecillas (San Fernando de Henares, Madrid: Campañas de excavación de 1989 y 1990», Estudios de Prehistoria y Arqueología Madrileñas, 10 (1995-1996), pp. 111-120.

- «La producción cerámica en el entorno del Henares durante los siglos IX y X» en Actas del V Encuentro de Historiadores del Valle del Henares, Guadalajara, 1996, pp. 79-86.

\section{Blázquez Garbajosa, Adrian}

- «La reconquista de Sigüenza y su significación geopolítica regional», Wad-alHayara, 12 (1985), pp. 35-42

- El señorio episcopal de Sigüenza: economía y sociedad (1123-1805), Guadalajara, 1988

- «Obispo, cabildo y concejo: tres entidades en lucha por el poder en Sigüenza, capital del señorío episcopal seguntino», SERrano Martín, Eliseo (Ed.), 
Señorío y feudalismo en la Península Ibérica (ss. XII-XIX), Zaragoza, 1993, t. 4, pp. 51-66.

\section{BLOCH, Maurice R.}

— «The social influence of salt», Scientific American 209 (1963), pp. 88-98.

\section{Bolens, Lucie}

- La cocina andaluza, un arte de vivir. Siglos XI-XIII, Madrid, 1992.

\section{Boloix GALlaRdo, Bárbara}

- «La taifa de Toledo en el siglo XI. Aproximación a sus límites y extensión territorial», Tulaytula, 8 (2001), pp. 23-57.

\section{BosCH VILÁ, Jacinto}

- «Establecimientos de grupos humanos norte-africanos en la Península Ibérica», Atti del Ier Congresso Internazionale di Studi Norte-Africani, Cagliari, 1965, pp. 147-165.

\section{Brogiolo, Gian Pietro}

- (Ed.), La fine delle ville romane: transformación nelle campagne tra tarda antichità e alto medioevo. $1^{\circ}$ Convengo Archaeologico di Garda, Mantua, 1995.

\section{Brogiolo, Gian Pietro, Chavarria, Alessandra y Valenti, Marco}

- (Eds.), Dopo la fine delle ville: Evoluzione delle campagne tra VI e IX sécolo, Mantua, 2005.

\section{Bueno SÁnchez, Marisa}

- «Estrategias de supervivencia en época tardoantigua y altomedieval. Reocupación de recintos celtibéricos en el alto Jalón (Soria)» I Jornadas de Jóvenes Investigadores de Arqueología: Dialogando con la Cultura Material. Madrid, 2008, Tomo 2, pp. 485-492.

- «Cerámica islámica en Medinaceli villa. Excavaciones de urgencia e investigación (1975-2009)», en Jornada Internacional sobre metodología de análisis de la cerámica tardoantigua y medieval, León, 2009 (en prensa).

\section{CABallero Zoreda, Luis y Latorre MaCarrón, José Ignacio}

- «La iglesia y el Monasterio de Santa María de Melque (Toledo). Arqueología y arquitectura. San Pedro de la Mata (Toledo) y Santa Comba de Bande (Orense)», Excavaciones Arqueológicas en España, 109 (1988).

\section{Cabourdin, Guy}


- (Ed.), Le sel et son histoire. Actes du colloque de l'association interuniversitaire de l'est, Nancy, 1981.

\section{Cabré Aguiló, Juan}

- Las cuevas de los Casares y de la Hoz, Archivo Español de Arte y Arqueología, 30 (1934).

\section{Carrasco Vayá, Jesús-F. y Hueso KortekaAs, Katia}

- Los paisajes ibéricos de la sal. 1. Las salinas de interior, Guadalajara, 2008.

\section{Castellano Gutiérrez, Antonio}

- «Las salinas de Jaén: (Contribución al estudio de la sal en Andalucía medieval)», Cuadernos de estudios medievales, VIII-IX (1980-1981), pp. 157166

\section{Castro Priego, Manuel}

- «Hallazgos numismáticos de época islámica en Guadalajara: El tesorillo taifa de Aranzueque», en García-Soto Mateos, Ernesto y García VAlero, Miguel Ángel (eds.), Actas del primer Simposio de Arqueología de Guadalajara. Homenaje a Encarnación Cabré Herreros. Sigüenza, 4-7 de octubre de 2000, Madrid, 2002, t. 2, pp. 569-578.

\section{Catalina García, Juan}

- La Alcarria en los dos primeros siglos de su reconquista, reimpr. Guadalajara, 1973.

\section{Cerdeño Serrano, Ma Luisa}

- «Notas sobre algunas cerámicas campaniformes de Alcolea de las Peñas (Guadalajara)», Wad-al-Hayara, 5 (1978), pp. 35-47.

\section{Cerdeño, Ma Luisa y García Huerta, Rosario}

- El Castro de la Coronilla. Chera, Guadalajara (1980-1986), Excavaciones Arqueológicas en España, 163 (1992).

\section{C.E.V.P.P.}

- «Cerámicas de época visigoda en la Península Ibérica. Precedentes y perduraciones», en A cerâmica medieval no Mediterrâneo ocidental, Mértola, 1991, pp. 49-67.

\section{Chalmeta Gendrón, Pedro}

— «Simancas y Alhandega», Hispania, 36, 133 (1976), pp. 359-445. 
- «Después de Simancas-alhandega. Año 238/938-940», Hispania, 40, 144 (1980), pp. 181-199.

- «Simancas-Alhandega: al año siguiente», Actas de las Jornadas de Cultura Árabe e Islámica: (1978), Madrid, 1981, pp. 623-640.

- «Al-Andalus» en Domínguez Ortíz, Antonio (Dir.), Historia de España, Barcelona, 1989, tomo III, pp. 9-114.

- Invasión e Islamización. La sumisión de Hispania y la formación de al-Andalus, Jaén, 2003.

\section{Chavarria Arnau, Alessandra}

- El final de las Villae en Hispania (siglos IV-VII d.C.), Bibliothèque de l'antiquité tardive, 7, (2007) Brepols, Belgium.

\section{CorTés, Ruiz, Ma Elena y LÁzAro Molinero, Inmaculada}

- «¿Continuidad o ruptura entre musulmanes y mudéjares?: el ejemplo de Molina de Aragón (Guadalajara)», Wad-al-Hayara, 22 (1995), pp. 177-214.

\section{Cruz García, Oscar}

- «Norias de tradición mudéjar en las salinas de Imón (Guadalajara)», Revista de Folklore, 107 (1989), pp. 147-166.

\section{Cuadrado Prieto, Miguel Ángel}

- «Excavaciones arqueológicas de urgencia en Guadalajara. Aguas Vivas» en Balbín, R. de; Valiente, J. y Mussat, M. T. (Eds.), Arqueología en Guadalajara. Talavera de la Reina, 1995, pp. 179-191.

- «El yacimiento hispano-visigodo de El Tesoro-Carramantiel, Gualda (Cifuentes, Guadalajara)», GARCÍA-Soto Mateos, Ernesto y GARCÍA VAlero, Miguel Ángel (Eds.), Actas del primer Simposio de Arqueología de Guadalajara: Sigüenza, 4-7 de octubre de 2000, t. 2, pp. 501-512.

\section{Daza Pardo, Enrique}

- «Formas de ocupación rural en la Sierra Norte de Guadalajara (siglos V-X). El despoblado de Morenglos (Alcolea de las Peñas, Guadalajara)», Cuadernos de Prehistoria y Arqueología de la Universidad Autónoma de Madrid, 31-32 (2005-2006); pp. 195-218.

- «Elementos para el estudio de la Arqueología altomedieval en la Sierra Norte de Guadalajara. Monacato, edilicia y poblamiento», en LóPEZ QUIROGA, J.; Martínez Tejera, A. M., y Morín de Pablos, J. (Eds), Monasterio e Territorio. Elites, edilicia y territorio en el Mediterráneo medieval (siglos V-XI), BAR Internacional Series S1720, 2007, pp. 399-408.

- «Los castillos olvidados. El papel de los asentamientos fortificados en altura en la génesis del poblamiento altomedieval del valle del Henares (siglos VII-XII)» Castillos de España, 148 (Diciembre 2007), pp. 13-25.

Deamos, Ma Belén, Fernández Miranda, Manuel, y Balbín Behrmann, Rodrigo 
— «Castilviejo de Guijosa (Sigüenza)», Wad-al-Hayara, 5 (1978), pp. 63-87.

\section{Donderis Guastavino, Amparo}

- «Historia de la sal y las salinas: fuentes para su estudio en el archivo municipal de Sigüenza» en Morére Molinero, Nuria (Ed.), Las salinas y la sal de interior en la Historia: economía, medio ambiente y sociedad, Madrid, 2008, t. I, pp. 31-44.

\section{ELÉXPURU, InéS}

- La cocina de al-Andalus, Madrid, 1994.

\section{ESPEJO, Cristóbal}

- «La renta de salinas hasta la muerte de Felipe II», Revista de Archivos, Bibliotecas y Museos, 38, 39 y 40 (1918-1919).

\section{Fernández Galiano, Dimas}

— «Notas de prehistoria seguntina» Wad-al-Hayara, 6 (1979), pp. 9-48.

\section{Fernández NaVARro, Esteban}

— «Estudio tecnológico de la cerámica nazarí de Granada „ransfertana, Monografias 4: Coloquio: Cerámica nazarí y meriní. Ceuta, 2000, pp. 41-70

- Tradición tecnológica de la cerámica de cocina almohade-nazarí, Granada, 2008.

\section{Ferrero Ros, Susana y García-Soto Mateos, Ernesto}

- «Excavaciones arqueológicas en el Atrio de la Iglesia de Nuestra Señora de los Huertos (Sigüenza, Guadalajara)» en Millán MARTínez, Juan Manuel y Rodríguez RuzA, Concepció (Eds.), Arqueología de Castilla-La Mancha. Actas de las I Jornadas (Cuenca 13-17 de diciembre de 2005), Cuenca, 2007, pp. 615640.

\section{Francovich, Riccardo y Hodges, Richard}

- Villa to village. The Transformation of the Roman Countryside in Italy, c. 4001000, Londres, 2003.

\section{Francovich, Riccardo y MANaCorda, Daniele}

- (Eds.), Diccionario de Arqueología, Barcelona, 2001.

\section{García-Contreras Ruiz, Guillermo}


- «Primera aproximación a la cerámica altomedieval del valle del Salado (Sigüenza, Guadalajara)» en GARCÍA PorRAS, Alberto (ed.), Actas del II Taller de cerámica: Cerámica medieval e Historia económica y social: problemas de método y casos de estudio, Granada, 2009 (en prensa).

- «Aportación al estudio de la cerámica andalusí en la Marca Media: el valle del Salado (Sigüenza, Guadalajara)» en Jornada Internacional sobre metodología de análisis de la cerámica tardoantigua y medieval, León, 2009 (en prensa).

\section{García de Cortazar y Ruiz de Aguirre, José Ángel}

- «La Extremadura castellano-leonesa: hacia la construcción de un modelo», Revista de Historia Económica, 2 (1987), pp. 365-370.

- Sociedad y organización del espacio en la España medieval, Granada, 2004.

\section{Garcia Grinda, José Luis}

- «Las salinas de Imón, en Guadalajara: parte de un conjunto salinero», Q. Revista del Consejo Superior de los Colegios de Arquitectos, 64 (1984), pp. 28-35.

\section{GARCÍA SÁNCHEz, Expiración}

- «La gastronomía andalusí»,en SalvatierRa Cuenca, Vicente (Ed.), El Zoco. Vida económica y artes tradicionales en al-Andalus y Marruecos, Madrid, 1995, pp. 49-57.

- (Ed.), Ibn al-Baytar al-Malaqi y la ciencia árabe: actas de los simposios internacionales sobre el científico árabe Ibn Al-Baytar, Málaga, 2008, 2 tomos.

\section{García SANJuÁn, Alejandro}

- «El concepto tributario y la caracterización de la sociedad andalusí: treinta años de debate historiográfico» en García SAnJuÁn, Alejandro, (Ed.), Saber y sociedad en al-Andalus. IV-V Jornadas de cultura islámica Almonaster la Real (Huelva), Huelva, 2006, pp. 81-152.

\section{GARCÍA-Soto Mateos, Ernesto}

- «La comarca seguntina en época islámica, siglos VIII-XII», Anales seguntinos, 21 (2005), pp. 7-37

\section{García-Soto Mateos, Ernesto y Ferrero Ros, Susana}

- «Excavaciones en el despoblado musulmán de Los Casares (Riba de Saélices, Guadalajara): Campañas de 1998, 1999 y 2000» en GARCíA-Soto MATEOS, Ernesto y García VAlero, Miguel Ángel (Eds.), Actas del primer Simposio de Arqueología de Guadalajara. Homenaje a Encarnación Cabré Herreros. Sigüenza, 4-7 de octubre de 2000, Madrid, 2002, t. 2, pp. 513-529.

- «Un posible barrio artesanal en el poblado hispanomusulmán de los Casares (Riba de Saélices, Guadalajara)» en Millán MARTínez, Juan Manuel y Rodríguez RuzA, Concepción (Eds.), Arqueología de Castilla-La Mancha. I Jornadas, Cuenca 13-17 de diciembre de 2005, Cuenca, 2007, pp. 659-680. 
— «Estudios de algunos complejos salineros contemporáneos de las comarcas de Atienza y Sigüenza: Cercadillo, Santamera, Bujalcayado-La Olmeda de Jadraque, El Atance y Cirueches», Wad Al Hayara, 23 (2007), pp. 85-120.

— «La Atalaya islámica del "Cerro de la Quebrada" o "El Mirador del Cid" de Sigüenza y algunas consideraciones sobre las fortificaciones islámicas del nordeste de la provincia de Guadalajara» en GARCÍA-SOTO MATEOS, Ernesto, García Valero, Miguel Ángel y Martínez Naranjo, Juan Pablo (Eds.), Actas del segundo simposio de Arqueología de Guadalajara. Molina de Aragón, 20-22 de abril de 2006, Madrid, 2008, pp. 265-278.

\section{García-Soto Mateos, Ernesto, Ferrero Ros, Susana y Guillén Álvarez de SOTOMAYOR, A.}

- «Los Casares: un poblado hispanomusulmán en las serranías del norte de la provincia de Guadalajara» en ABAD CASAL, Lorenzo (Ed.), Investigaciones arqueológicas en Castilla La Mancha: 1996-2002, Toledo, 2004, pp. 395-408.

\section{GaRiJo GaLÁn, Ildefonso}

- «Usos medicinales del agua en al-Andalus: Ibn al-Baytar», Álvarez DE Morales, Camilo (Ed.), Ciencias de la Naturaleza en al-Andalus. Textos y Estudios V, Granada, 1998, pp. 89-120.

\section{GENICOT, Léopold}

— Comunidades rurales en el Occidente medieval, Barcelona, 1993.

\section{GLICK, Thomas F.}

- Cristianos y musulmanes en la España medieval (711-1250), Madrid, 1991.

\section{GóMez MarTínez, Susana}

— «Cerámica islámica de Medinaceli», Boletín de Arqueología Medieval, 10 (1996), pp. 123-182.

\section{Gómez PantoJa, J.}

- «Notas históricas sobre la zona del Alto Henares en época romana», VALIENTE Malla, Jesús, (Ed.) La Celtización del Tajo Superior, Memorias del Seminario de Historia Antigua III, Alcalá de Henares 1992, pp. 116-122.

\section{González Ponce, J., Rodríguez Señas, J. y Serrano Comino, F}

- Principales suelos agrícolas de la provincia de Guadalajara. Su fertilidad y posibilidades de mejora. Madrid, 1987.

\section{Gual Camarena, Miguel}


- «Para un mapa de la sal hispana en la Edad Media», Homenaje a Jaime Vicens Vices, Barcelona, 1965, pp. 483-497.

\section{Gual Camarena, Miguel y López de Coca Castañer, José Enrique}

- «La sal del reino de Granada. Documentos para su estudio», Cuadernos de estudios medievales, II-III (1974-75), pp. 259-296.

\section{Guichard, Pierre}

- Al-Andalus. Estructura antropológica de una sociedad islámica en Occidente, Barcelona, 1976 (reimpr. Granada, 1998).

- «El problema de la existencia de estructuras de tipo "feudal" en la sociedad de Al-Andalus. (El ejemplo de la sociedad valenciana)», Estructuras feudales y feudalismo en el mundo mediterráneo (siglos X-XIII), Barcelona, 1984, pp. 117145.

\section{Hernández Giménez, Felix}

- «Travesía de la sierra de Guadarrama en el acceso a la raya musulmana del Duero (Concluirá)», Al-Andalus, 38, 1 (1967), pp. 69-186.

- «Travesía de la sierra de Guadarrama en el acceso a la raya musulmana del Duero», Al-Andalus, 38, 2 (1973), pp. 415-454.

\section{Herrera Casado, Antonio}

- «La Marca Media de al-Andalus en tierras de Guadalajara», Wad-al-Hayara, 12 (1985), pp. 9-26.

- Guía de campo de los castillos de Guadalajara, Guadalajara, 1999.

- Castillos y Fortalezas de Castilla-La Mancha, Guadalajara, 2003.

\section{HocQueT, Jean-Claude}

- Le sel et le pouvoir- De l'An mil à la Révolution française, Paris, 1984.

- «La navegación de la sal en el Atlántico (siglos XIII-XVIII)», en MALPICA Cuello, Antonio (Ed.), Navegación marítima del Mediterráneo al Atlántico, Granada, 2001, pp. 17-57.

\section{Hocquet, Jean-Claude, Malpica Cuello, Antonio y Weller, Olivier}

— Hommes et paisajes du sel: une aventure millénaire, Arles, 2001.

\section{Hueso KortekaAs, Katia y Carrasco Vayá, Jesús-F.}

— «Las salinas de Imón y de La Olmeda (Guadalajara): historia de la creación de un paisaje de la sal», Rivera Blanco, J. J. (Coord.), Actas del V Congreso Internacional "Restaurar la Memoria" patrimonio y territorio Valladolid, 2006, Valladolid, 2007, t. 1, pp. 507-510.

- Las salinas de los espacios naturales protegidos de la provincia de Guadalajara, Guadalajara, 2008. 


\section{Huetos Solano, Ma Dolores y Salas-Salvadó, Jordi}

- «Alimentación, dietética y nutrición en al-Andalus», SALAS-SALVAdó, Jordi, GARCÍA-LORDA, Pilar, SÁNCHEZ RIPOLlÉS, José Ma (Eds.), La alimentación y la nutrición a través de la Historia, Barcelona, 2005, pp. 217-246.

\section{IZQUIERDO BENITO, Ricardo}

- «Excavaciones en la ciudad hispano-musulmana de Vascos», Noticiario Arqueológico Hispánico, 7 (1979), pp. 249-392.

- «La ciudad hispano-musulmana de Vascos (Navalmoralejo, Toledo). Campaña 1979-1980», Noticiario Arqueológico Hispánico, 16 (1982), pp. 291-380.

- «La cerámica hispano-musulmana decorada de Vascos (Toledo)», Homenaje al profesor Martín Almagro Basch, (1983), t. 4, pp. 107-115

- «Tipología de la cerámica hispano-musulmana de Vascos (Toledo)», II Congreso Internacional de Cerámica Medieval en el Mediterráneo Occidental, 1986, pp. 113-125.

- «La cerámica común de Vascos (Navalmoralejo, Toledo», II Congreso de Arqueología Medieval Española, Huesca, 1987, t. 2, pp. 712-718.

\section{JACQUART, Danielle}

- «Islamic pharmacology in the Middle Ages: theories and substances», European review, 16 (2008), pp. 219-227.

\section{JiMÉnEZ Esteban, Jorge}

- «Aportación a la arqueología hispano-musulmana: Peñahora (Guadalajara)», Wad-al-Hayara, 16 (1989), pp. 283-292.

\section{JiMÉNEZ GUIJARRO, Jesús}

- «¿Aprovechamiento o explotación?: reflexiones acerca de la minería y uso de la sal durante la Prehistoria» MoréRe Molinero, Nuria (Ed.), Las salinas y la sal de interior en la historia: economía, medio ambiente y sociedad, Madrid, 2008, pp. 185-216.

\section{KIRCHNER, Helena}

- «Las técnicas y los conjuntos documentales. I La cerámica», en BARCELÓ, Miquel, et alii, Arqueología Medieval. En las afueras del "medievalismo», Barcelona, 1988, pp. 89-133.

- «Indígenas y extranjeros: cerámica y etnicidad en la formación de al-Andalus», Arqueología espacial, 21 (1999), pp. 153-208.

- «Indígenas y extranjeros, otra vez», Arqueología espacial, 22 (2000), pp. 255282.

— «Torneta y torno. Formas de producción, distribución y uso de la cerámica andalusí. El caso de Yâbisa», en Malpica Cuello, Antonio y CARVAJAL 
LóPEZ, José Cristóbal (Eds.), Estudios de cerámica tardorromana y altomedieval, Granada, 2007, pp. 221-245.

\section{KURLANSKY, Mark}

- Sal. Historia de la única piedra comestible, Barcelona, 2002.

\section{Ladero Quesada, Miguel Ángel}

- «La renta de la sal en la Corona de Castilla (Siglos XIII-XVI)», Homenaje al profesor Juan Torres Fontes, Murcia, 1987, t. I, pp. 821-838.

\section{LAYNA SERrano, Francisco}

- Historia de Guadalajara y sus Mendoza. Siglos XV-XVI, Madrid, 1942, 4 tomos.

- Castillos de Guadalajara, reed. Guadalajara, 1994. (original, 1934).

- Historia de la villa de Atienza, reed. Guadalajara, 2004 (original, Madrid 1945).

\section{LÁZARo, Inmaculada}

- «Los materiales islámicos de "El Turmiello" (Aragoncillo, Guadalajara)», Kalathos, 13-14 (1995), pp. 133-141.

\section{Llanos MARTínez CARrillo, María de los}

- «El obispado de Sigüenza en el Libro de caza: un itinerario geográfico», Don Juan Manuel VII centenario, Murcia, 1982, pp. 187-198.

\section{Llul Martínez de Bedoya, Pilar, Huete, Mario y Molina Bermejo, Jesús}

- «Un itinerario musulmán de ataque a la frontera castellana en el siglo X: fortalezas, castillos y atalayas entre Medinaceli y San Esteban de Gormaz», Castillos de España, 93 (1987), pp. 3-13.

\section{LÓPEz GóMEz, A.}

- «Salinas de la comarca de Imón (Guadalajara)», Revista de Estudios Geográficos, 122 (1970), pp. 371-394.

\section{LóPEZ QUiroga, Jorge}

- Arqueología del hábitat rural en la Península Ibérica (siglos V-X), Madrid, 2009.

\section{Malpica Cuello, Antonio}

- «Las salinas de Motril (aportación al estudio de la economía salinera del Reino de Granada a raíz de su conquista)», Baetica. Estudios de Arte, Geografía e Historia, 4 (1981), pp. 147-165. 
- «Fiscalidad y comercio de la sal en el reino de Granada en la edad media», Das Salz in der Rechts und Handelsgeschichte. Internationaler Salzgeschichtekongress, Berenkamp, 1991, pp. 65-94.

- «La vida económica en la frontera Nazarí-Castellana. Ganadería y sal en la zona Nororiental del Reino de Granada», Journal of Salt-History, 8-9 (1993), pp. 101-124.

- (Ed.), La cerámica altomedieval en el sur de al-Andalus, Granada, 1993.

- «El agua en al-Andalus. Un debate historiográfico y una propuesta de análisis», $V$ Semana de Estudios Medievales, Nájera, 1995, pp. 65-85.

- «La cultura de la sal en Andalucía Oriental en la Baja Edad Media. Formas de trabajo y explotación», en Just, Rüdiger (Ed.), Das Leben in der Saline. Arbaiter und Unternehmer, Halle (Saale), 1996, pp. 262-279.

- «El tráfico comercial de la sal en el reino de Granada en época medieval», en Pira, Stefano (ed.), Storia del commercio del sale tra Mediterraneo e Atlantico. Cagliari, 1997, pp. 83-112.

- «Estudio preliminar» en GUICHARD, Pierre, Al-Andalus. Estructura antropológica de una sociedad islámica en occidente, reed. Granada, 1998, pp. X-XLVIII.

- «Las salinas medievales del Alto Guadalquivir», SALvatierRA CuEnCA, Vicente (Ed.), Hispania, Al-Andalus, Castilla. Jornadas Históricas del Alto Guadalquivir, Jaén, 1998, pp. 281-300.

- «La vida económica en la frontera nazarí-castellana. Ganadería y sal en la zona nororiental del reino de Granada», Litchfield, Carol D., PALME, Rudolf y PiASECKI, Meter (Eds.), Le monde du sel. Mélanges offerts à Jean Claude Hocquet. Journal of Salt-History, 8-9 (2000-2001), pp. 101-124.

- «La sal y las salinas interiores del antiguo reino de Granada», PÉREZ HuRTAdo DE MendozA, Alejandro (Ed.), Salinas de Andalucía, Sevilla, 2004, pp. 113120.

- «Producción y comercio de la sal marítima en la España Mediterránea en época altomedieval», Molina Vidal, Jaime y SÁnchez Fernández, Ma José (Eds.), III Congreso Internacional de Estudios Históricos. El Mediterráneo: la cultural del mar y de la sal, Santa Pola, 2005, pp. 129-147.

- «La sal en Al-Andalus. Poblamiento y explotación de recursos salineros», AMORIM, Inés (Ed.), I Seminário Internacional sobre o sal portugués, Porto, 2005, pp. 257-277.

- "Análisis de las salinas medievales desde la Arqueología del Paisaje», en Morére Molinero, Nuria (Ed.), Las salinas y la sal de interior en la Historia: economía, medio ambiente y sociedad, Madrid, 2008, t. I, pp. 469-498.

- «El medio físico y la producción de sal. Propuestas para el análisis de las salinas granadinas desde una perspectiva arqueológica», MARTín Civantos, José María (Ed.), Medio ambiente y Arqueología Medieval, Granada, 2008, pp. 145-162.

- «Techniques et aménagements des salines médiévales de l'intérieur des terres en Andalousie orientale», en Weller, Olivier, DUfraisse, Alexa y PÉTREQUin, Pierre (Eds.) Sel, eau et forêt D'hier à aujourd'hui, Paris, 2008, pp. 433-450.

- «La explotación de la sal en el marco de la economía del reino nazarí de Granada» CAStellón, Blas (Coord) Sal y Salinas: Un gusto ancestral. Diario de Campo, 51 (noviembre-diciembre de 2008), México, pp. 59-67.

Malpica Cuello, Antonio y Carvajal López, José Cristóbal 
— (Eds.), Estudios de cerámica tardorromana y altomedieval, Granada, 2007.

\section{Malpica Cuello, Antonio y González Alcantud, José Antonio}

- (Eds.), La Sal: del gusto alimentario al arrendamiento de salinas, Granada, 1997.

\section{Malpica Cuello, Antonio, Morère Molinero, Nuria, Fábregas García, Adela y JimÉnEz GUIJARRo, Jesús}

— «Organización del territorio y explotación de la sal en el área del Río Salado (Sigüenza, Guadalajara, España): Antigüedad y Edad Media. Resultados de la I Campaña 2008», Actas del XI Encuentro de Historiadores del valle del Henares, Guadalajara, 2008, pp. 49-62.

\section{Malpica Cuello, Antonio, Morère Molinero, Nuria, Jiménez GuiJarro, Jesús} y García-CONTRERAS Ruiz, Guillermo

- «Paisajes de la sal en la Meseta castellana desde la Prehistoria a la Edad Media», X Jornadas de Arqueología Medieval: Paisajes históricos y Arqueología Medieval, Granada, 2009 (En prensa)

\section{MARTínez EnAMORAdo, Virgilio}

- «Reflexiones sobre el estudio de Al-Andalus como sociedad o, de nuevo, qué arqueología para Al-Andalus», GARcía SAnJuÁn, Alejandro, (Ed.), Saber y sociedad en al-Andalus. IV-V Jornadas de cultura islámica Almonaster la Real (Huelva), Huelva, 2006, pp. 193-238.

\section{MARTínez Lillo, Sergio}

- «Primeros materiales arqueológicos del Castillo de Olmos», I Congreso de Historia de Castilla-La Mancha, Talavera de la Reina, 1988, t. V, pp. 94-104.

\section{Martínez Lillo, S. y Matesanz Vera, P.}

- «Cerámicas cristianas y musulmanas de la Marca Media Central: siglos X, XI y XII», A Cerâmica medieval no Mediterrâneo ocidental, Mértola 1991, pp. 273284.

\section{MARTÍN VISO, Iñaki}

- Poblamiento y estructuras sociales en el norte de la Península Ibérica, Salamanca, 2000.

\section{Manzano Moreno, Eduardo}

- «Bereberes de al-Andalus: los factores de una evolución histórica», Al-Qantara, XI-2 (1990), pp. 397-428. 
- «Madrid en la frontera omeya de Toledo», Madrid del siglo IX al XI, Madrid, 1990, pp. 115-130.

- La frontera de al-Andalus en época de los Omeyas, Madrid, 1991.

- Conquistadores, emires y califas: los omeyas y la formación de al-Andalus, Barcelona, 2006.

- «Fuentes de información andalusí y temas preferentes en la historiografía sobre al-Andalus», DE LA IGLESIA DuARTE, José Ignacio (Coord.), Cristiandad e Islam en la Edad Media hispana: XVIII Semana de Estudios Medievales, Nájera, del 30 de julio al 3 de agosto de 2007, Logroño, 2008, pp. 99-112.

\section{Martínez Lillo, Sergio, Matesanz Vera, Pedro}

- «Cerámicas cristianas y musulmanas de la Marca Media Central: siglos X, XI y XII» en A cerâmica medieval no Mediterrâneo ocidental, Mértola, 1991, pp. 273-284.

\section{Martínez Peñín, Raquel}

- Estudio de la cerámica medieval del Castro de los judios, Puente Castro (León): campaña de 1999, León, 2007.

- «La producción cerámica medieval del Castrum Iudeorum (Puente Castro, León: análisis de los materiales de la campaña de 1999», Arqueología y Territorio Medieval, 14 (2007), pp. 163-207

\section{Martínez Seco, Paz y Ruiz Treviño, Carmen}

— «Hallazgos más destacados aparecidos en las intervenciones arqueológicas realizadas durante los últimos años en Sigüenza» en GARCíA-Soto MATEOS, Ernesto, García VAlero, Miguel Ángel y Martínez NARAnJo, Juan Pablo (Eds.), Actas del segundo simposio de Arqueología de Guadalajara. Molina de Aragón, 20-22 de abril de 2006, Madrid, 2008, pp. 383-400.

\section{Mas BARón, Albert}

- «Historia de la conservación de los alimentos», SALAS-SALVAdó, Jordi, GARCÍA-LORDA, Pilar, SÁNCHEZ RIPOLLÉS, José Ma (Eds.), La alimentación y la nutrición a través de la Historia, Barcelona, 2005, pp. 447-462.

\section{Minguella y ARnedo, Toribio}

- Historia de la diócesis de Sigüenza y sus obispos, Madrid, 1910, 1912 y 1913, 3 tomos.

\section{Molina PÉRez, Emilio}

- «Economía, propiedad, impuestos y sectores productivos», Historia de España / Ramón Menéndez Pidal, t. VIII «El retroceso territorial de al-Andalus. Almorávides y almohades Siglos XI al XIII», Madrid, 1977, pp. 211-300.

\section{Molinari, Alessandra}


- «Cerámica» en Francovich, Riccardo y Manacorda, Daniele (Eds.), Diccionario de Arqueología, Barcelona, 2001, pp. 53-61.

\section{Morére Molinero, Nuria}

- Carta arqueológica de la región seguntina, Guadalajara, 1983.

- «Dos conjuntos de tumbas antropomorfas de la Meseta Sur: Provincias de Guadalajara y Madrid», Actas del I Congreso de Arqueología Medieval Española. Zaragoza, 1986, t. V, pp. 276-288.

- «L'exploitation romaine du sel dans la région de Sigüenza» Gerion, 3 (1991), pp. 223-235.

- «La sal en la Península Ibérica. Los testimonios literarios antiguos», Historia Antiqua, XVIII (1994), 235-250.

- «Hommes et sel: Archèologie et Histoire jusqu'au premier millènaire au notre ère», en Figuls, A. y Weller, O. (Eds.), Trobada internacional d'arqueologia envers l'explotació de la sal a la prehistòria i protohistoria, Cardona, 2007, pp. 97-110.

- (Ed.), Las salinas y la sal de interior en la historia: economía, medio ambiente y sociedad, Madrid, 2008.

\section{Multhauf, Robert P.}

- El legado de Neptuno. Historia de la sal común, México D. F., 1985.

\section{Muñoz Muñoz, Jesús, Archilla Aldeanueva, Rafael y Rey Arnaiz, José María}

— «El clima de la provincia de Guadalajara», Anales de geografía de la Universidad Complutense, 12 (1992), pp. 11-60.

\section{OLMo EnCISO, Lauro}

- «Ciudad y procesos de transformación social entre los siglos VI y XI: de Recópolis a Racupel», CABALlero ZoredA, Luis (Ed.), Visigodos y Omeyas: un debate entre la Antigüedad Tardía y la Alta Edad Media, Mérida, 2001, pp. 385400.

- «Arqueología medieval en Guadalajara. Un estado de la cuestión» en GARCíASoto Mateos, Ernesto y García Valero, Miguel Ángel (eds.), Actas del primer Simposio de Arqueología de Guadalajara. Homenaje a Encarnación Cabré Herreros. Sigüenza, 4-7 de octubre de 2000, Madrid, 2002, t. 2, pp. 467499.

\section{Orejas del Saco Valle, Almudena}

- «Arqueología de los paisajes agrarios e historia rural», Arqueología espacial, 26 (2006), pp. 7-19.

\section{OrLandis, José}


— «El elemento germánico en la Iglesia Española del siglo VII», Anuario de Estudios Medievales, 3 (1966), pp. 27-64.

\section{Orton, Clive}

- Matemáticas para arqueólogos, Barcelona, 1988.

\section{Orton, Clive, Tyers, Paul y Vince, Alan}

- La cerámica en Arqueología, Barcelona, 1997.

\section{Pastor de Togneri, Reyna}

- «La sal en Castilla y León. Un problema de la alimentación y del trabajo y una política fiscal (siglos X-XIII)», Cuadernos de Historia de España, XXXVIIXXXVIII (1963), pp. 42-87.

\section{Pavón Maldonado, Basilio}

- Guadalajara medieval. Arte y arqueología árabe y mudéjar, Madrid, 1984.

\section{Pérez Alvarado, Sonia}

- Un indicador arqueológico del proceso de islamización. Las cerámicas omeyas de Marroquies bajos, Jaén, 2003.

\section{Pérez Hurtado de Mendoza, Alejandro}

- (Ed.), Salinas de Andalucía, Sevilla, 2004.

\section{Plata Montero, Alberto}

- El ciclo productivo de la sal y las salinas reales a mediados del siglo XIX, Álava, 2006.

\section{Quesada Quesada, Tomás}

- «Las salinas de interior de Andalucía oriental: ensayo de tipología», en Agricultura y regadio en Al-Andalus, síntesis y problemas: actas del II coloquio Historia y Medio Físico, Almería, 1995, pp. 317-334.

- «El agua salada y las salinas», en El agua en la agricultura de al-Andalus, Barcelona, 1995, pp. 57-80.

- «Las salinas de la tierra de Jaén al final de la Edad Media (ss. XIV-XVI)», Journal of Salt History, 4 (1996), pp. 5-34.

\section{Quesada Quesada, Tomás y Malpica Cuello, Antonio}

- «Las salinas de Andalucía oriental en época medieval. Planteamientos generales y perspectivas de investigación», Journal of Salt History, 2 (1994), pp. 144-168. 


\section{Quesada Quesada, Tomás y Rodríguez Aguilera, Ángel}

- «El complejo salinero de Cuenca», El agua en la agricultura de al-Andalus, Barcelona, 1995, pp. 131-142.

\section{RANZ Yubero, José Antonio}

- «El nombre de los despoblados en el Señorío Episcopal de Sigüenza», Anales Seguntinos, 9 (1993), pp. 139-146.

\section{Retuerce velasco, Manuel}

- «La cerámica islámica de Calatalifa. Apuntes sobre los grupos cerámicos de la Marca Media» Boletín del Museo Arqueológico Nacional, 2.1. (1984), pp. 117136.

— «Cerámicas islámicas procedentes de Torete (Guadalajara). Nuevos datos sobre los grupos cerámicos de la Marca Media», Boletín de la Asociación Española de Orientalistas, 20 (1984), pp. 338-357.

- «Cerámica islámica en la Comunidad de Madrid» en Madrid del siglo IX al XI, Madrid, 1990, pp. 145-164.

- "Carta arqueológica de la Meseta andalusí según el referente cerámico» Boletín de Arqueología Medieval, 8 (1994); pp. 7-110.

- «Arqueología y poblamiento en la Meseta Andalusí. El referente cerámico» en $V$ Semana de Estudios Medievales (Nájera, 1994), Logroño, 1995, pp. 87-124.

- La cerámica andalusí de la Meseta, Madrid, 1998, 2 tomos.

\section{Retuerce Velasco, Manuel y Zozaya, Juan}

- «Variantes geográficas de la cerámica omeya andalusí: los temas decorativos» en La ceramica medievale nel Mediterraneo Occidentale, (Siena-Faenza, 1984), Florencia, 1986, pp. 69-128.

\section{RODRÍGUEZ MARQUiNa, Javier}

- «Las salinas de Castilla en el siglo X y la genealogía de las familias condales», Homenaje a Fray Justo Pérez de Urbel, OSB, Burgos, 1976, t. I, pp. 143-151.

\section{${ }^{R}$ OSSELLÓ BORDOY, G ${ }^{\text {uillermo }}$}

- Ensayo de sistematización de la cerámica árabe en Mallorca, Palma de Mallorca, 1978.

_ El nombre de las cosas en al-Andalus. Una propuesta de terminología cerámica, Palma de Mallorca, 1991.

\section{Ruiz Jiménez, Ana}

- Las salinas de la Malaha, Proyecto de investigación DEA, Granada, 2007 (Inédito)

\section{SánChez de Mora, Antonio}


- La nobleza castellana en la plena Edad Media: el linaje de Lara (s. XI-XII), Tésis Doctoral, Universidad de Sevilla, 2003, Inédita (edición online: http://fondosdigitales.us.es/tesis/tesis/204/la-nobleza-castellana-en-la-plenaedad-media-el-linaje-de-lara-s-xi-xiii/)

\section{SÁNCHEZ DíAZ, Candida}

- «Mapa de la sal del Reino de Granada», Cuadernos de estudios medievales, XIIXIII (1984), pp. 199-204.

\section{SÁnCHEz Portocarrero, Diego}

- Nuevo catálogo de Obispos de la Santa Iglesia de Sigüenza, Madrid, 1646.

\section{Serrano Guerrero, Elena y Torra Pérez, María del Mar}

- «La secuencia islámica en el solar de c/ Ingeniero Mariño, 27 (Guadalajara)», García-Soto Mateos, Ernesto y García VAlero, Miguel Ángel (Eds.), Actas del primer Simposio de Arqueología de Guadalajara: Sigüenza, 4-7 de octubre de 2000 pp. 557-567.

\section{Serrano, E., Serrano, N. y Torra, M.}

- «Actuaciones arqueológicas: el túnel de "aguas Vivas" Guadalajara)», GARCÍASoto Mateos, Ernesto y García VAlero, Miguel Ángel (Eds.), Actas del primer Simposio de Arqueología de Guadalajara: Sigüenza, 4-7 de octubre de 2000, t. II, pp. 713-723.

\section{Serrano, Elena, Torra, Mar, Castro, Manuel y Sánchez, Aurelia}

— «Excavaciones en Guadalajara: secuencia andalusí desde época Emiral a Taifa y presentación de un singular conjunto numismático», Arqueología y Territorio Medieval, 11.1 (2004), pp. 79-113.

\section{Serrano-Piedecasas Fernández, Luis}

- «Elementos para una historia de la manufactura textil andalusí (siglos IX-XII)», Studia Historica. Hedieval, IV (1986), pp. 205-227.

\section{SHENNAN, Stephen}

- Arqueología cuantitativa, Barcelona, 1992.

Trallero Sanz, Antonio, Arroyo San José, Joaquín y Martínez Señor, Vanesa

- Las salinas de la Comarca de Atienza, Guadalajara, 2003.

\section{Trillo SanJosé, Carmen}


- «Los diferentes aprovechamientos del agua en una alquería del reino de Granada: La Malahá, del distrito del Quempe», Agricultura y regadío en AlAndalus, sintesis y problemas: Actas del coloquio, Almería 9 y 10 de junio de 1995, Almería, 1995, pp. 215-228.

\section{UlloA, Modesto}

— La Hacienda real de Castilla en el reinado de Felipe II, Madrid, 1977.

\section{VALiente Malla, Jesús}

- «El Abrigo de Peña Corva en Santamera, Riofrío del Llano, Guadalajara», Wad Al Hayara, 11 (1984), pp. 289-312.

- Guía de la Arqueología en Guadalajara, Guadalajara, 1997.

- «La facies Riosalido y los Campos de urnas en el Tajo Superior» en ARENAS, J. A. y Palacios, M. V., (eds.), El origen del mundo celtibérico. Actas de los encuentros sobre el origen del mundo celtibérico (Molina de Aragón, 1-3 de octubre de 1998), Molina de Aragón, 1999, pp. 88-95.

\section{Valiente Malla, Jesús y Cuadrado Prieto, Miguel Ángel}

- «Las torres de Atienza», Actas del primer Encuentro de Historiadores del valle del Henares, Guadalajara, 1988, pp. 631-642.

\section{Valiente Malla, Jesús y García-Gelabert Pérez, María Paz}

- «La cueva Harzal de Olmedillas: resultados de la prospección (Sigüenza, Guadalajara)», Wad-al-Hayara, 10 (1983), pp. 7-24.

\section{VALLEJo GIRVÉS, Margarita}

— «Nota sobre el obispado de Segontia en época visigoda», Wad-al-Hayara, 20 (1993), pp. 365-375.

- «La sede episcopal complutense y su relación con la toledana (400-711 d. C.) Anales Complutenses, IV-V (1992-1993); pp. 11-20.

- «Reflexiones sobre el poblamiento visigodo del valle del Henares», Actas del IV Encuentro de Historiadores del valle del Henares, Alcalá de Henares, 1994, pp. 69-74.

\section{VALLVÉ BERMEJO, Joaquín}

— «La industria en al-Andalus», Al-Qantara, I (1980), pp. 209-241.

- La división territorial de la España musulmana, Madrid, 1986.

\section{Vázquez Hoehne, Antonio}

- La Paramera de Sigüenza: estudio geomorfológico, Tesis Doctoral, Universidad Complutense de Madrid, 1994 (Inédita). Edición Online: http://eprints.ucm.es/tesis/19911996/H/0/H0019001.pdf 


\section{Vega Rivas, Elena, Daza Pardo, Enrique, López-Muñiz Moragas, Gonzalo y Martínez Ramos, Ma Piedad}

- «Nuevas aportaciones a la investigación de las necrópolis medievales de Sigüenza (Guadalajara): Hallazgos realizados en la Casa del Pintor, calle San Roque, 17» en García-Soto Mateos, Ernesto, García Valero, Miguel Ángel y Martínez Naranjo, Juan Pablo (Eds.), Actas del segundo simposio de Arqueología de Guadalajara. Molina de Aragón, 20-22 de abril de 2006, Madrid, 2008, pp. 299-312.

\section{Vela Cossio, Fernando, Daza PArdo, Enrique, Vega Rivas, Elena y Villafruela ArRANZ, Esther}

- «Noticias de las excavaciones arqueológicas en el claustro de la Catedral de Sigüenza (Guadalajara)» en GARcÍA-Soto Mateos, Ernesto, GARcía VALERO, Miguel Ángel y Martínez NARAnJo, Juan Pablo (Eds.), Actas del segundo simposio de Arqueología de Guadalajara. Molina de Aragón, 20-22 de abril de 2006, Madrid, 2008, pp. 325-340.

\section{Vigil-Escalera Guirado, Alfonso}

— «Aspectos sobre la cultura material en "Hispania" (ss. V-VII): problemas de visibilidad/invisibilidad del registro arqueológico», LÓPEZ QUIROGA, Jorge y MARTínez TEJERA, Artemio Manuel (Eds.), Gallia e Hispania en el contexto de la presencia "germánica" (ss. V-VII): balances y perspectivas, Oxford, 2006, pp. 89-108.

- «Granjas y aldeas tardoantiguas y altomedievales de la Meseta. Configuración espacial, socioeconómica y política de un territorio rural al norte de Toledo (ss. V-X d. C.)», Archivo Español de Arqueología, 80 (2007), póp. 239-284. Edición Online: http://aespa.revistas.csic.es/index.php/aespa/article/download/35/35

\section{WELLER, Olivier}

- «Aux origines de 1'exploitation du sel: questions de méthode», Journal of Salt History, 4 (1996), pp. 101-116.

\section{ZAMORA LuCAS, F.}

— «Batallas de Deza y Almenar en el año 974», Celtiberia, 22 (1981), pp. 261-265.

\section{ZoZAYa STABEL-HAnSen, Juan}

- «El proceso de islamización en la provincia de Soria», Actas del I Symposium de Arqueología Soriana, Soria, 1981, pp. 483-496

- «Evolución de un yacimiento: el castillo de Gormaz (Soria)», BAZZANA, André (Ed.), Castrum 3. Guerre, fortification et habitat dans le monde méditerranéen au Moyen Âge, Madrid-Roma, 1988, pp. 173-178.

- «Recientes estudios sobre la arqueología andalusí: La Frontera Media», Aragón en la Edad Media, IX (1991), pp. 371-388.

- «¿Poblados? ¿ciudades? ¿campamentos? ¿recintos castrales? En la Marca Media: hacia una tipología», Al-Ándalus país de ciudades. Actas del Congreso 
celebrado en Oropesa (Toledo), del 12 al 14 de marzo de 2005, Madrid, 2007, pp. 23-64.

\section{Zozaya, Juan y Fernández Uriel, Pilar}

— «Excavaciones en la fortaleza de Qal'at 'Abd-al-Salam (Alcalá de Henares, Madrid», Noticiario Arqueológico Hispánico. Serie Nueva, 17 (1983), pp. 411529. 